\title{
EFFECTIVENESSS OF THERMAL OXIDATION IN RELATION TO ANTERIOR CERVICAL
} PLATES

\author{
A Thesis \\ presented to \\ the Faculty of California Polytechnic State University, \\ San Luis Obispo
}

\begin{abstract}
In Partial Fulfillment
of the Requirements for the Degree

Master of Science in Engineering, with Specializations in

Materials Engineering
\end{abstract}

by

Katherine A. Miyashiro

January, 2009 


\section{(C) 2009 \\ Katherine A. Miyashiro \\ ALL RIGHTS RESERVED}




\section{COMMITTEE MEMBERSHIP}

TITLE: $\quad$ EFFECTIVENESSS OF THERMAL OXIDATION IN RELATION TO ANTERIOR CERVICAL PLATES

AUTHOR: $\quad$ Katherine A. Miyashiro

DATE SUBMITTED: January, 2009

COMMITTEE CHAIR: $\quad$ Dr. Trevor Harding, Materials Engineering Associate Professor

COMMITTEE MEMBER: Dr. Daniel Walsh, College of Engineering Associate Dean

COMMITTEE MEMBER: Dr. Alan Pelton, Materials Engineering lecturer, CTO NDC 


\begin{abstract}
EFFECTIVENESSS OF THERMAL OXIDATION IN RELATION TO ANTERIOR CERVICAL PLATES

Katherine A. Miyashiro
\end{abstract}

Ti-6Al-4V anterior cervical plates (ACP) are used in spinal fusion surgeries to fixate cervical vertebrae during graft adhesion. However, documented cases of implant failure and the potential for ACP corrosion raise concerns regarding any degradation of material resulting from extended implantation. In addition, abrasion during implantation may damage a section of the protective oxide layer, potentially exposing surrounding tissues to the harmful effects of bare titanium, aluminum, and vanadium. Thermal oxidation has been shown to improve corrosion-resistance and wear-resistance, depending on temperature and time. To quantify the attributes of the thermally grown oxide layer, Ti-6Al-4V coupons underwent thermal oxidation treatments in an atmosphere environment at 600 and $675^{\circ} \mathrm{C}$ for $1,4,8$, and 16 hours. Two sample types were produced: non-abraded and abraded.

Non-abraded samples underwent potentiodynamic polarization according to ASTM F2129, which included open circuit potential tests. Open circuit potentials $\left(\mathrm{E}_{\mathrm{OC}}\right)$ increased with increasing treatment time, indicating that longer treatment time resulted in thicker oxides. All samples treated at $675^{\circ} \mathrm{C}$ displayed higher $\mathrm{E}_{\mathrm{OC}}$ than samples treated at $600^{\circ} \mathrm{C}$, indicating an increase in oxide thickness with higher temperature. During the first hour of treatment at $675^{\circ} \mathrm{C}$, the rate of oxide growth was greater than the rate of oxide growth of all samples treated at $600^{\circ} \mathrm{C}$. Samples treated at $600^{\circ} \mathrm{C}$ for 4 and 8 hours displayed pitting during potentiodynamic polarization, but all other samples withstood the applied potentials and surfaces were further passivated.

To simulate damage during surgery, a single abrasion was made across samples in the abraded group with a diamond-tip indenter under a load of $471 \mathrm{~g}$ at $4.4 \mathrm{~mm} / \mathrm{s}$. Abraded samples were 
subjected to potential-step tests to assess repassivation ability after abrasion. All samples displayed repassivation ability, except for the sample treated at $600^{\circ} \mathrm{C}$ for 4 hours.

Surface roughness was measured with atomic force microscopy before and after thermal oxidation treatments. Lower surface roughness was desired to discourage osseointegration, or the growth of bone cells. No isothermal surface roughness trends were observed, as high surface roughness outliers were seen in samples treated at $675^{\circ} \mathrm{C}$ for 8 hours and $600^{\circ} \mathrm{C}$ for 4 hours. Rockwell hardness and Vickers microhardness were also measured to assess bulk changes in mechanical properties and hardness of the oxidized surfaces. No statistical change was seen in Rockwell hardness. Vickers hardness increased with increasing temperature and time, with the exception of the sample treated at $600^{\circ} \mathrm{C}$ for 4 hours. Metallography of the thermally oxidized samples was analyzed to determine if a change in microstructure had occurred due to thermal processing. No major change in grain size or the amount of alpha and beta grains was seen in samples treated at $600^{\circ} \mathrm{C}$, but samples treated for extended times at $675^{\circ} \mathrm{C}$ showed equiaxed enlarged alpha grains and a reduction in beta grains.

The breakdown of samples treated at $600^{\circ} \mathrm{C}$ exemplified possible differences in the alphabeta oxide behavior during thermal oxidation and corrosion. Outlying surface roughness and microhardness values related to the thermal oxidation treatments and resulting oxide structure. Due to delamination of oxides grown at $675^{\circ} \mathrm{C}$ for 4,8 , and 16 hours, the treatment parameters would not be effective in the ACP application. Therefore, through corrosion resistance, repassivation ability, low surface roughness, increased microhardness, and no microstructural change, thermal oxidation treatments at $600^{\circ} \mathrm{C}$ for more than 16 hours, and $675^{\circ} \mathrm{C}$ for 1 hour or less would be suitable treatments for anterior cervical plates.

Key words: Ti-6Al-4V, anterior cervical plates, thermal oxidation, corrosion, repassivation 


\section{ACKNOWLEDGEMENTS}

There were many over the last two years that supported me throughout my graduate studies, whether their encouragement was in the form of academic advice, equipment training, or providing a shoulder to lean on and an ear to listen with.

My thesis advisor, Dr. Trevor Harding, provided constant guidance during the past two years, and without such guidance, I would not be far from where I began. If not for Dr. Harding, I would know little of thesis organization, orthopaedic devices, and brewing processes.

For participating on my thesis committee, I am very grateful to Dr. Alan Pelton and Dr. Dan Walsh. Dr. Pelton taught me things about my own project that I had never even realized, sharing knowledge that developed my proficiency. Dr. Walsh was able to provide the testing equipment, opening study opportunities for current and future students.

I am forever grateful for the time and commitment my committee members granted me with, allowing me to further my education and personal growth, while delaying "the real world." Their approachable demeanors and accessible intelligence provided constant encouragement.

Raj Israel, Kevin Baker and Erin Baker of Beaumont Hospitals in Michigan were also extremely helpful, in providing materials and input throughout the study.

Members of the Materials Engineering department at Cal Poly were also vital during my project, as the students and faculty were always busy, but never too busy to stop and answer a question or take a moment to help me in some way. I particularly appreciated the help of Sean Kaylor, who taught me how to use various machining equipment. His patience and ingenuity were invaluable when helping to design an apparatus for my project.

The irreplaceable encouragement of my friends and family made the graduate process possible. They believed in me at times when I could not, and I would be nothing without them. 


\section{TABLE OF CONTENTS}

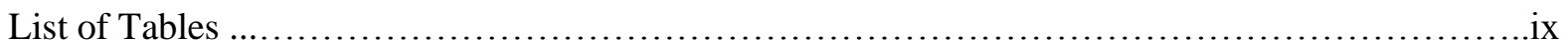

List of Figures

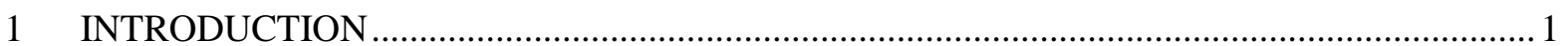

1.1 Anterior cervical plate failure due to damage and corrosion................................................2

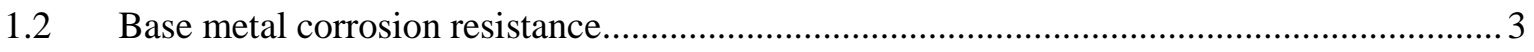

1.2.1 Surface modification comparison for improved wear and corrosion resistance ............. 4

1.2.2 Comparison of different surface treatments using corrosion tests..............................5

1.2.3 Comparison of surface treatments using repassivation and prior abrasion tests ........... 6

1.2.4 Comparison of surface treatments based on material properties after treatment........... 7

1.2.5 Parameters of effective thermal oxidation for ACP application ..................................... 8

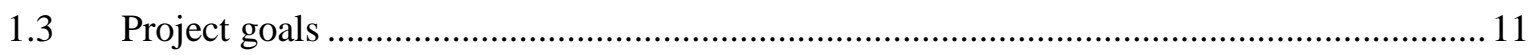

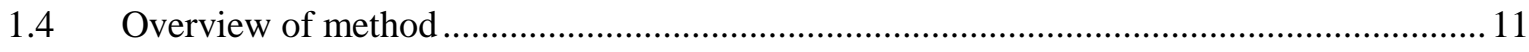

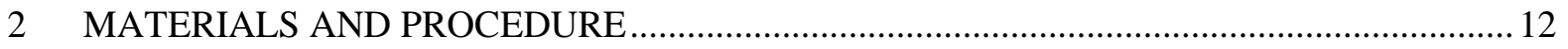

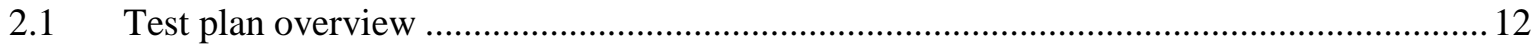

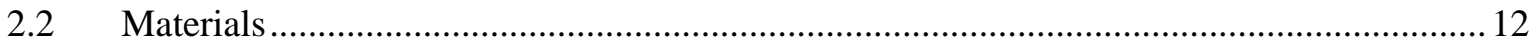

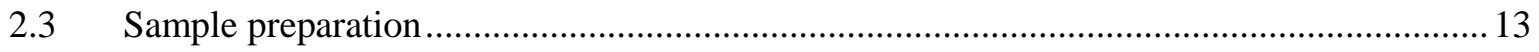

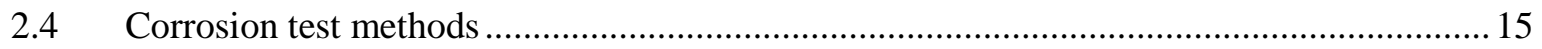

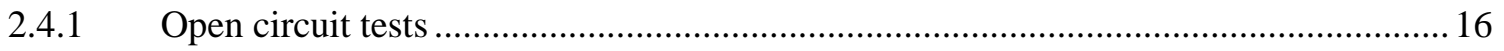

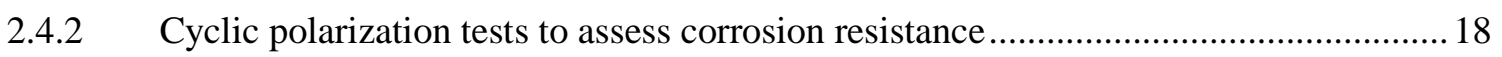

2.4.3 Potential step tests to assess repassivation ability ................................................... 20

2.4.4 Surface characterization and microscopy …............................................................ 21

3 RESULTS

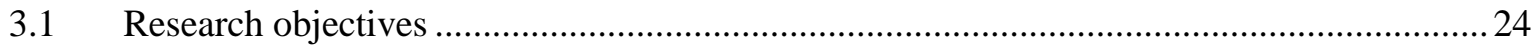

3.2 Evaluation of corrosion resistance of thermal oxidation .................................................24

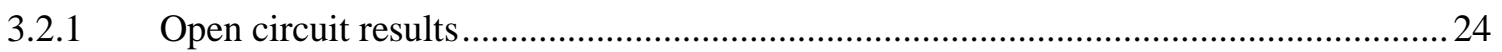

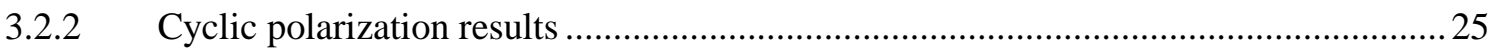

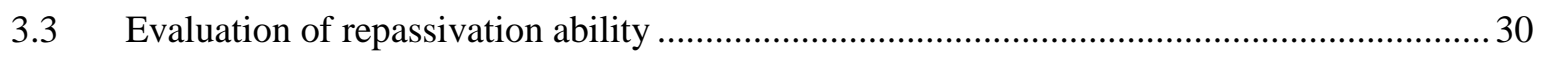

3.4 Effects of thermal oxidation on material properties ...................................................... 41

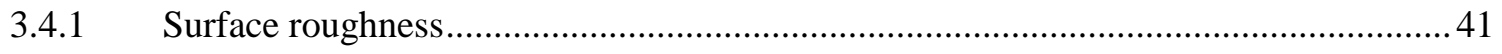

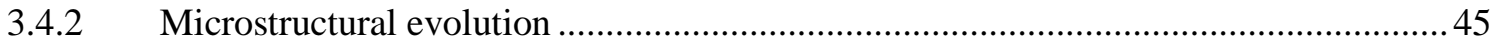

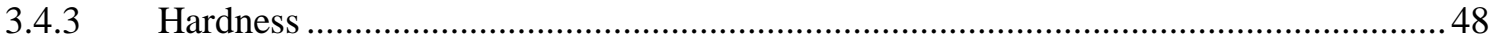




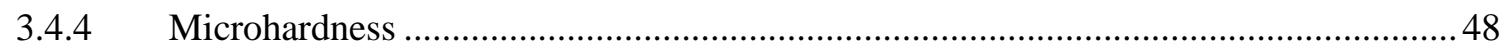

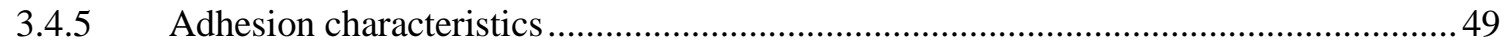

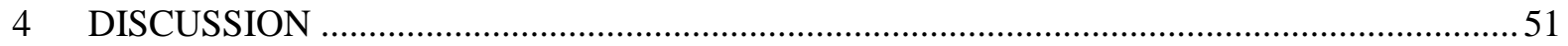

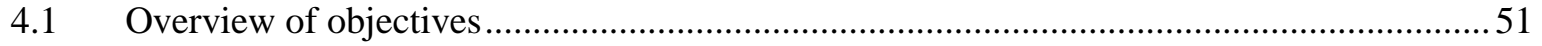

4.2 Evaluation of corrosion resistance of thermal oxidation ................................................51

4.2.1 Open circuit results in relation to oxide characteristics ............................................ 51

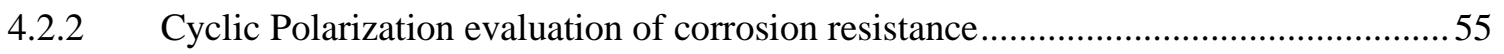

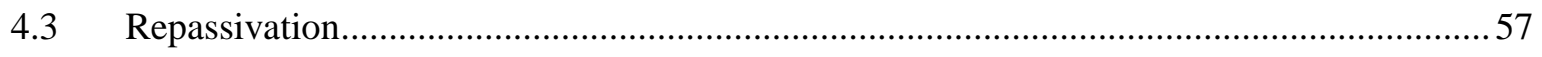

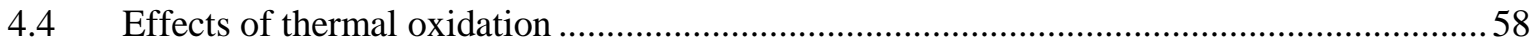

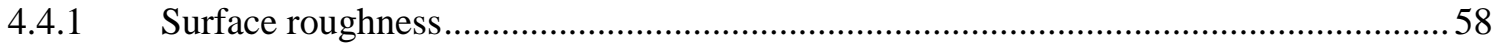

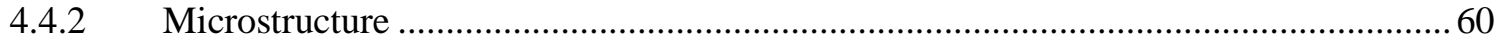

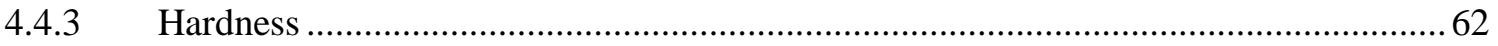

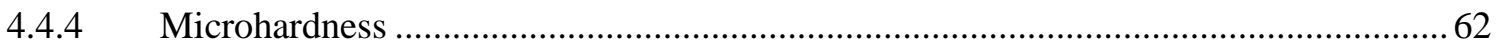

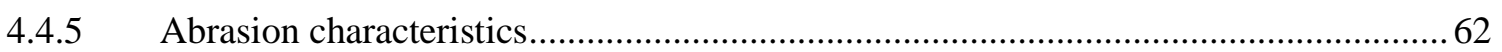

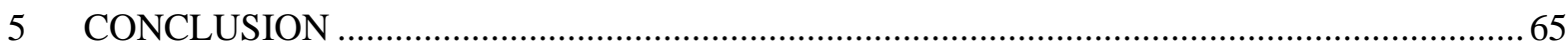

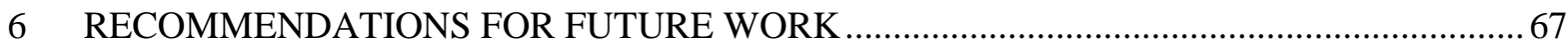

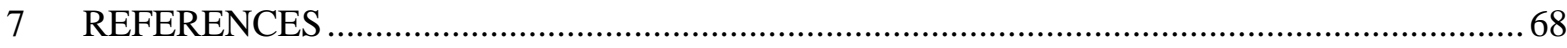

APPENDIX A: AFM Data for Non-Abraded Samples.................................... 71

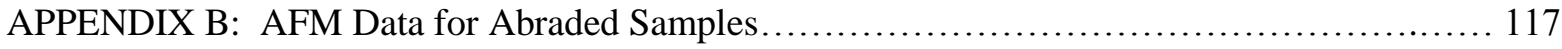

APPENDIX C: Potentiodynamic Polarization Data for Non-abraded Samples................. 144

APPENDIX D: Minitab Calculations for HRc Data....................................... 162 
Table I. Composition (at. \%) of Ti-6Al-4V rod stock, tested by Allvac. ........................................... 13

Table II. Breakdown values for CP tests of thermally oxidized Ti-6Al-4V. 


\section{LIST OF FIGURES}

Figure 1.1. X-ray of patient's cervical vertebrae, with screws of ACP inserted directly into individual vertebrae (Maroon).

Figure 1.2. The different ACP designs are held in place with bone screws, the placement of which depends on the patient's anatomy and the surgeon's judgment. Constrained "Orion" design by Medtronic Sofamor Danek (a.), "Slim-LOC" ACP by DePuy Spine (b), Semiconstrained "ABC" design by Medtronic Sofamor Danek (c), and segmented pieces of the "Atlantis" design by Medtronic Sofamor Danek (d), all provided by Beaumont Hospitals.

Figure 1.3. Scanning electron microscope image of abrasions across the surface of explanted ACP (a), found on other section of the ACP (b) (K. Miyashiro) ....................................................... 2

Figure 2.1 Microstructure of Ti-6Al-4V received from Beaumont Hospital, with light alpha grains bordered by dark beta regions

Figure 2.2. Abrasion apparatus for repassivation tests paused over recycled test sample (left). A SolidWorks representation shows the separate detailed pieces of the apparatus (right).

Figure 2.3. Section of abrasion across test sample. Width was measured for process consistency. ... 15

Figure 2.4. Corrosion cell with platinum counter electrodes, SCE, working electrode, and gas purge tube

Figure 2.5. Open circuit test ends with open circuit potential $\left(\mathrm{E}_{\mathrm{OC}}\right)$, the potential difference between the sample and the environment as the sample reaches equilibrium in the PBS. The $\mathrm{E}_{\mathrm{OC}}$ is the starting potential for cyclic polarization test.

Figure 2.6. Example of potentiodynamic polarization curve, with green arrows highlighting forward scan, and red arrows depicting surface passivation during reverse scan.

Figure 2.7. ASTM example of CP curve displaying breakdown during forward scan and repassivation during reverse scan.

Figure 2.8. ASTM example of CP curve depicting breakdown, with no hysteresis curve or repassivation 
Figure 2.9. AFM scan of sample surface before thermal oxidation treatment (a) and after treatment at $600^{\circ} \mathrm{C}$ for 16 hours (b)

Figure 2.10. Surface roughness after thermal oxidation of abraded samples at $600^{\circ} \mathrm{C}$ and $675^{\circ} \mathrm{C}$.

Measurements taken before abrasion and potential step tests.

Figure 3.1. Open circuit values for untreated sample and samples treated at $600^{\circ} \mathrm{C}$ and $675^{\circ} \mathrm{C}$

Figure 3.2. Cyclic polarization scan of sample treated at $600^{\circ} \mathrm{C}$ for 16 hours, with green arrows indicating forward scan and red arrows tracking reverse scan, displaying no breakdown and reduced reverse scan current.

Figure 3.3 Cyclic polarization test of sample treated at $600^{\circ} \mathrm{C}$ for 4 hours, with breakdown at $364 \mathrm{mV}$ and repassivation at $-180 \mathrm{mV}$.

Figure 3.4. Pits from cyclic polarization scan, located on the surface of Ti-6Al-4V sample thermally oxidized at $600^{\circ} \mathrm{C}$ for 4 hours.

Figure 3.5. Cyclic polarization of Ti-6Al-4V sample thermally oxidized at $675^{\circ} \mathrm{C}$ for 8 hours, with breakdown at $1.17 \mathrm{~V}$ and no hysteresis.

Figure 3.6. Cyclic polarization scan of Ti-6Al-4V sample thermally oxidized at $600^{\circ} \mathrm{C}$ for 8 hours with gradual increase in current and no hysteresis. .29

Figure 3.7. Potential step test of untreated sample, displaying repassivation ability at every potential step

Figure 3.8. Potential step graph of sample treated at $600^{\circ} \mathrm{C}$ for 1 hour, repassivating at every applied potential.

Figure 3.9. Potential step graph of sample thermally oxidized at $600^{\circ} \mathrm{C}$ for 4 hours, with difficulty repassivating. 
Figure 3.10. Pits on the surface of abraded sample treated for 4 hours at $600^{\circ} \mathrm{C}$ (a), view of pits, formed away from scar of abrasion in upper left corner (b)

Figure 3.11. Potential step test of sample treated at $600^{\circ} \mathrm{C}$ for 8 hours, with repassivation difficulty at $400 \mathrm{mV}$ application.

Figure 3.12. Potential step of sample treated at $600^{\circ} \mathrm{C}$ for 16 hours showed repassivation ability..... 36

Figure 3.13. Potential step graph of sample treated at $675^{\circ} \mathrm{C}$ for 1 hour, with excellent repassivation ability.... 37

Figure 3.14. Potential step test of sample treated at $675^{\circ} \mathrm{C}$ for 4 hours, with difficulty in repassivation at $200 \mathrm{mV}$ and $1.2 \mathrm{~V}$

Figure 3.15. Potential step graph of sample treated at $675^{\circ} \mathrm{C}$ for 8 hours, with only initial difficulty in repassivation.

Figure 3.16. Potential step graph of sample treated at $675^{\circ} \mathrm{C}$ for 16 hours shows excellent repassivation ability....

Figure 3.17. Surface roughness of non-abraded samples after thermal oxidation treatment. .41

Figure 3.18. Surface roughness of abraded samples after thermal oxidation treatment and before abrasion. 42

Figure 3.19. SEM images of samples treated at $600^{\circ} \mathrm{C}$ for 1 (a), 4 (b), 8 (c), and 16 (d) hours. .43

Figure 3.20. SEM images of samples treated at $675{ }^{\circ} \mathrm{C}$ for 1 (a), 4 (b), 8 (c), and 16 (d) hours. 44

Figure 3.21. Surface roughness of non-abraded samples after potentiodynamic polarization tests .... 45

Figure 3.22. Microstructure of untreated sample (a), and samples thermally oxidized at $600^{\circ} \mathrm{C}$ for 1 (b), 4(c), 8(d), and 16(e) hours 46 
Figure 3.23. Microstructure of Ti-6Al-4V thermally oxidized at $675 \mathrm{C}$ for 1 (a), 4(b), 8(c), and $16(\mathrm{~d})$ hours.

Figure 3.24. Range of HRc values of samples after thermal oxidation treatments

Figure 3.25. Microhardness data for abraded samples after thermal oxidation

Figure 3.26. Delamination of oxide around Rockwell hardness indentation (150kg load) of Ti-6Al-4V sample treated at $675^{\circ} \mathrm{C}$ for 16 hours.

Figure 3.27. SEM image of abrasion and delamination of samples treated at $675^{\circ} \mathrm{C}$ for 16(a), 8(b) and 4(c) hours.

Figure 4.1. Calculated values of oxygen penetration into Ti-6Al-4V substrate at $600^{\circ} \mathrm{C}$ and $675^{\circ} \mathrm{C}$ (Lee, Yoon, \& Yi, 2007). .52

Figure 4.2. Theoretical oxygen penetration vs. open circuit potential shows the different rates of the two thermal processes during the first hour.

Figure 4.3. Equivalent circuit used to generate impedance data for Ti-6Al-4V in PBS at $37^{\circ} \mathrm{C}$ by Azziz-Kerrzo (2001).

Figure 4.4. Inverted SEM image (a) and microstructure (b) of sample treated at $600^{\circ} \mathrm{C}$ for 16 hours. Light content represents the $\alpha$ phase and dark content represents the $\beta$ phase. The $\beta$ content is similar between the two images, but does not confirm whether the microstructure directly predicts the surface content.

Figure 4.5. Inverted SEM image (a) and microstructure (b) of sample treated at $675^{\circ} \mathrm{C}$ for 16 hours. Light content represents the $\alpha$ phase and dark content represents the $\beta$ phase. Amount of $\beta$ content is not similar between two images, neither confirming nor denying the direct relationship between $\beta$ content in microstructure and on sample surface. 


\section{INTRODUCTION}

Anterior cervical plates (ACP) promote fusion of the cervical vertebrae by providing adequate spinal placement and pressure during the healing process. ACPs are often installed with a disc graft, fixating the graft and the involved vertebrae in place while the bones fuse over time. As seen in Figure 1.1, ACPs generally consist of a metal plate with at least two holes to be screwed and secured into the spinal column. Various plate designs suited for different patient needs are pictured in Figure 1.2 a-d.

The placement and angle of the screws is at the surgeon's discretion, and some

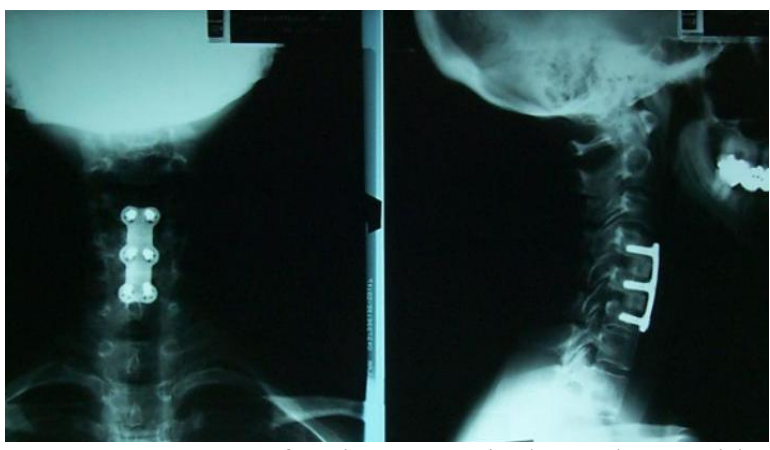

Figure 1.1. X-ray of patient's cervical vertebrae, with screws of ACP inserted directly into individual vertebrae (Maroon).

plates provide more freedom for screw movement during arthrodesis, or spinal fusion.
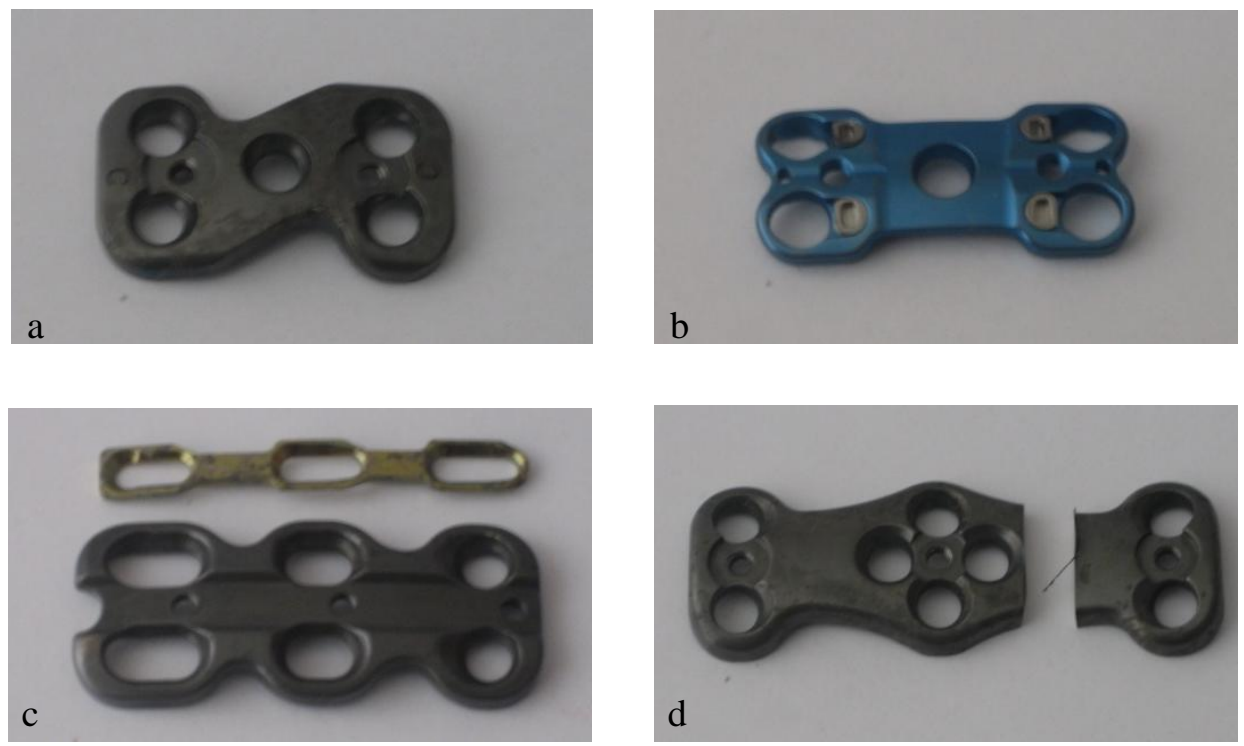

Figure 1.2. The different ACP designs are held in place with bone screws, the placement of which depends on the patient's anatomy and the surgeon's judgment. Constrained "Orion" design by Medtronic Sofamor Danek (a.), "Slim-LOC" ACP by DePuy Spine (b), Semi-constrained "ABC" design by Medtronic Sofamor Danek (c), and segmented pieces of the "Atlantis" design by Medtronic Sofamor Danek (d), all provided by Beaumont Hospitals. 


\subsection{Anterior cervical plate failure due to damage and corrosion}

Although the plate is designed to remain within the body for the life of the patient, an average of $15-25 \%$ of plates fail (Shapiro \& Snyder, 1997) and have to be removed. Forms of failure include plate fracture, screw fracture, and screw backout. Many failures are attributed to "surgical damage." Damage may include improper ACP screw positioning during surgery, placing a load on the ACP that the system was not designed to carry, or abrasion prior to implantation, which damages the surface of the plate as it is implanted into the patient's body. Figure 1.3 depicts an explanted ACP with surface damage, providing insight as to the amount and type of damage that may be caused during surgery and in-situ.
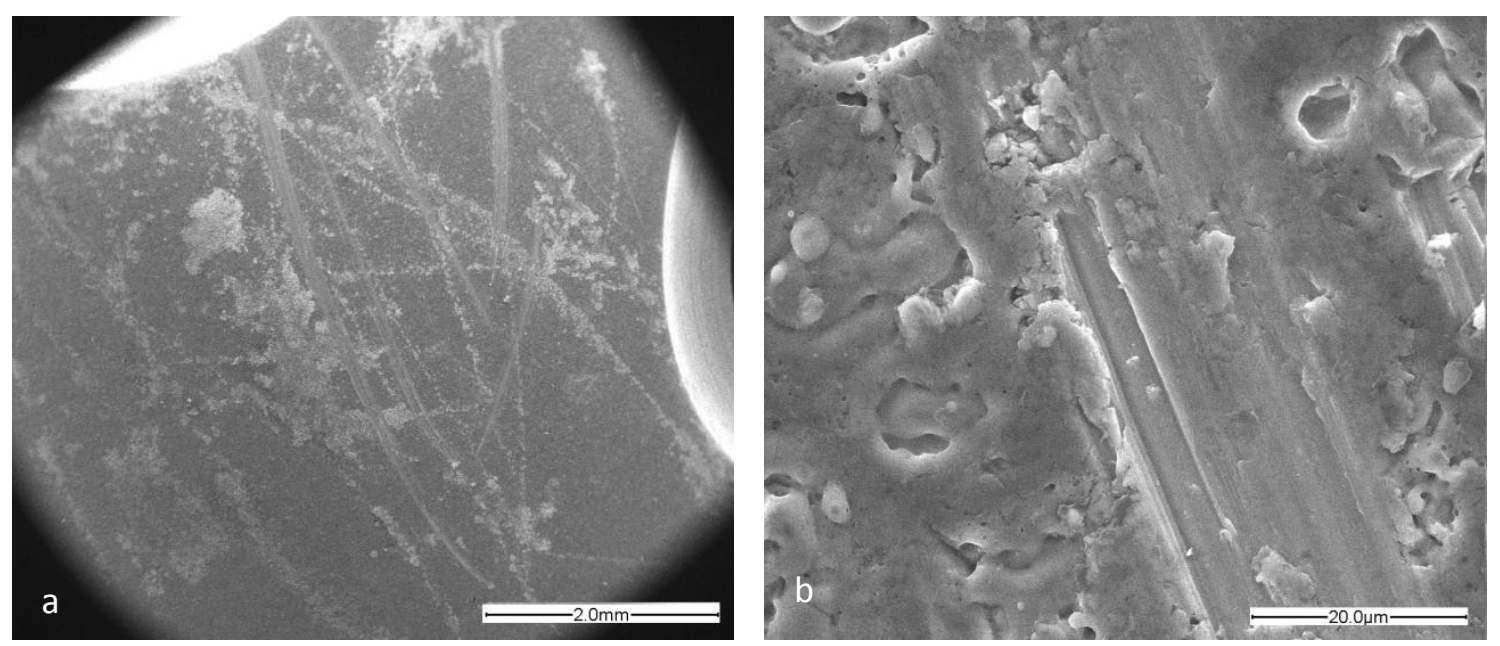

Figure 1.3. Scanning electron microscope image of abrasions across the surface of explanted ACP (a), found on other section of the ACP (b) (K. Miyashiro).

In addition, 5-10\% of cases result in infection of surrounding tissues (Shapiro \& Snyder, 1997). The metallic composition of ACPs creates a risk for in vivo corrosion, which may be related to the infection rate of periprosthetic tissues (Baker, 2007). The release of titanium and alloying elements of aluminum and vanadium are cause for concern, as the alloying elements have toxic effects, such as damage to the central nervous system (Aluminum). In addition, the 
local and systemic discoveries of metallic elements in cadavers from implants that undergo repeated wear indicate that a degradation of the surface may permit the migration of ions to nearby tissues (Jacobs, Gilbert, \& Urban, 1998). Although ACPs do not undergo repeated wear on a macro scale, the proximity of the ACP to vital tissues such as the spinal cord and brain make it a device of concern.

\subsection{Base metal corrosion resistance}

Ti-6Al-4V is a common alloy for ACPs, and is also used in other orthopedic devices such as hip implants, bone plates, and dental implants (Komotori, Lee, Dong, \& Dearnley, 2001; Vadiraj \& Kamaraj, 2007; Deanrley, Dahm, \& Cimenoglu, 2004). Its high strength-to-weight ratio and biocompatibility are effective in the ACP application, where loading and repeated wear are minimal and osseointegration, or the growth of bone cells, is not desirable.

Ti-6Al-4V is selected for ACPs for its strength and formability, but is not completely immune to corrosion and wear, both of which are affected by the surface conditions of the alloy (Deanrley et al., 2004). Therefore, the question remains as to whether surface modification may aid in corrosion resistance and reaction to wear, without altering the advantageous properties of the material that promoted Ti-6Al-4V selection for ACPs in the first place.

As a highly reactive metal, titanium readily oxidizes with its surrounding environment. The exposed substrate can form a thin natural oxide layer almost instantaneously, at $10^{-8} \mathrm{~s}$ (Gibbs, 2008), but the rate of formation of the natural oxide decreases greatly after establishment. The protective layer may be altered with various treatments to improve certain facets of biocompatibility, such as osseointegration, wear resistance, or corrosion resistance. Surface modifications depend on the application, the purpose of the implant, and the state of the Ti-6Al$4 \mathrm{~V}$ surface upon which they form. 
Titanium is often chosen for biomaterials not based on its cost, but for its strength, stiffness, and natural corrosion resistance. In addition, there has been no evidence of Ti causing inflammatory cells, granulation tissue, or necrotic debris at a metal-tissue interface. Formable to fit a variety of applications, titanium is alloyed with aluminum and vanadium to improve bulk material properties, and treated to improve surface properties. The natural oxide thickness can be enhanced by various treatments, but thermal oxidation shows superiority and validity by comparison in tests specific to conditions surrounding an ACP.

\subsubsection{Surface modification comparison for improved wear and corrosion resistance}

Various surface treatments serve as options to improve the corrosion and wear resistance of Ti-6Al-4V, in addition to altering the surface-cell interaction. The treatments include nitriding, aging in deionized water, passivating in nitric acid, anodizing, and thermal oxidation. Plasma nitriding involves bombarding the surface of a sample with nitrogen ions to create a TiN passive layer. Aging in deionized water requires the immersion of a sample into boiling water for a specified time to create a passive hydrated oxide layer on the surface. Immersion into nitric acid solutions at specific temperatures and times has been researched as an alternate oxidation treatment, creating a passive surface with stoichiometry similar to plasma nitriding. Thermal oxidation uses elevated temperatures and specific environments to create a crystallographic oxide layer. Each surface treatment holds potential for the ACP application, which requires a surface treatment that is corrosion resistant, provides wear protection, does not detrimentally alter the bulk properties of the material, and discourages osseointegration. As discussed in the following section, a comparison of the corrosive behavior, wear behavior, alteration of mechanical properties, and surface roughness after treatment presents thermal oxidation as an improved treatment for the ACP application. 


\subsubsection{Comparison of different surface treatments using corrosion tests}

Thermal oxidation, aging in deionized water, and nitric acid immersion were compared by Lee, Chang, and Yang (1999) through immersion tests and measurement of constituent release. Sample groups underwent a single passivation treatment: $400^{\circ} \mathrm{C}$ thermal oxidation treatment in air for 45 minutes, immersion in 34\% nitric acid for 1 hour, or aging in boiling deionized water for 24 hours. After immersion tests in an ethylenediaminetetraacetic acid (EDTA) Hank's solution, the thermal oxidation treatment released the least titanium, aluminum, and vanadium trace elements compared to the passivated and aged treatments. Comparison of the three treatments indicated thermal oxidation is most suited for the highly sensitive location of ACPs.

Nitrided samples were compared to thermally oxidized Ti-6Al-4V samples by Komotori et al.(2001). The open circuit potential ( $\left.\mathrm{E}_{\mathrm{OC}}\right)$, or potential of an immersed sample in equilibrium, of thermally oxidized samples was more consistent and reproducible, unlike the scattered $\mathrm{E}_{\mathrm{OC}}$ values obtained for TiN treatments. The reproducibility indicated higher stability of the oxide layer fabricated by thermal oxidation compared to nitriding. During cyclic polarization tests, breakdown of either surface modification occurred at potentials too high to be physiologically relevant (Rosenbloom \& Corbett, 2007).

The corrosive properties of thermally oxidized Ti-6Al-4V were also superior to nitric acid immersed Ti-6Al-4V in cyclic polarization tests (Petersen, Venugopalan, Lemons, \& Lucas). Samples were either passivated in $40 \%$ nitric acid for 0.5 hours or thermally oxidized at $350^{\circ} \mathrm{C}$ for 1 hour. The $14.8 \pm 0.3 \mathrm{~nm}$ thickness of oxide layers produced by thermal oxidation surpassed the $5.4 \pm 0.3 \mathrm{~nm}$ thickness produced by nitric acid immersion. Compared to untreated and passivated samples, the corrosion potential $\left(\mathrm{E}_{\mathrm{CORR}}\right)$ of thermally oxidized samples was more noble, and the rate of corrosion slower, displaying greater corrosion resistance than nitric acid passivation. 
Compared to other surface modification methods, thermal oxidation appears to be a viable surface treatment for corrosion resistance, but the potential wear of the ACP also requires a surface treatment that is wear-resistant and able to repassivate in-vivo.

\subsubsection{Comparison of surface treatments using repassivation and prior abrasion tests}

Wear testing of surface-treated Ti-6Al-4V resulted in delamination of the protective surface

layer in some cases. According to Borgioli, Galvanetto, Iozzelli, and Pradelli (2005), the amount of oxide in wear debris of samples that were thermally oxidized was greater than samples that were not surface treated. The increase in oxide in the debris indicated a decreased adhesion as a result of thermal oxidation treatments. However, the thermally oxidized samples resulted in more oxide in wear debris, as their treatment created a thicker oxide layer. The oxide debris was minimal in untreated samples, as the thickness of the oxide was significantly less than thermally oxidized samples. The thermal oxidation samples wore via the delamination of the hardened oxide layer, as opposed to wearing down the oxide of the sample and creating substrate wear. Samples that underwent thermal oxidation treatments also increased the hardness of the surface layers.

Wear of nitrided and thermally oxidized samples was also investigated by Borgioli, Galvanetto, Fossati, and Pradelli (2004), determining that glow-discharge nitride samples did not show an improved wear resistance of Ti-6Al-4V compared to furnace-fabricated oxide treatments. Oxide treatments were conducted in air at $700^{\circ} \mathrm{C}$ and $900^{\circ} \mathrm{C}$ for $0.5,2$, and 4 hours, forming a rough outer oxide in samples treated at $900^{\circ} \mathrm{C}$. The adherence of the layer fabricated at $700^{\circ} \mathrm{C}$ was greater than the adherence of the layer fabricated at $900^{\circ} \mathrm{C}$, but the wear volume of the oxidized samples was between 6 and 8 times lower than untreated and nitride samples. The nitride surface layer microfragmented during wear tests, creating more abrasive wear with the resulting nitride fragments. 
Komotori et al. (2001) studied the wear behavior of nitrided Ti-6Al-4V compared to thermally oxidized Ti-6Al-4V. After abrading with a diamond tip indenter under a 500g load at $0.25 \mathrm{~mm} / \mathrm{s}$, thermally oxidized samples showed greater oxide layer adhesion and greater resistance to scratch depth than TiN layers. In addition, the thermally oxidized samples showed a gradual change in hardness between the oxide and substrate, while TiN coatings showed a great change in hardness between coating and substrate. The TiN coatings showed more scratch damage, displaying larger scratch areas and corresponding scratch depths, compared to the thermal oxidation counterpart.

\subsubsection{Comparison of surface treatments based on material properties after treatment}

Komotori et al.(2001) also compared the hardness of nitrided Ti-6Al-4V samples to thermally oxidized Ti-6Al-4V samples. The surface roughness was greater for the TiN samples due to the large defects created by the nitriding process, but the two treatments had similar hardness values. Because bone cells better cultivate on a rough surface, the smoother surface of thermal oxidation is more applicable in the case of ACPs, where osseointegration is not desirable.

In addition, MacDonald, Rapuano, Deo, Stranick, Somasundaran, and Boskey (2004), and $\mathrm{Ku}$, Pioletti, Browne, and Gregson (2002), determined that the presence of aluminum on the surface of a material affects the attachment of osteoblasts. Particularly in the case of Ti-6Al-4V, where surface modification alters the surface content of aluminum, $\mathrm{Al}$ content can regulate the biological activity of a cell-adhesive protein, but cell growth reduces when the surface content of $\mathrm{Al}$ is reduced. $\mathrm{Ku}(2002)$ found less surface content of $\mathrm{Al}$ in samples that underwent thermal oxidation treatments than standard passivation treatments or no surface treatment at all.

In addition to surface roughness alterations, many researchers (Borgioli et al., 2004; Gülyerüz et al., 2004; Dearnley et al., 2004, Frangini et al., 1994) found that thermal oxidation increased the surface microhardness and microhardness gradients, according to temperature. Higher 
temperatures achieved higher hardness and roughness, but more delamination and scarring in wear studies. Therefore, the parameters of the thermal oxidation treatment can create oxidation layers with drastically different properties and must be selected with respect to the application, which in this study, is anterior cervical plates.

\subsubsection{Parameters of effective thermal oxidation for ACP application}

For anterior cervical plates, where corrosion resistance is required, fretting is minimal, and bone growth is not desired, thermal oxidation becomes an option for surface modification, with the proper treatment parameters. Important parameters of thermal oxidation treatments include environment, time, and treatment temperature.

Treatment parameters influence bone cell growth. The surface content of $\mathrm{Al}$ increases cell growth, and heating between 650 and $850^{\circ} \mathrm{C}$ encourages the diffusion of $\mathrm{Ti}$ and $\mathrm{Al}$ from the substrate, forming a multilayer of $\mathrm{Al}_{2} \mathrm{O}_{3}$ and $\mathrm{TiO}_{2}$ (MacDonald et al.2004). For thermal oxidation of Ti-6Al-4V anterior cervical plates, the diffusion of $\mathrm{Al}$ from the substrate should be minimal and the treatment temperature selected accordingly. Osteoblast cell adhesion to Ti-6Al-4V that had been thermally oxidized at $500^{\circ} \mathrm{C}$ and $700^{\circ} \mathrm{C}$ was compared by Saldaña, Vilaboa, Valles, Gonzales-Cabrero, and Munuera (2005), who determined that cell attachment was greater for the higher temperature. A comparison of treatment times determined that the maximum number of cell attachments was found on samples that had been oxidized for 3 hours, and remained constant for samples with longer oxidation times. Therefore, to discourage osseointegration, the oxidation temperature should be below $700^{\circ} \mathrm{C}$, and ideally, below $650^{\circ} \mathrm{C}$.

The importance of temperature in the thermal oxidation process is also brought to light in a study by S.J. Li, Yang, and S. Li (2004). The group stated that thermal oxidation treatments used to change mechanical properties of $\mathrm{Ti}-6 \mathrm{Al}-4 \mathrm{~V}$ and to create an oxide layer of $\mathrm{TiO}_{2}$ are not effective in improving wear resistance. Three different experimental conditions were tested: 
$750^{\circ} \mathrm{C}$ for 1 hour, water quench to cool; $1050^{\circ} \mathrm{C} 0.5$ hours, water quench to cool; $750^{\circ} \mathrm{C}$ for 1 hour, water quenched, and treated at $500^{\circ} \mathrm{C}$ for 24 hours, air cooled. The last of the three represented the thermally oxidized sample. The sample treated at $1050^{\circ} \mathrm{C}$ showed the greatest change in mechanical properties, the $750^{\circ} \mathrm{C}$ sample showed the least, and the thermally oxidized sample in between.

The susceptibility of Ti-6Al-4V's mechanical properties to treatment temperature was exercised, both with the treatment at $1050^{\circ} \mathrm{C}$ for 0.5 hours and $500^{\circ} \mathrm{C}$ for 24 hours. Therefore, to state that thermal oxidation treatments are not effective in improving wear resistance was not properly investigated by Li et al. (2004), as only one treatment compared to the "substrate" $750^{\circ} \mathrm{C}$ and $1050^{\circ} \mathrm{C}$ treatments was analyzed. Treatment time and temperature greatly affect the adhesion of the oxide layer to the substrate, an important treatment parameter not taken in to account by $\mathrm{Li}$ et al.(2004).

Dearnley et al. (2004) further emphasized the importance of thermal oxidation temperature. The group researched the corrosion-wear resistance of thermally oxidized Ti-6Al-4V compared to commercially pure $\mathrm{Ti}$, stating that a thermal oxidation temperature of "at least $600^{\circ} \mathrm{C}$ is required to produce an external $\mathrm{TiO}_{2}$ layer that has sufficient functionality for tribological situations." In addition, the group determined that higher temperatures create oxide layers that poorly adhere to their Ti substrate. Commercially pure and Ti-6Al-4V samples were thermally oxidized in air at $625^{\circ} \mathrm{C}$ for 36 hours. The microhardness (100g load) of the Ti-6Al-4V sample increased in both the commercially pure and Ti-6Al-4V samples. The thickness of the $\mathrm{TiO}_{2}$ layer on the Ti-6Al-4V samples was three times the thickness of the $\mathrm{TiO}_{2}$ layer on the $\mathrm{CP}$ samples, but correspondingly, the residual stress in the ceramic coating was greater for the Ti-6Al-4V samples than the CP samples. The wear resistance of both materials increased with thermal oxidation, and the coating failed via fracture along the $\mathrm{TiO}_{2}$-oxygen diffusion zone interface. Although the $\mathrm{CP}$ samples showed slightly more wear resistance than the Ti-6Al-4V samples, both maintained oxygen 
diffusion zones that wore at much lower rates than their untreated counterparts. Therefore, according to Dearnley et al. (2004), thermal oxidation was effective in wear resistance and increased microhardness at temperatures above $600^{\circ} \mathrm{C}$.

According to kinetics, temperature plays a vital role in oxide structure, but the structure and corresponding behavior of the oxide is also dependent upon treatment time. The effect of time and temperature on the Ti-6Al-4V oxide was investigated by Güleryüz et al. (2004). Treatments at 600 and $650^{\circ} \mathrm{C}$ in atmosphere for between 12 and 60 hours were analyzed using x-ray diffraction (XRD), surface roughness measurements, hardness measurements, microstructural examination, and immersion in $5 \mathrm{~m} \mathrm{HCl}$ for 60 hours.

XRD analysis showed that the surface oxide of the sample treated at $650^{\circ} \mathrm{C}$ mostly consisted of rutile $\mathrm{TiO}_{2}$, which differs in density from the small quantity of anatase and alpha $\mathrm{Ti}$ also present in the oxide formed at $600^{\circ} \mathrm{C}$. Surface roughness measurements depicted an increasing trend in roughness for both oxidation temperatures, with a greater rate in samples treated at $600^{\circ} \mathrm{C}$. Surface hardness also increased with an increase in oxidation temperature and time.

The weight loss for samples oxidized at $600^{\circ} \mathrm{C}$ increased with immersion time. Samples treated at $650^{\circ}$ did not show any weight loss until 36 hours of immersion, and the oxides of samples treated for longer times delaminated after immersion longer than 36 hours. Therefore, the thick oxide grown at higher temperatures was initially protective, and later rapidly detrimental to the substrate. The thermal oxide treatment at $600^{\circ} \mathrm{C}$ for 60 hours grew the most stable oxide layer, with the least weight loss in the aggressive environment.

Failure of oxide layers formed at $650^{\circ} \mathrm{C}$ was attributed to microcrack and micropore defects in the structure, resulting from thermal stresses placed on the oxide during its rapid formation. Longer treatment times at $600^{\circ} \mathrm{C}$ resulted in more rutile with fewer defects at the surface, creating a more immune layer over the reactive substrate.

In summary, the various research groups provided data supporting temperature's primary influence on the performance of a thermal oxidation treatment. According to MacDonald et al. 
(2004), Dearnley et al. (2004), and Güleryüz et al. (2004), treatments between 600 and $700^{\circ} \mathrm{C}$ would provide comparatively low surface roughness, increased surface microhardness and wear resistance, and a more stable, corrosion-resistant oxide layer. Much of the thermal oxidation reaction is dependent upon the selected temperatures, which affect the oxide thickness hardness, surface roughness and aluminum content, adhesion, and depth of the oxygen diffusion zone.

Each attribute is related to the overall performance of the oxide layer in a particular application, and in this study, the oxide layer must withstand conditions specific to ACPs. Therefore, the parameters of the study must test the susceptibility of fabricated oxide layers to corrosion and abrasion.

\subsection{Project goals}

Based on the location and surrounding environment of anterior cervical plates, three goals emerge in investigating surface modification via thermal oxidation of the Ti-6Al-4V alloy:

1. Determine if thermal oxidation is an effective treatment for corrosion resistance in this biomedical application

2. Determine whether a thermally oxidized sample can repassivate in a physiological media despite prior abrasion

3. Determine whether the process of thermal oxidation alters material characteristics, reducing the alloy's performance in an ACP application.

\subsection{Overview of method}

Temperatures of $600^{\circ} \mathrm{C}$ and $675^{\circ} \mathrm{C}$ were selected for thermal oxidation treatments in order to create reasonably thick, wear-resistant, corrosion resistant surfaces with appropriate adhesion, roughness, and ductility. Times of $1,4,8$, and 16 hours were chosen for each treatment.

The first goal was tested using open circuit (OC) and cyclic polarization (CP) tests according to ASTM F2129. Repassivation ability of Ti-6Al-4V, the second goal, was analyzed using 
potential-step tests. Material modification as a result of thermal oxidation was characterized using scanning electron microscopy (SEM) and atomic force microscopy (AFM) and quantified using hardness and microhardness measurements.

\section{MATERIALS AND PROCEDURE}

\subsection{Test plan overview}

Corrosion samples were separated into two groups: non-abraded and abraded. Non-abraded samples were designated with "N" and abraded samples were designated with "A." Samples were also designated with the treatment temperature and time to reference the thermal oxidation treatment during testing. The non-abraded and abraded groups underwent the same thermal oxidation treatments and surface analysis, but differed slightly in surface preparation, corrosion tests, and hardness tests. The non-abraded samples underwent open circuit (OC) and cyclic polarization $(\mathrm{CP})$ tests to evaluate corrosion resistance, and Rockwell hardness measurements to

determine any change in bulk properties. Abraded samples underwent abrasion and potential step tests to assess repassivation ability, and microhardness measurements to investigate the oxide hardness. The non-abraded group was analyzed first to determine if thermal oxidation fabricated oxide layers with effective corrosion resistance. Data from the abraded samples determined whether the thermally oxidized samples were able to repassivate in the physiological media despite prior abrasion and related surface damage. Atomic force microscopy (AFM) data and scanning electron microscope (SEM) were used to examine the alteration of the surface due to oxidation and testing.

\subsection{Materials}

Ti-6Al-4V rod stock was provided by Beaumont Hospitals, in Michigan. The chemical composition of the Ti-6Al-4V stock is included in Table I. 
Table I. Composition (at. \%) of Ti-6Al-4V rod stock, tested by Allvac.

\begin{tabular}{|l|l|l|l|l|l|l|l|l|}
\hline & $\mathrm{Ti}$ & $\mathrm{Al}$ & $\mathrm{V}$ & $\mathrm{Fe}$ & $\mathrm{O}$ & $\mathrm{C}$ & $\mathrm{N}$ & $\mathrm{Cu}$ \\
\hline Top & Bal & 6.50 & 4.04 & .17 & .19 & .040 & .03 & .02 \\
\hline Bottom & Bal & 6.30 & 4.11 & .19 & .16 & .048 & .03 & $<.01$ \\
\hline
\end{tabular}

Aluminum and vanadium act as $\alpha$-phase and $\beta$-phase stabilizers, respectively. The HCP $\alpha$ phase is rich in $\mathrm{Al}$, but depleted in $\mathrm{V}$, and precipitates out of the titanium matrix in the form of plates or needles, oriented within the BCC $\beta$ grains. Generally, the alloy is heated above 1000 ${ }^{\circ} \mathrm{C}$ to stabilize the $\beta$-phase and oil-quenched into the two-phase Widmanstatten structure. It is later annealed and cold worked at temperatures near, but not above the $\beta$ transus for fine-grained $\alpha$ and $\beta$ particles isolated at the grain boundaries.

In accordance with ASTM F1472, "Standard Specification for Wrought Titanium 6Aluminum -4Vanadium Alloy for Surgical Implant Applications," the as-rolled rod stock received from Beaumont was heat treated at $704^{\circ} \mathrm{C}$ for 2 hours and air cooled. The rod stock was then heated at $954^{\circ} \mathrm{C}$ for 1 hour, cooled in water, aged at $530^{\circ} \mathrm{C}$ for 4 hours, and air cooled. The $\beta$ transus was reported to be $1004^{\circ} \mathrm{C}$ at the top of the rod, and $1007^{\circ} \mathrm{C}$ at the bottom. As seen in Figure 2.1, the microstructure of Ti-6Al-4V is a compilation of fine $\alpha$ grains (light) and $\beta$ particles (dark).

\subsection{Sample preparation}

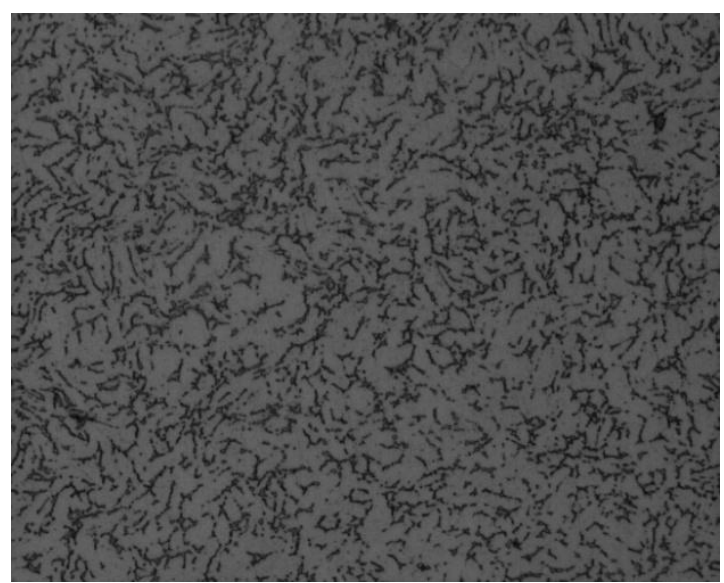

Figure 2.1 Microstructure of Ti-6Al-4V received from Beaumont Hospital, with light alpha grains bordered by dark beta regions.

The rods were sectioned into discs with a water-cooled abrasive saw and a diamond saw. All samples had a consistent diameter of 1.375 inches. Sample surfaces were ground from 35 grit to 
600 grit with silicon carbide sandpaper. Non-abraded samples were polished with $6 \mu \mathrm{m}$ diamond paste, and abraded samples were further polished with $3 \mu \mathrm{m}$ diamond paste.

Because each sample was cut, sanded, and polished by hand, samples were individually analyzed with an easyScan AFM before thermal oxidation. The samples were treated under atmospheric conditions in a Lindberg tube furnace at either 600 or $675^{\circ} \mathrm{C}$ for $1,4,8$, and 16 hours. One sample was treated for each temperature and time combination, and surface analysis was conducted after thermal oxidation treatments to assess individual changes.

Abraded samples underwent an abrasion process using a milling machine and the abrader pictured and detailed in Figure 2.2. The apparatus consisted of a hollow tube, a rod, an indenter holder, and a diamond-tip indenter. One end of the rod was inserted into the hollow tube and the other was inserted into an indenter holder that held the diamond-tip indenter as it abraded the surface. The hollow tube was held by the mil chuck. Before fitting into the hollow tube, the rod was heavily lubricated with a highly viscous synthetic lubricant to allow for free vertical motion and minimal horizontal motion of the fixture.
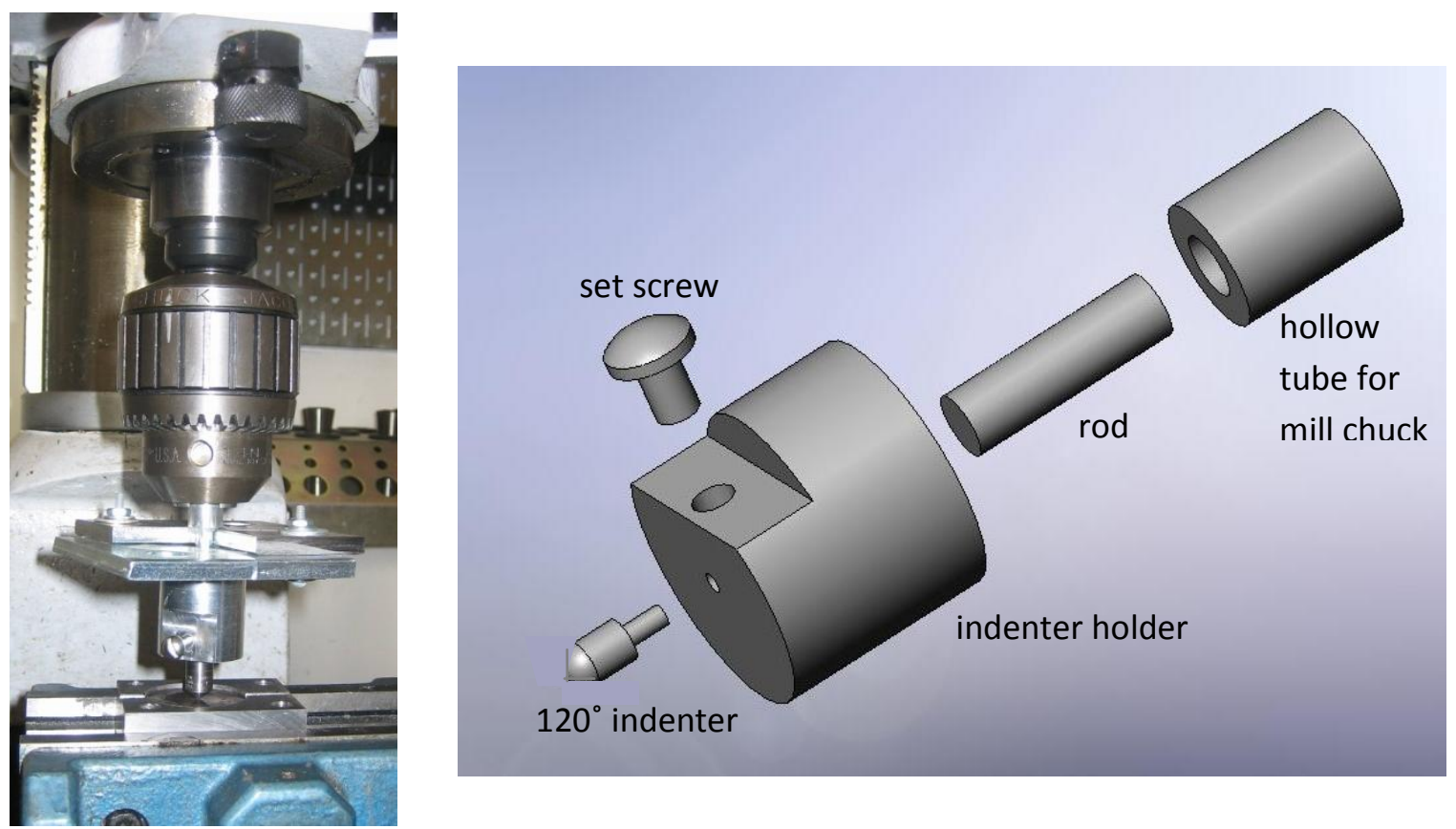

Figure 2.2. Abrasion apparatus for repassivation tests paused over recycled test sample (left). A SolidWorks representation shows the separate detailed pieces of the apparatus (right). 
A 395.2g weight was placed onto the fixture before the rod was inserted into the hollow bit. Added to the weight of the fixture and the diamond tip indenter, the final weight placed onto a sample was $471.5 \mathrm{~g}$, slightly less than the $500 \mathrm{~g}$ weight used by other researchers (Komotori et al. (2001), Komotori et al. (2007), Kahn et al. (1996). The load was applied to the surface at a rate of $4.4 \mathrm{~mm} / \mathrm{min}$, following literature and ASTM standard G171, "Scratch hardness of materials using a diamond stylus." A single abrasion was made across the diameter of each sample.

According to the literature, the depth of the scratch is dependent upon the oxide characteristics, such as hardness, roughness, and the depth of oxygen penetration. Therefore, the test required an abrasion system that repeatedly created the same abrasion, although the width and depth of scratches would vary from treatment to treatment. Following abrasion, samples were examined with an optical microscope, measuring sections of the scratch and comparing the scratch widths to ensure a consistent scratch across the sample. A typical abrasion section is pictured in Figure 2.3.

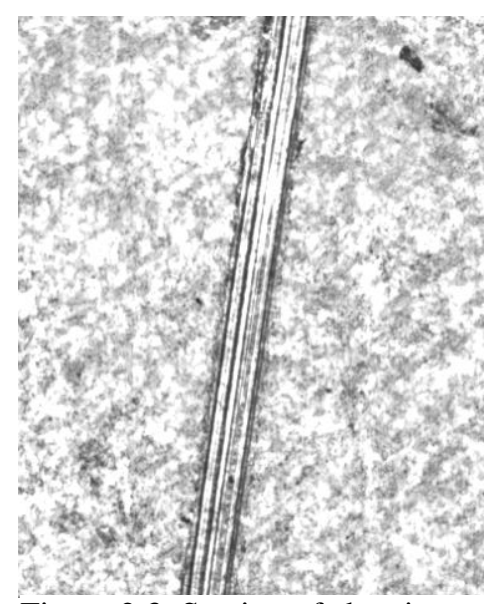

Figure 2.3. Section of abrasion across test sample. Width was measured for process consistency.

\subsection{Corrosion test methods}

In order to investigate a material's behavior in vitro, electrochemical tests apply potentials that assess the material's capabilities to withstand degradation. An applied potential simulates the potential difference between a sample and the human body, accelerating an in vivo corrosion reaction, which is monitored and controlled in the corrosion cell.

A corrosion cell, with anode, cathode, and electrolyte, creates the simulated physiological environment used in electrochemical tests of biomedical alloys. Seen in Figure 2.4, the corrosion cell is maintained at $37^{\circ} \mathrm{C}$. The phosphate buffered saline (PBS) solution is at a pH similar to the human body, 7.35 in the case of blood. The corrosion cell was composed of a three-electrode 
system, including a $\mathrm{KCl}$ saturated calomel electrode (SCE), platinum counter electrodes, and working electrode, or sample under investigation. A potentiostat applied the potential that drives the experiment and measured the resulting current of the sample.

For both non-abraded and abraded samples, a small hole was drilled into each sample and a stainless steel wire was looped through to create an electrical connection for testing. Silicone epoxy masked the samples after a specific surface area had been stamped and marked off. The same stamp created a uniform test surface area on the center of each sample. The epoxy covered the rest of the sample and the stainless steel wire, exposing only the stamped area for testing.

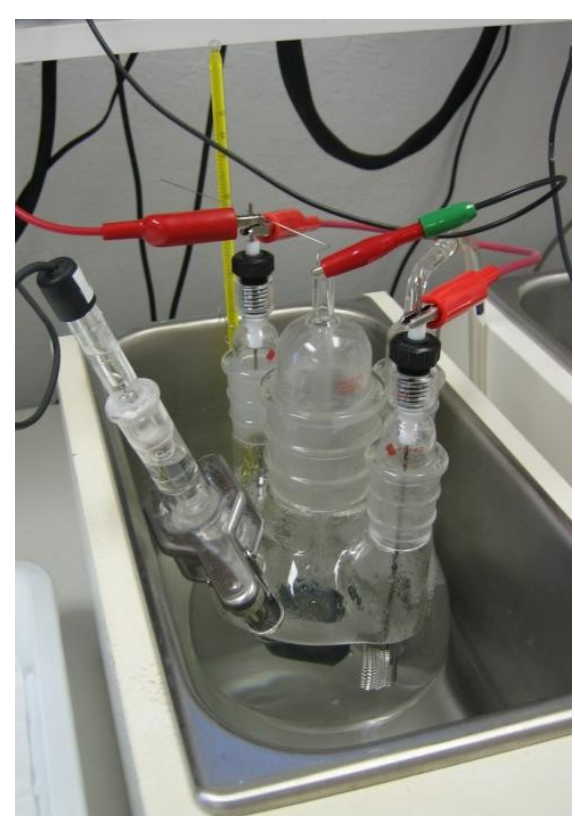

Figure 2.4. Corrosion cell with platinum counter electrodes, SCE, working electrode, and gas purge tube.

Heat shrink tube covered the wire that was not in direct contact with the hole drilled into the sample to ensure that only the specific marked off area of the sample would be tested. The diameter of the exposed area was measured twice and averaged to compute the surface area for the PowerCORR software.

\subsubsection{Open circuit tests}

Potentiodynamic polarization, or cyclic polarization $(\mathrm{CP})$, began with a nitrogen purge, ridding the solution of excess oxygen that could affect the redox reaction. The deaerated PBS served as the electrolyte for the rest of the test, as the nitrogen purge continued throughout. After the nitrogen purge, non-abraded samples were placed into the corrosion cell with no applied potential and open circuit (OC) measurements were taken. The resulting potential difference 
between the sample and solution was measured over 1 hour as the sample reached equilibrium, as seen in Figure 2.5. The final potential of the OC test is regarded as the open circuit potential, $\mathrm{E}_{\mathrm{OC}}$, and provided the starting point for the cyclic polarization tests.

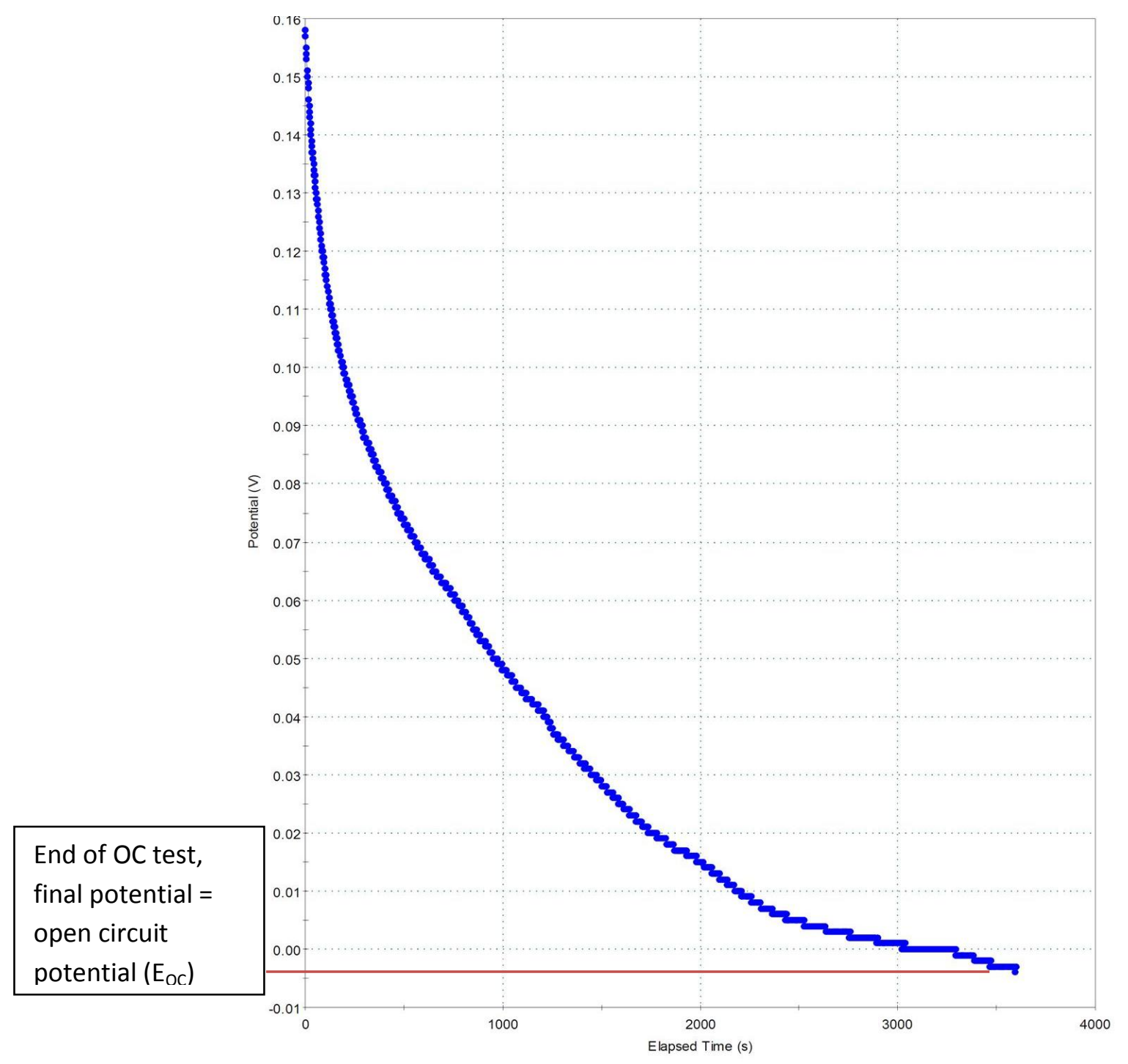

Figure 2.5. Open circuit test ends with open circuit potential $\left(\mathrm{E}_{\mathrm{OC}}\right)$, the potential difference between the sample and the environment as the sample reaches equilibrium in the PBS. The $\mathrm{E}_{\mathrm{OC}}$ is the starting potential for cyclic polarization test. 


\subsubsection{Cyclic polarization tests to assess corrosion resistance}

Potentiodynamic polarization cycles a sample through a set of applied potentials at a constant rate, with a maximum applied potential that is pertinent to the application conditions. The potentiodynamic polarization tests in this study followed ASTM standard F2129, "Conducting cyclic potentiodynamic polarization measurements to determine the corrosion susceptibility of small implant devices." Following the ASTM standard, a phosphate buffered solution (PBS) of pH 7.4 was deaerated using $99.99 \%$ pure nitrogen for at least 0.5 hours before each test, and continued to purge throughout the test. The corrosion cells were in a water bath, keeping the temperature of the solution at $37 \pm 1^{\circ} \mathrm{C}$ throughout the entire test. The temperature and $\mathrm{pH}$ were measured before and after each test.

As described previously, the $\mathrm{E}_{\mathrm{OC}}$ serves as the starting potential for the $\mathrm{CP}$ test. Previously, $\mathrm{CP}$ tests were initiated at potentials $100 \mathrm{mV}$ below the $\mathrm{E}_{\mathrm{OC}}$, negating the information determined by the OC test. However, current convention according to ASTM F2129 begins the test at $\mathrm{E}_{\mathrm{OC}}$, only applying potentials above the rest potential at $1 \mathrm{mV} / \mathrm{s}$. During the forward scan, applied potential was increased to a maximum potential, previously established in the experimental set up. In initial tests, applied potentials reached $800 \mathrm{mV}$, but to fully test the material above parameters that apply to the human body, later CP tests applied up to $1.2 \mathrm{mV}$ before cycling back down to the starting potential. In vivo rest potentials are usually below $+400 \mathrm{mV}$, therefore an $800 \mathrm{mV}$ potential limit included a factor of safety and was set by ASTM (Rosenbloom \& Corbett, 2007).

The reverse scan, or decrease of applied potential at the same rate as the forward scan, began directly after the maximum potential was reached.

As seen in the potentiodynamic polarization graph in Figure 2.6, the corrosion potential, or $\mathrm{E}_{\mathrm{CORR}}$, can also be measured using a $\mathrm{CP}$ test. As the equilibrium point between anodic and cathodic reactions, $\mathrm{E}_{\mathrm{CORR}}$ is helpful for determining the corrosion rate of a sample. However, this study focuses on the oxide layer's resistance to accelerated corrosion, and assesses whether or not 
the protective oxide will be a valid candidate in the repassivation study. Therefore, open circuit, breakdown, and repassivation potentials are more pertinent to the application of ACPs in this study.

Breakdown potential $\left(\mathrm{E}_{\mathrm{b}}\right)$, or the potential at which a pit is initiated, is defined as a sudden increase in current, greater than a decade, as seen in Figure 2.7

and Figure 2.8. A slow increase is not considered breakdown, by ASTM standards. A pit is initiated when the applied potential is large enough to break down the protective oxide layer and allow current to flow.

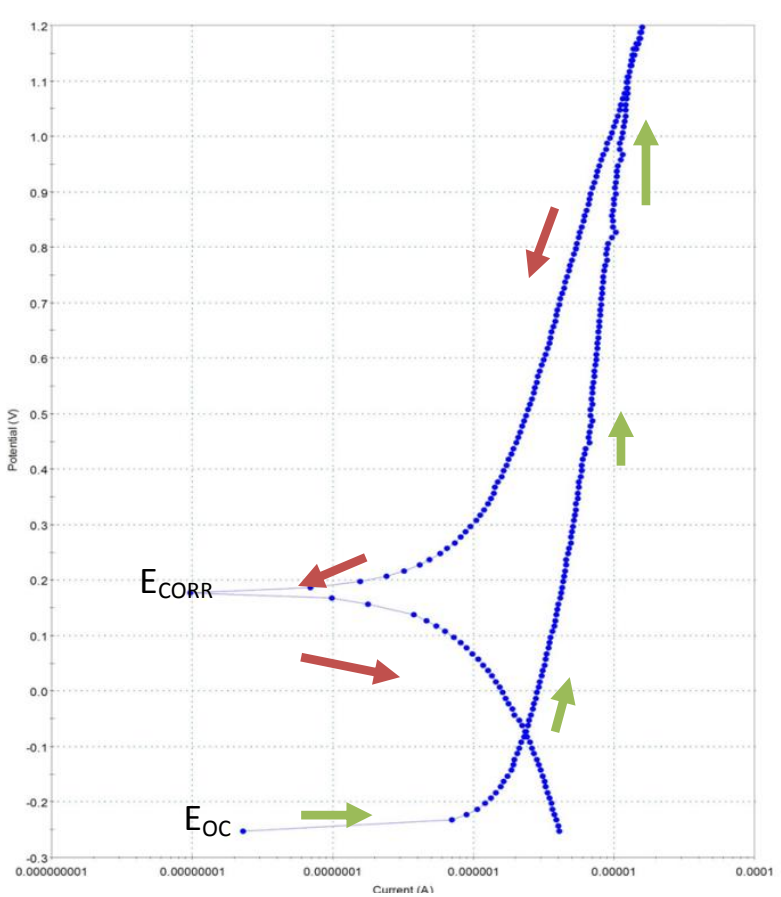

Figure 2.6. Example of potentiodynamic polarization

The decrease in applied current allows the sample to begin repairing its passive layer. curve, with green arrows highlighting forward scan, and red arrows depicting surface passivation during reverse scan.

While the hysteresis curve remains open, pits will not be able to initiate, but will continue to propagate at sites that have already initiated, as the passive layer has not been repaired and bare metal is still exposed to free electrons into the solution.

Repassivation graphically occurs as the sample cycles down through lower applied potential and the current line of the decreasing potential crosses over the current measurement of the increasing potential, as seen in Figure 2.7. Repassivation potentials are designated as Ep.

As the potential continues to decrease into a region where the metal was originally thermodynamically stable, the material is sometimes able to repair the damage, recreating a

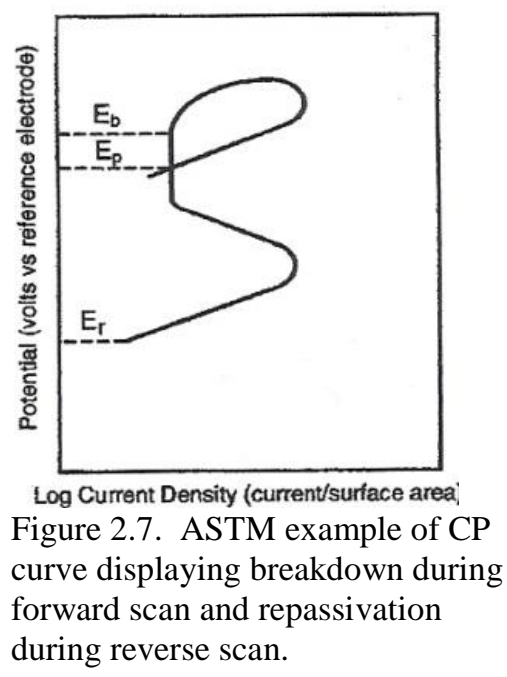


passive layer where the potential has been removed. However, as seen in Figure 2.8, not all samples complete their hysteresis curve, indicating that the sample cannot repair the damage done by the test. Pits continue to grow, as the sample is not able to re-oxidize and form a passive protective layer.

In this study, potentiodynamic polarization tests were conducted by the author at Confirmd, a biomedical device testing facility in San Carlos, CA. All equipment for

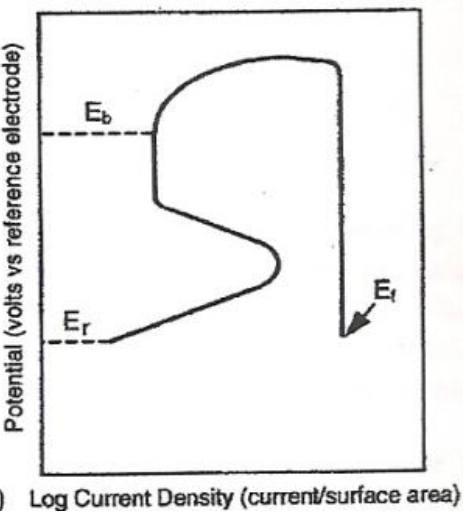

Figure 2.8. ASTM example of CP curve depicting breakdown, with no hysteresis curve or repassivation.

potentiodynamic tests, including the corrosion cell, electrodes (SCE, platinum mesh), potentiostat (Princeton Applied Research 273A), and software (PowerCORR), was property of Confirmd. Following the standard, the CP tests were started at the rest potential $\left(\mathrm{E}_{\mathrm{R}}, \mathrm{E}_{\mathrm{OC}}\right)$ determined by the $\mathrm{OC}$ tests, and were conducted at a rate of $1 \mathrm{mV} / \mathrm{min}$. Any breakdown was noted and included in the final report, along with other findings.

\subsubsection{Potential step tests to assess repassivation ability}

A potential step test is similar to the $\mathrm{CP}$ test, but the applied potential is controlled by the investigator, not the computer. Instead of changing the potential at a set rate, as in potentiodynamic testing, potential steps change the potential by a set amount at the discretion of the investigator. The potential is held until that section of the test is concluded and the potential is changed, and the resulting current is measured throughout.

The potential hold test, unlike a CP test, monitors the resulting current at a single applied potential. The potential hold can provide insight as to whether or not the material exhibits breakdown and repassivation when a specific potential is applied, and is useful in determining the behavior of an abraded or damaged sample. 
At the surface of the sample, the oxide provides a protective barrier between the substrate and the liquid. An increased potential difference between the two relies upon the passive oxide layer to prevent electrons and ions from leaving the metal. However, a large increase in potential may cause a breakdown in the protective oxide layer, leaking electrons out into the surrounding solution, and increasing the current monitored by the computer. If a material is able to repassivate by reconstructing the passive layer through a series of chemical reactions, the current of electrons flowing out into the solution will decrease.

During potential step tests, the corrosion cell was held in a water bath at $37 \pm 1{ }^{\circ} \mathrm{C}$, and the $\mathrm{pH}$ and temperature of the PBS test solution were measured before and after each test. However, no open circuit potential was measured after the cell was deaerated for at least 30 minutes.

When the sample was submerged into the solution, no potential was applied and the resulting current was measured. As the current approached zero and a steady state was reached, the first $200 \mathrm{mV}$ step in potential was applied. Once a steady state was again achieved, another $200 \mathrm{mV}$ was applied, adding to a total $400 \mathrm{mV}$. The process was repeated until at least $800 \mathrm{mV}$ had been reached.

\subsubsection{Surface characterization and microscopy}

Each sample was measured for surface roughness using a Nanosurf easyScan atomic force microscope in AC mode, with a vibrational amplitude of 700 and set point of $44-48 \%$. Set point and scan rate varied depending on the roughness of the sample surface, and all scans were over a $25 \mu \mathrm{m} \times 25 \mu \mathrm{m}$ area.

Average roughness measurements $\left(\mathrm{R}_{\mathrm{a}}\right)$ were taken three times for each sample and averaged. Measurements were taken before and after thermal oxidation, and after cyclic polarization tests in the case of non-abraded samples. AFM images obtained before and after thermal oxidation are presented in Figure 2.8, and the resulting change in surface roughness can be seen in Figure 2.9. 
Average roughness values changed $20-40 R_{a}$ for samples treated at $600^{\circ} \mathrm{C}$ and $46-260 R_{a}$ for samples treated at $675^{\circ} \mathrm{C}$.
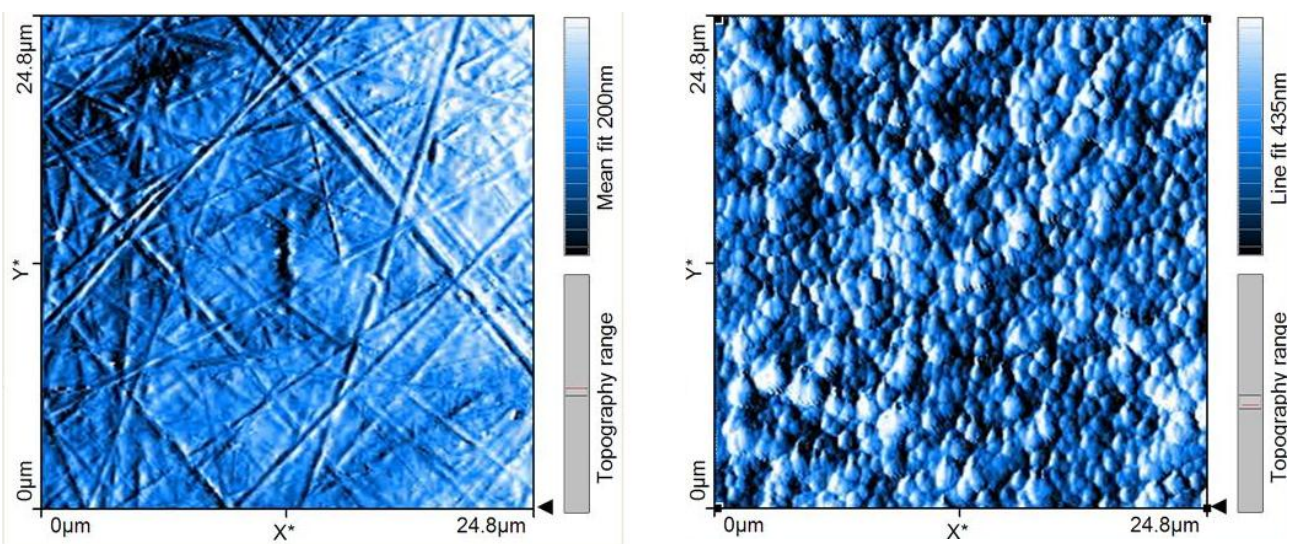

Figure 2.9. AFM scan of sample surface before thermal oxidation treatment (a) and after treatment at $600^{\circ} \mathrm{C}$ for 16 hours (b).

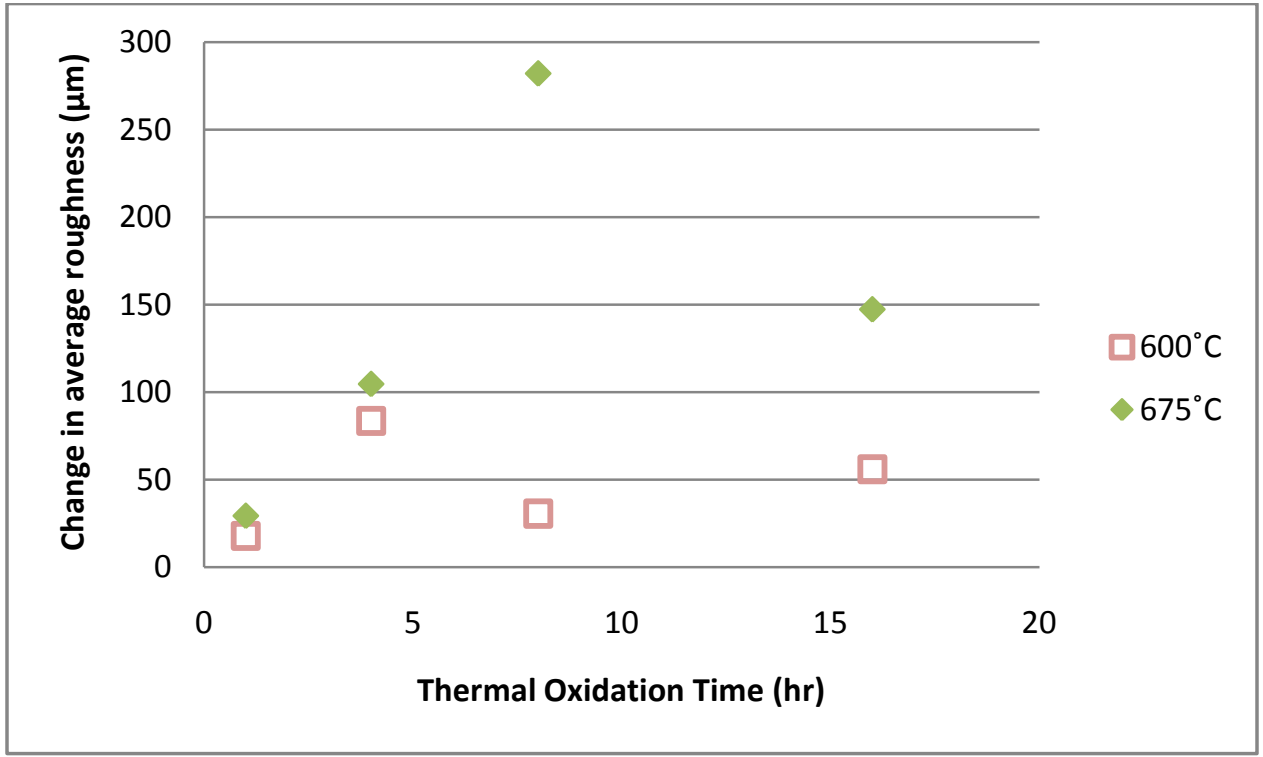

Figure 2.10. Surface roughness after thermal oxidation of abraded samples at $600^{\circ} \mathrm{C}$ and $675^{\circ} \mathrm{C}$. Measurements taken before abrasion and potential step tests.

Scanning electron microscopy with an FEI Quanta 200, 15-20keV and spot size of 4 or 5, provided qualitative analysis of oxide growth after each treatment, and observation of delamination as a result of abrasion. 
To assess the effect of thermal oxidation on bulk microstructure, the hardness (HRc, $150 \mathrm{~kg}$ load) of non-abraded samples was measured using a Rockwell C indenter. Hardness values were compared before and after heat treatments to determine whether a change in microstructure had taken place as a result of aging. In addition, the microstructure of samples was analyzed for any change in grain size or reduction in volume fraction of grain species.

Microhardness of abraded samples was measured with a Buehler MICROMET® tester (HV, $100 \mathrm{~g}$ load) after thermal oxidation and before abrasion to analyze the hardness of the coating in relation to the oxidation treatment.

After corrosion tests, cross-sections of heat-treated samples were mounted in Bakelite, ground, polished, and etched with Kroll's solution $\left(94 \% \mathrm{H}_{2} \mathrm{O}, 4 \% \mathrm{HNO}_{3}, 2 \% \mathrm{HF}\right)$. The microstructures of the heat treated samples were compared through optical microscopy, contrasting the microstructure with temperature and time of treatment. 


\section{RESULTS}

\subsection{Research objectives}

The procedures in the previous section were used to satisfy the following objectives regarding the corrosion and repassivation study of thermally oxidized Ti-6Al-4V.

1. Determine if thermal oxidation is an effective treatment for corrosion resistance in this biomedical application

2. Determine whether a thermally oxidized sample can repassivate in a physiological media despite prior abrasion

3. Determine whether the process of thermal oxidation alters material characteristics, reducing the alloy's performance in an ACP application.

\subsection{Evaluation of corrosion resistance of thermal oxidation}

\subsubsection{Open circuit results}

Oxidation treatments at 600 and $675^{\circ} \mathrm{C}$ resulted in increased open circuit potentials compared to the untreated sample as seen in Figure 3.1. Samples treated at $675^{\circ} \mathrm{C}$ had more noble $\mathrm{E}_{\mathrm{OC}}$ values than samples treated at $600^{\circ} \mathrm{C}$. Samples treated at $600^{\circ} \mathrm{C}$ show a steady increase in $\mathrm{E}_{\mathrm{OC}}$

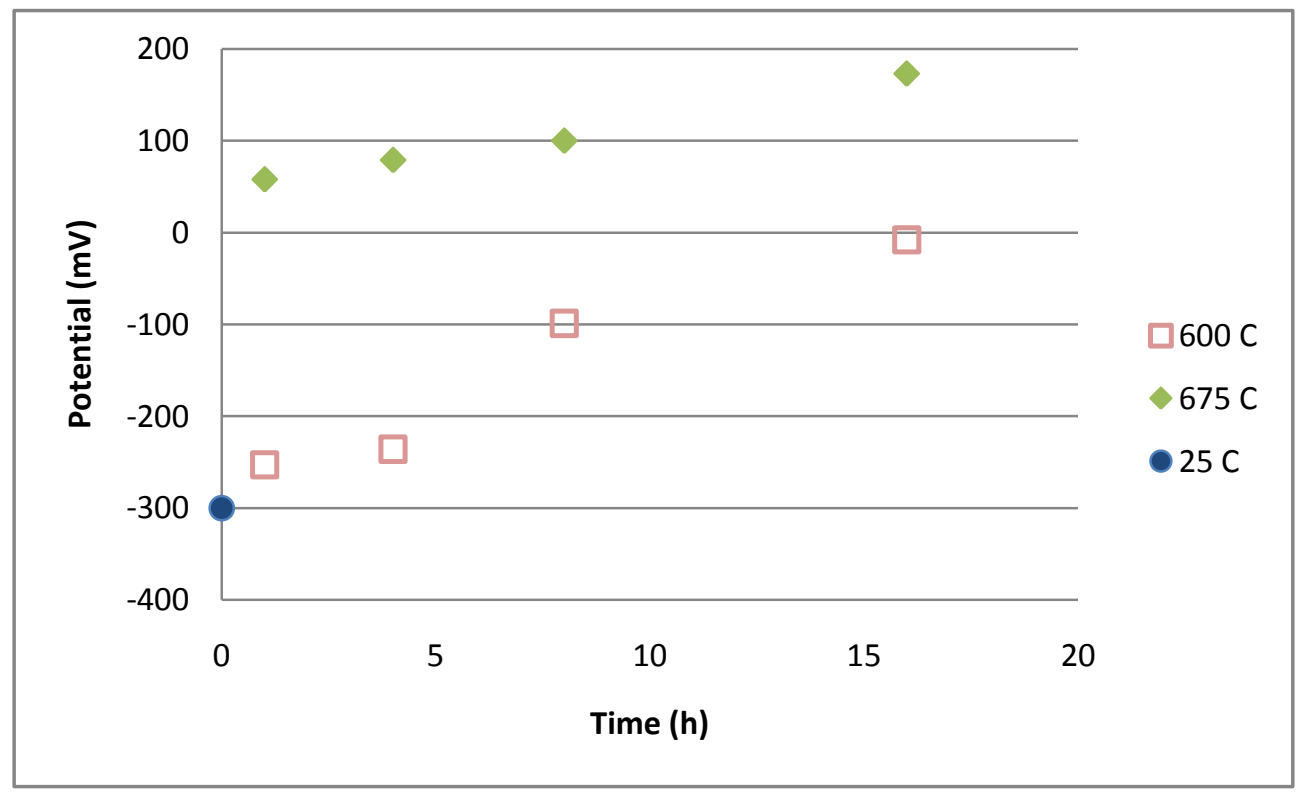

Figure 3.1. Open circuit values for untreated sample and samples treated at $600^{\circ} \mathrm{C}$ and $675^{\circ} \mathrm{C}$. 
values with time. Samples treated at $675^{\circ} \mathrm{C}$ experienced a dramatic increase in $\mathrm{E}_{\mathrm{OC}}$ after 1 hour of thermal oxidation, but a slight increase in samples treated for longer times.

\subsubsection{Cyclic polarization results}

The majority of cyclic polarization tests did not result in breakdown, as shown in Table II. These samples all showed CP curves similar to that in Figure 3.2. In each case, no evidence of breakdown was observed, and the reverse scan displayed lower current values than the forward scan.

Table II. Breakdown values for CP tests of thermally oxidized Ti-6Al-4V

\begin{tabular}{|c|c|c|}
\hline Temperature $\left({ }^{\circ} \mathrm{C}\right)$ & Time $(\mathrm{hr})$ & $\mathrm{E}_{\mathrm{b}}(\mathrm{mV})$ \\
\hline 25 & 0 & none \\
\hline \multirow{3}{*}{600} & 1 & none \\
\cline { 2 - 3 } & 4 & 364 \\
\cline { 2 - 3 } & 8 & none \\
\cline { 2 - 3 } & 16 & none \\
\hline \multirow{5}{*}{675} & 1 & none \\
\cline { 2 - 3 } & 4 & none \\
\cline { 2 - 3 } & 8 & 1170 \\
\cline { 2 - 3 } & 16 & none \\
\hline
\end{tabular}




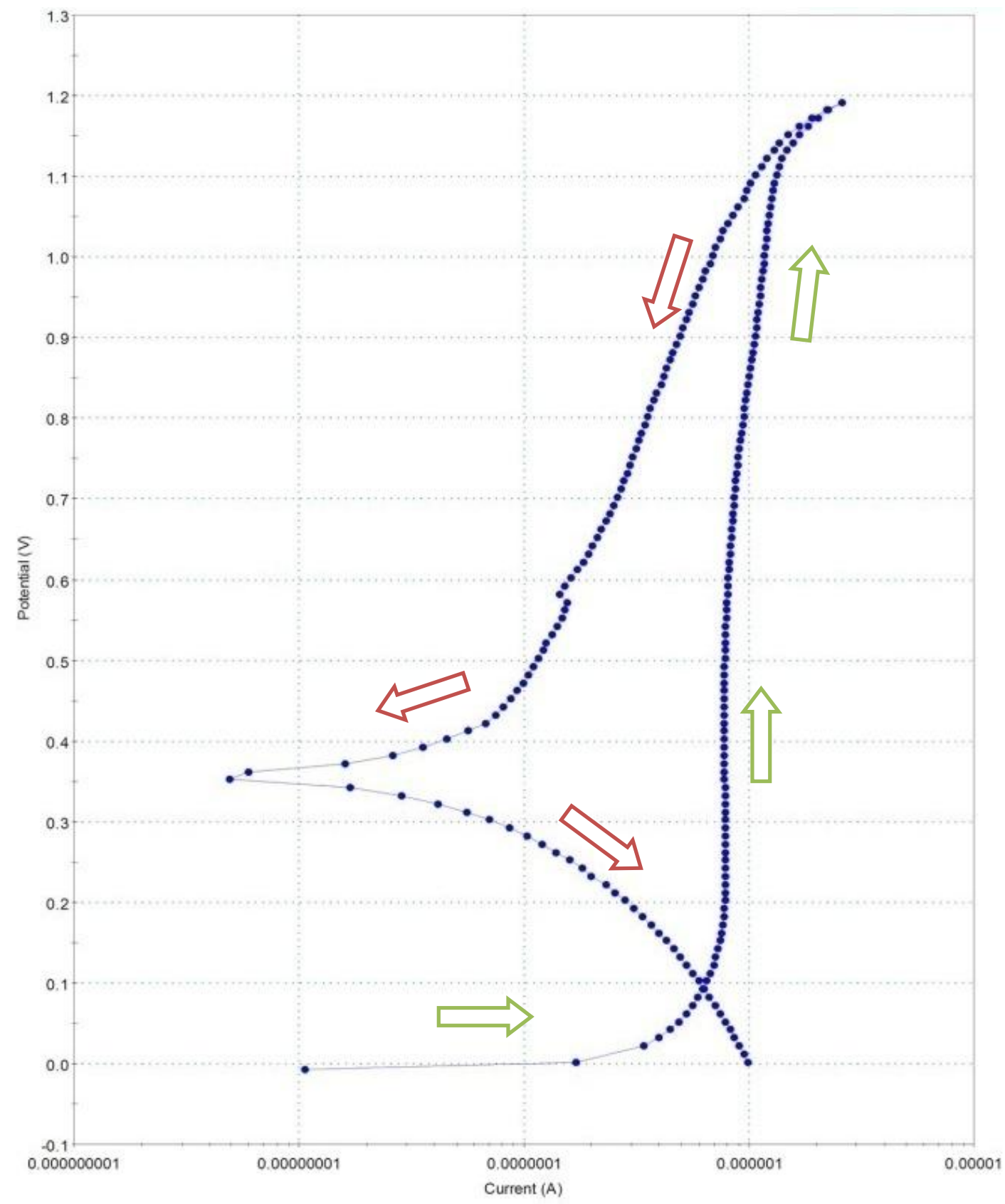

Figure 3.2. Cyclic polarization scan of sample treated at $600^{\circ} \mathrm{C}$ for 16 hours, with green arrows indicating forward scan and red arrows tracking reverse scan, displaying no breakdown and reduced reverse scan current.

However, N-600-4 and N-675-8 exhibited breakdown during cyclic polarization tests. N600-4 broke down at $364 \mathrm{mV}$, causing an increase in the current flow (Figure 3.3). 
According to

the ASTM standard

used in the cyclic

polarization tests,

the protection

potential, $\mathrm{E}_{\mathrm{p}}$, is

indicated when the

reverse scan

intersects the

forward scan at a

value lower than

the breakdown

potential, $\mathrm{E}_{\mathrm{b}}$. N-

600-4 was able to

repassivate, but far

below the potential

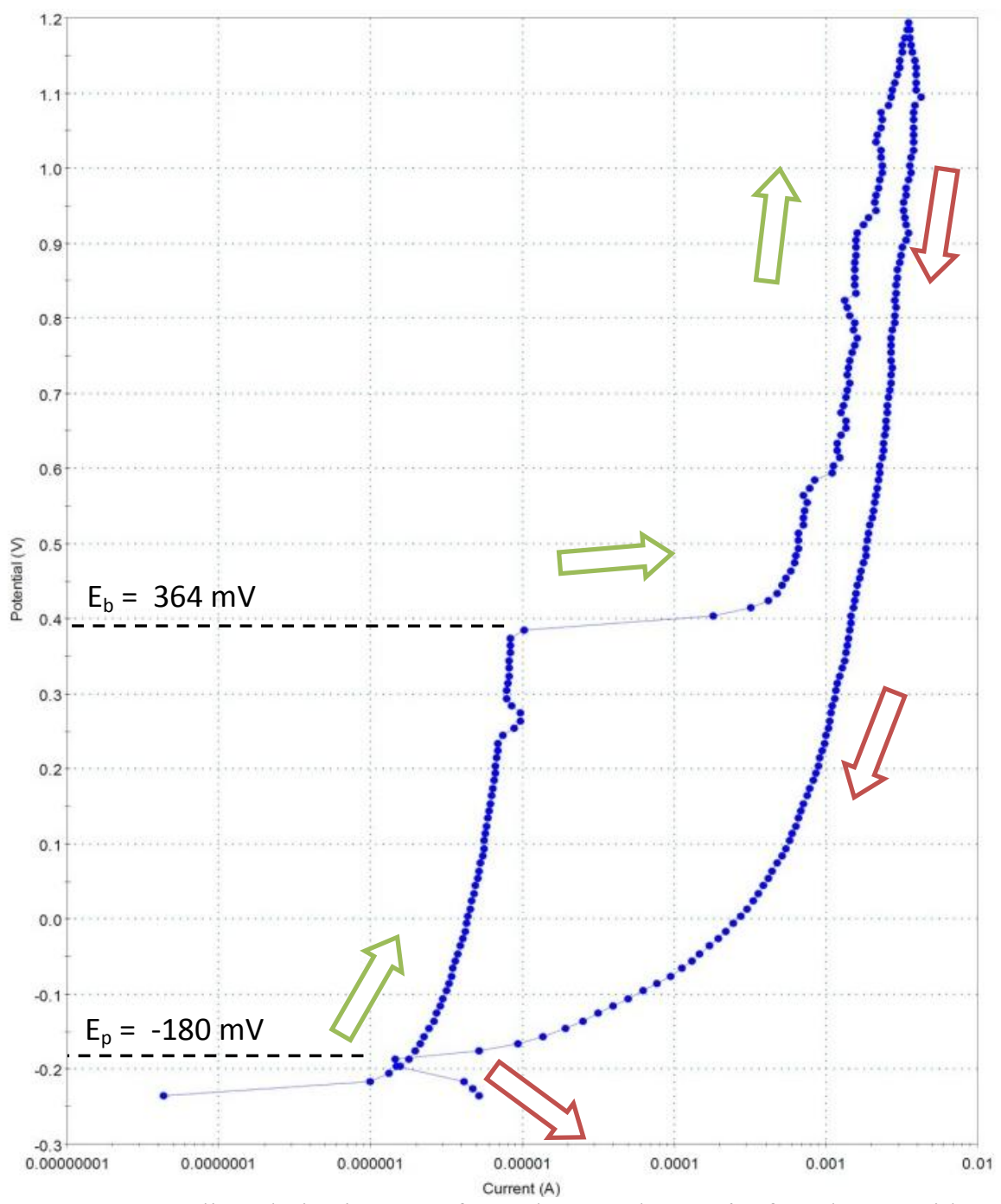

Figure 3.3 Cyclic polarization test of sample treated at $600^{\circ} \mathrm{C}$ for 4 hours, with at which it broke breakdown at $364 \mathrm{mV}$ and repassivation at $-180 \mathrm{mV}$.

down. Images of possible pits on the surface of N-600-4 after the polarization tests are presented in Figure 3.4.

Figure 3.4. Pits from cyclic polarization scan, located on the surface of Ti-6Al-4V sample thermally oxidized at $600^{\circ} \mathrm{C}$ for 4 hours.

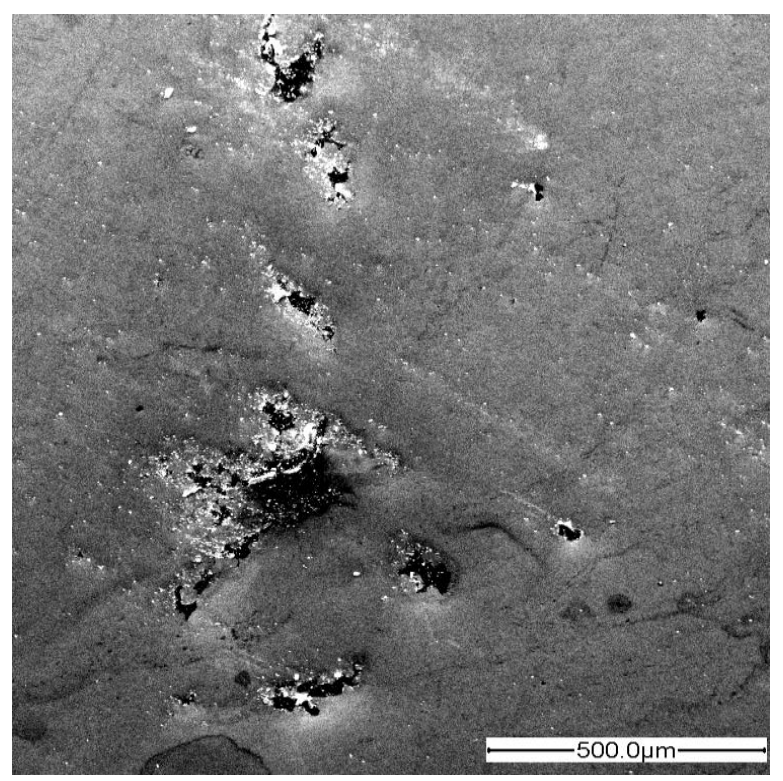


$\mathrm{N}-675-8$ broke down at $1.17 \mathrm{~V}$, a potential above physiological relevance to the human body. As seen in Figure 3.5, the reverse scan did not cross over the forward scan, indicating that the pit propagated for the duration of the reverse scan. However, no pits were detected on the surface of N-675-8 with the SEM.

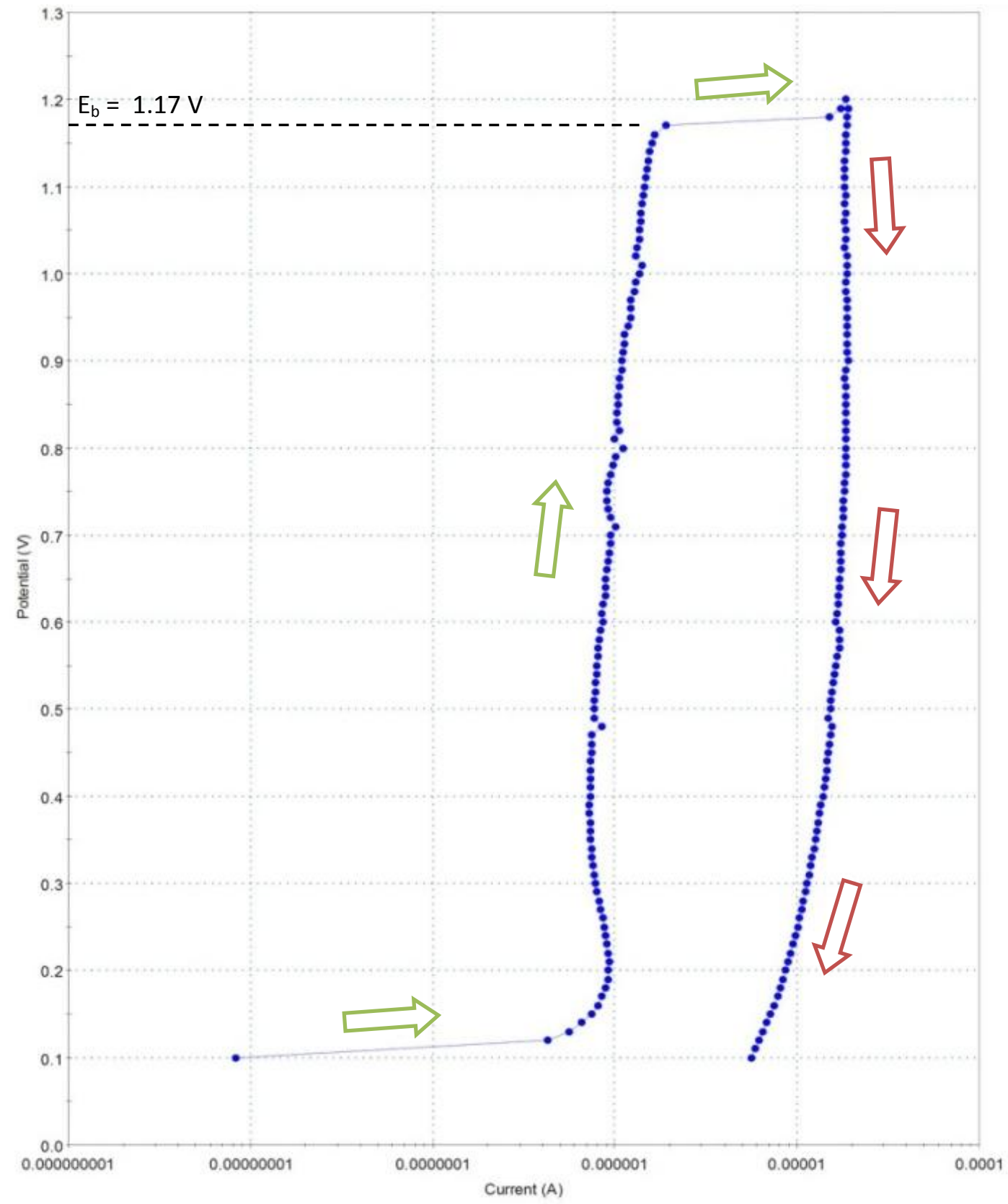

Figure 3.5. Cyclic polarization of Ti-6Al-4V sample thermally oxidized at $675^{\circ} \mathrm{C}$ for 8 hours, with breakdown at $1.17 \mathrm{~V}$ and no hysteresis. 
The CP scan of N-600-8 was also unlike Figure 3.6, in its shape and display of current increases. Although there was an increase in current, beginning at $400 \mathrm{mV}$, the increase was not large enough to declare breakdown by ASTM standards. However, the gradual current increase in the forward scan was overlapped during the reverse scan, and the reverse scan current remained at a higher value throughout the entire reverse scan. No pits were detected on the surface of N-600-8 with the SEM.

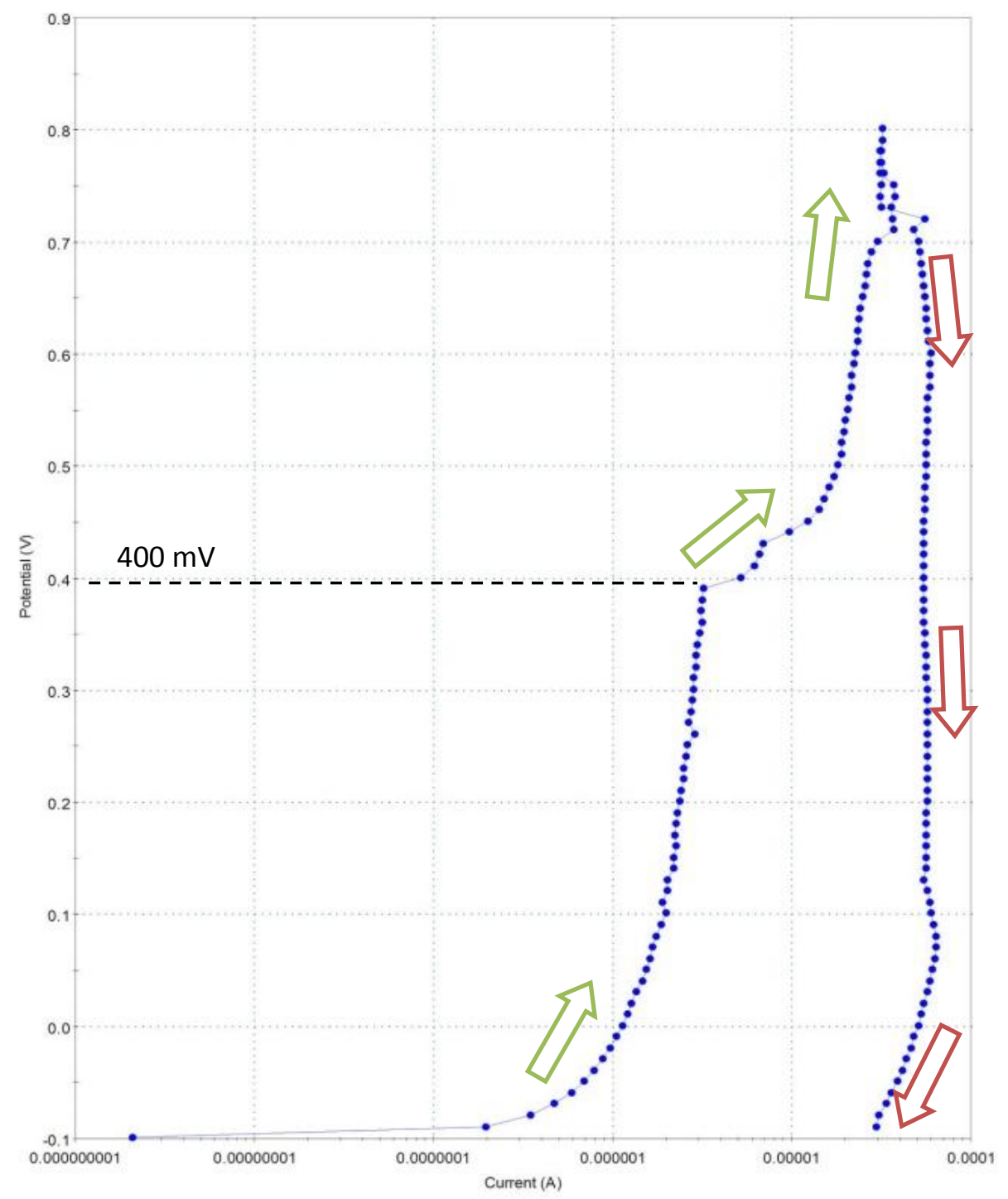

Figure 3.6. Cyclic polarization scan of Ti-6Al-4V sample thermally oxidized at $600^{\circ} \mathrm{C}$ for 8 hours with gradual increase in current and no hysteresis. 


\subsection{Evaluation of repassivation ability}

The samples were abraded once under a $471.5 \mathrm{~g}$ weight at $4.4 \mathrm{~mm} / \mathrm{s}$ after TO treatments, masked with silicone epoxy to expose a uniform test area, and tested the next day after the epoxy cured. The prior abrasion simulated damage during surgery, in which a sample may be abraded and later immersed into human body fluids.

The abraded samples underwent a step polarization sequence, in which potentials of 0,200 , $400,600,800 \mathrm{mV}$, and $1 \mathrm{~V}$ were applied. After the application of a potential step, a decreasing current represented repassivation of the sample.

The potential step graph for A-0 can be seen in Figure 3.7. The sample displays the ability to repassivate until $400 \mathrm{mV}$ are applied, and the decreasing current trend is interrupted by sudden small increases in current. However, the sample continues to repassivate, and the current continues to decrease. When $600 \mathrm{mV}$ is applied, the sample has more sudden increases in current along its decreasing current path, but the recovery places the current measurements in line with the shape of the curve. The application of $800 \mathrm{mV}$ causes many sudden leaks of current and repassivation. 


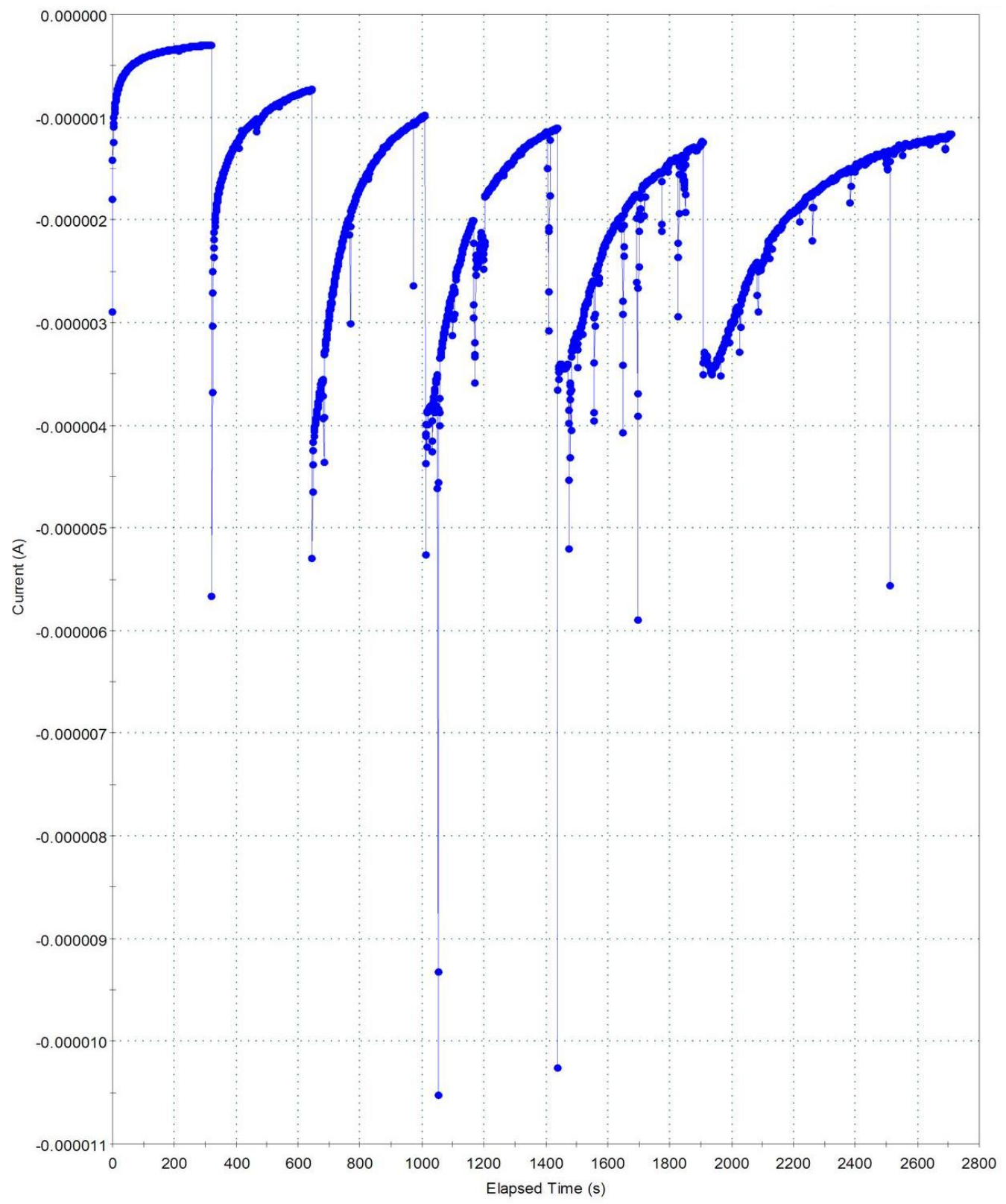

Figure 3.7. Potential step test of untreated sample, displaying repassivation ability at every potential step. 
As seen in Figure 3.8, all current trends decreased after each potential application to the sample treated at $600^{\circ} \mathrm{C}$ for 1 hour. Unlike A-O, there were very few potential leaks after polarizing at each potential, although a slight increase in current occurred as no potential was applied and the sample was reaching equilibrium. The rate of current decrease was higher for applied potentials $600 \mathrm{mV}, 800 \mathrm{mV}$, and $1 \mathrm{~V}$, but the sample was able to repassivate after each polarization step.

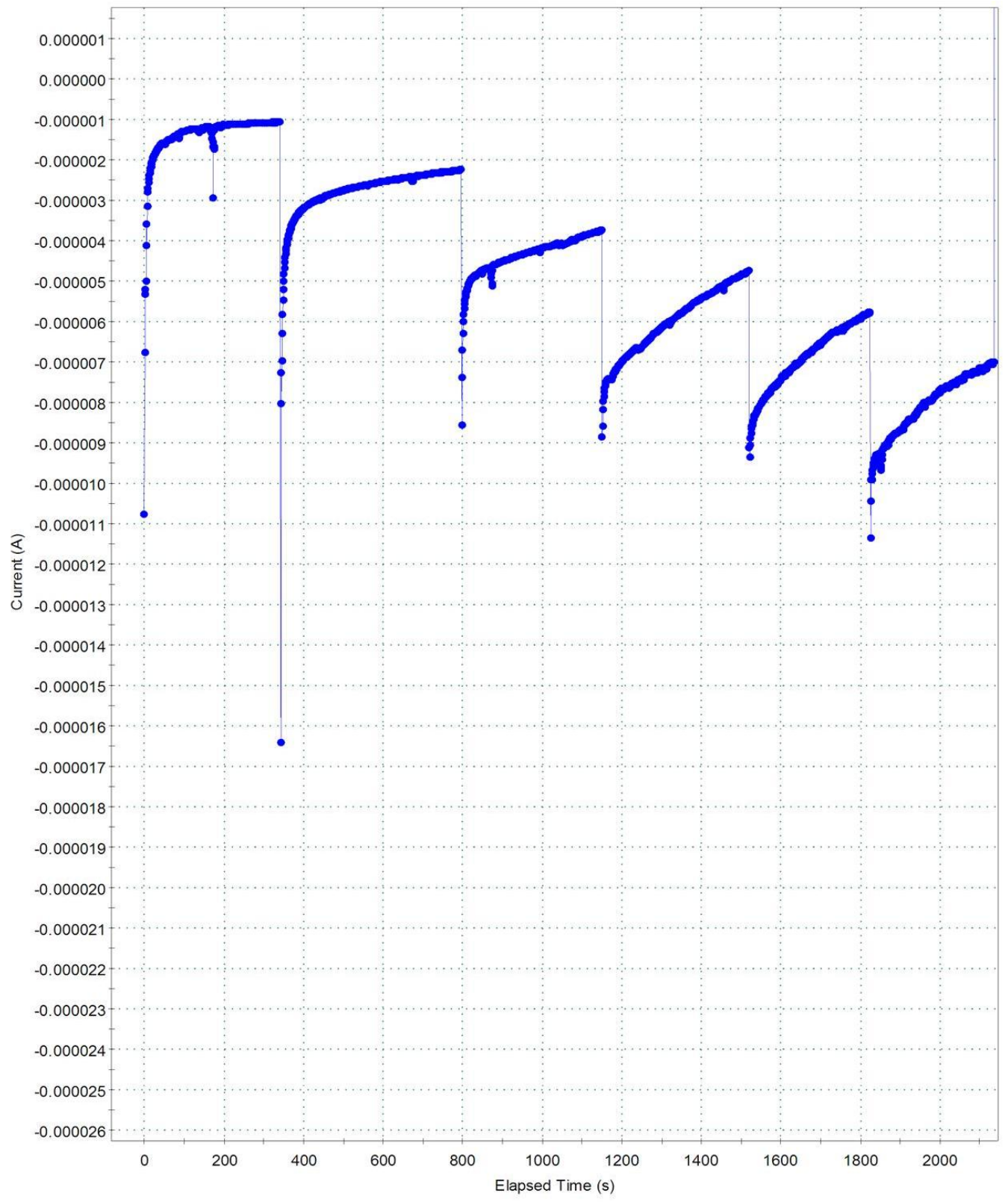

Figure 3.8. Potential step graph of sample treated at $600^{\circ} \mathrm{C}$ for 1 hour, repassivating at every applied potential. 
The sample treated at $600^{\circ} \mathrm{C}$ for 4 hours showed inconsistent attempts to repassivate after $200 \mathrm{mV}$ was applied, as seen in Figure 3.9. After the current at the $200 \mathrm{mV}$ application began to decrease and A-600-4 was polarized to $400 \mathrm{mV}$ and $600 \mathrm{mV}$, the recovery was not smooth or consistent, with great current fluctuations.

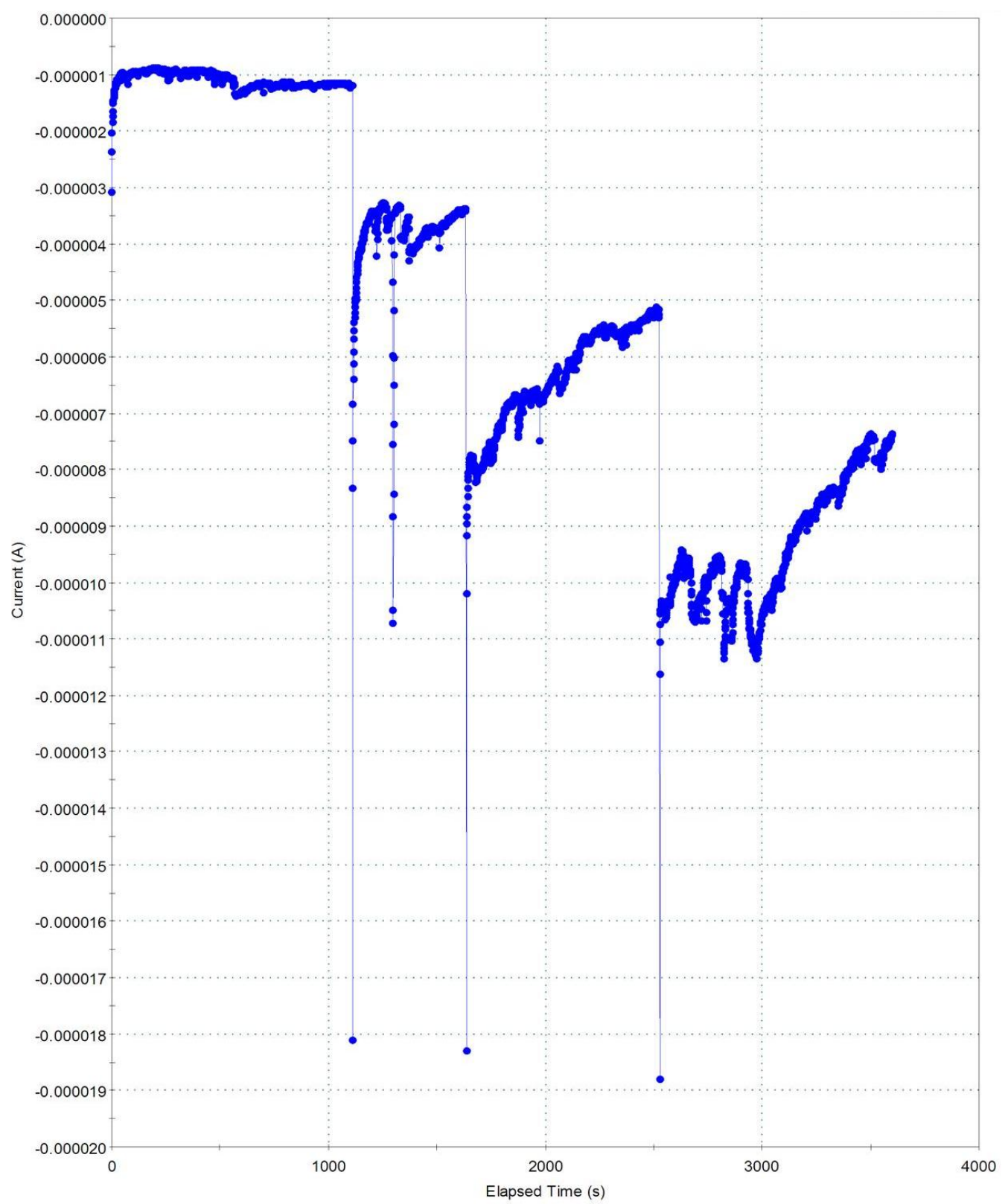

Figure 3.9. Potential step graph of sample thermally oxidized at $600^{\circ} \mathrm{C}$ for 4 hours, with difficulty repassivating. 
Breaks in the oxide layer found on the surface of sample A-600-4 after repassivation tests are shown in Figure 3.10. Figure 3.10a shows two possible pits, with the larger right pit about a $20 \mu \mathrm{m}$ diameter. All pits and breaks in oxide layer were not in the abrasion, but $200 \mu \mathrm{m}$ away, as seen in Figure 3.10b.
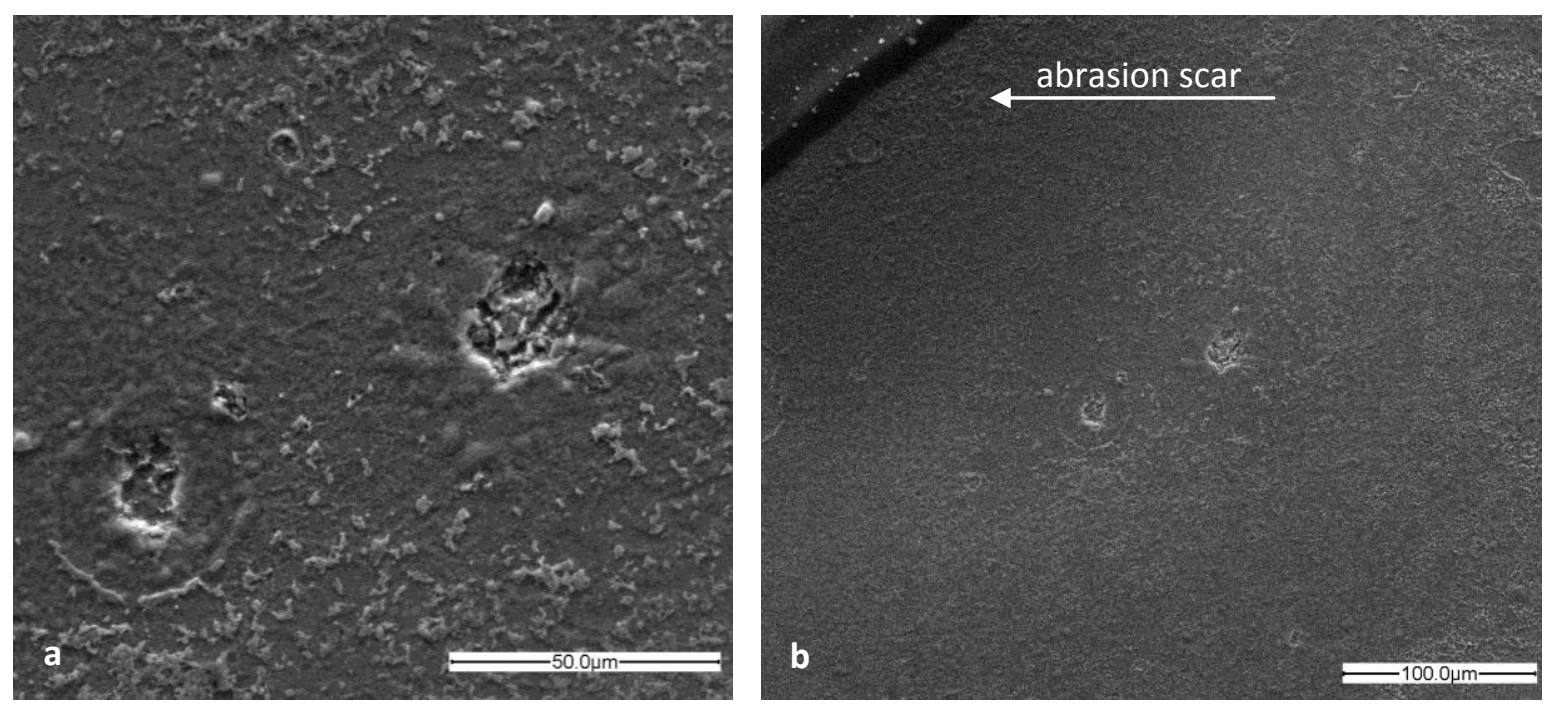

Figure 3.10. Pits on the surface of abraded sample treated for 4 hours at $600^{\circ} \mathrm{C}$ (a), view of pits, formed away from scar of abrasion in upper left corner (b).

The response of the sample treated at $600^{\circ} \mathrm{C}$ for 8 hours (Figure 3.11) was similar to the sample treated for 4 hours, but the current fluctuations were seen mostly in the $400 \mathrm{mV}$ application. After a constant applied potential of $400 \mathrm{mV}$, the sample was able to repassivate, and the higher potentials were applied. Each higher potential displayed a slight decreasing current, indicating that the sample was able to repassivate, although trends were not as smooth as the current resulting from the $200 \mathrm{mV}$ polarization. Unlike samples treated for shorter times, the current began at a positive value and decreased, where the current began at negative values for A0, A-600-4, and A-600-8. 


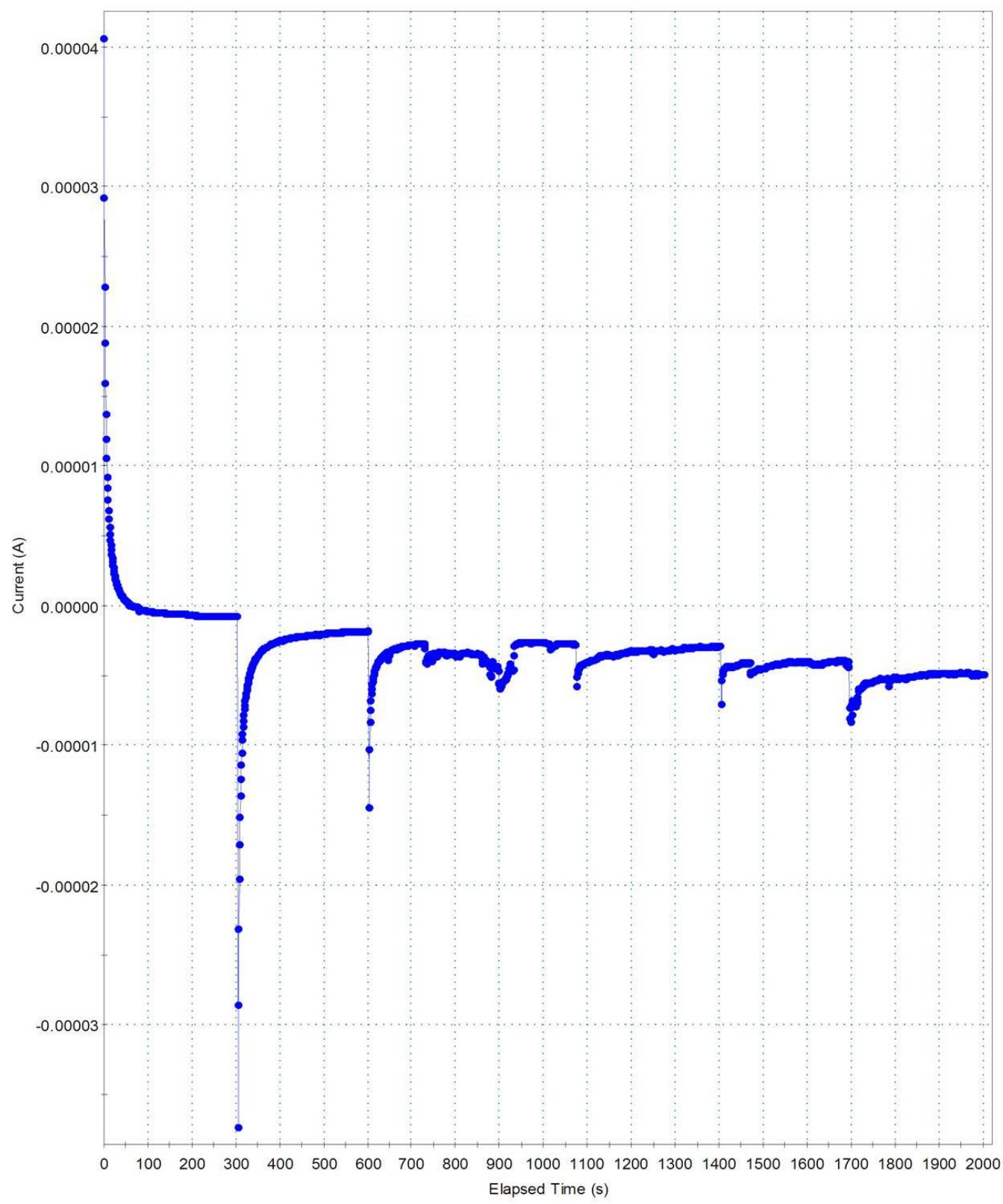

Figure 3.11. Potential step test of sample treated at $600^{\circ} \mathrm{C}$ for 8 hours, with repassivation difficulty at $400 \mathrm{mV}$ application.

Repassivation was also seen in the sample treated at $600^{\circ} \mathrm{C}$ for 16 hours (Figure 3.12) which did not breakdown during the CP scans. The current with no applied potential was initially positive and decreasing, like A-600-8. A small current increase occurred during the $400 \mathrm{mV}$ polarization, but the sample repassivated and the current decreased. The current also increased 
for 30 seconds during the $600 \mathrm{mV}$ polarization, but decreased and indicated repassivation. Both the $800 \mathrm{mV}$ and $1 \mathrm{~V}$ showed decreasing current.

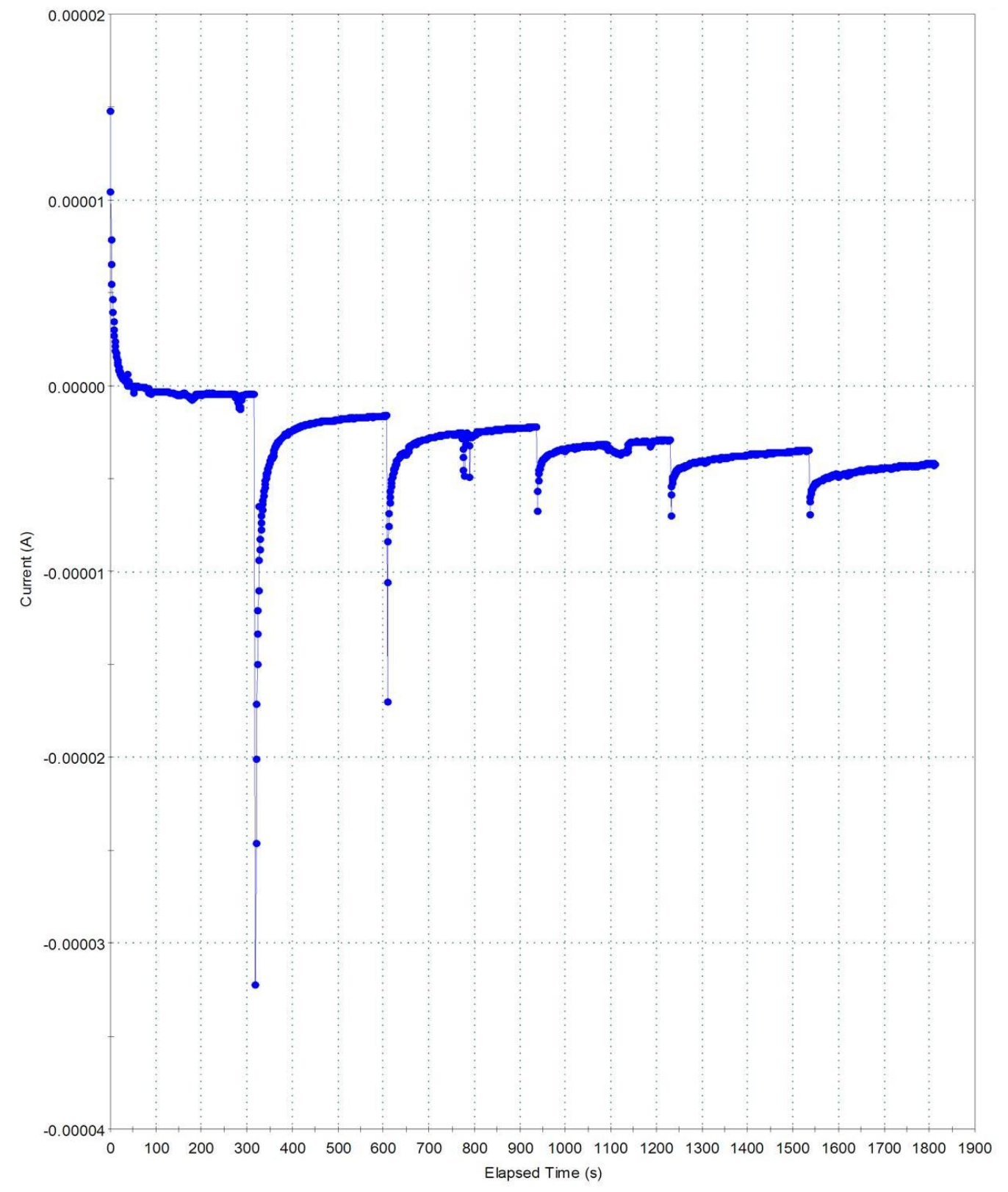

Figure 3.12. Potential step of sample treated at $600^{\circ} \mathrm{C}$ for 16 hours showed repassivation ability. 
The samples treated at $675^{\circ} \mathrm{C}$ had similar results as the samples treated at $600^{\circ} \mathrm{C}$, with most polarization resulting in a decreasing current.

Seen in Figure 3.13, the current scan of the sample treated at $675^{\circ} \mathrm{C}$ for 1 hour is initially positive when no potential is applied, and approaches zero before being polarized to $200 \mathrm{mV}$. Decreasing current trends from 200, 400, 600, 800mV, and $1 \mathrm{~V}$ are all smooth.

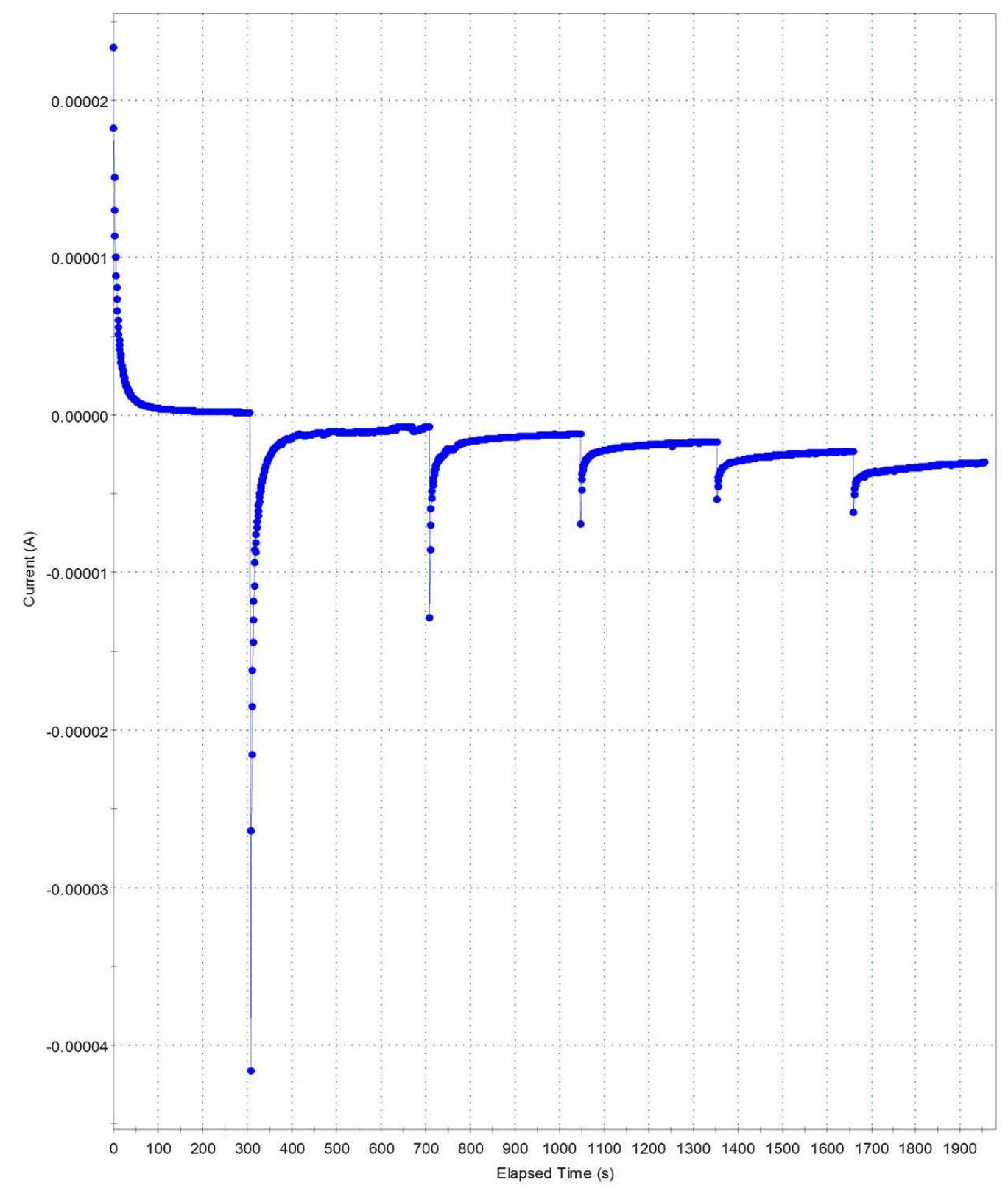

Figure 3.13. Potential step graph of sample treated at $675^{\circ} \mathrm{C}$ for 1 hour, with excellent repassivation ability. 
The sample treated at $675^{\circ} \mathrm{C}$ for 4 hours also began at a positive current (Figure 3.14), which decreased as no potential was applied. The applied current of $200 \mathrm{mV}$ led to a decrease in current, with a small increase and decrease during the approach towards 0A. Another slight increase and decrease was seen when A-675-4 was polarized to $400 \mathrm{mV}$, and again when $1 \mathrm{~V}$ was applied.

Similar to CP tests, $1.2 \mathrm{~V}$ was applied to investigate the capability of the material. Despite current fluctuations throughout the recovery process, the overall current trend decreased and approached zero, indicating repassivation at $1.2 \mathrm{~V}$.

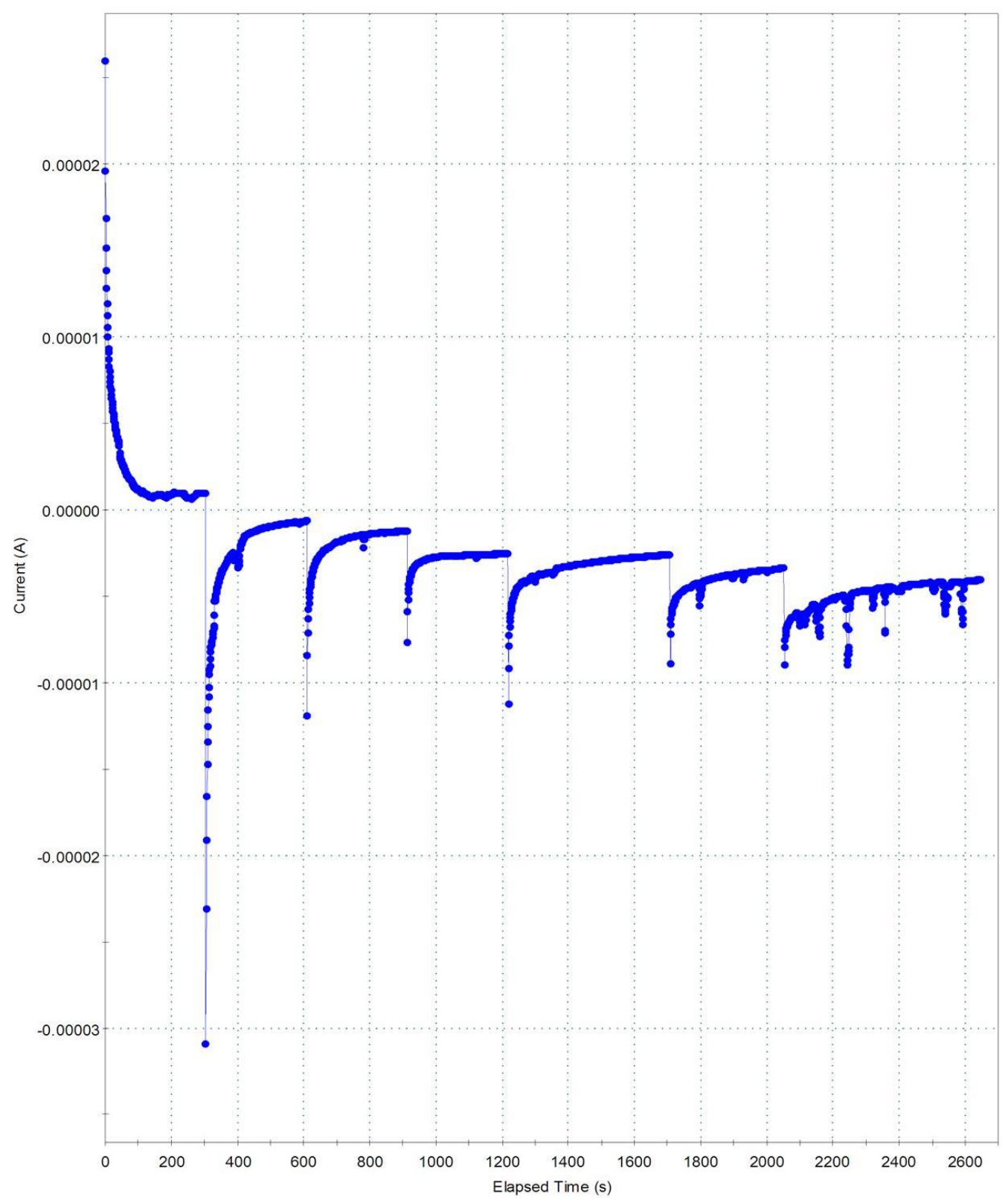

Figure 3.14. Potential step test of sample treated at $675^{\circ} \mathrm{C}$ for 4 hours, with difficulty in repassivation at $200 \mathrm{mV}$ and $1.2 \mathrm{~V}$. 
The test of the sample treated at $675^{\circ} \mathrm{C}$ for 8 hours began with a positive current (Figure 3.15), but did not approach zero. Instead, equilibrium was reached at $1 \mu \mathrm{A}$ before the sample was polarized to $200 \mathrm{mV}$. The current fluctuated when $200 \mathrm{mV}$ was applied, but eventually the current decreased. Decreasing trends were much smoother for $400,600,800 \mathrm{mV}$, and $1 \mathrm{~V}$. The sample was polarized to $1.2 \mathrm{~V}$ and was able to repassivate.

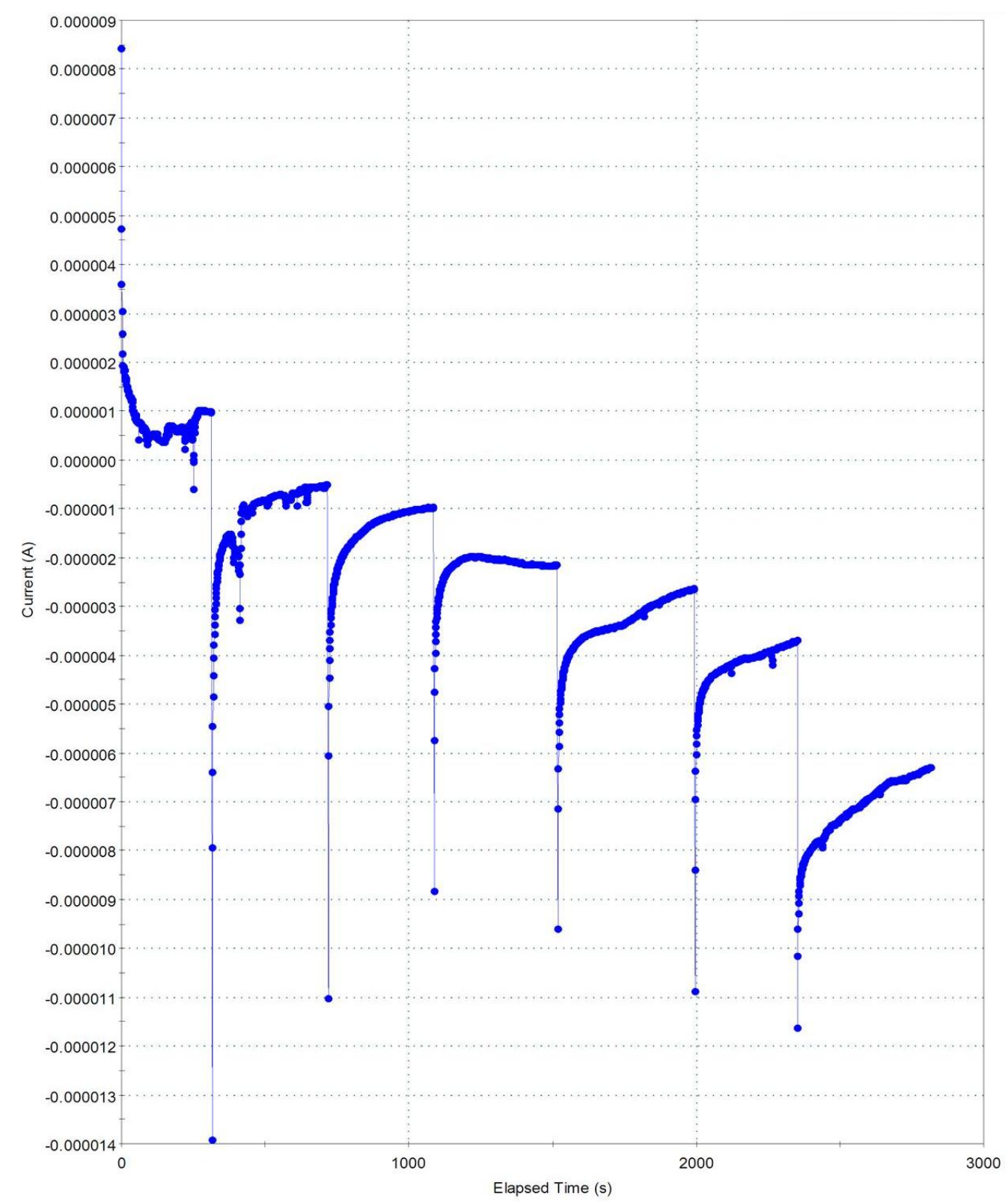

Figure 3.15. Potential step graph of sample treated at $675^{\circ} \mathrm{C}$ for 8 hours, with only initial difficulty in repassivation. 
The potential-step test of the sample treated at $675^{\circ} \mathrm{C}$ for 16 hours also began at a positive current and decreased when no potential was applied, as seen in Figure 3.16. Throughout each polarization step, the current decreased smoothly, with few current fluctuations. Even polarizing to $1.2 \mathrm{~V}$ resulted in only a slight current fluctuation, but the sample repassivated and the current continued to decrease.

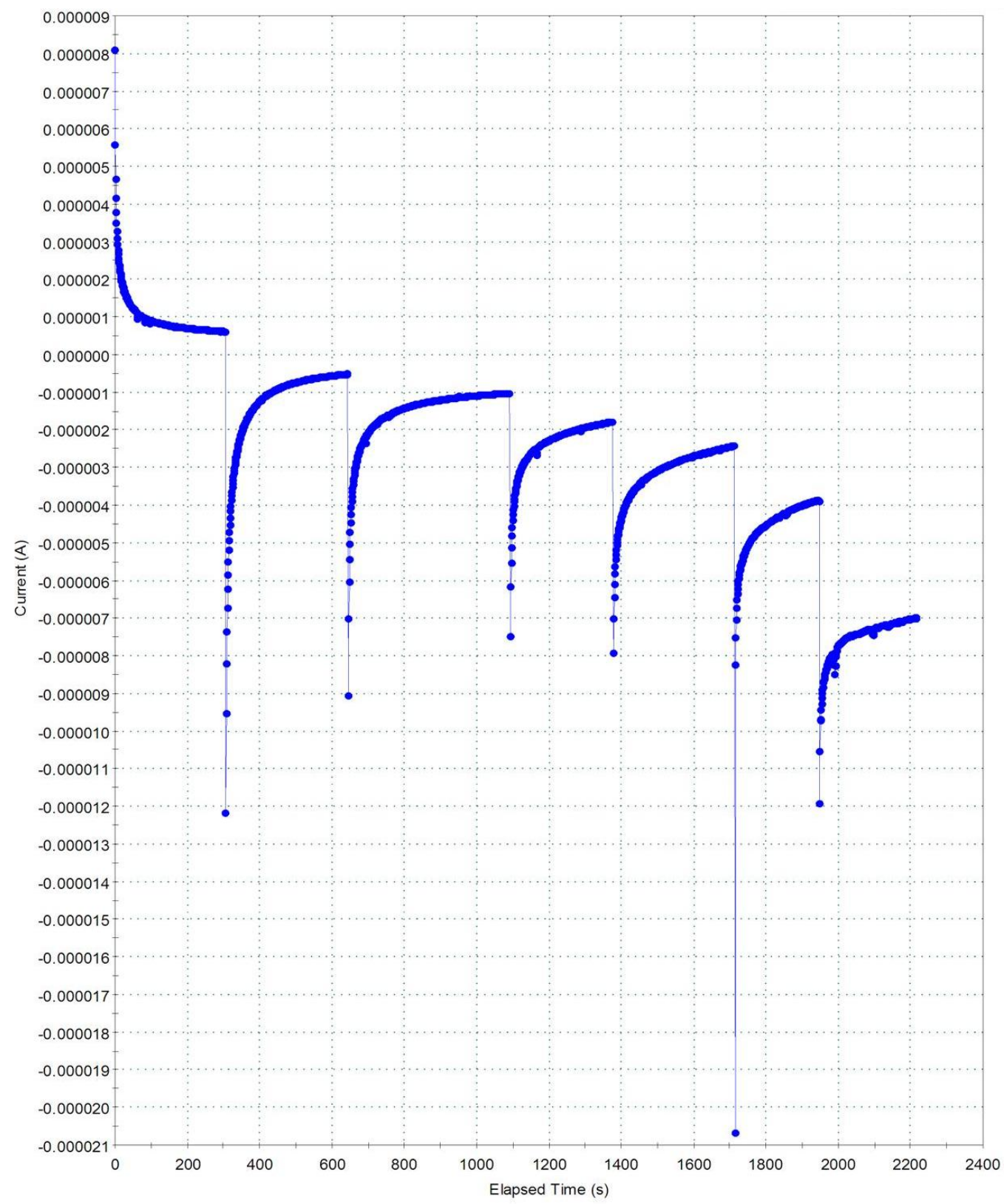

Figure 3.16. Potential step graph of sample treated at $675^{\circ} \mathrm{C}$ for 16 hours shows excellent repassivation ability. 


\subsection{Effects of thermal oxidation on material properties}

\subsubsection{Surface roughness}

AFM measurements of the average surface roughness $(\mathrm{Ra})$ showed an increase in surface roughness for each heat treatment, but no trend according to treatment time, as shown in Figure 3.17. Samples treated at $675^{\circ} \mathrm{C}$ had higher surface roughness values than samples treated at $600^{\circ} \mathrm{C}$. As seen in Figure 3.17, the greatest increase in average surface roughness for nonabraded samples treated at $675^{\circ} \mathrm{C}$ was the 4 hour treatment, followed by the 8 hour, and 16 hour

treatment. Unfortunately, post-heat-treatment roughness measurements for the $600^{\circ} \mathrm{C} 4$ hour and 8 hour treatment were lost.

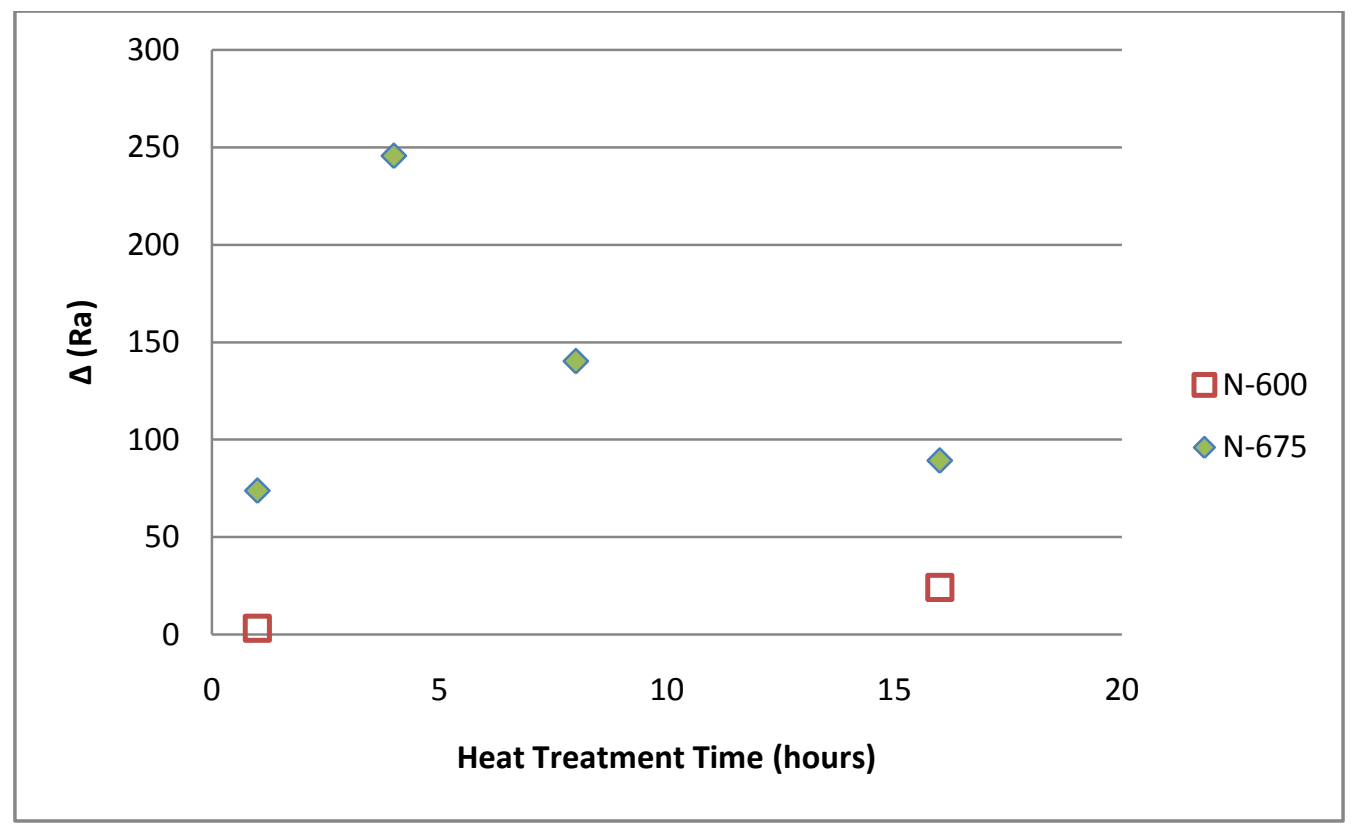

Figure 3.17. Surface roughness of non-abraded samples after thermal oxidation treatment.

Roughness measurements for abraded samples were taken after the thermal oxidation treatments. Before thermal oxidation, the samples were polished with a $3 \mu \mathrm{m}$ diamond paste. As seen in Figure 3.18, the highest surface roughness occurred in samples treated at $600^{\circ} \mathrm{C}$ for 4 
hours and $675^{\circ} \mathrm{C}$ for 8 hours. There was no trend in surface roughness for samples treated at $600^{\circ} \mathrm{C}$. The surface roughness of samples treated at $675^{\circ} \mathrm{C}$ reached a maximum after 8 hours of treatment, decreasing after 16 hours.

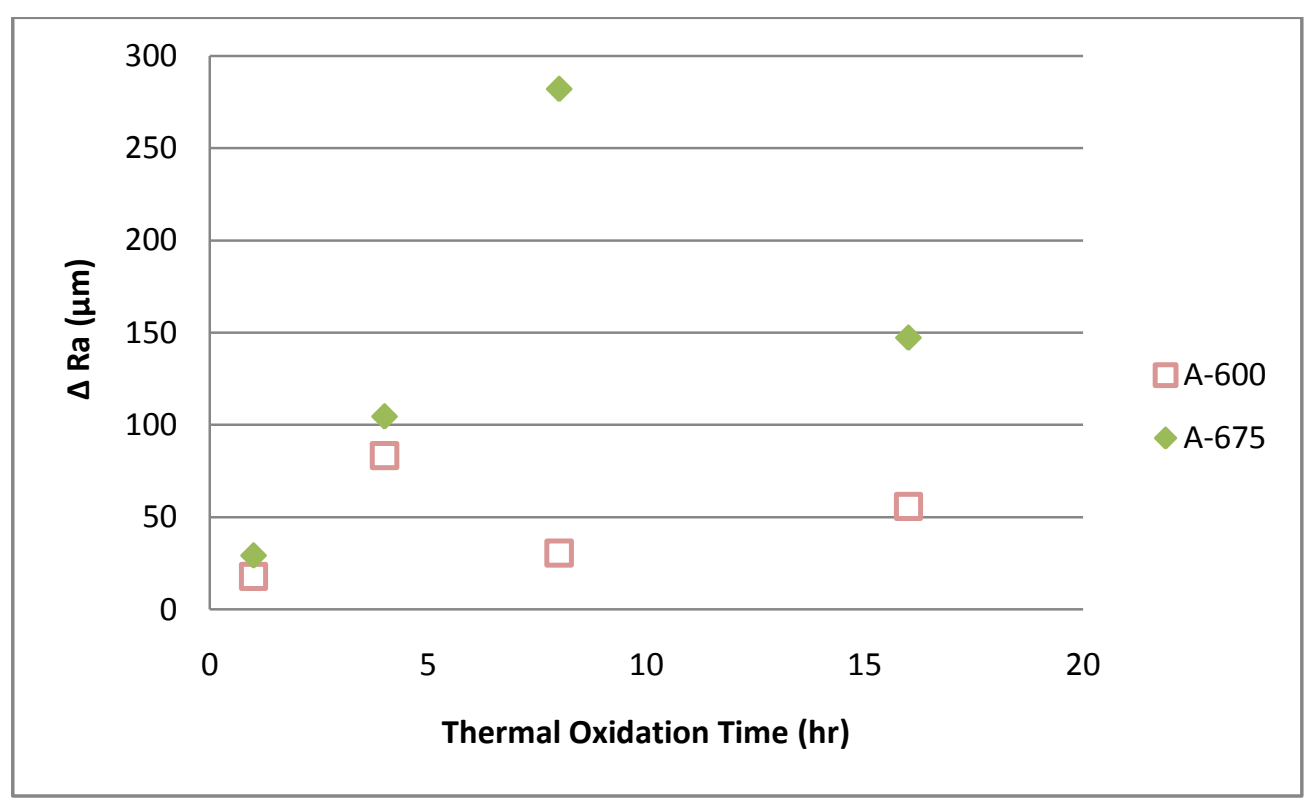

Figure 3.18. Surface roughness of abraded samples after thermal oxidation treatment and before abrasion.

Images of non-abraded samples taken after thermal oxidation treatments showed an increase in surface roughness of $600^{\circ} \mathrm{C}$ (Figure 3.19) and $675^{\circ} \mathrm{C}$ (Figure 3.20) treatments, the magnitude of which depended on the time and temperature.

The change in topography of the oxide layer as a result of the thermal oxidation treatments is seen in the SEM images of the non-abraded samples treated at $600^{\circ} \mathrm{C}$, presented in Figure 3.19. The non-uniform growth is seen initially emerging in the shorter treatments, and is greatly defined by the white regions of the N-600-16 SEM image. 

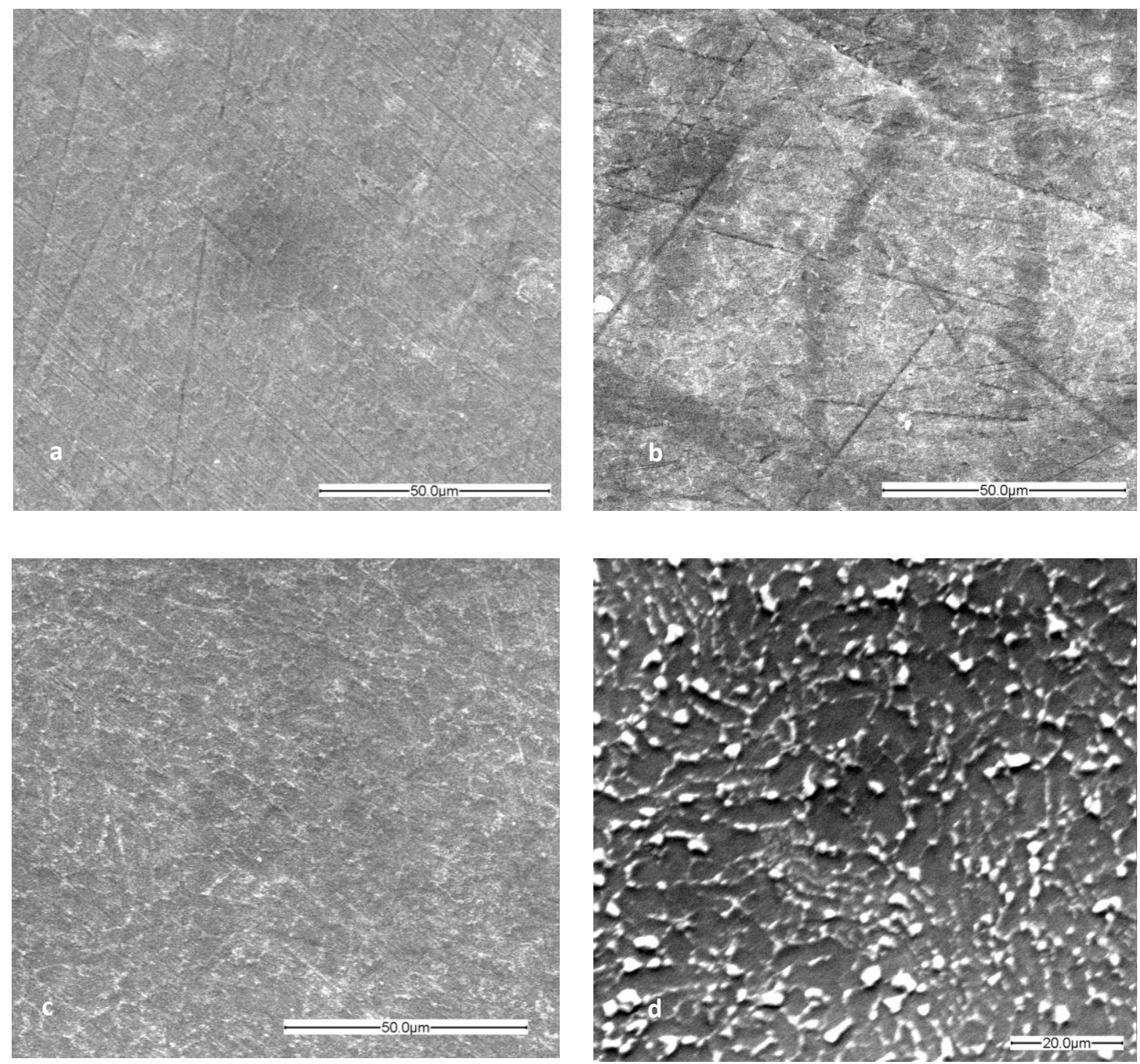

Figure 3.19. SEM images of samples treated at $600^{\circ} \mathrm{C}$ for 1 (a), 4 (b), 8 (c), and 16 (d) hours.

Non-uniform oxide growth is also seen in samples treated at $675^{\circ} \mathrm{C}$, as the light areas increase in size after longer treatments (Figure 3.20). Images a and c display the dominant growth of one species, as the size of the white components increases after 8 hours of thermal treatments. The decrease in magnification of $\mathrm{N}-675-16$ to $657 \mathrm{x}$ causes the peaks to falsely appear smaller compared to the $1024 x$ image of N-675-8. 

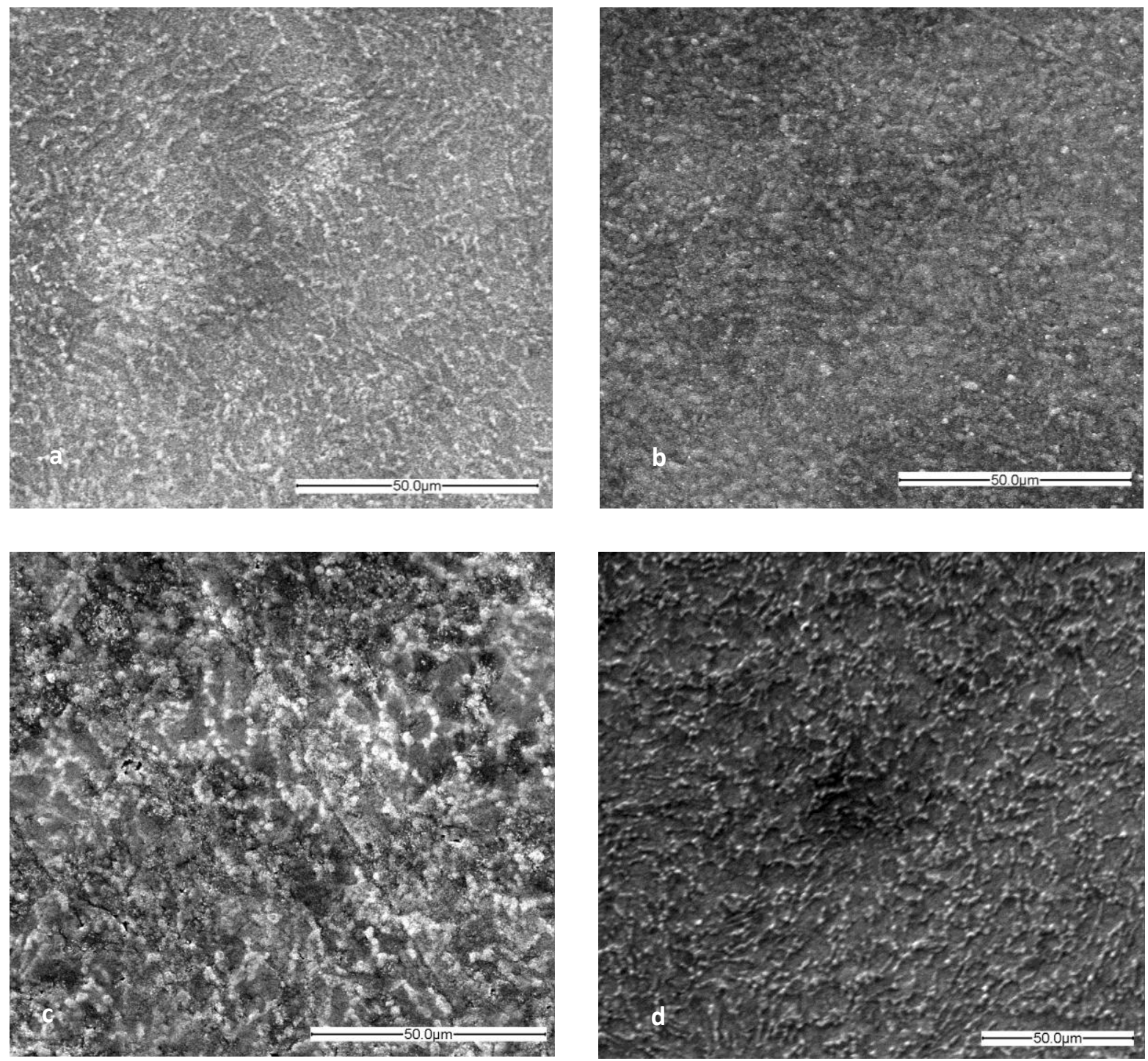

Figure 3.20. SEM images of samples treated at $675^{\circ} \mathrm{C}$ for 1 (a), 4 (b), 8 (c), and 16 (d) hours.

Additional surface roughness measurements of non-abraded samples were taken after potentiodynamic polarization tests to characterize any change in surface properties as a result of the electrochemical treatment. As seen in Figure 3.21, surface roughness changed after corrosion tests, indicating that the surfaces were modified by the applied potentials. 


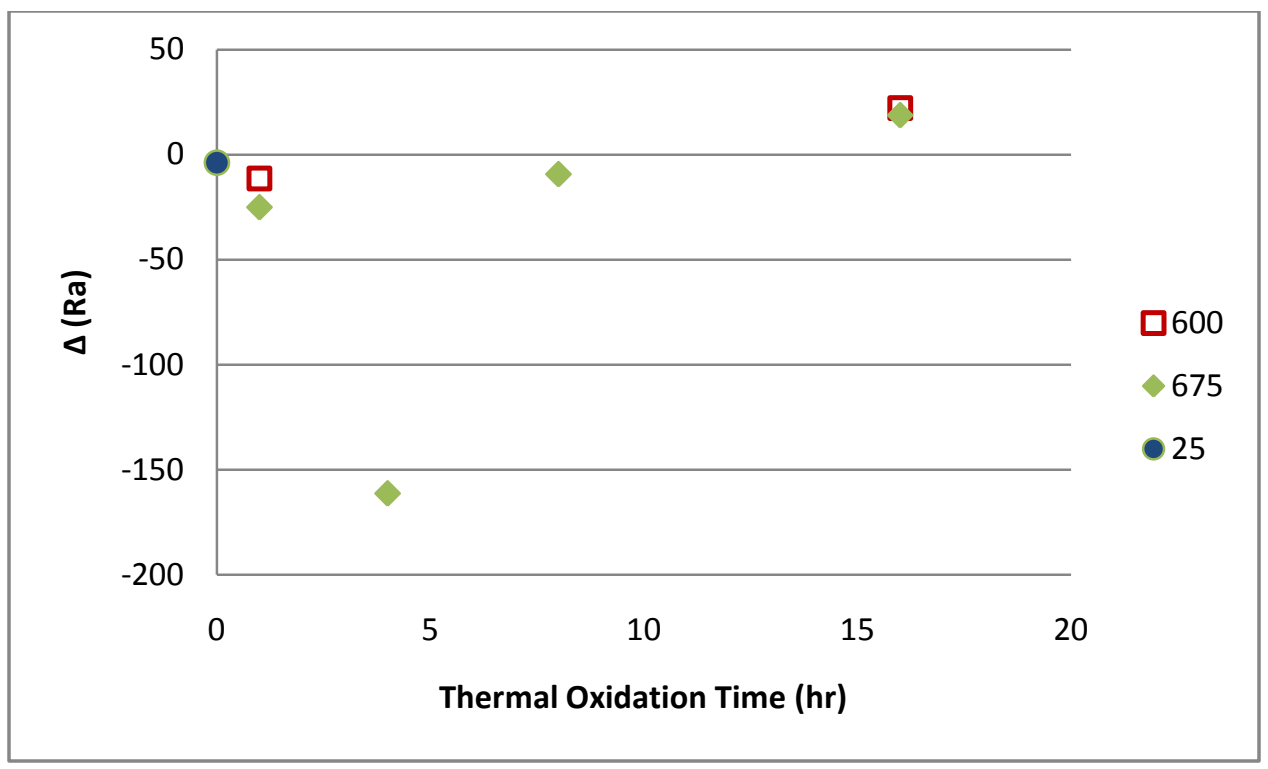

Figure 3.21. Surface roughness of non-abraded samples after potentiodynamic polarization tests

\subsubsection{Microstructural evolution}

The microstructure after varying heat treatments was examined to analyze any reduction or growth of grains and particles. As seen in Figure 3.22, the microstructures for the samples treated at $600^{\circ} \mathrm{C}$ show a slight reduction in the presence of $\beta$ phase, which appears as the darker artifacts. In addition, compared to the untreated sample (Figure 3.22a), N-600-16 shows an increase in the size of the $\alpha$ grains (Figure 3.22e). 

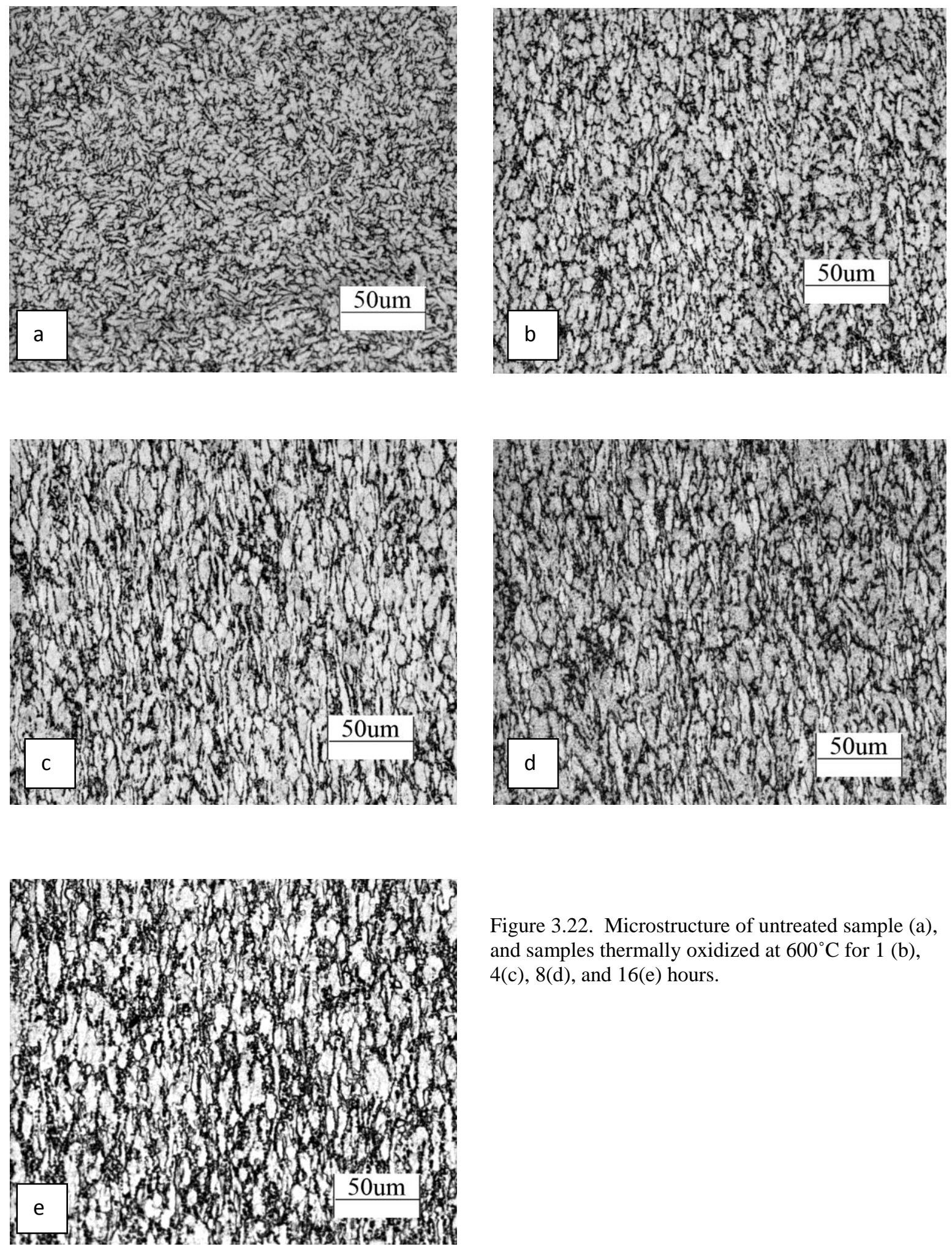

Figure 3.22. Microstructure of untreated sample (a), and samples thermally oxidized at $600^{\circ} \mathrm{C}$ for 1 (b), 4(c), 8(d), and 16(e) hours. 
Figure 3.23 presents the microstructural evolution of the samples treated at $675^{\circ} \mathrm{C}$, where the reduction in $\beta$ grains and growth of $\alpha$ grains is more evident, as compared to the samples treated at $600^{\circ} \mathrm{C}$.
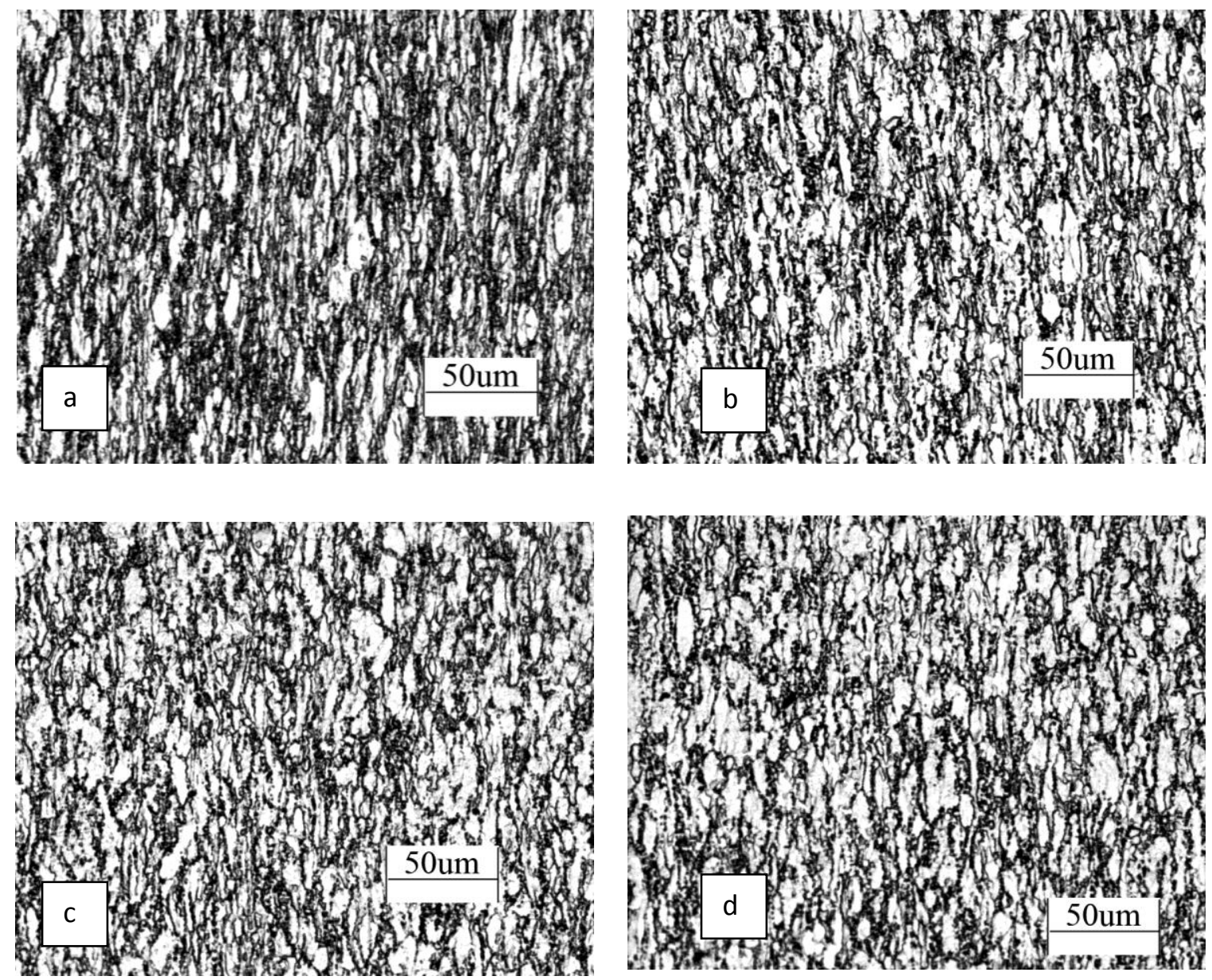

Figure 3.23. Microstructure of Ti-6Al-4V thermally oxidized at $675 \mathrm{C}$ for 1 (a), 4(b), 8(c), and 16(d) hours.

More grains became equiaxed in the samples treated at $675^{\circ} \mathrm{C}$, although the microstructures of both temperatures displayed decreasing contents of beta particles with longer treatment times. 


\subsubsection{Hardness}

Analysis of variance (ANOVA) of HRc measurements taken after heat treatments showed no statistical difference in hardness values as a result of thermal oxidation temperatures. Figure 3.24 presents the range of HRc values. However, one-way ANOVA also indicated that there was a statistical difference in samples treated at $675^{\circ} \mathrm{C}$ for different times, but no statistical difference between samples treated at $600^{\circ} \mathrm{C}$ for different times. There was no statistical difference between untreated samples and samples treated at $600^{\circ} \mathrm{C}$, and the untreated sample compared to samples treated at $675^{\circ} \mathrm{C}$.

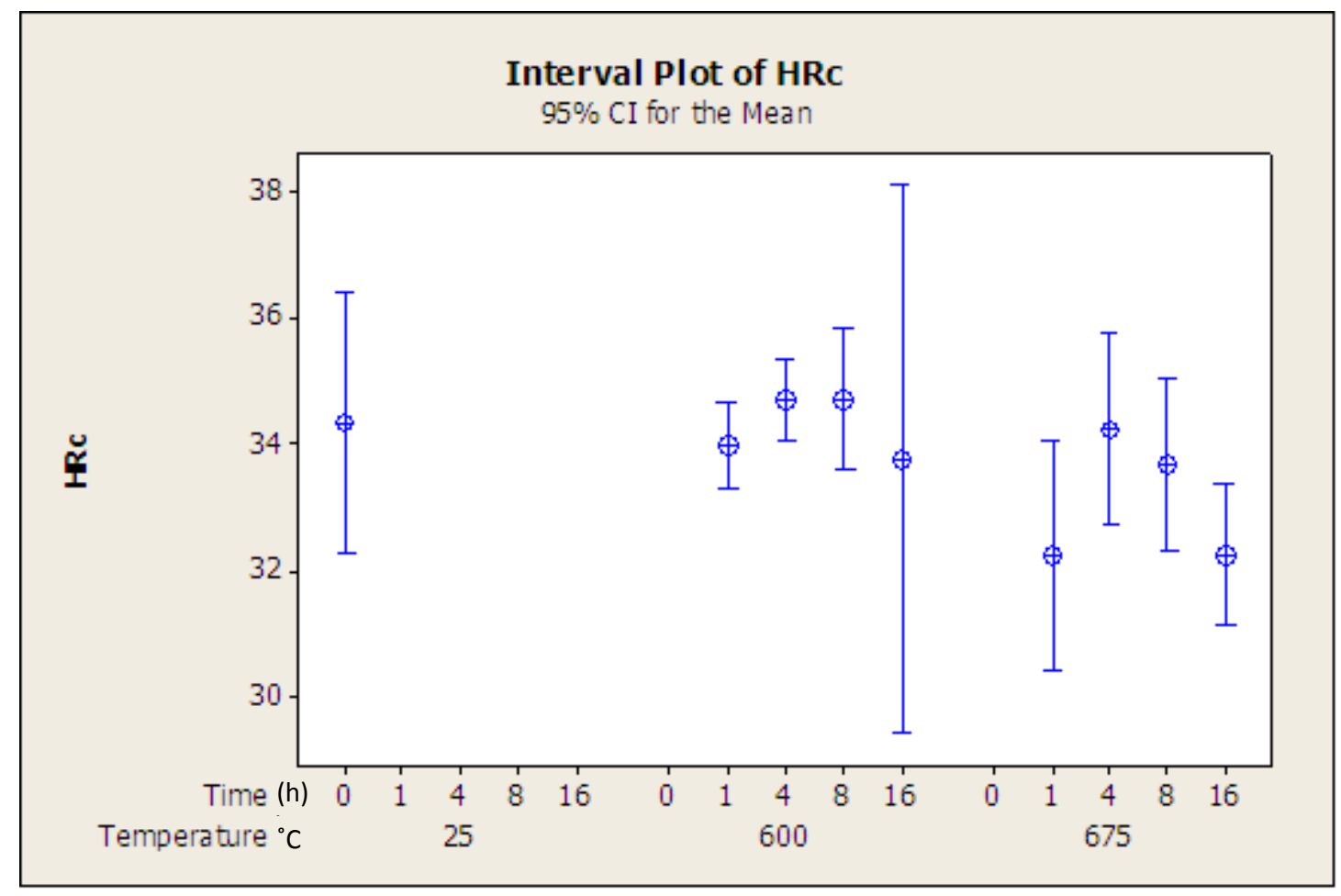

Figure 3.24. Range of HRc values of samples after thermal oxidation treatments

\subsubsection{Microhardness}

The microhardness of the separate heat treatments is displayed in Figure 3.25. The oxide layer of the samples treated at $675^{\circ} \mathrm{C}$ had higher microhardness values, particularly at extended 
oxidation times. Values from the samples treated at $600^{\circ} \mathrm{C}$ remained relatively low, showing little increase at larger thermal oxidation times.

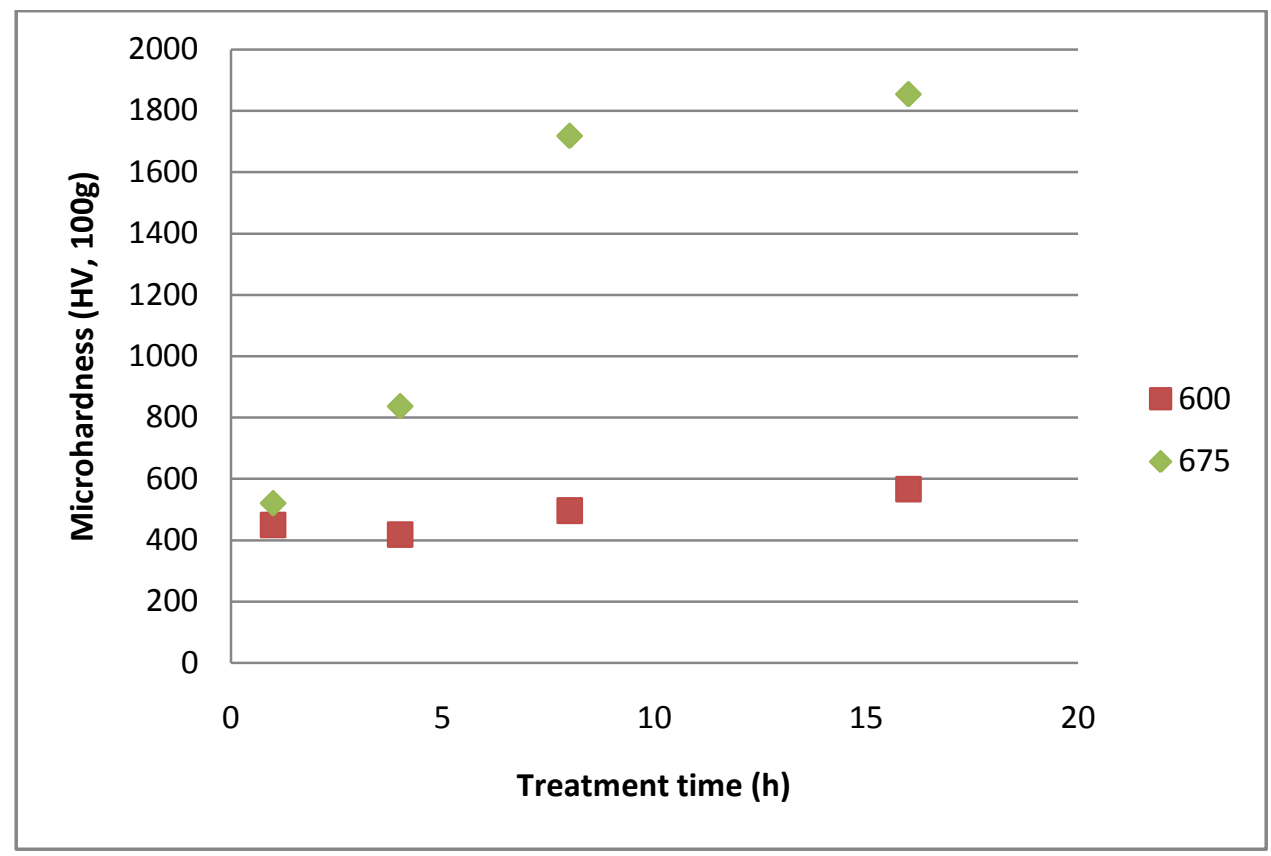

Figure 3.25. Microhardness data for abraded samples after thermal oxidation.

\subsubsection{Adhesion characteristics}

During HRc measurements after heat treatment, delamination of the oxide layer was observed in the sample treated at $675^{\circ} \mathrm{C}$ for 16 hours, but not at shorter times or in samples treated at $600^{\circ} \mathrm{C}$. As seen in Figure 3.26, the bare substrate was exposed around the Rockwell indentation, causing the substrate to crack along the indentation circumference.

Abrasion testing also resulted in delamination of oxides fabricated at higher temperatures and times. Samples exhibiting

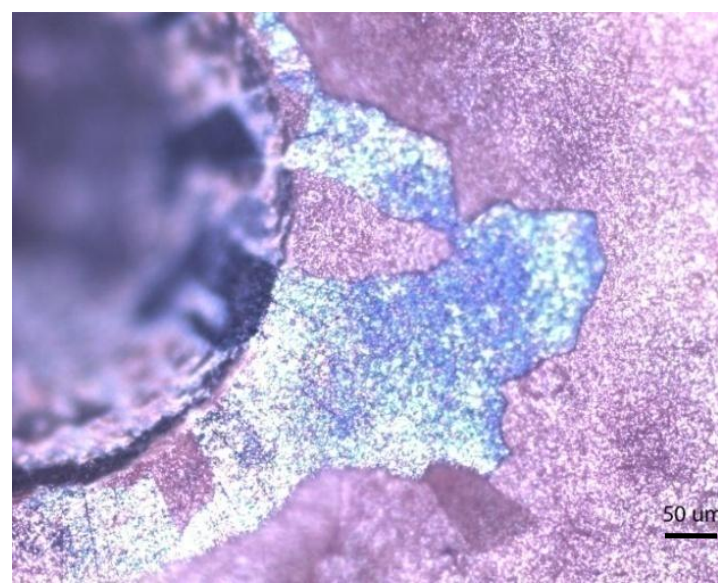

Figure 3.26. Delamination of oxide around Rockwell hardness indentation (150kg load) of Ti$6 \mathrm{Al}-4 \mathrm{~V}$ sample treated at $675^{\circ} \mathrm{C}$ for 16 hours. 
delamination included A-675-16, A-675-8, and A-675-4, as seen in Figure 3.27. The magnitude of delamination decreased with decreasing time and temperature, as most of the length of the abrasion in A-675-16 was lined by delaminated scale, and some regions of A-675-8 and A-675-4 showed no delamination. Abrasion width also varied for each sample, with the width of A-67516 at $100 \mu \mathrm{m}, \mathrm{A}-675-8$ at $75 \mu \mathrm{m}$, and A-675-4 at $50 \mu \mathrm{m}$. The oxide of samples treated at $600^{\circ} \mathrm{C}$ did not delaminate.
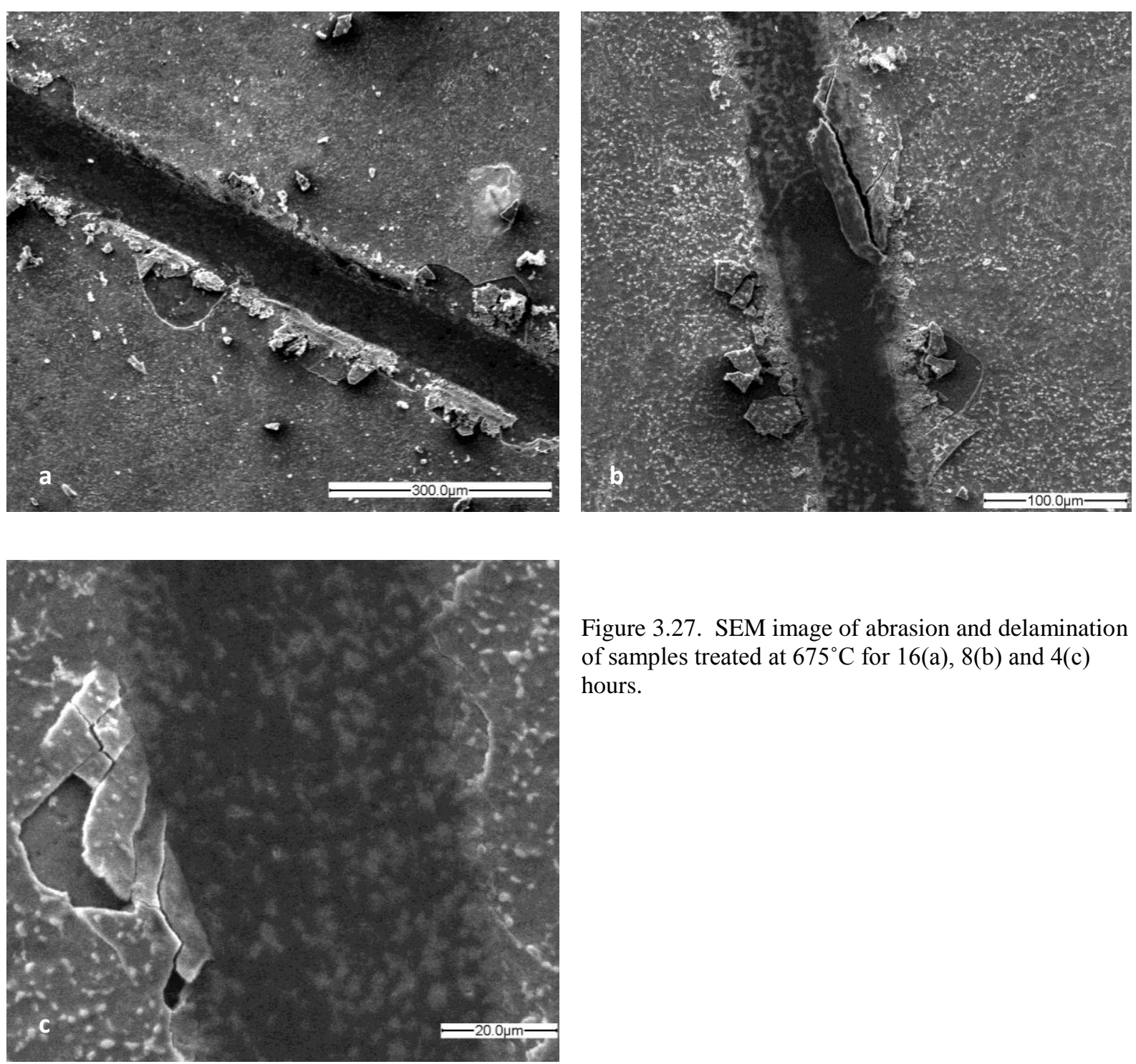

Figure 3.27. SEM image of abrasion and delamination of samples treated at $675^{\circ} \mathrm{C}$ for $16(\mathrm{a}), 8(\mathrm{~b})$ and $4(\mathrm{c})$ hours. 


\section{DISCUSSION}

\subsection{Overview of objectives}

A series of tests and examinations were conducted to satisfy objectives concerning the effects of thermal oxidation on Ti-6Al-4V with pertinence to conditions undergone by an anterior cervical plate:

1. Determine if thermal oxidation is an effective treatment for corrosion resistance in this biomedical application

2. Determine whether a thermally oxidized sample can repassivate in a physiological media despite prior abrasion

3. Determine whether the process of thermal oxidation alters material characteristics, reducing the alloy's performance in an ACP application.

\subsection{Evaluation of corrosion resistance of thermal oxidation}

Open circuit and cyclic polarization tests were conducted to evaluate thermal oxidation of Ti6Al-4V discs at $600^{\circ} \mathrm{C}$ and $675^{\circ} \mathrm{C}$ as a method to increase corrosion resistance.

\subsubsection{Open circuit results in relation to oxide characteristics}

Open circuit tests measure the potential difference between the sample and the surrounding solution, as no current is applied. Theoretically, the potential difference is proportional to the resistance of the oxide layer separating the reactive substrate from the solution. The open circuit potential of samples thermally oxidized at $600^{\circ} \mathrm{C}$ and $675^{\circ} \mathrm{C}$ increased with longer treatment time.

The dependence upon temperature for thickness of the oxide layer is supported in findings by Lee, Yoon, and Yi (2007), who calculated the oxide penetration using an equation derived from weight gain after TO treatments. Using the kinetic values from Lee et al. (2007), the oxygen penetration is deeper for the $675^{\circ} \mathrm{C} 1$ hour treatment than the depth attained at $600^{\circ} \mathrm{C}$ for 16 hours, 
as seen in Figure 4.1. Therefore, the thermal oxidation process is more dependent upon temperature than time in terms of oxygen penetration and oxide thickness.

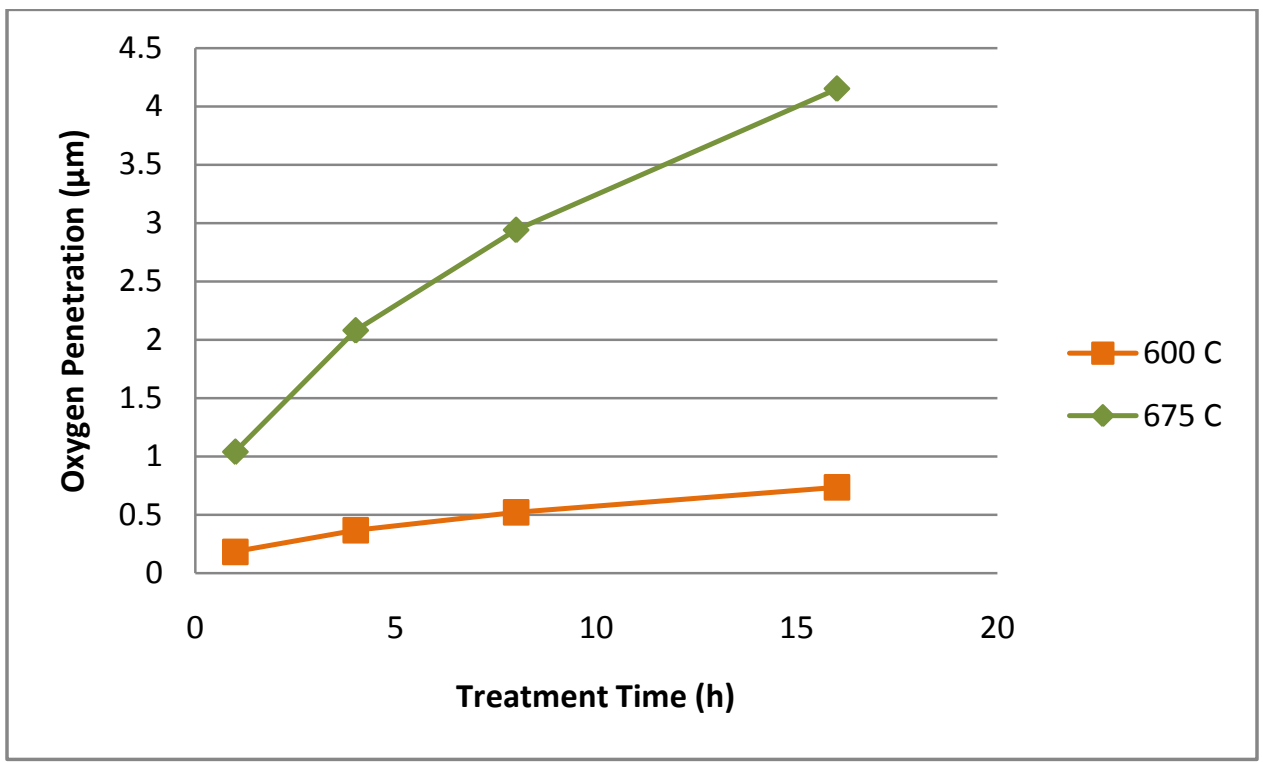

Figure 4.1. Calculated values of oxygen penetration into Ti-6Al-4V substrate at $600^{\circ} \mathrm{C}$ and $675^{\circ} \mathrm{C}$ (Lee, Yoon, \& Yi, 2007)

Although the activation energy for oxygen diffusion differs from the activation energy of oxide formation, the findings of Lee et al. (2007) provide insight as to the difference temperature plays in the kinetics of the oxidation. Based on the open circuit trends seen in Figure 4.1, the oxide growth rate of samples treated at $600^{\circ} \mathrm{C}$ and $675^{\circ} \mathrm{C}$ are not equal. These trends indicate the oxygen absorption kinetics change with oxidation temperature, supported by the findings of Frangini et al. (1994). This group studied the kinetics of thermally oxidized Ti-6Al-4V at 600, 650 , and $700^{\circ} \mathrm{C}$ and observed the linear oxidation rate for the $600^{\circ} \mathrm{C}$ treatments. However, the $700^{\circ} \mathrm{C}$ treatments did not possess the same uniform linearity in short and long oxidations. The non-uniform oxidation rate during a short time period at high temperature may explain how the oxide thickness of the samples treated at $675^{\circ} \mathrm{C}$ dwarfed thicknesses of samples treated at $600^{\circ} \mathrm{C}$ in the same amount of time. Figure 4.2 graphs the calculated oxide penetration (Lee, Yoon, \& Yi, 
2007) against the open circuit potential. The oxidation rate for the $675^{\circ} \mathrm{C} 1$ hour treatment leads to a greater $\mathrm{E}_{\mathrm{OC}}$ than the $600^{\circ} \mathrm{C}$ treatment rate. The small increase in open circuit potential with longer treatments at $675^{\circ} \mathrm{C}$ illustrates how longer treatment times provide little additional corrosion resistance.

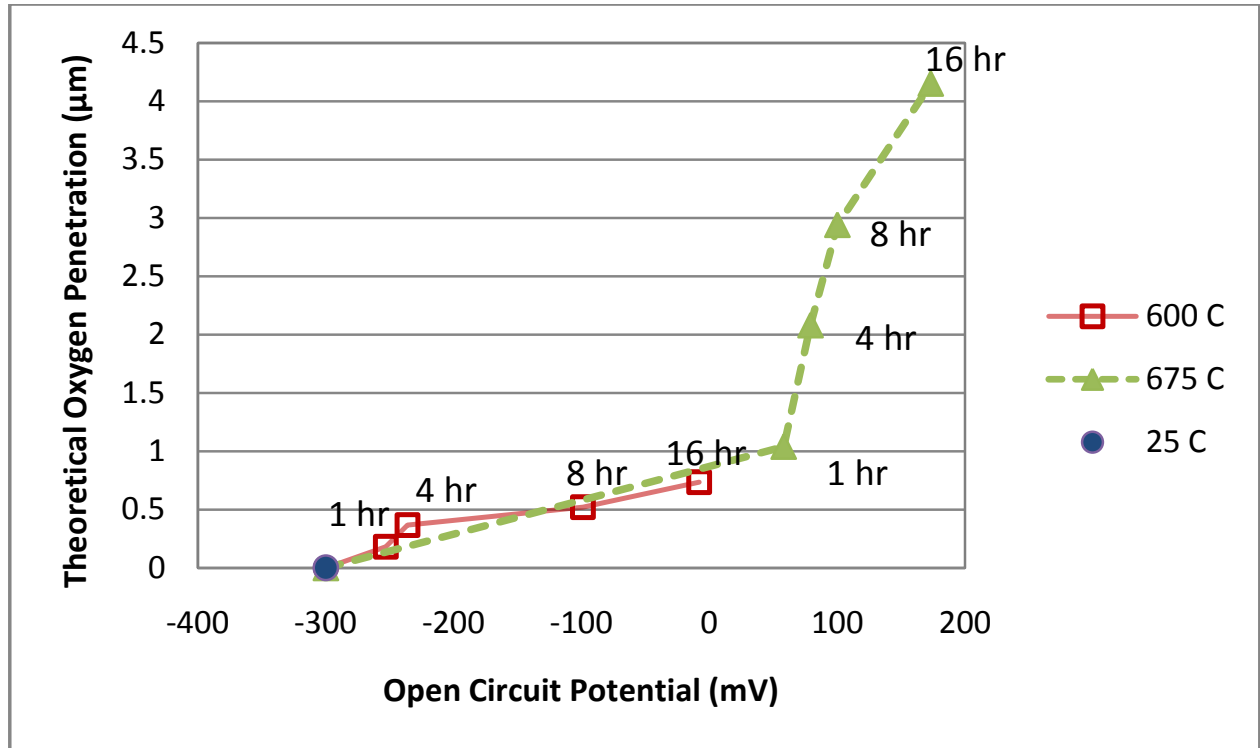

Figure 4.2. Theoretical oxygen penetration vs. open circuit potential shows the different rates of the two thermal processes during the first hour.

Samples treated at $675^{\circ} \mathrm{C}$ had more noble $\mathrm{E}_{\mathrm{OC}}$ values than samples treated at $600^{\circ} \mathrm{C}$, as their oxides posed greater resistance between the sample substrate and the electrolyte. Based on open circuit potentials, and not on direct measurement, the oxide thickness of the sample treated at $675^{\circ} \mathrm{C}$ for 1 hour appears thicker than the oxide of the sample treated at $600^{\circ} \mathrm{C}$ for 16 hours (Figure 3.1), agreeing with theory presented by Lee et al (2007). However, the theory of infinitely increasing oxygen penetration with increasing treatment time is disproved in Figure 4.2. As treatment time increased, oxygen penetration increased, but the open circuit potential did not greatly increase. As this group utilized the weight of a sample to assess oxygen penetration, the 
increase in weight corresponded with an increase in the density of the oxide, not necessarily the oxide thickness.

According to the findings of Güleryüz et al. (2004), the oxide becomes denser at higher temperatures and longer treatment times. Using XRD analysis, the group determined the presence of more rutile on samples treated at high temperatures and longer times, and anatase on samples treated at lower temperatures and shorter times. As rutile has higher density than anatase, the increase in density with treatment corresponded to the increase in open circuit potentials seen in this study, as higher temperature samples resulted in less porous oxides with higher resistance.

Resistance can be attributed to the thickness or density of the oxide formed on the sample surface, according to Aziz-Kerrzo, Conroy, Fenelon, Farrell, and Breslin (2001). The group measured the resistance of oxide layers on Ti-6Al-4V according to the equivalent circuit seen in Figure 4.3, which indicates the dependence of the potential difference on the oxide layer characteristics. $R_{S}$ represents the resistance of the solution, $R_{p r}$ and $Q_{p r}$ the resistance and capacitance of the porous oxide layer, and $\mathrm{Q}_{1}, \mathrm{R}_{1}$, and $\mathrm{Q}_{2}$ represent capacitance and resistance of the oxygen diffusion zone, or barrier layer, respectively.

(b)

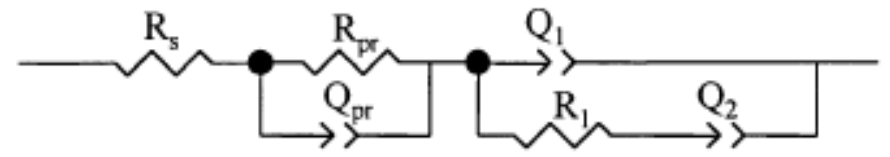

Figure 4.3. Equivalent circuit used to generate impedance data for Ti-6Al-4V in PBS at $37^{\circ} \mathrm{C}$ by Azziz-Kerrzo et al. (2001).

The open circuit values are a reflection of the resistance formed by the oxygen diffusion zone on the substrate $\left(R_{1}\right)$ and the resistance of the porous outer layer $\left(R_{p r}\right)$. The open circuit potentials of both thermal oxidation temperatures increased compared to the untreated sample, as the 
increased resistance of the thermal oxide layer created a larger barrier between the substrate and the solution. However, the structure of the resulting oxide was dependent upon the treatment temperature, affecting the cyclic polarization and abrasion resistance of the sample.

\subsubsection{Cyclic Polarization evaluation of corrosion resistance}

Six of the eight thermal oxidation treatments were successful, serving as effective barriers to corrosion resistance. Samples treated at $600^{\circ} \mathrm{C}$ for 1 and 16 hours and $675^{\circ} \mathrm{C}$ for 1,4 , and 16 hours did not breakdown, despite relatively wide the difference in their open circuit potentials. In addition, the current values of the reverse scans were lower than the forward scans, indicating that the surfaces were further passivated by the polarization process. Corrosion potential ( $\left.\mathrm{E}_{\mathrm{CORR}}\right)$ values above the $\mathrm{E}_{\mathrm{OC}}$ values indicated that samples had become nobler, and reactions on the sample surfaces would become anodic at higher voltages. N-675-8 experienced breakdown at $1.17 \mathrm{mV}$, a value too high to be considered physiologically relevant, therefore N-675-8 can be considered corrosion resistant in this case. In addition, the evolution of oxygen can occur at $800 \mathrm{mV}$, which may lead to false readings of current increase and breakdown (Rosenbloom \& Corbett, 2007).

Unlike the successful treatments, the sample treated at $600^{\circ} \mathrm{C}$ for 4 hours broke down at $364 \mathrm{mV}$, repassivating far below the potential at which it broke down. The sample followed the open circuit potential trend, but displayed increased current values during the reverse scan. The sample treated at $600^{\circ} \mathrm{C}$ for 8 hours also displayed increased current values during the reverse scan. Unlike samples treated at $600^{\circ} \mathrm{C}$ for 1 and 16 hours, higher current values on the reverse scans of samples treated for 4 and 8 hours indicated that the surface was detrimentally modified, not further passivated. Damage from cyclic polarization indicates that the oxide grown at $600^{\circ} \mathrm{C}$ may be structurally vulnerable to corrosion. 
According to Göbel, Haanappel, and Stroosnijder (2001), the diffiusion coefficients of oxygen in $\beta$ titanium are higher than $\alpha$ titanium, at $1.8 \times 10^{-8} \mathrm{~cm}^{2} / \mathrm{s}$ and $1.8 \pm .3 \times 10^{-10} \mathrm{~cm}^{2} / \mathrm{s}$, respectively. A higher oxygen diffusion coefficient for $\beta$ titanium compared to $\alpha$ titanium may have caused structural differences in the thermally-grown oxide (Anandan \& Rajam, 2008), as the oxide structures on the $\beta$ grains differ in thickness and texture from the oxide on the $\alpha$ grains. Anadan and Rajam (2008) also determined that during the oxidation reaction, $\alpha$ oxide dissolves faster than $\beta$ oxide.

The difference in the oxide structures may be related to the breakdown of samples treated at $600^{\circ} \mathrm{C}$ for 4 and 8 hours, as one oxide species may have been preferentially dissolved in the $\mathrm{CP}$ scan. At these temperatures, the $\beta$ oxide may have grown in greater proportion than the $\alpha$ oxide, due to its higher diffusion coefficient. A large topographical range with high $\beta$ "peaks" and low $\alpha$ "valleys" could lead to a slightly more volatile environment in the valleys, causing the deterioration of alpha oxide. The smoother topography of samples treated at $600^{\circ} \mathrm{C}$ for 1 and 16 hours would not have the variation in environments along the sample surface that cause localized breakdown, as the 1 hour treatment would not create high enough peaks, and the 16 hour treatment would allow the valleys to grow to heights comparable to the peaks. However, without the surface roughness data for N-600-4 and N-600-8, these conclusions are only speculation.

The breakdown of N-675-8 is also contrary to theory, as the open circuit value of N-675-8 fit the trend of samples treated at $675^{\circ} \mathrm{C}$. In addition, no pits were found on the surface of the tested area with the SEM, nor was corrosion macroscopically observed on any other portion of the sample. The lack of hysteresis in the CP scan indicates that a pit would have propagated for the duration of the reverse scan, but the pit may not have been observed in the SEM or may have formed between the mask and the surface. In any case, the breakdown occurred at $1.17 \mathrm{mV}$, generally greater than in vivo rest potentials. 
Although three CP scans showed atypical behavior compared to the other five scans, six of the eight treatments were deemed successful, verifying thermal oxidation as a valid treatment for corrosion resistance.

\subsection{Repassivation}

Six of the eight thermal oxidation treatments were successful in resisting corrosion during cyclic polarization tests, and to satisfy the second project objective, all treatments were abraded before step polarization to assess their repassivation ability.

The most consistent and smooth repassivation was seen in A-600-1, A-600-16, A-675-1 and A675-16, with minimal leaks of current during the repassivation process. Each treatment showed more consistent and smooth recovery than A-0, possibly indicating an improvement in repassivation with thermal oxidation. Some samples did exhibit transient effects, such as A-6008 , which repassivated after every potential step, with slight current fluctuations at $200 \mathrm{mV}$ polarization. A-675-4 and A-675-8 also displayed the ability to repassivate, although A-675-8 was less stable for $0 \mathrm{mV}$ and $200 \mathrm{mV}$ applied potentials. The current fluctuations of A-675-4 were at $1.2 \mathrm{~V}$, above physiological relevance.

During polarization, the current of A-600-4 fluctuated more than any other treatment, even A0. An increase in current after polarization would indicate the material's inability to repassivate, releasing electrons to the surrounding solution. Instability during repassivation was depicted by the current fluctuations, which indicated an oxidation reaction occurring on the surface of the sample. As a hypothesis, the fluctuations may have been indicative of multiple oxidation sites, causing increases in current while other sites were reducing and repassivating.

In addition to breakdown in the $\mathrm{CP}$ scan, the Potential step scan illustrates how a 4 hour thermal oxidation treatment at $600^{\circ} \mathrm{C}$ creates a vulnerable oxide regardless of abrasion, as seen by the location of the pits developed in this study. Komotori et al. (2001) also found corrosion near, 
but not within the abrasion scar in a thermally oxidized Ti-6Al-4V sample that underwent cyclic polarization in a $\mathrm{NaCl}$ solution. This provides evidence that the corrosive behavior of thermally oxidized Ti-6Al-4V is more dependent upon the oxide fabricated during treatment than the effects of a single abrasion.

Seven of the eight abraded thermally oxidized samples showed less current fluctuation than the untreated sample, indicating that the oxide layer and oxide diffusion zone beneath were more effective in repassivating than the untreated material. Komotori et al. (2001) also found that thermal oxidation of Ti-6Al-4V alloys made the alloys less prone to corrosion after prior abrasion.

\subsection{Effects of thermal oxidation}

\subsubsection{Surface roughness}

As seen in this experiment and observed by other researchers, the surface roughness of the Ti-6Al-4V samples increased after thermal oxidation, and the magnitude of surface roughness was dependent upon treatment temperature and time.

Gülyerüz et al. (2004) found that the growth of the oxide layer is accompanied by increasing surface roughness, and the increase accelerated with treatment at $650^{\circ} \mathrm{C}$, compared to $600^{\circ} \mathrm{C}$. The trend seen by Gülyerüz et al. (2004) was also seen in this experiment, as the samples treated at $675^{\circ} \mathrm{C}$ had greater surface roughness values than the samples treated at $600^{\circ} \mathrm{C}$.

Great surface roughness encourages osseointegration, which is not desired in ACPs. Therefore, greater roughness values seen in the samples treated at $675^{\circ} \mathrm{C}$ for 8 and 16 hours would be less advantageous candidates for the ACP application. The sample treated at $600^{\circ} \mathrm{C}$ for 4 hours also had an outlying surface roughness compared to the lower roughness of samples treated for 1,8 , and 16 hours, but all samples treated at $600^{\circ} \mathrm{C}$ had lower roughness values than samples treated at $675^{\circ} \mathrm{C}$. 
Outliers within the isothermal groups indicate the difference in oxide structure at different thermal oxidation times. A difference in oxide structure was observed by Anadan and Rajam (2008), who determined that the texture and thickness of the oxide was affected by the presence of alpha grains and beta grains on the substrate. The texture and thickness differences were a result of the higher diffusion coefficients of nitrogen and oxygen in beta titanium, compared to alpha titanium (Anadan \& Rajam, 2008). The different diffusion coefficients would cause the oxides to grown at uneven rates, contributing to their topographical differences and a high surface roughness at particular treatment times. In the present study, uneven oxide growth was displayed in the SEM images of the surfaces after heat treatment, where the $\beta$ oxide appears as high peaks.

The abraded sample treated at $600^{\circ} \mathrm{C}$ for 4 hours had a higher surface roughness than other samples treated at $600^{\circ} \mathrm{C}$. The high surface roughness may indicate that after 4 hours more oxygen was absorbed by one phase than the other. According to Anadan and Rajam (2008), alpha oxide is also preferentially dissolved in a polarization experiment, which may be why the sample treated at $600^{\circ} \mathrm{C}$ for 4 hours broke down in cyclic polarization tests and was unable to repassivate in potential step tests.

The surface roughness for the sample treated at $675^{\circ} \mathrm{C}$ for 8 hours was also highest among all samples treated at $675^{\circ} \mathrm{C}$, but the sample treated for 16 hours was similar to the roughness for the 4 hour treatment. The changing oxidation rates are verified by the findings of Frangini et al. (1994), who found that the oxidation rates of different temperatures change with the treatment time, as does the surface morphology. Alpha and beta phases have different maximum dissolution levels for oxygen (Gobel et al., 2001), which may affect the rate at which they are absorbed. This theory was supported by the decreasing surface roughness of the longer treatments, as one species may have started to reach its maximum dissolution level, changing its rate of absorption, while the other species continued to absorb oxygen at its same rate.

Researchers (Güleryüz et al., 2004; Frangini et al., 1994) determined that at oxidation temperatures above $650^{\circ} \mathrm{C}$, the surface oxide becomes a dual-layer system; with the surface scale 
mostly composed of rutile, but the surface of samples treated at $600^{\circ} \mathrm{C}$ contain mostly rutile and some anatase. The rate of oxygen absorption and oxide scale growth increased with treatment temperature, but changed according to treatment time (Frangini et al., 1994). The variation in oxide growth was displayed in this study by the change in surface roughness of the samples treated at $675^{\circ} \mathrm{C}$.

\subsubsection{Microstructure}

Microstructural analysis was indicative of any microstructural changes as a result of thermal oxidation, and any bulk changes may be insinuative of surface changes. The analysis provided evidence to help determine whether any microstructural changes occurred, possibly altering material characteristics such as hardness.

The grain size and amount of $\beta$ phase, was similar across the samples treated at $600^{\circ} \mathrm{C}$. Both observations indicate little microstructural change throughout the thermal oxidation treatment, with the microstructure of samples treated for 16 hours appearing similar to the microstructure of samples treated for 4 and 8 hours. Therefore, thermal oxidation treatments at $600^{\circ} \mathrm{C}$ did not result in microstructural changes.

Changes in $\beta$ content and the $\alpha$ grain size were seen in the samples treated at $675^{\circ} \mathrm{C}$. The size of the $\alpha$ grains grew with increasing treatment time, as the amount of $\beta$ phase decreased. The change in microstructure is consistent with the findings of Semiatin et al. (2004), as the heat treatment caused primary $\alpha$ to grow, and the $\beta$ to reduce to form secondary platelet $\alpha$.

The content of $\alpha$ and $\beta$ in the microstructure may directly relate to the proportion of their respective oxides on the sample surface. Of the sample treated at $600^{\circ} \mathrm{C}$ for 16 hours, the microstructure and an inverted SEM image of the surface oxide are pictured in Figure 4.4. An inverted SEM surface image and the microstructure of the sample treated at $675^{\circ} \mathrm{C}$ for 16 hours are presented in Figure 4.5. In both images, the dark regions represent the $\beta$ content, and the light represent the $\alpha$. Although the slightly scales differ, the amount of $\alpha$ and $\beta$ content is similar 
between the images. Comparing the SEM image and micrograph does not confirm the possibility that the slight reduction of $\beta$ particles in the microstructure is related to the accumulation of $\beta$ oxide on the surface. However, the amount of dark $\beta$ content in the images is similar, and the possibility of direct proportion cannot be eliminated.
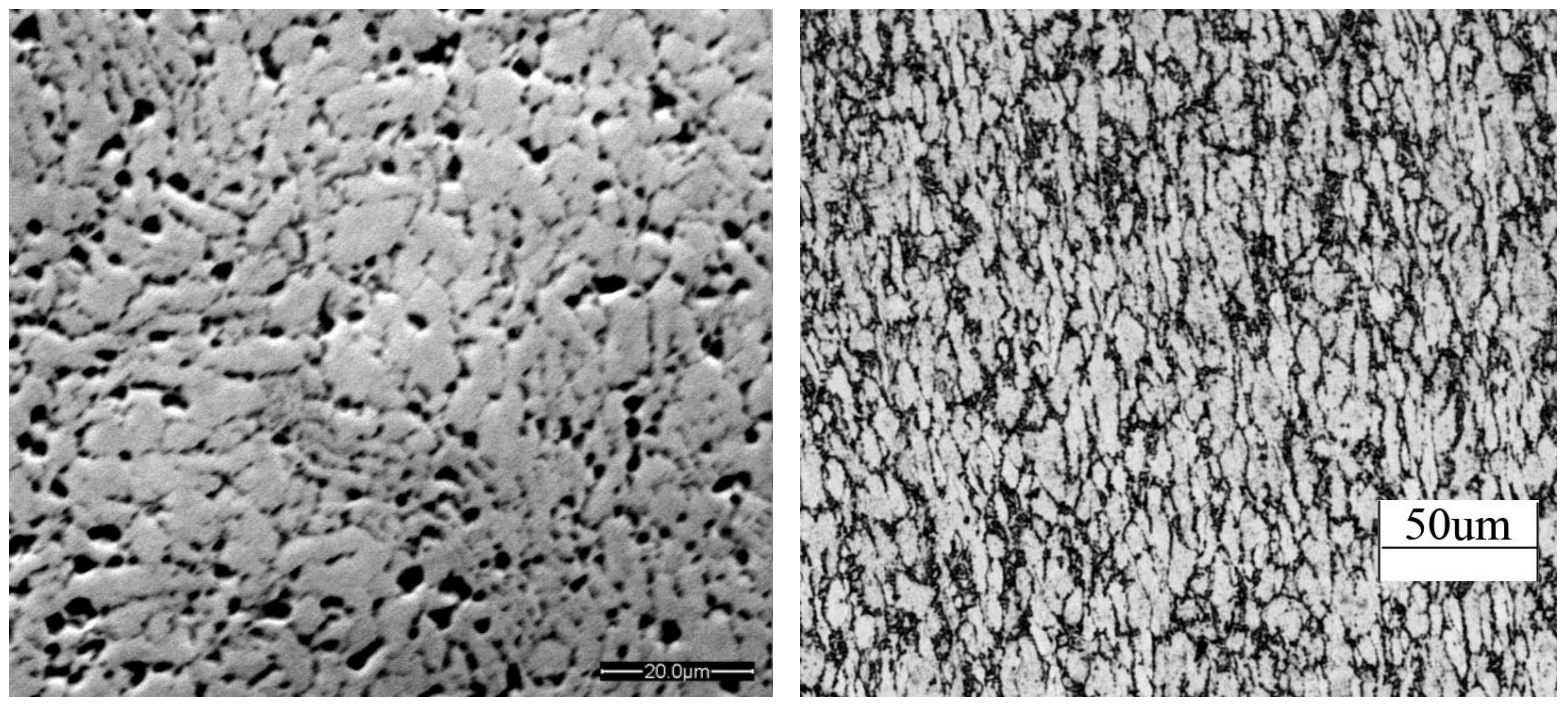

Figure 4.5. Inverted SEM image (a) and microstructure (b) of sample treated at $600^{\circ} \mathrm{C}$ for 16 hours. Light content represents the $\alpha$ phase and dark content represents the $\beta$ phase. The $\beta$ content is similar between the two images, but does not confirm whether the microstructure directly predicts the surface content.
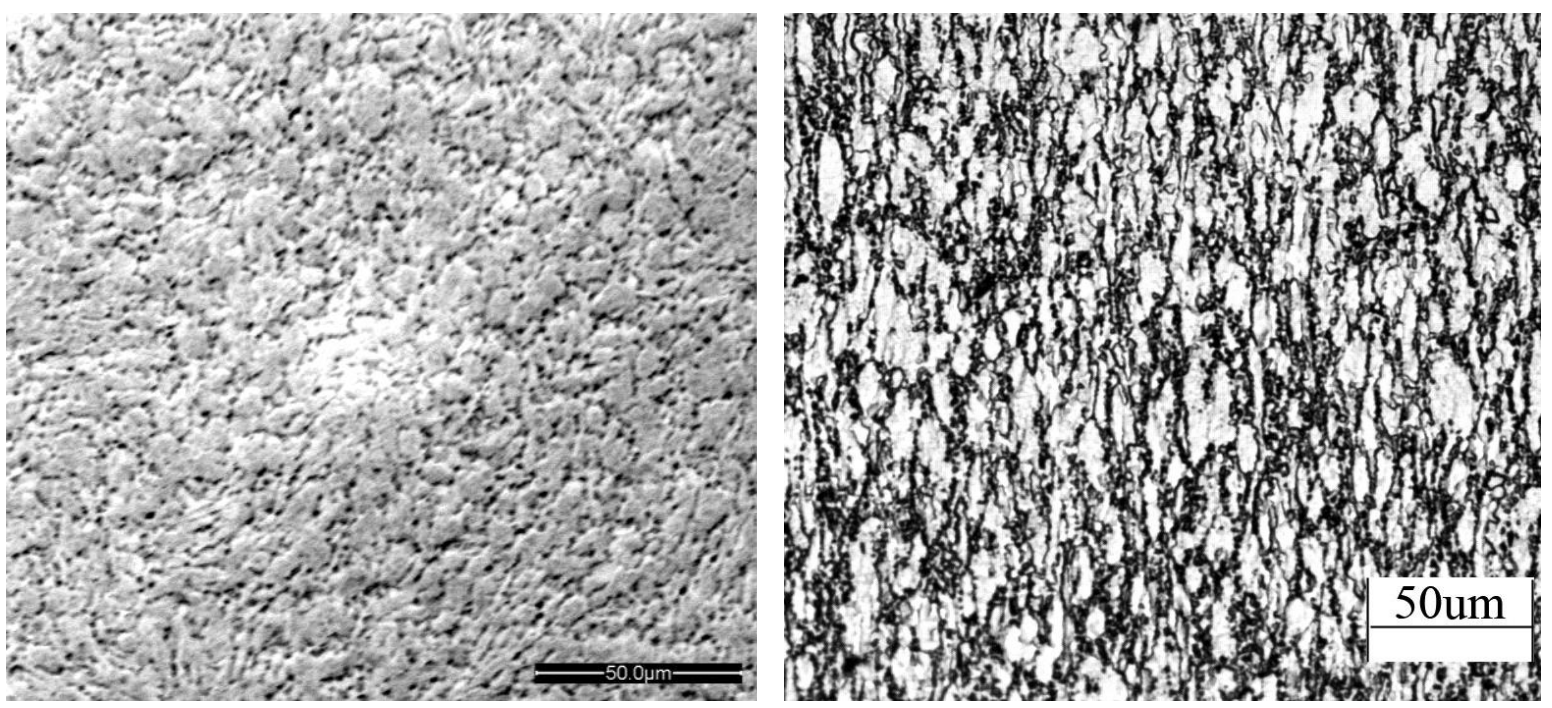

Figure 4.4. Inverted SEM image (a) and microstructure (b) of sample treated at $675^{\circ} \mathrm{C}$ for 16 hours. Light content represents the $\alpha$ phase and dark content represents the $\beta$ phase. Amount of $\beta$ content is not similar between two images, neither confirming nor denying the direct relationship between $\beta$ content in microstructure and on sample surface. 


\subsubsection{Hardness}

The hardness values $\left(\mathrm{HR}_{\mathrm{C}}\right)$ of $600^{\circ} \mathrm{C}$ and $675^{\circ} \mathrm{C}$ were not significantly different from the hardness of the untreated sample, indicating that the hardness of the material was not altered by the thermal oxidation process. Although hardness values of the two temperatures were statistically different from one another, their values were within the range of the untreated sample hardness values, indicating that the oxidation treatment had little, if any, effect on hardness. Even the 16 hour treatment at $675^{\circ} \mathrm{C}$ maintained the same range of hardness values. Although major microstructural changes resulting in grain enlargement and decreased hardness may occur at higher temperatures and longer treatment times, but they were not observed in this study.

\subsubsection{Microhardness}

The increasing trend in microhardness with temperature and time is supported by Gülyerüz et al. (2004), who reported that surface hardness increases with thermal oxidation as the oxygen diffuses into the matrix and places strain into the lattice. The microhardness values are in accordance with findings by Dearnley et al. (2004). After thermal oxidation, the microhardness $(100 \mathrm{~g})$ increased from $369 \mathrm{HV}$ in the untreated sample to $755 \mathrm{HV}$ in the thermally oxidized sample (Dearnley et al., 2004). An increasing trend in microhardness with treatment time seen in this study indicates that the $600^{\circ} \mathrm{C} 16$ hour treatment microhardness value of $560 \mathrm{HV}$ is on the same scale as Dearnley et al. (2004), who thermally oxidized at $625^{\circ} \mathrm{C}$ for 36 hours.

The microhardness of A-600-4 was lower than the other samples treated at $600^{\circ} \mathrm{C}$, but its surface roughness was the highest of the group. Therefore, in accordance with the findings of other researchers (Gülyerüz et al. 2004), the high surface roughness may have affected the indentations by altering the indentation width.

\subsubsection{Abrasion characteristics}

Dearnley et al. (2004) also determined that the increased thickness and microhardness of the oxide layer contained greater residual stresses than untreated samples, which was seen by the 
delamination behavior of the samples with higher microhardness values. The increased strain on the lattice as a result of thermal oxidation treatments at the higher temperature (Gülyerüz et al., 2004) resulted in a more brittle surface oxide scale, which delaminated during both hardness tests and abrasion tests.

The delamination in N-675-16, A-675-16, A-675-8, and A-675-4 appeared to separate the rutile scale of the dual-layer oxide that formed at higher temperatures. The oxide fractured above the oxygen diffusion zone, similar to the findings of Dearnley et al. (2004), who determined that higher temperatures create outer oxide layers that poorly adhere to the substrate and fracture along the $\mathrm{TiO}_{2}$-oxygen diffusion zone interface. However, the inner oxygen diffusion zone is far more adherent (Frangini et al. 1994, Borgioli et al. 2004), but not as hard or thick as the outer scale. In addition, the accelerated growth rate at the higher temperature may have placed more intrinsic and thermal stress on the oxide (Gülyerüz et al., 2004), causing its brittle behavior during abrasion.

The lack of delamination in samples treated at $600^{\circ} \mathrm{C}$ is in accordance with the findings of researchers (Gülyerüz et al., 2004, Frangini et al., 1994), as longer treatments resulted in fewer defects, more rutile, and better adhesion of the oxide to the substrate.

The abrasion width varied from sample to sample, indicating that the thermal oxidation treatments affected the abrasion resistance. Larger abrasion widths were seen in samples treated at higher temperatures and times. As the diamond-tip indenter had a tip radius of $120^{\circ}$, a larger width would indicate deeper penetration of the indenter into the sample surface. As all samples were abraded with the same indenter, weight, and rate, less resistance to abrasion was displayed in samples with wider abrasion scars.

Similar to the findings of Li et al. (2004), thermal oxidation treatments that altered the mechanical properties of a material were ineffective in improving wear resistance. The Rockwell hardness was not affected by the thermal oxidation treatments, but the wear resistance and 
damage to the material were affected, particularly in samples treated at $675^{\circ} \mathrm{C}$. A-675-16 showed the widest abrasion length and microstructural grain growth, partially verifying the findings of $\mathrm{Li}$ et al. (2004), as the mechanical properties were not altered, but the wear resistance was not increased. Samples treated for shorter time periods had smaller abrasion scars, indicating more wear resistance than the sample treated at $675^{\circ} \mathrm{C}$ for 16 hours, with no statistical difference in hardness. 


\section{CONCLUSION}

Overall, thermal oxidation appears as a viable option for enhancing corrosion and wear performance in Ti-6Al-4V anterior cervical plates. Samples treated at $600^{\circ} \mathrm{C}$ for 1 and 16 hours showed improved characteristics, including microhardness increase, more noble open circuit potential, resistance to corrosion, repassivation ability, and oxide adhesion. The sample treated for 1 hour displayed the positive attributes to a lesser degree, with a less noble open circuit potential and lower microhardness values. Therefore, treatments at $600^{\circ} \mathrm{C}$ for 16 hours created a protective surface oxide that was resistant to corrosion and abrasion, and with lower surface roughness than samples treated at $675^{\circ} \mathrm{C}$.

Despite success in the cyclic polarization and Potential step tests, the samples treated at $675^{\circ} \mathrm{C}$

for 4,8 , and 16 hours had the highest microhardness and the most brittle scale due to their dual-layer oxide, causing the most delamination after a single abrasion. In addition to the high surface roughness measured in the treatments, samples treated at $675^{\circ} \mathrm{C}$ for longer than 1 hour would not create viable surface oxides for an ACP that may undergo surgical damage.

Thermal oxidation treatments altered the corrosion resistance, repassivation ability, surface roughness, microhardness, and adhesion of the protective oxide layer of Ti-6Al-4V. Trends with increasing time and temperature were seen in the open circuit potential values, microhardness, and quantity of delamination. Hardness was not significantly different for thermally oxidized samples compared to untreated samples, indicating that any grain growth from heat treatment did not alter the bulk material properties. Outliers in cyclic polarization tests, Potential step tests, and surface roughness measurements reflected the characteristics of the fabricated oxide structures and the propensity of the oxide to particular temperature and time combinations. 
In non-abraded thermal oxidation treatments, the corrosion resistance was improved in some samples and reduced in others. All samples treated at $675^{\circ} \mathrm{C}$ were successfully resistant to breakdown, although the sample treated for 8 hours broke down at a physiologically irrelevant $1.7 \mathrm{~V}$. The samples treated at $600^{\circ} \mathrm{C}$ for 1 and 16 hours were also successful and did not breakdown during cyclic polarization. The oxide layers produced by 4 and 8 hour treatments broke down and retained surface damage, indicating the susceptibility of specific treatment times and temperatures to corrosion.

Of the abraded samples, all but the sample treated at $600^{\circ} \mathrm{C}$ for 4 hours were able to repassivate. Although some samples displayed leaks of current during Potential step tests, they were eventually able to repassivate, restoring their passive layer and decreasing the flow of current to the surrounding environment. As speculation, preferential dissolution of one species of oxide may have occurred in the samples treated at $600^{\circ} \mathrm{C}$ for 4 hours. Pits located on the surface of both the non-abraded and abraded samples, away from the abrasion scar, indicated the surface's lack of corrosion resistance.

Of samples treated at $675^{\circ} \mathrm{C}$, the highest surface roughness of non-abraded and abraded samples were the 4 and 8 hour treatments, respectively. The highest surface roughness of abraded samples treated at $600^{\circ} \mathrm{C}$ was after 4 hours of treatment. The non-linear increases in surface roughness of both temperatures represented heterogeneous oxide structure, with growth rates of alpha and beta oxides dependent on temperature and time. In addition, the higher surface roughness seen in samples treated at $675^{\circ} \mathrm{C}$ would be advantageous for osseointegration, which is not desired for the ACP application. 


\section{RECOMMENDATIONS FOR FUTURE WORK}

Corrosion resistance and surface effects from thermal oxidation of Ti-6Al-4V may be further explored in many ways, but two advancements are specific to this study: analysis of the oxide produced by $600^{\circ} \mathrm{C}$ for times within a short range of 4 hours; studies of oxides produced at $600^{\circ} \mathrm{C}$ for longer than 16 hours.

In this study, the structure of the oxide produced at $600^{\circ} \mathrm{C}$ for 4 hours was an outlier in surface roughness and breakdown. A study of oxides produced at times between 1 and 8 hours may provide insight to the structural evolution of the oxide during thermal oxidation and the growth rates of the alpha and beta oxides. Additional techniques such as x-ray diffraction (XRD) or an AFM with higher resolution would provide data to compare to resources reviewed in this study.

Oxides produced at $600^{\circ} \mathrm{C}$ for longer than 16 hours could be investigated to determine whether the microhardness and open circuit potential continue to increase, and whether the surface roughness and adhesion continue to change with treatment time. The oxides could also be corrosion tested under different conditions, such as in vitro wear to simulate abrasion from screws during arthrodesis. Such testing could determine whether a 16 hour treatment is the minimum time necessary to achieve desirable properties, or whether a longer treatment is required.

An additional study may further analyze the cyclic polarization behavior of the thermally oxidized samples for corrosion rates, behavior in the transpassive region, and current density monitoring. Much material information apart from breakdown potential can be obtained from cyclic polarization graphs, and a comparison of different thermal oxidation treatments, or even different surface treatments, can be compared to find optimal treatment methods. 


\section{REFERENCES}

Aluminum. (n.d.). Retrieved November 5, 2006, from www.lenntech.com/period-chart-elements/Alen.htm

Anandan, C., \& Rajam, K. S. (2008). MicroRaman study of the effect of oxide layer on nitriding of Ti-6Al-4V. Applied Surface Sciences , 2783-2789.

ASTM International. (2006). Standard Test Method for Conducting Cyclic Potentiodynamic Polarization Measurements to Determine the Corrosion Susceptibility of Small Implant Devices. In A. C. F04. West Conshohoken: ASTM International.

Aziz-Kerrzo, M., Conroy, K. G., Fenelon, A. M., Farrell, S. T., \& Breslin, C. B. (2001). Electrochemical studies on the stability and corrosion resistance of titanium-based implant materials. Biomaterials , 1531-1539.

Baker, K. (2007, November 2). Ph.D student, Michigan Tech University. (K. Miyashiro, Interviewer)

Borgioli, F., Galvanetto, E., Fossati, A., \& Pradelli, G. (2004). Glow-discharge and furnace treatments of Ti-6Al-4V. Surface and Coatings Technology, 255-262.

Borgioli, F., Galvanetto, E., Iozzelli, F., \& Pradelli, G. (2005). Improvement of wear resistance of Ti6Al-4V alloy by means of thermal oxidation. Materials Letters , 2159-2162.

Deanrley, P. A., Dahm, K. L., \& Cimenoglu, H. (2004). The corrosion-wear behavior of thermally oxidised CP-Ti and Ti-6Al-4V. Wear, 469-479.

Electrochemistry. (n.d.). Retrieved May 2007, from Anderson Materials:

www.andersonmaterials.com/images/electro4.jpg

Frangini, S., \& Mignone, A. (1994). Various aspects of the air oxidation behavior of a Ti-6Al-4V alloy at temperatures in the range of 600-700 C. Journal of Materials Science, 714-720.

Gibbs, D. (2008). Lecturer, Materials Engineering Department, Cal Poly. (K. Miyashiro, Interviewer)

Gobel, M., Haanappel, V., \& Stroosnijder, M. F. (2001). On the determination of diffusion coefficients of oxygen in one phase Ti and two-phase Ti-4Nb by microhardness measurements. Oxidation of Metals .

Güleryüz, H., \& Cimenoglu, H. (2004). Effect of thermal oxidation on corrosion and corrosion-wear behavior of a Ti-6Al-4V alloy. Biomaterials , 3325-3333.

Jacobs, J. J., Gilbert, J. L., \& Urban, R. M. (1998). Current Concepts Review- Corrosion of Metal Orthopaedic Implants. The Journal of Bone and Joint Surgery, 268-282.

Jones, D. (1991). Principles and Prevention of Corrosion. MacMillan Pub Co. 
Kahn, M. A., Williams, R. L., \& Williams, D. F. (1996). In-vitro corrosion and wear of titanium alloys in the biological environment. Biomaterials , 2117-2126.

Komotori, J., Hisamori, N., \& Ohmori, Y. (2007). The corrosion/wear mechanisms of Ti-6Al-4V alloy for different scratching rates. Wear , 412-418.

Komotori, J., Lee, B. J., Dong, H., \& Dearnley, P. A. (2001). Corrosion response of surface engineered titanium alloys damaged by prior abrasion. Wear , 1239-1249.

Ku, C.-H., Pioletti, D. P., Browne, M., \& Gregson, P. J. (2002). Effect of different Ti-6Al-4V surface treatments on osteoblasts behaviour. Biomaterials , 1447-1454.

Lee, H.-S., Yoon, J.-H., \& Yi, Y.-M. (2007). Oxidation behavior of titanium alloy under diffusion bonding. Thermochinica Acta , 105-108.

Lee, T. M., Chang, E., \& Yang, C. Y. (1999, October 14). A comparison of the surface characteristics and ion release of Ti-6Al-4V and heat-treated Ti-6Al-4V. Tainan, Taiwan, Republic of China.

Lewandowska, M., Pisarek, M., Rozniatowski, K., Gradzka-Dahlke, M., Janik-Czachor, M., \& Kurzydlowski, K. (2007). Nanoscale characterization of anodic oxide films on Ti-6Al-4V alloy. Thin Solid Films , 6460-6464.

Li, S. J., Yang, R., Li, S., Hao, Y. L., Cui, Y. Y., Niinomi, M., et al. (2004). Wear characteristics of Ti-Nb-Ta-Zr and Ti-6Al-4V alloys for biomedical applications. Wear , 869-876.

MacDonald, D. E., Rapuano, B. E., Deo, N., Stranick, M., Somasundaran, P., \& Boskey, A. L. (2004). Thermal and chemical modification of titanium-aluminum-vanadium implant materials: effects on surface properties, glycoprotein adsorption, and MG63 cell attachment. Biomaterials, 3135-3146.

Maroon, J. (n.d.). Anterior Cervical Discectomy with or without Fusion and Plating:. Retrieved May 2007, from Joseph Maroon.com: http://www.josephmaroon.com/

Moftakhar, R., \& Trost, G. R. (2004). Anterior cervical plates: a historical perspective. Neurosurg Focus .

P. Tengvall, M. T. (2001). Titanium in Medicine: Material Science, Surface Science, Engineering, Biological Responses and Medical Applications. Springer.

Petersen, D., Venugopalan, R., Lemons, J., \& Lucas, L. Comparative Evaluation of Surface Characteristics of 21 SRx Titanium Alloy. Birmingham: University of Alabama at Birmingham, Biomedical Engineering Department.

Rosenbloom, S. N., \& Corbett, R. A. (2007). An assessment of ASTM F2129 Electrochemical Testing of Small Medical Implants- lessons learned. NACE International- Corrosion 2007 Conference \& Expo (pp. 1-9). National Association of Corrosion Engineers.

Saldana, L., Vilaboa, N., Valles, G., Gonzales-Cabrero, J., \& Munuera, L. (2005). Osteoblast response to thermally oxidized Ti6Al4V alloy. Wiley Periodicals , 97-107. 
Semiatin, S. L., Brown, T. M., Goff, T. A., Fagin, P. N., Barker, D. R., Turner, R. E., et al. (2004). Diffusion coefficients for modeling the heat treatment of Ti-6Al-4V. Metallurgical and Materials Transactions , 3015 .

Shapiro, S. A., \& Snyder, W. (1997). Spinal instrumentation with a low complication rate. Spine, 566-574.

Vadiraj, A., \& Kamaraj, M. (2007). Effect of surface treatments on fretting fatigue damage of biomedical titanium alloys. Tribology International, 82-88.

Zhu, X. M., \& Lei, M. K. (2005). Surface engineering of biomedical metallic materials. Current Applied Physics , 522-525. 
APPENDIX A: AFM Data of Non-Abraded Samples

$\mathrm{N}-0$ before heat treatment

\section{Nanosurf Image Document}

File: Image1
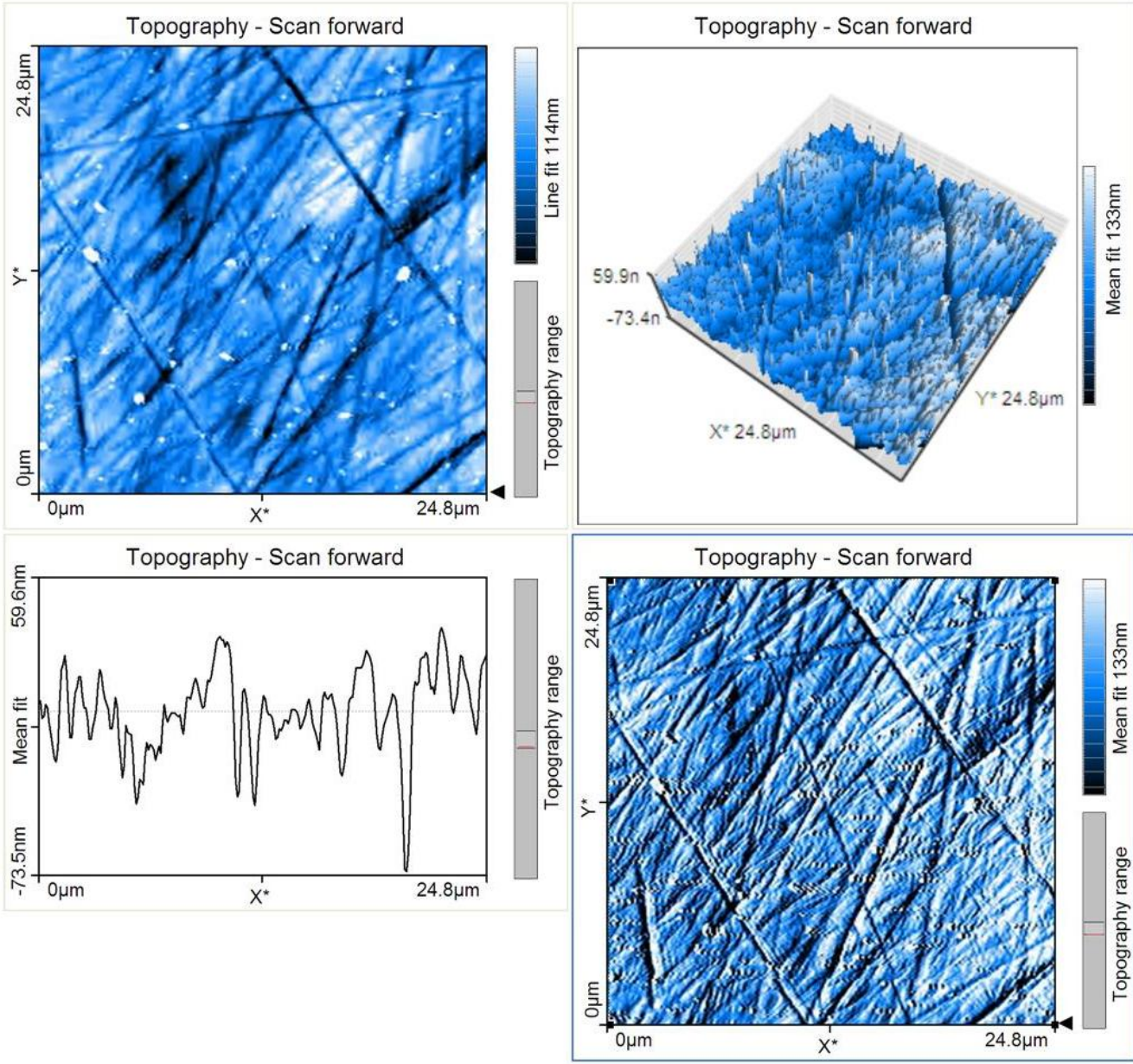

Parameter:

$\begin{array}{ll}- \text { Area Roughness -- } \\ \text { Area } & =618 \mathrm{pm}^{\wedge} 2 \\ \mathrm{Sa} & =18.154 \mathrm{~nm} \\ \mathrm{Sq} & =23.653 \mathrm{~nm} \\ \mathrm{Sy} & =346.22 \mathrm{~nm} \\ \mathrm{Sp} & =241.32 \mathrm{~nm} \\ \mathrm{~Sv} & =-104.9 \mathrm{~nm} \\ \mathrm{Sm} & =-188.22 \mathrm{fm} \\ -- \text { Line Roughness -- } & \\ \mathrm{Ra} & =19.519 \mathrm{~nm} \\ \mathrm{Rq} & =27.869 \mathrm{~nm} \\ \mathrm{Ry} & =235.94 \mathrm{~nm} \\ \mathrm{Rp} & =159.92 \mathrm{~nm} \\ \text { Rv } & =-76.028 \mathrm{~nm} \\ \text { Rm } & =15.651 \mathrm{pm} \\ - \text { Scan -- } & \\ \text { Image size } & =25 \mu \mathrm{m} \\ \text { Scan direction } & =D o w n \\ \text { Time/Line } & =0.3 \mathrm{~s} \\ \text { Points } & =256\end{array}$

$\begin{array}{lll}\text { Lines } & =256 \\ \text { X-Slope } & =500 \mathrm{~m}^{\circ} \\ \text { Y-Slope } & =7.5^{\circ} \\ \text { Rotation } & =90^{\circ} \\ \text { X-Pos } & =0 \mathrm{~m} \\ \text { Y-Pos } & =0 \mathrm{~m} \\ \text { Z-Plane } & =0 \mathrm{~m} \\ \text { Overscan } & =5 \% \\ \text { Const.Height-Mode } & =\text { Disabled } \\ \text { Date } & =16-07-2008 \\ \text { Time } & =14: 55: 00 \\ \text {--Feedback -- } & & \\ \text { Set point } & =50 \% \\ \text { P-Gain } & =10000 \\ \text { I-Gain } & =1800 \\ \text { Tip voltage } & =0 \mathrm{~V} \\ \text { Feedback mode } & =\text { Free } \\ \text { Feedback algo. } & =\text { Adaptive PI } \\ \text { Vibration freq. } & =183.647 \mathrm{kHz} \\ \text { Vibration ampl. } & =0.7 \mathrm{~V}\end{array}$

$\begin{array}{ll}\text { Excitation ampl. } & =0.57 \mathrm{~V} \\ \text { Error range } & =20 \mathrm{~V} \\ - \text {-Global -- } & \\ \text { Op. mode } & =\text { Dynamic Force } \\ \text { Cantilever type } & =\text { ACLA } \\ \text { Head type } & =\text { EZ2-AFM } \\ \text { Scan head } & =10-07-239 . \text { hed } \\ \text { Software ver. } & =1-5-1-0 \\ \text { Firmware ver. } & =2-1-1-2 \\ \text { Controller S/N } & =023-06-252 \\ - \text { Module -- } & \\ \text { Controller Board } & =2 \\ \text { AFM Basic Module } & =2 \\ \text { AFM Dynamic Module } & =2 \\ \text { AFM Extension Module } & =1 \\ \text { Video Module } & =0 \\ \text { Signal Module S } & =0 \\ \text { Signal Module A } & =0 \\ \text { Nanosurf Report } & =0 \\ \text { Scripting Interface } & =0\end{array}$




\section{Nanosurf Image Document}

File: Image2
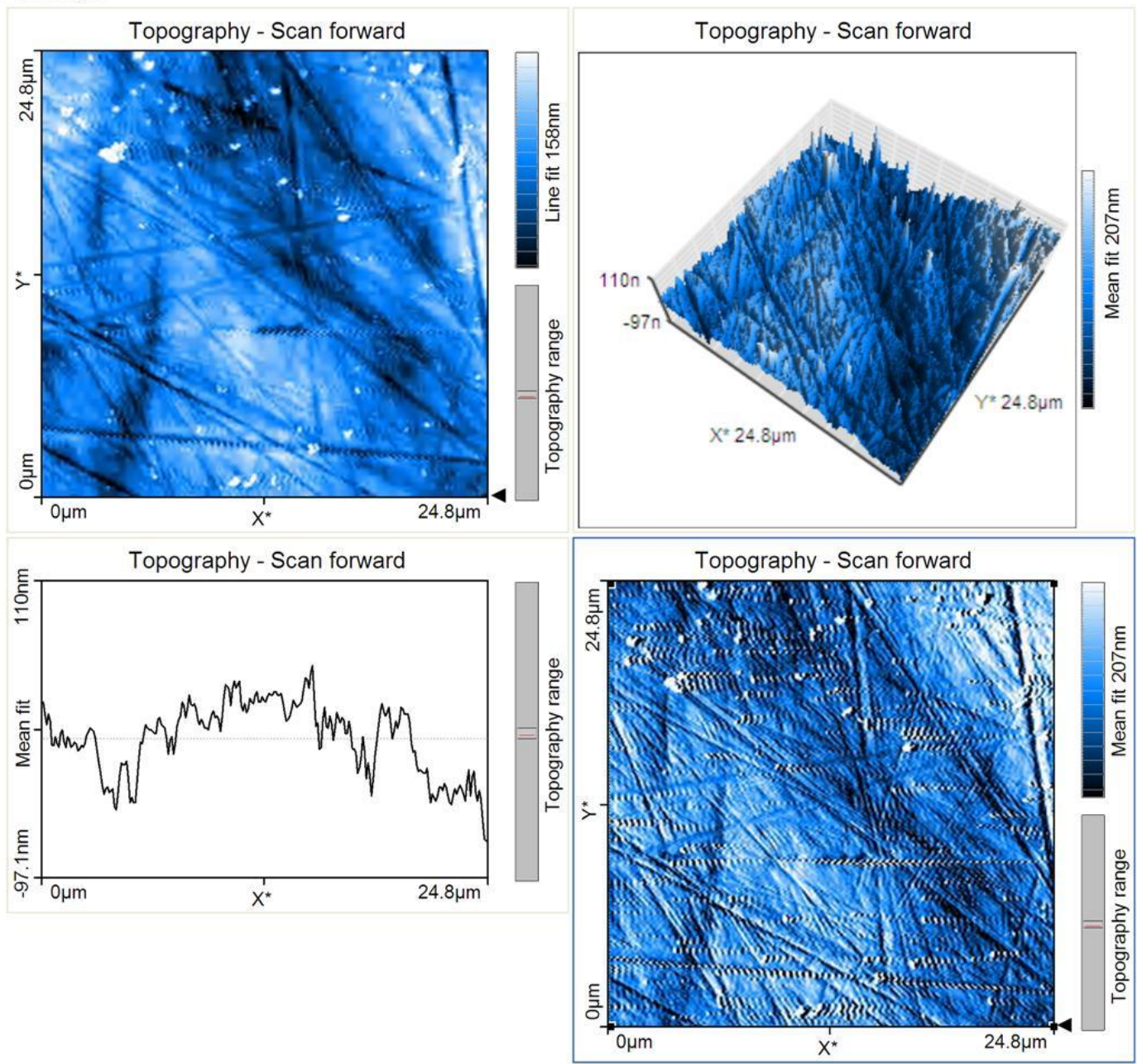

Parameter:

\begin{tabular}{|c|c|c|c|c|c|}
\hline \multicolumn{2}{|c|}{-- Area Roughness -- } & \multirow{2}{*}{$\begin{array}{l}\text { Lines } \\
X \text {-Slope }\end{array}$} & \multirow{2}{*}{$\begin{array}{l}=256 \\
=3.5^{\circ}\end{array}$} & \multirow{2}{*}{$\begin{array}{l}\text { Excitation ampl. } \\
\text { Error range }\end{array}$} & \multirow{2}{*}{$\begin{array}{l}=0.55 \mathrm{~V} \\
=20 \mathrm{~V}\end{array}$} \\
\hline Area & $=618 \mathrm{pm}^{\wedge} 2$ & & & & \\
\hline $\mathrm{Sa}$ & $=28.97 \mathrm{~nm}$ & Y-Slope & $=7^{\circ}$ & -- Global -- & \\
\hline $\mathrm{Sq}$ & $=35.363 \mathrm{~nm}$ & Rotation & $=-14.2 f^{\circ}$ & Op. mode & = Dynamic Force \\
\hline Sy & $=339.68 \mathrm{~nm}$ & X-Pos & $=8.9 \mu \mathrm{m}$ & Cantilever type & $=A C L A$ \\
\hline Sp & $=230.15 \mathrm{~nm}$ & Y-Pos & $=18 \mu \mathrm{m}$ & Head type & $=\mathrm{EZ2}-\mathrm{AFM}$ \\
\hline Sv & $=-109.54 \mathrm{~nm}$ & Z-Plane & $=2.7 \mu \mathrm{m}$ & Scan head & $=10-07-239$.hed \\
\hline Sm & $=117.72 \mathrm{pm}$ & Overscan & $=5 \%$ & Software ver. & $=1-5-1-0$ \\
\hline \multicolumn{2}{|c|}{-- Line Roughness -- } & \multicolumn{2}{|c|}{ Const. Height-Mode= Disabled } & Firmware ver. & $=2-1-1-2$ \\
\hline $\mathrm{Ra}$ & $=28.992 \mathrm{~nm}$ & Date & $=16-07-2008$ & Controller S/N & $=023-06-252$ \\
\hline $\mathrm{Rq}$ & $=34.312 \mathrm{~nm}$ & Time & $=15: 16: 51$ & -- Module -- & \\
\hline Ry & $=185.55 \mathrm{~nm}$ & -- Feedback -- & & Controller Board & $=2$ \\
\hline $\mathrm{Rp}$ & $=103.68 \mathrm{~nm}$ & Set point & $=48 \%$ & AFM Basic Module & $=2$ \\
\hline $\mathrm{Rv}$ & $=-81.867 \mathrm{~nm}$ & P-Gain & $=10000$ & \multicolumn{2}{|c|}{ AFM Dynamic Module $=2$} \\
\hline $\mathrm{Rm}$ & $=161.44 \mathrm{pm}$ & I-Gain & $=1700$ & \multicolumn{2}{|c|}{ AFM Extension Modul $=1$} \\
\hline -- Scan -- & & Tip voltage & $=0 \mathrm{~V}$ & Video Module & $=0$ \\
\hline Image size & $=25 \mu \mathrm{m}$ & Feedback mode & $=$ Free & Signal Module S & $=0$ \\
\hline Scan direction & $=$ Down & Feedback algo. & = Adaptive PI & Signal Module A & $=0$ \\
\hline Time/Line & $=0.3 \mathrm{~s}$ & Vibration freq. & $=183.627 \mathrm{kHz}$ & Nanosurf Report & $=0$ \\
\hline Points & $=256$ & Vibration ampl. & $=0.7 \mathrm{~V}$ & Scripting Interface & $=0$ \\
\hline
\end{tabular}




\section{Nanosurf Image Document}

File: Image3

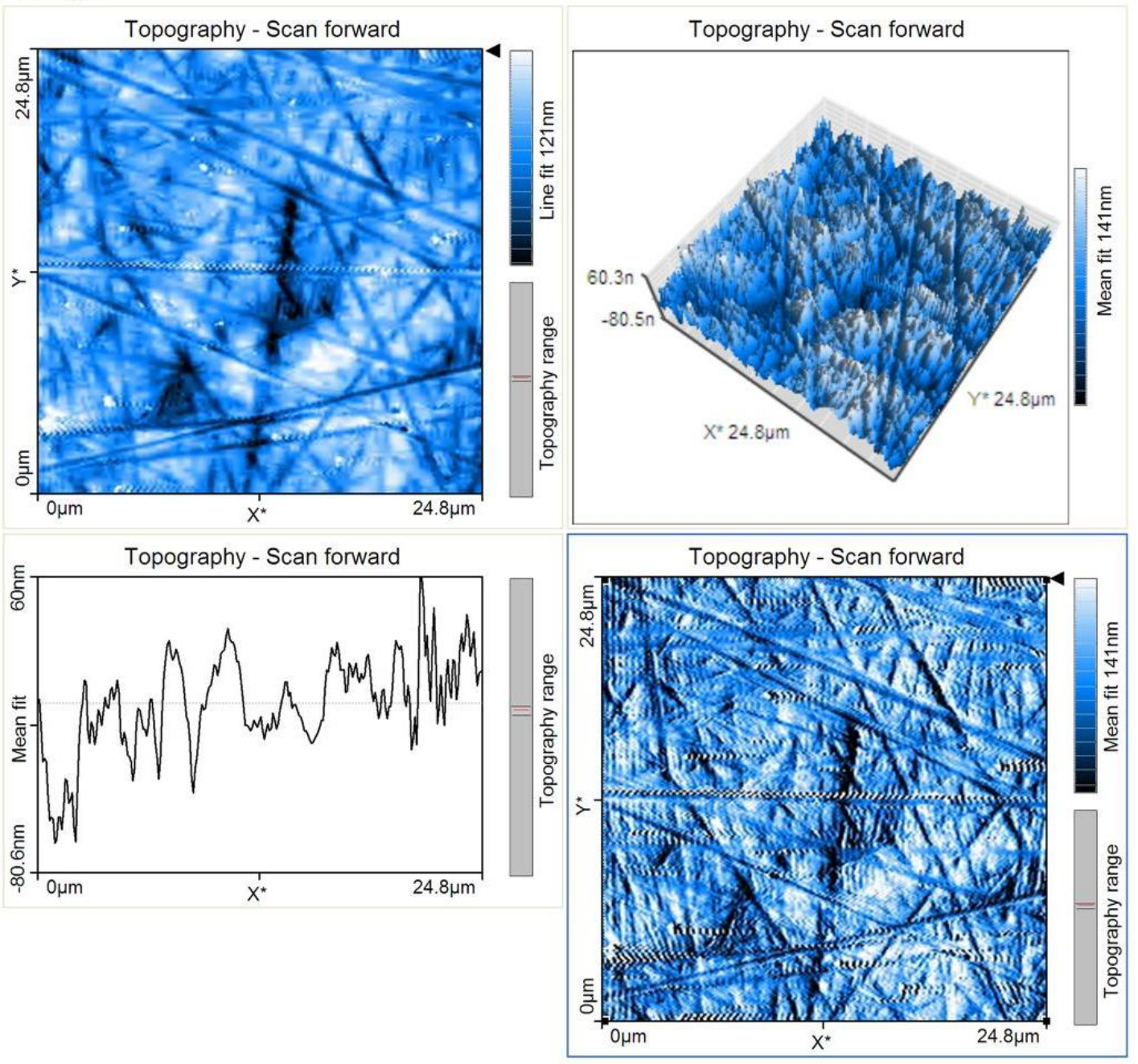

Parameter:

\begin{tabular}{|c|c|c|c|c|c|}
\hline \multicolumn{2}{|c|}{-- Area Roughness -- } & \multirow{2}{*}{$\begin{array}{l}\text { Lines } \\
\text { X-Slope }\end{array}$} & \multirow{2}{*}{$\begin{array}{l}=256 \\
=3.5^{\circ}\end{array}$} & \multirow{2}{*}{$\begin{array}{l}\text { Excitation ampl. } \\
\text { Error range }\end{array}$} & \multirow{2}{*}{$\begin{array}{l}=0.56 \mathrm{~V} \\
=20 \mathrm{~V}\end{array}$} \\
\hline Area & $=618 \mathrm{pm}^{\wedge} 2$ & & & & \\
\hline Sa & $=18.551 \mathrm{~nm}$ & Y-Slope & $=6^{\circ}$ & -- Global -- & \\
\hline $\mathrm{Sq}$ & $=23.692 \mathrm{~nm}$ & Rotation & $=90^{\circ}$ & Op. mode & $=$ Dynamic Force \\
\hline Sy & $=270.31 \mathrm{~nm}$ & X-Pos & $=8.9 \mu \mathrm{m}$ & Cantilever type & $=A C L A$ \\
\hline Sp & $=163.31 \mathrm{~nm}$ & Y-Pos & $=18 \mu \mathrm{m}$ & Head type & $=E Z 2-A F M$ \\
\hline Sv & $=-107.01 \mathrm{~nm}$ & Z-Plane & $=0 \mu \mathrm{m}$ & Scan head & $=10-07-239$. hed \\
\hline Sm & $=215.43 \mathrm{pm}$ & Overscan & $=5 \%$ & Software ver. & $=1-5-1-0$ \\
\hline \multicolumn{2}{|c|}{-- Line Roughness -- } & \multicolumn{2}{|c|}{ Const. Height-Mod $\epsilon=$ Disabled } & Firmware ver. & $=2-1-1-2$ \\
\hline $\mathrm{Ra}$ & $=21.657 \mathrm{~nm}$ & Date & $=16-07-2008$ & Controller S/N & $=023-06-252$ \\
\hline $\mathrm{Rq}$ & $=28.23 \mathrm{~nm}$ & Time & $=15: 28: 36$ & -- Module -- & \\
\hline Ry & $=153.08 \mathrm{~nm}$ & \multicolumn{2}{|l|}{-- Feedback -- } & Controller Board & $=2$ \\
\hline $\mathrm{Rp}$ & $=88.668 \mathrm{~nm}$ & Set point & $=48 \%$ & AFM Basic Module & $=2$ \\
\hline Rv & $=-64.411 \mathrm{~nm}$ & P-Gain & $=10000$ & \multicolumn{2}{|c|}{ AFM Dynamic Module $=2$} \\
\hline $\mathrm{Rm}$ & $=206.74 \mathrm{pm}$ & I-Gain & $=1700$ & \multicolumn{2}{|c|}{ AFM Extension Module $=1$} \\
\hline -- Scan -- & & Tip voltage & $=0 \mathrm{~V}$ & Video Module & $=0$ \\
\hline Image size & $=25 \mu \mathrm{m}$ & Feedback mode & $=$ Free & Signal Module S & $=0$ \\
\hline Scan direction & $=U p$ & Feedback algo. & $=$ Adaptive PI & Signal Module A & $=0$ \\
\hline Time/Line & $=0.3 \mathrm{~s}$ & Vibration freq. & $=183.617 \mathrm{kHz}$ & Nanosurf Report & $=0$ \\
\hline Points & $=256$ & Vibration ampl. & $=0.7 \mathrm{~V}$ & Scripting Interface & $=0$ \\
\hline
\end{tabular}


$\mathrm{N}-0$ after potentiodynamic polarization

\section{Nanosurf Image Document}

File: Image4
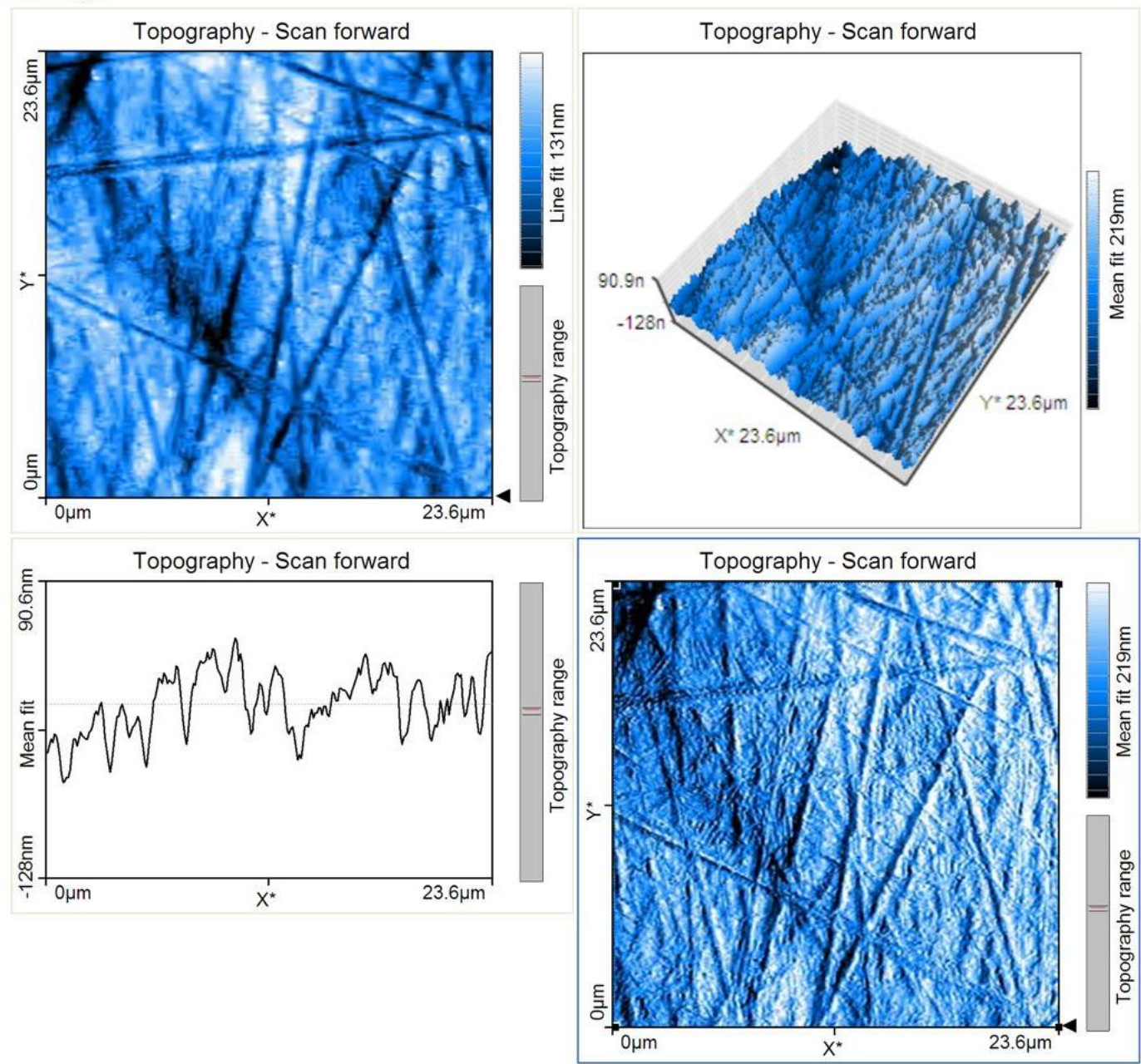

Parameter:

- Area Roughness --

\begin{tabular}{|c|c|}
\hline Area & $=559 \mathrm{pm}^{\wedge} 2$ \\
\hline $\mathrm{Sa}$ & $=28.424 \mathrm{~nm}$ \\
\hline $\mathrm{Sq}$ & $=36.181 \mathrm{~nm}$ \\
\hline Sy & $=303.21 \mathrm{~nm}$ \\
\hline $\mathrm{Sp}$ & $=131.26 \mathrm{~nm}$ \\
\hline Sv & $=-171.95 \mathrm{~nm}$ \\
\hline $\mathrm{Sm}$ & $=210.69 \mathrm{pm}$ \\
\hline
\end{tabular}

-- Line Roughness --

$\mathrm{Ra} \quad=30.861 \mathrm{~nm}$

$\mathrm{Rq} \quad=36.256 \mathrm{~nm}$

Ry $\quad=148.65 \mathrm{~nm}$

$\mathrm{Rp} \quad=75.506 \mathrm{~nm}$

$\mathrm{Rv} \quad=-73.145 \mathrm{~nm}$

$\mathrm{Rm} \quad=295.69 \mathrm{pm}$

-- Scan --

Image size

$=295.69 \mathrm{pm}$

Scan direction

$=24 \mu \mathrm{m}$

Time/Line

$=$ Down

$=0.3 \mathrm{~s}$

Points

$=256$

$\begin{array}{ll}\text { Lines } & =256 \\ \text { X-Slope } & =6.5^{\circ} \\ \text { Y-Slope } & =3.5^{\circ} \\ \text { Rotation } & =-14.2 \mathrm{f}^{\circ} \\ \text { X-Pos } & =-1.1 \mu \mathrm{m} \\ \text { Y-Pos } & =19 \mu \mathrm{m} \\ \text { Z-Plane } & =0 \mu \mathrm{m} \\ \text { Overscan } & =5 \% \\ \text { Const.Height-Mode } & =\text { Disabled } \\ \text { Date } & =21-07-2008 \\ \text { Time } & =16: 11: 35 \\ \text {--Feedback -- } & \\ \text { Set point } & =48 \% \\ \text { P-Gain } & =10000 \\ \text { l-Gain } & =1500 \\ \text { Tip voltage } & =0 \mathrm{~V} \\ \text { Feedback mode } & =\text { Free } \\ \text { Feedback algo. } & =\text { Adaptive PI } \\ \text { Vibration freq. } & =183.577 \mathrm{kHz} \\ \text { Vibration ampl. } & =0.7 \mathrm{~V}\end{array}$

$\begin{array}{ll}\text { Excitation ampl. } & =0.46 \mathrm{~V} \\ \text { Error range } & =20 \mathrm{~V} \\ \text { - Global -- } & \\ \text { Op. mode } & =\text { Dynamic Force } \\ \text { Cantilever type } & =\text { ACLA } \\ \text { Head type } & =\text { EZ2-AFM } \\ \text { Scan head } & =10-07-239 . \text { hed } \\ \text { Software ver. } & =1-5-1-0 \\ \text { Firmware ver. } & =2-1-1-2 \\ \text { Controller S/N } & =023-06-252 \\ - \text { Module -- } & \\ \text { Controller Board } & =2 \\ \text { AFM Basic Module } & =2 \\ \text { AFM Dynamic Module } & =2 \\ \text { AFM Extension Module } & =1 \\ \text { Video Module } & =0 \\ \text { Signal Module S } & =0 \\ \text { Signal Module A } & =0 \\ \text { Nanosurf Report } & =0 \\ \text { Scripting Interface } & =0\end{array}$




\section{Nanosurf Image Document}

File: Image1

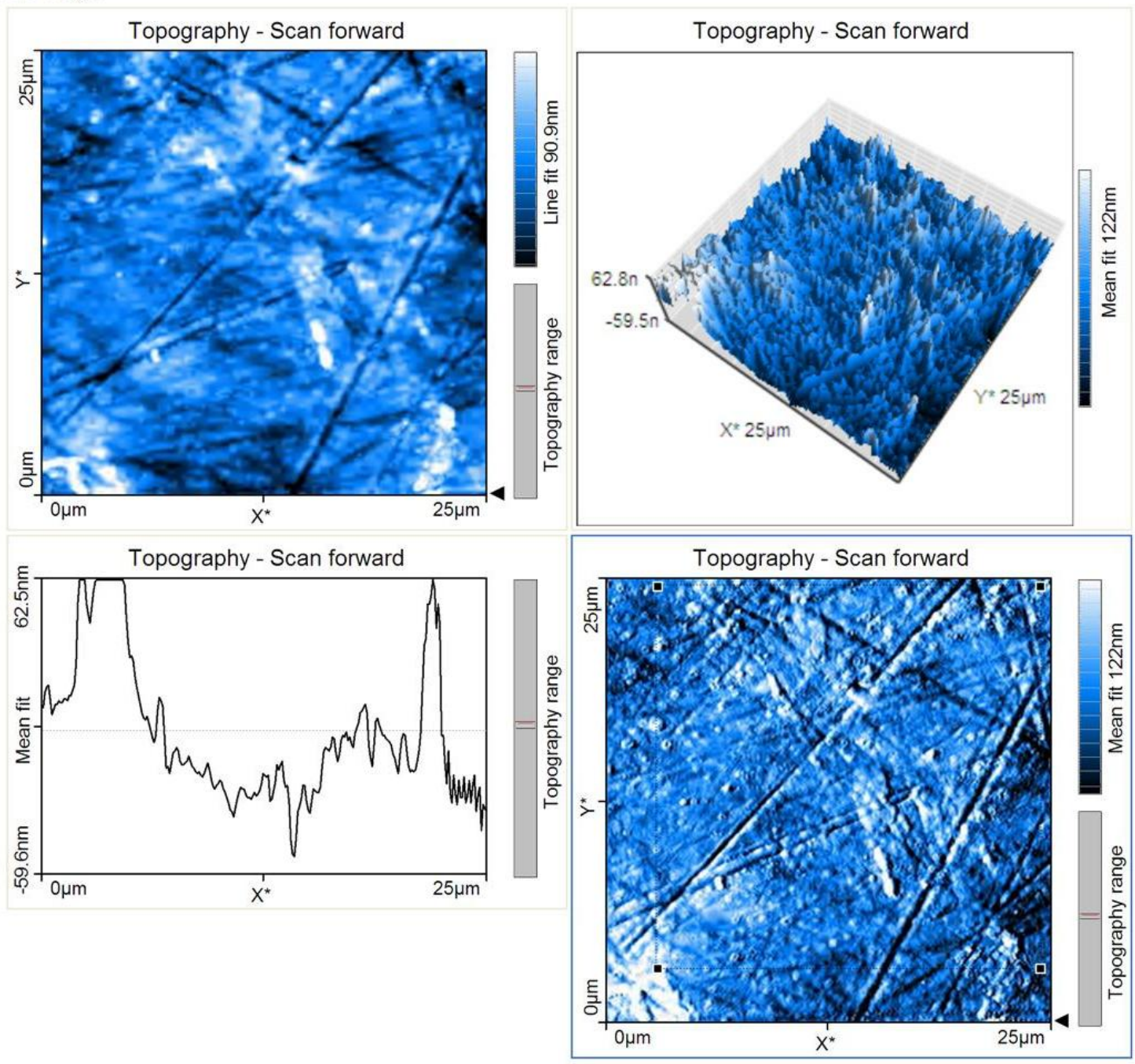

\section{Parameter:}

\begin{tabular}{|c|c|c|c|c|c|}
\hline \multicolumn{2}{|c|}{-- Area Roughness -- } & \multirow{2}{*}{$\begin{array}{l}\text { Lines } \\
\text { X-Slope }\end{array}$} & \multirow{2}{*}{$\begin{array}{l}=256 \\
=6^{\circ}\end{array}$} & \multirow{2}{*}{$\begin{array}{l}\text { Excitation ampl. } \\
\text { Error range }\end{array}$} & \multirow{2}{*}{$\begin{array}{l}=0.29 \mathrm{~V} \\
=20 \mathrm{~V}\end{array}$} \\
\hline Area & $=474.3 \mathrm{pm}^{\wedge} 2$ & & & & \\
\hline $\mathrm{Sa}$ & $=13.425 \mathrm{~nm}$ & Y-Slope & $=4^{\circ}$ & -- Global -- & \\
\hline $\mathrm{Sq}$ & $=17.56 \mathrm{~nm}$ & Rotation & $=90^{\circ}$ & Op. mode & $=$ Dynamic Force \\
\hline Sy & $=173.32 \mathrm{~nm}$ & X-Pos & $=15 \mu \mathrm{m}$ & Cantilever type & $=A C L A$ \\
\hline Sp & $=107.43 \mathrm{~nm}$ & Y-Pos & $=13 \mu \mathrm{m}$ & Head type & $=E Z 2-A F M$ \\
\hline Sv & $=-65.891 \mathrm{~nm}$ & Z-Plane & $=2.5 \mu \mathrm{m}$ & Scan head & $=10-07-239 \cdot$ hed \\
\hline Sm & $=464.28 \mathrm{pm}$ & Overscan & $=5 \%$ & Software ver. & $=1-5-1-0$ \\
\hline \multicolumn{2}{|c|}{-- Line Roughness -- } & \multicolumn{2}{|c|}{ Const. Height-Mod $\epsilon=$ Disabled } & Firmware ver. & $=2-1-1-2$ \\
\hline $\mathrm{Ra}$ & $=13.018 \mathrm{~nm}$ & Date & $=10-08-2008$ & Controller S/N & $=023-06-252$ \\
\hline $\mathrm{Rq}$ & $=16.301 \mathrm{~nm}$ & Time & $=14: 39: 56$ & -- Module -- & \\
\hline Ry & $=82.022 \mathrm{~nm}$ & -- Feedback -- & & Controller Board & $=2$ \\
\hline Rp & $=46.043 \mathrm{~nm}$ & Set point & $=48 \%$ & AFM Basic Module & $=2$ \\
\hline Rv & $=-35.978 \mathrm{~nm}$ & P-Gain & $=10000$ & \multicolumn{2}{|c|}{ AFM Dynamic Module $=2$} \\
\hline $\mathrm{Rm}$ & $=238.86 \mathrm{pm}$ & 1-Gain & $=1400$ & \multicolumn{2}{|c|}{ AFM Extension Module $=1$} \\
\hline -- Scan -- & & Tip voltage & $=0 \mathrm{~V}$ & Video Module & $=0$ \\
\hline Image size & $=25 \mu \mathrm{m}$ & Feedback mode & $=$ Free & Signal Module S & $=0$ \\
\hline Scan direction & $=$ Down & Feedback algo. & = Adaptive PI & Signal Module A & $=0$ \\
\hline Time/Line & $=0.4 \mathrm{~s}$ & Vibration freq. & $=179.207 \mathrm{kHz}$ & Nanosurf Report & $=0$ \\
\hline Points & $=256$ & Vibration ampl. & $=0.7 \mathrm{~V}$ & Scripting Interface & $=0$ \\
\hline
\end{tabular}




\section{Nanosurf Image Document}

File: Image2
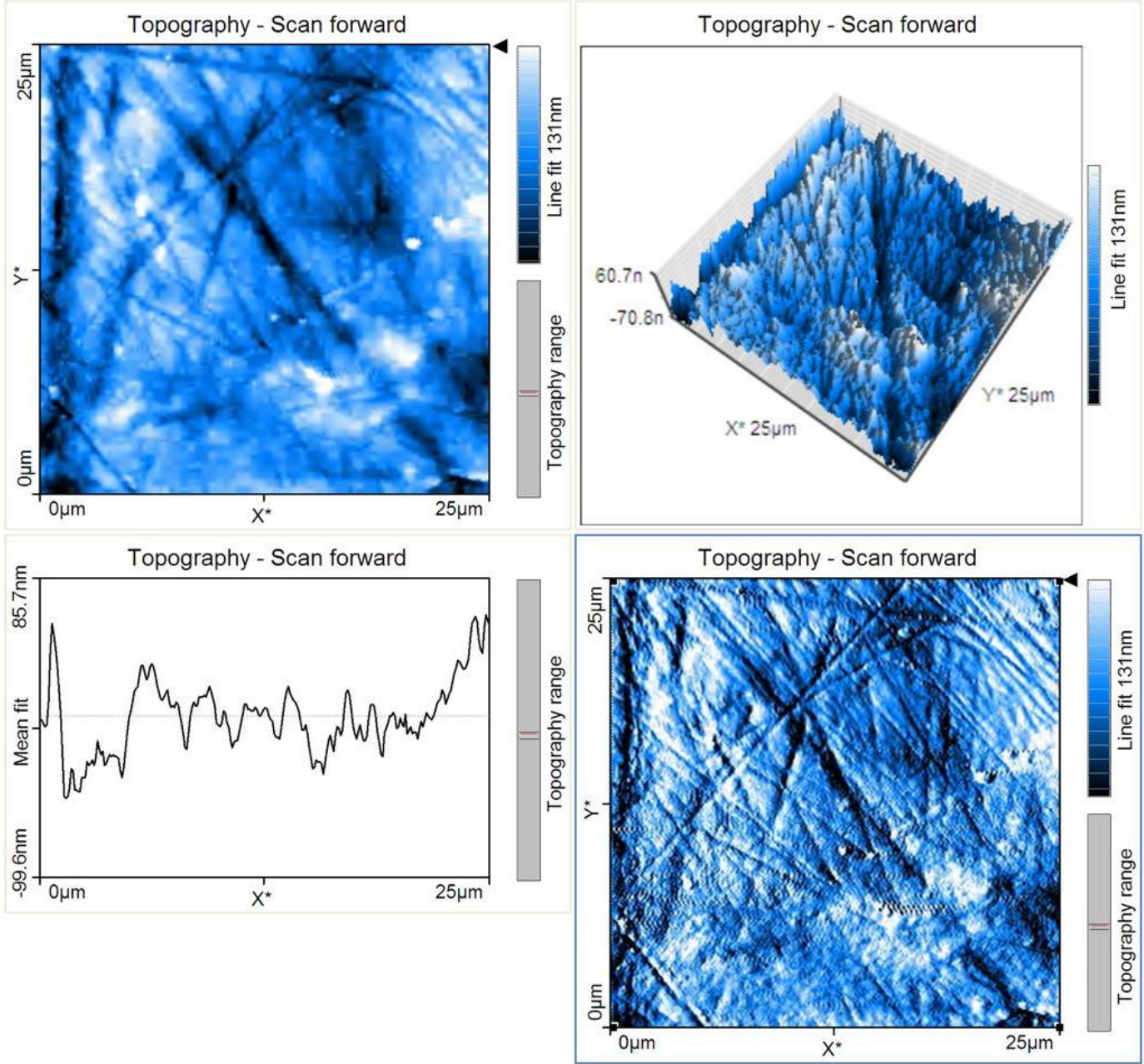

\section{Parameter:}

\begin{tabular}{|c|c|c|c|c|c|}
\hline \multicolumn{2}{|c|}{-- Area Roughness -- } & \multirow{2}{*}{$\begin{array}{l}\text { Lines } \\
\text { X-Slope }\end{array}$} & \multirow{2}{*}{$\begin{array}{l}=256 \\
=5.5^{\circ}\end{array}$} & \multirow{2}{*}{$\begin{array}{l}\text { Excitation ampl. } \\
\text { Error range }\end{array}$} & \multirow{2}{*}{$\begin{array}{l}=0.21 \mathrm{~V} \\
=20 \mathrm{~V}\end{array}$} \\
\hline Area & $=629.9 \mathrm{pm}^{\wedge} 2$ & & & & \\
\hline $\mathrm{Sa}$ & $=20.656 \mathrm{~nm}$ & Y-Slope & $=5^{\circ}$ & -- Global -- & \\
\hline $\mathrm{Sq}$ & $=25.905 \mathrm{~nm}$ & Rotation & $=-0.888 \mathrm{f}^{\circ}$ & Op. mode & = Dynamic Force \\
\hline Sy & $=211.06 \mathrm{~nm}$ & X-Pos & $=15 \mu \mathrm{m}$ & Cantilever type & $=A C L A$ \\
\hline Sp & $=118.6 \mathrm{~nm}$ & Y-Pos & $=13 \mu \mathrm{m}$ & Head type & $=\mathrm{EZ2}-\mathrm{AFM}$ \\
\hline Sv & $=-92.459 \mathrm{~nm}$ & Z-Plane & $=0 \mu \mathrm{m}$ & Scan head & $=10-07-239$. hed \\
\hline Sm & $=8.0434 \mathrm{fm}$ & Overscan & $=5 \%$ & Software ver. & $=1-5-1-0$ \\
\hline \multicolumn{2}{|c|}{-- Line Roughness -- } & \multicolumn{2}{|c|}{ Const. Height-Mod $\epsilon=$ Disabled } & Firmware ver. & $=2-1-1-2$ \\
\hline $\mathrm{Ra}$ & $=14.549 \mathrm{~nm}$ & Date & $=10-08-2008$ & Controller S/N & $=023-06-252$ \\
\hline $\mathrm{Rq}$ & $=19.349 \mathrm{~nm}$ & Time & $=14: 47: 19$ & -- Module -- & \\
\hline Ry & $=103.32 \mathrm{~nm}$ & -- Feedback -- & & Controller Board & $=2$ \\
\hline $\mathrm{Rp}$ & $=41.222 \mathrm{~nm}$ & Set point & $=48 \%$ & AFM Basic Module & $=2$ \\
\hline Rv & $=-62.096 \mathrm{~nm}$ & P-Gain & $=10000$ & \multicolumn{2}{|c|}{ AFM Dynamic Module $=2$} \\
\hline $\mathrm{Rm}$ & $=1.6087 \mathrm{fm}$ & I-Gain & $=1400$ & \multicolumn{2}{|c|}{ AFM Extension Modul $\epsilon=1$} \\
\hline -- Scan -- & & Tip voltage & $=0 \mathrm{~V}$ & Video Module & $=0$ \\
\hline Image size & $=25 \mu \mathrm{m}$ & Feedback mode & $=$ Free & Signal Module S & $=0$ \\
\hline Scan direction & $=U p$ & Feedback algo. & = Adaptive $\mathrm{PI}$ & Signal Module A & $=0$ \\
\hline Time/Line & $=0.4 \mathrm{~s}$ & Vibration freq. & $=179.207 \mathrm{kHz}$ & Nanosurf Report & $=0$ \\
\hline Points & $=256$ & Vibration ampl. & $=0.7 \mathrm{~V}$ & Scripting Interface & $=0$ \\
\hline
\end{tabular}


N-600-1 after heat treatment

\section{Nanosurf Image Document}

File: Image5
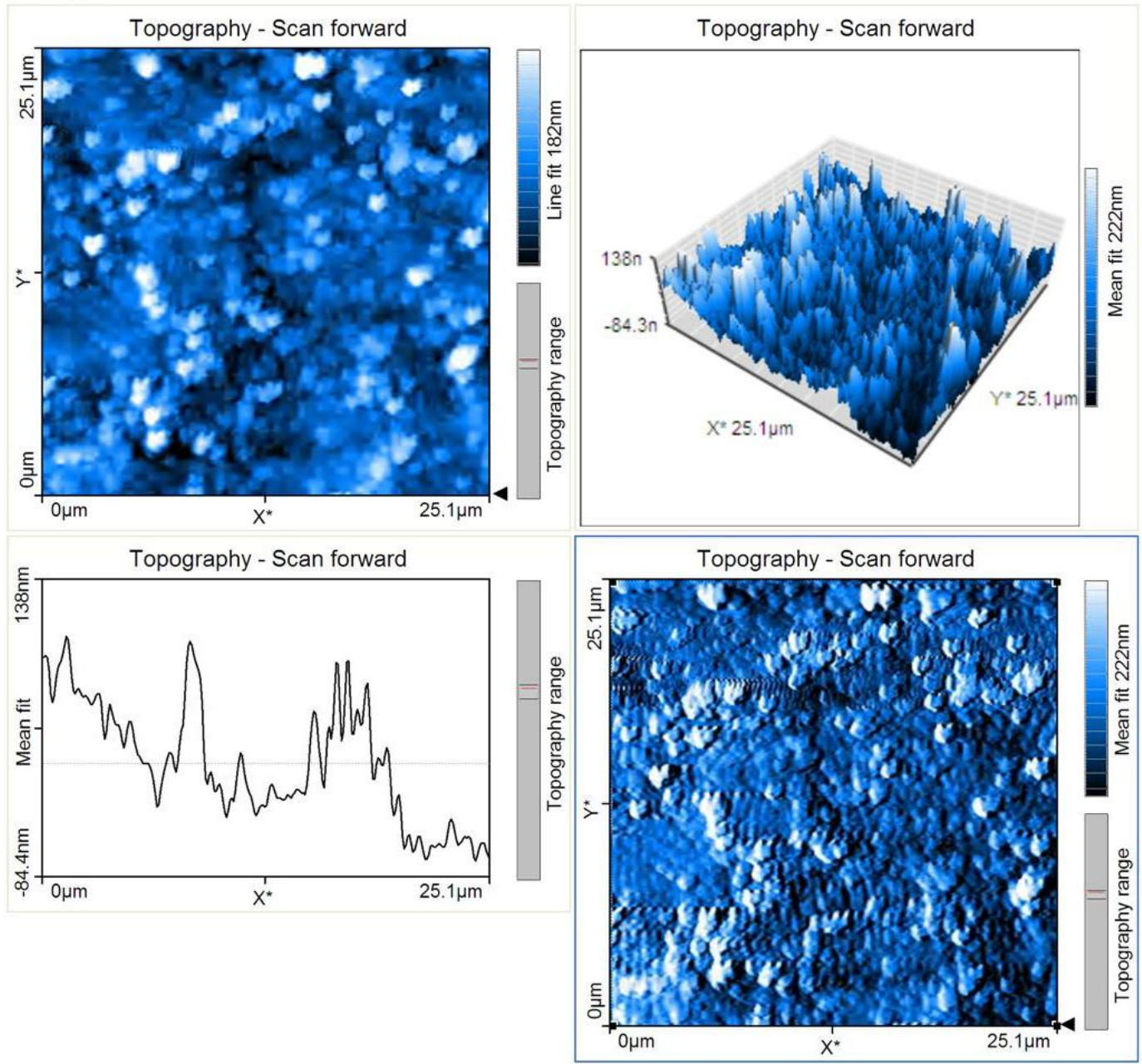

Parameter:

\begin{tabular}{|c|c|c|c|c|c|}
\hline \multicolumn{2}{|c|}{-- Area Roughness -- } & \multirow{2}{*}{$\begin{array}{l}\text { Lines } \\
\text { X-Slope }\end{array}$} & \multirow{2}{*}{$\begin{array}{l}=256 \\
=-500 \mathrm{~m}^{\circ}\end{array}$} & \multirow{2}{*}{$\begin{array}{l}\text { Excitation ampl. } \\
\text { Error range }\end{array}$} & \multirow{2}{*}{$\begin{array}{l}=0.18 \mathrm{~V} \\
=20 \mathrm{~V}\end{array}$} \\
\hline Area & $=637.4 \mathrm{pm}^{\wedge} 2$ & & & & \\
\hline Sa & $=30.223 \mathrm{~nm}$ & Y-Slope & $=0 \mathrm{~m}^{\circ}$ & -- Global -- & \\
\hline $\mathrm{Sq}$ & $=39.409 \mathrm{~nm}$ & Rotation & $=-1.78 \mathrm{f}^{\circ}$ & Op. mode & $=$ Dynamic Force \\
\hline Sy & $=286.55 \mathrm{~nm}$ & X-Pos & $=-15 \mu \mathrm{m}$ & Cantilever type & $=A C L A$ \\
\hline Sp & $=191.77 \mathrm{~nm}$ & Y-Pos & $=-16 \mu \mathrm{m}$ & Head type & $=E Z 2-A F M$ \\
\hline Sv & $=-94.778 \mathrm{~nm}$ & Z-Plane & $=0 \mu \mathrm{m}$ & Scan head & $=10-07-239$. hed \\
\hline $\mathrm{Sm}$ & $=208.84 \mathrm{pm}$ & Overscan & $=5 \%$ & Software ver. & $=1-5-1-0$ \\
\hline \multicolumn{2}{|c|}{-- Line Roughness -- } & \multicolumn{2}{|c|}{ Const. Height-Mod $\epsilon=$ Disabled } & Firmware ver. & $=2-1-1-2$ \\
\hline Ra & $=30.726 \mathrm{~nm}$ & Date & $=03-06-2008$ & Controller S/N & $=023-06-252$ \\
\hline $\mathrm{Rq}$ & $=40.163 \mathrm{~nm}$ & Time & $=21: 43: 16$ & -- Module -- & \\
\hline Ry & $=203.47 \mathrm{~nm}$ & -- Feedback -- & & Controller Board & $=2$ \\
\hline $\mathrm{Rp}$ & $=126.14 \mathrm{~nm}$ & Set point & $=50 \%$ & AFM Basic Module & $=2$ \\
\hline Rv & $=-77.334 \mathrm{~nm}$ & P-Gain & $=8000$ & \multicolumn{2}{|c|}{ AFM Dynamic Module $=2$} \\
\hline $\mathrm{Rm}$ & $=267.69 \mathrm{pm}$ & I-Gain & $=2000$ & \multicolumn{2}{|c|}{ AFM Extension Modul $=1$} \\
\hline -- Scan -- & & Tip voltage & $=0 \mathrm{~V}$ & Video Module & $=0$ \\
\hline Image size & $=25 \mu \mathrm{m}$ & Feedback mode & $=$ Free & Signal Module S & $=0$ \\
\hline Scan direction & $=$ Down & Feedback algo. & $=$ Adaptive PI & Signal Module A & $=0$ \\
\hline Time/Line & $=0.2 \mathrm{~s}$ & Vibration freq. & $=184.532 \mathrm{kHz}$ & Nanosurf Report & $=0$ \\
\hline Points & $=256$ & Vibration ampl. & $=0.7 \mathrm{~V}$ & Scripting Interface & $=0$ \\
\hline
\end{tabular}




\section{Nanosurf Image Document}

File: Image6

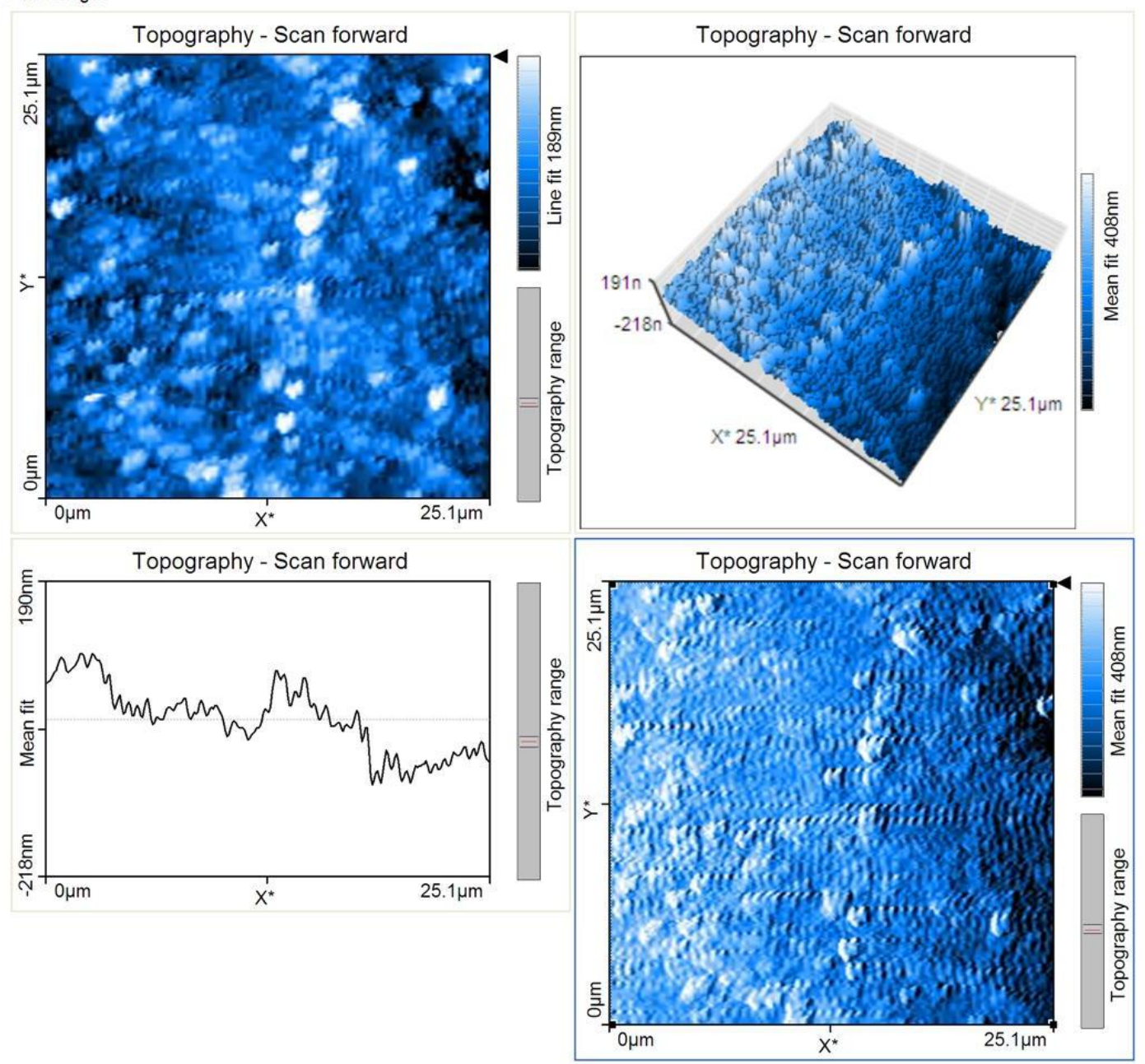

Parameter:

\begin{tabular}{|c|c|c|c|c|c|}
\hline \multicolumn{2}{|c|}{-- Area Roughness -- } & \multirow{2}{*}{$\begin{array}{l}\text { Lines } \\
\text { X-Slope }\end{array}$} & \multirow{2}{*}{$\begin{array}{l}=256 \\
=-500 \mathrm{~m}^{\circ}\end{array}$} & \multirow{2}{*}{$\begin{array}{l}\text { Excitation ampl. } \\
\text { Error range }\end{array}$} & \multirow{2}{*}{$\begin{array}{l}=0.19 \mathrm{~V} \\
=20 \mathrm{~V}\end{array}$} \\
\hline Area & $=637.4 \mathrm{pm}^{\wedge} 2$ & & & & \\
\hline $\mathrm{Sa}$ & $=62.714 \mathrm{~nm}$ & Y-Slope & $=0 \mathrm{~m}^{\circ}$ & -- Global -- & \\
\hline $\mathrm{Sq}$ & $=76.151 \mathrm{~nm}$ & Rotation & $=-1.78 f^{\circ}$ & Op. mode & $=$ Dynamic Force \\
\hline Sy & $=500.77 \mathrm{~nm}$ & X-Pos & $=-15 \mu \mathrm{m}$ & Cantilever type & $=A C L A$ \\
\hline $\mathrm{Sp}$ & $=259.88 \mathrm{~nm}$ & Y-Pos & $=-16 \mu \mathrm{m}$ & Head type & $=$ EZ2-AFM \\
\hline Sv & $=-240.9 \mathrm{~nm}$ & Z-Plane & $=0 \mu \mathrm{m}$ & Scan head & $=10-07-239 . \mathrm{hed}$ \\
\hline $\mathrm{Sm}$ & $=3.071 \mathrm{pm}$ & Overscan & $=5 \%$ & Software ver. & $=1-5-1-0$ \\
\hline \multicolumn{2}{|c|}{-- Line Roughness -- } & \multicolumn{2}{|c|}{ Const. Height-Mod $\epsilon=$ Disabled } & Firmware ver. & $=2-1-1-2$ \\
\hline $\mathrm{Ra}$ & $=61.484 \mathrm{~nm}$ & Date & $=03-06-2008$ & Controller S/N & $=023-06-252$ \\
\hline $\mathrm{Rq}$ & $=71.423 \mathrm{~nm}$ & Time & $=21: 52: 52$ & -- Module -- & \\
\hline Ry & $=272.42 \mathrm{~nm}$ & -- Feedback -- & & Controller Board & $=2$ \\
\hline $\mathrm{Rp}$ & $=132.21 \mathrm{~nm}$ & Set point & $=50 \%$ & AFM Basic Module & $=2$ \\
\hline $\mathrm{Rv}$ & $=-140.22 \mathrm{~nm}$ & P-Gain & $=8000$ & \multicolumn{2}{|c|}{ AFM Dynamic Module $=2$} \\
\hline $\mathrm{Rm}$ & $=104.6 \mathrm{pm}$ & I-Gain & $=2000$ & \multicolumn{2}{|c|}{ AFM Extension Modul $\epsilon=1$} \\
\hline -- Scan -- & & Tip voltage & $=0 \mathrm{~V}$ & Video Module & $=0$ \\
\hline Image size & $=25 \mu \mathrm{m}$ & Feedback mode & $=$ Free & Signal Module S & $=0$ \\
\hline Scan direction & $=U p$ & Feedback algo. & = Adaptive PI & Signal Module A & $=0$ \\
\hline Time/Line & $=0.2 \mathrm{~s}$ & Vibration freq. & $=184.532 \mathrm{kHz}$ & Nanosurf Report & $=0$ \\
\hline Points & $=256$ & Vibration ampl. & $=0.7 \mathrm{~V}$ & Scripting Interface & $=0$ \\
\hline
\end{tabular}




\section{N-600-1 after CP}

\section{Nanosurf Image Document}

File: Image11
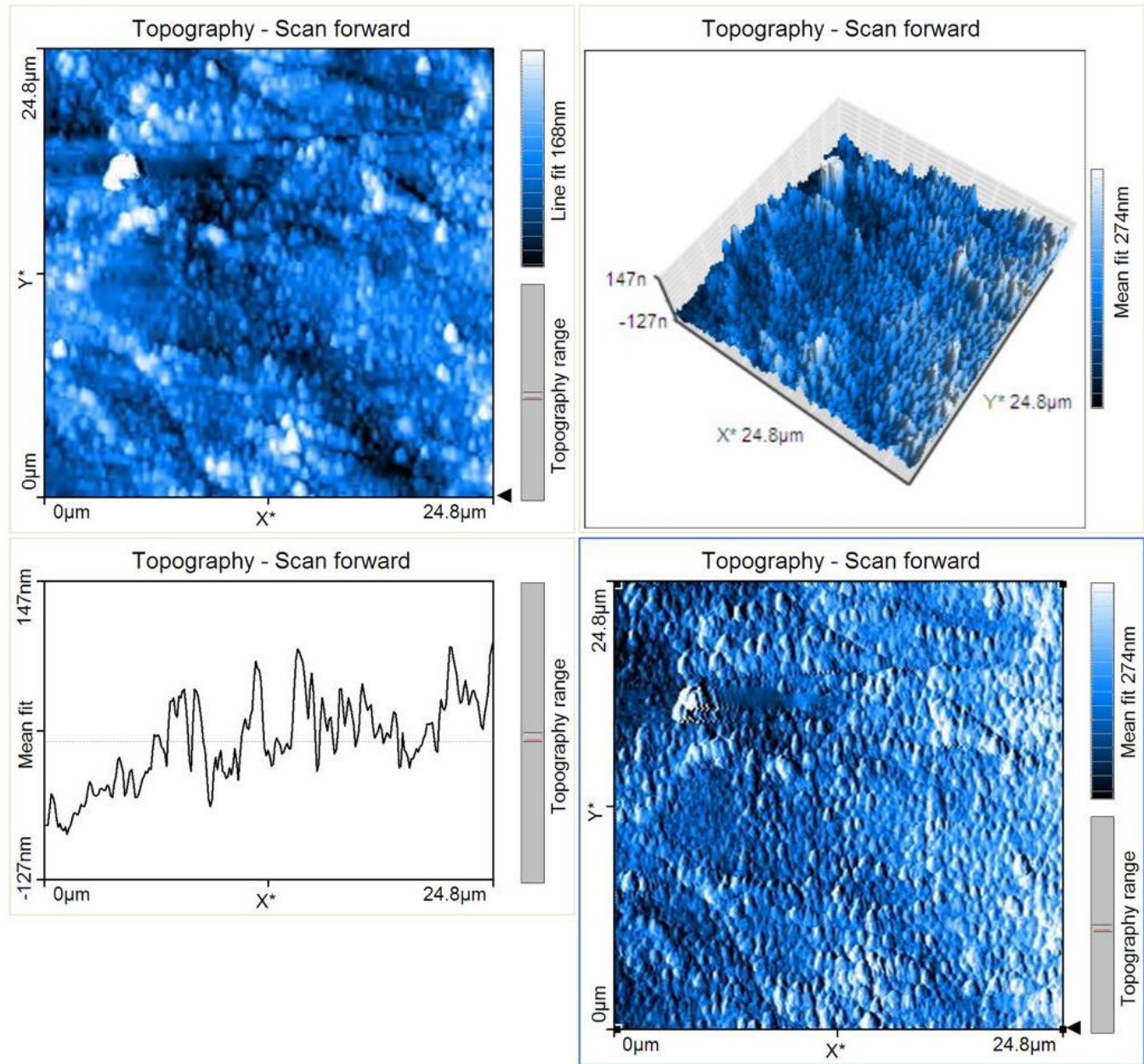

\section{Parameter:}

$\begin{array}{ll}- \text { Area Roughness -- } \\ \text { Area } & =618 \mathrm{pm}^{\wedge} 2 \\ \mathrm{Sa} & =38.725 \mathrm{~nm} \\ \mathrm{Sq} & =48.252 \mathrm{~nm} \\ \mathrm{Sy} & =445.74 \mathrm{~nm} \\ \mathrm{Sp} & =305.42 \mathrm{~nm} \\ \mathrm{~Sv} & =-140.32 \mathrm{~nm} \\ \mathrm{Sm} & =3157.8 \mathrm{fm} \\ - \text { Line Roughness -- } & \\ \mathrm{Ra} & =31.789 \mathrm{~nm} \\ \mathrm{Rq} & =37.56 \mathrm{~nm} \\ \mathrm{Ry} & =160.46 \mathrm{~nm} \\ \mathrm{Rp} & =85.183 \mathrm{~nm} \\ \mathrm{Rv} & =-75.276 \mathrm{~nm} \\ \text { Rm } & =-103.78 \mathrm{pm} \\ - \text { Scan -- } & \\ \text { Image size } & =25 \mu \mathrm{m} \\ \text { Scan direction } & =D o w n \\ \text { Time/Line } & =0.4 \mathrm{~s} \\ \text { Points } & =256\end{array}$

$\begin{array}{lll}\text { Lines } & =256 \\ \text { X-Slope } & =1^{\circ} \\ \text { Y-Slope } & =500 \mathrm{~m}^{\circ} \\ \text { Rotation } & =90^{\circ} \\ \text { X-Pos } & =0 \mathrm{~m} \\ \text { Y-Pos } & =0 \mathrm{~m} \\ \text { Z-Plane } & =0 \mathrm{~m} \\ \text { Overscan } & =5 \% \\ \text { Const.Height-Mode } & =\text { Disabled } \\ \text { Date } & =08-08-2008 \\ \text { Time } & =13: 03: 09 \\ \text {-- Feedback -- } & & \\ \text { Set point } & =44 \% \\ \text { P-Gain } & =10000 \\ \text { l-Gain } & =2300 \\ \text { Tip voltage } & =0.1 \mathrm{~V} \\ \text { Feedback mode } & =\text { Free } \\ \text { Feedback algo. } & =\text { Adaptive PI } \\ \text { Vibration freq. } & =181.347 \mathrm{kHz} \\ \text { Vibration ampl. } & =0.7 \mathrm{~V}\end{array}$

$\begin{array}{ll}\text { Excitation ampl. } & =0.22 \mathrm{~V} \\ \text { Error range } & =20 \mathrm{~V} \\ \text { - Global -- } & \\ \text { Op. mode } & =\text { Dynamic Force } \\ \text { Cantilever type } & =\text { ACLA } \\ \text { Head type } & =\text { EZ2-AFM } \\ \text { Scan head } & =10-07-239 . \text { hed } \\ \text { Software ver. } & =1-5-1-0 \\ \text { Firmware ver. } & =2-1-1-2 \\ \text { Controller S/N } & =023-06-252 \\ - \text { - Module -- } & \\ \text { Controller Board } & =2 \\ \text { AFM Basic Module } & =2 \\ \text { AFM Dynamic Module } & =2 \\ \text { AFM Extension Modul } & =1 \\ \text { Video Module } & =0 \\ \text { Signal Module S } & =0 \\ \text { Signal Module A } & =0 \\ \text { Nanosurf Report } & =0 \\ \text { Scripting Interface } & =0\end{array}$




\section{Nanosurf Image Document}

File: Image12
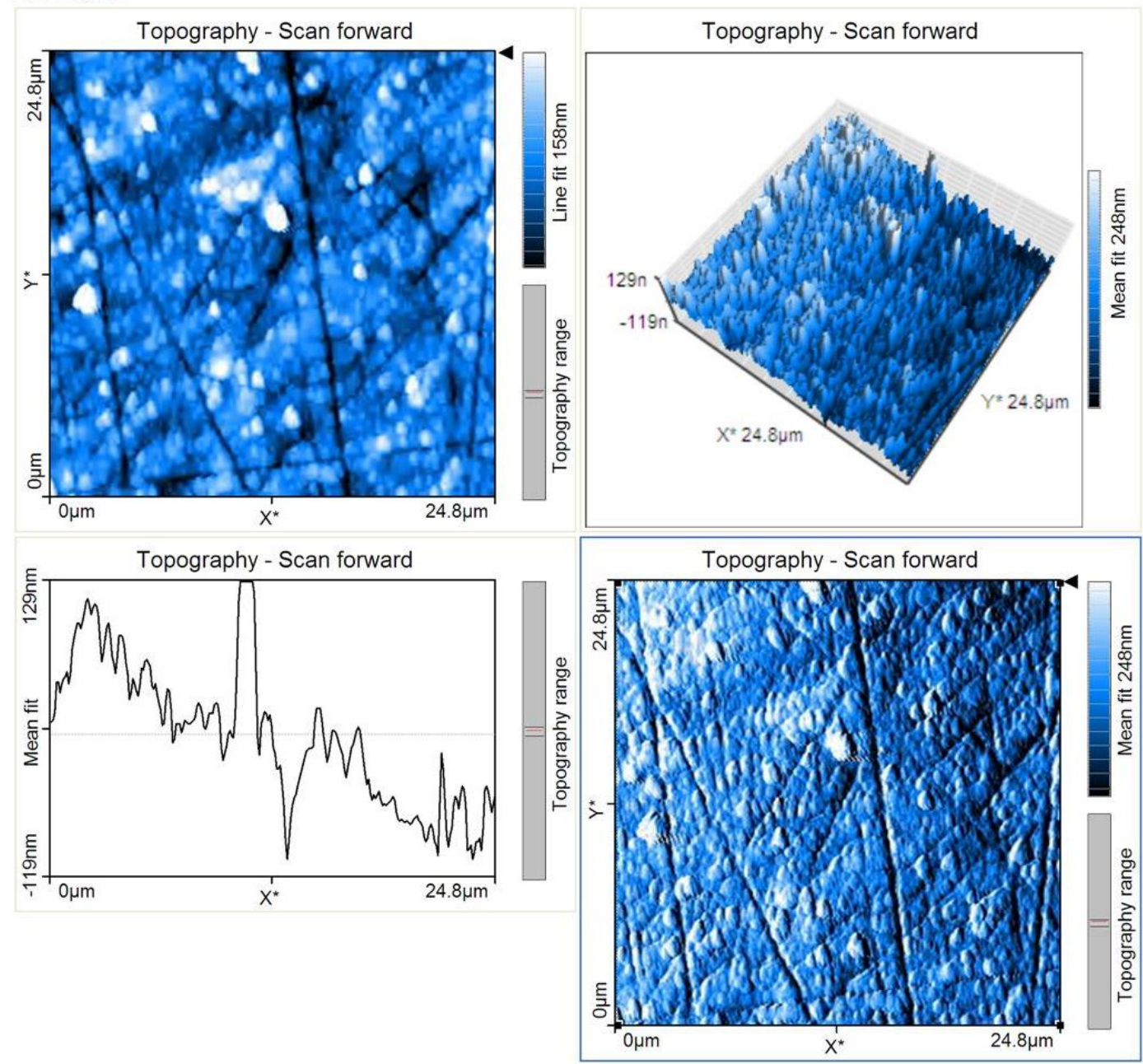

Parameter:

\begin{tabular}{|c|c|c|c|c|c|}
\hline \multicolumn{2}{|c|}{-- Area Roughness -- } & \multirow{2}{*}{$\begin{array}{l}\text { Lines } \\
\text { X-Slope }\end{array}$} & \multirow{2}{*}{$\begin{array}{l}=256 \\
=1^{\circ}\end{array}$} & \multirow{2}{*}{$\begin{array}{l}\text { Excitation ampl. } \\
\text { Error range }\end{array}$} & \multirow{2}{*}{$\begin{array}{l}=0.22 \mathrm{~V} \\
=20 \mathrm{~V}\end{array}$} \\
\hline Area & $=618 \mathrm{pm}^{\wedge} 2$ & & & & \\
\hline Sa & $=35.11 \mathrm{~nm}$ & Y-Slope & $=500 \mathrm{~m}^{\circ}$ & -- Global -. & \\
\hline $\mathrm{Sq}$ & $=44.337 \mathrm{~nm}$ & Rotation & $=90^{\circ}$ & Op. mode & $=$ Dynamic Force \\
\hline Sy & $=392.82 \mathrm{~nm}$ & X-Pos & $=0 \mathrm{~m}$ & Cantilever type & $=A C L A$ \\
\hline Sp & $=256.29 \mathrm{~nm}$ & Y-Pos & $=0 \mathrm{~m}$ & Head type & $=E Z 2-A F M$ \\
\hline Sv & $=-136.53 \mathrm{~nm}$ & Z-Plane & $=0 \mathrm{~m}$ & Scan head & $=10-07-239 . \mathrm{hed}$ \\
\hline $\mathrm{Sm}$ & $=210.56 \mathrm{pm}$ & Overscan & $=5 \%$ & Software ver. & $=1-5-1-0$ \\
\hline \multicolumn{2}{|c|}{-- Line Roughness -- } & \multicolumn{2}{|c|}{ Const. Height-Mode= Disabled } & Firmware ver. & $=2-1-1-2$ \\
\hline $\mathrm{Ra}$ & $=28.649 \mathrm{~nm}$ & Date & $=08-08-2008$ & Controller S/N & $=023-06-252$ \\
\hline $\mathrm{Rq}$ & $=35.294 \mathrm{~nm}$ & Time & $=13: 16: 22$ & -- Module -- & \\
\hline Ry & $=182.81 \mathrm{~nm}$ & \multicolumn{2}{|l|}{-- Feedback -- } & Controller Board & $=2$ \\
\hline Rp & $=79.99 \mathrm{~nm}$ & Set point & $=44 \%$ & AFM Basic Module & $=2$ \\
\hline $\mathrm{Rv}$ & $=-102.82 \mathrm{~nm}$ & P-Gain & $=10000$ & \multicolumn{2}{|c|}{ AFM Dynamic Module = 2} \\
\hline $\mathrm{Rm}$ & $=238.86 \mathrm{pm}$ & I-Gain & $=2200$ & \multicolumn{2}{|c|}{ AFM Extension Module= 1} \\
\hline -- Scan -- & & Tip voltage & $=0.1 \mathrm{~V}$ & Video Module & $=0$ \\
\hline Image size & $=25 \mu \mathrm{m}$ & Feedback mode & $=$ Free & Signal Module S & $=0$ \\
\hline Scan direction & $=U p$ & Feedback algo. & = Adaptive PI & Signal Module A & $=0$ \\
\hline Time/Line & $=0.4 \mathrm{~s}$ & Vibration freq. & $=181.344 \mathrm{kHz}$ & Nanosurf Report & $=0$ \\
\hline Points & $=256$ & Vibration ampl. & $=0.7 \mathrm{~V}$ & Scripting Interface & $=0$ \\
\hline
\end{tabular}




\section{Nanosurf Image Document}

File: Image13
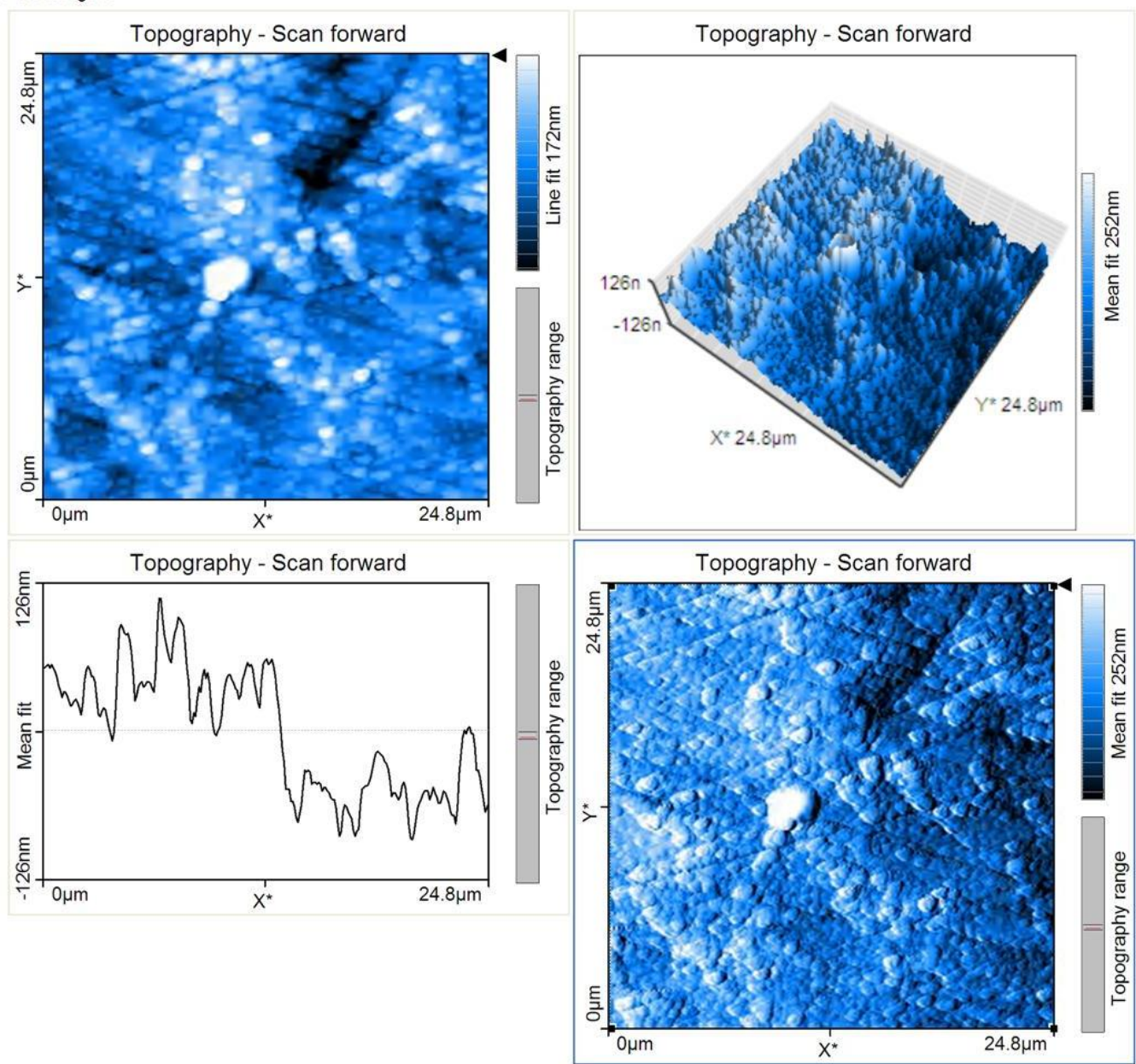

Parameter:

\begin{tabular}{|c|c|c|c|c|c|}
\hline \multicolumn{2}{|c|}{-- Area Roughness -- } & \multirow{2}{*}{$\begin{array}{l}\text { Lines } \\
X \text {-Slope }\end{array}$} & \multirow{2}{*}{$\begin{array}{l}=256 \\
=1^{\circ}\end{array}$} & \multirow{2}{*}{$\begin{array}{l}\text { Excitation ampl. } \\
\text { Error range }\end{array}$} & \multirow{2}{*}{$\begin{array}{l}=0.23 \mathrm{~V} \\
=20 \mathrm{~V}\end{array}$} \\
\hline Area & $=618 \mathrm{pm}^{\wedge} 2$ & & & & \\
\hline $\mathrm{Sa}$ & $=37.157 \mathrm{~nm}$ & Y-Slope & $=1^{\circ}$ & -- Global -- & \\
\hline $\mathrm{Sq}$ & $=45.097 \mathrm{~nm}$ & Rotation & $=-0.888 f^{\circ}$ & Op. mode & $=$ Dynamic Force \\
\hline Sy & $=307.42 \mathrm{~nm}$ & X-Pos & $=0 \mathrm{fm}$ & Cantilever type & $=A C L A$ \\
\hline $\mathrm{Sp}$ & $=180.6 \mathrm{~nm}$ & Y-Pos & $=0 \mathrm{fm}$ & Head type & $=\mathrm{EZ2}-\mathrm{AFM}$ \\
\hline Sv & $=-126.83 \mathrm{~nm}$ & Z-Plane & $=0 \mathrm{fm}$ & Scan head & $=10-07-239$. hed \\
\hline $\mathrm{Sm}$ & $=163.6 \mathrm{pm}$ & Overscan & $=5 \%$ & Software ver. & $=1-5-1-0$ \\
\hline \multicolumn{2}{|c|}{-- Line Roughness -- } & \multicolumn{2}{|c|}{ Const. Height-Mod $\epsilon=$ Disabled } & Firmware ver. & $=2-1-1-2$ \\
\hline $\mathrm{Ra}$ & $=43.541 \mathrm{~nm}$ & Date & $=08-08-2008$ & Controller $\mathrm{S} / \mathrm{N}$ & $=023-06-252$ \\
\hline $\mathrm{Rq}$ & $=61.145 \mathrm{~nm}$ & Time & $=13: 24: 51$ & -- Module -- & \\
\hline Ry & $=275.58 \mathrm{~nm}$ & -- Feedback -- & & Controller Board & $=2$ \\
\hline $\mathrm{Rp}$ & $=174.01 \mathrm{~nm}$ & Set point & $=44 \%$ & AFM Basic Module & $=2$ \\
\hline Rv & $=-101.58 \mathrm{~nm}$ & P-Gain & $=10000$ & \multicolumn{2}{|c|}{ AFM Dynamic Module $=2$} \\
\hline $\mathrm{Rm}$ & $=262.74 \mathrm{pm}$ & I-Gain & $=2100$ & \multicolumn{2}{|c|}{ AFM Extension Modul $\epsilon=1$} \\
\hline -- Scan -- & & Tip voltage & $=0.1 \mathrm{~V}$ & Video Module & $=0$ \\
\hline Image size & $=25 \mu \mathrm{m}$ & Feedback mode & $=$ Free & Signal Module S & $=0$ \\
\hline Scan direction & $=U p$ & Feedback algo. & = Adaptive PI & Signal Module A & $=0$ \\
\hline Time/Line & $=0.4 \mathrm{~s}$ & Vibration freq. & $=181.344 \mathrm{kHz}$ & Nanosurf Report & $=0$ \\
\hline Points & $=256$ & Vibration ampl. & $=0.7 \mathrm{~V}$ & Scripting Interface & $=0$ \\
\hline
\end{tabular}




\section{N-600-4 after CP}

\section{Nanosurf Image Document}

File: Image14

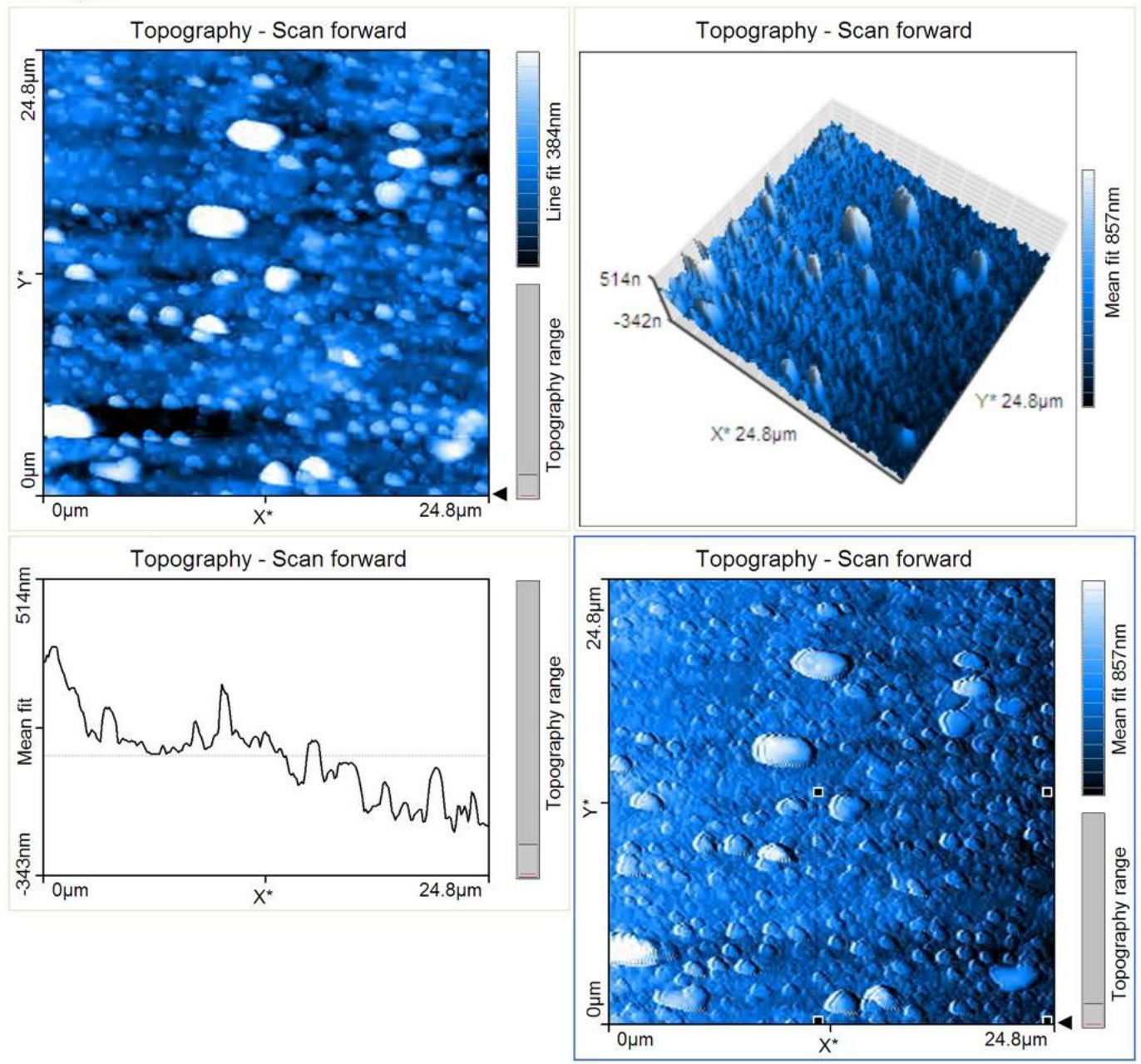

Parameter

\begin{tabular}{|c|c|c|c|c|c|}
\hline \multicolumn{2}{|l|}{-- Tool -- } & Time/Line & $=0.6 \mathrm{~s}$ & Vibration ampl. & $=0.7 \mathrm{~V}$ \\
\hline Width & $=12.86 \mu \mathrm{m}$ & Points & $=256$ & Excitation ampl. & $=0.23 \mathrm{~V}$ \\
\hline Height & $=12.86 \mu \mathrm{m}$ & Lines & $=256$ & Error range & $=20 \mathrm{~V}$ \\
\hline \multicolumn{2}{|c|}{-- Area Roughness -- } & X-Slope & $=-1^{\circ}$ & -- Global -- & \\
\hline Area & $=168 \mathrm{pm}^{\wedge} 2$ & Y-Slope & $=1.5^{\circ}$ & Op. mode & $=$ Dynamic Force \\
\hline $\mathrm{Sa}$ & $=113.82 \mathrm{~nm}$ & Rotation & $=90^{\circ}$ & Cantilever type & $=A C L A$ \\
\hline $\mathrm{Sq}$ & $=135.79 \mathrm{~nm}$ & X-Pos & $=0 \mathrm{~m}$ & Head type & $=E Z 2-A F M$ \\
\hline Sy & $=774.88 \mathrm{~nm}$ & Y-Pos & $=0 \mathrm{~m}$ & Scan head & $=10-07-239$. hed \\
\hline $\mathrm{Sp}$ & $=441 \mathrm{~nm}$ & Z-Plane & $=0 \mathrm{~m}$ & Software ver. & $=1-5-1-0$ \\
\hline Sv & $=-333.88 \mathrm{~nm}$ & Overscan & $=5 \%$ & Firmware ver. & $=2-1-1-2$ \\
\hline $\mathrm{Sm}$ & $=-86.08 \mathrm{~nm}$ & \multicolumn{2}{|c|}{ Const. Height-Mode= Disabled } & Controller S/N & $=023-06-252$ \\
\hline \multicolumn{2}{|c|}{-- Line Roughness -- } & Date & $=08-08-2008$ & -- Module -- & \\
\hline $\mathrm{Ra}$ & $=99.685 \mathrm{~nm}$ & Time & $=13: 46: 44$ & Controller Board & $=2$ \\
\hline $\mathrm{Rq}$ & $=118 \mathrm{~nm}$ & \multicolumn{2}{|l|}{-- Feedback -- } & AFM Basic Module & $=2$ \\
\hline Ry & $=482.01 \mathrm{~nm}$ & Set point & $=48 \%$ & \multicolumn{2}{|c|}{ AFM Dynamic Module $=2$} \\
\hline $\mathrm{Rp}$ & $=284.26 \mathrm{~nm}$ & P-Gain & $=10000$ & \multicolumn{2}{|c|}{ AFM Extension Modul $\epsilon=1$} \\
\hline Rv & $=-197.75 \mathrm{~nm}$ & I-Gain & $=1900$ & Video Module & $=0$ \\
\hline $\mathrm{Rm}$ & $=916.92 \mathrm{pm}$ & Tip voltage & $=0.1 \mathrm{~V}$ & Signal Module S & $=0$ \\
\hline -- Scan -- & & Feedback mode & $=$ Free & Signal Module A & $=0$ \\
\hline Image size & $=25 \mu \mathrm{m}$ & Feedback algo. & $=$ Adaptive PI & Nanosurf Report & $=0$ \\
\hline Scan direction & $=$ Down & Vibration freq. & $=181.334 \mathrm{kHz}$ & Scripting Interface & $=0$ \\
\hline
\end{tabular}




\section{Nanosurf Image Document}

File: Image15

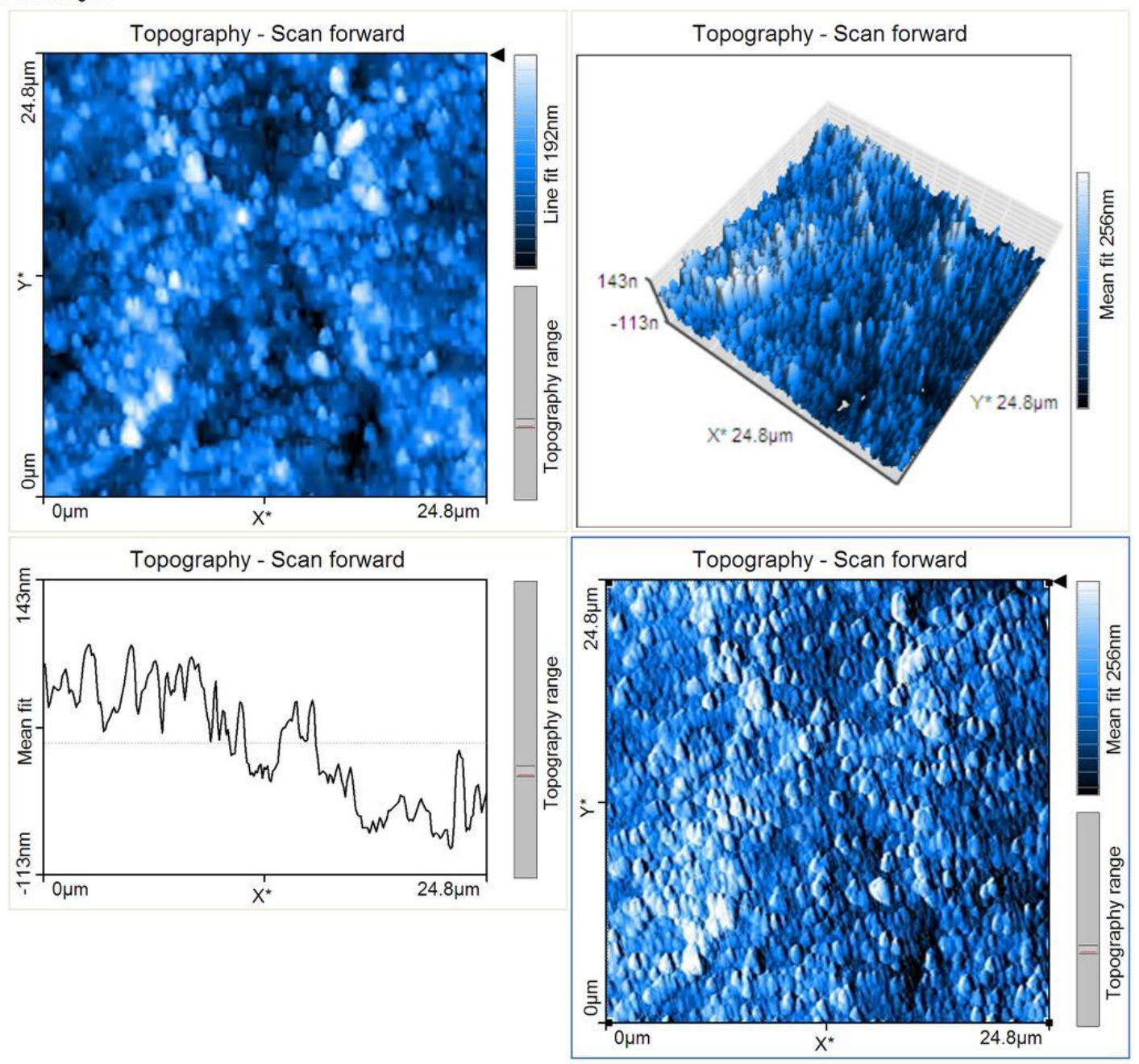

Parameter:

\begin{tabular}{|c|c|c|c|c|c|}
\hline \multicolumn{2}{|c|}{-- Area Roughness -- } & \multirow{2}{*}{$\begin{array}{l}\text { Lines } \\
\text { X-Slope }\end{array}$} & \multirow{2}{*}{$\begin{array}{l}=256 \\
=500 \mathrm{~m}^{\circ}\end{array}$} & \multirow{2}{*}{$\begin{array}{l}\text { Excitation ampl. } \\
\text { Error range }\end{array}$} & \multirow{2}{*}{$\begin{array}{l}=0.22 \mathrm{~V} \\
=20 \mathrm{~V}\end{array}$} \\
\hline Area & $=618 \mathrm{pm}^{\wedge} 2$ & & & & \\
\hline $\mathrm{Sa}$ & $=35.054 \mathrm{~nm}$ & Y-Slope & $=3^{\circ}$ & -- Global -- & \\
\hline $\mathrm{Sq}$ & $=43.557 \mathrm{~nm}$ & Rotation & $=90^{\circ}$ & Op. mode & $=$ Dynamic Force \\
\hline Sy & $=336.31 \mathrm{~nm}$ & X-Pos & $=0 \mathrm{~m}$ & Cantilever type & $=A C L A$ \\
\hline Sp & $=178.06 \mathrm{~nm}$ & Y-Pos & $=0 \mathrm{~m}$ & Head type & $=E Z 2-A F M$ \\
\hline Sv & $=-158.24 \mathrm{~nm}$ & Z-Plane & $=0 \mathrm{~m}$ & Scan head & $=10-07-239 \cdot$ hed \\
\hline Sm & $=-3016.3 \mathrm{fm}$ & Overscan & $=5 \%$ & Software ver. & $=1-5-1-0$ \\
\hline \multicolumn{2}{|c|}{-- Line Roughness -- } & \multicolumn{2}{|c|}{ Const. Height-Mod $\epsilon=$ Disabled } & Firmware ver. & $=2-1-1-2$ \\
\hline $\mathrm{Ra}$ & $=31.146 \mathrm{~nm}$ & Date & $=08-08-2008$ & Controller S/N & $=023-06-252$ \\
\hline $\mathrm{Rq}$ & $=39.703 \mathrm{~nm}$ & Time & $=14: 15: 41$ & -- Module -- & \\
\hline Ry & $=214.23 \mathrm{~nm}$ & -- Feedback -- & & Controller Board & $=2$ \\
\hline $\mathrm{Rp}$ & $=136.9 \mathrm{~nm}$ & Set point & $=48 \%$ & AFM Basic Module & $=2$ \\
\hline $\mathrm{Rv}$ & $=-77.324 \mathrm{~nm}$ & P-Gain & $=10000$ & \multicolumn{2}{|c|}{ AFM Dynamic Module $=2$} \\
\hline $\mathrm{Rm}$ & $=46.949 \mathrm{pm}$ & I-Gain & $=1800$ & \multicolumn{2}{|c|}{ AFM Extension Modul $\epsilon=1$} \\
\hline -- Scan -- & & Tip voltage & $=0.1 \mathrm{~V}$ & Video Module & $=0$ \\
\hline Image size & $=25 \mu \mathrm{m}$ & Feedback mode & $=$ Free & Signal Module S & $=0$ \\
\hline Scan direction & $=U p$ & Feedback algo. & = Adaptive PI & Signal Module A & $=0$ \\
\hline Time/Line & $=0.5 \mathrm{~s}$ & Vibration freq. & $=181.334 \mathrm{kHz}$ & Nanosurf Report & $=0$ \\
\hline Points & $=256$ & Vibration ampl. & $=0.7 \mathrm{~V}$ & Scripting Interface & $=0$ \\
\hline
\end{tabular}


Nanosurt Image Document

File: Image16

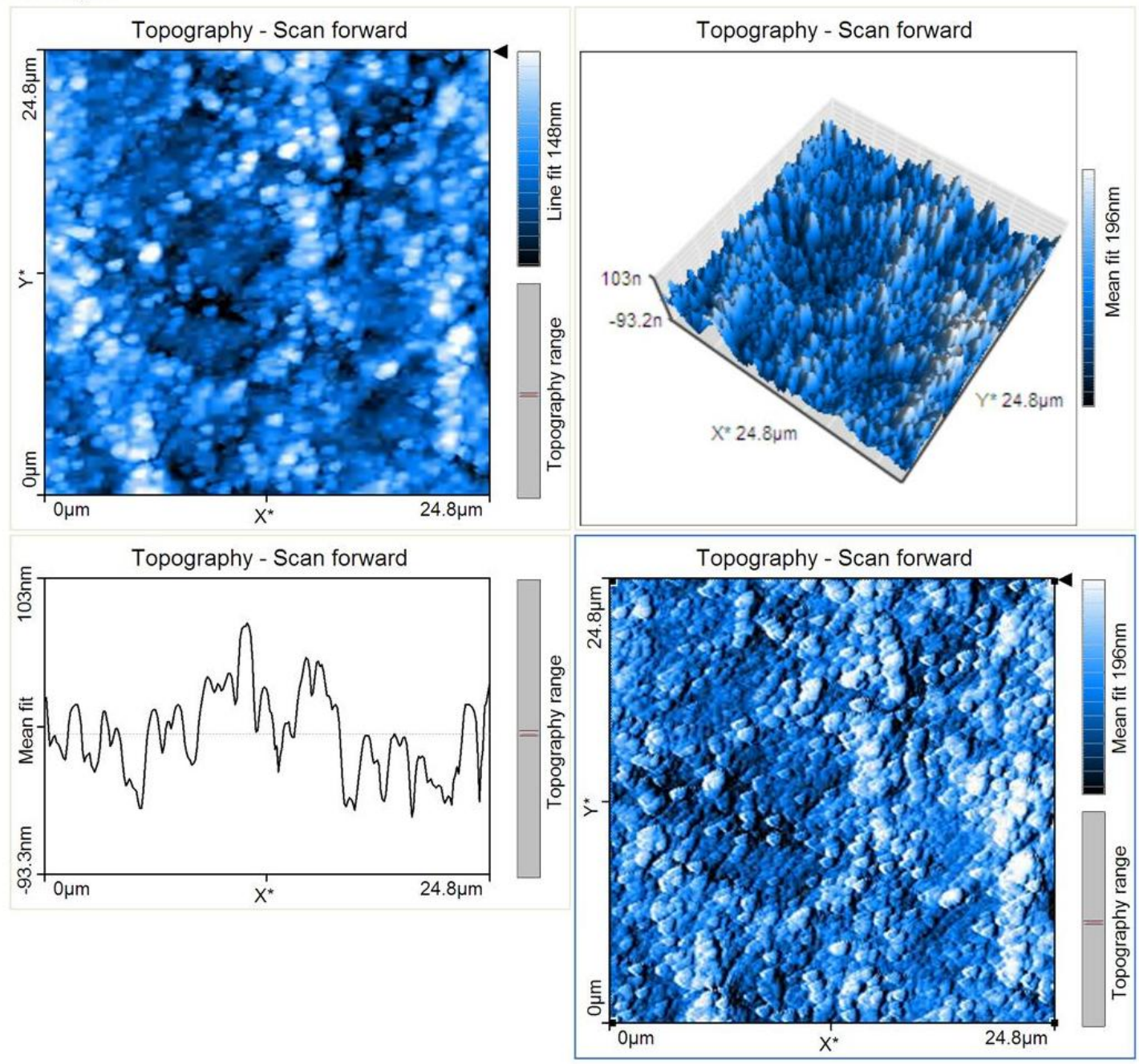

Parameter:

\begin{tabular}{|c|c|c|c|c|c|}
\hline \multicolumn{2}{|c|}{-- Area Roughness -- } & \multirow{2}{*}{$\begin{array}{l}\text { Lines } \\
\text { X-Slope }\end{array}$} & \multirow{2}{*}{$\begin{array}{l}=256 \\
=2^{\circ}\end{array}$} & \multirow{2}{*}{$\begin{array}{l}\text { Excitation ampl. } \\
\text { Error range }\end{array}$} & \multirow{2}{*}{$\begin{array}{l}=0.22 \mathrm{~V} \\
=20 \mathrm{~V}\end{array}$} \\
\hline Area & $=618 \mathrm{pm}^{\wedge} 2$ & & & & \\
\hline $\mathrm{Sa}$ & $=27.188 \mathrm{~nm}$ & Y-Slope & $=2.5^{\circ}$ & -- Global -- & \\
\hline $\mathrm{Sq}$ & $=33.671 \mathrm{~nm}$ & Rotation & $=-14.2 f^{\circ}$ & Op. mode & $=$ Dynamic Force \\
\hline Sy & $=245.22 \mathrm{~nm}$ & X-Pos & $=0 \mathrm{fm}$ & Cantilever type & $=A C L A$ \\
\hline Sp & $=146.44 \mathrm{~nm}$ & Y-Pos & $=0 \mathrm{fm}$ & Head type & $=E Z 2-A F M$ \\
\hline Sv & $=-98.784 \mathrm{~nm}$ & Z-Plane & $=0 \mathrm{fm}$ & Scan head & $=10-07-239$. hed \\
\hline $\mathrm{Sm}$ & $=1642.5 \mathrm{fm}$ & Overscan & $=5 \%$ & Software ver. & $=1-5-1-0$ \\
\hline \multicolumn{2}{|c|}{-- Line Roughness -- } & \multicolumn{2}{|c|}{ Const. Height-Mode= Disabled } & Firmware ver. & $=2-1-1-2$ \\
\hline $\mathrm{Ra}$ & $=35.159 \mathrm{~nm}$ & Date & $=08-08-2008$ & Controller S/N & $=023-06-252$ \\
\hline $\mathrm{Rq}$ & $=42.384 \mathrm{~nm}$ & Time & $=14: 26: 24$ & -- Module -- & \\
\hline Ry & $=178.59 \mathrm{~nm}$ & \multicolumn{2}{|l|}{-- Feedback -- } & Controller Board & $=2$ \\
\hline $\mathrm{Rp}$ & $=88.164 \mathrm{~nm}$ & Set point & $=48 \%$ & AFM Basic Module & $=2$ \\
\hline Rv & $=-90.428 \mathrm{~nm}$ & P-Gain & $=10000$ & \multicolumn{2}{|c|}{ AFM Dynamic Module $=2$} \\
\hline $\mathrm{Rm}$ & $=77.424 \mathrm{pm}$ & I-Gain & $=1900$ & \multicolumn{2}{|c|}{ AFM Extension Modul $\epsilon=1$} \\
\hline \multicolumn{2}{|l|}{-- Scan -- } & Tip voltage & $=0.1 \mathrm{~V}$ & Video Module & $=0$ \\
\hline Image size & $=25 \mu \mathrm{m}$ & Feedback mode & $=$ Free & Signal Module S & $=0$ \\
\hline Scan direction & $=U p$ & Feedback algo. & = Adaptive PI & Signal Module A & $=0$ \\
\hline Time/Line & $=0.5 \mathrm{~s}$ & Vibration freq. & $=181.344 \mathrm{kHz}$ & Nanosurf Report & $=0$ \\
\hline Points & $=256$ & Vibration ampl. & $=0.7 \mathrm{~V}$ & Scripting Interface & $=0$ \\
\hline
\end{tabular}




\section{N-600-8 after CP}

\section{Nanosurf Image Document}

File: Image1
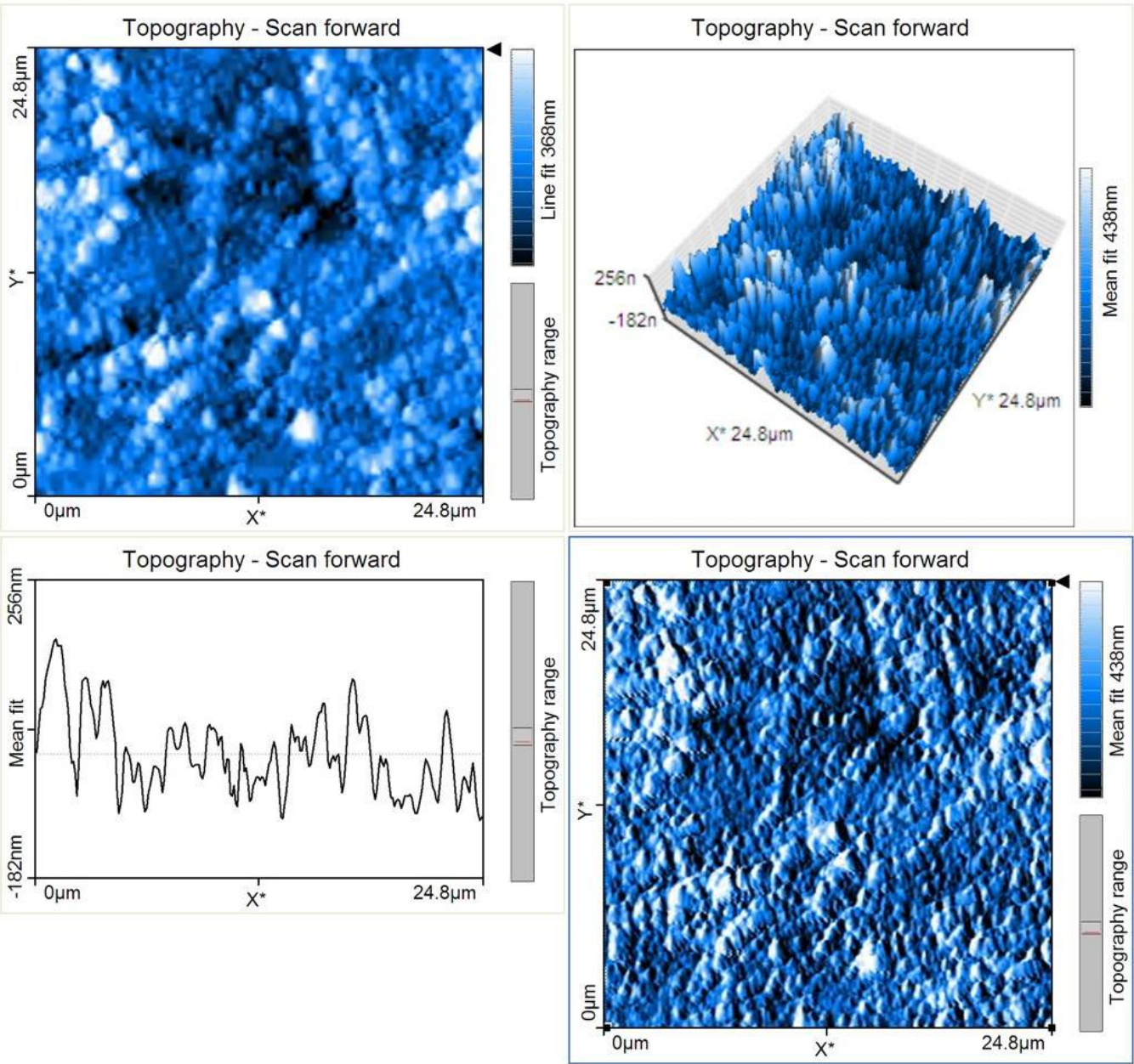

Parameter:

\begin{tabular}{|c|c|c|c|c|c|}
\hline \multicolumn{2}{|c|}{-- Area Roughness -- } & \multirow{2}{*}{$\begin{array}{l}\text { Lines } \\
\text { X-Slope }\end{array}$} & \multirow{2}{*}{$\begin{array}{l}=256 \\
=2.5^{\circ}\end{array}$} & \multirow{2}{*}{$\begin{array}{l}\text { Excitation ampl. } \\
\text { Error range }\end{array}$} & \multirow{2}{*}{$\begin{array}{l}=0.37 \mathrm{~V} \\
=20 \mathrm{~V}\end{array}$} \\
\hline Area & $=618 \mathrm{pm}^{\wedge} 2$ & & & & \\
\hline $\mathrm{Sa}$ & $=58.331 \mathrm{~nm}$ & Y-Slope & $=500 \mathrm{~m}^{\circ}$ & -- Global -- & \\
\hline $\mathrm{Sq}$ & $=76.196 \mathrm{~nm}$ & Rotation & $=90^{\circ}$ & Op. mode & = Dynamic Force \\
\hline Sy & $=662.92 \mathrm{~nm}$ & X-Pos & $=0 \mathrm{~m}$ & Cantilever type & $=A C L A$ \\
\hline Sp & $=434.25 \mathrm{~nm}$ & Y-Pos & $=0 \mathrm{~m}$ & Head type & $=E Z 2-A F M$ \\
\hline Sv & $=-228.67 \mathrm{~nm}$ & Z-Plane & $=0 \mathrm{~m}$ & Scan head & $=10-07-239$. hed \\
\hline $\mathrm{Sm}$ & $=583.95 \mathrm{fm}$ & Overscan & $=5 \%$ & Software ver. & $=1-5-1-0$ \\
\hline \multicolumn{2}{|c|}{-- Line Roughness -- } & \multicolumn{2}{|c|}{ Const. Height-Mod $\epsilon=$ Disabled } & Firmware ver. & $=2-1-1-2$ \\
\hline $\mathrm{Ra}$ & $=37.287 \mathrm{~nm}$ & Date & $=08-08-2008$ & Controller S/N & $=023-06-252$ \\
\hline $\mathrm{Rq}$ & $=47.477 \mathrm{~nm}$ & Time & $=11: 37: 56$ & -- Module -- & \\
\hline Ry & $=225.4 \mathrm{~nm}$ & -- Feedback -- & & Controller Board & $=2$ \\
\hline$R p$ & $=134.14 \mathrm{~nm}$ & Set point & $=48 \%$ & AFM Basic Module & $=2$ \\
\hline Rv & $=-91.26 \mathrm{~nm}$ & P-Gain & $=10000$ & \multicolumn{2}{|c|}{ AFM Dynamic Module $=2$} \\
\hline $\mathrm{Rm}$ & $=66.717 \mathrm{pm}$ & I-Gain & $=2200$ & \multicolumn{2}{|c|}{ AFM Extension Modul $\epsilon=1$} \\
\hline -- Scan -- & & Tip voltage & $=0 \mathrm{~V}$ & Video Module & $=0$ \\
\hline Image size & $=25 \mu \mathrm{m}$ & Feedback mode & $=$ Free & Signal Module S & $=0$ \\
\hline Scan direction & $=U p$ & Feedback algo. & = Adaptive PI & Signal Module A & $=0$ \\
\hline Time/Line & $=0.3 \mathrm{~s}$ & Vibration freq. & $=181.367 \mathrm{kHz}$ & Nanosurf Report & $=0$ \\
\hline Points & $=256$ & Vibration ampl. & $=0.7 \mathrm{~V}$ & Scripting Interface & $=0$ \\
\hline
\end{tabular}




\section{Nanosurf Image Document}

File: Image2

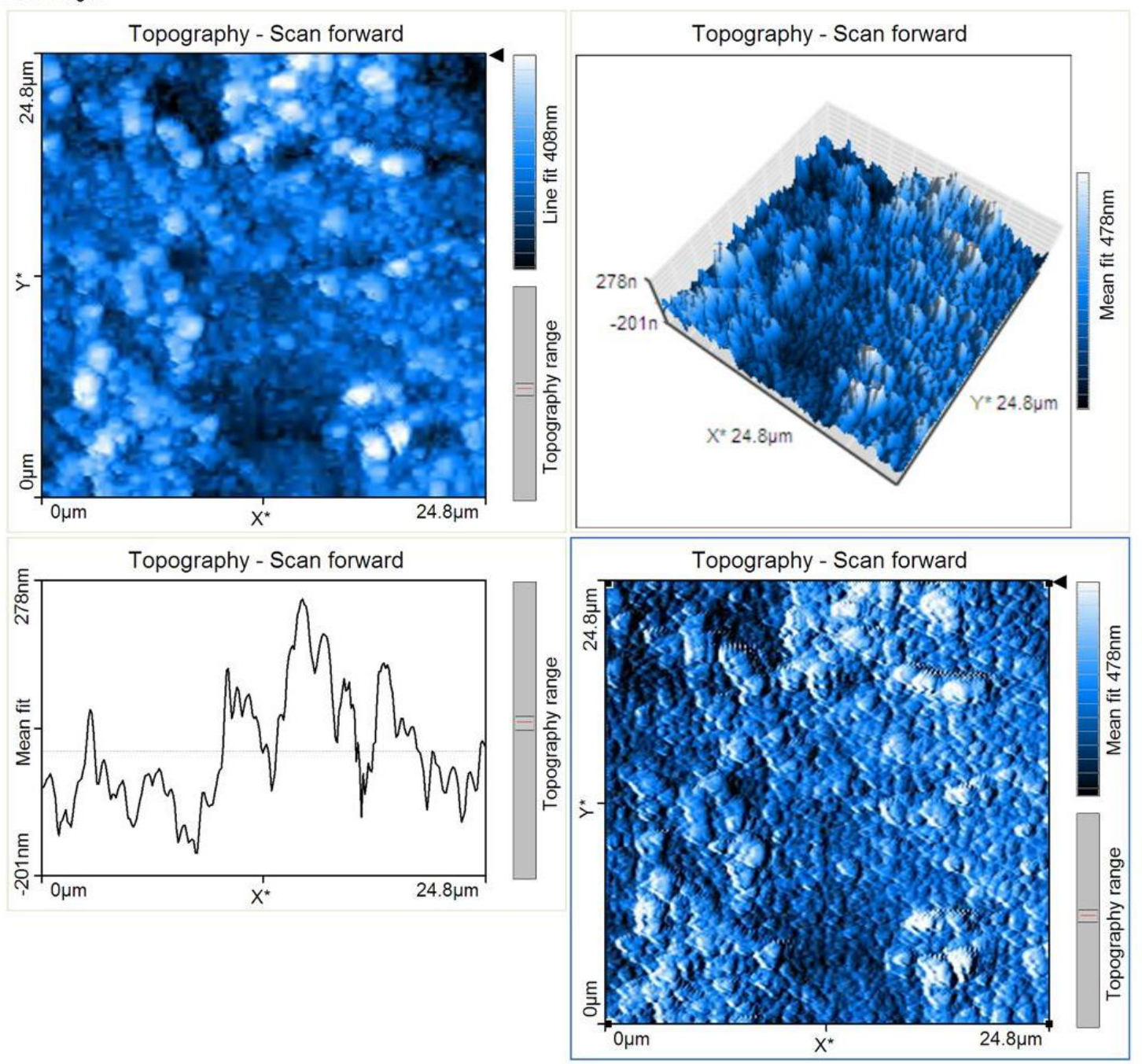

Parameter:

\begin{tabular}{|c|c|c|c|c|c|}
\hline \multicolumn{2}{|c|}{-- Area Roughness -- } & \multirow{2}{*}{$\begin{array}{l}\text { Lines } \\
\text { X-Slope }\end{array}$} & \multirow{2}{*}{$\begin{array}{l}=256 \\
=2^{\circ}\end{array}$} & \multirow{2}{*}{$\begin{array}{l}\text { Excitation ampl. } \\
\text { Error range }\end{array}$} & \multirow{2}{*}{$\begin{array}{l}=0.27 \mathrm{~V} \\
=20 \mathrm{~V}\end{array}$} \\
\hline Area & $=618 \mathrm{pm}^{\wedge} 2$ & & & & \\
\hline Sa & $=65.672 \mathrm{~nm}$ & Y-Slope & $=500 \mathrm{~m}^{\circ}$ & -- Global -- & \\
\hline $\mathrm{Sq}$ & $=82.834 \mathrm{~nm}$ & Rotation & $=-0.888 f^{\circ}$ & Op. mode & $=$ Dynamic Force \\
\hline Sy & $=626.02 \mathrm{~nm}$ & X-Pos & $=0 \mathrm{fm}$ & Cantilever type & $=A C L A$ \\
\hline Sp & $=395.88 \mathrm{~nm}$ & Y-Pos & $=0 \mathrm{fm}$ & Head type & $=\mathrm{EZ2}-\mathrm{AFM}$ \\
\hline Sv & $=-230.15 \mathrm{~nm}$ & Z-Plane & $=0 \mathrm{fm}$ & Scan head & $=10-07-239 \cdot \mathrm{hed}$ \\
\hline Sm & $=203.95 \mathrm{pm}$ & Overscan & $=5 \%$ & Software ver. & $=1-5-1-0$ \\
\hline \multicolumn{2}{|c|}{-- Line Roughness -- } & \multicolumn{2}{|c|}{ Const. Height-Mode= Disabled } & Firmware ver. & $=2-1-1-2$ \\
\hline $\mathrm{Ra}$ & $=57.071 \mathrm{~nm}$ & Date & $=08-08-2008$ & Controller S/N & $=023-06-252$ \\
\hline $\mathrm{Rq}$ & $=70.466 \mathrm{~nm}$ & Time & $=11: 50: 00$ & -- Module -- & \\
\hline Ry & $=365.83 \mathrm{~nm}$ & -- Feedback -- & & Controller Board & $=2$ \\
\hline$R p$ & $=212.6 \mathrm{~nm}$ & Set point & $=48 \%$ & AFM Basic Module & $=2$ \\
\hline Rv & $=-153.23 \mathrm{~nm}$ & P-Gain & $=10000$ & \multicolumn{2}{|c|}{ AFM Dynamic Module $=2$} \\
\hline $\mathrm{Rm}$ & $=254.51 \mathrm{pm}$ & I-Gain & $=2100$ & \multicolumn{2}{|c|}{ AFM Extension Modul $=1$} \\
\hline -- Scan -- & & Tip voltage & $=0 \mathrm{~V}$ & Video Module & $=0$ \\
\hline Image size & $=25 \mu \mathrm{m}$ & Feedback mode & $=$ Free & Signal Module S & $=0$ \\
\hline Scan direction & $=U p$ & Feedback algo. & = Adaptive PI & Signal Module A & $=0$ \\
\hline Time/Line & $=0.4 \mathrm{~s}$ & Vibration freq. & $=181.367 \mathrm{kHz}$ & Nanosurf Report & $=0$ \\
\hline Points & $=256$ & Vibration ampl. & $=0.7 \mathrm{~V}$ & Scripting Interface & $=0$ \\
\hline
\end{tabular}




\section{Nanosurf Image Document}

File: Image4

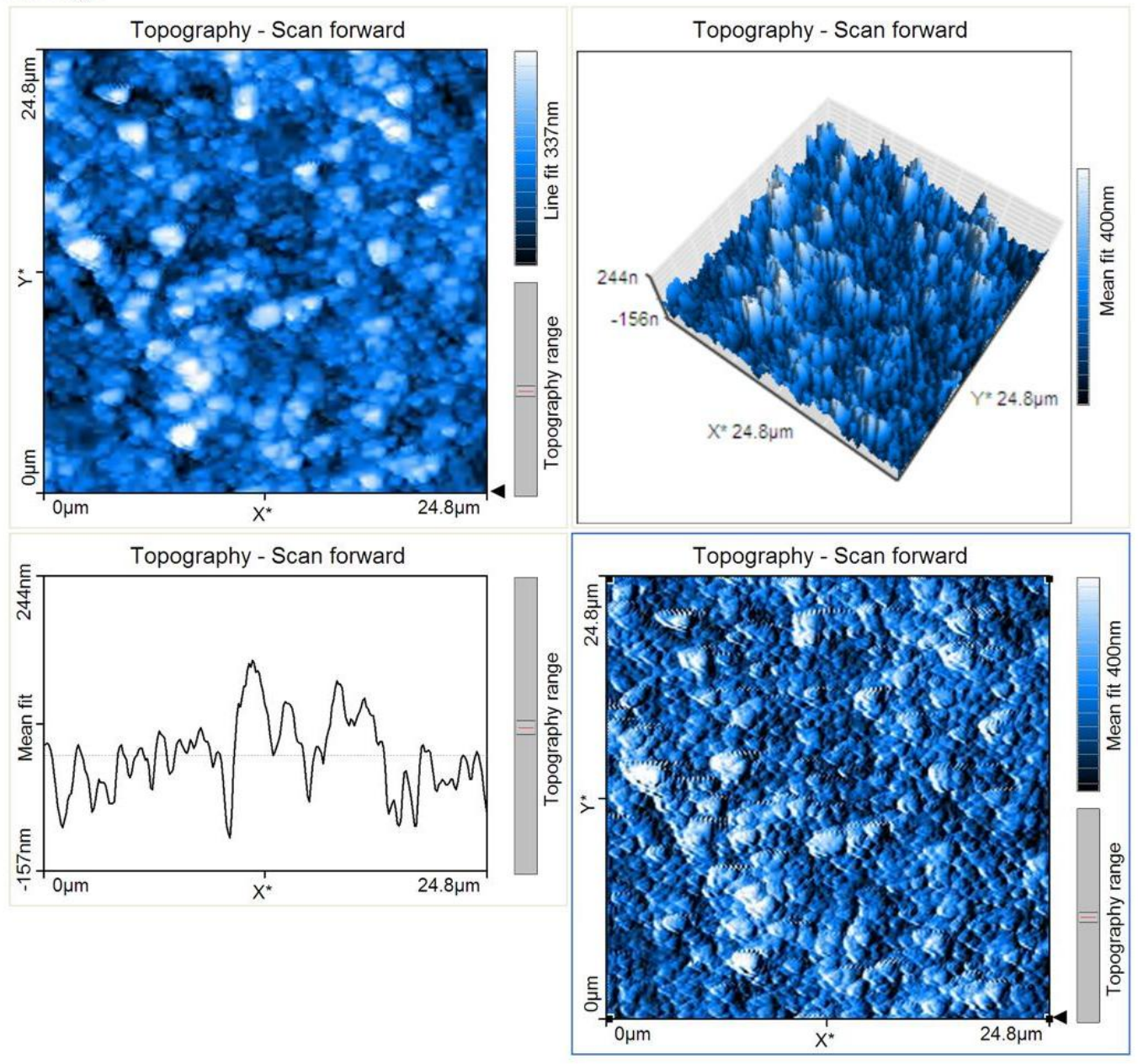

Parameter:

\begin{tabular}{|c|c|c|c|c|c|}
\hline \multicolumn{2}{|c|}{-- Area Roughness -- } & \multirow{2}{*}{$\begin{array}{l}\text { Lines } \\
\text { X-Slope }\end{array}$} & \multirow{2}{*}{$\begin{array}{l}=256 \\
=2^{\circ}\end{array}$} & \multirow{2}{*}{$\begin{array}{l}\text { Excitation ampl. } \\
\text { Error range }\end{array}$} & \multirow{2}{*}{$\begin{array}{l}=0.25 \mathrm{~V} \\
=20 \mathrm{~V}\end{array}$} \\
\hline Area & $=618 \mathrm{pm}^{\wedge} 2$ & & & & \\
\hline Sa & $=50.943 \mathrm{~nm}$ & Y-Slope & $=500 \mathrm{~m}^{\circ}$ & -. Global -. & \\
\hline $\mathrm{Sq}$ & $=65.991 \mathrm{~nm}$ & Rotation & $=-0.888 f^{\circ}$ & Op. mode & $=$ Dynamic Force \\
\hline Sy & $=548.01 \mathrm{~nm}$ & X-Pos & $=0 \mathrm{fm}$ & Cantilever type & $=A C L A$ \\
\hline $\mathrm{Sp}$ & $=370.57 \mathrm{~nm}$ & Y-Pos & $=0 \mathrm{fm}$ & Head type & $=E Z 2-A F M$ \\
\hline Sv & $=-177.43 \mathrm{~nm}$ & Z-Plane & $=0 \mathrm{fm}$ & Scan head & $=10-07-239 \cdot$ hed \\
\hline $\mathrm{Sm}$ & $=79.699 \mathrm{pm}$ & Overscan & $=5 \%$ & Software ver. & $=1-5-1-0$ \\
\hline \multicolumn{2}{|c|}{-- Line Roughness -- } & \multicolumn{2}{|c|}{ Const .Height-Mode= Disabled } & Firmware ver. & $=2-1-1-2$ \\
\hline $\mathrm{Ra}$ & $=42.079 \mathrm{~nm}$ & Date & $=08-08-2008$ & Controller $\mathrm{S} / \mathrm{N}$ & $=023-06-252$ \\
\hline $\mathrm{Rq}$ & $=51.877 \mathrm{~nm}$ & Time & $=12: 04: 42$ & -- Module -- & \\
\hline Ry & $=236.37 \mathrm{~nm}$ & \multicolumn{2}{|l|}{-- Feedback -- } & Controller Board & $=2$ \\
\hline $\mathrm{Rp}$ & $=124.31 \mathrm{~nm}$ & Set point & $=48 \%$ & AFM Basic Module & $=2$ \\
\hline Rv & $=-112.06 \mathrm{~nm}$ & P-Gain & $=10000$ & \multicolumn{2}{|c|}{ AFM Dynamic Module $=2$} \\
\hline $\mathrm{Rm}$ & $=-9.8821 \mathrm{pm}$ & I-Gain & $=2100$ & \multicolumn{2}{|c|}{ AFM Extension Modul $\epsilon=1$} \\
\hline - Scan -- & & Tip voltage & $=0 \mathrm{~V}$ & Video Module & $=0$ \\
\hline Image size & $=25 \mu \mathrm{m}$ & Feedback mode & $=$ Free & Signal Module S & $=0$ \\
\hline Scan direction & $=$ Down & Feedback algo. & = Adaptive PI & Signal Module A & $=0$ \\
\hline Time/Line & $=0.4 \mathrm{~s}$ & Vibration freq. & $=181.357 \mathrm{kHz}$ & Nanosurf Report & $=0$ \\
\hline Points & $=256$ & Vibration ampl. & $=0.7 \mathrm{~V}$ & Scripting Interface & $=0$ \\
\hline
\end{tabular}


N-600-16 after heat treatment

\section{Nanosurf Image Document}

File: Image5
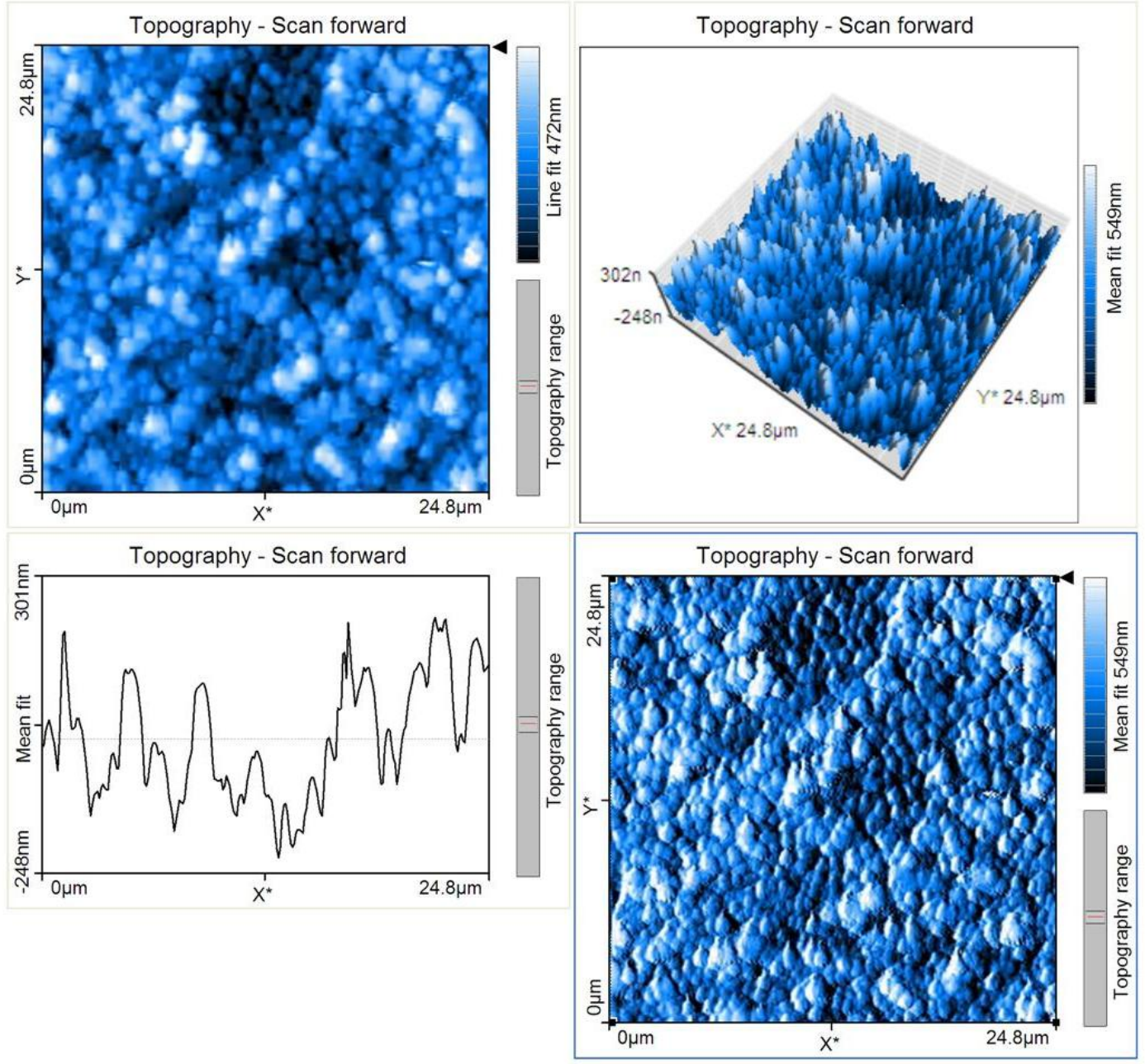

Parameter:

-- Area Roughness --

\begin{tabular}{|c|c|}
\hline Area & $=618 \mathrm{pm}^{\wedge} 2$ \\
\hline $\mathrm{Sa}$ & $=77.73 \mathrm{~nm}$ \\
\hline $\mathrm{Sq}$ & $=96.645 \mathrm{~nm}$ \\
\hline Sy & $=659.97 \mathrm{~nm}$ \\
\hline Sp & $=356.02 \mathrm{~nm}$ \\
\hline Sv & $=-303.94 \mathrm{~nm}$ \\
\hline $\mathrm{Sm}$ & $=208.15 \mathrm{pm}$ \\
\hline
\end{tabular}

-- Line Roughness --

$\begin{array}{ll}\text { Ra } & =80.528 \mathrm{~nm} \\ \mathrm{Rq} & =98.613 \mathrm{~nm} \\ \mathrm{Ry} & =429.72 \mathrm{~nm} \\ \mathrm{Rp} & =232.69 \mathrm{~nm} \\ \mathrm{Rv} & =-197.03 \mathrm{~nm} \\ \mathrm{Rm} & =196.85 \mathrm{pm} \\ - \text { - Scan -- } & \\ \text { Image size } & =25 \mu \mathrm{m} \\ \text { Scan direction } & =U p \\ \text { Time/Line } & =0.4 \mathrm{~s} \\ \text { Points } & =256\end{array}$

$\begin{array}{lll}\text { Lines } & =256 \\ \text { X-Slope } & =-1^{\circ} \\ \text { Y-Slope } & =1.5^{\circ} \\ \text { Rotation } & =90^{\circ} \\ \text { X-Pos } & =0 \mathrm{~m} \\ \text { Y-Pos } & =0 \mathrm{~m} \\ \text { Z-Plane } & =0 \mathrm{~m} \\ \text { Overscan } & =5 \% \\ \text { Const.Height-Mode } & =\text { Disabled } \\ \text { Date } & =01-08-2008 \\ \text { Time } & =14: 46: 27 \\ - \text { - Feedback -- } & & \\ \text { Set point } & =50 \% \\ \text { P-Gain } & =10000 \\ \text { I-Gain } & =1500 \\ \text { Tip voltage } & =0 \mathrm{~V} \\ \text { Feedback mode } & =\text { Free } \\ \text { Feedback algo. } & =\text { Adaptive PI } \\ \text { Vibration freq. } & =181.337 \mathrm{kHz} \\ \text { Vibration ampl. } & =0.7 \mathrm{~V}\end{array}$

$\begin{array}{ll}\text { Excitation ampl. } & =0.25 \mathrm{~V} \\ \text { Error range } & =20 \mathrm{~V} \\ - \text { - Global -- } & \\ \text { Op. mode } & =\text { Dynamic Force } \\ \text { Cantilever type } & =\text { ACLA } \\ \text { Head type } & =\text { EZ2-AFM } \\ \text { Scan head } & =10-07-239 . \text { hed } \\ \text { Software ver. } & =1-5-1-0 \\ \text { Firmware ver. } & =2-1-1-2 \\ \text { Controller S/N } & =023-06-252 \\ \text { - Module -- } & \\ \text { Controller Board } & =2 \\ \text { AFM Basic Module } & =2 \\ \text { AFM Dynamic Module } & =2 \\ \text { AFM Extension Module } & =1 \\ \text { Video Module } & =0 \\ \text { Signal Module S } & =0 \\ \text { Signal Module A } & =0 \\ \text { Nanosurf Report } & =0 \\ \text { Scripting Interface } & =0\end{array}$




\section{Nanosurf Image Document}

File: Image6
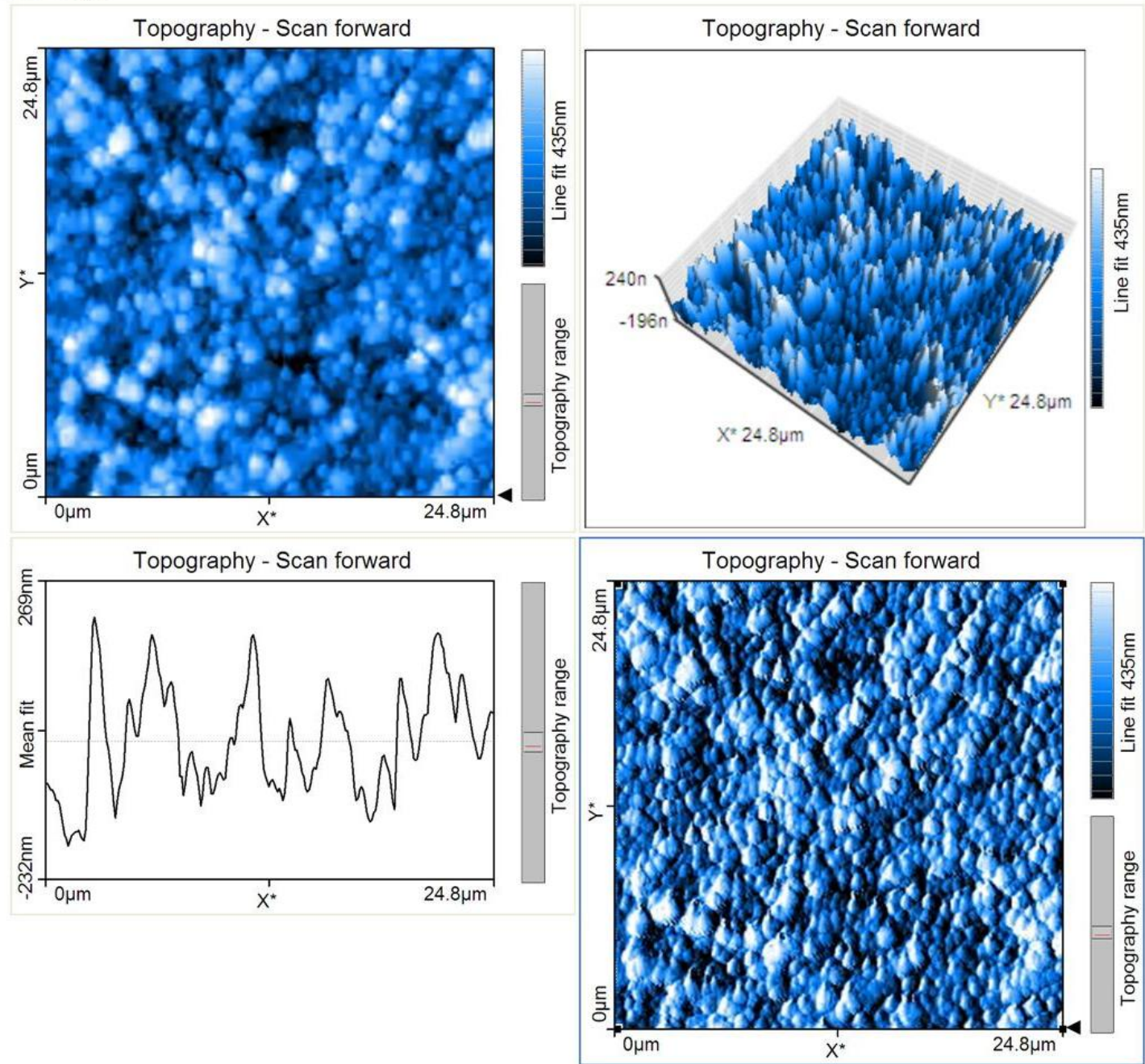

\section{Parameter:}

\begin{tabular}{|c|c|c|c|c|c|}
\hline \multicolumn{2}{|c|}{-- Area Roughness -- } & \multirow{2}{*}{$\begin{array}{l}\text { Lines } \\
\text { X-Slope }\end{array}$} & \multirow{2}{*}{$\begin{array}{l}=256 \\
=-1^{\circ}\end{array}$} & \multirow{2}{*}{$\begin{array}{l}\text { Excitation ampl. } \\
\text { Error range }\end{array}$} & \multirow{2}{*}{$\begin{array}{l}=0.24 \mathrm{~V} \\
=20 \mathrm{~V}\end{array}$} \\
\hline Area & $=618 \mathrm{pm}^{\wedge} 2$ & & & & \\
\hline $\mathrm{Sa}$ & $=67.184 \mathrm{~nm}$ & Y-Slope & $=1.5^{\circ}$ & -- Global -- & \\
\hline $\mathrm{Sq}$ & $=83.178 \mathrm{~nm}$ & Rotation & $=90^{\circ}$ & Op. mode & $=$ Dynamic Force \\
\hline Sy & $=561.08 \mathrm{~nm}$ & X-Pos & $=0 \mathrm{~m}$ & Cantilever type & $=A C L A$ \\
\hline Sp & $=303.94 \mathrm{~nm}$ & Y-Pos & $=0 \mathrm{~m}$ & Head type & $=E Z 2-A F M$ \\
\hline Sv & $=-257.13 n m$ & Z-Plane & $=0 \mathrm{~m}$ & Scan head & $=10-07-239$. hed \\
\hline $\mathrm{Sm}$ & $=-98.129 \mathrm{fm}$ & Overscan & $=5 \%$ & Software ver. & $=1-5-1-0$ \\
\hline \multicolumn{2}{|c|}{-- Line Roughness -- } & \multicolumn{2}{|c|}{ Const. Height-Mode= Disabled } & Firmware ver. & $=2-1-1-2$ \\
\hline $\mathrm{Ra}$ & $=43.861 \mathrm{~nm}$ & Date & $=01-08-2008$ & Controller S/N & $=023-06-252$ \\
\hline $\mathrm{Rq}$ & $=52.976 \mathrm{~nm}$ & Time & $=14: 57: 32$ & -- Module -- & \\
\hline Ry & $=242.69 \mathrm{~nm}$ & -- Feedback -- & & Controller Board & $=2$ \\
\hline $\mathrm{Rp}$ & $=138.64 \mathrm{~nm}$ & Set point & $=50 \%$ & AFM Basic Module & $=2$ \\
\hline Rv & $=-104.06 \mathrm{~nm}$ & P-Gain & $=10000$ & \multicolumn{2}{|c|}{ AFM Dynamic Module $=2$} \\
\hline $\mathrm{Rm}$ & $=1.6087 \mathrm{fm}$ & I-Gain & $=1500$ & \multicolumn{2}{|c|}{ AFM Extension Modul $\epsilon=1$} \\
\hline -- Scan -- & & Tip voltage & $=0 \mathrm{~V}$ & Video Module & $=0$ \\
\hline Image size & $=25 \mu \mathrm{m}$ & Feedback mode & $=$ Free & Signal Module S & $=0$ \\
\hline Scan direction & $=$ Down & Feedback algo. & = Adaptive PI & Signal Module A & $=0$ \\
\hline Time/Line & $=0.4 \mathrm{~s}$ & Vibration freq. & $=181.337 \mathrm{kHz}$ & Nanosurf Report & $=0$ \\
\hline Points & $=256$ & Vibration ampl. & $=0.7 \mathrm{~V}$ & Scripting Interface & $=0$ \\
\hline
\end{tabular}




\section{Nanosurf Image Document}

File: Image8
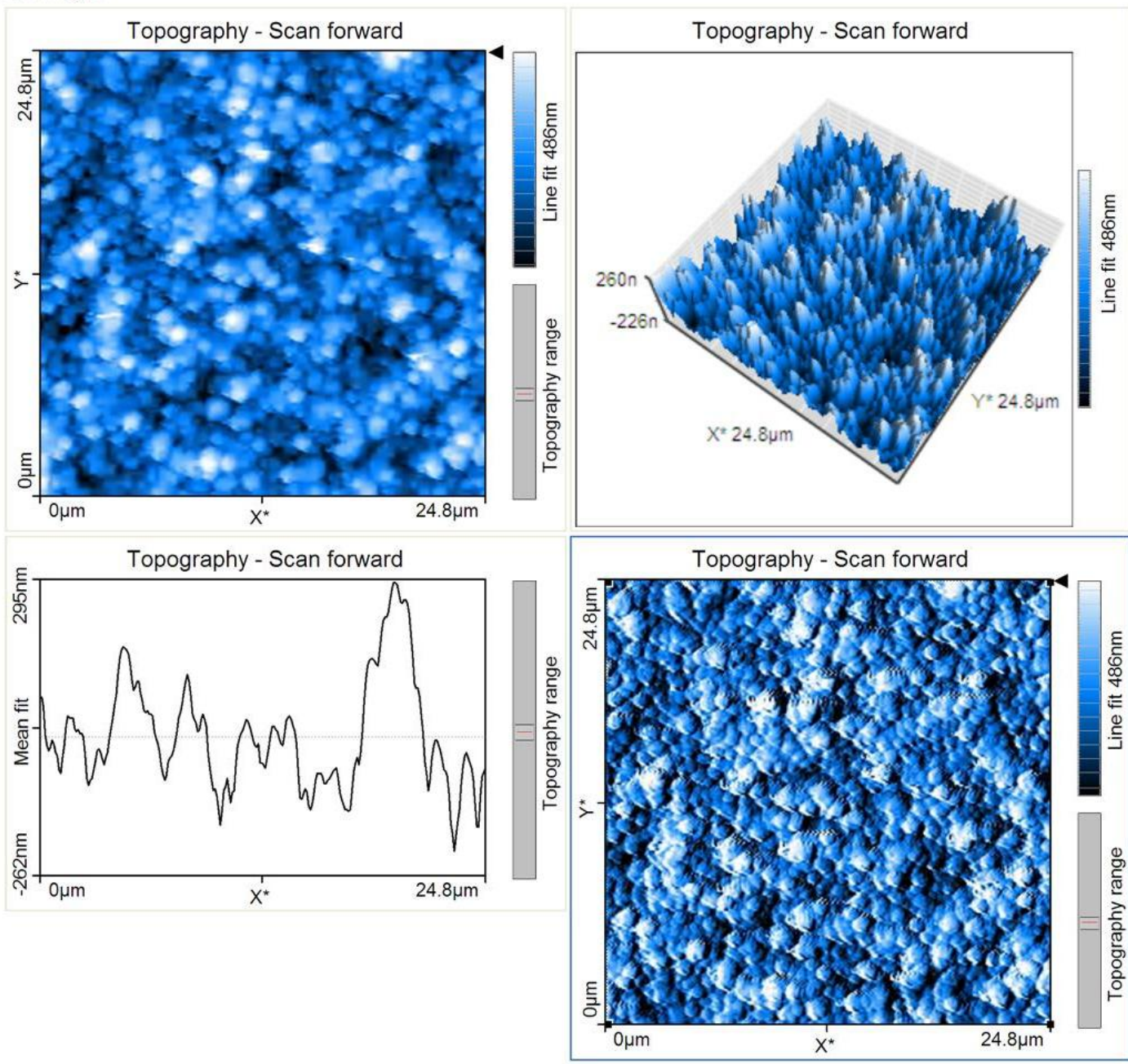

Parameter:

\begin{tabular}{|c|c|c|c|c|c|}
\hline \multicolumn{2}{|c|}{-- Area Roughness -- } & Lines & $=256$ & Excitation ampl. & $=0.25 \mathrm{~V}$ \\
\hline Area & $=618 \mathrm{pm}^{\wedge} 2$ & X-Slope & $=-1^{\circ}$ & Error range & $=20 \mathrm{~V}$ \\
\hline Sa & $=73.116 \mathrm{~nm}$ & Y-Slope & $=1^{\circ}$ & -- Global -- & \\
\hline $\mathrm{Sq}$ & $=90.555 \mathrm{~nm}$ & Rotation & $=-14.2 f^{\circ}$ & Op. mode & $=$ Dynamic Force \\
\hline Sy & $=670.09 \mathrm{~nm}$ & X-Pos & $=0 \mathrm{fm}$ & Cantilever type & $=A C L A$ \\
\hline Sp & $=391.87 \mathrm{~nm}$ & Y-Pos & $=0 \mathrm{fm}$ & Head type & $=E Z 2-A F M$ \\
\hline Sv & $=-278.22 \mathrm{~nm}$ & Z-Plane & $=0 \mathrm{fm}$ & Scan head & $=10-07-239$. hed \\
\hline $\mathrm{Sm}$ & $=42.471 \mathrm{pm}$ & Overscan & $=5 \%$ & Software ver. & $=1-5-1-0$ \\
\hline \multicolumn{2}{|c|}{-- Line Roughness -- } & \multicolumn{2}{|c|}{ Const. Height-Mod $\epsilon=$ Disabled } & Firmware ver. & $=2-1-1-2$ \\
\hline $\mathrm{Ra}$ & $=59.873 \mathrm{~nm}$ & Date & $=01-08-2008$ & Controller $\mathrm{S} / \mathrm{N}$ & $=023-06-252$ \\
\hline $\mathrm{Rq}$ & $=73.576 \mathrm{~nm}$ & Time & $=15: 13: 36$ & -- Module -- & \\
\hline Ry & $=336.52 \mathrm{~nm}$ & -- Feedback -- & & Controller Board & $=2$ \\
\hline $\mathrm{Rp}$ & $=192.36 \mathrm{~nm}$ & Set point & $=50 \%$ & AFM Basic Module & $=2$ \\
\hline Rv & $=-144.16 n m$ & P-Gain & $=10000$ & \multicolumn{2}{|c|}{ AFM Dynamic Module $=2$} \\
\hline $\mathrm{Rm}$ & $=43.655 \mathrm{pm}$ & I-Gain & $=1600$ & \multicolumn{2}{|c|}{ AFM Extension Module $=1$} \\
\hline -- Scan -- & & Tip voltage & $=0 \mathrm{~V}$ & Video Module & $=0$ \\
\hline Image size & $=25 \mu \mathrm{m}$ & Feedback mode & $=$ Free & Signal Module S & $=0$ \\
\hline Scan direction & $=U p$ & Feedback algo. & $=$ Adaptive PI & Signal Module A & $=0$ \\
\hline Time/Line & $=0.4 \mathrm{~s}$ & Vibration freq. & $=181.337 \mathrm{kHz}$ & Nanosurf Report & $=0$ \\
\hline Points & $=256$ & Vibration ampl. & $=0.7 \mathrm{~V}$ & Scripting Interface & $=0$ \\
\hline
\end{tabular}




\section{N-600-16 after CP}

\section{Nanosurf Image Document}

File: Image5

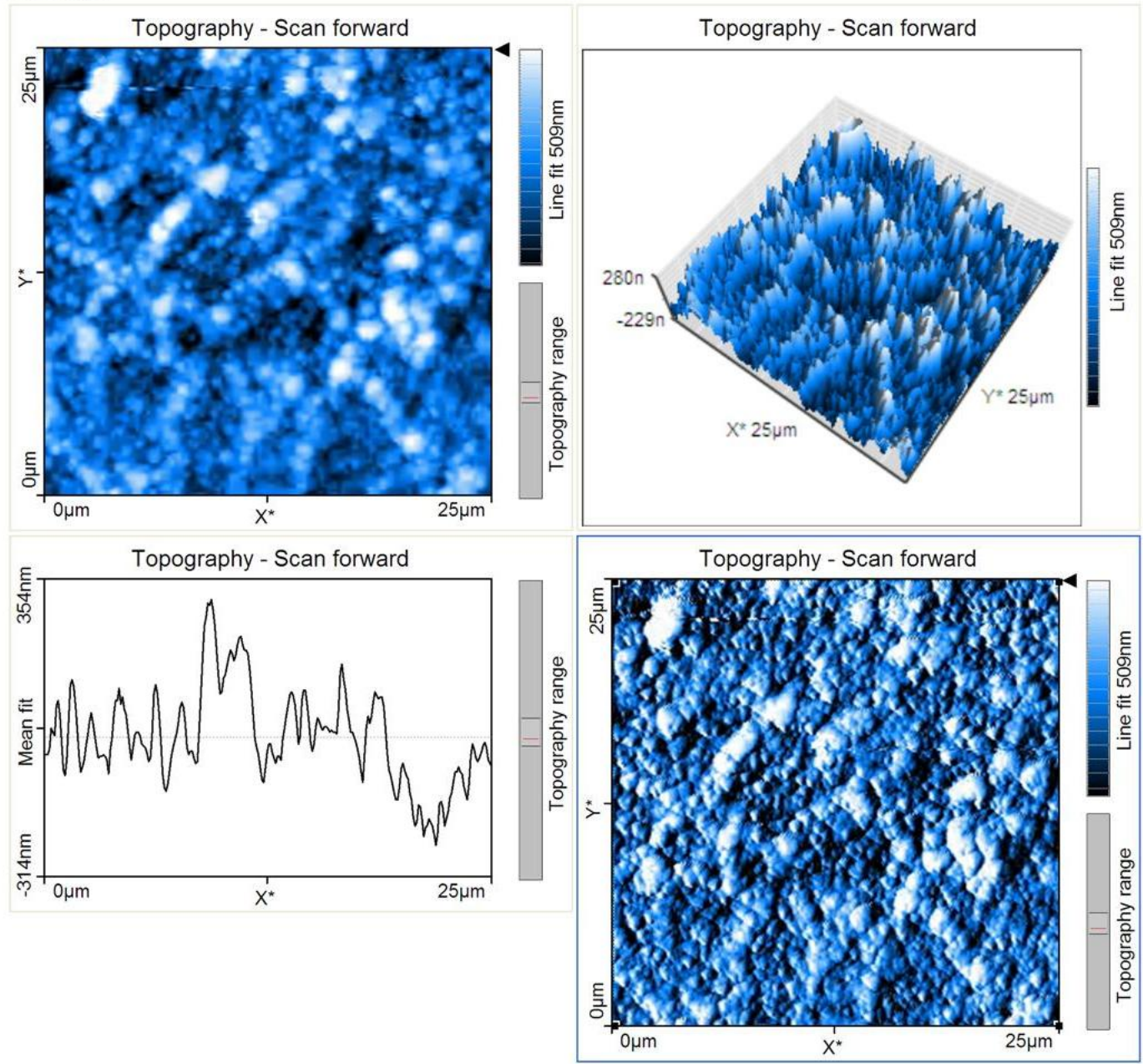

Parameter

\begin{tabular}{|c|c|c|c|c|c|}
\hline \multicolumn{2}{|c|}{-- Area Roughness -- } & \multirow{2}{*}{$\begin{array}{l}\text { Lines } \\
\text { X-Slope }\end{array}$} & \multirow{2}{*}{$\begin{array}{l}=256 \\
=-500 \mathrm{~m}^{\circ}\end{array}$} & \multirow{2}{*}{$\begin{array}{l}\text { Excitation ampl. } \\
\text { Error range }\end{array}$} & \multirow{2}{*}{$\begin{array}{l}=0.17 \mathrm{~V} \\
=20 \mathrm{~V}\end{array}$} \\
\hline Area & $=629.9 \mathrm{pm}^{\wedge} 2$ & & & & \\
\hline $\mathrm{Sa}$ & $=81.339 \mathrm{~nm}$ & Y-Slope & $=-500 \mathrm{~m}^{\circ}$ & -- Global -- & \\
\hline $\mathrm{Sq}$ & $=103.77 \mathrm{~nm}$ & Rotation & $=-1.78 f^{\circ}$ & Op. mode & = Dynamic Force \\
\hline Sy & $=1029.4 \mathrm{~nm}$ & X-Pos & $=6.3 \mu \mathrm{m}$ & Cantilever type & $=A C L A$ \\
\hline Sp & $=685.59 \mathrm{~nm}$ & Y-Pos & $=19 \mu \mathrm{m}$ & Head type & $=E Z 2-A F M$ \\
\hline Sv & $=-343.79 n m$ & Z-Plane & $=0 \mu \mathrm{m}$ & Scan head & $=10-07-239$. hed \\
\hline Sm & $=2099.3 \mathrm{fm}$ & Overscan & $=5 \%$ & Software ver. & $=1-5-1-0$ \\
\hline \multicolumn{2}{|c|}{-- Line Roughness -- } & \multicolumn{2}{|c|}{ Const. Height-Mod $\epsilon=$ Disabled } & Firmware ver. & $=2-1-1-2$ \\
\hline $\mathrm{Ra}$ & $=85.601 \mathrm{~nm}$ & Date & $=10-08-2008$ & Controller $\mathrm{S} / \mathrm{N}$ & $=023-06-252$ \\
\hline $\mathrm{Rq}$ & $=103.66 \mathrm{~nm}$ & Time & $=15: 33: 48$ & -- Module -- & \\
\hline Ry & $=449.12 \mathrm{~nm}$ & -- Feedback -- & & Controller Board & $=2$ \\
\hline Rp & $=268.73 \mathrm{~nm}$ & Set point & $=48 \%$ & AFM Basic Module & $=2$ \\
\hline $\mathrm{Rv}$ & $=-180.39 \mathrm{~nm}$ & P-Gain & $=10000$ & \multicolumn{2}{|c|}{ AFM Dynamic Module $=2$} \\
\hline $\mathrm{Rm}$ & $=1648.9 \mathrm{fm}$ & I-Gain & $=1100$ & \multicolumn{2}{|c|}{ AFM Extension Module $=1$} \\
\hline -- Scan -- & & Tip voltage & $=0 \mathrm{~V}$ & Video Module & $=0$ \\
\hline Image size & $=25 \mu \mathrm{m}$ & Feedback mode & $=$ Free & Signal Module S & $=0$ \\
\hline Scan direction & $=U p$ & Feedback algo. & = Adaptive PI & Signal Module A & $=0$ \\
\hline Time/Line & $=0.5 \mathrm{~s}$ & Vibration freq. & $=179.237 \mathrm{kHz}$ & Nanosurf Report & $=0$ \\
\hline Points & $=256$ & Vibration ampl. & $=0.7 \mathrm{~V}$ & Scripting Interface & $=0$ \\
\hline
\end{tabular}




\section{Nanosurf Image Document}

File: Image6

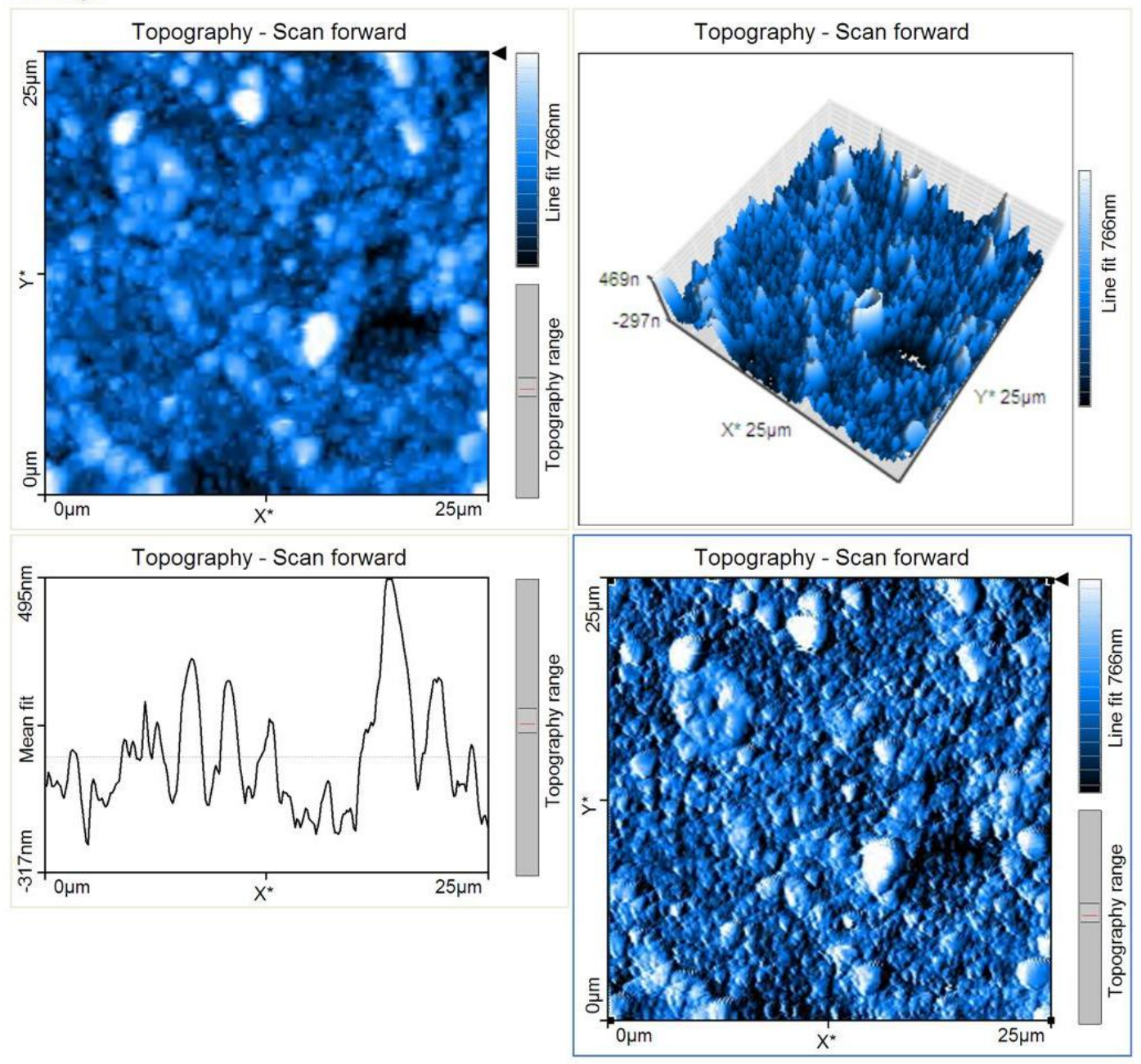

Parameter:

$\begin{array}{ll}\text {-- Area Roughness -- } \\ \text { Area } & =629.9 \mathrm{pm}^{\wedge} 2 \\ \mathrm{Sa} & =102.43 \mathrm{~nm} \\ \mathrm{Sq} & =136.38 \mathrm{~nm} \\ \mathrm{Sy} & =1202.7 \mathrm{~nm} \\ \mathrm{Sp} & =832.34 \mathrm{~nm} \\ \mathrm{~Sv} & =-370.36 \mathrm{~nm} \\ \mathrm{Sm} & =210.81 \mathrm{pm}\end{array}$

-- Line Roughness --

$\mathrm{Ra} \quad=81.618 \mathrm{~nm}$

$\mathrm{Rq} \quad=99.092 \mathrm{~nm}$

Ry $\quad=464.09 \mathrm{~nm}$

$\mathrm{Rp} \quad=279.7 \mathrm{~nm}$

Rv $\quad=-184.39 \mathrm{~nm}$

$\mathrm{Rm} \quad=210.03 \mathrm{pm}$

-- Scan --

Image size

Scan direction

Time/Line

Points

$\begin{array}{ll}\text { Lines } & =256 \\ \text { X-Slope } & =-500 \mathrm{~m}^{\circ} \\ \text { Y-Slope } & =-500 \mathrm{~m}^{\circ} \\ \text { Rotation } & =-1.78 \mathrm{f}^{\circ} \\ \text { X-Pos } & =6.3 \mu \mathrm{m} \\ \text { Y-Pos } & =19 \mu \mathrm{m} \\ \text { Z-Plane } & =0 \mu \mathrm{m} \\ \text { Overscan } & =5 \% \\ \text { Const.Height-Mode } & =\text { Disabled } \\ \text { Date } & =10-08-2008 \\ \text { Time } & =15: 41: 38 \\ - \text { - Feedback -- } & \\ \text { Set point } & =48 \% \\ \text { P-Gain } & =10000 \\ \text { I-Gain } & =1100 \\ \text { Tip voltage } & =0 \mathrm{~V} \\ \text { Feedback mode } & =\text { Free } \\ \text { Feedback algo. } & =\text { Adaptive PI } \\ \text { Vibration freq. } & =179.247 \mathrm{kHz} \\ \text { Vibration ampl. } & =0.7 \mathrm{~V}\end{array}$

$\begin{array}{ll}\text { Excitation ampl. } & =0.17 \mathrm{~V} \\ \text { Error range } & =20 \mathrm{~V} \\ - \text { Global -- } & \\ \text { Op. mode } & =\text { Dynamic Force } \\ \text { Cantilever type } & =\text { ACLA } \\ \text { Head type } & =\text { EZ2-AFM } \\ \text { Scan head } & =10-07-239 . \text { hed } \\ \text { Software ver. } & =1-5-1-0 \\ \text { Firmware ver. } & =2-1-1-2 \\ \text { Controller S/N } & =023-06-252 \\ - \text { Module -- } & \\ \text { Controller Board } & =2 \\ \text { AFM Basic Module } & =2 \\ \text { AFM Dynamic Module } & =2 \\ \text { AFM Extension Module } & =1 \\ \text { Video Module } & =0 \\ \text { Signal Module S } & =0 \\ \text { Signal Module A } & =0 \\ \text { Nanosurf Report } & =0 \\ \text { Scripting Interface } & =0\end{array}$


N-675-1 after heat treatment

\section{Nanosurf Image Document}

File: Image3
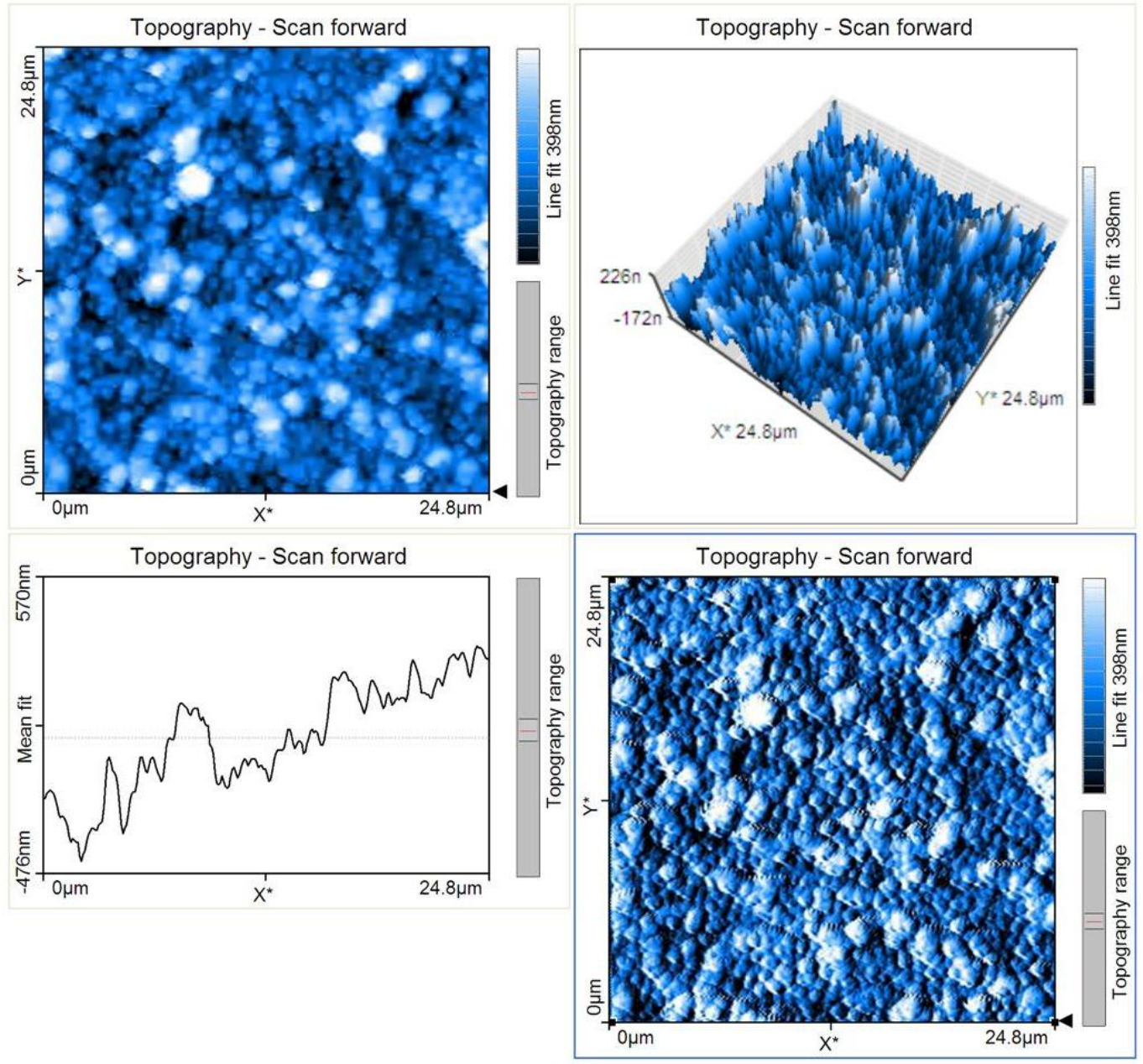

Parameter:

-- Area Roughness --

$\begin{array}{ll}\text { Area } & =618 \mathrm{pm}^{\wedge} 2 \\ \text { Sa } & =62.134 \mathrm{~nm} \\ \text { Sq } & =78.277 \mathrm{~nm} \\ \text { Sy } & =613.58 \mathrm{~nm} \\ \text { Sp } & =366.99 \mathrm{~nm} \\ \text { Sv } & =-246.59 \mathrm{~nm} \\ \text { Sm } & =93.121 \mathrm{pm}\end{array}$

-- Line Roughness --

$\mathrm{Ra} \quad=56.218 \mathrm{~nm}$

$\mathrm{Rq} \quad=70.657 \mathrm{~nm}$

Ry $\quad=324.29 \mathrm{~nm}$

Rp $\quad=174.82 \mathrm{~nm}$

$=-149.48 \mathrm{~nm}$

$\mathrm{Rm} \quad=86.484 \mathrm{pm}$

-- Scan --

$=25 \mu \mathrm{m}$

Scan direction

$=$ Down

Time/Line $\quad=0.4 \mathrm{~s}$

Points

$\begin{array}{lll}\text { Lines } & =256 \\ \text { X-Slope } & =2^{\circ} \\ \text { Y-Slope } & =2.5^{\circ} \\ \text { Rotation } & =-14.2 \mathrm{f}^{\circ} \\ \text { X-Pos } & =0 \mathrm{fm} \\ \text { Y-Pos } & =0 \mathrm{fm} \\ \text { Z-Plane } & =0 \mathrm{fm} \\ \text { Overscan } & =5 \% \\ \text { Const.Height-Mode } & =\text { Disabled } \\ \text { Date } & & =01-08-2008 \\ \text { Time } & =14: 27: 26 \\ - \text {-Feedback -- } & & \\ \text { Set point } & =50 \% \\ \text { P-Gain } & =10000 \\ \text { I-Gain } & =1800 \\ \text { Tip voltage } & =0 \mathrm{~V} \\ \text { Feedback mode } & =\text { Free } \\ \text { Feedback algo. } & =\text { Adaptive PI } \\ \text { Vibration freq. } & =181.347 \mathrm{kHz} \\ \text { Vibration ampl. } & =0.7 \mathrm{~V}\end{array}$

$\begin{array}{ll}\text { Excitation ampl. } & =0.27 \mathrm{~V} \\ \text { Error range } & =20 \mathrm{~V} \\ - \text { - Global -- } & \\ \text { Op. } \text { mode } & =\text { Dynamic Force } \\ \text { Cantilever type } & =\text { ACLA } \\ \text { Head type } & =\text { EZ2-AFM } \\ \text { Scan head } & =10-07-239 . \text { hed } \\ \text { Software ver. } & =1-5-1-0 \\ \text { Firmware ver. } & =2-1-1-2 \\ \text { Controller S/N } & =023-06-252 \\ - \text { - Module -- } & \\ \text { Controller Board } & =2 \\ \text { AFM Basic Module } & =2 \\ \text { AFM Dynamic Module } & =2 \\ \text { AFM Extension Module } & =1 \\ \text { Video Module } & =0 \\ \text { Signal Module S } & =0 \\ \text { Signal Module A } & =0 \\ \text { Nanosurf Report } & =0 \\ \text { Scripting Interface } & =0\end{array}$




\section{Nanosurf Image Document}

File: Image4

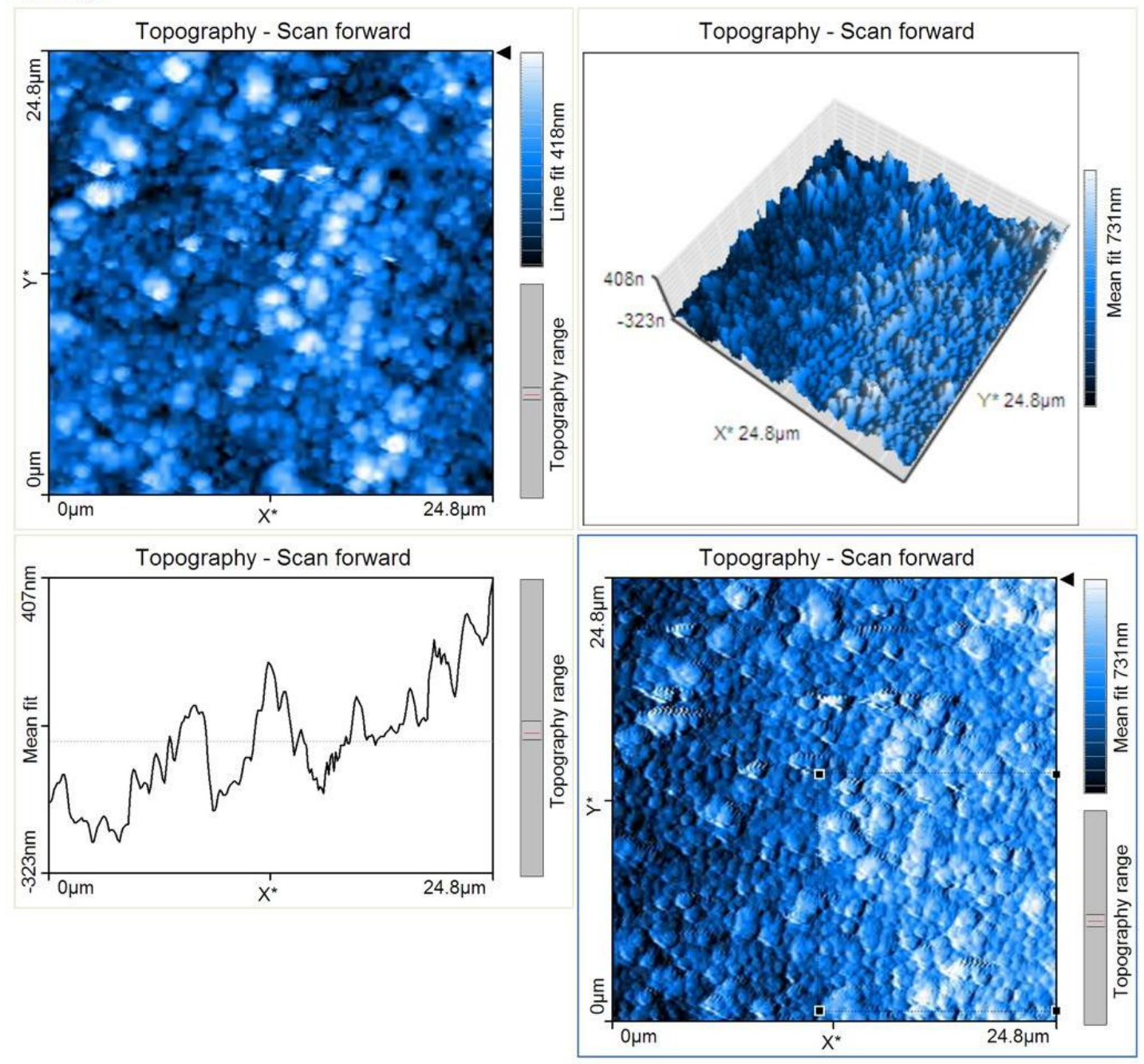

Parameter:

\begin{tabular}{|c|c|c|c|c|c|}
\hline \multicolumn{2}{|c|}{-- Area Roughness -- } & \multirow{2}{*}{$\begin{array}{l}\text { Lines } \\
\text { X-Slope }\end{array}$} & \multirow{2}{*}{$\begin{array}{l}=256 \\
=2^{\circ}\end{array}$} & \multirow{2}{*}{$\begin{array}{l}\text { Excitation ampl. } \\
\text { Error range }\end{array}$} & \multirow{2}{*}{$\begin{array}{l}=0.26 \mathrm{~V} \\
=20 \mathrm{~V}\end{array}$} \\
\hline Area & $=180.8 \mathrm{pm}^{\wedge} 2$ & & & & \\
\hline $\mathrm{Sa}$ & $=112.4 \mathrm{~nm}$ & Y-Slope & $=2.5^{\circ}$ & -- Global -. & \\
\hline $\mathrm{Sq}$ & $=133.39 \mathrm{~nm}$ & Rotation & $=-14.2 f^{\circ}$ & Op. mode & = Dynamic Force \\
\hline Sy & $=620.33 \mathrm{~nm}$ & X-Pos & $=0 \mathrm{fm}$ & Cantilever type & $=A C L A$ \\
\hline Sp & $=452.17 \mathrm{~nm}$ & Y-Pos & $=0 \mathrm{fm}$ & Head type & $=E Z 2-A F M$ \\
\hline Sv & $=-168.15 \mathrm{~nm}$ & Z-Plane & $=0 \mathrm{fm}$ & Scan head & $=10-07-239$. hed \\
\hline Sm & $=101.39 \mathrm{~nm}$ & Overscan & $=5 \%$ & Software ver. & $=1-5-1-0$ \\
\hline \multicolumn{2}{|c|}{-- Line Roughness -- } & \multicolumn{2}{|c|}{ Const. Height-Mode= Disabled } & Firmware ver. & $=2-1-1-2$ \\
\hline $\mathrm{Ra}$ & $=111.3 \mathrm{~nm}$ & Date & $=01-08-2008$ & Controller S/N & $=023-06-252$ \\
\hline $\mathrm{Rq}$ & $=124.19 \mathrm{~nm}$ & Time & $=14: 37: 01$ & -- Module -- & \\
\hline Ry & $=510.68 \mathrm{~nm}$ & -- Feedback -- & & Controller Board & $=2$ \\
\hline $\mathrm{Rp}$ & $=228.65 \mathrm{~nm}$ & Set point & $=50 \%$ & AFM Basic Module & $=2$ \\
\hline Rv & $=-282.03 \mathrm{~nm}$ & P-Gain & $=10000$ & \multicolumn{2}{|c|}{ AFM Dynamic Module $=2$} \\
\hline $\mathrm{Rm}$ & $=16.474 \mathrm{pm}$ & I-Gain & $=1700$ & \multicolumn{2}{|c|}{ AFM Extension Modul $\epsilon=1$} \\
\hline -- Scan -- & & Tip voltage & $=0 \mathrm{~V}$ & Video Module & $=0$ \\
\hline Image size & $=25 \mu \mathrm{m}$ & Feedback mode & $=$ Free & Signal Module S & $=0$ \\
\hline Scan direction & $=U p$ & Feedback algo. & = Adaptive PI & Signal Module A & $=0$ \\
\hline Time/Line & $=0.4 \mathrm{~s}$ & Vibration freq. & $=181 \cdot 347 \mathrm{kHz}$ & Nanosurf Report & $=0$ \\
\hline Points & $=256$ & Vibration ampl. & $=0.7 \mathrm{~V}$ & Scripting Interface & $=0$ \\
\hline
\end{tabular}




\section{Nanosurf Image Document}

File: Image3

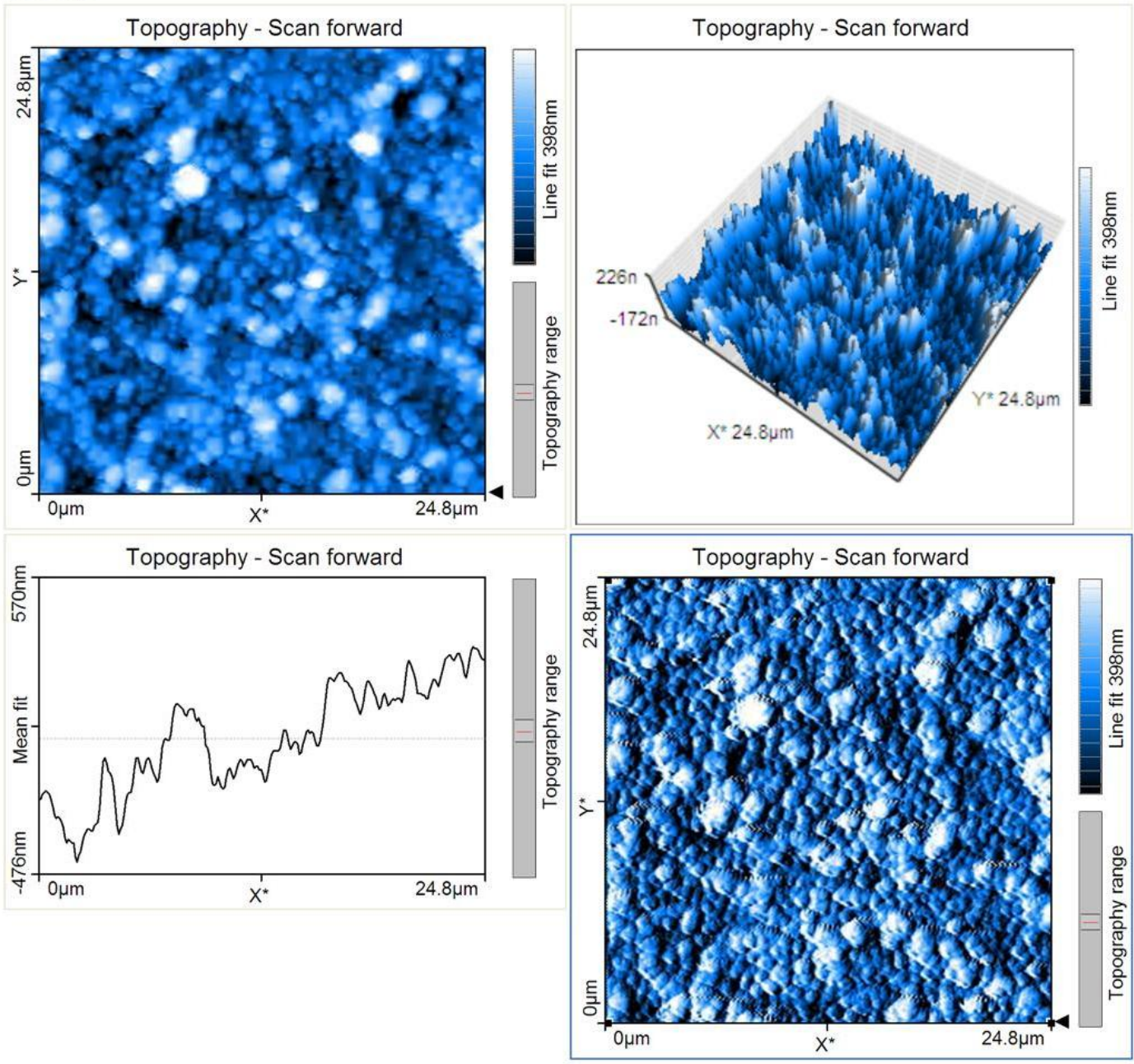

\section{Parameter:}

-- Area Roughness --

Area $\quad=618 \mathrm{pm}^{\wedge} 2$

$\mathrm{Sa} \quad=62.134 \mathrm{~nm}$

$\begin{array}{ll}\text { Lines } & =256 \\ \text { X-Slope } & =2^{\circ} \\ \text { Y-Slope } & =2.5^{\circ} \\ \text { Rotation } & =-14.2 \mathrm{f}^{\circ} \\ \text { X-Pos } & =0 \mathrm{fm} \\ \text { Y-Pos } & =0 \mathrm{fm} \\ \text { Z-Plane } & =0 \mathrm{fm} \\ \text { Overscan } & =5 \%\end{array}$

$\begin{array}{ll}\text { Excitation ampl. } & =0.27 \mathrm{~V} \\ \text { Error range } & =20 \mathrm{~V} \\ - \text { - Global -- } & \\ \text { Op. mode } & =\text { Dynamic Force } \\ \text { Cantilever type } & =\text { ACLA } \\ \text { Head type } & =\text { EZ2-AFM } \\ \text { Scan head } & =10-07-239 . \text { hed } \\ \text { Software ver. } & =1-5-1-0 \\ \text { Firmware ver. } & =2-1-1-2 \\ \text { Controller S/N } & =023-06-252 \\ \text { - Module -- } & \\ \text { Controller Board } & =2 \\ \text { AFM Basic Module } & =2 \\ \text { AFM Dynamic Module } & =2 \\ \text { AFM Extension Modul } & =1 \\ \text { Video Module } & =0 \\ \text { Signal Module S } & =0 \\ \text { Signal Module A } & =0 \\ \text { Nanosurf Report } & =0 \\ \text { Scripting Interface } & =0\end{array}$




\section{N-675-1 after CP}

\section{Nanosurf Image Document}

File: Image6

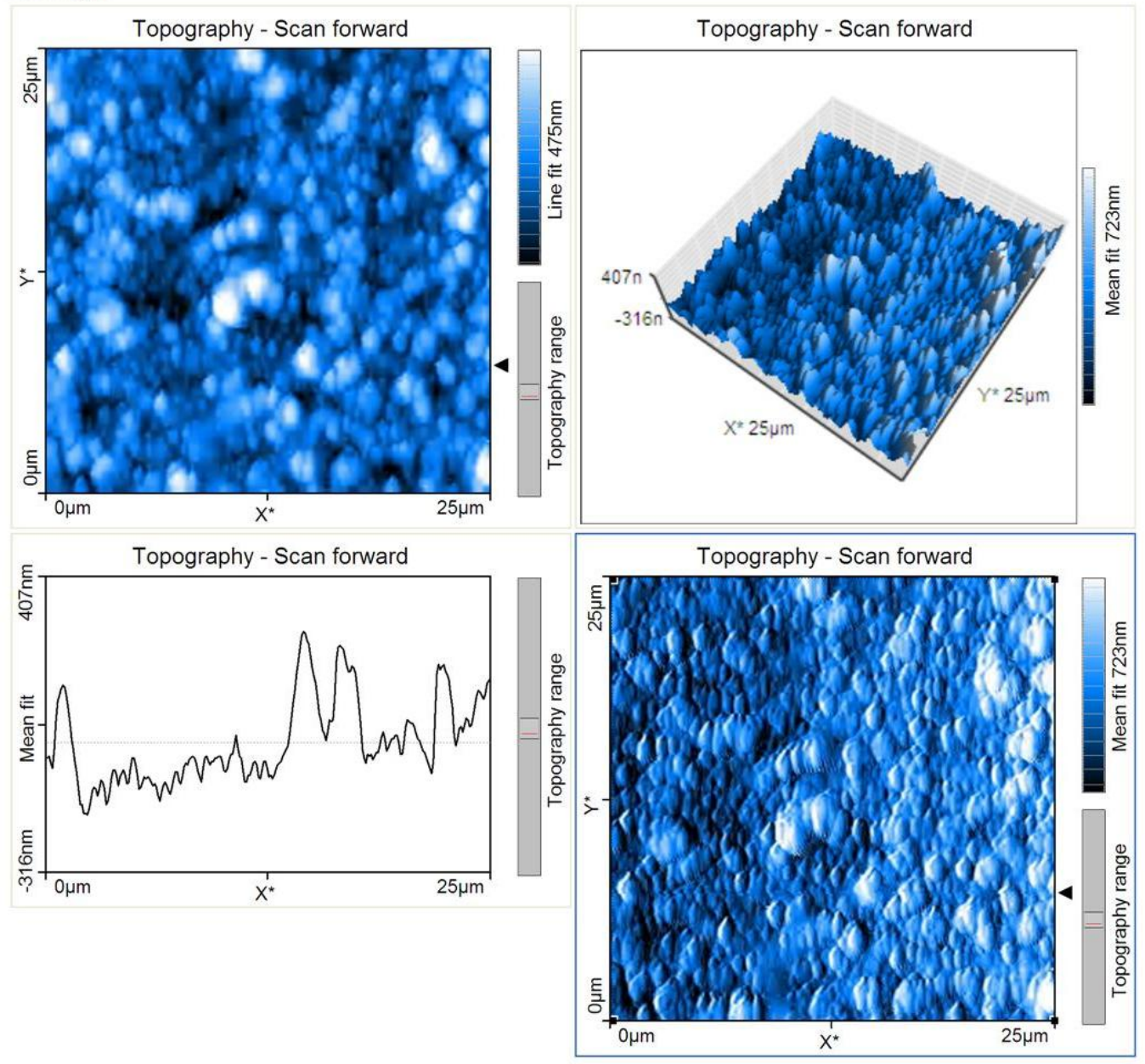

Parameter:

\begin{tabular}{|c|c|c|c|c|c|}
\hline \multicolumn{2}{|c|}{-- Area Roughness -- } & \multirow{2}{*}{$\begin{array}{l}\text { Lines } \\
X \text {-Slope }\end{array}$} & \multirow{2}{*}{$\begin{array}{l}=256 \\
=1.5^{\circ}\end{array}$} & \multirow{2}{*}{$\begin{array}{l}\text { Excitation ampl. } \\
\text { Error range }\end{array}$} & \multirow{2}{*}{$\begin{array}{l}=0.21 \mathrm{~V} \\
=20 \mathrm{~V}\end{array}$} \\
\hline Area & $=629.9 \mathrm{pm}^{\wedge} 2$ & & & & \\
\hline $\mathrm{Sa}$ & $=93.521 \mathrm{~nm}$ & Y-Slope & $=4.5^{\circ}$ & -- Global -- & \\
\hline $\mathrm{Sq}$ & $=117.37 \mathrm{~nm}$ & Rotation & $=90^{\circ}$ & Op. mode & $=$ Dynamic Force \\
\hline Sy & $=858.8 \mathrm{~nm}$ & X-Pos & $=0 \mathrm{~m}$ & Cantilever type & $=A C L A$ \\
\hline Sp & $=508.05 \mathrm{~nm}$ & Y-Pos & $=0 \mathrm{~m}$ & Head type & $=\mathrm{EZ2}-\mathrm{AFM}$ \\
\hline Sv & $=-350.75 \mathrm{~nm}$ & Z-Plane & $=0 \mathrm{~m}$ & Scan head & $=10-07-239 \cdot$ hed \\
\hline $\mathrm{Sm}$ & $=22.967 \mathrm{pm}$ & Overscan & $=5 \%$ & Software ver. & $=1-5-1-0$ \\
\hline \multicolumn{2}{|c|}{-- Line Roughness -- } & \multicolumn{2}{|c|}{ Const. Height-Mode= Disabled } & Firmware ver. & $=2-1-1-2$ \\
\hline $\mathrm{Ra}$ & $=92.697 \mathrm{~nm}$ & Date & $=09-08-2008$ & Controller S/N & $=023-06-252$ \\
\hline $\mathrm{Rq}$ & $=111.7 \mathrm{~nm}$ & Time & $=16: 12: 30$ & -- Module -- & \\
\hline Ry & $=481.38 \mathrm{~nm}$ & \multicolumn{2}{|l|}{-- Feedback -- } & Controller Board & $=2$ \\
\hline $\mathrm{Rp}$ & $=260.26 \mathrm{~nm}$ & Set point & $=48 \%$ & AFM Basic Module & $=2$ \\
\hline Rv & $=-221.11 \mathrm{~nm}$ & P-Gain & $=10000$ & \multicolumn{2}{|c|}{ AFM Dynamic Module $=2$} \\
\hline $\mathrm{Rm}$ & $=35.418 \mathrm{pm}$ & I-Gain & $=1700$ & \multicolumn{2}{|c|}{ AFM Extension Modul $=1$} \\
\hline -- Scan -- & & Tip voltage & $=0 \mathrm{~V}$ & Video Module & $=0$ \\
\hline Image size & $=25 \mu \mathrm{m}$ & Feedback mode & $=$ Free & Signal Module S & $=0$ \\
\hline Scan direction & $=$ Idle & Feedback algo. & = Adaptive PI & Signal Module A & $=0$ \\
\hline Time/Line & $=0.5 \mathrm{~s}$ & Vibration freq. & $=181.307 \mathrm{kHz}$ & Nanosurf Report & $=0$ \\
\hline Points & $=256$ & Vibration ampl. & $=0.7 \mathrm{~V}$ & Scripting Interface & $=0$ \\
\hline
\end{tabular}




\section{Nanosurf Image Document}

File: Image7
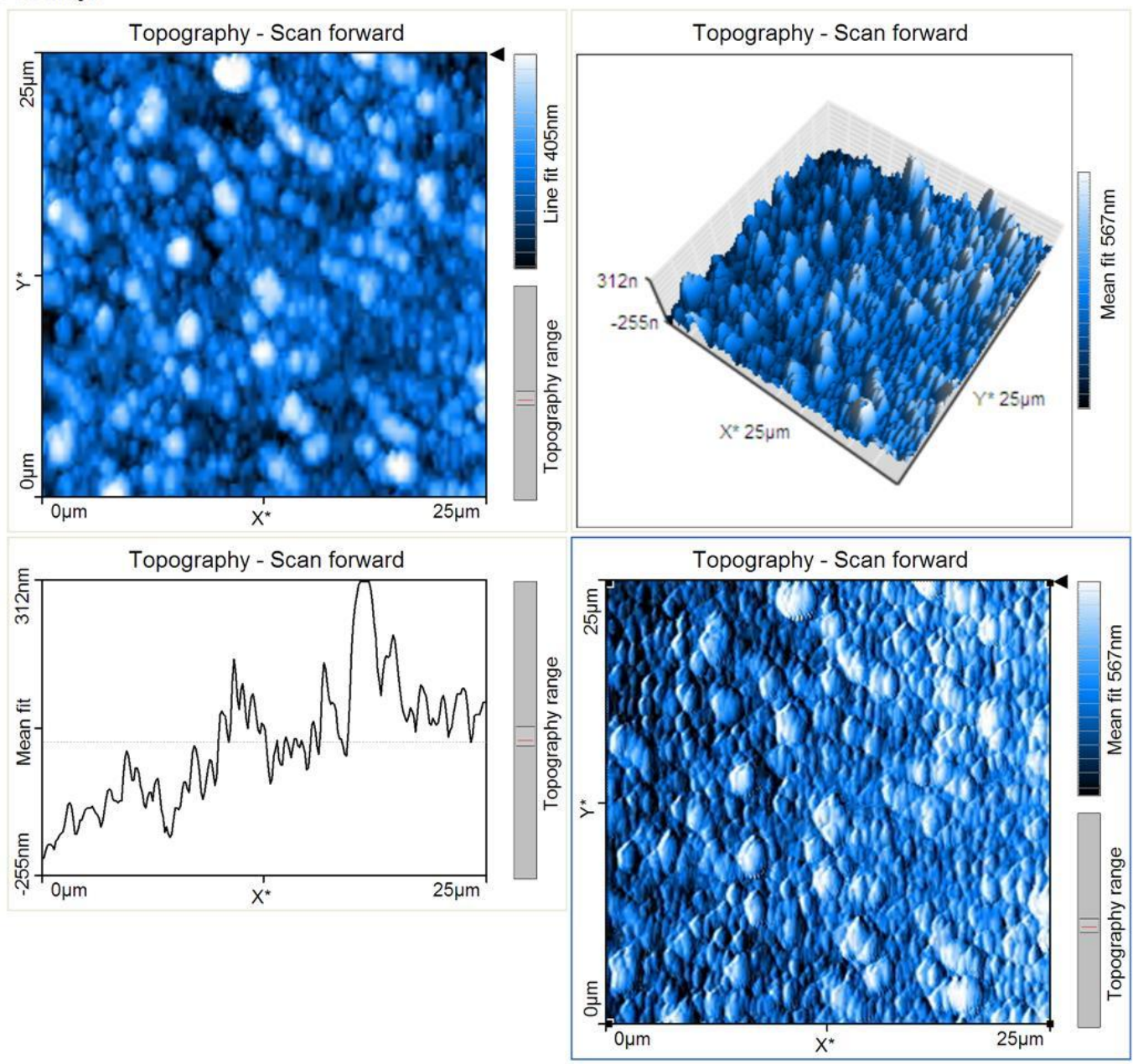

Parameter:

\begin{tabular}{|c|c|c|c|c|c|}
\hline \multicolumn{2}{|c|}{-- Area Roughness -- } & \multirow{2}{*}{$\begin{array}{l}\text { Lines } \\
\text { X-Slope }\end{array}$} & \multirow{2}{*}{$\begin{array}{l}=256 \\
=1.5^{\circ}\end{array}$} & \multirow{2}{*}{$\begin{array}{l}\text { Excitation ampl. } \\
\text { Error range }\end{array}$} & \multirow{2}{*}{$\begin{array}{l}=0.22 \mathrm{~V} \\
=20 \mathrm{~V}\end{array}$} \\
\hline Area & $=629.9 \mathrm{pm}^{\wedge} 2$ & & & & \\
\hline $\mathrm{Sa}$ & $=80.775 \mathrm{~nm}$ & Y-Slope & $=4.5^{\circ}$ & -- Global -- & \\
\hline $\mathrm{Sq}$ & $=100.64 \mathrm{~nm}$ & Rotation & $=90^{\circ}$ & Op. mode & $=$ Dynamic Force \\
\hline Sy & $=663.55 \mathrm{~nm}$ & X-Pos & $=0 \mathrm{~m}$ & Cantilever type & $=A C L A$ \\
\hline $\mathrm{sp}$ & $=374.37 \mathrm{~nm}$ & Y-Pos & $=0 \mathrm{~m}$ & Head type & $=E Z 2-A F M$ \\
\hline Sv & $=-289.18 \mathrm{~nm}$ & Z-Plane & $=0 \mathrm{~m}$ & Scan head & $=10-07-239 \cdot$ hed \\
\hline Sm & $=-3.3895 \mathrm{pm}$ & Overscan & $=5 \%$ & Software ver. & $=1-5-1-0$ \\
\hline \multicolumn{2}{|c|}{-- Line Roughness -- } & \multicolumn{2}{|c|}{ Const. Height-Mod $\epsilon=$ Disabled } & Firmware ver. & $=2-1-1-2$ \\
\hline $\mathrm{Ra}$ & $=69.139 \mathrm{~nm}$ & Date & $=09-08-2008$ & Controller S/N & $=023-06-252$ \\
\hline $\mathrm{Rq}$ & $=82.023 \mathrm{~nm}$ & Time & $=16: 18: 18$ & -- Module -- & \\
\hline Ry & $=372.79 \mathrm{~nm}$ & -- Feedback -- & & Controller Board & $=2$ \\
\hline $\mathrm{Rp}$ & $=184.67 \mathrm{~nm}$ & Set point & $=48 \%$ & AFM Basic Module & $=2$ \\
\hline Rv & $=-188.12 n m$ & P-Gain & $=10000$ & \multicolumn{2}{|c|}{ AFM Dynamic Module $=2$} \\
\hline $\mathrm{Rm}$ & $=-64.242 \mathrm{pm}$ & I-Gain & $=1700$ & \multicolumn{2}{|c|}{ AFM Extension Modul $=1$} \\
\hline - Scan -- & & Tip voltage & $=0 \mathrm{~V}$ & Video Module & $=0$ \\
\hline Image size & $=25 \mu \mathrm{m}$ & Feedback mode & $=$ Free & Signal Module S & $=0$ \\
\hline Scan direction & $=U p$ & Feedback algo. & = Adaptive $\mathrm{PI}$ & Signal Module A & $=0$ \\
\hline Time/Line & $=0.5 \mathrm{~s}$ & Vibration freq. & $=181.307 \mathrm{kHz}$ & Nanosurf Report & $=0$ \\
\hline Points & $=256$ & Vibration ampl. & $=0.7 \mathrm{~V}$ & Scripting Interface & $=0$ \\
\hline
\end{tabular}




\section{Nanosurf Image Document}

File: Image8

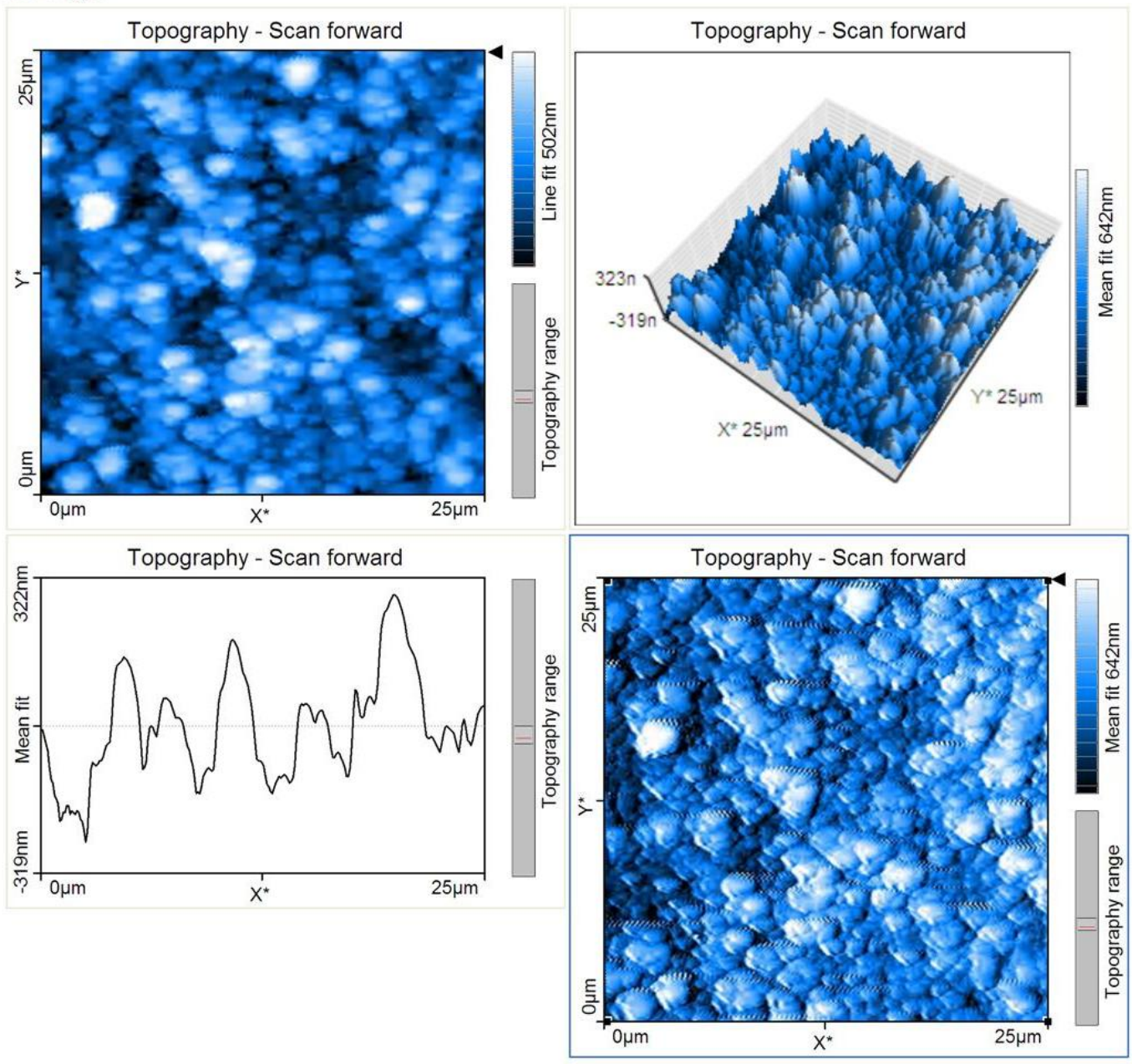

Parameter:

\begin{tabular}{|c|c|c|c|c|c|}
\hline \multicolumn{2}{|c|}{-- Area Roughness -- } & \multirow{2}{*}{$\begin{array}{l}\text { Lines } \\
\text { X-Slope }\end{array}$} & \multirow{2}{*}{$\begin{array}{l}=256 \\
=3.5^{\circ}\end{array}$} & \multirow{2}{*}{$\begin{array}{l}\text { Excitation ampl. } \\
\text { Error range }\end{array}$} & \multirow{2}{*}{$\begin{array}{l}=0.22 \mathrm{~V} \\
=20 \mathrm{~V}\end{array}$} \\
\hline Area & $=629.9 \mathrm{pm}^{\wedge} 2$ & & & & \\
\hline $\mathrm{Sa}$ & $=90.669 \mathrm{~nm}$ & Y-Slope & $=2.5^{\circ}$ & -- Global -- & \\
\hline $\mathrm{Sq}$ & $=111.77 \mathrm{~nm}$ & Rotation & $=-14.2 f^{\circ}$ & Op. mode & $=$ Dynamic Force \\
\hline Sy & $=755.91 \mathrm{~nm}$ & X-Pos & $=0 \mathrm{fm}$ & Cantilever type & $=A C L A$ \\
\hline Sp & $=419.49 \mathrm{~nm}$ & Y-Pos & $=0 \mathrm{fm}$ & Head type & $=E Z 2-A F M$ \\
\hline Sv & $=-336.41 \mathrm{~nm}$ & Z-Plane & $=0 \mathrm{fm}$ & Scan head & $=10-07-239$. hed \\
\hline Sm & $=-3157.8 \mathrm{fm}$ & Overscan & $=5 \%$ & Software ver. & $=1-5-1-0$ \\
\hline \multicolumn{2}{|c|}{-- Line Roughness -- } & \multicolumn{2}{|c|}{ Const. Height-Mode= Disabled } & Firmware ver. & $=2-1-1-2$ \\
\hline $\mathrm{Ra}$ & $=71.963 \mathrm{~nm}$ & Date & $=09-08-2008$ & Controller S/N & $=023-06-252$ \\
\hline $\mathrm{Rq}$ & $=92.506 \mathrm{~nm}$ & Time & $=16: 27: 29$ & -- Module -- & \\
\hline Ry & $=455.44 \mathrm{~nm}$ & -- Feedback -- & & Controller Board & $=2$ \\
\hline Rp & $=227.5 \mathrm{~nm}$ & Set point & $=48 \%$ & AFM Basic Module & $=2$ \\
\hline $\mathrm{RV}$ & $=-227.94 \mathrm{~nm}$ & P-Gain & $=10000$ & \multicolumn{2}{|c|}{ AFM Dynamic Module $=2$} \\
\hline $\mathrm{Rm}$ & $=-97.188 \mathrm{pm}$ & I-Gain & $=1700$ & \multicolumn{2}{|c|}{ AFM Extension Modul $=1$} \\
\hline -- Scan -- & & Tip voltage & $=0 \mathrm{~V}$ & Video Module & $=0$ \\
\hline Image size & $=25 \mu \mathrm{m}$ & Feedback mode & $=$ Free & Signal Module S & $=0$ \\
\hline Scan direction & $=U p$ & Feedback algo. & $=$ Adaptive PI & Signal Module A & $=0$ \\
\hline Time/Line & $=0.4 \mathrm{~s}$ & Vibration freq. & $=181 \cdot 307 \mathrm{kHz}$ & Nanosurf Report & $=0$ \\
\hline Points & $=256$ & Vibration ampl. & $=0.7 \mathrm{~V}$ & Scripting Interface & $=0$ \\
\hline
\end{tabular}


N-675-4 after heat treatment

\section{Nanosurf Image Document}

File: Image 18
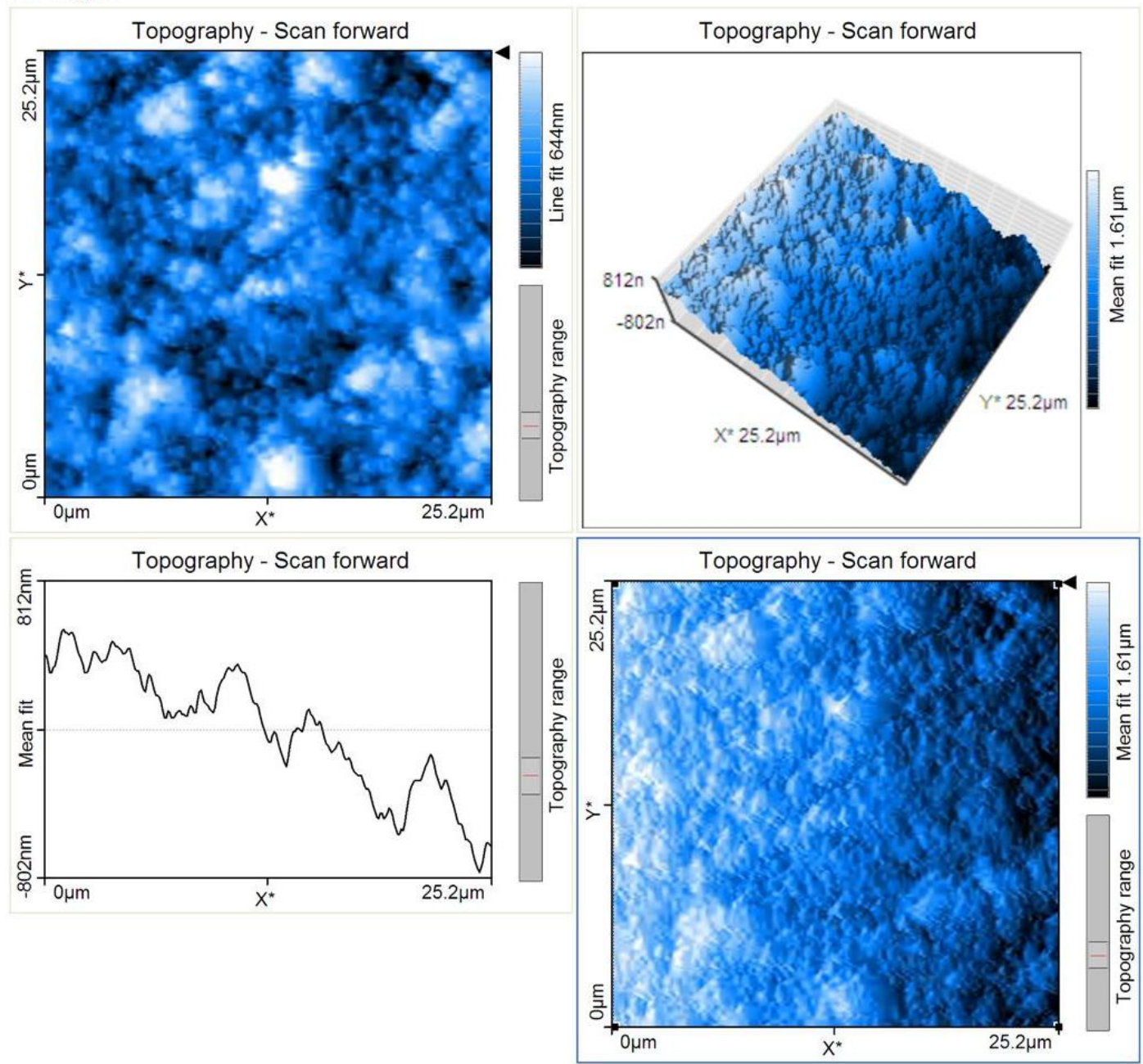

Parameter:

\begin{tabular}{|c|c|c|c|c|c|}
\hline \multicolumn{2}{|c|}{-- Area Roughness -- } & \multirow{2}{*}{$\begin{array}{l}\text { Lines } \\
\text { X-Slope }\end{array}$} & \multirow{2}{*}{$\begin{array}{l}=256 \\
=-500 \mathrm{~m}^{\circ}\end{array}$} & \multirow{2}{*}{$\begin{array}{l}\text { Excitation ampl. } \\
\text { Error range }\end{array}$} & \multirow{2}{*}{$\begin{array}{l}=0.24 \mathrm{~V} \\
=20 \mathrm{~V}\end{array}$} \\
\hline Area & $=638.1 \mathrm{pm}^{\wedge} 2$ & & & & \\
\hline $\mathrm{Sa}$ & $=291.96 \mathrm{~nm}$ & Y-Slope & $=-1.5^{\circ}$ & -- Global -- & \\
\hline $\mathrm{Sq}$ & $=339.79 \mathrm{~nm}$ & Rotation & $=90^{\circ}$ & Op. mode & $=$ Dynamic Force \\
\hline Sy & $=1628.6 \mathrm{~nm}$ & X-Pos & $=5.5 \mu \mathrm{m}$ & Cantilever type & $=A C L A$ \\
\hline $\mathrm{Sp}$ & $=808.09 \mathrm{~nm}$ & Y-Pos & $=-7.7 \mu \mathrm{m}$ & Head type & $=E Z 2-A F M$ \\
\hline Sv & $=-820.53 \mathrm{~nm}$ & Z-Plane & $=0 \mu \mathrm{m}$ & Scan head & $=10-07-239$. hed \\
\hline $\mathrm{Sm}$ & $=-9.4478 p m$ & Overscan & $=5 \%$ & Software ver. & $=1-5-1-0$ \\
\hline \multicolumn{2}{|c|}{-- Line Roughness -- } & \multicolumn{2}{|c|}{ Const. Height-Mode= Disabled } & Firmware ver. & $=2-1-1-2$ \\
\hline $\mathrm{Ra}$ & $=288.48 \mathrm{~nm}$ & Date & $=04-06-2008$ & Controller $\mathrm{S} / \mathrm{N}$ & $=023-06-252$ \\
\hline $\mathrm{Rq}$ & $=334.02 \mathrm{~nm}$ & Time & $=21: 39: 22$ & -- Module -- & \\
\hline Ry & $=1256.3 \mathrm{~nm}$ & -- Feedback -- & & Controller Board & $=2$ \\
\hline $\mathrm{Rp}$ & $=624.25 \mathrm{~nm}$ & Set point & $=44 \%$ & AFM Basic Module & $=2$ \\
\hline Rv & $=-632.01 \mathrm{~nm}$ & P-Gain & $=12000$ & \multicolumn{2}{|c|}{ AFM Dynamic Module $=2$} \\
\hline $\mathrm{Rm}$ & $=-22.237 \mathrm{pm}$ & 1-Gain & $=2100$ & \multicolumn{2}{|c|}{ AFM Extension Modul $\epsilon=1$} \\
\hline -- Scan -- & & Tip voltage & $=0 \mathrm{~V}$ & Video Module & $=0$ \\
\hline Image size & $=25 \mu \mathrm{m}$ & Feedback mode & $=$ Free & Signal Module S & $=0$ \\
\hline Scan direction & $=U p$ & Feedback algo. & = Adaptive PI & Signal Module A & $=0$ \\
\hline Time/Line & $=0.2 \mathrm{~s}$ & Vibration freq. & $=184.509 \mathrm{kHz}$ & Nanosurf Report & $=0$ \\
\hline Points & $=256$ & Vibration ampl. & $=0.7 \mathrm{~V}$ & Scripting Interface & $=0$ \\
\hline
\end{tabular}




\section{Nanosurf Image Document}

File: Image21

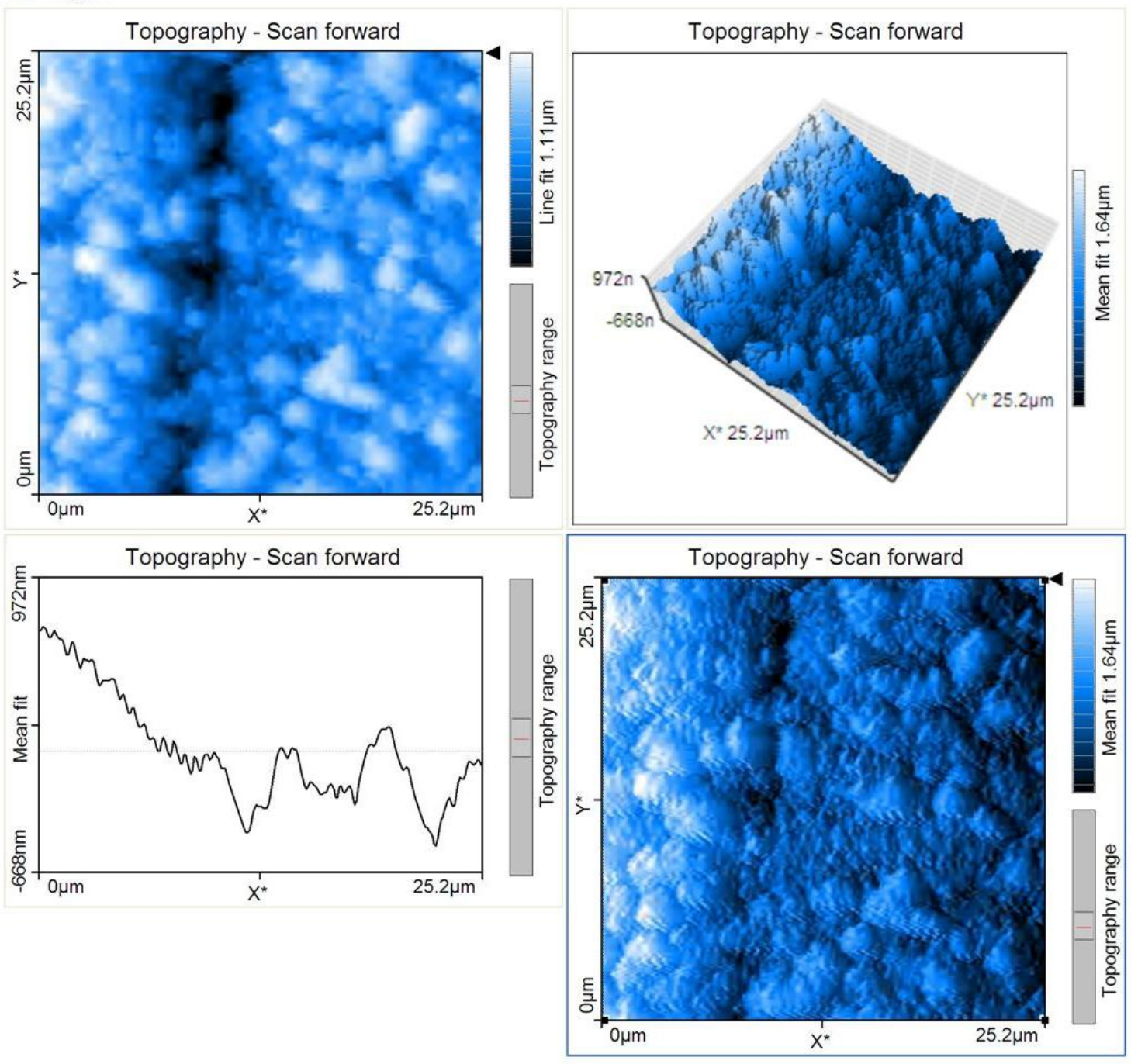

\section{Parameter:}

\begin{tabular}{|c|c|c|c|c|c|}
\hline \multicolumn{2}{|c|}{-- Area Roughness -- } & \multirow{2}{*}{$\begin{array}{l}\text { Lines } \\
\text { X-Slope }\end{array}$} & \multirow{2}{*}{$\begin{array}{l}=256 \\
=-500 \mathrm{~m}^{\circ}\end{array}$} & \multirow{2}{*}{$\begin{array}{l}\text { Excitation ampl. } \\
\text { Error range }\end{array}$} & \multirow{2}{*}{$\begin{array}{l}=0.24 \mathrm{~V} \\
=20 \mathrm{~V}\end{array}$} \\
\hline Area & $=638.1 \mathrm{pm} \mathrm{m}^{\wedge} 2$ & & & & \\
\hline Sa & $=245.69 \mathrm{~nm}$ & Y-Slope & $=-1.5^{\circ}$ & -- Global -- & \\
\hline $\mathrm{Sq}$ & $=305.19 \mathrm{~nm}$ & Rotation & $=90^{\circ}$ & Op. mode & $=$ Dynamic Force \\
\hline Sy & $=1757.2 \mathrm{~nm}$ & X-Pos & $=5.5 \mu \mathrm{m}$ & Cantilever type & $=A C L A$ \\
\hline Sp & $=1094.9 \mathrm{~nm}$ & Y-Pos & $=-7.7 \mu \mathrm{m}$ & Head type & $=E Z 2-A F M$ \\
\hline Sv & $=-662.39 \mathrm{~nm}$ & Z-Plane & $=0 \mu \mathrm{m}$ & Scan head & $=10-07-239$. hed \\
\hline $\mathrm{Sm}$ & $=2514.4 \mathrm{fm}$ & Overscan & $=5 \%$ & Software ver. & $=1-5-1-0$ \\
\hline \multicolumn{2}{|c|}{-- Line Roughness -- } & \multicolumn{2}{|c|}{ Const. Height-Mode= Disabled } & Firmware ver. & $=2-1-1-2$ \\
\hline $\mathrm{Ra}$ & $=294.93 \mathrm{~nm}$ & Date & $=04-06-2008$ & Controller $\mathrm{S} / \mathrm{N}$ & $=023-06-252$ \\
\hline $\mathrm{Rq}$ & $=344.88 \mathrm{~nm}$ & Time & $=21: 51: 10$ & -- Module -- & \\
\hline Ry & $=1280.1 \mathrm{~nm}$ & -- Feedback -- & & Controller Board & $=2$ \\
\hline $\mathrm{Rp}$ & $=695.25 \mathrm{~nm}$ & Set point & $=44 \%$ & AFM Basic Module & $=2$ \\
\hline Rv & $=-584.84 \mathrm{~nm}$ & P-Gain & $=12000$ & \multicolumn{2}{|c|}{ AFM Dynamic Module $=2$} \\
\hline $\mathrm{Rm}$ & $=37.066 \mathrm{pm}$ & I-Gain & $=2200$ & \multicolumn{2}{|c|}{ AFM Extension Modul $\epsilon=1$} \\
\hline -- Scan -- & & Tip voltage & $=0 \mathrm{~V}$ & Video Module & $=0$ \\
\hline Image size & $=25 \mu \mathrm{m}$ & Feedback mode & $=$ Free & Signal Module S & $=0$ \\
\hline Scan direction & $=U p$ & Feedback algo. & $=$ Adaptive $\mathrm{PI}$ & Signal Module A & $=0$ \\
\hline Time/Line & $=0.2 \mathrm{~s}$ & Vibration freq. & $=184.509 \mathrm{kHz}$ & Nanosurf Report & $=0$ \\
\hline Points & $=256$ & Vibration ampl. & $=0.7 \mathrm{~V}$ & Scripting Interface & $=0$ \\
\hline
\end{tabular}




\section{Nanosurf Image Document}

File: Image23

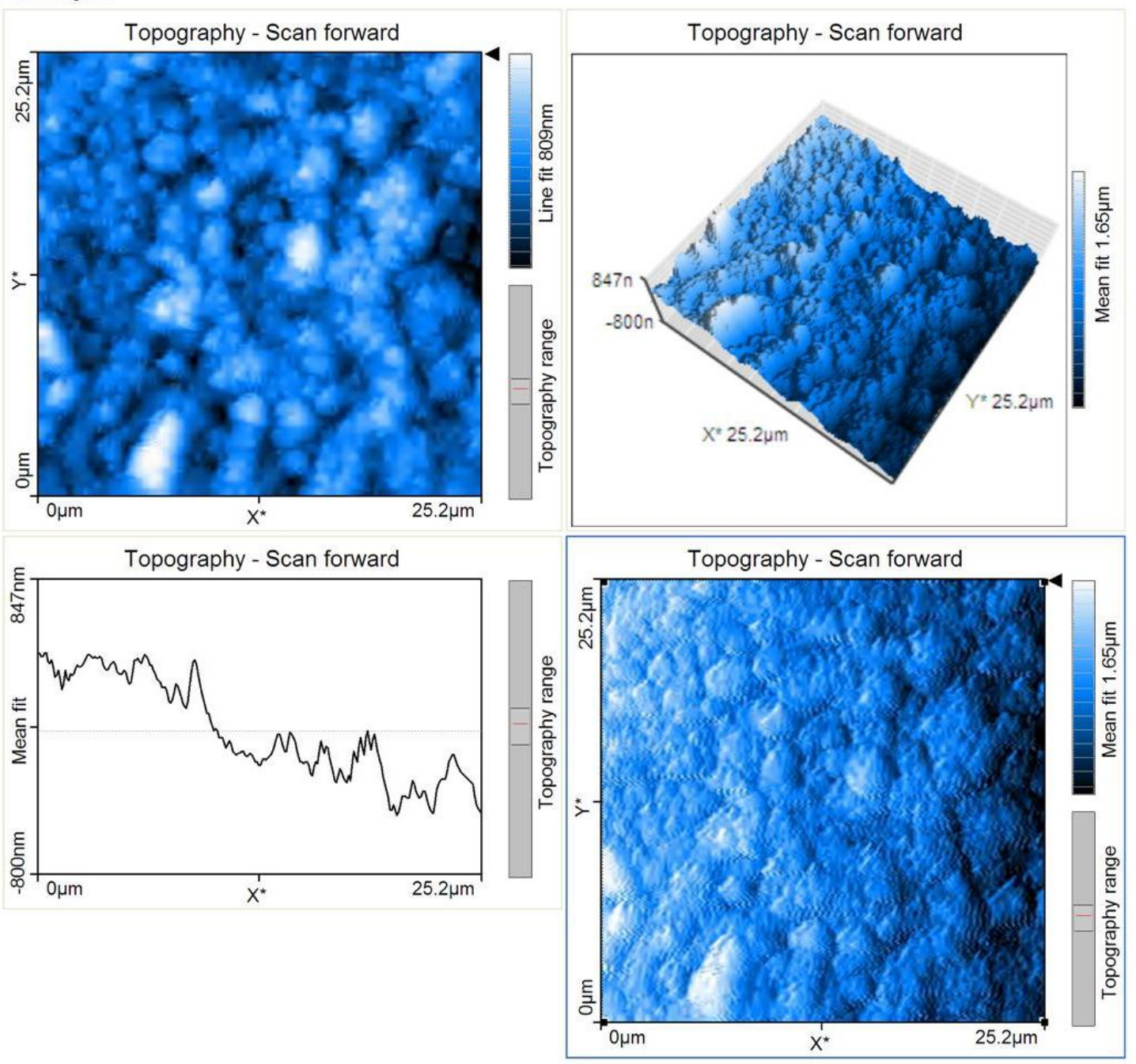

Parameter:

\begin{tabular}{|c|c|c|c|c|c|}
\hline \multicolumn{2}{|c|}{-- Area Roughness -- } & \multirow{2}{*}{$\begin{array}{l}\text { Lines } \\
\text { X-Slope }\end{array}$} & \multirow{2}{*}{$\begin{array}{l}=256 \\
=-500 \mathrm{~m}^{\circ}\end{array}$} & \multirow{2}{*}{$\begin{array}{l}\text { Excitation ampl. } \\
\text { Error range }\end{array}$} & \multirow{2}{*}{$\begin{array}{l}=0.23 \mathrm{~V} \\
=20 \mathrm{~V}\end{array}$} \\
\hline Area & $=638.1 \mathrm{pm} \wedge 2$ & & & & \\
\hline $\mathrm{Sa}$ & $=243.1 \mathrm{~nm}$ & Y-Slope & $=-1.5^{\circ}$ & -- Global -- & \\
\hline $\mathrm{Sq}$ & $=297.45 \mathrm{~nm}$ & Rotation & $=90^{\circ}$ & Op. mode & $=$ Dynamic Force \\
\hline Sy & $=1750.3 \mathrm{~nm}$ & X-Pos & $=5.5 \mu \mathrm{m}$ & Cantilever type & $=A C L A$ \\
\hline Sp & $=974.03 \mathrm{~nm}$ & Y-Pos & $=-7.7 \mu \mathrm{m}$ & Head type & $=E Z 2-A F M$ \\
\hline Sv & $=-776.25 \mathrm{~nm}$ & Z-Plane & $=0 \mu \mathrm{m}$ & Scan head & $=10-07-239$. hed \\
\hline Sm & $=204.74 \mathrm{pm}$ & Overscan & $=5 \%$ & Software ver. & $=1-5-1-0$ \\
\hline \multicolumn{2}{|c|}{-- Line Roughness -- } & \multicolumn{2}{|c|}{ Const. Height-Mod $\epsilon=$ Disabled } & Firmware ver. & $=2-1-1-2$ \\
\hline $\mathrm{Ra}$ & $=197.08 \mathrm{~nm}$ & Date & $=04-06-2008$ & Controller $\mathrm{S} / \mathrm{N}$ & $=023-06-252$ \\
\hline $\mathrm{Rq}$ & $=255.02 \mathrm{~nm}$ & Time & $=22: 04: 32$ & -- Module -- & \\
\hline Ry & $=1171.3 \mathrm{~nm}$ & -- Feedback -- & & Controller Board & $=2$ \\
\hline $\mathrm{Rp}$ & $=396.14 \mathrm{~nm}$ & Set point & $=44 \%$ & AFM Basic Module & $=2$ \\
\hline Rv & $=-775.14 \mathrm{~nm}$ & P-Gain & $=12000$ & \multicolumn{2}{|c|}{ AFM Dynamic Module $=2$} \\
\hline $\mathrm{Rm}$ & $=155.67 \mathrm{pm}$ & I-Gain & $=2000$ & \multicolumn{2}{|c|}{ AFM Extension Modul $\epsilon=1$} \\
\hline -- Scan -- & & Tip voltage & $=0 \mathrm{~V}$ & Video Module & $=0$ \\
\hline Image size & $=25 \mu \mathrm{m}$ & Feedback mode & $=$ Free & Signal Module S & $=0$ \\
\hline Scan direction & $=U p$ & Feedback algo. & $=$ Adaptive PI & Signal Module A & $=0$ \\
\hline Time/Line & $=0.3 \mathrm{~s}$ & Vibration freq. & $=184.509 \mathrm{kHz}$ & Nanosurf Report & $=0$ \\
\hline Points & $=256$ & Vibration ampl. & $=0.7 \mathrm{~V}$ & Scripting Interface & $=0$ \\
\hline
\end{tabular}




\section{N-675-4 after CP}

\section{Nanosurf Image Document}

File: Image1
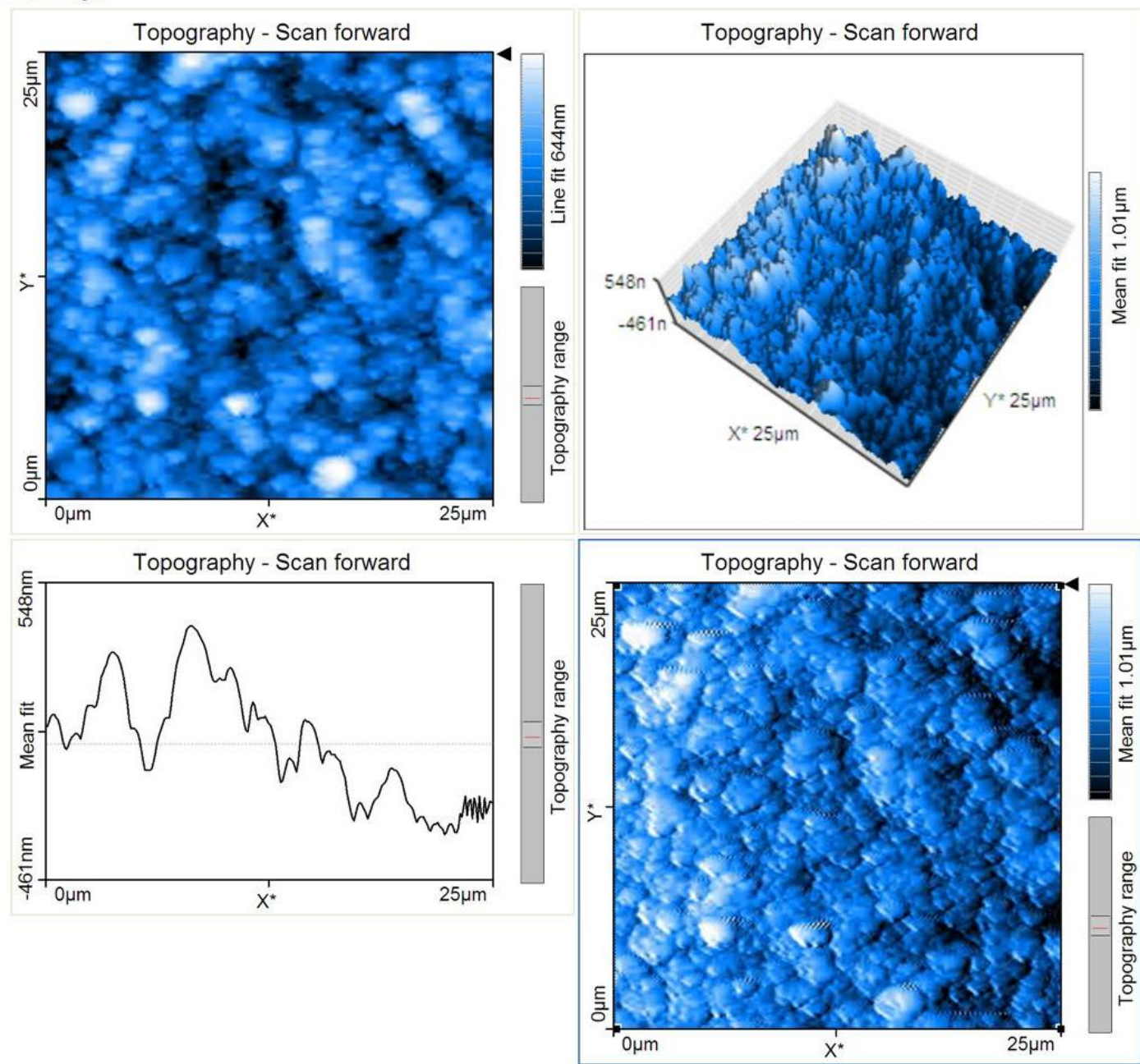

Parameter

\begin{tabular}{|c|c|c|c|c|c|}
\hline \multicolumn{2}{|c|}{-- Area Roughness -- } & \multirow{2}{*}{$\begin{array}{l}\text { Lines } \\
\text { X-Slope }\end{array}$} & \multirow{2}{*}{$\begin{array}{l}=256 \\
=1.5^{\circ}\end{array}$} & \multirow{2}{*}{$\begin{array}{l}\text { Excitation ampl. } \\
\text { Error range }\end{array}$} & \multirow{2}{*}{$\begin{array}{l}=0.35 \mathrm{~V} \\
=20 \mathrm{~V}\end{array}$} \\
\hline Area & $=629.9 \mathrm{pm}^{\wedge} 2$ & & & & \\
\hline $\mathrm{Sa}$ & $=130.04 \mathrm{~nm}$ & Y-Slope & $=1^{\circ}$ & -- Global -- & \\
\hline $\mathrm{Sq}$ & $=161.41 \mathrm{~nm}$ & Rotation & $=-14.2 f^{\circ}$ & Op. mode & = Dynamic Force \\
\hline Sy & $=1125.3 \mathrm{~nm}$ & X-Pos & $=0 \mathrm{fm}$ & Cantilever type & $=A C L A$ \\
\hline $\mathrm{Sp}$ & $=587.75 \mathrm{~nm}$ & Y-Pos & $=0 \mathrm{fm}$ & Head type & $=\mathrm{EZ2}-\mathrm{AFM}$ \\
\hline Sv & $=-537.57 \mathrm{~nm}$ & Z-Plane & $=0 \mathrm{fm}$ & Scan head & $=10-07-239 . \mathrm{hed}$ \\
\hline $\mathrm{Sm}$ & $=168.16 \mathrm{pm}$ & Overscan & $=5 \%$ & Software ver. & $=1-5-1-0$ \\
\hline \multicolumn{2}{|c|}{-- Line Roughness -- } & \multicolumn{2}{|c|}{ Const. Height-Mode= Disabled } & Firmware ver. & $=2-1-1-2$ \\
\hline $\mathrm{Ra}$ & $=116.97 \mathrm{~nm}$ & Date & $=09-08-2008$ & Controller S/N & $=023-06-252$ \\
\hline $\mathrm{Rq}$ & $=139.83 \mathrm{~nm}$ & Time & $=15: 21: 58$ & -- Module -- & \\
\hline Ry & $=598.61 \mathrm{~nm}$ & -- Feedback -- & & Controller Board & $=2$ \\
\hline $\mathrm{Rp}$ & $=351.77 \mathrm{~nm}$ & Set point & $=50 \%$ & AFM Basic Module & $=2$ \\
\hline $\mathrm{Rv}$ & $=-246.84 \mathrm{~nm}$ & P-Gain & $=10000$ & \multicolumn{2}{|c|}{ AFM Dynamic Module $=2$} \\
\hline $\mathrm{Rm}$ & $=250.39 \mathrm{pm}$ & I-Gain & $=1500$ & \multicolumn{2}{|c|}{ AFM Extension Modul $\epsilon=1$} \\
\hline -- Scan -- & & Tip voltage & $=0 \mathrm{~V}$ & Video Module & $=0$ \\
\hline Image size & $=25 \mu \mathrm{m}$ & Feedback mode & $=$ Free & Signal Module S & $=0$ \\
\hline Scan direction & $=U p$ & Feedback algo. & = Adaptive PI & Signal Module A & $=0$ \\
\hline Time/Line & $=0.4 \mathrm{~s}$ & Vibration freq. & $=181.197 \mathrm{kHz}$ & Nanosurf Report & $=0$ \\
\hline Points & $=256$ & Vibration ampl. & $=0.7 \mathrm{~V}$ & Scripting Interface & $=0$ \\
\hline
\end{tabular}




\section{Nanosurf Image Document}

File: Image2

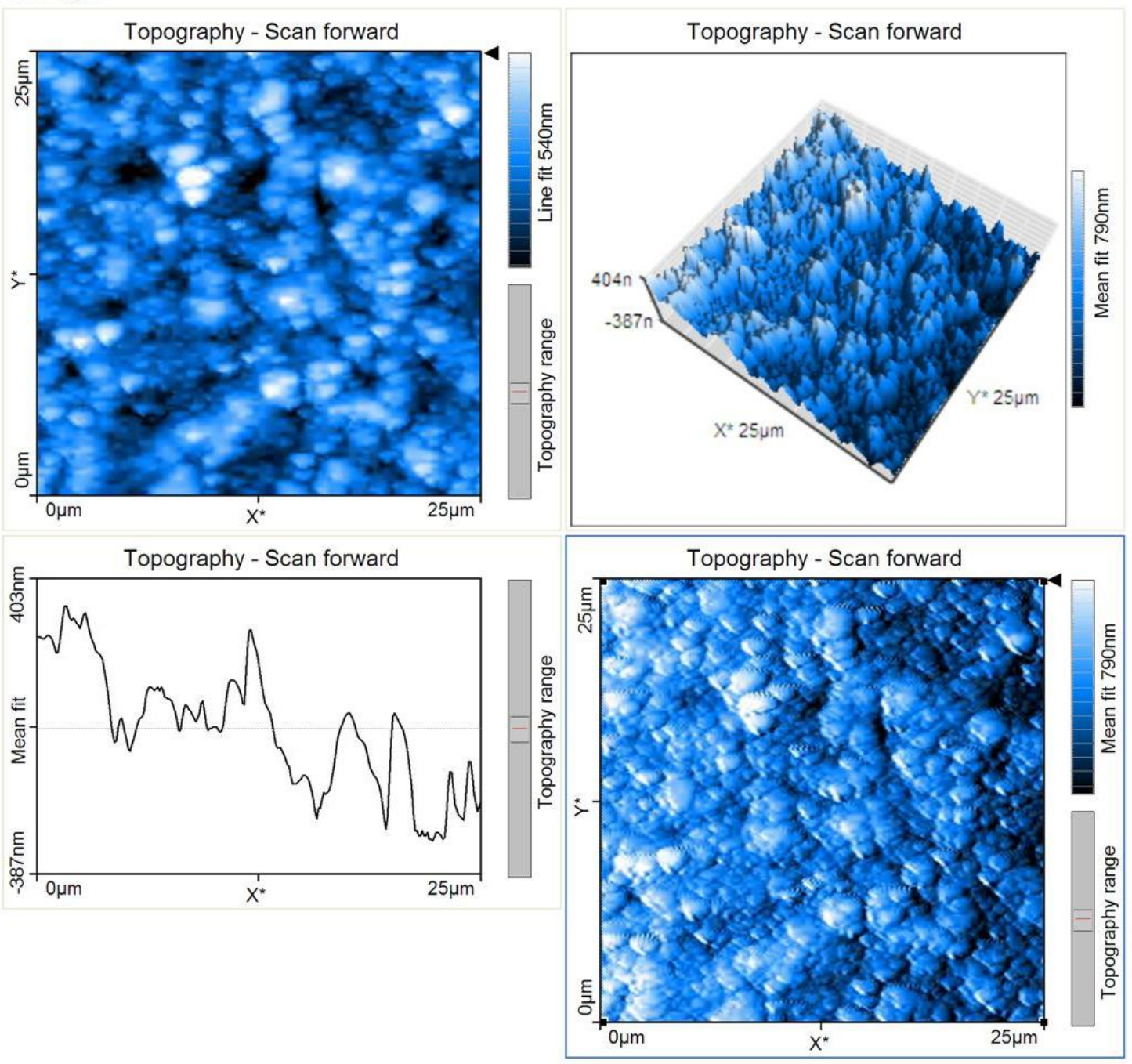

Parameter:

\begin{tabular}{|c|c|c|c|c|c|}
\hline \multicolumn{2}{|c|}{-- Area Roughness -- } & \multirow{2}{*}{$\begin{array}{l}\text { Lines } \\
\text { X-Slope }\end{array}$} & \multirow{2}{*}{$\begin{array}{l}=256 \\
=1.5^{\circ}\end{array}$} & \multirow{2}{*}{$\begin{array}{l}\text { Excitation ampl. } \\
\text { Error range }\end{array}$} & \multirow{2}{*}{$\begin{array}{l}=0.25 \mathrm{~V} \\
=20 \mathrm{~V}\end{array}$} \\
\hline Area & $=629.9 \mathrm{pm}^{\wedge} 2$ & & & & \\
\hline Sa & $=113.8 \mathrm{~nm}$ & Y-Slope & $=1^{\circ}$ & -- Global -- & \\
\hline $\mathrm{Sq}$ & $=140.69 \mathrm{~nm}$ & Rotation & $=-14.2 f^{\circ}$ & Op. mode & $=$ Dynamic Force \\
\hline Sy & $=961.91 \mathrm{~nm}$ & X-Pos & $=0 \mathrm{fm}$ & Cantilever type & $=A C L A$ \\
\hline Sp & $=576.79 \mathrm{~nm}$ & Y-Pos & $=0 \mathrm{fm}$ & Head type & $=E Z 2-A F M$ \\
\hline Sv & $=-385.12 \mathrm{~nm}$ & Z-Plane & $=0 \mathrm{fm}$ & Scan head & $=10-07-239 \cdot$ hed \\
\hline Sm & $=85.538 \mathrm{pm}$ & Overscan & $=5 \%$ & Software ver. & $=1-5-1-0$ \\
\hline \multicolumn{2}{|c|}{-- Line Roughness -- } & \multicolumn{2}{|c|}{ Const. Height-Mode= Disabled } & Firmware ver. & $=2-1-1-2$ \\
\hline $\mathrm{Ra}$ & $=97.317 \mathrm{~nm}$ & Date & $=09-08-2008$ & Controller S/N & $=023-06-252$ \\
\hline $\mathrm{Rq}$ & $=117.79 \mathrm{~nm}$ & Time & $=15: 28: 05$ & -- Module -- & \\
\hline Ry & $=550.11 \mathrm{~nm}$ & -- Feedback -- & & Controller Board & $=2$ \\
\hline Rp & $=283.49 \mathrm{~nm}$ & Set point & $=50 \%$ & AFM Basic Module & $=2$ \\
\hline Rv & $=-266.62 n m$ & P-Gain & $=10000$ & \multicolumn{2}{|c|}{ AFM Dynamic Module $=2$} \\
\hline $\mathrm{Rm}$ & $=825.25 \mathrm{fm}$ & |-Gain & $=1500$ & \multicolumn{2}{|c|}{ AFM Extension Module $=1$} \\
\hline -- Scan -- & & Tip voltage & $=0 \mathrm{~V}$ & Video Module & $=0$ \\
\hline Image size & $=25 \mu \mathrm{m}$ & Feedback mode & $=$ Free & Signal Module S & $=0$ \\
\hline Scan direction & $=U p$ & Feedback algo. & = Adaptive $\mathrm{PI}$ & Signal Module A & $=0$ \\
\hline Time/Line & $=0.4 \mathrm{~s}$ & Vibration freq. & $=181.247 \mathrm{kHz}$ & Nanosurf Report & $=0$ \\
\hline Points & $=256$ & Vibration ampl. & $=0.7 \mathrm{~V}$ & Scripting Interface & $=0$ \\
\hline
\end{tabular}




\section{Nanosurf Image Document}

File: Image3
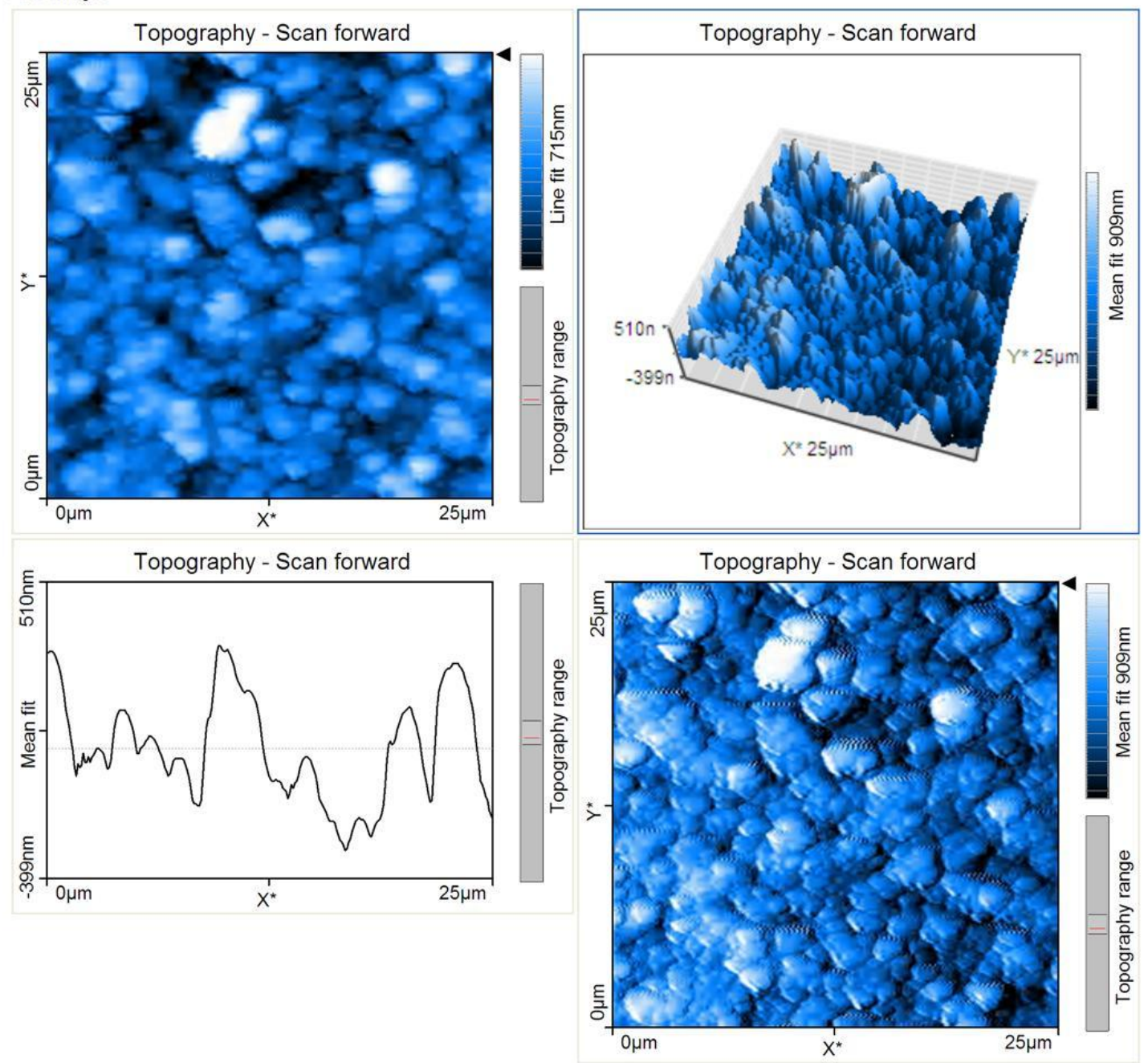

Parameter:

$\begin{array}{ll}- \text { - Area Roughness -- } \\ \text { Area } & =629.9 \mathrm{pm}^{\wedge} 2 \\ \mathrm{Sa} & =123.35 \mathrm{~nm} \\ \mathrm{Sq} & =155.83 \mathrm{~nm} \\ \mathrm{Sy} & =1090.5 \mathrm{~nm} \\ \mathrm{Sp} & =672.09 \mathrm{~nm} \\ \mathrm{~Sv} & =-418.44 \mathrm{~nm} \\ \mathrm{Sm} & =150.01 \mathrm{pm} \\ - \text { - Line Roughness -- } & \\ \mathrm{Ra} & =81.927 \mathrm{~nm} \\ \mathrm{Rq} & =99.046 \mathrm{~nm} \\ \mathrm{Ry} & =425.29 \mathrm{~nm} \\ \mathrm{Rp} & =215.27 \mathrm{~nm} \\ \mathrm{Rv} & =-210.02 \mathrm{~nm} \\ \mathrm{Rm} & =112.02 \mathrm{pm} \\ - \text { Scan -- } & \\ \text { Image size } & =25 \mu \mathrm{m} \\ \text { Scan direction } & =U p \\ \text { Time/Line } & =0.4 \mathrm{~s} \\ \text { Points } & =256\end{array}$

$\begin{array}{lll}\text { Lines } & =256 \\ \text { X-Slope } & =1.5^{\circ} \\ \text { Y-Slope } & =1^{\circ} \\ \text { Rotation } & =-14.2 \mathrm{f}^{\circ} \\ \text { X-Pos } & =0 \mathrm{fm} \\ \text { Y-Pos } & =0 \mathrm{fm} \\ \text { Z-Plane } & =0 \mathrm{fm} \\ \text { Overscan } & =5 \% \\ \text { Const.Height-Mode } & =\text { Disabled } \\ \text { Date } & & =09-08-2008 \\ \text { Time } & & =15: 35: 43 \\ \text { - Feedback -- } & & \\ \text { Set point } & & =50 \% \\ \text { P-Gain } & =10000 \\ \text { I-Gain } & =1500 \\ \text { Tip voltage } & =0 \mathrm{~V} \\ \text { Feedback mode } & =\text { Free } \\ \text { Feedback algo. } & =\text { Adaptive PI } \\ \text { Vibration freq. } & =181.237 \mathrm{kHz} \\ \text { Vibration ampl. } & =0.7 \mathrm{~V}\end{array}$

$\begin{array}{ll}\text { Excitation ampl. } & =0.24 \mathrm{~V} \\ \text { Error range } & =20 \mathrm{~V} \\ - \text { - Global -- } & \\ \text { Op. mode } & =\text { Dynamic Force } \\ \text { Cantilever type } & =\text { ACLA } \\ \text { Head type } & =\text { EZ2-AFM } \\ \text { Scan head } & =10-07-239 . \text { hed } \\ \text { Software ver. } & =1-5-1-0 \\ \text { Firmware ver. } & =2-1-1-2 \\ \text { Controller S/N } & =023-06-252 \\ \text { - Module -- } & \\ \text { Controller Board } & =2 \\ \text { AFM Basic Module } & =2 \\ \text { AFM Dynamic Module } & =2 \\ \text { AFM Extension Module } & =1 \\ \text { Video Module } & =0 \\ \text { Signal Module S } & =0 \\ \text { Signal Module A } & =0 \\ \text { Nanosurf Report } & =0 \\ \text { Scripting Interface } & =0\end{array}$


N-675-8 after heat treatment

\section{Nanosurf Image Document}

File: Image10
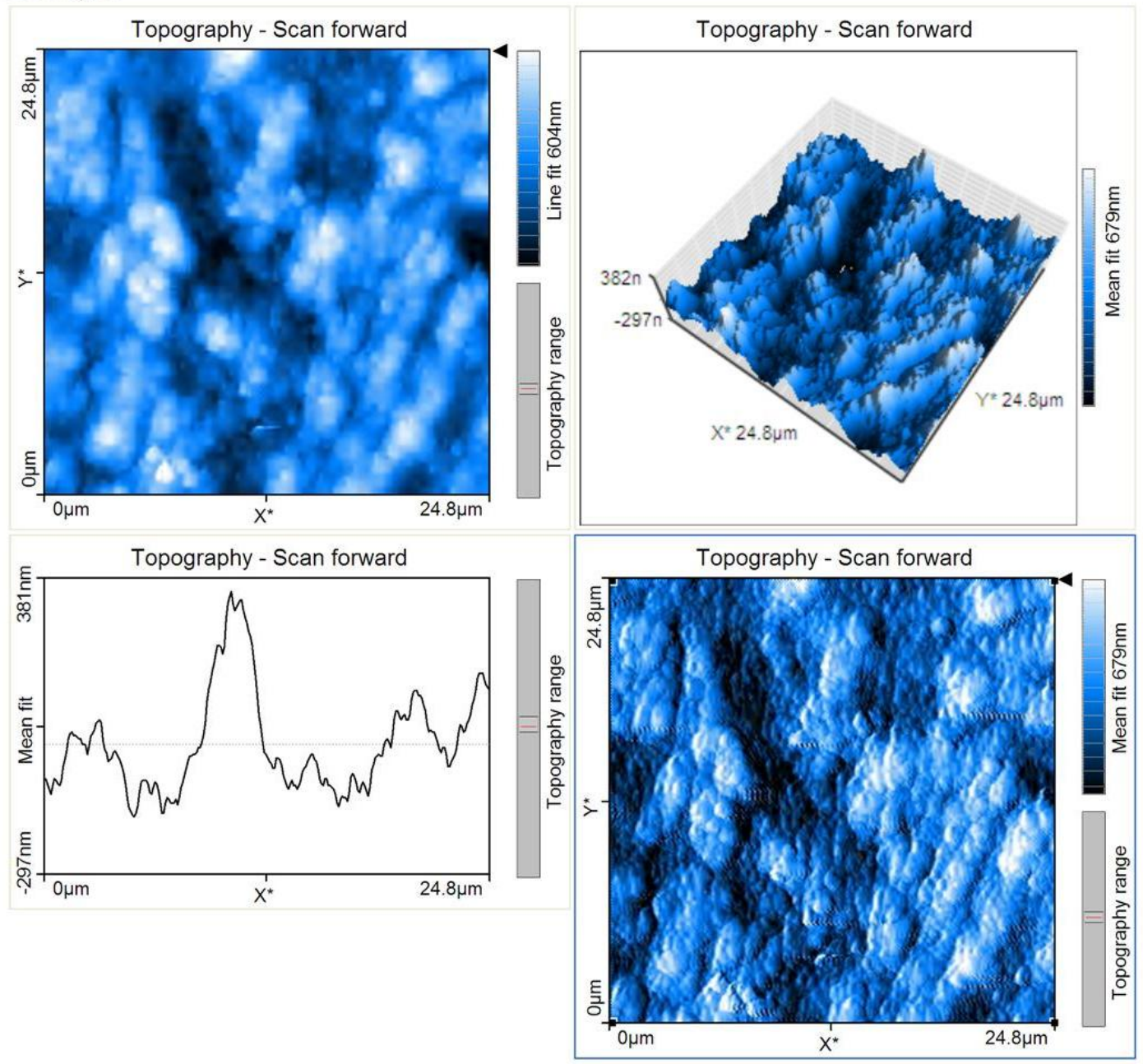

Parameter:

$\begin{array}{ll}- \text { - Area Roughness -- } \\ \text { Area } & =618 \mathrm{pm}^{\wedge} 2 \\ \text { Sa } & =104.1 \mathrm{~nm} \\ \text { Sq } & =125.12 \mathrm{~nm} \\ \text { Sy } & =750.85 \mathrm{~nm} \\ \text { Sp } & =429.61 \mathrm{~nm} \\ \text { Sv } & =-321.23 \mathrm{~nm} \\ \text { Sm } & =210.7 \mathrm{pm} \\ \text { - Line Roughness -- } & \\ \text { Ra } & =120.51 \mathrm{~nm} \\ \text { Rq } & =140.44 \mathrm{~nm} \\ \text { Ry } & =532.19 \mathrm{~nm} \\ \text { Rp } & =239.69 \mathrm{~nm} \\ \text { Rv } & =-292.51 \mathrm{~nm} \\ \text { Rm } & =158.96 \mathrm{pm} \\ - \text { Scan -- } & \\ \text { Image size } & =25 \mu \mathrm{m} \\ \text { Scan direction } & =U p \\ \text { Time/Line } & =0.4 \mathrm{~s} \\ \text { Points } & =256\end{array}$

$\begin{array}{lll}\text { Lines } & =256 \\ \text { X-Slope } & =4.5^{\circ} \\ \text { Y-Slope } & =-0.444 \mathrm{f}^{\circ} \\ \text { Rotation } & =90^{\circ} \\ \text { X-Pos } & =0 \mathrm{~m} \\ \text { Y-Pos } & =0 \mathrm{~m} \\ \text { Z-Plane } & =0 \mathrm{~m} \\ \text { Overscan } & =5 \% \\ \text { Const.Height-Mode } & =\text { Disabled } \\ \text { Date } & & =01-08-2008 \\ \text { Time } & =15: 30: 05 \\ \text {--Feedback -- } & \\ \text { Set point } & =50 \% \\ \text { P-Gain } & =10000 \\ \text { I-Gain } & =1800 \\ \text { Tip voltage } & =0 \mathrm{~V} \\ \text { Feedback mode } & =\text { Free } \\ \text { Feedback algo. } & =\text { Adaptive PI } \\ \text { Vibration freq. } & =181.337 \mathrm{kHz} \\ \text { Vibration ampl. } & =0.7 \mathrm{~V}\end{array}$

$\begin{array}{ll}\text { Excitation ampl. } & =0.24 \mathrm{~V} \\ \text { Error range } & =20 \mathrm{~V} \\ - \text { - Global -- } & \\ \text { Op. mode } & =\text { Dynamic Force } \\ \text { Cantilever type } & =\text { ACLA } \\ \text { Head type } & =\text { EZ2-AFM } \\ \text { Scan head } & =10-07-239 . \text { hed } \\ \text { Software ver. } & =1-5-1-0 \\ \text { Firmware ver. } & =2-1-1-2 \\ \text { Controller S/N } & =023-06-252 \\ \text { - Module -- } & \\ \text { Controller Board } & =2 \\ \text { AFM Basic Module } & =2 \\ \text { AFM Dynamic Module } & =2 \\ \text { AFM Extension Module } & =1 \\ \text { Video Module } & =0 \\ \text { Signal Module S } & =0 \\ \text { Signal Module A } & =0 \\ \text { Nanosurf Report } & =0 \\ \text { Scripting Interface } & =0\end{array}$




\section{Nanosurf Image Document}

File: Image 16

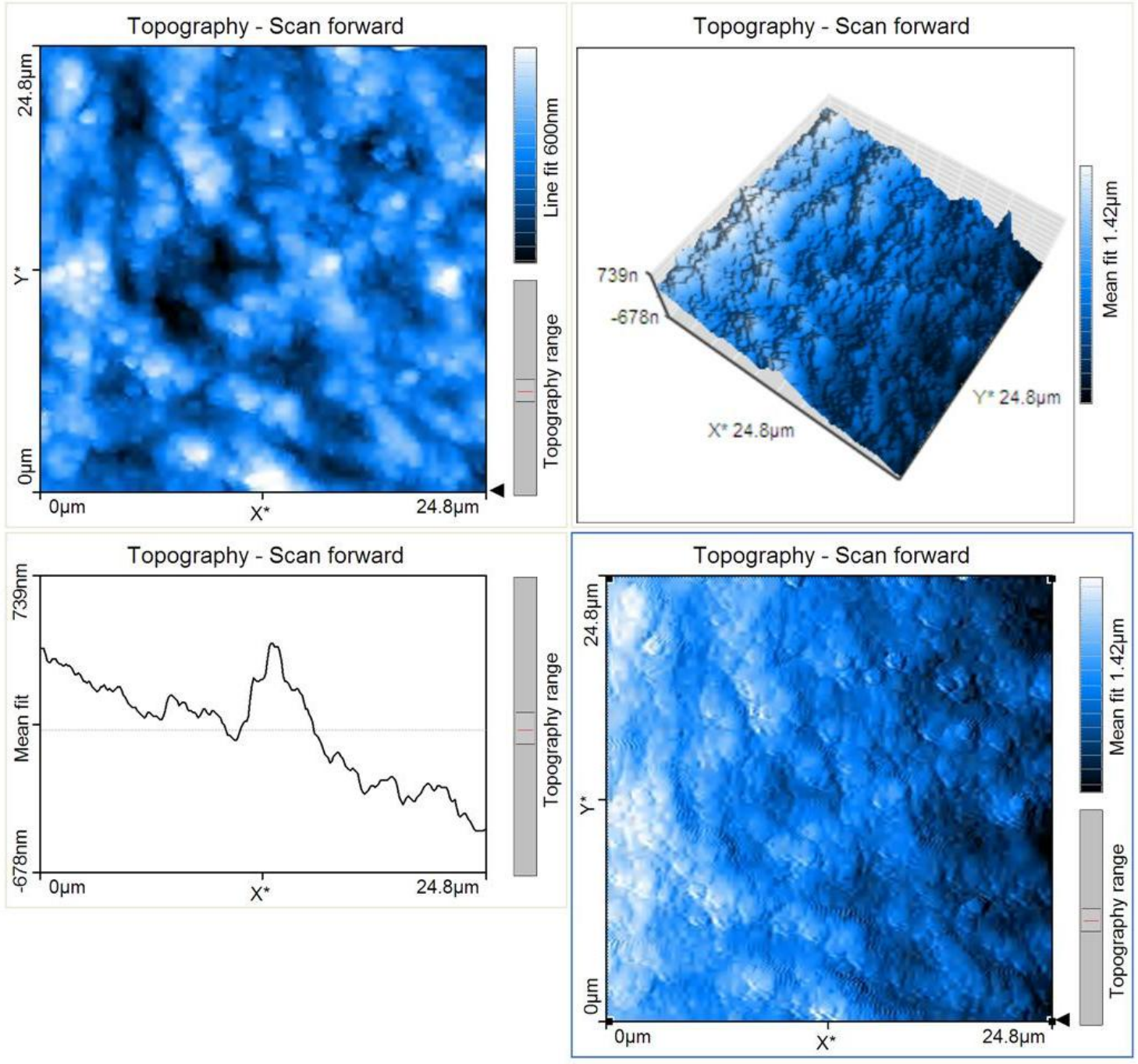

Parameter:

\begin{tabular}{|c|c|c|c|c|c|}
\hline \multicolumn{2}{|c|}{-- Area Roughness -- } & \multirow{2}{*}{$\begin{array}{l}\text { Lines } \\
\text { X-Slope }\end{array}$} & \multirow{2}{*}{$\begin{array}{l}=256 \\
=1.5^{\circ}\end{array}$} & \multirow{2}{*}{$\begin{array}{l}\text { Excitation ampl. } \\
\text { Error range }\end{array}$} & \multirow{2}{*}{$\begin{array}{l}=0.23 \mathrm{~V} \\
=20 \mathrm{~V}\end{array}$} \\
\hline Area & $=618 \mathrm{pm}^{\wedge} 2$ & & & & \\
\hline Sa & $=229.83 \mathrm{~nm}$ & Y-Slope & $=-2.5^{\circ}$ & -- Global -- & \\
\hline $\mathrm{Sq}$ & $=276.71 \mathrm{~nm}$ & Rotation & $=-14.2 f^{\circ}$ & Op. mode & $=$ Dynamic Force \\
\hline Sy & $=1416.1 \mathrm{~nm}$ & X-Pos & $=0 \mathrm{fm}$ & Cantilever type & $=A C L A$ \\
\hline Sp & $=725.44 \mathrm{~nm}$ & Y-Pos & $=0 \mathrm{fm}$ & Head type & $=E Z 2-A F M$ \\
\hline Sv & $=-690.65 \mathrm{~nm}$ & Z-Plane & $=0 \mathrm{fm}$ & Scan head & $=10-07-239$. hed \\
\hline $\mathrm{Sm}$ & $=71.465 \mathrm{pm}$ & Overscan & $=5 \%$ & Software ver. & $=1-5-1-0$ \\
\hline \multicolumn{2}{|c|}{-- Line Roughness -- } & \multicolumn{2}{|c|}{ Const. Height-Mod $\epsilon=$ Disabled } & Firmware ver. & $=2-1-1-2$ \\
\hline $\mathrm{Ra}$ & $=215.48 \mathrm{~nm}$ & Date & $=01-08-2008$ & Controller S/N & $=023-06-252$ \\
\hline $\mathrm{Rq}$ & $=274.64 \mathrm{~nm}$ & Time & $=15: 59: 51$ & -- Module -- & \\
\hline Ry & $=1007.9 \mathrm{~nm}$ & -- Feedback -- & & Controller Board & $=2$ \\
\hline $\mathrm{Rp}$ & $=652.63 \mathrm{~nm}$ & Set point & $=50 \%$ & AFM Basic Module & $=2$ \\
\hline Rv & $=-355.24 \mathrm{~nm}$ & P-Gain & $=10000$ & AFM Dynamic Module & $=2$ \\
\hline $\mathrm{Rm}$ & $=272.63 \mathrm{pm}$ & I-Gain & $=1900$ & AFM Extension Modul & $\epsilon=1$ \\
\hline \multicolumn{2}{|l|}{-- Scan -- } & Tip voltage & $=0 \mathrm{~V}$ & Video Module & $=0$ \\
\hline Image size & $=25 \mu \mathrm{m}$ & Feedback mode & $=$ Free & Signal Module S & $=0$ \\
\hline Scan direction & $=$ Down & Feedback algo. & $=$ Adaptive PI & Signal Module A & $=0$ \\
\hline Time/Line & $=0.4 \mathrm{~s}$ & Vibration freq. & $=181.337 \mathrm{kHz}$ & Nanosurf Report & $=0$ \\
\hline Points & $=256$ & Vibration ampl. & $=0.7 \mathrm{~V}$ & Scripting Interface & $=0$ \\
\hline
\end{tabular}




\section{Nanosurf Image Document}

File: Image19
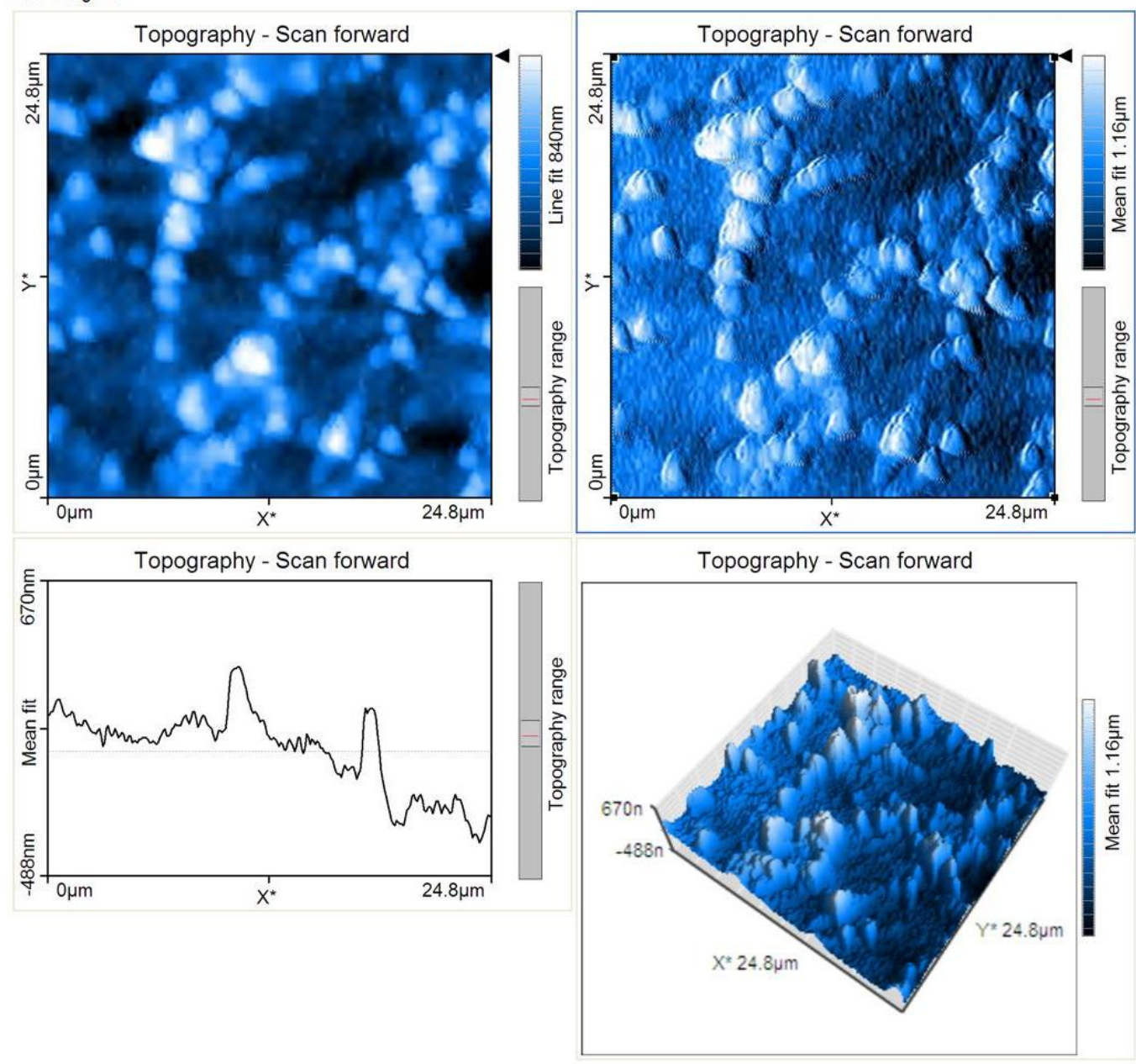

Parameter:

-- Area Roughness --

Area $\quad=618 \mathrm{pm}^{\wedge} 2$

$\mathrm{Sa} \quad \quad=156.85 \mathrm{~nm}$

$=196.99 \mathrm{~nm}$

$=1235.6 \mathrm{~nm}$

$=766.98 \mathrm{~nm}$

$=-468.62 \mathrm{~nm}$

$=-4.8695 \mathrm{pm}$

Sm Line Roughness --

$\mathrm{Ra} \quad=168.47 \mathrm{~nm}$

$\mathrm{Rq} \quad=208.6 \mathrm{~nm}$

Ry $\quad=852.05 \mathrm{~nm}$

$\mathrm{Rp} \quad=413.26 \mathrm{~nm}$

$\mathrm{Rv} \quad=-438.79 \mathrm{~nm}$

$\mathrm{Rm} \quad=-95.541 \mathrm{pm}$

-- Scan --

Image size

Scan direction

$=25 \mu \mathrm{m}$

$=U \mathrm{p}$

Time/Line

$=0.6 \mathrm{~s}$

Points

$\begin{array}{lll}\text { Lines } & =256 \\ \text { X-Slope } & =3^{\circ} \\ \text { Y-Slope } & =-1^{\circ} \\ \text { Rotation } & =90^{\circ} \\ \text { X-Pos } & =0 \mathrm{~m} \\ \text { Y-Pos } & =0 \mathrm{~m} \\ \text { Z-Plane } & =0 \mathrm{~m} \\ \text { Overscan } & =5 \% \\ \text { Const.Height-Mode } & =\text { Disabled } \\ \text { Date } & & =01-08-2008 \\ \text { Time } & =16: 32: 38 \\ \text { - Feedback -- } & & =50 \% \\ \text { Set point } & =10000 \\ \text { P-Gain } & =1600 \\ \text { I-Gain } & =0.1 \mathrm{~V} \\ \text { Tip voltage } & =\text { Free } \\ \text { Feedback mode } & \text { Feedback algo. } & =\text { Adaptive PI } \\ \text { Vibration freq. } & =181.337 \mathrm{kHz} \\ \text { Vibration ampl. } & =0.7 \mathrm{~V}\end{array}$

$\begin{array}{ll}\text { Excitation ampl. } & =0.23 \mathrm{~V} \\ \text { Error range } & =20 \mathrm{~V} \\ - \text { - Global -- } & \\ \text { Op. mode } & =\text { Dynamic Force } \\ \text { Cantilever type } & =\text { ACLA } \\ \text { Head type } & =\text { EZ2-AFM } \\ \text { Scan head } & =10-07-239 . \text { hed } \\ \text { Software ver. } & =1-5-1-0 \\ \text { Firmware ver. } & =2-1-1-2 \\ \text { Controller S/N } & =023-06-252 \\ \text { - Module -- } & \\ \text { Controller Board } & =2 \\ \text { AFM Basic Module } & =2 \\ \text { AFM Dynamic Module } & =2 \\ \text { AFM Extension Modul } & =1 \\ \text { Video Module } & =0 \\ \text { Signal Module S } & =0 \\ \text { Signal Module A } & =0 \\ \text { Nanosurf Report } & =0 \\ \text { Scripting Interface } & =0\end{array}$




\section{N-675-8 after CP}

\section{Nanosurf Image Document}

File: Image1
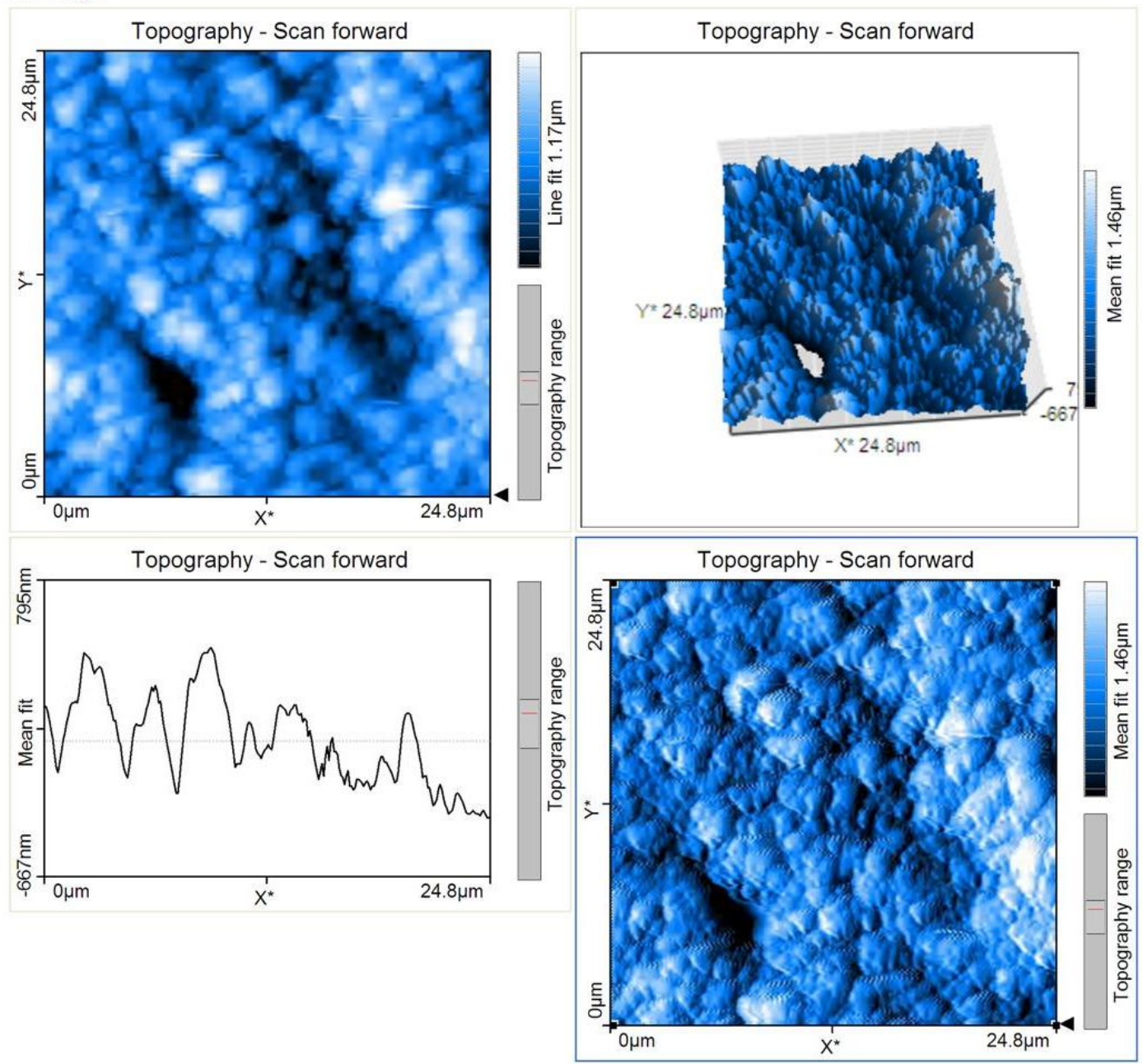

\section{Parameter:}

-- Area Roughness --

\begin{tabular}{|c|c|}
\hline Area & $=618 \mathrm{pm}^{\wedge} 2$ \\
\hline $\mathrm{Sa}$ & $=198.18 \mathrm{~nm}$ \\
\hline $\mathrm{Sq}$ & $=251.11 \mathrm{~nm}$ \\
\hline Sy & $=2181.3 \mathrm{~nm}$ \\
\hline$S p$ & $=949.36 \mathrm{~nm}$ \\
\hline Sv & $=-1231.9 n m$ \\
\hline $\mathrm{Sm}$ & $=211.36 \mathrm{pm}$ \\
\hline
\end{tabular}

-- Line Roughness --

$\begin{array}{ll}\mathrm{Ra} & =204.63 \mathrm{~nm} \\ \mathrm{Rq} & =249.16 \mathrm{~nm} \\ \mathrm{Ry} & =1012.7 \mathrm{~nm} \\ \mathrm{Rp} & =540.26 \mathrm{~nm} \\ \mathrm{Rv} & =-472.47 \mathrm{~nm} \\ \mathrm{Rm} & =262.74 \mathrm{pm} \\ - \text { Scan -- } & \\ \text { Image size } & =25 \mu \mathrm{m} \\ \text { Scan direction } & =\text { Down } \\ \text { Time/Line } & =0.4 \mathrm{~s} \\ \text { Points } & =256\end{array}$

$\begin{array}{lll}\text { Lines } & =256 \\ \text { X-Slope } & =3^{\circ} \\ \text { Y-Slope } & =-1.5^{\circ} \\ \text { Rotation } & =-0.888 \mathrm{f}^{\circ} \\ \text { X-Pos } & =2.2 \mu \mathrm{m} \\ \text { Y-Pos } & =-4.2 \mu \mathrm{m} \\ \text { Z-Plane } & =0 \mu \mathrm{m} \\ \text { Overscan } & =5 \% \\ \text { Const.Height-Mode } & =\text { Disabled } \\ \text { Date } & =08-08-2008 \\ \text { Time } & =17: 21: 50 \\ - \text {-Feedback -- } & \\ \text { Set point } & =48 \% \\ \text { P-Gain } & =10000 \\ \text { I-Gain } & =1500 \\ \text { Tip voltage } & =0 \mathrm{~V} \\ \text { Feedback mode } & =\text { Free } \\ \text { Feedback algo. } & =\text { Adaptive PI } \\ \text { Vibration freq. } & =181.347 \mathrm{kHz} \\ \text { Vibration ampl. } & =0.7 \mathrm{~V}\end{array}$

$\begin{array}{ll}\text { Excitation ampl. } & =0.25 \mathrm{~V} \\ \text { Error range } & =20 \mathrm{~V} \\ - \text { - Global -- } & \\ \text { Op. mode } & =\text { Dynamic Force } \\ \text { Cantilever type } & =\text { ACLA } \\ \text { Head type } & =\text { EZ2-AFM } \\ \text { Scan head } & =10-07-239 . \text { hed } \\ \text { Software ver. } & =1-5-1-0 \\ \text { Firmware ver. } & =2-1-1-2 \\ \text { Controller S/N } & =023-06-252 \\ - \text { - Module -- } & \\ \text { Controller Board } & =2 \\ \text { AFM Basic Module } & =2 \\ \text { AFM Dynamic Module } & =2 \\ \text { AFM Extension Module } & =1 \\ \text { Video Module } & =0 \\ \text { Signal Module S } & =0 \\ \text { Signal Module A } & =0 \\ \text { Nanosurf Report } & =0 \\ \text { Scripting Interface } & =0\end{array}$




\section{Nanosurf Image Document}

File: Image2
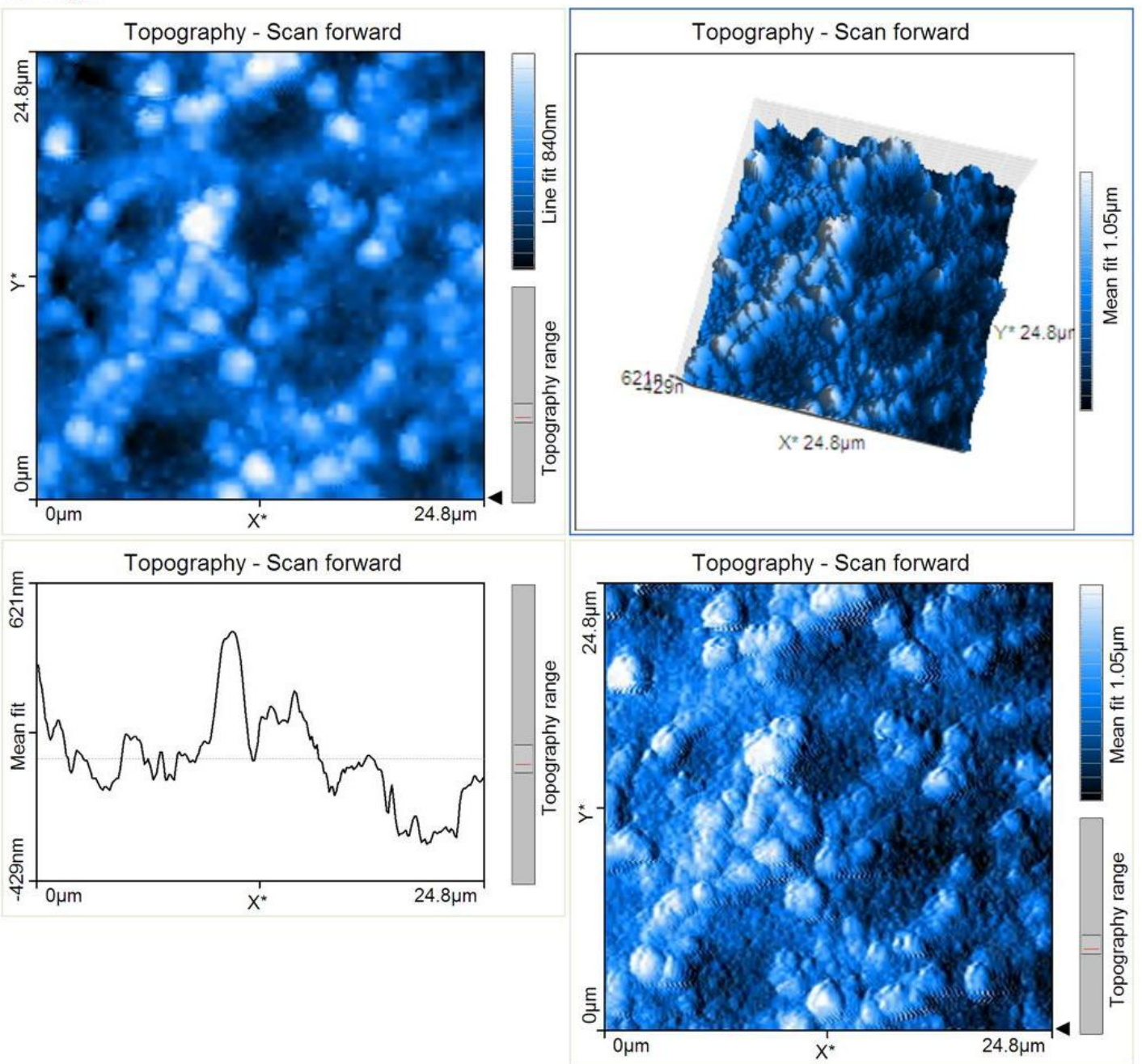

Parameter:

-- Area Roughness --

\begin{tabular}{|c|c|}
\hline Area & $=618 \mathrm{pm}^{\wedge} 2$ \\
\hline Sa & $=159.38 \mathrm{~nm}$ \\
\hline $\mathrm{Sq}$ & $=194.87 \mathrm{~nm}$ \\
\hline Sy & $=1171.3 \mathrm{~nm}$ \\
\hline $\mathrm{Sp}$ & $=762.76 \mathrm{~nm}$ \\
\hline Sv & $=-408.53 \mathrm{~nm}$ \\
\hline Sm & $=2704.2 \mathrm{fm}$ \\
\hline
\end{tabular}

-- Line Roughness --

$\begin{array}{ll}\text { Ra } & =173.83 \mathrm{~nm} \\ \mathrm{Rq} & =201.25 \mathrm{~nm} \\ \mathrm{Ry} & =717.95 \mathrm{~nm} \\ \mathrm{Rp} & =391.72 \mathrm{~nm} \\ \mathrm{Rv} & =-326.23 \mathrm{~nm} \\ \mathrm{Rm} & =-59.301 \mathrm{pm} \\ - \text { Scan -- } & \\ \text { Image size } & =25 \mu \mathrm{m} \\ \text { Scan direction } & =\text { Down } \\ \text { Time/Line } & =0.4 \mathrm{~s} \\ \text { Points } & =256\end{array}$

$\begin{array}{lll}\text { Lines } & =256 \\ \text { X-Slope } & =3.5^{\circ} \\ \text { Y-Slope } & =500 \mathrm{~m}^{\circ} \\ \text { Rotation } & =90^{\circ} \\ \text { X-Pos } & =2.2 \mu \mathrm{m} \\ \text { Y-Pos } & =-4.2 \mu \mathrm{m} \\ \text { Z-Plane } & =0 \mu \mathrm{m} \\ \text { Overscan } & =5 \% \\ \text { Const.Height-Mode } & =\text { Disabled } \\ \text { Date } & =08-08-2008 \\ \text { Time } & =17: 31: 33 \\ \text {--Feedback -- } & \\ \text { Set point } & =48 \% \\ \text { P-Gain } & =10000 \\ \text { I-Gain } & =1700 \\ \text { Tip voltage } & =0 \mathrm{~V} \\ \text { Feedback mode } & =\text { Free } \\ \text { Feedback algo. } & =\text { Adaptive PI } \\ \text { Vibration freq. } & =181.327 \mathrm{kHz} \\ \text { Vibration ampl. } & =0.7 \mathrm{~V}\end{array}$

$\begin{array}{ll}\text { Excitation ampl. } & =0.23 \mathrm{~V} \\ \text { Error range } & =20 \mathrm{~V} \\ - \text { - Global -- } & \\ \text { Op. mode } & =\text { Dynamic Force } \\ \text { Cantilever type } & =\text { ACLA } \\ \text { Head type } & =\text { EZ2-AFM } \\ \text { Scan head } & =10-07-239 \text {.hed } \\ \text { Software ver. } & =1-5-1-0 \\ \text { Firmware ver. } & =2-1-1-2 \\ \text { Controller S/N } & =023-06-252 \\ \text { - Module -- } & \\ \text { Controller Board } & =2 \\ \text { AFM Basic Module } & =2 \\ \text { AFM Dynamic Module } & =2 \\ \text { AFM Extension Modul } & =1 \\ \text { Video Module } & =0 \\ \text { Signal Module S } & =0 \\ \text { Signal Module A } & =0 \\ \text { Nanosurf Report } & =0 \\ \text { Scripting Interface } & =0\end{array}$




\section{Nanosurf Image Document}

File: Image3
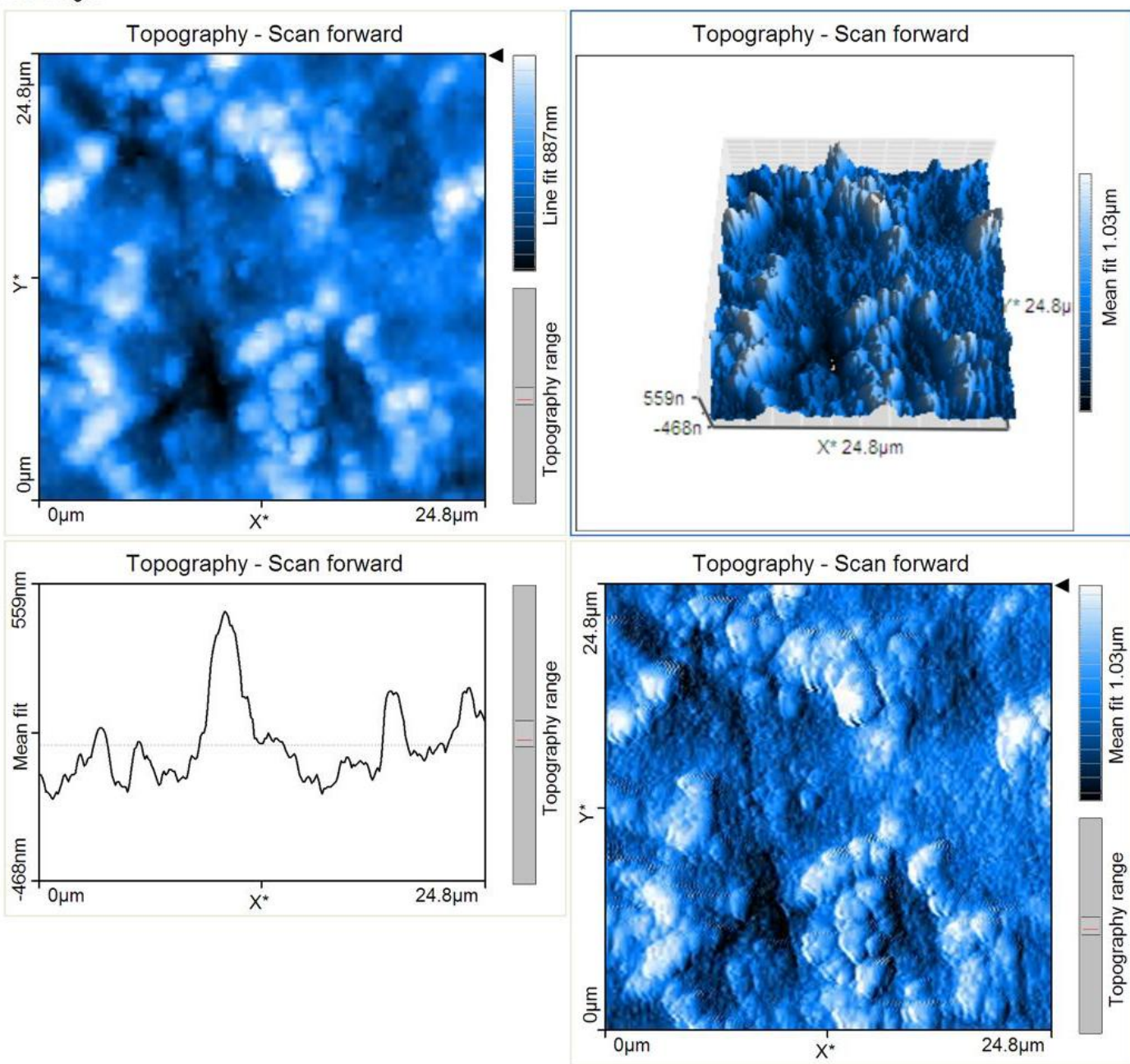

Parameter:

\begin{tabular}{|c|c|}
\hline \multicolumn{2}{|c|}{-- Area Roughness -- } \\
\hline Area & $=618 \mathrm{pm}^{\wedge} 2$ \\
\hline Sa & $=141.54 \mathrm{~nm}$ \\
\hline $\mathrm{Sq}$ & $=177.74 \mathrm{~nm}$ \\
\hline Sy & $=1261.3 \mathrm{~nm}$ \\
\hline Sp & $=760.65 \mathrm{~nm}$ \\
\hline Sv & $=-500.67 \mathrm{~nm}$ \\
\hline $\mathrm{Sm}$ & $=118.52 \mathrm{pm}$ \\
\hline \multicolumn{2}{|c|}{-- Line Roughness -- } \\
\hline $\mathrm{Ra}$ & $=98.04 \mathrm{~nm}$ \\
\hline $\mathrm{Rq}$ & $=120.88 \mathrm{~nm}$ \\
\hline Ry & $=515.74 \mathrm{~nm}$ \\
\hline $\mathrm{Rp}$ & $=282.35 \mathrm{~nm}$ \\
\hline Rv & $=-233.39 \mathrm{~nm}$ \\
\hline $\mathrm{Rm}$ & $=82.366 \mathrm{pm}$ \\
\hline \multicolumn{2}{|l|}{-- Scan -- } \\
\hline Image size & $=25 \mu \mathrm{m}$ \\
\hline Scan direction & $=U p$ \\
\hline Time/Line & $=0.5 \mathrm{~s}$ \\
\hline Points & $=256$ \\
\hline
\end{tabular}

$\begin{array}{lll}\text { Lines } & =256 \\ \text { X-Slope } & =3^{\circ} \\ \text { Y-Slope } & =3.5^{\circ} \\ \text { Rotation } & =-0.888 \mathrm{f}^{\circ} \\ \text { X-Pos } & =2.2 \mu \mathrm{m} \\ \text { Y-Pos } & =-4.2 \mu \mathrm{m} \\ \text { Z-Plane } & =0 \mu \mathrm{m} \\ \text { Overscan } & =5 \% \\ \text { Const.Height-Mode } & =\text { Disabled } \\ \text { Date } & =08-08-2008 \\ \text { Time } & =17: 43: 11 \\ \text { - Feedback -- } & \\ \text { Set point } & =48 \% \\ \text { P-Gain } & =10000 \\ \text { I-Gain } & =1600 \\ \text { Tip voltage } & =0 \mathrm{~V} \\ \text { Feedback mode } & =\text { Free } \\ \text { Feedback algo. } & =\text { Adaptive PI } \\ \text { Vibration freq. } & =181.327 \mathrm{kHz} \\ \text { Vibration ampl. } & =0.7 \mathrm{~V}\end{array}$

$\begin{array}{ll}\text { Excitation ampl. } & =0.23 \mathrm{~V} \\ \text { Error range } & =20 \mathrm{~V} \\ - \text { - Global -- } & \\ \text { Op. mode } & =\text { Dynamic Force } \\ \text { Cantilever type } & =\text { ACLA } \\ \text { Head type } & =\text { EZ2-AFM } \\ \text { Scan head } & =10-07-239 . \text { hed } \\ \text { Software ver. } & =1-5-1-0 \\ \text { Firmware ver. } & =2-1-1-2 \\ \text { Controller S/N } & =023-06-252 \\ - \text { - Module -- } & \\ \text { Controller Board } & =2 \\ \text { AFM Basic Module } & =2 \\ \text { AFM Dynamic Module } & =2 \\ \text { AFM Extension Modul }=1 & =1 \\ \text { Video Module } & =0 \\ \text { Signal Module S } & =0 \\ \text { Signal Module A } & =0 \\ \text { Nanosurf Report } & =0 \\ \text { Scripting Interface } & =0\end{array}$


N-675-16 after heat treatment

\section{Nanosurf Image Document}

File: Image5
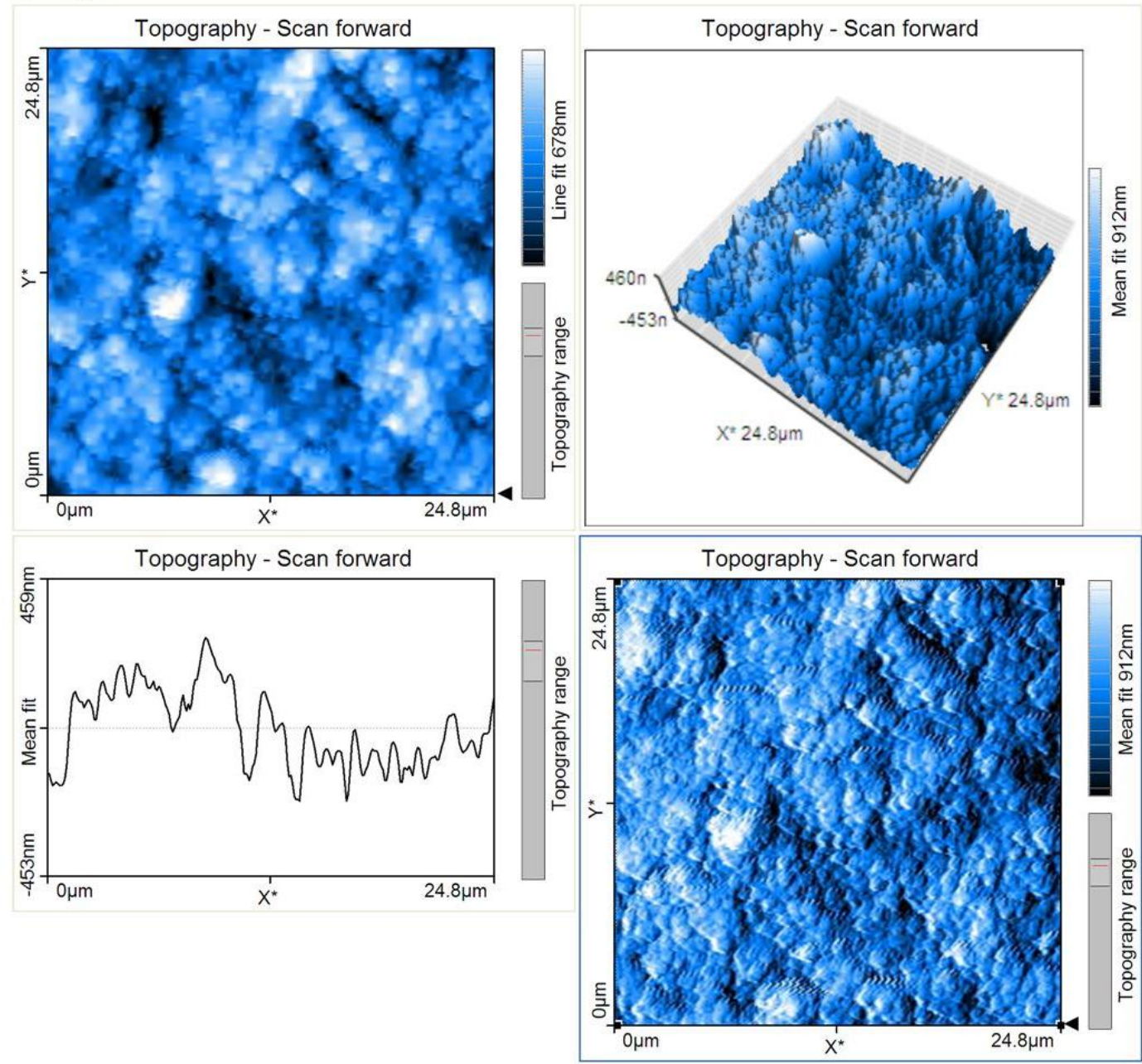

Parameter:

$\begin{array}{ll}- \text { - Area Roughness -- } \\ \text { Area } & =618 \mathrm{pm}^{\wedge} 2 \\ \mathrm{Sa} & =113.27 \mathrm{~nm} \\ \mathrm{Sq} & =141.74 \mathrm{~nm} \\ \mathrm{Sy} & =1119.2 \mathrm{~nm} \\ \mathrm{Sp} & =594.29 \mathrm{~nm} \\ \mathrm{~Sv} & =-524.92 \mathrm{~nm} \\ \mathrm{Sm} & =211.65 \mathrm{pm} \\ - \text { Line Roughness -- } & \\ \mathrm{Ra} & =127.53 \mathrm{~nm} \\ \mathrm{Rq} & =148.92 \mathrm{~nm} \\ \mathrm{Ry} & =703.4 \mathrm{~nm} \\ \text { Rp } & =289.62 \mathrm{~nm} \\ \text { Rv } & =-413.78 \mathrm{~nm} \\ \text { Rm } & =197.68 \mathrm{pm} \\ -- \text { Scan -- } & \\ \text { Image size } & =25 \mu \mathrm{m} \\ \text { Scan direction } & =D o w n \\ \text { Time/Line } & =0.3 \mathrm{~s} \\ \text { Points } & =256\end{array}$

$\begin{array}{lll}\text { Lines } & =256 \\ \text { X-Slope } & =0{ }^{\circ} \\ \text { Y-Slope } & =-500 \mathrm{~m}^{\circ} \\ \text { Rotation } & =-14.2 \mathrm{f}^{\circ} \\ \text { X-Pos } & =18 \mu \mathrm{m} \\ \text { Y-Pos } & =72 \mathrm{~nm} \\ \text { Z-Plane } & =0 \mathrm{~nm} \\ \text { Overscan } & =5 \% \\ \text { Const.Height-Mode } & =\text { Disabled } \\ \text { Date } & =31-07-2008 \\ \text { Time } & =17: 25: 40 \\ - \text {-Feedback -- } & & \\ \text { Set point } & =50 \% \\ \text { P-Gain } & =10000 \\ \text { I-Gain } & =1900 \\ \text { Tip voltage } & =0 \mathrm{~V} \\ \text { Feedback mode } & =\text { Free } \\ \text { Feedback algo. } & =\text { Adaptive PI } \\ \text { Vibration freq. } & =181.337 \mathrm{kHz} \\ \text { Vibration ampl. } & =0.7 \mathrm{~V}\end{array}$

$\begin{array}{ll}\text { Excitation ampl. } & =0.27 \mathrm{~V} \\ \text { Error range } & =20 \mathrm{~V} \\ - \text { - Global -- } & \\ \text { Op. mode } & =\text { Dynamic Force } \\ \text { Cantilever type } & =\text { ACLA } \\ \text { Head type } & =\text { EZ2-AFM } \\ \text { Scan head } & =10-07-239 . \text { hed } \\ \text { Software ver. } & =1-5-1-0 \\ \text { Firmware ver. } & =2-1-1-2 \\ \text { Controller S/N } & =023-06-252 \\ \text { - Module -- } & \\ \text { Controller Board } & =2 \\ \text { AFM Basic Module } & =2 \\ \text { AFM Dynamic Module } & =2 \\ \text { AFM Extension Modul } & =1 \\ \text { Video Module } & =0 \\ \text { Signal Module S } & =0 \\ \text { Signal Module A } & =0 \\ \text { Nanosurf Report } & =0 \\ \text { Scripting Interface } & =0\end{array}$




\section{Nanosurf Image Document}

File: Image6
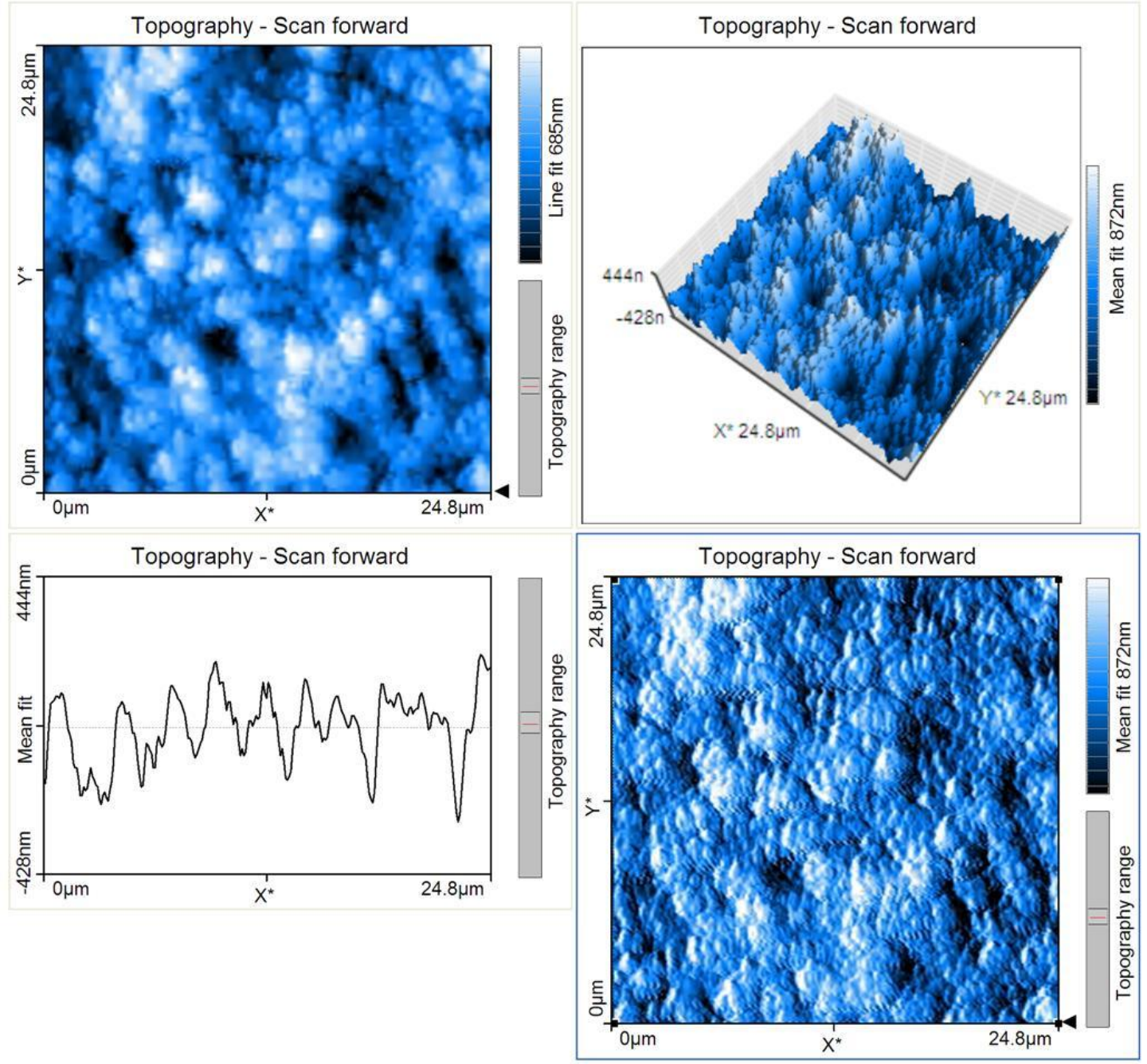

Parameter:

\begin{tabular}{|c|c|c|c|c|c|}
\hline \multicolumn{2}{|c|}{-- Area Roughness -- } & \multirow{2}{*}{$\begin{array}{l}\text { Lines } \\
\text { X-Slope }\end{array}$} & \multirow{2}{*}{$\begin{array}{l}=256 \\
=-1^{\circ}\end{array}$} & \multirow{2}{*}{$\begin{array}{l}\text { Excitation ampl. } \\
\text { Error range }\end{array}$} & \multirow{2}{*}{$\begin{array}{l}=0.25 \mathrm{~V} \\
=20 \mathrm{~V}\end{array}$} \\
\hline Area & $=618 \mathrm{pm}^{\wedge} 2$ & & & & \\
\hline $\mathrm{Sa}$ & $=116.65 \mathrm{~nm}$ & Y-Slope & $=-500 \mathrm{~m}^{\circ}$ & -- Global -- & \\
\hline $\mathrm{Sq}$ & $=146.12 \mathrm{~nm}$ & Rotation & $=90^{\circ}$ & Op. mode & $=$ Dynamic Force \\
\hline Sy & $=918.26 \mathrm{~nm}$ & X-Pos & $=18 \mu \mathrm{m}$ & Cantilever type & $=A C L A$ \\
\hline Sp & $=453.65 \mathrm{~nm}$ & Y-Pos & $=72 \mathrm{~nm}$ & Head type & $=E Z 2-A F M$ \\
\hline Sv & $=-464.61 \mathrm{~nm}$ & Z-Plane & $=0 \mathrm{~nm}$ & Scan head & $=10-07-239 \cdot$ hed \\
\hline Sm & $=212.33 \mathrm{pm}$ & Overscan & $=5 \%$ & Software ver. & $=1-5-1-0$ \\
\hline \multicolumn{2}{|c|}{-- Line Roughness -- } & \multicolumn{2}{|c|}{ Const. Height-Mode= Disabled } & Firmware ver. & $=2-1-1-2$ \\
\hline $\mathrm{Ra}$ & $=119.14 \mathrm{~nm}$ & Date & $=31-07-2008$ & Controller $\mathrm{S} / \mathrm{N}$ & $=023-06-252$ \\
\hline $\mathrm{Rq}$ & $=151.82 \mathrm{~nm}$ & Time & $=17: 37: 07$ & -- Module -- & \\
\hline Ry & $=682.11 \mathrm{~nm}$ & -- Feedback -- & & Controller Board & $=2$ \\
\hline$R p$ & $=340.27 \mathrm{~nm}$ & Set point & $=50 \%$ & AFM Basic Module & $=2$ \\
\hline $\mathrm{Rv}$ & $=-341.84 \mathrm{~nm}$ & P-Gain & $=10000$ & \multicolumn{2}{|c|}{ AFM Dynamic Module $=2$} \\
\hline $\mathrm{Rm}$ & $=154.02 \mathrm{pm}$ & |-Gain & $=1900$ & \multicolumn{2}{|c|}{ AFM Extension Modul $\epsilon=1$} \\
\hline -- Scan -- & & Tip voltage & $=0 \mathrm{~V}$ & Video Module & $=0$ \\
\hline Image size & $=25 \mu \mathrm{m}$ & Feedback mode & $=$ Free & Signal Module S & $=0$ \\
\hline Scan direction & $=$ Down & Feedback algo. & = Adaptive PI & Signal Module A & $=0$ \\
\hline Time/Line & $=0.3 \mathrm{~s}$ & Vibration freq. & $=181.337 \mathrm{kHz}$ & Nanosurf Report & $=0$ \\
\hline Points & $=256$ & Vibration ampl. & $=0.7 \mathrm{~V}$ & Scripting Interface & $=0$ \\
\hline
\end{tabular}




\section{Nanosurf Image Document}

File: Image7

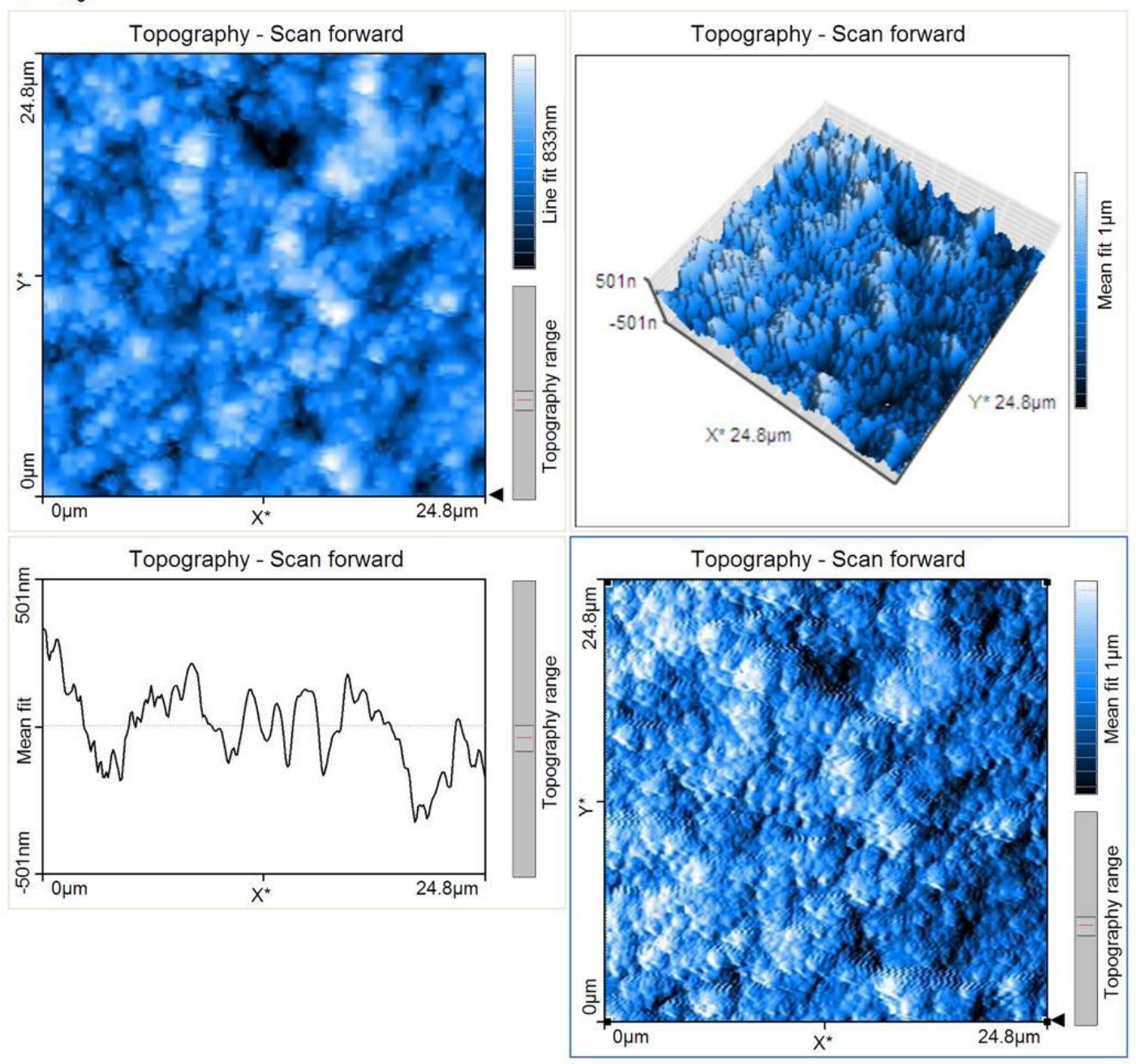

Parameter:

\begin{tabular}{|c|c|c|c|c|c|}
\hline \multicolumn{2}{|c|}{-- Area Roughness -- } & \multirow{2}{*}{$\begin{array}{l}\text { Lines } \\
\text { X-Slope }\end{array}$} & \multirow{2}{*}{$\begin{array}{l}=256 \\
=0^{\circ}\end{array}$} & \multirow{2}{*}{$\begin{array}{l}\text { Excitation ampl. } \\
\text { Error range }\end{array}$} & \multirow{2}{*}{$\begin{array}{l}=0.26 \mathrm{~V} \\
=20 \mathrm{~V}\end{array}$} \\
\hline Area & $=618 \mathrm{pm}^{\wedge} 2$ & & & & \\
\hline $\mathrm{Sa}$ & $=143.49 \mathrm{~nm}$ & Y-Slope & $=-1^{\circ}$ & -- Global -- & \\
\hline $\mathrm{Sq}$ & $=174.71 \mathrm{~nm}$ & Rotation & $=-16 f^{\circ}$ & Op. mode & = Dynamic Force \\
\hline Sy & $=1026.9 \mathrm{~nm}$ & X-Pos & $=16 \mu \mathrm{m}$ & Cantilever type & $=A C L A$ \\
\hline $\mathrm{Sp}$ & $=476.42 \mathrm{~nm}$ & Y-Pos & $=-25 \mathrm{~nm}$ & Head type & $=E Z 2-A F M$ \\
\hline Sv & $=-550.43 \mathrm{~nm}$ & Z-Plane & $=0 \mathrm{~nm}$ & Scan head & $=10-07-239$. hed \\
\hline $\mathrm{Sm}$ & $=2215.1 \mathrm{fm}$ & Overscan & $=5 \%$ & Software ver. & $=1-5-1-0$ \\
\hline \multicolumn{2}{|c|}{-- Line Roughness -- } & \multicolumn{2}{|c|}{ Const. Height-Mode= Disabled } & Firmware ver. & $=2-1-1-2$ \\
\hline $\mathrm{Ra}$ & $=109.22 \mathrm{~nm}$ & Date & $=31-07-2008$ & Controller $\mathrm{S} / \mathrm{N}$ & $=023-06-252$ \\
\hline $\mathrm{Rq}$ & $=134.29 \mathrm{~nm}$ & Time & $=17: 46: 43$ & -- Module -- & \\
\hline Ry & $=567.19 \mathrm{~nm}$ & -- Feedback -- & & Controller Board & $=2$ \\
\hline $\mathrm{Rp}$ & $=231.53 \mathrm{~nm}$ & Set point & $=50 \%$ & AFM Basic Module & $=2$ \\
\hline Rv & $=-335.66 \mathrm{~nm}$ & P-Gain & $=10000$ & \multicolumn{2}{|c|}{ AFM Dynamic Module $=2$} \\
\hline $\mathrm{Rm}$ & $=91.426 \mathrm{pm}$ & I-Gain & $=1900$ & \multicolumn{2}{|c|}{ AFM Extension Module $=1$} \\
\hline -- Scan - & & Tip voltage & $=0 \mathrm{~V}$ & Video Module & $=0$ \\
\hline Image size & $=25 \mu \mathrm{m}$ & Feedback mode & $=$ Free & Signal Module S & $=0$ \\
\hline Scan direction & $=$ Down & Feedback algo. & = Adaptive PI & Signal Module A & $=0$ \\
\hline Time/Line & $=0.3 \mathrm{~s}$ & Vibration freq. & $=181.337 \mathrm{kHz}$ & Nanosurf Report & $=0$ \\
\hline Points & $=256$ & Vibration ampl. & $=0.7 \mathrm{~V}$ & Scripting Interface & $=0$ \\
\hline
\end{tabular}




\section{N-675-16 after CP}

\section{Nanosurf Image Document}

File: Image7

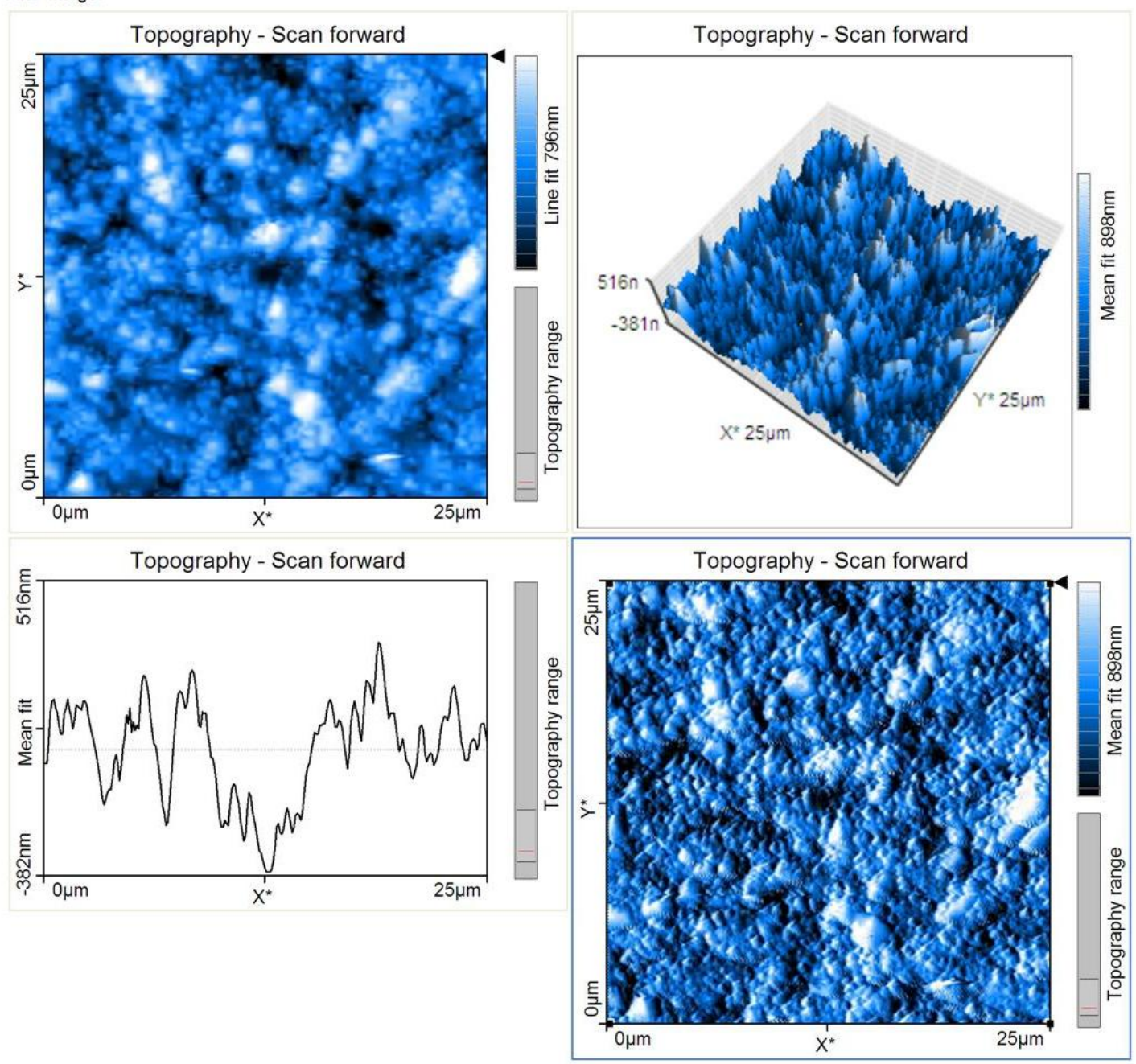

Parameter:

\begin{tabular}{|c|c|c|c|c|c|}
\hline \multicolumn{2}{|c|}{-- Area Roughness -- } & \multirow{2}{*}{$\begin{array}{l}\text { Lines } \\
\text { X-Slope }\end{array}$} & \multirow{2}{*}{$\begin{array}{l}=256 \\
=1.5^{\circ}\end{array}$} & \multirow{2}{*}{$\begin{array}{l}\text { Excitation ampl. } \\
\text { Error range }\end{array}$} & \multirow{2}{*}{$\begin{array}{l}=0.16 \mathrm{~V} \\
=20 \mathrm{~V}\end{array}$} \\
\hline Area & $=629.9 \mathrm{pm}^{\wedge} 2$ & & & & \\
\hline $\mathrm{Sa}$ & $=119.36 \mathrm{~nm}$ & Y-Slope & $=1^{\circ}$ & -- Global -- & \\
\hline $\mathrm{Sq}$ & $=153.39 \mathrm{~nm}$ & Rotation & $=90^{\circ}$ & Op. mode & = Dynamic Force \\
\hline Sy & $=1374.5 \mathrm{~nm}$ & X-Pos & $=6.3 \mu \mathrm{m}$ & Cantilever type & $=A C L A$ \\
\hline $\mathrm{Sp}$ & $=858.7 \mathrm{~nm}$ & Y-Pos & $=19 \mu \mathrm{m}$ & Head type & $=\mathrm{EZ2}-\mathrm{AFM}$ \\
\hline Sv & $=-515.85 \mathrm{~nm}$ & Z-Plane & $=0 \mu \mathrm{m}$ & Scan head & $=10-07-239$. hed \\
\hline Sm & $=-4.6796 \mathrm{pm}$ & Overscan & $=5 \%$ & Software ver. & $=1-5-1-0$ \\
\hline \multicolumn{2}{|c|}{-- Line Roughness -- } & \multicolumn{2}{|c|}{ Const. Height-Mod $\epsilon=$ Disabled } & Firmware ver. & $=2-1-1-2$ \\
\hline $\mathrm{Ra}$ & $=137.69 \mathrm{~nm}$ & Date & $=10-08-2008$ & Controller $\mathrm{S} / \mathrm{N}$ & $=023-06-252$ \\
\hline $\mathrm{Rq}$ & $=165.93 \mathrm{~nm}$ & Time & $=15: 54: 23$ & -- Module -- & \\
\hline Ry & $=686.96 \mathrm{~nm}$ & \multicolumn{2}{|l|}{-- Feedback -- } & Controller Board & $=2$ \\
\hline $\mathrm{Rp}$ & $=365.93 \mathrm{~nm}$ & Set point & $=48 \%$ & AFM Basic Module & $=2$ \\
\hline Rv & $=-321.03 \mathrm{~nm}$ & P-Gain & $=10000$ & \multicolumn{2}{|c|}{ AFM Dynamic Module $=2$} \\
\hline $\mathrm{Rm}$ & $=-14.541 \mathrm{~nm}$ & I-Gain & $=1100$ & \multicolumn{2}{|c|}{ AFM Extension Modul $\epsilon=1$} \\
\hline -- Scan -- & & Tip voltage & $=0 \mathrm{~V}$ & Video Module & $=0$ \\
\hline Image size & $=25 \mu \mathrm{m}$ & Feedback mode & $=$ Free & Signal Module S & $=0$ \\
\hline Scan direction & $=U p$ & Feedback algo. & = Adaptive PI & Signal Module A & $=0$ \\
\hline Time/Line & $=0.5 \mathrm{~s}$ & Vibration freq. & $=179.237 \mathrm{kHz}$ & Nanosurf Report & $=0$ \\
\hline Points & $=256$ & Vibration ampl. & $=0.7 \mathrm{~V}$ & Scripting Interface & $=0$ \\
\hline
\end{tabular}




\section{Nanosurf Image Document}

File: Image8

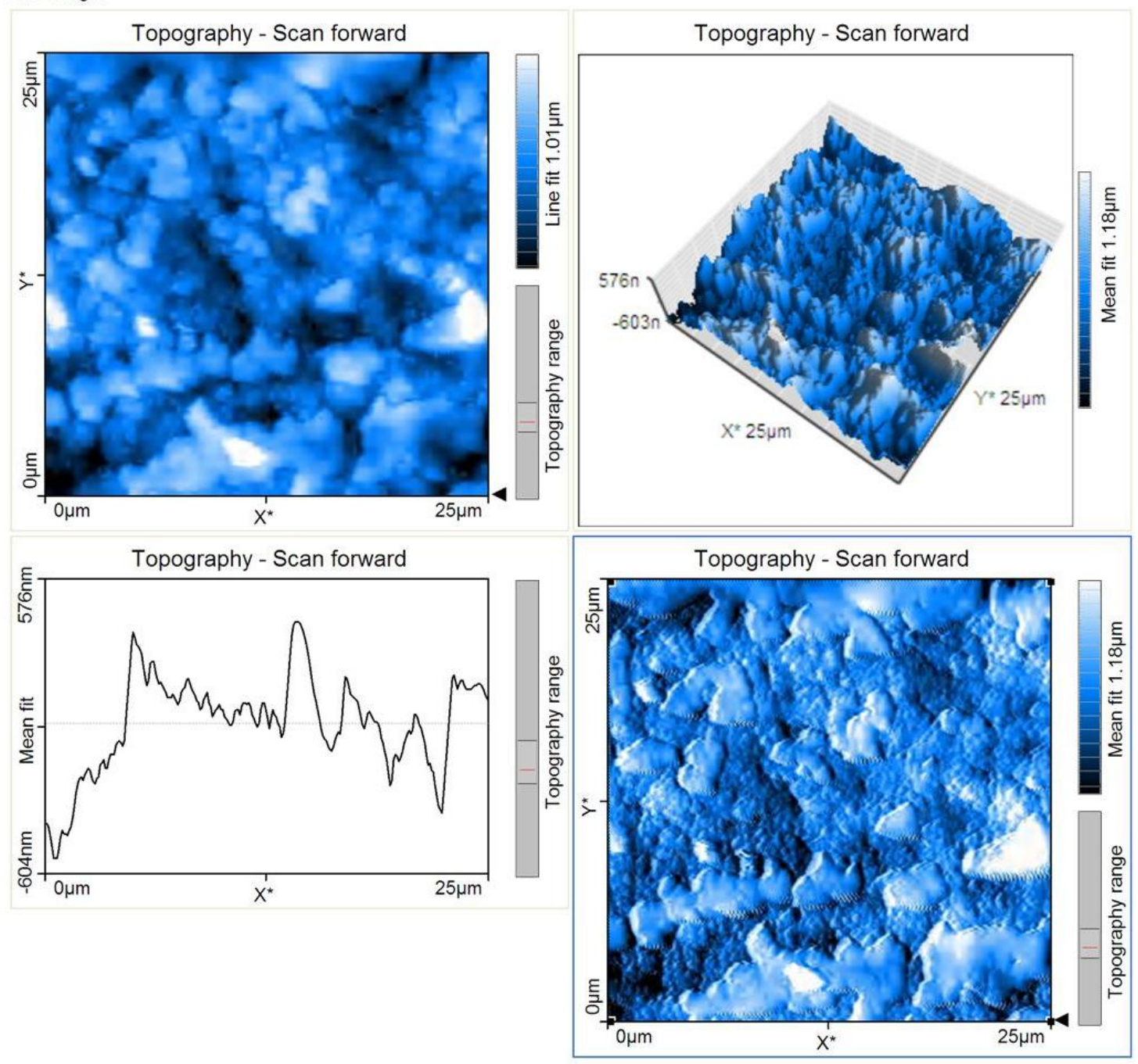

Parameter:

\begin{tabular}{|c|c|c|c|c|c|}
\hline \multicolumn{2}{|c|}{-- Area Roughness -- } & \multirow{2}{*}{$\begin{array}{l}\text { Lines } \\
\text { X-Slope }\end{array}$} & \multirow{2}{*}{$\begin{array}{l}=256 \\
=1.5^{\circ}\end{array}$} & \multirow{2}{*}{$\begin{array}{l}\text { Excitation ampl. } \\
\text { Error range }\end{array}$} & \multirow{2}{*}{$\begin{array}{l}=0.17 \mathrm{~V} \\
=20 \mathrm{~V}\end{array}$} \\
\hline Area & $=629.9 \mathrm{pm}^{\wedge} 2$ & & & & \\
\hline $\mathrm{Sa}$ & $=166.75 \mathrm{~nm}$ & Y-Slope & $=1^{\circ}$ & -- Global -- & \\
\hline $\mathrm{Sq}$ & $=217.84 \mathrm{~nm}$ & Rotation & $=90^{\circ}$ & Op. mode & = Dynamic Force \\
\hline Sy & $=2015.5 \mathrm{~nm}$ & X-Pos & $=1 \mu \mathrm{m}$ & Cantilever type & $=A C L A$ \\
\hline Sp & $=1245.4 \mathrm{~nm}$ & Y-Pos & $=19 \mu \mathrm{m}$ & Head type & $=E Z 2-A F M$ \\
\hline Sv & $=-770 \cdot 14 \mathrm{~nm}$ & Z-Plane & $=0.62 \mu \mathrm{m}$ & Scan head & $=10-07-239 \cdot$ hed \\
\hline $\mathrm{Sm}$ & $=4.8244 \mathrm{pm}$ & Overscan & $=5 \%$ & Software ver. & $=1-5-1-0$ \\
\hline \multicolumn{2}{|c|}{-- Line Roughness -- } & \multicolumn{2}{|c|}{ Const. Height-Mod $\epsilon=$ Disabled } & Firmware ver. & $=2-1-1-2$ \\
\hline $\mathrm{Ra}$ & $=140.19 \mathrm{~nm}$ & Date & $=10-08-2008$ & Controller S/N & $=023-06-252$ \\
\hline $\mathrm{Rq}$ & $=179.7 \mathrm{~nm}$ & Time & $=16: 12: 32$ & -- Module -- & \\
\hline Ry & $=907.3 \mathrm{~nm}$ & \multicolumn{2}{|l|}{-- Feedback -- } & Controller Board & $=2$ \\
\hline $\mathrm{Rp}$ & $=411.3 \mathrm{~nm}$ & Set point & $=48 \%$ & AFM Basic Module & $=2$ \\
\hline Rv & $=-496 n m$ & P-Gain & $=10000$ & \multicolumn{2}{|c|}{ AFM Dynamic Module $=2$} \\
\hline $\mathrm{Rm}$ & $=-31.297 \mathrm{pm}$ & I-Gain & $=1200$ & \multicolumn{2}{|c|}{ AFM Extension Modul $=1$} \\
\hline -- Scan -- & & Tip voltage & $=0 \mathrm{~V}$ & Video Module & $=0$ \\
\hline Image size & $=25 \mu \mathrm{m}$ & Feedback mode & $=$ Free & Signal Module S & $=0$ \\
\hline Scan direction & $=$ Down & Feedback algo. & = Adaptive $\mathrm{PI}$ & Signal Module A & $=0$ \\
\hline Time/Line & $=0.5 \mathrm{~s}$ & Vibration freq. & $=179.257 \mathrm{kHz}$ & Nanosurf Report & $=0$ \\
\hline Points & $=256$ & Vibration ampl. & $=0.7 \mathrm{~V}$ & Scripting Interface & $=0$ \\
\hline
\end{tabular}




\section{Nanosurf Image Document}

File: Image9

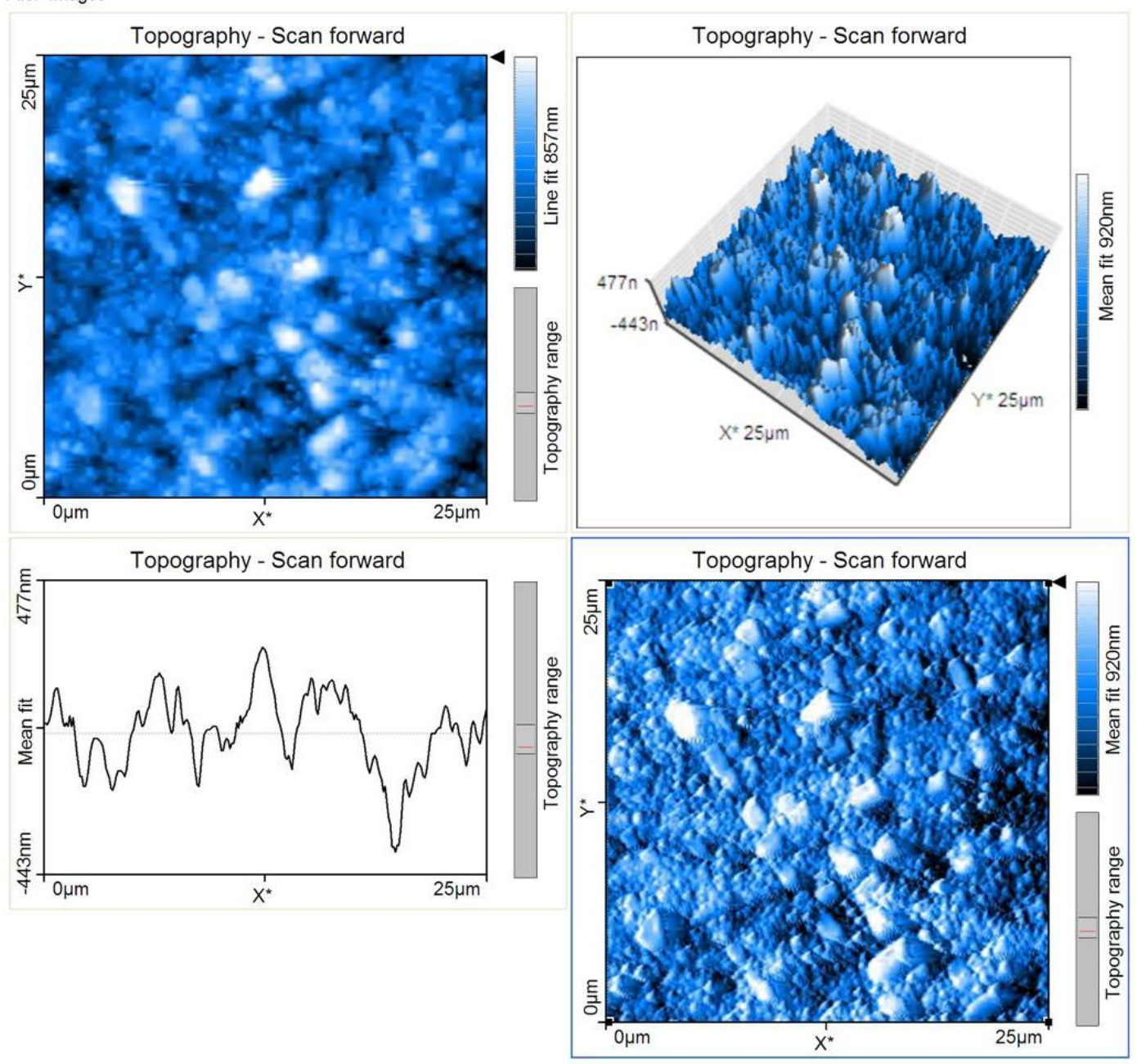

Parameter:

\begin{tabular}{|c|c|c|c|c|c|}
\hline \multicolumn{2}{|c|}{-- Area Roughness -- } & \multirow{2}{*}{$\begin{array}{l}\text { Lines } \\
\text { X-Slope }\end{array}$} & \multirow{2}{*}{$\begin{array}{l}=256 \\
=1.5^{\circ}\end{array}$} & \multirow{2}{*}{$\begin{array}{l}\text { Excitation ampl. } \\
\text { Error range }\end{array}$} & \multirow{2}{*}{$\begin{array}{l}=0.15 \mathrm{~V} \\
=20 \mathrm{~V}\end{array}$} \\
\hline Area & $=629.9 \mathrm{pm}^{\wedge} 2$ & & & & \\
\hline $\mathrm{Sa}$ & $=116.54 \mathrm{~nm}$ & Y-Slope & $=1^{\circ}$ & -- Global -- & \\
\hline $\mathrm{Sq}$ & $=150.77 \mathrm{~nm}$ & Rotation & $=90^{\circ}$ & Op. mode & $=$ Dynamic Force \\
\hline Sy & $=1358.5 \mathrm{~nm}$ & X-Pos & $=1 \mu \mathrm{m}$ & Cantilever type & $=A C L A$ \\
\hline $\mathrm{Sp}$ & $=794.39 \mathrm{~nm}$ & Y-Pos & $=19 \mu \mathrm{m}$ & Head type & $=\mathrm{EZ2}-\mathrm{AFM}$ \\
\hline Sv & $=-564.14 \mathrm{~nm}$ & Z-Plane & $=0 \mu \mathrm{m}$ & Scan head & $=10-07-239 \cdot$ hed \\
\hline $\mathrm{Sm}$ & $=-3138.5 \mathrm{fm}$ & Overscan & $=5 \%$ & Software ver. & $=1-5-1-0$ \\
\hline \multicolumn{2}{|c|}{-- Line Roughness -- } & \multicolumn{2}{|c|}{ Const. Height-Mode= Disabled } & Firmware ver. & $=2-1-1-2$ \\
\hline $\mathrm{Ra}$ & $=134.33 \mathrm{~nm}$ & Date & $=10-08-2008$ & Controller S/N & $=023-06-252$ \\
\hline $\mathrm{Rq}$ & $=186.81 \mathrm{~nm}$ & Time & $=16: 21: 25$ & -- Module -- & \\
\hline Ry & $=847.42 \mathrm{~nm}$ & -- Feedback -- & & Controller Board & $=2$ \\
\hline $\mathrm{Rp}$ & $=394.61 \mathrm{~nm}$ & Set point & $=48 \%$ & AFM Basic Module & $=2$ \\
\hline Rv & $=-452.81 \mathrm{~nm}$ & P-Gain & $=10000$ & \multicolumn{2}{|c|}{ AFM Dynamic Module $=2$} \\
\hline $\mathrm{Rm}$ & $=2472.5 \mathrm{fm}$ & I-Gain & $=1200$ & \multicolumn{2}{|c|}{ AFM Extension Modul $=1$} \\
\hline - Scan -- & & Tip voltage & $=0 \mathrm{~V}$ & Video Module & $=0$ \\
\hline Image size & $=25 \mu \mathrm{m}$ & Feedback mode & $=$ Free & Signal Module S & $=0$ \\
\hline Scan direction & $=U p$ & Feedback algo. & = Adaptive PI & Signal Module A & $=0$ \\
\hline Time/Line & $=0.5 \mathrm{~s}$ & Vibration freq. & $=179.257 \mathrm{kHz}$ & Nanosurf Report & $=0$ \\
\hline Points & $=256$ & Vibration ampl. & $=0.7 \mathrm{~V}$ & Scripting Interface & $=0$ \\
\hline
\end{tabular}


APPENDIX B: AFM Data of Abraded Samples

A-0

Nanosurf Image Document
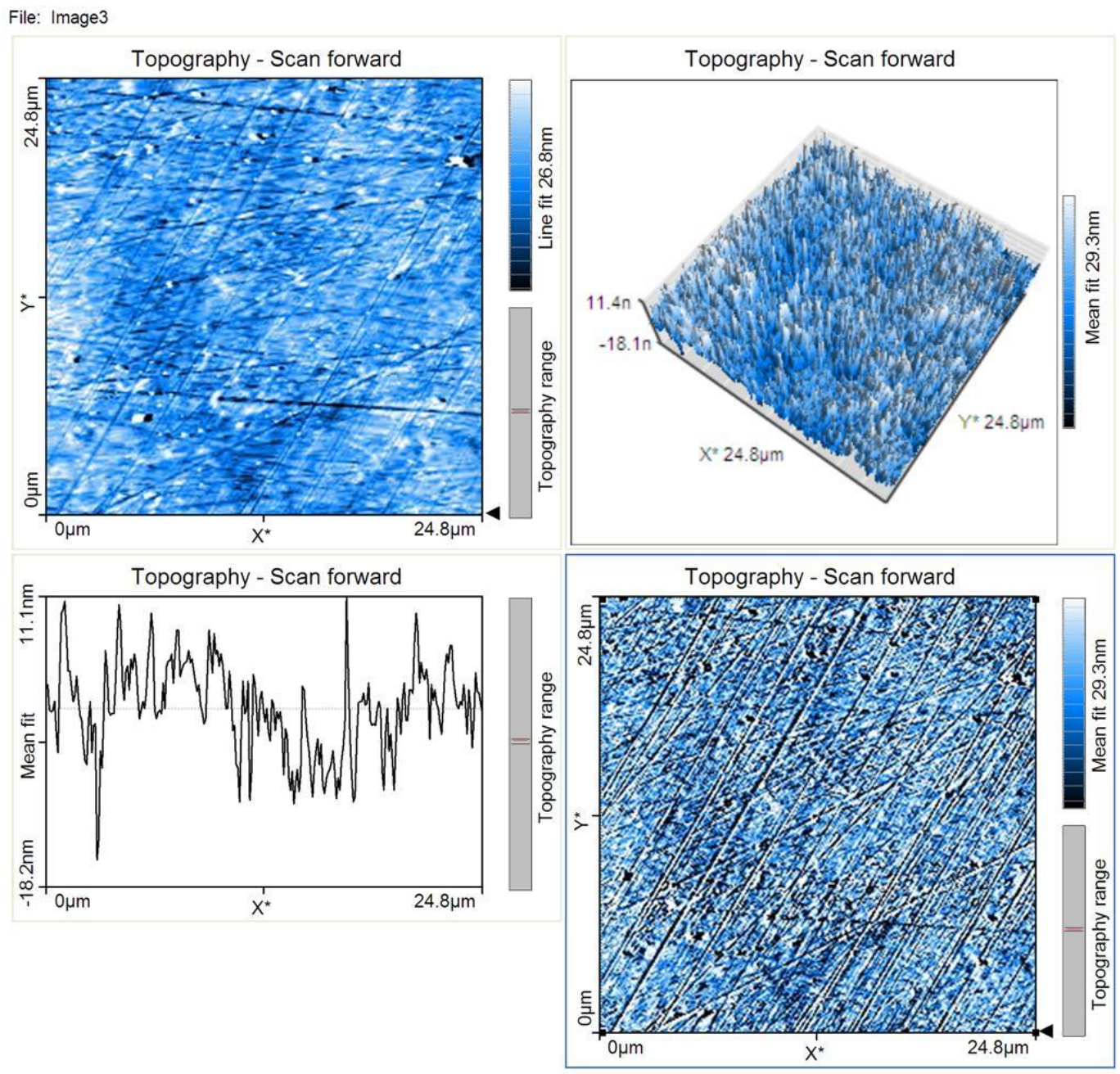

\begin{tabular}{|c|c|}
\hline \multicolumn{2}{|l|}{ Parameter: } \\
\hline \multicolumn{2}{|c|}{-- Area Roughness -- } \\
\hline Area & $=618 \mathrm{pm}^{\wedge} 2$ \\
\hline $\mathrm{Sa}$ & $=4.0598 \mathrm{~nm}$ \\
\hline $\mathrm{Sq}$ & $=6.555 \mathrm{~nm}$ \\
\hline Sy & $=219.71 \mathrm{~nm}$ \\
\hline Sp & $=173.43 \mathrm{~nm}$ \\
\hline Sv & $=-46.282 \mathrm{~nm}$ \\
\hline Sm & $=206.62 \mathrm{pm}$ \\
\hline \multicolumn{2}{|c|}{-- Line Roughness -- } \\
\hline $\mathrm{Ra}$ & $=3156.1 \mathrm{pm}$ \\
\hline $\mathrm{Rq}$ & $=3.9659 \mathrm{~nm}$ \\
\hline Ry & $=23.405 \mathrm{~nm}$ \\
\hline$R p$ & $=8.4942 \mathrm{~nm}$ \\
\hline $\mathrm{Rv}$ & $=-14.91 \mathrm{~nm}$ \\
\hline $\mathrm{Rm}$ & $=256.15 \mathrm{pm}$ \\
\hline \multicolumn{2}{|l|}{-- Scan -- } \\
\hline Image size & $=25 \mu \mathrm{m}$ \\
\hline Scan direction & $=$ Down \\
\hline Time/Line & $=0.3 \mathrm{~s}$ \\
\hline Points & $=256$ \\
\hline
\end{tabular}

$\begin{array}{lll}\text { Lines } & =256 \\ \text { X-Slope } & =-250 \mathrm{~m}^{\circ} \\ \text { Y-Slope } & =500 \mathrm{~m}^{\circ} \\ \text { Rotation } & =-1.78 \mathrm{f}^{\circ} \\ \text { X-Pos } & =0 \mathrm{fm} \\ \text { Y-Pos } & =0 \mathrm{fm} \\ \text { Z-Plane } & =0 \mathrm{fm} \\ \text { Overscan } & =5 \% \\ \text { Const.Height-Mode } & =\text { Disabled } \\ \text { Date } & =05-09-2008 \\ \text { Time } & =12: 05: 19 \\ - \text {-Feedback -- } & & \\ \text { Set point } & =48 \% \\ \text { P-Gain } & =10000 \\ \text { I-Gain } & =1600 \\ \text { Tip voltage } & =0 \mathrm{~V} \\ \text { Feedback mode } & =\text { Free } \\ \text { Feedback algo. } & =\text { Adaptive PI } \\ \text { Vibration freq. } & =179.074 \mathrm{kHz} \\ \text { Vibration ampl. } & =0.7 \mathrm{~V}\end{array}$

$\begin{array}{ll}\text { Excitation ampl. } & =0.19 \mathrm{~V} \\ \text { Error range } & =20 \mathrm{~V} \\ - \text { - Global -- } & \\ \text { Op. mode } & =\text { Dynamic Force } \\ \text { Cantilever type } & =\text { ACLA } \\ \text { Head type } & =\text { EZ2-AFM } \\ \text { Scan head } & =10-07-239 . \text { hed } \\ \text { Software ver. } & =1-5-1-0 \\ \text { Firmware ver. } & =2-1-1-2 \\ \text { Controller S/N } & =023-06-252 \\ - \text { Module -- } & \\ \text { Controller Board } & =2 \\ \text { AFM Basic Module } & =2 \\ \text { AFM Dynamic Module } & =2 \\ \text { AFM Extension Module } & =1 \\ \text { Video Module } & =0 \\ \text { Signal Module S } & =0 \\ \text { Signal Module A } & =0 \\ \text { Nanosurf Report } & =0 \\ \text { Scripting Interface } & =0\end{array}$




\section{Nanosurf Image Document}

File: Image7

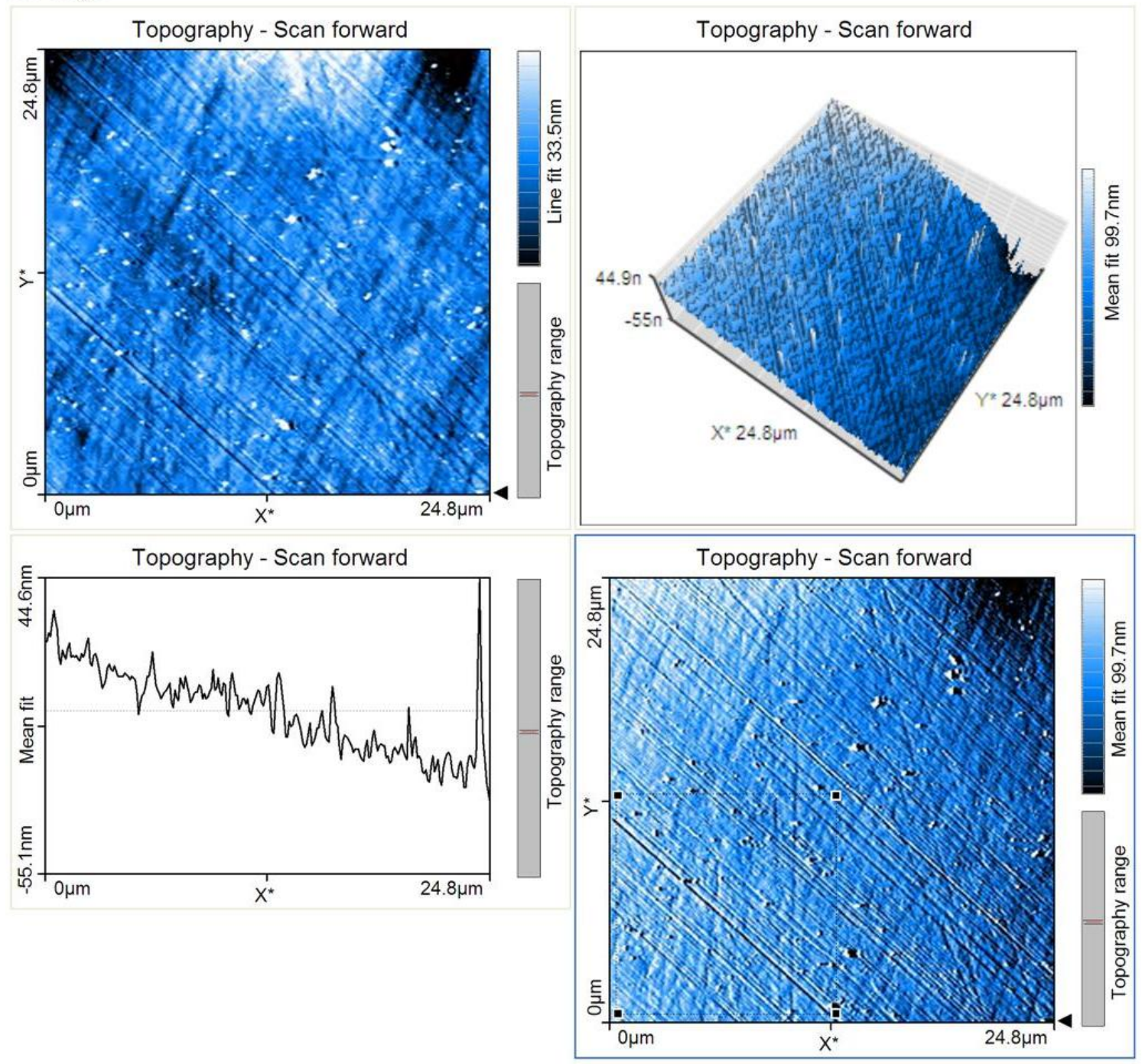

Parameter:

\begin{tabular}{|c|c|c|c|c|c|}
\hline \multicolumn{2}{|l|}{-- Area Roughness -- } & Time/Line & $=0.3 \mathrm{~s}$ & Vibration ampl. & $=0.7 \mathrm{~V}$ \\
\hline Area & $=153.3 \mathrm{pm}^{\wedge} 2$ & Points & $=256$ & Excitation ampl. & $=0.2 \mathrm{~V}$ \\
\hline Sa & $=10.257 \mathrm{~nm}$ & Lines & $=256$ & Error range & $=20 \mathrm{~V}$ \\
\hline $\mathrm{Sq}$ & $=12.639 \mathrm{~nm}$ & X-Slope & $=-250 \mathrm{~m}^{\circ}$ & -- Global -- & \\
\hline Sy & $=138.53 \mathrm{~nm}$ & Y-Slope & $=750 \mathrm{~m}^{\circ}$ & Op. mode & $=$ Dynamic Force \\
\hline $\mathrm{Sp}$ & $=122.4 \mathrm{~nm}$ & Rotation & $=90^{\circ}$ & Cantilever type & $=A C L A$ \\
\hline Sv & $=-16.13 \mathrm{~nm}$ & X-Pos & $=0 \mathrm{~m}$ & Head type & $=E Z 2-A F M$ \\
\hline $\mathrm{Sm}$ & $=9.5636 \mathrm{~nm}$ & Y-Pos & $=0 \mathrm{~m}$ & Scan head & $=10-07-239$. hed \\
\hline -- Tool -- & & Z-Plane & $=0 \mathrm{~m}$ & Software ver. & $=1-5-1-0$ \\
\hline Width & $=12.28 \mu \mathrm{m}$ & Overscan & $=5 \%$ & Firmware ver. & $=2-1-1-2$ \\
\hline Height & $=12.28 \mu \mathrm{m}$ & \multicolumn{2}{|c|}{ Const. Height-Mod $\epsilon=$ Disabled } & Controller S/N & $=023-06-252$ \\
\hline -- Line Roughness - & & Date & $=05-09-2008$ & -- Module -- & \\
\hline $\mathrm{Ra}$ & $=5.7415 \mathrm{~nm}$ & Time & $=12: 23: 39$ & Controller Board & $=2$ \\
\hline $\mathrm{Rq}$ & $=7.351 \mathrm{~nm}$ & -- Feedback -- & & AFM Basic Module & $=2$ \\
\hline Ry & $=43.225 \mathrm{~nm}$ & Set point & $=48 \%$ & AFM Dynamic Module & $=2$ \\
\hline $\mathrm{Rp}$ & $=30.465 \mathrm{~nm}$ & P-Gain & $=10000$ & AFM Extension Module & $\varepsilon=1$ \\
\hline Rv & $=-12.759 \mathrm{~nm}$ & I-Gain & $=1600$ & Video Module & $=0$ \\
\hline $\mathrm{Rm}$ & $=13.497 \mathrm{~nm}$ & Tip voltage & $=0 \mathrm{~V}$ & Signal Module S & $=0$ \\
\hline -- Scan -- & & Feedback mode & $=$ Free & Signal Module A & $=0$ \\
\hline Image size & $=25 \mu \mathrm{m}$ & Feedback algo. & $=$ Adaptive $\mathrm{PI}$ & Nanosurf Report & $=0$ \\
\hline Scan direction & $=$ Down & Vibration freq. & $=179.044 \mathrm{kHz}$ & Scripting Interface & $=0$ \\
\hline
\end{tabular}




\section{Nanosurf Image Document}

File: Image 10

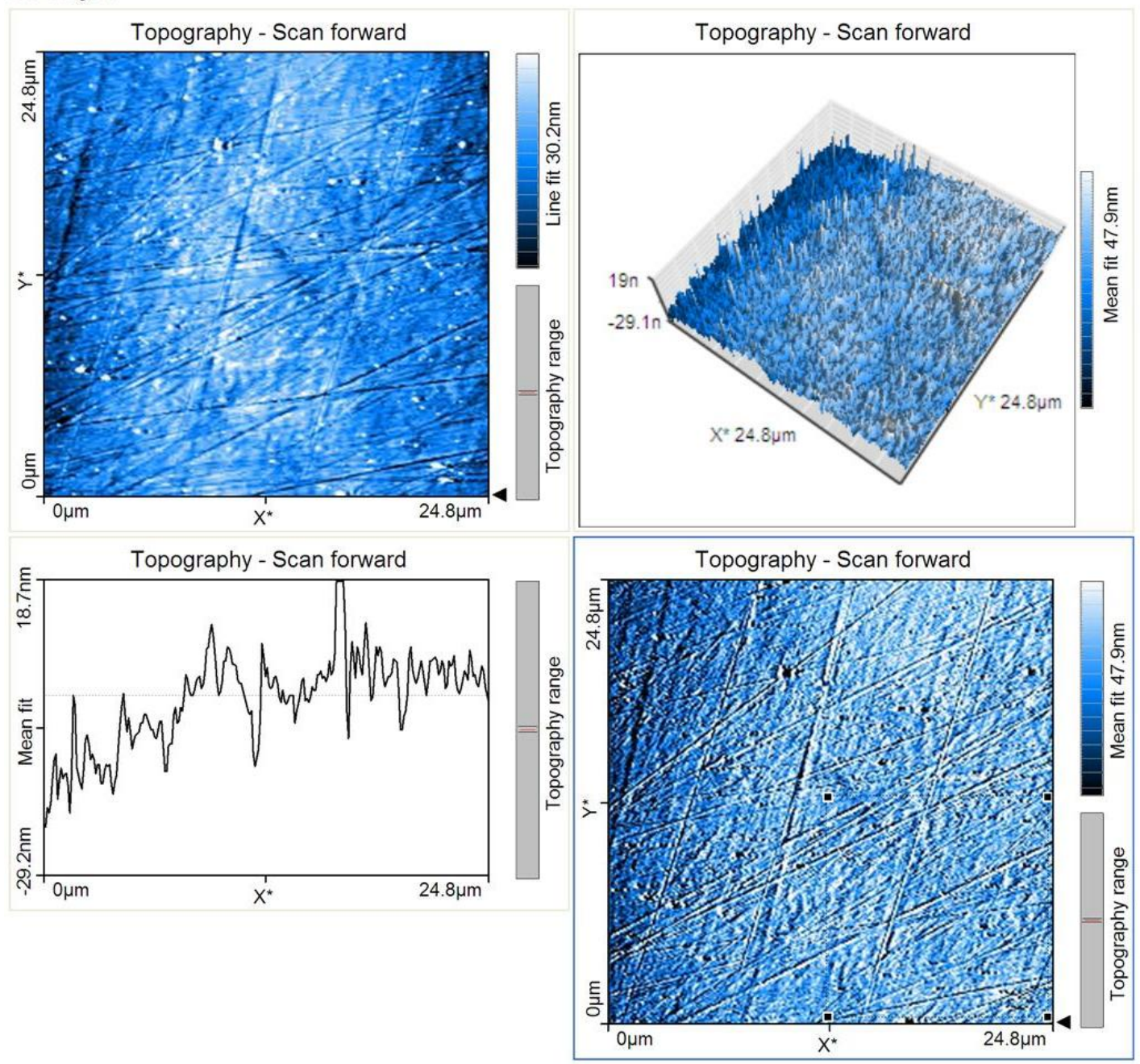

Parameter:

\begin{tabular}{|c|c|c|c|c|c|}
\hline \multicolumn{2}{|c|}{-- Area Roughness -- } & \multirow{2}{*}{$\begin{array}{l}\text { Lines } \\
\text { X-Slope }\end{array}$} & \multirow{2}{*}{$\begin{array}{l}=256 \\
=-250 \mathrm{~m}^{\circ}\end{array}$} & \multirow{2}{*}{$\begin{array}{l}\text { Excitation ampl. } \\
\text { Error range }\end{array}$} & \multirow{2}{*}{$\begin{array}{l}=0.19 \mathrm{~V} \\
=20 \mathrm{~V}\end{array}$} \\
\hline Area & $=155.7 \mathrm{pm}^{\wedge} 2$ & & & & \\
\hline $\mathrm{Sa}$ & $=5.1719 \mathrm{~nm}$ & Y-Slope & $=500 \mathrm{~m}^{\circ}$ & -- Global -- & \\
\hline $\mathrm{Sq}$ & $=7.2843 \mathrm{~nm}$ & Rotation & $=0 \mathrm{~m}^{\circ}$ & Op. mode & $=$ Dynamic Force \\
\hline Sy & $=149.49 \mathrm{~nm}$ & X-Pos & $=0 \mathrm{~mm}$ & Cantilever type & $=A C L A$ \\
\hline $\mathrm{Sp}$ & $=130.62 \mathrm{~nm}$ & Y-Pos & $=0 \mathrm{~mm}$ & Head type & $=E Z 2-A F M$ \\
\hline Sv & $=-18.871 \mathrm{~nm}$ & Z-Plane & $=0 \mathrm{~mm}$ & Scan head & $=10-07-239$. hed \\
\hline $\mathrm{Sm}$ & $=4.1017 \mathrm{~nm}$ & Overscan & $=5 \%$ & Software ver. & $=1-5-1-0$ \\
\hline \multicolumn{2}{|c|}{-- Line Roughness -- } & \multicolumn{2}{|c|}{ Const. Height-Mod $\epsilon=$ Disabled } & Firmware ver. & $=2-1-1-2$ \\
\hline $\mathrm{Ra}$ & $=4.2242 \mathrm{~nm}$ & Date & $=05-09-2008$ & Controller $\mathrm{S} / \mathrm{N}$ & $=023-06-252$ \\
\hline $\mathrm{Rq}$ & $=5.5436 \mathrm{~nm}$ & Time & $=12: 38: 21$ & -- Module -- & \\
\hline Ry & $=39.64 \mathrm{~nm}$ & -- Feedback -- & & Controller Board & $=2$ \\
\hline Rp & $=21.89 \mathrm{~nm}$ & Set point & $=48 \%$ & AFM Basic Module & $=2$ \\
\hline $\mathrm{Rv}$ & $=-17.75 \mathrm{~nm}$ & P-Gain & $=10000$ & \multicolumn{2}{|c|}{ AFM Dynamic Module $=2$} \\
\hline $\mathrm{Rm}$ & $=5.4156 \mathrm{~nm}$ & I-Gain & $=1600$ & \multicolumn{2}{|c|}{ AFM Extension Modul $=1$} \\
\hline -- Scan -- & & Tip voltage & $=0 \mathrm{~V}$ & Video Module & $=0$ \\
\hline Image size & $=25 \mu \mathrm{m}$ & Feedback mode & $=$ Free & Signal Module S & $=0$ \\
\hline Scan direction & $=$ Down & Feedback algo. & = Adaptive PI & Signal Module A & $=0$ \\
\hline Time/Line & $=0.3 \mathrm{~s}$ & Vibration freq. & $=179.044 \mathrm{kHz}$ & Nanosurf Report & $=0$ \\
\hline Points & $=256$ & Vibration ampl. & $=0.7 \mathrm{~V}$ & Scripting Interface & $=0$ \\
\hline
\end{tabular}


A-600-1 after heat treatment

\section{Nanosurf Image Document}

File: Image 16

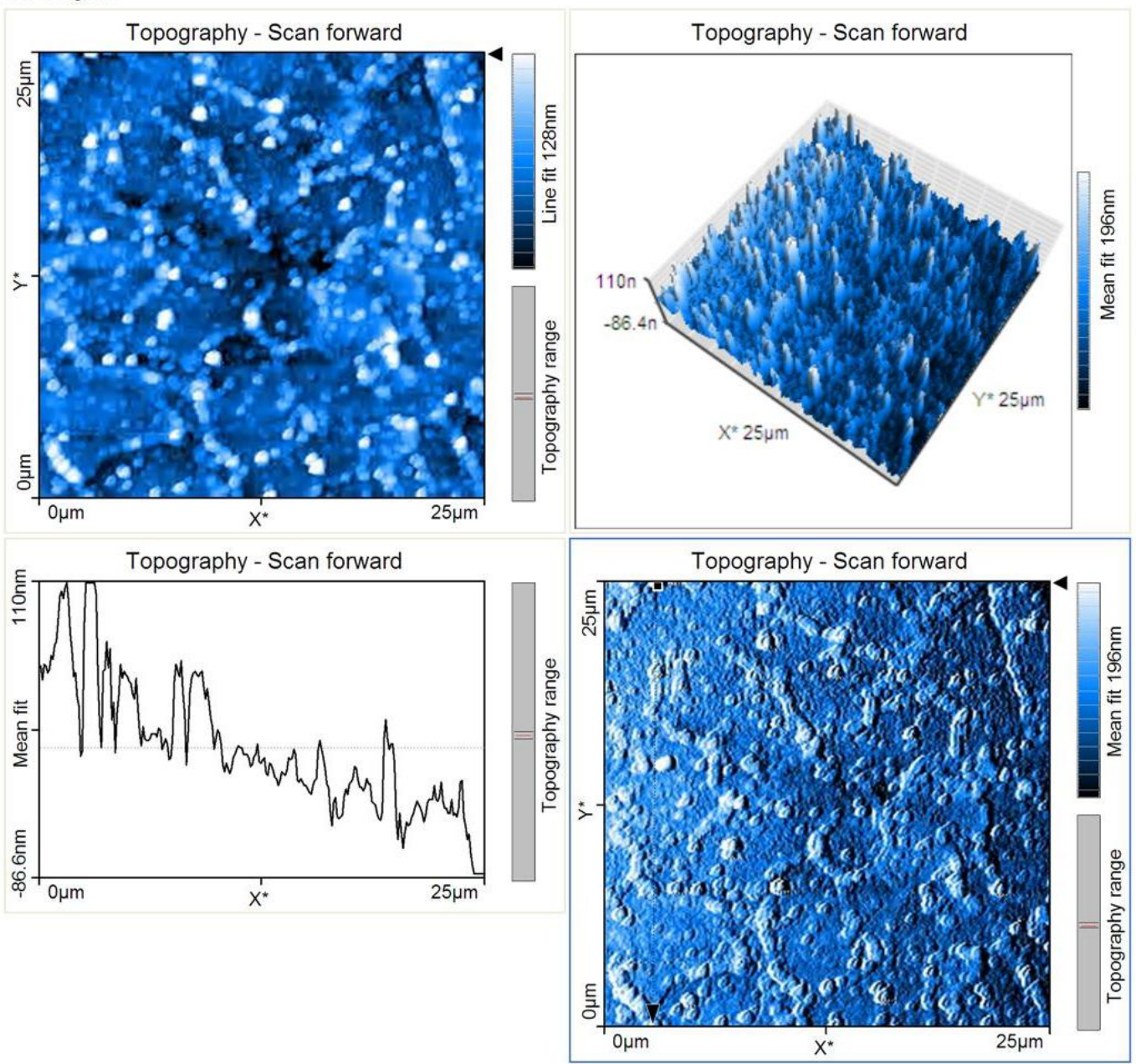

Parameter:

\begin{tabular}{|c|c|c|c|c|c|}
\hline \multicolumn{2}{|l|}{ - Tool -- } & Time/Line & \multirow{2}{*}{$\begin{array}{l}=0.6 \mathrm{~s} \\
=256\end{array}$} & \multirow{2}{*}{$\begin{array}{l}\text { Vibration ampl. } \\
\text { Excitation ampl. }\end{array}$} & \multirow{2}{*}{$\begin{array}{l}=0.7 \mathrm{~V} \\
=0.23 \mathrm{~V}\end{array}$} \\
\hline Length & $=24.81 \mu \mathrm{m}$ & Points & & & \\
\hline DeltaZ & $=57.35 \mathrm{~nm}$ & Lines & $=256$ & Error range & $=20 \mathrm{~V}$ \\
\hline -- Area Roughness & & X-Slope & $=-250 \mathrm{~m}^{\circ}$ & -- Global -- & \\
\hline Area & $=629.9 \mathrm{pm}^{\wedge} 2$ & Y-Slope & $=-2.5^{\circ}$ & Op. mode & $=$ Dynamic Force \\
\hline $\mathrm{Sa}$ & $=27.711 \mathrm{~nm}$ & Rotation & $=90^{\circ}$ & Cantilever type & $=A C L A$ \\
\hline $\mathrm{Sq}$ & $=34.497 \mathrm{~nm}$ & X-Pos & $=11 \mu \mathrm{m}$ & Head type & $=E Z 2-A F M$ \\
\hline Sy & $=297.3 \mathrm{~nm}$ & Y-Pos & $=0.46 \mu \mathrm{m}$ & Scan head & $=10-07-239 \cdot$ hed \\
\hline Sp & $=198.94 \mathrm{~nm}$ & Z-Plane & $=0 \mu \mathrm{m}$ & Software ver. & $=1-5-1-0$ \\
\hline Sv & $=-98.363 \mathrm{~nm}$ & Overscan & $=5 \%$ & Firmware ver. & $=2-1-1-2$ \\
\hline Sm & $=-191.43 \mathrm{fm}$ & \multicolumn{2}{|c|}{ Const. Height-Mod $\epsilon=$ Disabled } & Controller $\mathrm{S} / \mathrm{N}$ & $=023-06-252$ \\
\hline -- Line Roughness - & & Date & $=09-09-2008$ & -- Module -- & \\
\hline $\mathrm{Ra}$ & $=35.492 \mathrm{~nm}$ & Time & $=13: 39: 38$ & Controller Board & $=2$ \\
\hline $\mathrm{Rq}$ & $=42.495 \mathrm{~nm}$ & -- Feedback -- & & AFM Basic Module & $=2$ \\
\hline Ry & $=178.59 \mathrm{~nm}$ & Set point & $=48 \%$ & AFM Dynamic Module & $=2$ \\
\hline $\mathrm{Rp}$ & $=111.78 \mathrm{~nm}$ & P-Gain & $=10000$ & AFM Extension Modul & $\epsilon=1$ \\
\hline Rv & $=-66.811 \mathrm{~nm}$ & I-Gain & $=1900$ & Video Module & $=0$ \\
\hline $\mathrm{Rm}$ & $=76.6 \mathrm{pm}$ & Tip voltage & $=0 \mathrm{~V}$ & Signal Module S & $=0$ \\
\hline -- Scan -- & & Feedback mode & $=$ Free & Signal Module A & $=0$ \\
\hline Image size & $=25 \mu \mathrm{m}$ & Feedback algo. & = Adaptive $\mathrm{PI}$ & Nanosurf Report & $=0$ \\
\hline
\end{tabular}




\section{Nanosurf Image Document}

File: Image17

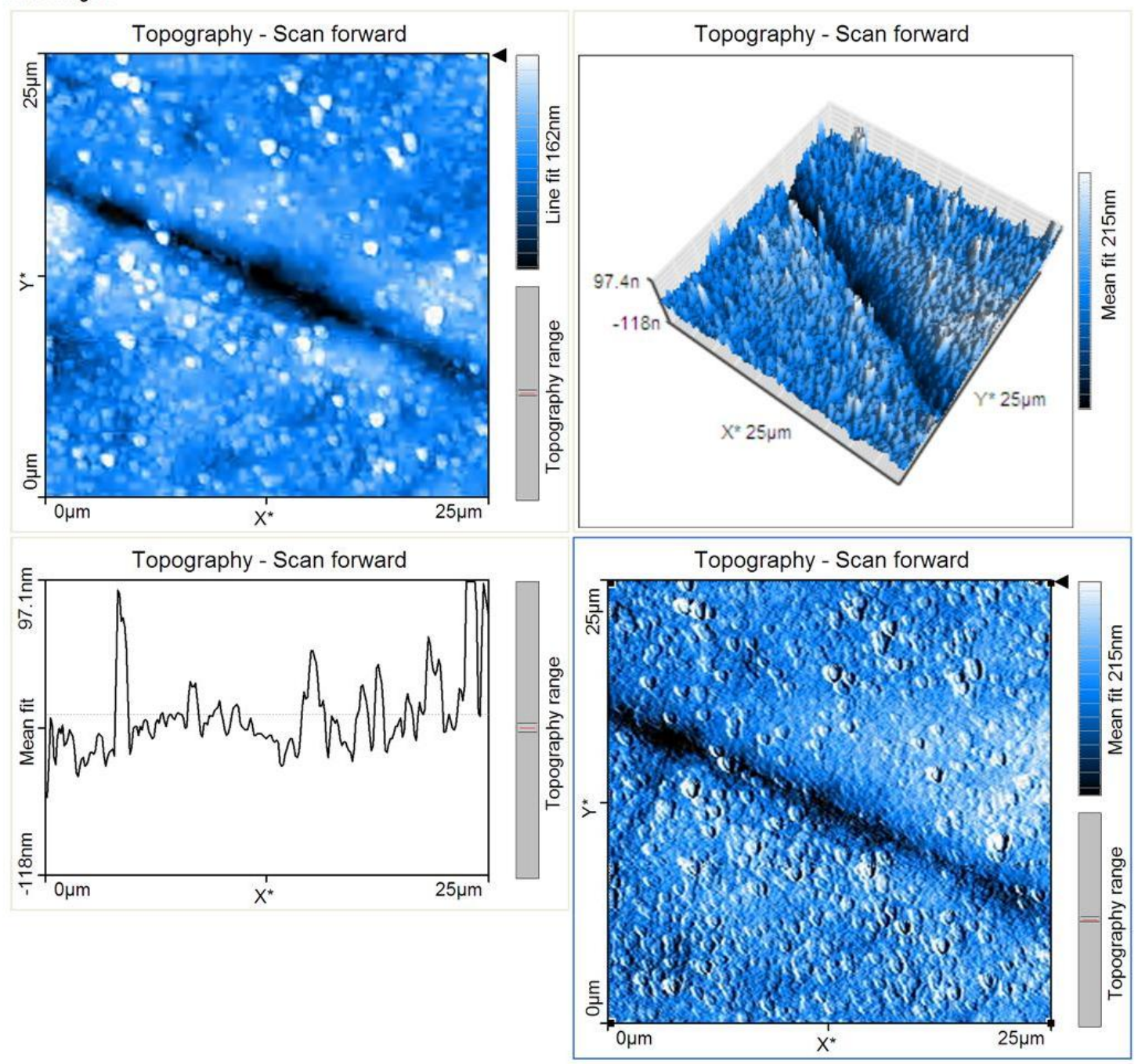

Parameter:

\begin{tabular}{|c|c|c|c|c|c|}
\hline \multicolumn{2}{|c|}{-- Area Roughness -- } & \multirow{2}{*}{$\begin{array}{l}\text { Lines } \\
\text { X-Slope }\end{array}$} & \multirow{2}{*}{$\begin{array}{l}=256 \\
=-1.25^{\circ}\end{array}$} & \multirow{2}{*}{$\begin{array}{l}\text { Excitation ampl. } \\
\text { Error range }\end{array}$} & \multirow{2}{*}{$\begin{array}{l}=0.23 \mathrm{~V} \\
=20 \mathrm{~V}\end{array}$} \\
\hline Area & $=629.9 \mathrm{pm}^{\wedge} 2$ & & & & \\
\hline Sa & $=25.009 \mathrm{~nm}$ & Y-Slope & $=-1.75^{\circ}$ & -- Global -- & \\
\hline $\mathrm{Sq}$ & $=34.785 \mathrm{~nm}$ & Rotation & $=0^{\circ}$ & Op. mode & $=$ Dynamic Force \\
\hline Sy & $=377 \mathrm{~nm}$ & X-Pos & $=11 \mu \mathrm{m}$ & Cantilever type & $=A C L A$ \\
\hline $\mathrm{Sp}$ & $=213.28 \mathrm{~nm}$ & Y-Pos & $=0.46 \mu \mathrm{m}$ & Head type & $=\mathrm{EZ2}-\mathrm{AFM}$ \\
\hline Sv & $=-163.73 \mathrm{~nm}$ & Z-Plane & $=0 \mu \mathrm{m}$ & Scan head & $=10-07-239 \cdot$ hed \\
\hline $\mathrm{Sm}$ & $=215.35 \mathrm{pm}$ & Overscan & $=5 \%$ & Software ver. & $=1-5-1-0$ \\
\hline \multicolumn{2}{|c|}{-- Line Roughness -- } & \multicolumn{2}{|c|}{ Const. Height-Mod $\epsilon=$ Disabled } & Firmware ver. & $=2-1-1-2$ \\
\hline $\mathrm{Ra}$ & $=20.37 \mathrm{~nm}$ & Date & $=09-09-2008$ & Controller $\mathrm{S} / \mathrm{N}$ & $=023-06-252$ \\
\hline $\mathrm{Rq}$ & $=26.298 \mathrm{~nm}$ & Time & $=13: 49: 13$ & -- Module -- & \\
\hline Ry & $=154.34 \mathrm{~nm}$ & -- Feedback -- & & Controller Board & $=2$ \\
\hline $\mathrm{Rp}$ & $=101.7 \mathrm{~nm}$ & Set point & $=48 \%$ & AFM Basic Module & $=2$ \\
\hline Rv & $=-52.64 \mathrm{~nm}$ & P-Gain & $=10000$ & \multicolumn{2}{|c|}{ AFM Dynamic Module $=2$} \\
\hline $\mathrm{Rm}$ & $=32.344 \mathrm{pm}$ & I-Gain & $=1900$ & \multicolumn{2}{|c|}{ AFM Extension Modul $=1$} \\
\hline -- Scan -- & & Tip voltage & $=0 \mathrm{~V}$ & Video Module & $=0$ \\
\hline Image size & $=25 \mu \mathrm{m}$ & Feedback mode & $=$ Free & Signal Module S & $=0$ \\
\hline Scan direction & $=U p$ & Feedback algo. & = Adaptive PI & Signal Module A & $=0$ \\
\hline Time/Line & $=0.6 \mathrm{~s}$ & Vibration freq. & $=179.054 \mathrm{kHz}$ & Nanosurf Report & $=0$ \\
\hline Points & $=256$ & Vibration ampl. & $=0.7 \mathrm{~V}$ & Scripting Interface & $=0$ \\
\hline
\end{tabular}




\section{Nanosurf Image Document}

File: Image18
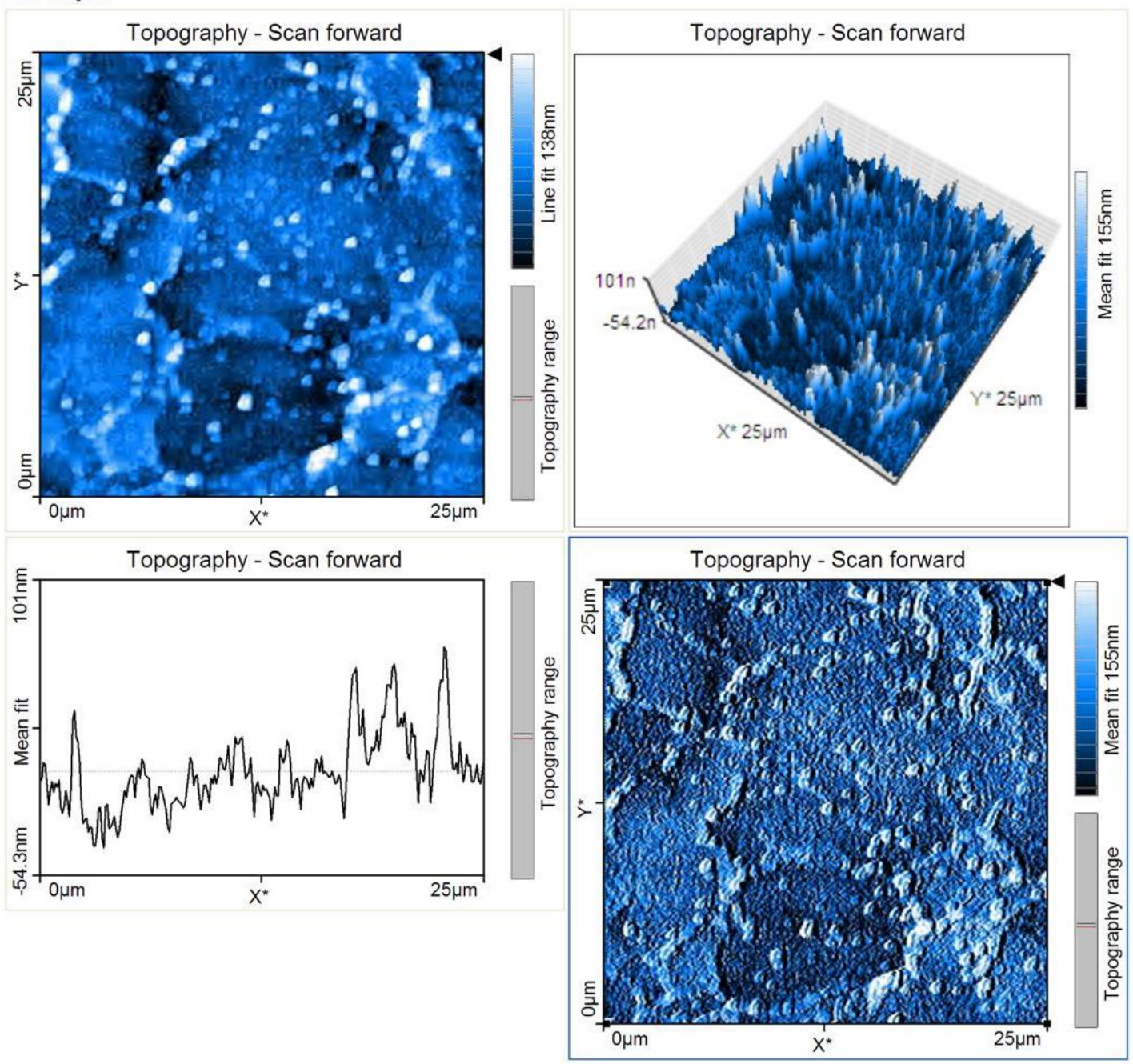

\section{Parameter:}

\begin{tabular}{|c|c|c|c|c|c|}
\hline \multicolumn{2}{|c|}{-- Area Roughness -- } & \multirow{2}{*}{$\begin{array}{l}\text { Lines } \\
\text { X-Slope }\end{array}$} & \multirow{2}{*}{$\begin{array}{l}=256 \\
=250 \mathrm{~m}^{\circ}\end{array}$} & \multirow{2}{*}{$\begin{array}{l}\text { Excitation ampl. } \\
\text { Error range }\end{array}$} & \multirow{2}{*}{$\begin{array}{l}=0.23 \mathrm{~V} \\
=20 \mathrm{~V}\end{array}$} \\
\hline Area & $=629.9 \mathrm{pm}^{\wedge} 2$ & & & & \\
\hline Sa & $=19.386 \mathrm{~nm}$ & Y-Slope & $=-2.25^{\circ}$ & -- Global -- & \\
\hline$S q$ & $=25.752 \mathrm{~nm}$ & Rotation & $=90^{\circ}$ & Op. mode & $=$ Dynamic Force \\
\hline Sy & $=225.4 \mathrm{~nm}$ & X-Pos & $=11 \mu \mathrm{m}$ & Cantilever type & $=A C L A$ \\
\hline Sp & $=149.6 \mathrm{~nm}$ & Y-Pos & $=0.46 \mu \mathrm{m}$ & Head type & $=\mathrm{EZ2}-\mathrm{AFM}$ \\
\hline Sv & $=-75.801 \mathrm{~nm}$ & Z-Plane & $=0 \mu \mathrm{m}$ & Scan head & $=10-07-239$. hed \\
\hline $\mathrm{Sm}$ & $=-776.99 \mathrm{fm}$ & Overscan & $=5 \%$ & Software ver. & $=1-5-1-0$ \\
\hline \multicolumn{2}{|c|}{-- Line Roughness -- } & \multicolumn{2}{|c|}{ Const. Height-Mod $\epsilon=$ Disabled } & Firmware ver. & $=2-1-1-2$ \\
\hline $\mathrm{Ra}$ & $=17.102 \mathrm{~nm}$ & Date & $=09-09-2008$ & Controller S/N & $=023-06-252$ \\
\hline $\mathrm{Rq}$ & $=25.744 \mathrm{~nm}$ & Time & $=13: 59: 45$ & -- Module -- & \\
\hline Ry & $=160.67 \mathrm{~nm}$ & -- Feedback -- & & Controller Board & $=2$ \\
\hline Rp & $=121.3 \mathrm{~nm}$ & Set point & $=48 \%$ & AFM Basic Module & $=2$ \\
\hline Rv & $=-39.368 \mathrm{~nm}$ & P-Gain & $=10000$ & \multicolumn{2}{|c|}{ AFM Dynamic Module $=2$} \\
\hline $\mathrm{Rm}$ & $=43.655 \mathrm{pm}$ & I-Gain & $=1800$ & \multicolumn{2}{|c|}{ AFM Extension Module $=1$} \\
\hline -- Scan -- & & Tip voltage & $=0 \mathrm{~V}$ & Video Module & $=0$ \\
\hline Image size & $=25 \mu \mathrm{m}$ & Feedback mode & $=$ Free & Signal Module S & $=0$ \\
\hline Scan direction & $=U p$ & Feedback algo. & = Adaptive PI & Signal Module A & $=0$ \\
\hline Time/Line & $=0.6 \mathrm{~s}$ & Vibration freq. & $=179.064 \mathrm{kHz}$ & Nanosurf Report & $=0$ \\
\hline Points & $=256$ & Vibration ampl. & $=0.7 \mathrm{~V}$ & Scripting Interface & $=0$ \\
\hline
\end{tabular}


A-600-4 after heat treatment

\section{Nanosurf Image Document}

File: Image2
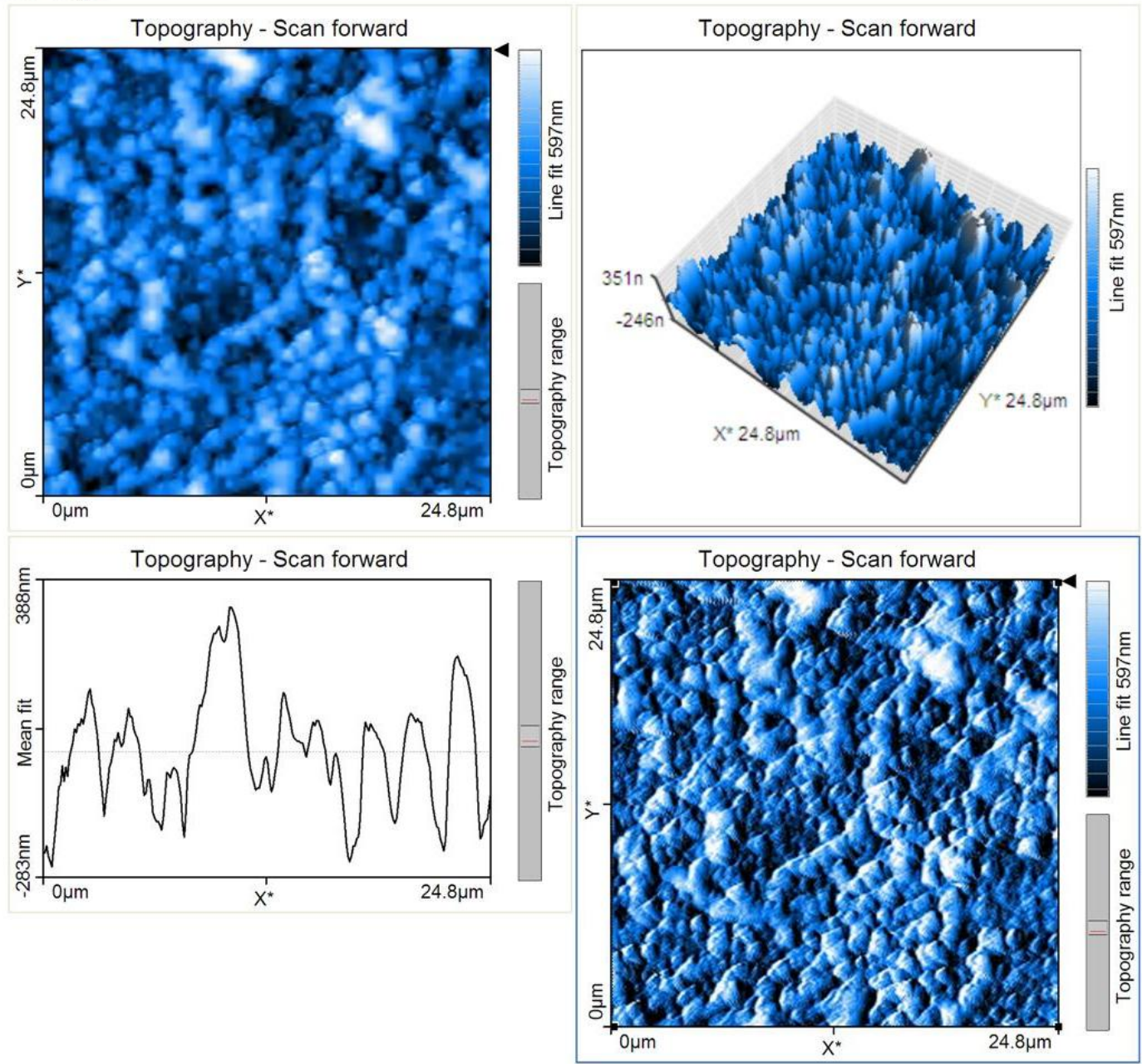

Parameter:

\begin{tabular}{|c|c|c|c|c|c|}
\hline \multicolumn{2}{|c|}{-- Area Roughness -- } & \multirow{2}{*}{$\begin{array}{l}\text { Lines } \\
\text { X-Slope }\end{array}$} & \multirow{2}{*}{$\begin{array}{l}=256 \\
=500 \mathrm{~m}^{\circ}\end{array}$} & \multirow{2}{*}{$\begin{array}{l}\text { Excitation ampl. } \\
\text { Error range }\end{array}$} & \multirow{2}{*}{$\begin{array}{l}=0.25 \mathrm{~V} \\
=20 \mathrm{~V}\end{array}$} \\
\hline Area & $=618 \mathrm{pm}^{\wedge} 2$ & & & & \\
\hline Sa & $=89.336 \mathrm{~nm}$ & Y-Slope & $=5.25^{\circ}$ & -- Global -- & \\
\hline $\mathrm{Sq}$ & $=109.84 \mathrm{~nm}$ & Rotation & $=90^{\circ}$ & Op. mode & $=$ Dynamic Force \\
\hline Sy & $=725.96 \mathrm{~nm}$ & X-Pos & $=0 \mathrm{~m}$ & Cantilever type & $=A C L A$ \\
\hline $\mathrm{Sp}$ & $=393.56 \mathrm{~nm}$ & Y-Pos & $=0 \mathrm{~m}$ & Head type & $=E Z 2-A F M$ \\
\hline Sv & $=-332.41 \mathrm{~nm}$ & Z-Plane & $=0 \mathrm{~m}$ & Scan head & $=10-07-239$. hed \\
\hline $\mathrm{Sm}$ & $=6.7227 \mathrm{pm}$ & Overscan & $=5 \%$ & Software ver. & $=1-5-1-0$ \\
\hline \multicolumn{2}{|c|}{-- Line Roughness -- } & \multicolumn{2}{|c|}{ Const. Height-Mode= Disabled } & Firmware ver. & $=2-1-1-2$ \\
\hline $\mathrm{Ra}$ & $=83.344 \mathrm{~nm}$ & Date & $=09-09-2008$ & Controller $\mathrm{S} / \mathrm{N}$ & $=023-06-252$ \\
\hline $\mathrm{Rq}$ & $=105.53 \mathrm{~nm}$ & Time & $=16: 15: 08$ & -- Module -- & \\
\hline Ry & $=500.35 \mathrm{~nm}$ & -- Feedback -- & & Controller Board & $=2$ \\
\hline $\mathrm{Rp}$ & $=278.22 \mathrm{~nm}$ & Set point & $=48 \%$ & AFM Basic Module & $=2$ \\
\hline Rv & $=-222.13 \mathrm{~nm}$ & P-Gain & $=10000$ & \multicolumn{2}{|c|}{ AFM Dynamic Module $=2$} \\
\hline $\mathrm{Rm}$ & $=1.6087 \mathrm{fm}$ & I-Gain & $=1300$ & \multicolumn{2}{|c|}{ AFM Extension Modul $\epsilon=1$} \\
\hline -- Scan -- & & Tip voltage & $=0 \mathrm{~V}$ & Video Module & $=0$ \\
\hline Image size & $=25 \mu \mathrm{m}$ & Feedback mode & $=$ Free & Signal Module S & $=0$ \\
\hline Scan direction & $=U p$ & Feedback algo. & = Adaptive PI & Signal Module A & $=0$ \\
\hline Time/Line & $=0.5 \mathrm{~s}$ & Vibration freq. & $=179.094 \mathrm{kHz}$ & Nanosurf Report & $=0$ \\
\hline Points & $=256$ & Vibration ampl. & $=0.7 \mathrm{~V}$ & Scripting Interface & $=0$ \\
\hline
\end{tabular}




\section{Nanosurf Image Document}

File: Image3

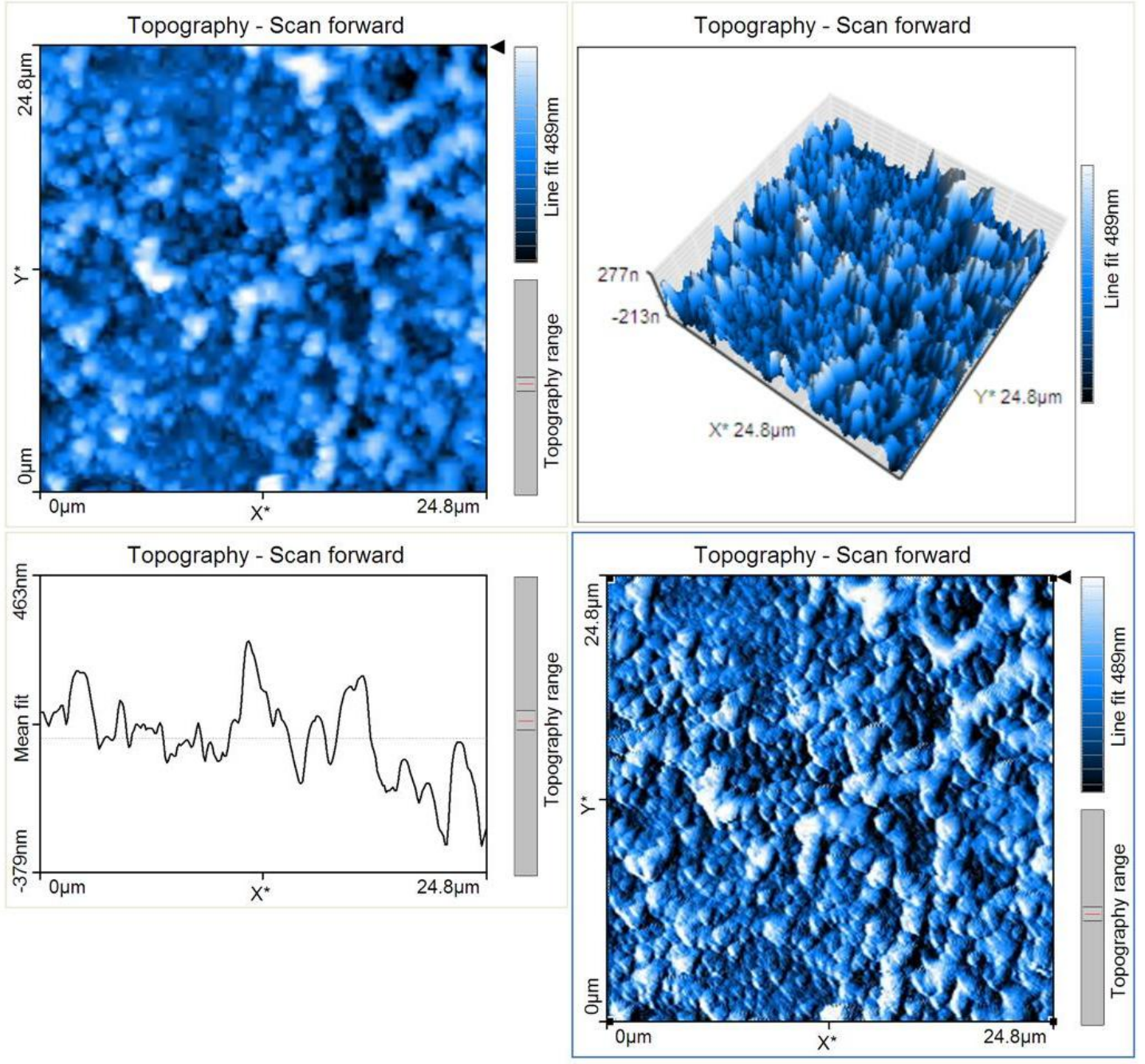

Parameter:

\begin{tabular}{|c|c|c|c|c|c|}
\hline \multicolumn{2}{|c|}{-- Area Roughness -- } & \multirow{2}{*}{$\begin{array}{l}\text { Lines } \\
\text { X-Slope }\end{array}$} & \multirow{2}{*}{$\begin{array}{l}=256 \\
=500 \mathrm{~m}^{\circ}\end{array}$} & \multirow{2}{*}{$\begin{array}{l}\text { Excitation ampl. } \\
\text { Error range }\end{array}$} & \multirow{2}{*}{$\begin{array}{l}=0.25 \mathrm{~V} \\
=20 \mathrm{~V}\end{array}$} \\
\hline Area & $=618 \mathrm{pm}^{\wedge} 2$ & & & & \\
\hline Sa & $=73.841 \mathrm{~nm}$ & Y-Slope & $=4.75^{\circ}$ & -- Global -- & \\
\hline $\mathrm{Sq}$ & $=91.994 \mathrm{~nm}$ & Rotation & $=0^{\circ}$ & Op. mode & $=$ Dynamic Force \\
\hline Sy & $=714.58 \mathrm{~nm}$ & X-Pos & $=0 \mathrm{~m}$ & Cantilever type & $=A C L A$ \\
\hline Sp & $=444.79 \mathrm{~nm}$ & Y-Pos & $=0 \mathrm{~m}$ & Head type & $=E Z 2-A F M$ \\
\hline Sv & $=-269.79 \mathrm{~nm}$ & Z-Plane & $=0 \mathrm{~m}$ & Scan head & $=10-07-239$. hed \\
\hline Sm & $=210.94 \mathrm{pm}$ & Overscan & $=5 \%$ & Software ver. & $=1-5-1-0$ \\
\hline \multicolumn{2}{|c|}{-- Line Roughness -- } & \multicolumn{2}{|c|}{ Const. Height-Mod $\epsilon=$ Disabled } & Firmware ver. & $=2-1-1-2$ \\
\hline $\mathrm{Ra}$ & $=75.381 \mathrm{~nm}$ & Date & $=09-09-2008$ & Controller S/N & $=023-06-252$ \\
\hline $\mathrm{Rq}$ & $=99.454 \mathrm{~nm}$ & Time & $=16: 25: 07$ & -- Module -- & \\
\hline Ry & $=485.8 \mathrm{~nm}$ & -- Feedback -- & & Controller Board & $=2$ \\
\hline $\mathrm{Rp}$ & $=311.96 \mathrm{~nm}$ & Set point & $=48 \%$ & AFM Basic Module & $=2$ \\
\hline $\mathrm{Rv}$ & $=-173.85 \mathrm{~nm}$ & P-Gain & $=10000$ & AFM Dynamic Module & $=2$ \\
\hline $\mathrm{Rm}$ & $=210.03 \mathrm{pm}$ & I-Gain & $=1300$ & AFM Extension Modul & $\epsilon=1$ \\
\hline \multicolumn{2}{|l|}{-- Scan -- } & Tip voltage & $=0 \mathrm{~V}$ & Video Module & $=0$ \\
\hline Image size & $=25 \mu \mathrm{m}$ & Feedback mode & $=$ Free & Signal Module S & $=0$ \\
\hline Scan direction & $=U p$ & Feedback algo. & $=$ Adaptive PI & Signal Module A & $=0$ \\
\hline Time/Line & $=0.5 \mathrm{~s}$ & Vibration freq. & $=179.094 \mathrm{kHz}$ & Nanosurf Report & $=0$ \\
\hline Points & $=256$ & Vibration ampl. & $=0.7 \mathrm{~V}$ & Scripting Interface & $=0$ \\
\hline
\end{tabular}




\section{Nanosurf Image Document}

File: Image4

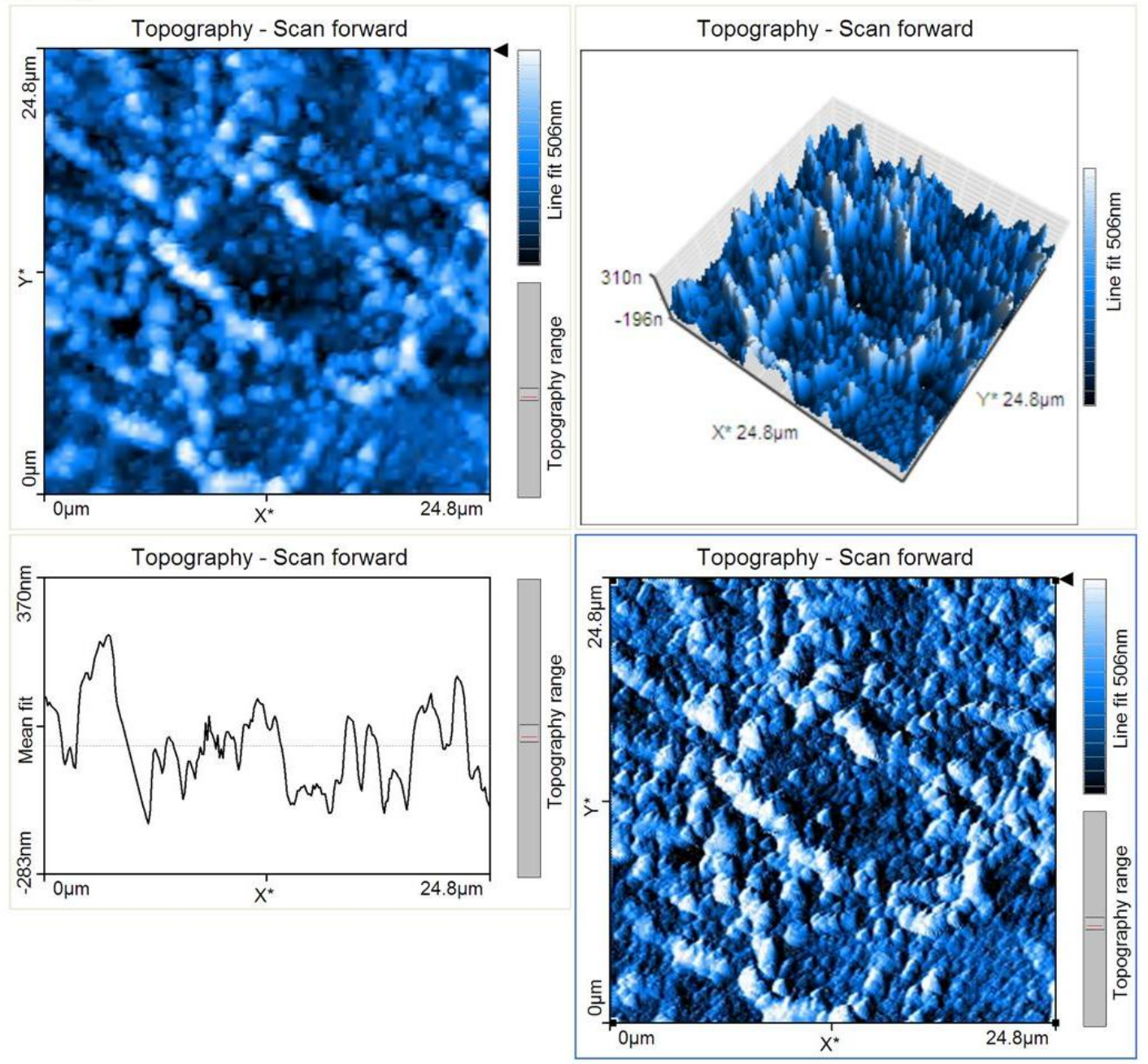

Parameter:

\begin{tabular}{|c|c|c|c|c|c|}
\hline \multicolumn{2}{|c|}{-- Area Roughness -- } & \multirow{2}{*}{$\begin{array}{l}\text { Lines } \\
\text { X-Slope }\end{array}$} & \multirow{2}{*}{$\begin{array}{l}=256 \\
=-1.5^{\circ}\end{array}$} & \multirow{2}{*}{$\begin{array}{l}\text { Excitation ampl. } \\
\text { Error range }\end{array}$} & \multirow{2}{*}{$\begin{array}{l}=0.23 \mathrm{~V} \\
=20 \mathrm{~V}\end{array}$} \\
\hline Area & $=618 \mathrm{pm}^{\wedge} 2$ & & & & \\
\hline $\mathrm{Sa}$ & $=82.47 \mathrm{~nm}$ & Y-Slope & $=4.25^{\circ}$ & -- Global -- & \\
\hline $\mathrm{Sq}$ & $=102.38 \mathrm{~nm}$ & Rotation & $=90^{\circ}$ & Op. mode & $=$ Dynamic Force \\
\hline Sy & $=706.14 \mathrm{~nm}$ & X-Pos & $=0 \mathrm{~m}$ & Cantilever type & $=A C L A$ \\
\hline Sp & $=383.44 \mathrm{~nm}$ & Y-Pos & $=0 \mathrm{~m}$ & Head type & $=\mathrm{EZ2}-\mathrm{AFM}$ \\
\hline Sv & $=-322.71 \mathrm{~nm}$ & Z-Plane & $=0 \mathrm{~m}$ & Scan head & $=10-07-239$. hed \\
\hline $\mathrm{Sm}$ & $=4.2582 \mathrm{pm}$ & Overscan & $=5 \%$ & Software ver. & $=1-5-1-0$ \\
\hline \multicolumn{2}{|c|}{-- Line Roughness -- } & \multicolumn{2}{|c|}{ Const. Height-Mode= Disabled } & Firmware ver. & $=2-1-1-2$ \\
\hline $\mathrm{Ra}$ & $=110.37 \mathrm{~nm}$ & Date & $=09-09-2008$ & Controller S/N & $=023-06-252$ \\
\hline $\mathrm{Rq}$ & $=127.99 \mathrm{~nm}$ & Time & $=16: 35: 34$ & -- Module -- & \\
\hline Ry & $=491.08 \mathrm{~nm}$ & -- Feedback -- & & Controller Board & $=2$ \\
\hline $\mathrm{Rp}$ & $=310.27 \mathrm{~nm}$ & Set point & $=48 \%$ & AFM Basic Module & $=2$ \\
\hline Rv & $=-180.8 \mathrm{~nm}$ & P-Gain & $=10000$ & \multicolumn{2}{|c|}{ AFM Dynamic Module $=2$} \\
\hline $\mathrm{Rm}$ & $=-2469.3 \mathrm{fm}$ & I-Gain & $=1300$ & \multicolumn{2}{|c|}{ AFM Extension Modul $\epsilon=1$} \\
\hline -- Scan -- & & Tip voltage & $=0 \mathrm{~V}$ & Video Module & $=0$ \\
\hline Image size & $=25 \mu \mathrm{m}$ & Feedback mode & $=$ Free & Signal Module S & $=0$ \\
\hline Scan direction & $=U p$ & Feedback algo. & = Adaptive PI & Signal Module A & $=0$ \\
\hline Time/Line & $=0.5 \mathrm{~s}$ & Vibration freq. & $=179.074 \mathrm{kHz}$ & Nanosurf Report & $=0$ \\
\hline Points & $=256$ & Vibration ampl. & $=0.7 \mathrm{~V}$ & Scripting Interface & $=0$ \\
\hline
\end{tabular}


A-600-8 after heat treatment

\section{Nanosurf Image Document}

File: Image12
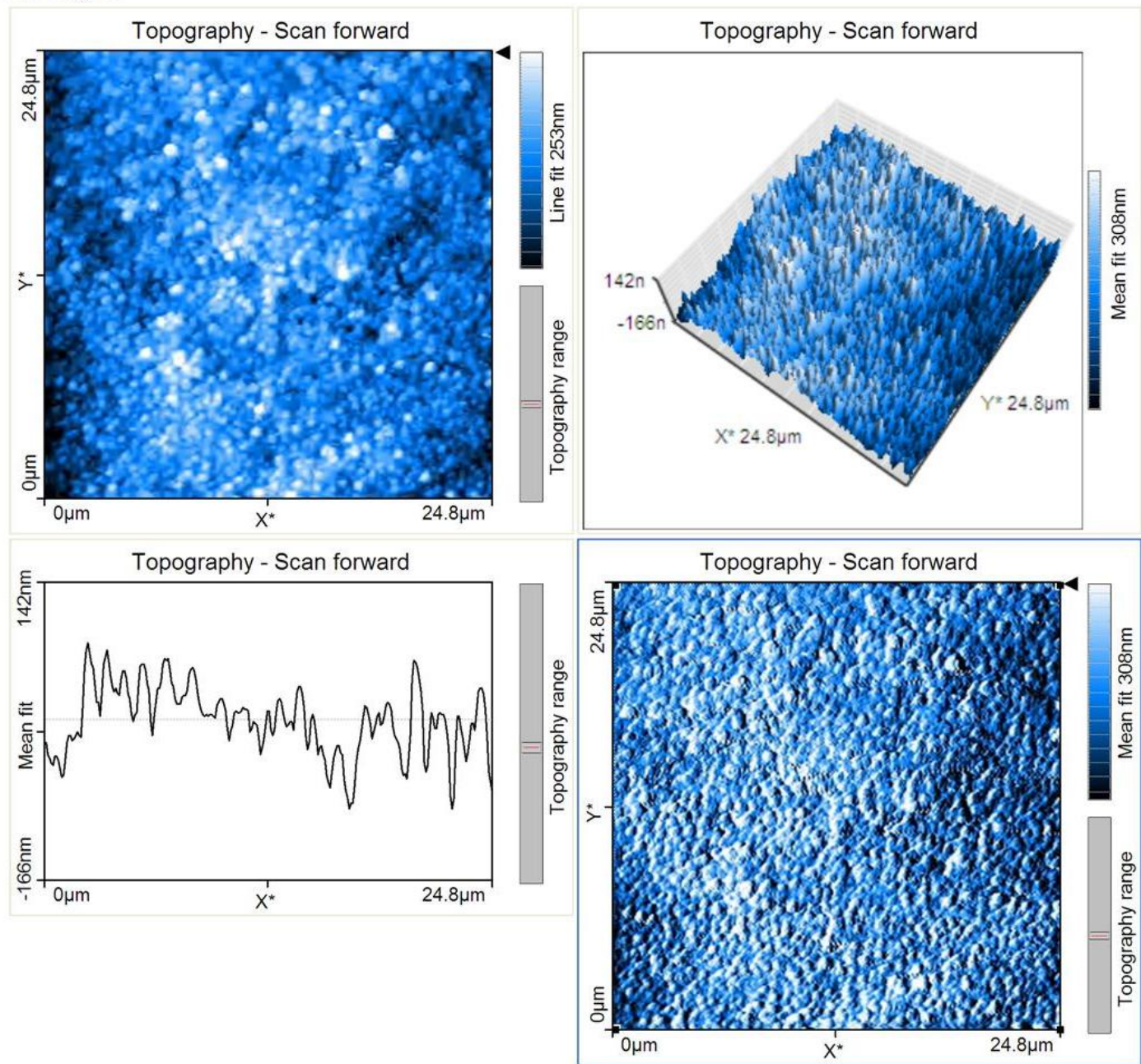

Parameter:

\begin{tabular}{|c|c|c|c|c|c|}
\hline \multicolumn{2}{|c|}{-- Area Roughness -- } & \multirow{2}{*}{$\begin{array}{l}\text { Lines } \\
\text { X-Slope }\end{array}$} & \multirow{2}{*}{$\begin{array}{l}=256 \\
=500 \mathrm{~m}^{\circ}\end{array}$} & \multirow{2}{*}{$\begin{array}{l}\text { Excitation ampl. } \\
\text { Error range }\end{array}$} & \multirow{2}{*}{$\begin{array}{l}=0.19 \mathrm{~V} \\
=20 \mathrm{~V}\end{array}$} \\
\hline Area & $=618 \mathrm{pm}^{\wedge} 2$ & & & & \\
\hline $\mathrm{Sa}$ & $=42.105 \mathrm{~nm}$ & Y-Slope & $=-1^{\circ}$ & -- Global -- & \\
\hline $\mathrm{Sq}$ & $=52.867 \mathrm{~nm}$ & Rotation & $=90^{\circ}$ & Op. mode & $=$ Dynamic Force \\
\hline Sy & $=399.78 \mathrm{~nm}$ & X-Pos & $=-0.19 \mu \mathrm{m}$ & Cantilever type & $=A C L A$ \\
\hline Sp & $=217.49 \mathrm{~nm}$ & Y-Pos & $=13 \mu \mathrm{m}$ & Head type & $=\mathrm{EZ2}-\mathrm{AFM}$ \\
\hline Sv & $=-182.28 \mathrm{~nm}$ & Z-Plane & $=-0.23 \mu \mathrm{m}$ & Scan head & $=10-07-239 . \mathrm{hed}$ \\
\hline $\mathrm{Sm}$ & $=-6.6937 \mathrm{pm}$ & Overscan & $=5 \%$ & Software ver. & $=1-5-1-0$ \\
\hline \multicolumn{2}{|c|}{-- Line Roughness -- } & \multicolumn{2}{|c|}{ Const. Height-Mode= Disabled } & Firmware ver. & $=2-1-1-2$ \\
\hline $\mathrm{Ra}$ & $=46.235 \mathrm{~nm}$ & Date & $=05-09-2008$ & Controller S/N & $=023-06-252$ \\
\hline $\mathrm{Rq}$ & $=57.025 \mathrm{~nm}$ & Time & $=12: 52: 11$ & -- Module -- & \\
\hline Ry & $=286.34 \mathrm{~nm}$ & \multicolumn{2}{|l|}{-- Feedback -- } & Controller Board & $=2$ \\
\hline $\mathrm{Rp}$ & $=140.52 \mathrm{~nm}$ & Set point & $=48 \%$ & AFM Basic Module & $=2$ \\
\hline Rv & $=-145.82 \mathrm{~nm}$ & P-Gain & $=10000$ & \multicolumn{2}{|c|}{ AFM Dynamic Module $=2$} \\
\hline $\mathrm{Rm}$ & $=10.709 \mathrm{pm}$ & I-Gain & $=1700$ & \multicolumn{2}{|c|}{ AFM Extension Modul $\epsilon=1$} \\
\hline -- Scan -- & & Tip voltage & $=0 \mathrm{~V}$ & Video Module & $=0$ \\
\hline Image size & $=25 \mu \mathrm{m}$ & Feedback mode & $=$ Free & Signal Module S & $=0$ \\
\hline Scan direction & $=U p$ & Feedback algo. & = Adaptive PI & Signal Module A & $=0$ \\
\hline Time/Line & $=0.4 \mathrm{~s}$ & Vibration freq. & $=179.044 \mathrm{kHz}$ & Nanosurf Report & $=0$ \\
\hline Points & $=256$ & Vibration ampl. & $=0.7 \mathrm{~V}$ & Scripting Interface & $=0$ \\
\hline
\end{tabular}




\section{Nanosurf Image Document}

File: Image13

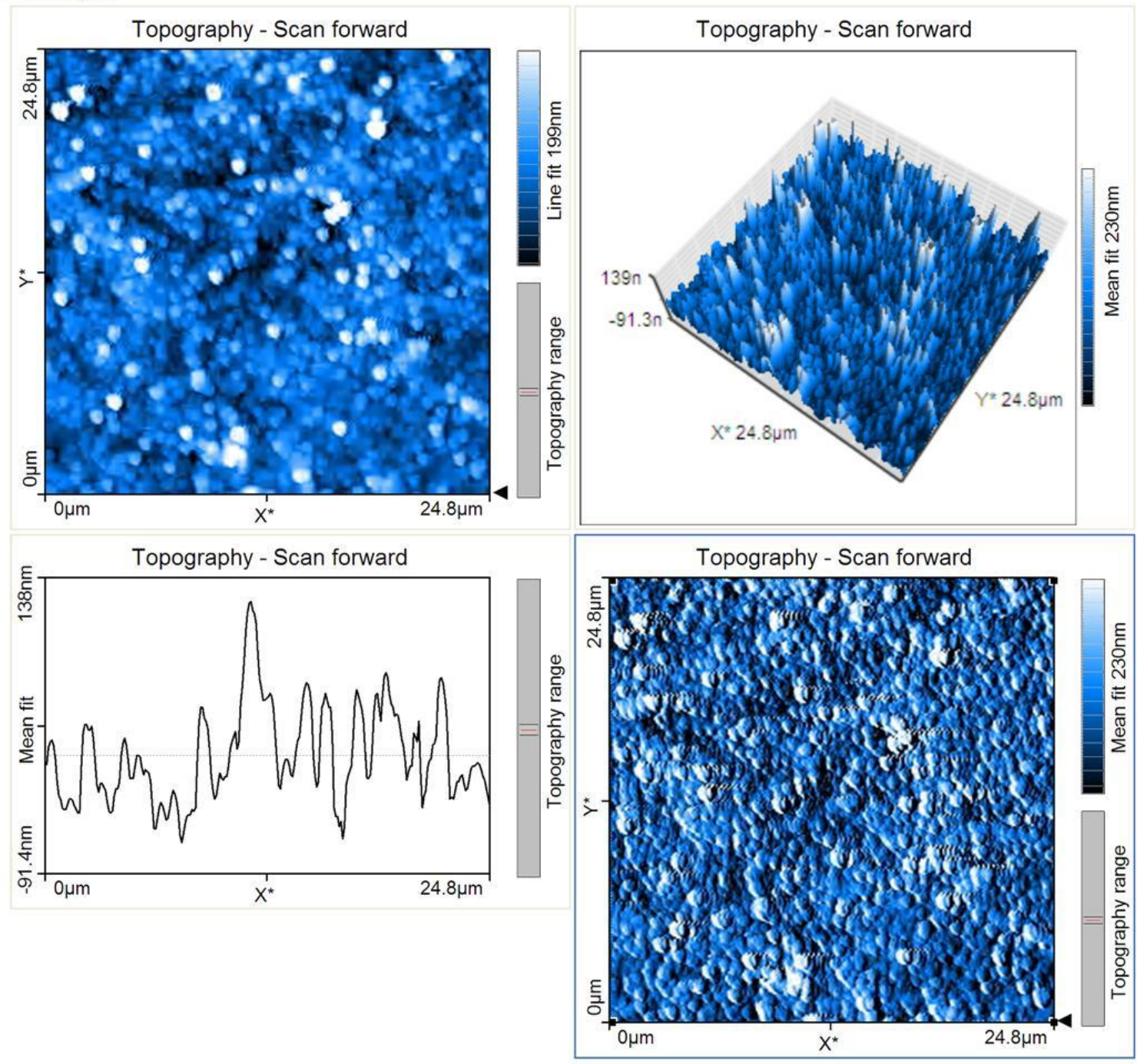

Parameter:

\begin{tabular}{|c|c|c|c|c|c|}
\hline \multicolumn{2}{|c|}{-- Area Roughness -- } & \multirow{2}{*}{$\begin{array}{l}\text { Lines } \\
\text { X-Slope }\end{array}$} & \multirow{2}{*}{$\begin{array}{l}=256 \\
=500 \mathrm{~m}^{\circ}\end{array}$} & \multirow{2}{*}{$\begin{array}{l}\text { Excitation ampl. } \\
\text { Error range }\end{array}$} & \multirow{2}{*}{$\begin{array}{l}=0.23 \mathrm{~V} \\
=20 \mathrm{~V}\end{array}$} \\
\hline Area & $=618 \mathrm{pm}^{\wedge} 2$ & & & & \\
\hline $\mathrm{Sa}$ & $=28.166 \mathrm{~nm}$ & Y-Slope & $=-1^{\circ}$ & -- Global -- & \\
\hline $\mathrm{Sq}$ & $=38.112 \mathrm{~nm}$ & Rotation & $=-0.888 f^{\circ}$ & Op. mode & $=$ Dynamic Force \\
\hline Sy & $=358.45 \mathrm{~nm}$ & X-Pos & $=-0.19 \mu \mathrm{m}$ & Cantilever type & $=A C L A$ \\
\hline Sp & $=253.34 \mathrm{~nm}$ & Y-Pos & $=13 \mu \mathrm{m}$ & Head type & $=\mathrm{EZ2}-\mathrm{AFM}$ \\
\hline Sv & $=-105.11 \mathrm{~nm}$ & Z-Plane & $=0 \mu \mathrm{m}$ & Scan head & $=10-07-239$.hed \\
\hline $\mathrm{Sm}$ & $=148.82 \mathrm{pm}$ & Overscan & $=5 \%$ & Software ver. & $=1-5-1-0$ \\
\hline \multicolumn{2}{|c|}{-- Line Roughness -- } & \multicolumn{2}{|c|}{ Const. Height-Mod $\epsilon=$ Disabled } & Firmware ver. & $=2-1-1-2$ \\
\hline $\mathrm{Ra}$ & $=34.104 \mathrm{~nm}$ & Date & $=05-09-2008$ & Controller $\mathrm{S} / \mathrm{N}$ & $=023-06-252$ \\
\hline $\mathrm{Rq}$ & $=44.996 \mathrm{~nm}$ & Time & $=13: 04: 20$ & -- Module -- & \\
\hline Ry & $=251.55 \mathrm{~nm}$ & -- Feedback -- & & Controller Board & $=2$ \\
\hline $\mathrm{Rp}$ & $=163.82 \mathrm{~nm}$ & Set point & $=48 \%$ & AFM Basic Module & $=2$ \\
\hline Rv & $=-87.723 \mathrm{~nm}$ & P-Gain & $=10000$ & AFM Dynamic Module & $=2$ \\
\hline $\mathrm{Rm}$ & $=113.66 \mathrm{pm}$ & I-Gain & $=1700$ & AFM Extension Module & $\epsilon=1$ \\
\hline \multicolumn{2}{|l|}{-- Scan -- } & Tip voltage & $=0 \mathrm{~V}$ & Video Module & $=0$ \\
\hline Image size & $=25 \mu \mathrm{m}$ & Feedback mode & $=$ Free & Signal Module S & $=0$ \\
\hline Scan direction & $=$ Down & Feedback algo. & $=$ Adaptive PI & Signal Module A & $=0$ \\
\hline Time/Line & $=0.4 \mathrm{~s}$ & Vibration freq. & $=179.094 \mathrm{kHz}$ & Nanosurf Report & $=0$ \\
\hline Points & $=256$ & Vibration ampl. & $=0.7 \mathrm{~V}$ & Scripting Interface & $=0$ \\
\hline
\end{tabular}




\section{Nanosurf Image Document}

File: Image14
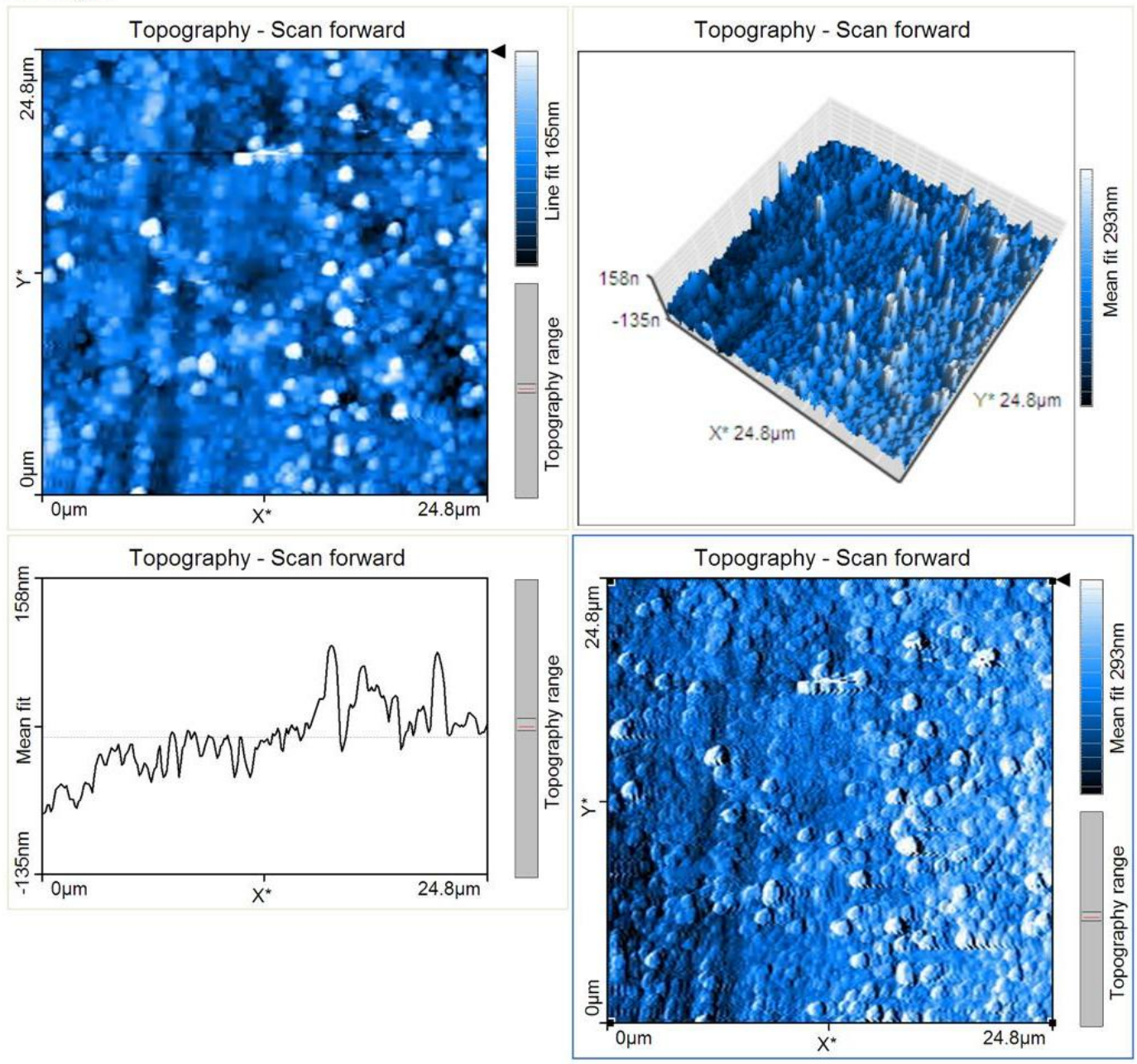

Parameter:

\begin{tabular}{|c|c|c|c|c|c|}
\hline \multicolumn{2}{|c|}{-- Area Roughness -- } & \multirow{2}{*}{$\begin{array}{l}\text { Lines } \\
\text { X-Slope }\end{array}$} & \multirow{2}{*}{$\begin{array}{l}=256 \\
=0^{\circ}\end{array}$} & \multirow{2}{*}{$\begin{array}{l}\text { Excitation ampl. } \\
\text { Error range }\end{array}$} & \multirow{2}{*}{$\begin{array}{l}=0.19 \mathrm{~V} \\
=20 \mathrm{~V}\end{array}$} \\
\hline Area & $=618 \mathrm{pm}^{\wedge} 2$ & & & & \\
\hline $\mathrm{Sa}$ & $=37.571 \mathrm{~nm}$ & Y-Slope & $=0.389 \mathrm{f}^{\circ}$ & -- Global -- & \\
\hline $\mathrm{Sq}$ & $=47.713 \mathrm{~nm}$ & Rotation & $=90^{\circ}$ & Op. mode & = Dynamic Force \\
\hline Sy & $=493.82 \mathrm{~nm}$ & X-Pos & $=-0.19 \mu \mathrm{m}$ & Cantilever type & $=A C L A$ \\
\hline $\mathrm{Sp}$ & $=352.86 \mathrm{~nm}$ & Y-Pos & $=13 \mu \mathrm{m}$ & Head type & $=E Z 2-A F M$ \\
\hline Sv & $=-140.95 \mathrm{~nm}$ & Z-Plane & $=0 \mu \mathrm{m}$ & Scan head & $=10-07-239$. hed \\
\hline Sm & $=215.66 \mathrm{pm}$ & Overscan & $=5 \%$ & Software ver. & $=1-5-1-0$ \\
\hline \multicolumn{2}{|c|}{-- Line Roughness -- } & \multicolumn{2}{|c|}{ Const. Height-Mode= Disabled } & Firmware ver. & $=2-1-1-2$ \\
\hline $\mathrm{Ra}$ & $=23.075 \mathrm{~nm}$ & Date & $=05-09-2008$ & Controller S/N & $=023-06-252$ \\
\hline $\mathrm{Rq}$ & $=36.593 \mathrm{~nm}$ & Time & $=13: 11: 24$ & -- Module -- & \\
\hline Ry & $=257.03 \mathrm{~nm}$ & -- Feedback -- & & Controller Board & $=2$ \\
\hline Rp & $=201.1 \mathrm{~nm}$ & Set point & $=48 \%$ & AFM Basic Module & $=2$ \\
\hline Rv & $=-55.928 \mathrm{~nm}$ & P-Gain & $=10000$ & \multicolumn{2}{|c|}{ AFM Dynamic Module $=2$} \\
\hline $\mathrm{Rm}$ & $=42.96 \mathrm{~nm}$ & I-Gain & $=1800$ & \multicolumn{2}{|c|}{ AFM Extension Modul $=1$} \\
\hline -- Scan -- & & Tip voltage & $=0 \mathrm{~V}$ & Video Module & $=0$ \\
\hline Image size & $=25 \mu \mathrm{m}$ & Feedback mode & $=$ Free & Signal Module S & $=0$ \\
\hline Scan direction & $=U p$ & Feedback algo. & = Adaptive PI & Signal Module A & $=0$ \\
\hline Time/Line & $=0.3 \mathrm{~s}$ & Vibration freq. & $=179.054 \mathrm{kHz}$ & Nanosurf Report & $=0$ \\
\hline Points & $=256$ & Vibration ampl. & $=0.7 \mathrm{~V}$ & Scripting Interface & $=0$ \\
\hline
\end{tabular}


A-600-16 after heat treatment

\section{Nanosurf Image Document}

File: Image15
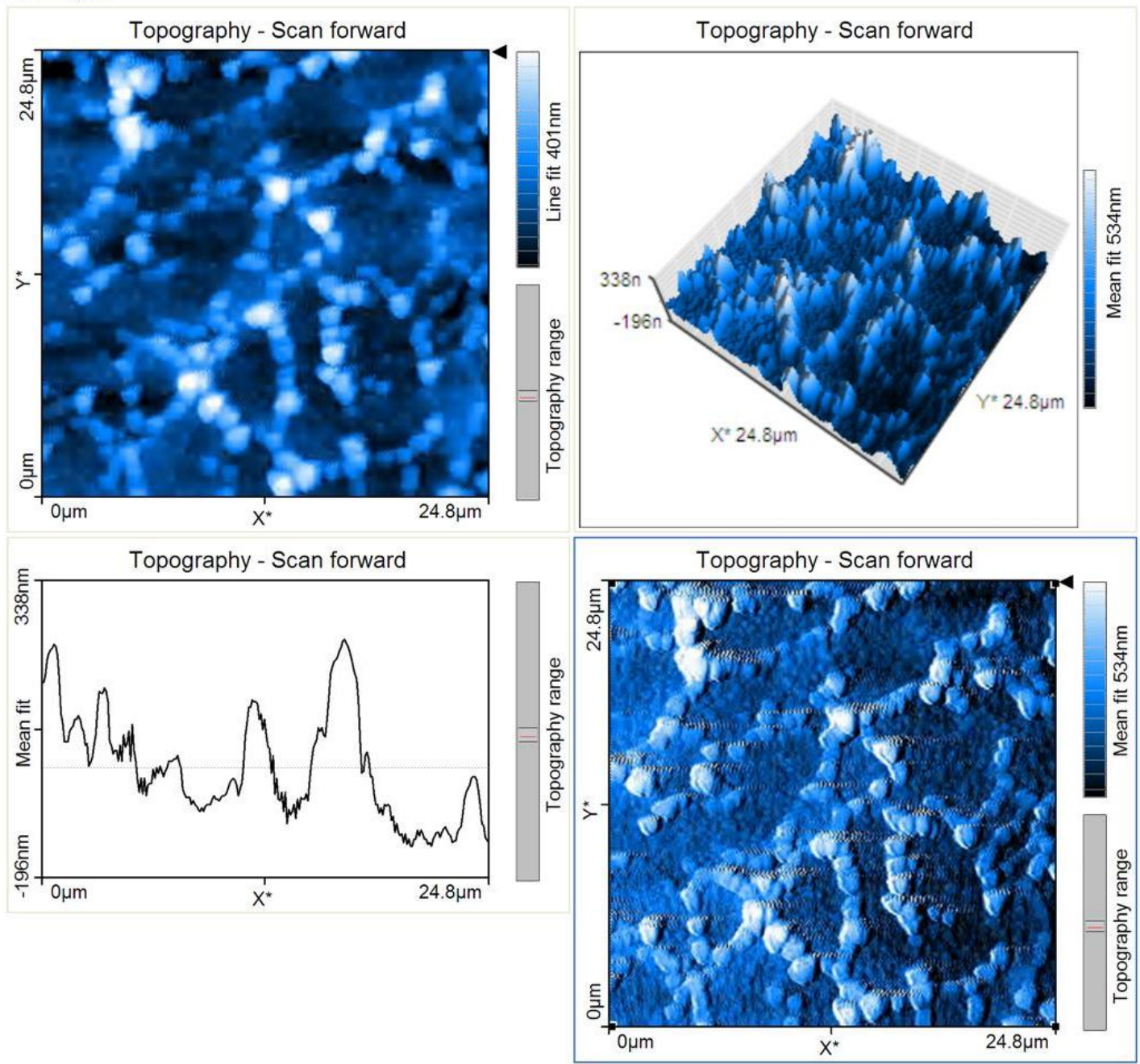

Parameter:

\begin{tabular}{|c|c|c|c|}
\hline \multicolumn{2}{|c|}{-- Area Roughness -- } & \multirow{2}{*}{$\begin{array}{l}\text { Lines } \\
\text { X-Slope }\end{array}$} & \multirow{2}{*}{$\begin{array}{l}=256 \\
=3^{\circ}\end{array}$} \\
\hline Area & $=618 \mathrm{pm}^{\wedge} 2$ & & \\
\hline $\mathrm{Sa}$ & $=74.267 \mathrm{~nm}$ & Y-Slope & $=6^{\circ}$ \\
\hline $\mathrm{Sq}$ & $=94.2 \mathrm{~nm}$ & Rotation & $=-14.2 f^{\circ}$ \\
\hline Sy & $=565.93 \mathrm{~nm}$ & X-Pos & $=-0.19 \mu \mathrm{m}$ \\
\hline Sp & $=371.84 \mathrm{~nm}$ & Y-Pos & $=13 \mu \mathrm{m}$ \\
\hline Sv & $=-194.09 \mathrm{~nm}$ & Z-Plane & $=0 \mu \mathrm{m}$ \\
\hline $\mathrm{Sm}$ & $=4.892 \mathrm{pm}$ & Overscan & $=5 \%$ \\
\hline \multicolumn{2}{|c|}{-- Line Roughness -- } & \multicolumn{2}{|c|}{ Const. Height-Mod $\epsilon=$ Disabled } \\
\hline $\mathrm{Ra}$ & $=46.303 \mathrm{~nm}$ & Date & $=05-09-2008$ \\
\hline $\mathrm{Rq}$ & $=59.784 \mathrm{~nm}$ & Time & $=13: 21: 09$ \\
\hline Ry & $=281.7 \mathrm{~nm}$ & -- Feedback -- & \\
\hline $\mathrm{Rp}$ & $=162.17 \mathrm{~nm}$ & Set point & $=48 \%$ \\
\hline Rv & $=-119.53 \mathrm{~nm}$ & P-Gain & $=10000$ \\
\hline $\mathrm{Rm}$ & $=85.66 \mathrm{pm}$ & I-Gain & $=1700$ \\
\hline -- Scan -- & & Tip voltage & $=0 \mathrm{~V}$ \\
\hline Image size & $=25 \mu \mathrm{m}$ & Feedback mode & $=$ Free \\
\hline Scan direction & $=U p$ & Feedback algo. & = Adaptive PI \\
\hline Time/Line & $=0.5 \mathrm{~s}$ & Vibration freq. & $=179.034 \mathrm{kHz}$ \\
\hline
\end{tabular}

$\begin{array}{ll}\text { Excitation ampl. } & =0.19 \mathrm{~V} \\ \text { Error range } & =20 \mathrm{~V} \\ - \text { Global -- } & \\ \text { Op. mode } & =\text { Dynamic Force } \\ \text { Cantilever type } & =\text { ACLA } \\ \text { Head type } & =\text { EZ2-AFM } \\ \text { Scan head } & =10-07-239 . \text { hed } \\ \text { Software ver. } & =1-5-1-0 \\ \text { Firmware ver. } & =2-1-1-2 \\ \text { Controller S/N } & =023-06-252 \\ - \text { Module -- } & \\ \text { Controller Board } & =2 \\ \text { AFM Basic Module } & =2 \\ \text { AFM Dynamic Module } & =2 \\ \text { AFM Extension Module } & =1 \\ \text { Video Module } & =0 \\ \text { Signal Module S } & =0 \\ \text { Signal Module A } & =0 \\ \text { Nanosurf Report } & =0\end{array}$




\section{Nanosurf Image Document}

File: Image16
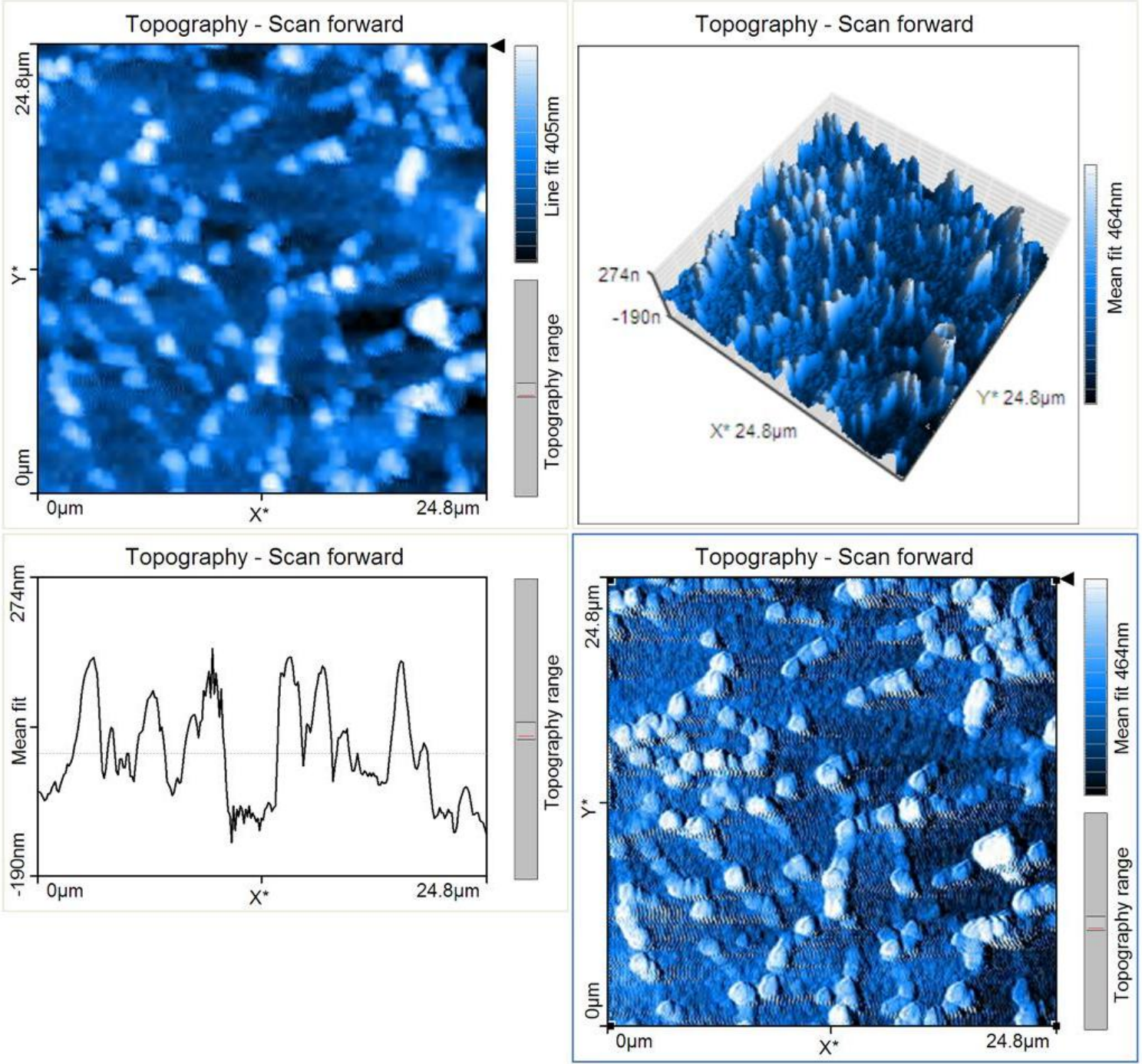

Parameter:

-- Area Roughness --

$\begin{array}{lll}\text { Area } & =618 \mathrm{pm}^{\wedge} 2 \\ \text { Sa } & & =68.638 \mathrm{~nm} \\ \text { Sq } & & =87.758 \mathrm{~nm} \\ \text { Sy } & & =636.56 \mathrm{~nm} \\ \text { Sp } & & =417.59 \mathrm{~nm} \\ \text { Sv } & & =-218.97 \mathrm{~nm} \\ \text { Sm } & & =92.192 \mathrm{pm}\end{array}$

-- Line Roughness --

$\mathrm{Ra} \quad=68.968 \mathrm{~nm}$

$\mathrm{Rq} \quad=84.162 \mathrm{~nm}$

Ry $\quad=369.62 \mathrm{~nm}$

$\mathrm{Rp} \quad=217.67 \mathrm{~nm}$

Rv $\quad=-151.95 \mathrm{~nm}$

$\mathrm{Rm} \quad=32.947 \mathrm{pm}$

-- Scan --

$\begin{array}{lll}\text { Lines } & =256 \\ \text { X-Slope } & =6^{\circ} \\ \text { Y-Slope } & =4.25^{\circ} \\ \text { Rotation } & =90^{\circ} \\ \text { X-Pos } & =-0.19 \mu \mathrm{m} \\ \text { Y-Pos } & =13 \mu \mathrm{m} \\ \text { Z-Plane } & =0 \mu \mathrm{m} \\ \text { Overscan } & =5 \% \\ \text { Const.Height-Mode } & =\text { Disabled } \\ \text { Date } & =05-09-2008 \\ \text { Time } & =13: 29: 37 \\ \text { - Feedback -- } & \\ \text { Set point } & =48 \% \\ \text { P-Gain } & =10000 \\ \text { I-Gain } & =1600 \\ \text { Tip voltage } & =0 \mathrm{~V} \\ \text { Feedback mode } & =\text { Free } \\ \text { Feedback algo. } & =\text { Adaptive PI } \\ \text { Vibration freq. } & =179.024 \mathrm{kHz} \\ \text { Vibration ampl. } & =0.7 \mathrm{~V}\end{array}$

Excitation ampl. $\quad=0.19 \mathrm{~V}$

Error range $\quad=20 \mathrm{~V}$

-- Global --

Op. mode $=$ Dynamic Force

Cantilever type = ACLA

Head type = EZ2-AFM

Scan head $\quad=10-07-239$. hed

Software ver. $\quad=1-5-1-0$

Firmware ver. $\quad=2-1-1-2$

Controller S $/ \mathrm{N} \quad=023-06-252$

-- Module --

Controller Board $\quad=2$

AFM Basic Module $\quad=2$

AFM Dynamic Module $=2$

AFM Extension Modul $\epsilon=1$

Video Module $\quad=0$

Signal Module $S \quad=0$

Signal Module $A \quad=0$

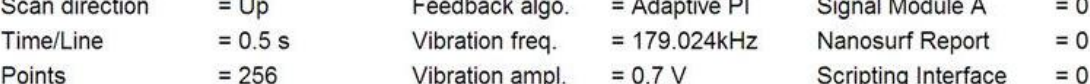




\section{Nanosurf Image Document}

File: Image17

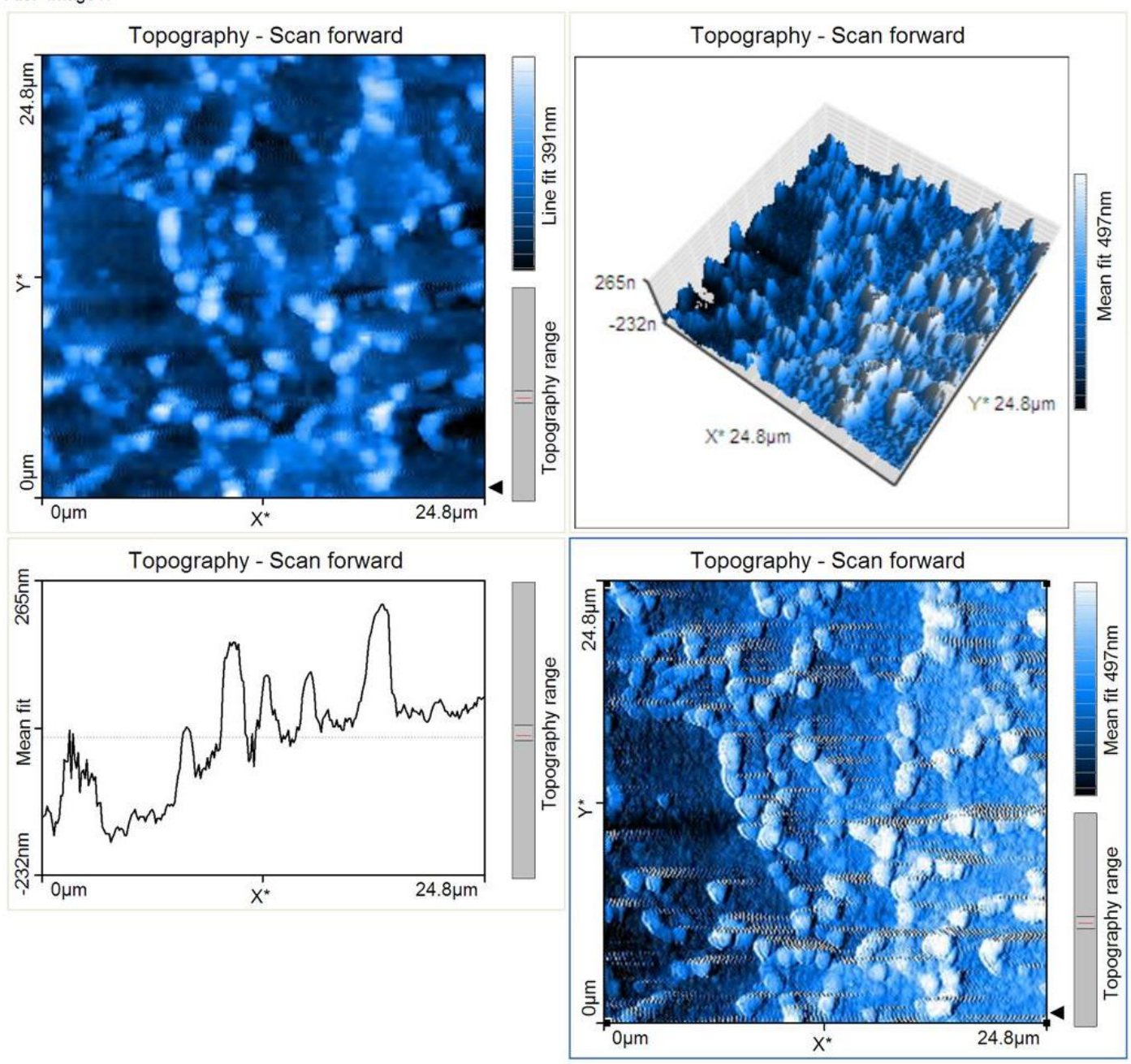

Parameter:

\begin{tabular}{|c|c|c|c|c|c|}
\hline \multicolumn{2}{|c|}{-- Area Roughness -- } & \multirow{2}{*}{$\begin{array}{l}\text { Lines } \\
\text { X-Slope }\end{array}$} & \multirow{2}{*}{$\begin{array}{l}=256 \\
=4.5^{\circ}\end{array}$} & \multirow{2}{*}{$\begin{array}{l}\text { Excitation ampl. } \\
\text { Error range }\end{array}$} & \multirow{2}{*}{$\begin{array}{l}=0.21 \mathrm{~V} \\
=20 \mathrm{~V}\end{array}$} \\
\hline Area & $=618 \mathrm{pm}^{\wedge} 2$ & & & & \\
\hline $\mathrm{Sa}$ & $=88.541 \mathrm{~nm}$ & Y-Slope & $=6^{\circ}$ & -- Global -- & \\
\hline $\mathrm{Sq}$ & $=108.15 \mathrm{~nm}$ & Rotation & $=-14.2 f^{\circ}$ & Op. mode & $=$ Dynamic Force \\
\hline Sy & $=676.84 \mathrm{~nm}$ & X-Pos & $=-0.19 \mu \mathrm{m}$ & Cantilever type & $=A C L A$ \\
\hline $\mathrm{Sp}$ & $=400.09 \mathrm{~nm}$ & Y-Pos & $=13 \mu \mathrm{m}$ & Head type & $=\mathrm{EZ2}-\mathrm{AFM}$ \\
\hline Sv & $=-276.74 n m$ & Z-Plane & $=0 \mu \mathrm{m}$ & Scan head & $=10-07-239 \cdot$ hed \\
\hline $\mathrm{Sm}$ & $=52.493 \mathrm{pm}$ & Overscan & $=5 \%$ & Software ver. & $=1-5-1-0$ \\
\hline \multicolumn{2}{|c|}{-- Line Roughness -- } & \multicolumn{2}{|c|}{ Const. Height-Mode= Disabled } & Firmware ver. & $=2-1-1-2$ \\
\hline $\mathrm{Ra}$ & $=70.085 \mathrm{~nm}$ & Date & $=05-09-2008$ & Controller S/N & $=023-06-252$ \\
\hline $\mathrm{Rq}$ & $=81.274 \mathrm{~nm}$ & Time & $=13: 42: 09$ & -- Module -- & \\
\hline Ry & $=272.63 \mathrm{~nm}$ & -- Feedback -- & & Controller Board & $=2$ \\
\hline $\mathrm{Rp}$ & $=119.09 \mathrm{~nm}$ & Set point & $=48 \%$ & AFM Basic Module & $=2$ \\
\hline Rv & $=-153.54 \mathrm{~nm}$ & P-Gain & $=10000$ & AFM Dynamic Module & $=2$ \\
\hline $\mathrm{Rm}$ & $=-68.361 \mathrm{pm}$ & |-Gain & $=1600$ & AFM Extension Module & $\varepsilon=1$ \\
\hline -- Scan -- & & Tip voltage & $=0 \mathrm{~V}$ & Video Module & $=0$ \\
\hline Image size & $=25 \mu \mathrm{m}$ & Feedback mode & $=$ Free & Signal Module S & $=0$ \\
\hline Scan direction & $=U p$ & Feedback algo. & = Adaptive PI & Signal Module A & $=0$ \\
\hline Time/Line & $=0.7 \mathrm{~s}$ & Vibration freq. & $=179.074 \mathrm{kHz}$ & Nanosurf Report & $=0$ \\
\hline Points & $=256$ & Vibration ampl. & $=0.7 \mathrm{~V}$ & Scripting Interface & $=0$ \\
\hline
\end{tabular}




\section{A-675-1 after heat treatment}

\section{Nanosurf Image Document}

File: Image9

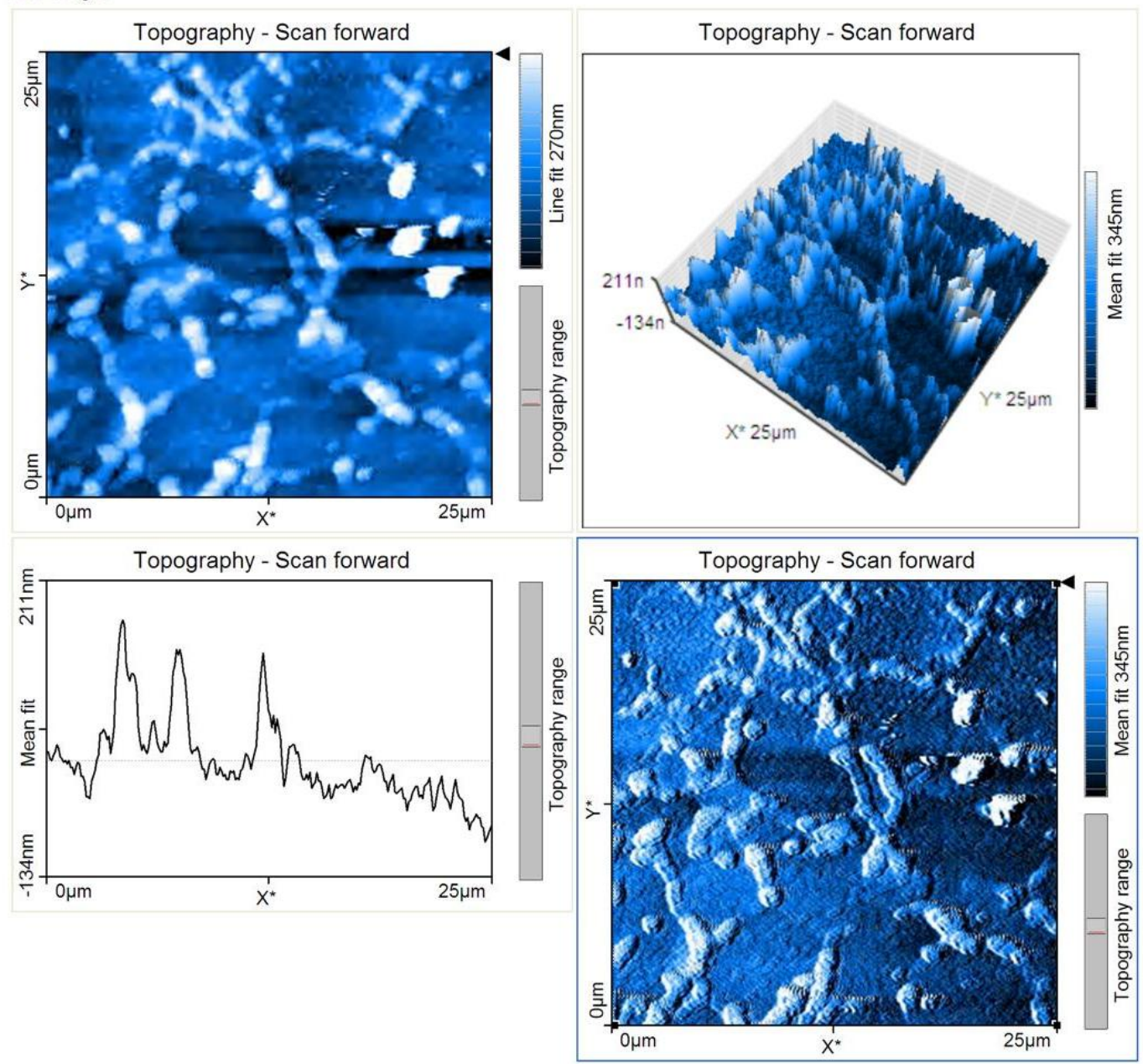

Parameter

$\begin{array}{ll}\text { - Area Roughness -- } \\ \text { Area } & =629.9 \mathrm{pm}^{\wedge} 2 \\ \text { Sa } & =51.993 \mathrm{~nm} \\ \text { Sq } & =71.199 \mathrm{~nm} \\ \text { Sy } & =879.89 \mathrm{~nm} \\ \text { Sp } & =731.97 \mathrm{~nm} \\ \text { Sv } & =-147.91 \mathrm{~nm} \\ \text { Sm } & =1282.1 \mathrm{fm}\end{array}$

-- Line Roughness --

$\mathrm{Ra} \quad=35.197 \mathrm{~nm}$

$\mathrm{Rq} \quad=43.888 \mathrm{~nm}$

Ry $\quad=220.13 \mathrm{~nm}$

Rp $\quad=135.03 \mathrm{~nm}$

Rv $\quad=-85.104 \mathrm{~nm}$

$\mathrm{Rm} \quad=30.81 \mathrm{~nm}$

-- Scan --

Image size

Scan direction

Time/Line

Points

$\begin{array}{ll}\text { Lines } & =256 \\ \text { X-Slope } & =350 \mathrm{~m}^{\circ} \\ \text { Y-Slope } & =750 \mathrm{~m}^{\circ} \\ \text { Rotation } & =-14.2 \mathrm{f}^{\circ} \\ \text { X-Pos } & =11 \mu \mathrm{m} \\ \text { Y-Pos } & =0.46 \mu \mathrm{m} \\ \text { Z-Plane } & =0 \mu \mathrm{m} \\ \text { Overscan } & =5 \% \\ \text { Const.Height-Mode } & =\text { Disabled } \\ \text { Date } & =09-09-2008 \\ \text { Time } & =12: 28: 58 \\ \text {-Feedback -- } & \\ \text { Set point } & =48 \% \\ \text { P-Gain } & =10000 \\ \text { I-Gain } & =1900 \\ \text { Tip voltage } & =0 \mathrm{~V} \\ \text { Feedback mode } & =\text { Free } \\ \text { Feedback algo. } & =\text { Adaptive PI } \\ \text { Vibration freq. } & =179.074 \mathrm{kHz} \\ \text { Vibration ampl. } & =0.7 \mathrm{~V}\end{array}$




\section{Nanosurf Image Document}

File: Image8
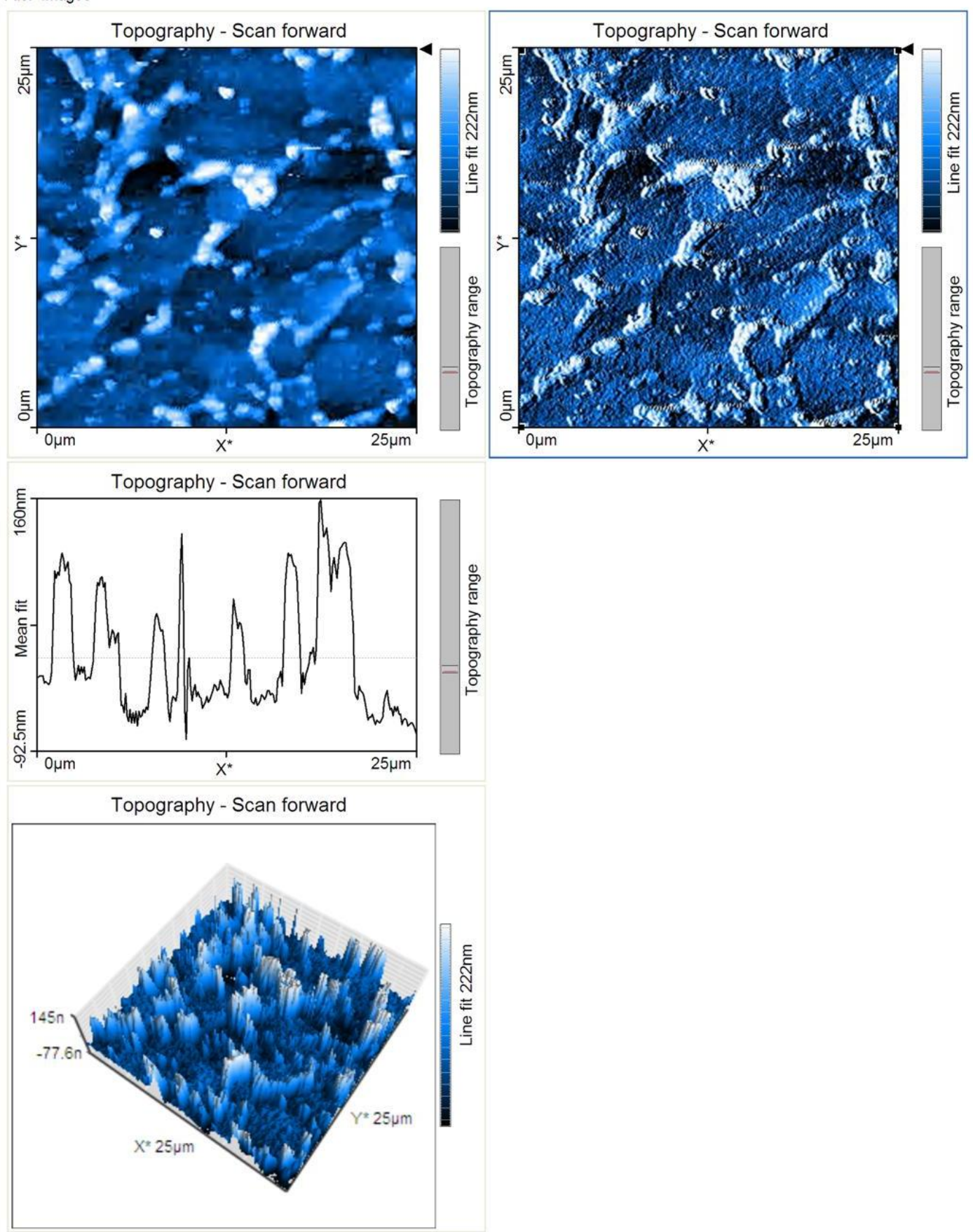

Parameter:

-- Area Roughness -

Area $\quad=629.9 \mathrm{pm}^{\wedge} 2$

$\mathrm{Sa} \quad=32.942 \mathrm{~nm}$

Lines

$X$-Slope

$=256$

Y-Slope

$=350 \mathrm{~m}^{\circ}$

$=44.709 \mathrm{~nm}$

$=371.31 \mathrm{~nm}$

$=259.03 \mathrm{~nm}$

$=-112.28 \mathrm{~nm}$

Rotation

$=750 \mathrm{~m}^{\circ}$

$\mathrm{X}$-Pos

$=-14.2 f^{\circ}$

Y-Pos

$=11 \mu \mathrm{m}$

Z-Plane

$=0.46 \mu \mathrm{m}$

$=-136.74 \mathrm{fm}$

-- Line Roughness --

Overscan $\quad=5 \%$

Const. . Height-Mod $\epsilon=$ Disabled

$\mathrm{Ra}=2815 \mathrm{fnm}$

nato

= กล_กล_- 2 กns

\begin{tabular}{|c|c|}
\hline Excitation ampl. & $=0.29 \mathrm{~V}$ \\
\hline Error range & $=20 \mathrm{~V}$ \\
\hline \multicolumn{2}{|l|}{-- Global -- } \\
\hline Op. mode & $=$ Dynamic Force \\
\hline Cantilever type & $=A C L A$ \\
\hline Head type & $=E Z 2-A F M$ \\
\hline Scan head & $=10-07-239 \cdot$ hed \\
\hline Software ver. & $=1-5-1-0$ \\
\hline Firmware ver. & $=2-1-1-2$ \\
\hline Contraller $\mathrm{C} / \mathrm{N}$ & $=$ กว2_กล_ว5? \\
\hline
\end{tabular}




\section{Nanosurf Image Document}

File: Image10
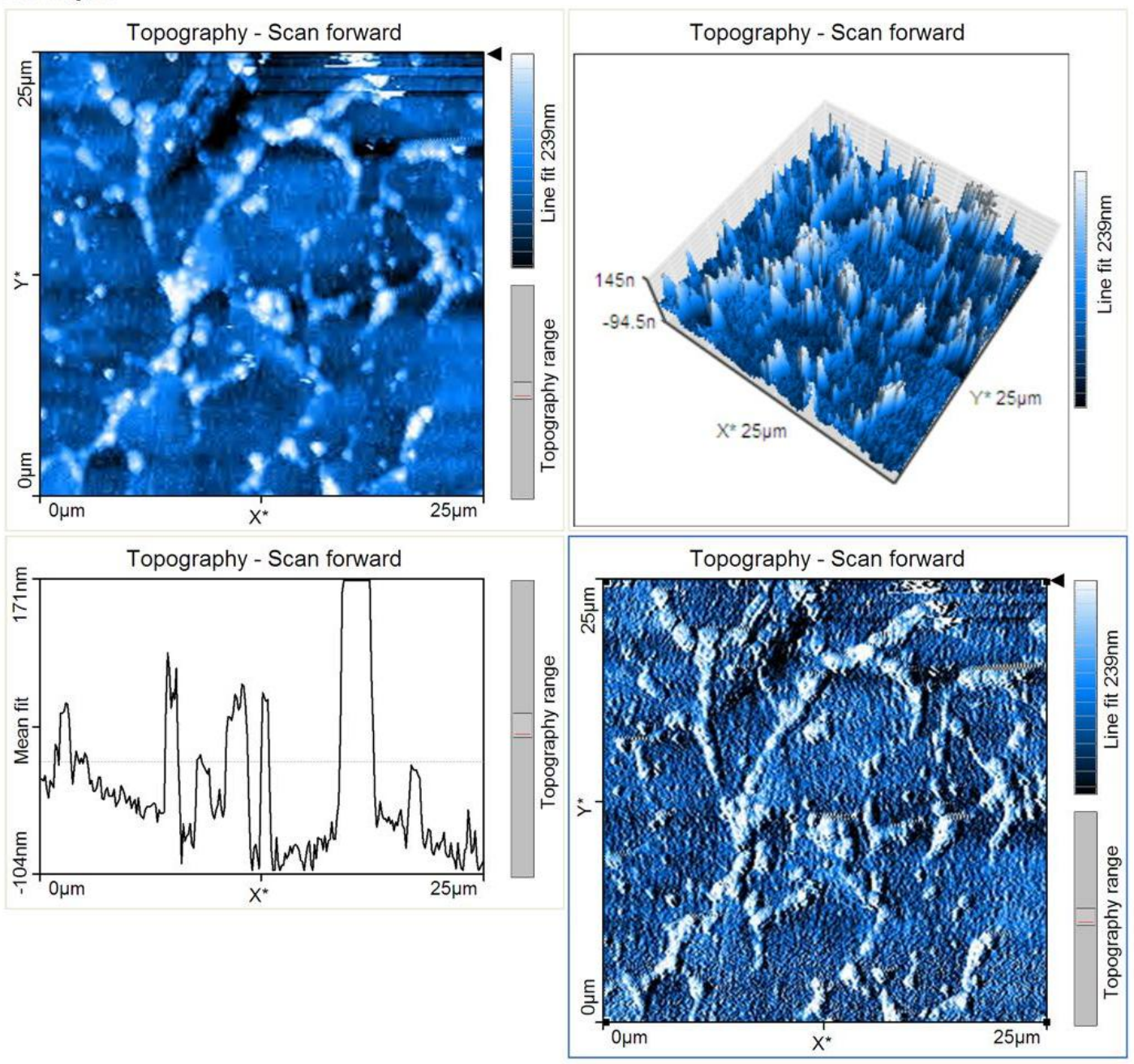

Parameter:

\begin{tabular}{|c|c|c|c|c|c|}
\hline \multicolumn{2}{|c|}{-- Area Roughness -- } & \multirow{2}{*}{$\begin{array}{l}\text { Lines } \\
X \text {-Slope }\end{array}$} & \multirow{2}{*}{$\begin{array}{l}=256 \\
=350 \mathrm{~m}^{\circ}\end{array}$} & \multirow{2}{*}{$\begin{array}{l}\text { Excitation ampl. } \\
\text { Error range }\end{array}$} & \multirow{2}{*}{$\begin{array}{l}=0.25 \mathrm{~V} \\
=20 \mathrm{~V}\end{array}$} \\
\hline Area & $=629.9 \mathrm{pm}^{\wedge} 2$ & & & & \\
\hline Sa & $=36.056 \mathrm{~nm}$ & Y-Slope & $=750 \mathrm{~m}^{\circ}$ & -- Global -- & \\
\hline $\mathrm{Sq}$ & $=51.933 \mathrm{~nm}$ & Rotation & $=-14.2 f^{\circ}$ & Op. mode & = Dynamic Force \\
\hline Sy & $=1098.8 \mathrm{~nm}$ & X-Pos & $=11 \mu \mathrm{m}$ & Cantilever type & $=A C L A$ \\
\hline Sp & $=907.61 \mathrm{~nm}$ & Y-Pos & $=0.46 \mu \mathrm{m}$ & Head type & $=E Z 2-A F M$ \\
\hline Sv & $=-191.14 \mathrm{~nm}$ & Z-Plane & $=0 \mu \mathrm{m}$ & Scan head & $=10-07-239$. hed \\
\hline $\mathrm{Sm}$ & $=31.799 \mathrm{pm}$ & Overscan & $=5 \%$ & Software ver. & $=1-5-1-0$ \\
\hline \multicolumn{2}{|c|}{-- Line Roughness -- } & \multicolumn{2}{|c|}{ Const. Height-Mod $\epsilon=$ Disabled } & Firmware ver. & $=2-1-1-2$ \\
\hline $\mathrm{Ra}$ & $=39.772 \mathrm{~nm}$ & Date & $=09-09-2008$ & Controller S/N & $=023-06-252$ \\
\hline $\mathrm{Rq}$ & $=51.093 \mathrm{~nm}$ & Time & $=12: 38: 15$ & -- Module -- & \\
\hline Ry & $=325.98 \mathrm{~nm}$ & \multicolumn{2}{|l|}{-- Feedback -- } & Controller Board & $=2$ \\
\hline $\mathrm{Rp}$ & $=239 \mathrm{~nm}$ & Set point & $=48 \%$ & AFM Basic Module & $=2$ \\
\hline $\mathrm{Rv}$ & $=-86.976 \mathrm{~nm}$ & P-Gain & $=10000$ & \multicolumn{2}{|c|}{ AFM Dynamic Module $=2$} \\
\hline $\mathrm{Rm}$ & $=-822.03 \mathrm{fm}$ & I-Gain & $=1900$ & \multicolumn{2}{|c|}{ AFM Extension Module $=1$} \\
\hline \multicolumn{2}{|l|}{-- Scan -- } & Tip voltage & $=0 \mathrm{~V}$ & Video Module & $=0$ \\
\hline Image size & $=25 \mu \mathrm{m}$ & Feedback mode & $=$ Free & Signal Module S & $=0$ \\
\hline Scan direction & $=U p$ & Feedback algo. & $=$ Adaptive PI & Signal Module A & $=0$ \\
\hline Time/Line & $=0.6 \mathrm{~s}$ & Vibration freq. & $=179.084 \mathrm{kHz}$ & Nanosurf Report & $=0$ \\
\hline Points & $=256$ & Vibration ampl. & $=0.7 \mathrm{~V}$ & Scripting Interface & $=0$ \\
\hline
\end{tabular}


A-675-4 after heat treatment

\section{Nanosurf Image Document}

File: Image11

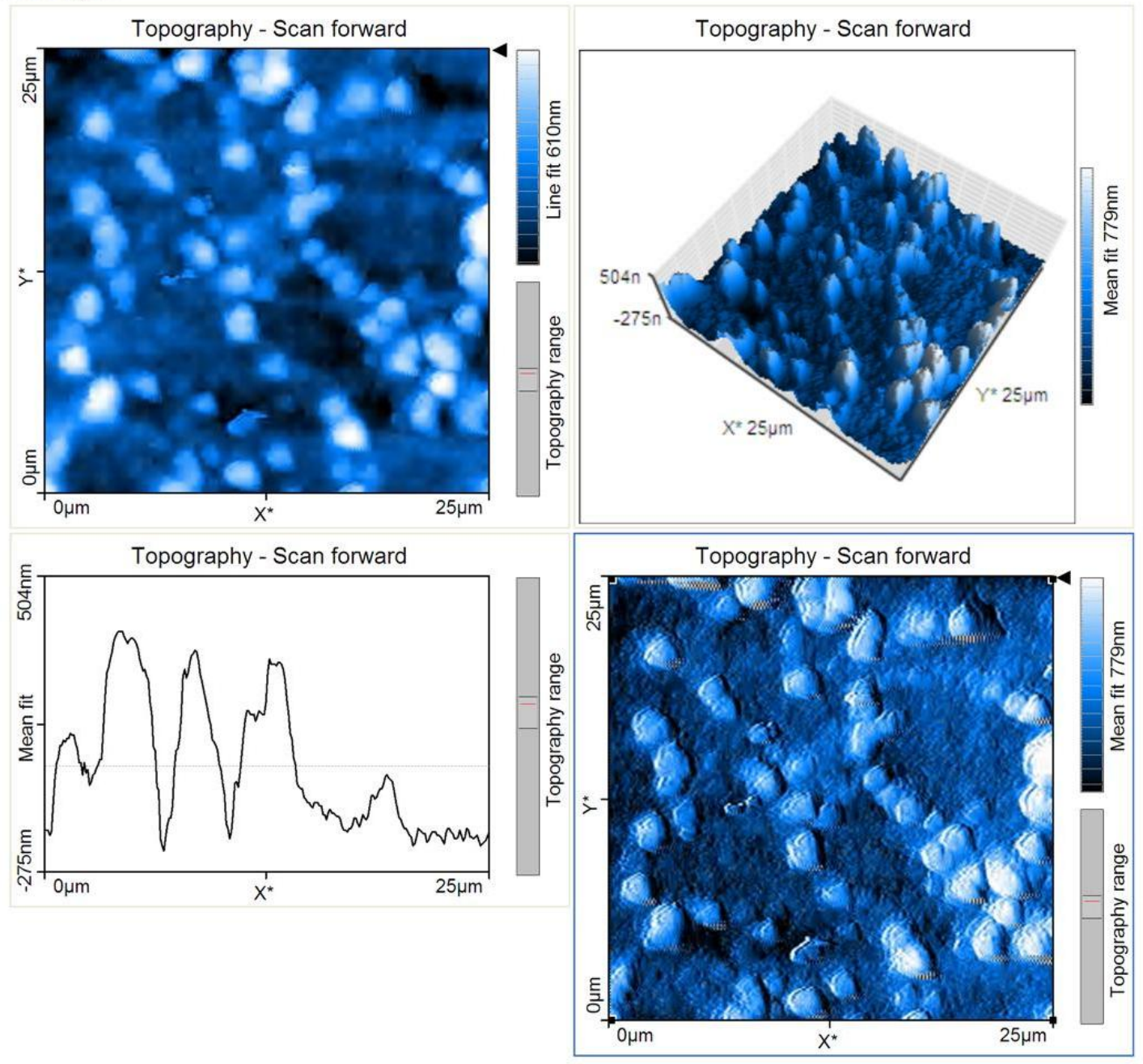

Parameter:

\begin{tabular}{|c|c|c|c|c|c|}
\hline \multicolumn{2}{|c|}{-- Area Roughness -- } & \multirow{2}{*}{$\begin{array}{l}\text { Lines } \\
\text { X-Slope }\end{array}$} & \multirow{2}{*}{$\begin{array}{l}=256 \\
=-1.25^{\circ}\end{array}$} & \multirow{2}{*}{$\begin{array}{l}\text { Excitation ampl. } \\
\text { Error range }\end{array}$} & \multirow{2}{*}{$\begin{array}{l}=0.25 \mathrm{~V} \\
=20 \mathrm{~V}\end{array}$} \\
\hline Area & $=629.9 \mathrm{pm}^{\wedge} 2$ & & & & \\
\hline $\mathrm{Sa}$ & $=111.75 \mathrm{~nm}$ & Y-Slope & $=2.5^{\circ}$ & -- Global -- & \\
\hline $\mathrm{Sq}$ & $=142.88 \mathrm{~nm}$ & Rotation & $=90^{\circ}$ & Op. mode & $=$ Dynamic Force \\
\hline Sy & $=940.82 \mathrm{~nm}$ & X-Pos & $=11 \mu \mathrm{m}$ & Cantilever type & $=A C L A$ \\
\hline $\mathrm{Sp}$ & $=647 \mathrm{~nm}$ & Y-Pos & $=0.46 \mu \mathrm{m}$ & Head type & $=\mathrm{EZ2}-\mathrm{AFM}$ \\
\hline Sv & $=-293.82 n m$ & Z-Plane & $=0 \mu \mathrm{m}$ & Scan head & $=10-07-239 \cdot$ hed \\
\hline $\mathrm{Sm}$ & $=214.63 \mathrm{pm}$ & Overscan & $=5 \%$ & Software ver. & $=1-5-1-0$ \\
\hline \multicolumn{2}{|c|}{-- Line Roughness -- } & \multicolumn{2}{|c|}{ Const. Height-Mode= Disabled } & Firmware ver. & $=2-1-1-2$ \\
\hline $\mathrm{Ra}$ & $=105.3 \mathrm{~nm}$ & Date & $=09-09-2008$ & Controller S/N & $=023-06-252$ \\
\hline $\mathrm{Rq}$ & $=148.5 \mathrm{~nm}$ & Time & $=12: 48: 21$ & -- Module -- & \\
\hline Ry & $=673.67 \mathrm{~nm}$ & \multicolumn{2}{|l|}{-- Feedback -- } & Controller Board & $=2$ \\
\hline Rp & $=483.4 \mathrm{~nm}$ & Set point & $=48 \%$ & AFM Basic Module & $=2$ \\
\hline Rv & $=-190.27 \mathrm{~nm}$ & P-Gain & $=10000$ & \multicolumn{2}{|c|}{ AFM Dynamic Module $=2$} \\
\hline $\mathrm{Rm}$ & $=190.26 \mathrm{pm}$ & I-Gain & $=1800$ & \multicolumn{2}{|c|}{ AFM Extension Module= 1} \\
\hline -- Scan -- & & Tip voltage & $=0 \mathrm{~V}$ & Video Module & $=0$ \\
\hline Image size & $=25 \mu \mathrm{m}$ & Feedback mode & $=$ Free & Signal Module S & $=0$ \\
\hline Scan direction & $=U p$ & Feedback algo. & = Adaptive PI & Signal Module A & $=0$ \\
\hline Time/Line & $=0.6 \mathrm{~s}$ & Vibration freq. & $\begin{aligned}= & 179.084 \mathrm{kHz} \\
& \ldots\end{aligned}$ & Nanosurf Report & $=0$ \\
\hline
\end{tabular}




\section{Nanosurf Image Document}

File: Image13

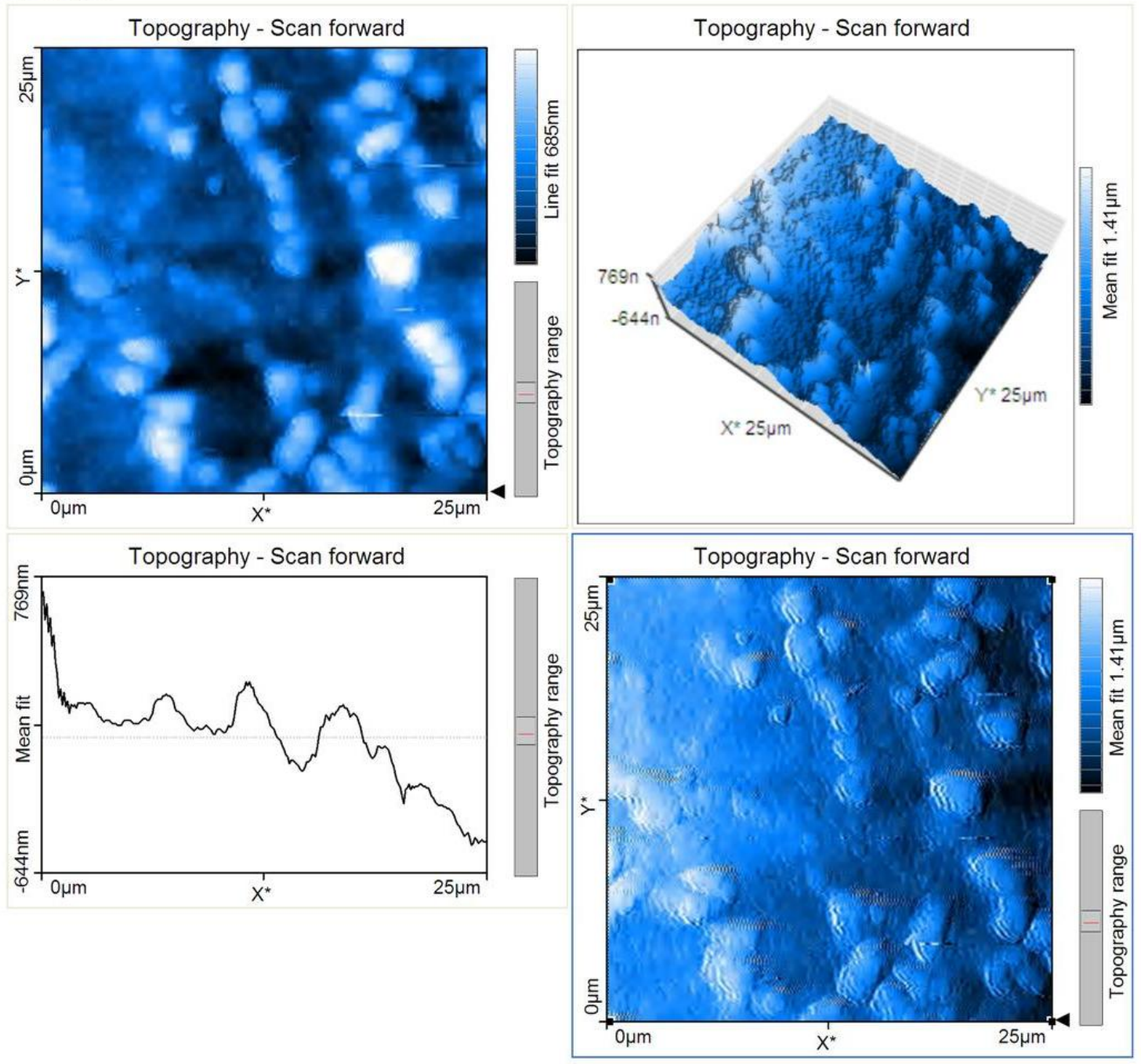

Parameter:

\begin{tabular}{|c|c|c|c|c|c|}
\hline \multicolumn{2}{|c|}{-- Area Roughness -- } & \multirow{2}{*}{$\begin{array}{l}\text { Lines } \\
\text { X-Slope }\end{array}$} & \multirow{2}{*}{$\begin{array}{l}=256 \\
=-1.75^{\circ}\end{array}$} & \multirow{2}{*}{$\begin{array}{l}\text { Excitation ampl. } \\
\text { Error range }\end{array}$} & \multirow{2}{*}{$\begin{array}{l}=0.26 \mathrm{~V} \\
=20 \mathrm{~V}\end{array}$} \\
\hline Area & $=629.9 \mathrm{pm}^{\wedge} 2$ & & & & \\
\hline Sa & $=209 \mathrm{~nm}$ & Y-Slope & $=2.5^{\circ}$ & -- Global -- & \\
\hline $\mathrm{Sq}$ & $=249.99 \mathrm{~nm}$ & Rotation & $=-14.2 \mathrm{f}^{\circ}$ & Op. mode & = Dynamic For \\
\hline Sy & $=1.457 \mu \mathrm{m}$ & X-Pos & $=11 \mu \mathrm{m}$ & Cantilever type & $=A C L A$ \\
\hline Sp & $=828.54 \mathrm{~nm}$ & Y-Pos & $=0.46 \mu \mathrm{m}$ & Head type & $=E Z 2-A F M$ \\
\hline Sv & $=-628.45 \mathrm{~nm}$ & Z-Plane & $=0 \mu \mathrm{m}$ & Scan head & $=10-07-239$. hed \\
\hline $\mathrm{Sm}$ & $=500.3 \mathrm{fm}$ & Overscan & $=5 \%$ & Software ver. & $=1-5-1-0$ \\
\hline \multicolumn{2}{|c|}{-- Line Roughness -- } & \multicolumn{2}{|c|}{ Const. Height-Mod $\epsilon=$ Disabled } & Firmware ver. & $=2-1-1-2$ \\
\hline $\mathrm{Ra}$ & $=90.752 \mathrm{~nm}$ & Date & $=09-09-2008$ & Controller $\mathrm{S} / \mathrm{N}$ & $=023-06-252$ \\
\hline $\mathrm{Rq}$ & $=113.23 \mathrm{~nm}$ & Time & $=13: 05: 51$ & -- Module -- & \\
\hline Ry & $=532.4 \mathrm{~nm}$ & \multicolumn{2}{|l|}{-- Feedback -- } & Controller Board & $=2$ \\
\hline $\mathrm{Rp}$ & $=273.4 \mathrm{~nm}$ & Set point & $=48 \%$ & AFM Basic Module & $=2$ \\
\hline Rv & $=-259.01 \mathrm{~nm}$ & P-Gain & $=10000$ & \multicolumn{2}{|c|}{ AFM Dynamic Module $=2$} \\
\hline $\mathrm{Rm}$ & $=259.11 \mathrm{~nm}$ & |-Gain & $=1900$ & \multicolumn{2}{|c|}{ AFM Extension Modul $\epsilon=1$} \\
\hline \multicolumn{2}{|l|}{-- Scan -- } & Tip voltage & $=0 \mathrm{~V}$ & Video Module & $=0$ \\
\hline Image size & $=25 \mu \mathrm{m}$ & Feedback mode & $=$ Free & Signal Module S & $=0$ \\
\hline Scan direction & $=$ Down & Feedback algo. & $=$ Adaptive PI & Signal Module A & $=0$ \\
\hline Time/Line & $=0.6 \mathrm{~s}$ & Vibration freq. & $=179.094 \mathrm{kHz}$ & Nanosurf Report & $=0$ \\
\hline Points & $=256$ & Vibration ampl. & $=0.7 \mathrm{~V}$ & Scripting Interface & $=0$ \\
\hline
\end{tabular}




\section{Nanosurf Image Document}

File: Image15

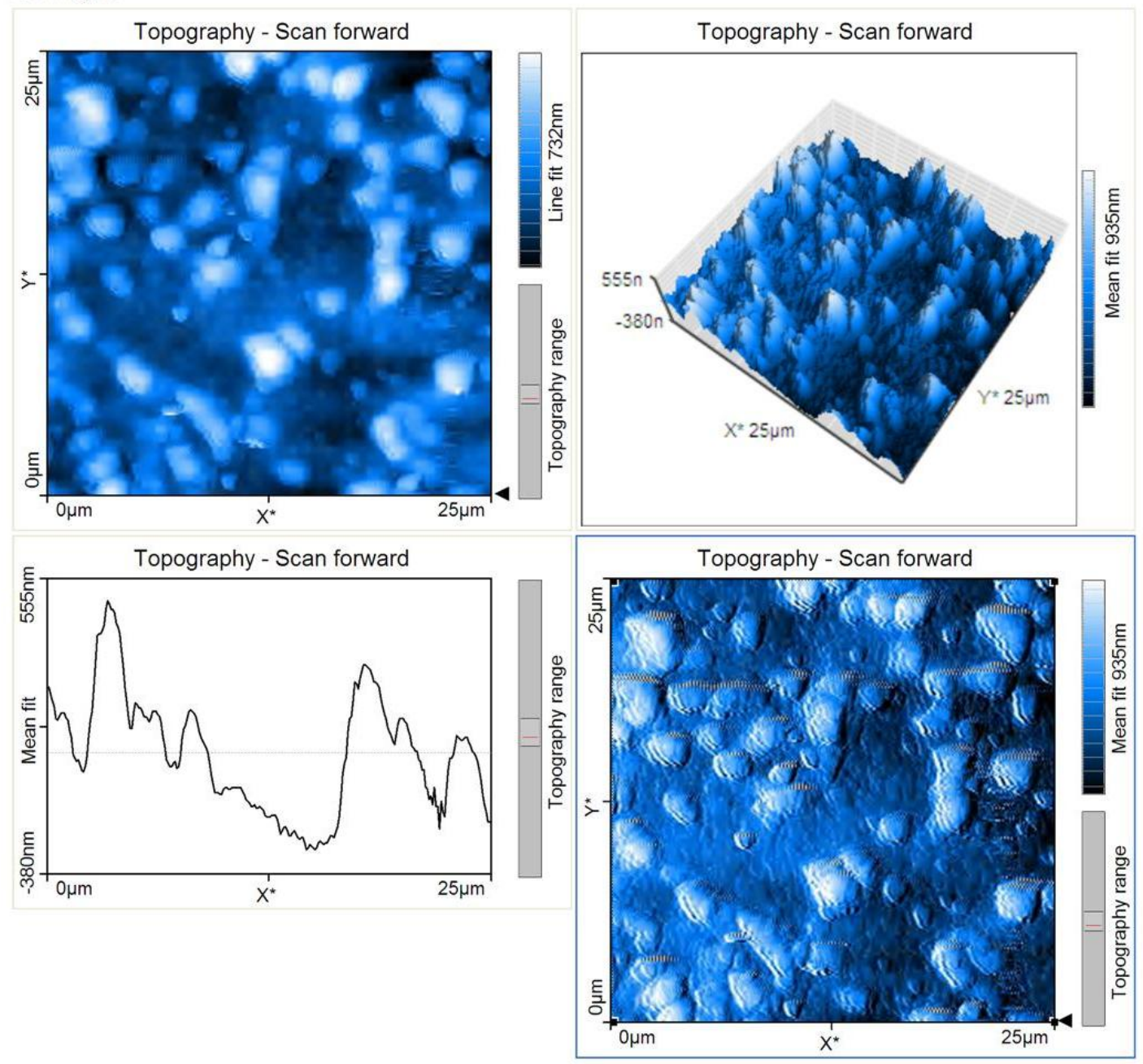

Parameter:

\begin{tabular}{|c|c|c|c|c|c|}
\hline \multicolumn{2}{|c|}{-- Area Roughness -- } & \multirow{2}{*}{$\begin{array}{l}\text { Lines } \\
\text { X-Slope }\end{array}$} & \multirow{2}{*}{$\begin{array}{l}=256 \\
=-1.75^{\circ}\end{array}$} & \multirow{2}{*}{$\begin{array}{l}\text { Excitation ampl. } \\
\text { Error range }\end{array}$} & \multirow{2}{*}{$\begin{array}{l}=0.25 \mathrm{~V} \\
=20 \mathrm{~V}\end{array}$} \\
\hline Area & $=629.9 \mathrm{pm}^{\wedge} 2$ & & & & \\
\hline $\mathrm{Sa}$ & $=135.73 \mathrm{~nm}$ & Y-Slope & $=2.5^{\circ}$ & -- Global -. & \\
\hline $\mathrm{Sq}$ & $=166.95 \mathrm{~nm}$ & Rotation & $=-14.2 f^{\circ}$ & Op. mode & = Dynamic Force \\
\hline Sy & $=1206.3 \mathrm{~nm}$ & X-Pos & $=11 \mu \mathrm{m}$ & Cantilever type & $=A C L A$ \\
\hline Sp & $=757.7 \mathrm{~nm}$ & Y-Pos & $=0.46 \mu \mathrm{m}$ & Head type & $=\mathrm{EZ2}-\mathrm{AFM}$ \\
\hline Sv & $=-448.59 \mathrm{~nm}$ & Z-Plane & $=0 \mu \mathrm{m}$ & Scan head & $=10-07-239 . \mathrm{hed}$ \\
\hline Sm & $=65.204 \mathrm{pm}$ & Overscan & $=5 \%$ & Software ver. & $=1-5-1-0$ \\
\hline \multicolumn{2}{|c|}{-- Line Roughness -- } & \multicolumn{2}{|c|}{ Const. Height-Mod $\epsilon=$ Disabled } & Firmware ver. & $=2-1-1-2$ \\
\hline $\mathrm{Ra}$ & $=130.66 \mathrm{~nm}$ & Date & $=09-09-2008$ & Controller $\mathrm{S} / \mathrm{N}$ & $=023-06-252$ \\
\hline $\mathrm{Rq}$ & $=163.91 \mathrm{~nm}$ & Time & $=13: 22: 46$ & -- Module -- & \\
\hline Ry & $=649.21 \mathrm{~nm}$ & -- Feedback -- & & Controller Board & $=2$ \\
\hline Rp & $=387.74 \mathrm{~nm}$ & Set point & $=48 \%$ & AFM Basic Module & $=2$ \\
\hline Rv & $=-261.47 \mathrm{~nm}$ & P-Gain & $=10000$ & \multicolumn{2}{|c|}{ AFM Dynamic Module $=2$} \\
\hline $\mathrm{Rm}$ & $=-88.952 \mathrm{pm}$ & I-Gain & $=1900$ & \multicolumn{2}{|c|}{ AFM Extension Module $=1$} \\
\hline -- Scan -- & & Tip voltage & $=0 \mathrm{~V}$ & Video Module & $=0$ \\
\hline Image size & $=25 \mu \mathrm{m}$ & Feedback mode & $=$ Free & Signal Module S & $=0$ \\
\hline Scan direction & $=$ Down & Feedback algo. & = Adaptive PI & Signal Module A & $=0$ \\
\hline Time/Line & $=0.6 \mathrm{~s}$ & Vibration freq. & $=179.074 \mathrm{kHz}$ & Nanosurf Report & $=0$ \\
\hline Points & $=256$ & Vibration ampl. & $=0.7 \mathrm{~V}$ & Scripting Interface & $=0$ \\
\hline
\end{tabular}


A-675-8 after heat treatment

\section{Nanosurf Image Document}

File: Image18
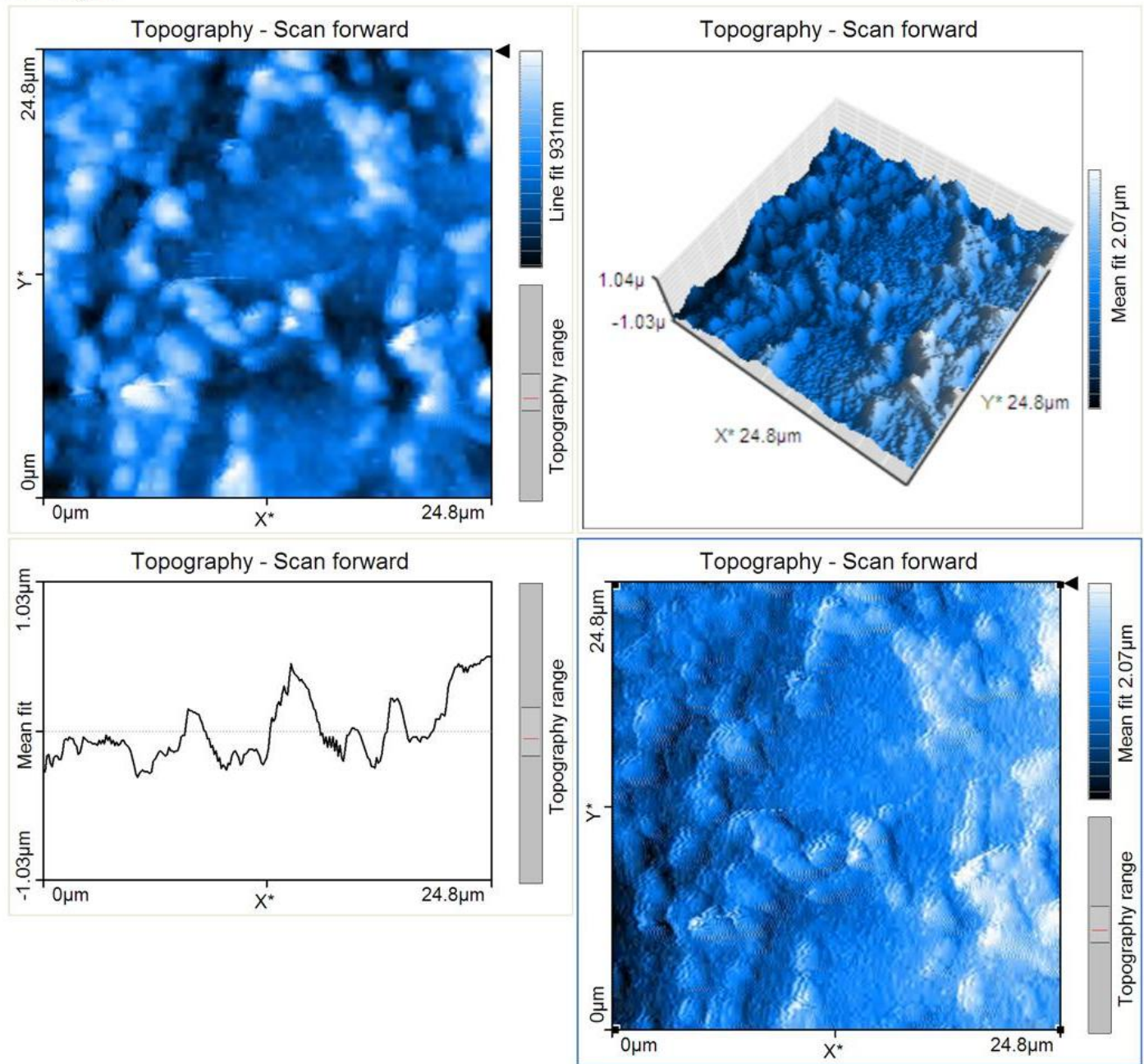

Parameter

\begin{tabular}{|c|c|c|c|c|c|}
\hline \multicolumn{2}{|c|}{-- Area Roughness -- } & \multirow{2}{*}{$\begin{array}{l}\text { Lines } \\
\text { X-Slope }\end{array}$} & \multirow{2}{*}{$\begin{array}{l}=256 \\
=2^{\circ}\end{array}$} & \multirow{2}{*}{$\begin{array}{l}\text { Excitation ampl. } \\
\text { Error range }\end{array}$} & \multirow{2}{*}{$\begin{array}{l}=0.18 \mathrm{~V} \\
=20 \mathrm{~V}\end{array}$} \\
\hline Area & $=618 \mathrm{pm}^{\wedge} 2$ & & & & \\
\hline $\mathrm{Sa}$ & $=267.45 \mathrm{~nm}$ & Y-Slope & $=2^{\circ}$ & -- Global -- & \\
\hline $\mathrm{Sq}$ & $=336.37 \mathrm{~nm}$ & Rotation & $=90^{\circ}$ & Op. mode & $=$ Dynamic Force \\
\hline Sy & $=2174.1 \mathrm{~nm}$ & X-Pos & $=-12 \mu \mathrm{m}$ & Cantilever type & $=A C L A$ \\
\hline Sp & $=1208.5 \mathrm{~nm}$ & Y-Pos & $=-8.7 \mu \mathrm{m}$ & Head type & $=E Z 2-A F M$ \\
\hline Sv & $=-965.6 \mathrm{~nm}$ & Z-Plane & $=0 \mu \mathrm{m}$ & Scan head & $=10-07-239$. hed \\
\hline $\mathrm{Sm}$ & $=66.861 \mathrm{pm}$ & Overscan & $=5 \%$ & Software ver. & $=1-5-1-0$ \\
\hline \multicolumn{2}{|c|}{-- Line Roughness -- } & \multicolumn{2}{|c|}{ Const. Height-Mode= Disabled } & Firmware ver. & $=2-1-1-2$ \\
\hline $\mathrm{Ra}$ & $=249.53 \mathrm{~nm}$ & Date & $=04-09-2008$ & Controller S/N & $=023-06-252$ \\
\hline $\mathrm{Rq}$ & $=308.62 \mathrm{~nm}$ & Time & $=18: 01: 05$ & -- Module -- & \\
\hline Ry & $=1158.8 \mathrm{~nm}$ & -- Feedback -- & & Controller Board & $=2$ \\
\hline $\mathrm{Rp}$ & $=601.64 \mathrm{~nm}$ & Set point & $=48 \%$ & AFM Basic Module & $=2$ \\
\hline Rv & $=-557.21 \mathrm{~nm}$ & P-Gain & $=10000$ & \multicolumn{2}{|c|}{ AFM Dynamic Module $=2$} \\
\hline $\mathrm{Rm}$ & $=28.829 \mathrm{pm}$ & I-Gain & $=1500$ & \multicolumn{2}{|c|}{ AFM Extension Modul $=1$} \\
\hline -- Scan -- & & Tip voltage & $=0 \mathrm{~V}$ & Video Module & $=0$ \\
\hline Image size & $=25 \mu \mathrm{m}$ & Feedback mode & $=$ Free & Signal Module S & $=0$ \\
\hline Scan direction & $=U p$ & Feedback algo. & = Adaptive PI & Signal Module A & $=0$ \\
\hline Time/Line & $=0.6 \mathrm{~s}$ & Vibration freq. & $=179.034 \mathrm{kHz}$ & Nanosurf Report & $=0$ \\
\hline Points & $=256$ & Vibration ampl. & $=0.7 \mathrm{~V}$ & Scripting Interface & $=0$ \\
\hline
\end{tabular}




\section{Nanosurf Image Document}

File: Image19

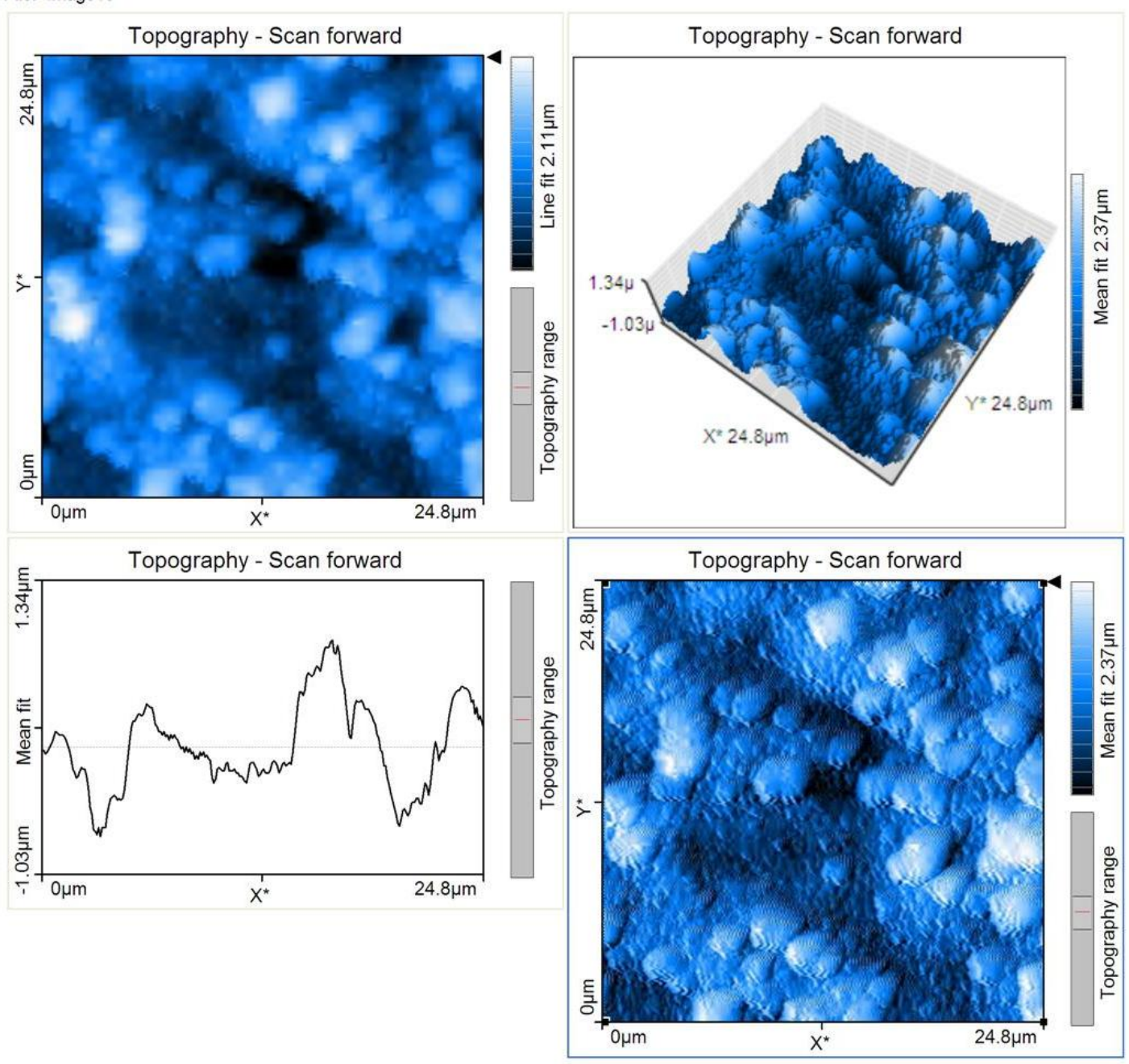

Parameter:

\begin{tabular}{|c|c|c|c|}
\hline \multicolumn{2}{|c|}{-- Area Roughness -- } & \multirow{2}{*}{$\begin{array}{l}\text { Lines } \\
\text { X-Slope }\end{array}$} & \multirow{2}{*}{$\begin{array}{l}=256 \\
=1^{\circ}\end{array}$} \\
\hline Area & $=618 \mathrm{pm}^{\wedge} 2$ & & \\
\hline Sa & $=332.85 \mathrm{~nm}$ & Y-Slope & $=1^{\circ}$ \\
\hline $\mathrm{Sq}$ & $=406.47 \mathrm{~nm}$ & Rotation & $=-14.2 f^{\circ}$ \\
\hline Sy & $=2309.7 \mathrm{~nm}$ & X-Pos & $=-12 \mu \mathrm{m}$ \\
\hline Sp & $=1345.6 \mathrm{~nm}$ & Y-Pos & $=-8.7 \mu \mathrm{m}$ \\
\hline Sv & $=-964.12 \mathrm{~nm}$ & Z-Plane & $=0 \mu \mathrm{m}$ \\
\hline $\mathrm{Sm}$ & $=209.53 \mathrm{pm}$ & Overscan & $=5 \%$ \\
\hline \multicolumn{2}{|c|}{-- Line Roughness -- } & \multicolumn{2}{|c|}{ Const. Height-Mode= Disabled } \\
\hline $\mathrm{Ra}$ & $=311.47 \mathrm{~nm}$ & Date & $=04-09-2008$ \\
\hline $\mathrm{Rq}$ & $=404.73 \mathrm{~nm}$ & Time & $=18: 11: 06$ \\
\hline Ry & $=1655.4 \mathrm{~nm}$ & \multicolumn{2}{|l|}{-- Feedback -- } \\
\hline $\mathrm{Rp}$ & $=833.68 \mathrm{~nm}$ & Set point & $=48 \%$ \\
\hline Rv & $=-821.72 \mathrm{~nm}$ & P-Gain & $=10000$ \\
\hline $\mathrm{Rm}$ & $=135.9 \mathrm{pm}$ & I-Gain & $=1500$ \\
\hline \multicolumn{2}{|l|}{-- Scan -- } & Tip voltage & $=0 \mathrm{~V}$ \\
\hline Image size & $=25 \mu \mathrm{m}$ & Feedback mode & $=$ Free \\
\hline Scan direction & $=U p$ & Feedback algo. & $=$ Adaptive PI \\
\hline Time/Line & $=0.6 \mathrm{~s}$ & Vibration freq. & $=179.124 \mathrm{kHz}$ \\
\hline Points & $=256$ & Vibration ampl. & $=0.7 \mathrm{~V}$ \\
\hline
\end{tabular}

$\begin{array}{ll}\text { Excitation ampl. } & =0.25 \mathrm{~V} \\ \text { Error range } & =20 \mathrm{~V} \\ - \text { - Global -- } & \\ \text { Op. mode } & =\text { Dynamic Force } \\ \text { Cantilever type } & =\text { ACLA } \\ \text { Head type } & =\text { EZ2-AFM } \\ \text { Scan head } & =10-07-239 . \text { hed } \\ \text { Software ver. } & =1-5-1-0 \\ \text { Firmware ver. } & =2-1-1-2 \\ \text { Controller S/N } & =023-06-252 \\ \text { - Module -- } & \\ \text { Controller Board } & =2 \\ \text { AFM Basic Module } & =2 \\ \text { AFM Dynamic Module } & =2 \\ \text { AFM Extension Modul } & =1 \\ \text { Video Module } & =0 \\ \text { Signal Module S } & =0 \\ \text { Signal Module A } & =0 \\ \text { Nanosurf Report } & =0 \\ \text { Scripting Interface } & =0\end{array}$




\section{Nanosurf Image Document}

File: Image20
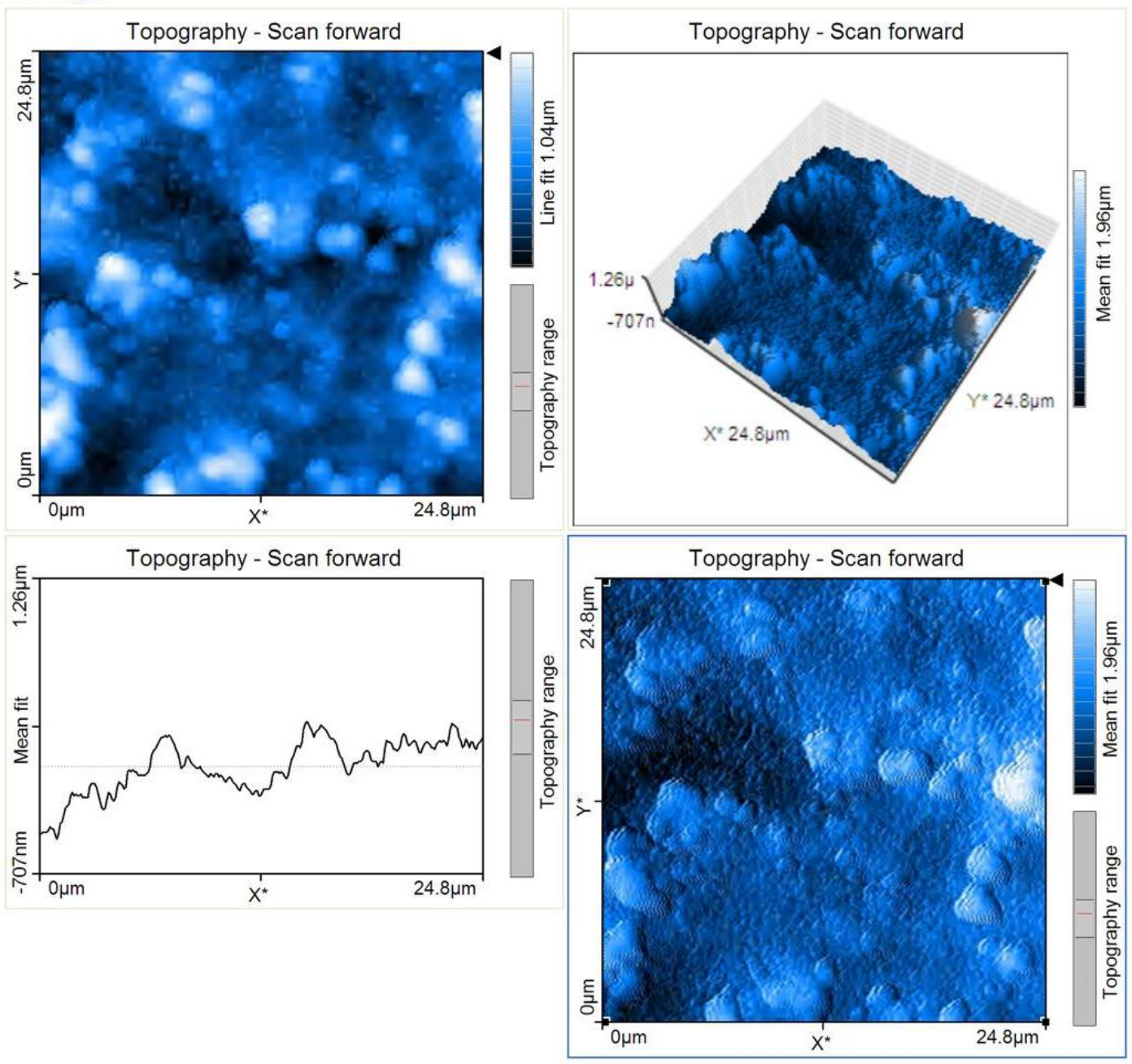

Parameter:

\begin{tabular}{|c|c|c|c|c|c|}
\hline \multicolumn{2}{|c|}{-- Area Roughness -- } & \multirow{2}{*}{$\begin{array}{l}\text { Lines } \\
\text { X-Slope }\end{array}$} & \multirow{2}{*}{$\begin{array}{l}=256 \\
=-1^{\circ}\end{array}$} & \multirow{2}{*}{$\begin{array}{l}\text { Excitation ampl. } \\
\text { Error range }\end{array}$} & \multirow{2}{*}{$\begin{array}{l}=0.2 \mathrm{~V} \\
=20 \mathrm{~V}\end{array}$} \\
\hline Area & $=618 \mathrm{pm}^{\wedge} 2$ & & & & \\
\hline $\mathrm{Sa}$ & $=197.92 \mathrm{~nm}$ & Y-Slope & $=1^{\circ}$ & -- Global -- & \\
\hline $\mathrm{Sq}$ & $=263.57 \mathrm{~nm}$ & Rotation & $=90^{\circ}$ & Op. mode & $=$ Dynamic Force \\
\hline Sy & $=1.876 \mu \mathrm{m}$ & X-Pos & $=-12 \mu \mathrm{m}$ & Cantilever type & $=A C L A$ \\
\hline$S p$ & $=1211.9 \mathrm{~nm}$ & Y-Pos & $=-8.7 \mu \mathrm{m}$ & Head type & $=\mathrm{EZ2}-\mathrm{AFM}$ \\
\hline Sv & $=-664.08 \mathrm{~nm}$ & Z-Plane & $=0 \mu \mathrm{m}$ & Scan head & $=10-07-239 \cdot$ hed \\
\hline $\mathrm{Sm}$ & $=110.48 \mathrm{pm}$ & Overscan & $=5 \%$ & Software ver. & $=1-5-1-0$ \\
\hline \multicolumn{2}{|c|}{-- Line Roughness -- } & \multicolumn{2}{|c|}{ Const. Height-Mode= Disabled } & Firmware ver. & $=2-1-1-2$ \\
\hline $\mathrm{Ra}$ & $=305.07 \mathrm{~nm}$ & Date & $=04-09-2008$ & Controller S/N & $=023-06-252$ \\
\hline $\mathrm{Rq}$ & $=399.55 \mathrm{~nm}$ & Time & $=18: 22: 29$ & -- Module -- & \\
\hline Ry & $=1709.4 \mathrm{~nm}$ & \multicolumn{2}{|l|}{-- Feedback -- } & Controller Board & $=2$ \\
\hline $\mathrm{Rp}$ & $=1084.2 \mathrm{~nm}$ & Set point & $=48 \%$ & AFM Basic Module & $=2$ \\
\hline Rv & $=-625.22 \mathrm{~nm}$ & P-Gain & $=10000$ & \multicolumn{2}{|c|}{ AFM Dynamic Module $=2$} \\
\hline $\mathrm{Rm}$ & $=145.79 \mathrm{pm}$ & I-Gain & $=1500$ & \multicolumn{2}{|c|}{ AFM Extension Module $=1$} \\
\hline -- Scan -- & & Tip voltage & $=0 \mathrm{~V}$ & Video Module & $=0$ \\
\hline Image size & $=25 \mu \mathrm{m}$ & Feedback mode & $=$ Free & Signal Module S & $=0$ \\
\hline Scan direction & $=U p$ & Feedback algo. & = Adaptive PI & Signal Module A & $=0$ \\
\hline Time/Line & $=0.7 \mathrm{~s}$ & Vibration freq. & $=179.054 \mathrm{kHz}$ & Nanosurf Report & $=0$ \\
\hline Points & $=256$ & Vibration ampl. & $=0.7 \mathrm{~V}$ & Scripting Interface & $=0$ \\
\hline
\end{tabular}


A-675-16 after heat treatment

\section{Nanosurf Image Document}

File: Image5
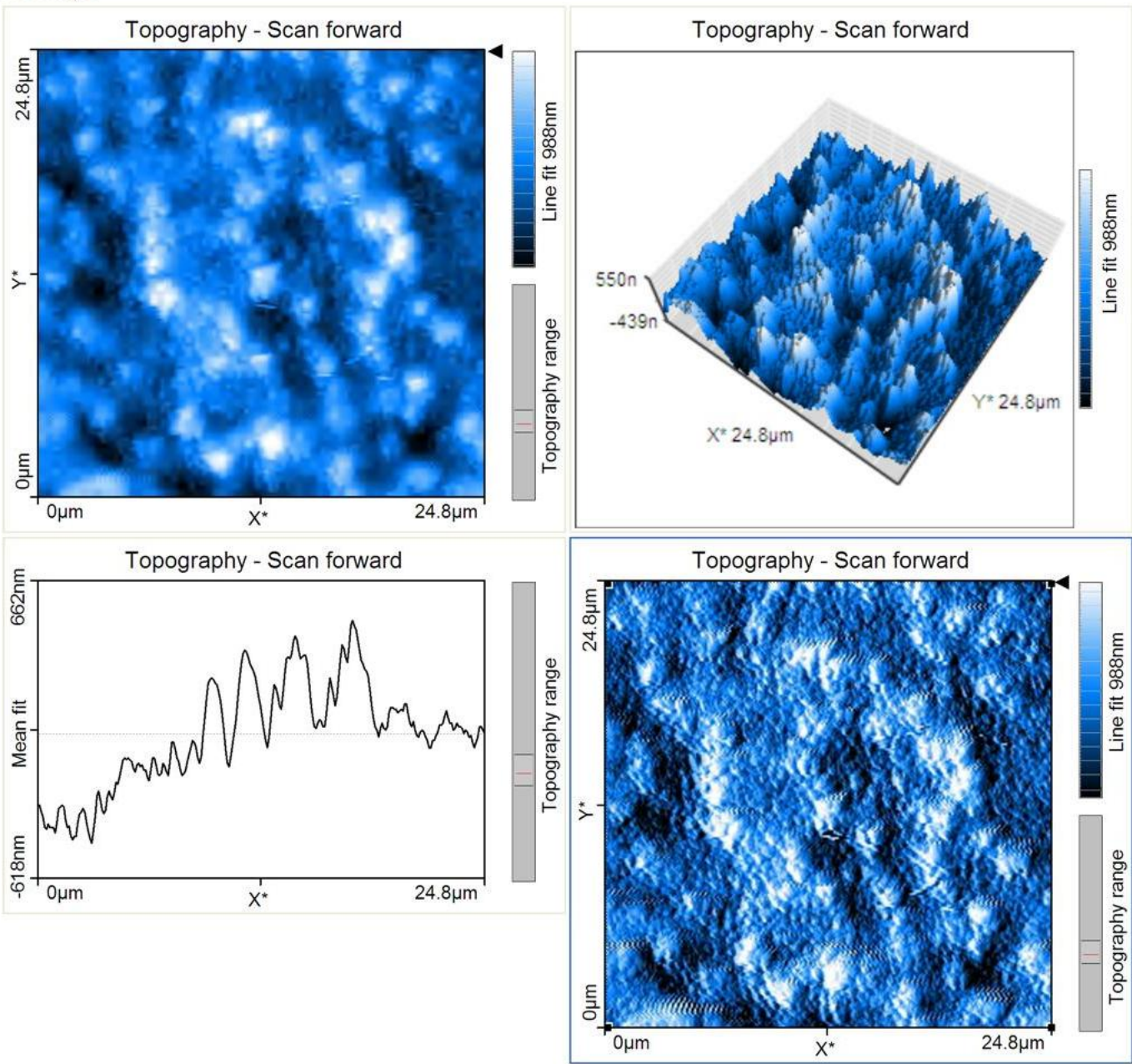

Parameter:

\begin{tabular}{|c|c|c|c|c|c|}
\hline \multicolumn{2}{|c|}{-- Area Roughness -- } & \multirow{2}{*}{$\begin{array}{l}\text { Lines } \\
\text { X-Slope }\end{array}$} & \multirow{2}{*}{$\begin{array}{l}=256 \\
=1.5^{\circ}\end{array}$} & \multirow{2}{*}{$\begin{array}{l}\text { Excitation ampl. } \\
\text { Error range }\end{array}$} & \multirow{2}{*}{$\begin{array}{l}=0.18 \mathrm{~V} \\
=20 \mathrm{~V}\end{array}$} \\
\hline Area & $=618 \mathrm{pm}^{\wedge} 2$ & & & & \\
\hline Sa & $=141.63 \mathrm{~nm}$ & Y-Slope & $=2.5^{\circ}$ & -- Global -- & \\
\hline $\mathrm{Sq}$ & $=176.87 \mathrm{~nm}$ & Rotation & $=-14.2 \mathrm{f}^{\circ}$ & Op. mode & $=$ Dynamic Force \\
\hline Sy & $=1105.3 \mathrm{~nm}$ & X-Pos & $=0 \mathrm{fm}$ & Cantilever type & $=A C L A$ \\
\hline $\mathrm{Sp}$ & $=621.28 \mathrm{~nm}$ & Y-Pos & $=0 \mathrm{fm}$ & Head type & $=E Z 2-A F M$ \\
\hline Sv & $=-484.01 \mathrm{~nm}$ & Z-Plane & $=0 \mathrm{fm}$ & Scan head & $=10-07-239$. hed \\
\hline $\mathrm{Sm}$ & $=-107.78 \mathrm{fm}$ & Overscan & $=5 \%$ & Software ver. & $=1-5-1-0$ \\
\hline \multicolumn{2}{|c|}{-- Line Roughness -- } & \multicolumn{2}{|c|}{ Const. Height-Mod $\epsilon=$ Disabled } & Firmware ver. & $=2-1-1-2$ \\
\hline $\mathrm{Ra}$ & $=161.94 \mathrm{~nm}$ & Date & $=22-08-2008$ & Controller $\mathrm{S} / \mathrm{N}$ & $=023-06-252$ \\
\hline $\mathrm{Rq}$ & $=192.79 \mathrm{~nm}$ & Time & $=19: 23: 50$ & -- Module -- & \\
\hline Ry & $=800.61 \mathrm{~nm}$ & -- Feedback -- & & Controller Board & $=2$ \\
\hline$R p$ & $=480.43 \mathrm{~nm}$ & Set point & $=46 \%$ & AFM Basic Module & $=2$ \\
\hline Rv & $=-320.18 \mathrm{~nm}$ & P-Gain & $=10000$ & \multicolumn{2}{|c|}{ AFM Dynamic Module $=2$} \\
\hline $\mathrm{Rm}$ & $=1.6087 \mathrm{fm}$ & I-Gain & $=1400$ & \multicolumn{2}{|c|}{ AFM Extension Module $=1$} \\
\hline -- Scan -- & & Tip voltage & $=0 \mathrm{~V}$ & Video Module & $=0$ \\
\hline Image size & $=25 \mu \mathrm{m}$ & Feedback mode & $=$ Free & Signal Module S & $=0$ \\
\hline Scan direction & $=U p$ & Feedback algo. & = Adaptive PI & Signal Module A & $=0$ \\
\hline Time/Line & $=0.4 \mathrm{~s}$ & Vibration freq. & $=179.074 \mathrm{kHz}$ & Nanosurf Report & $=0$ \\
\hline Points & $=256$ & Vibration ampl. & $=0.7 \mathrm{~V}$ & Scripting Interface & $=0$ \\
\hline
\end{tabular}




\section{Nanosurf Image Document}

File: Image6
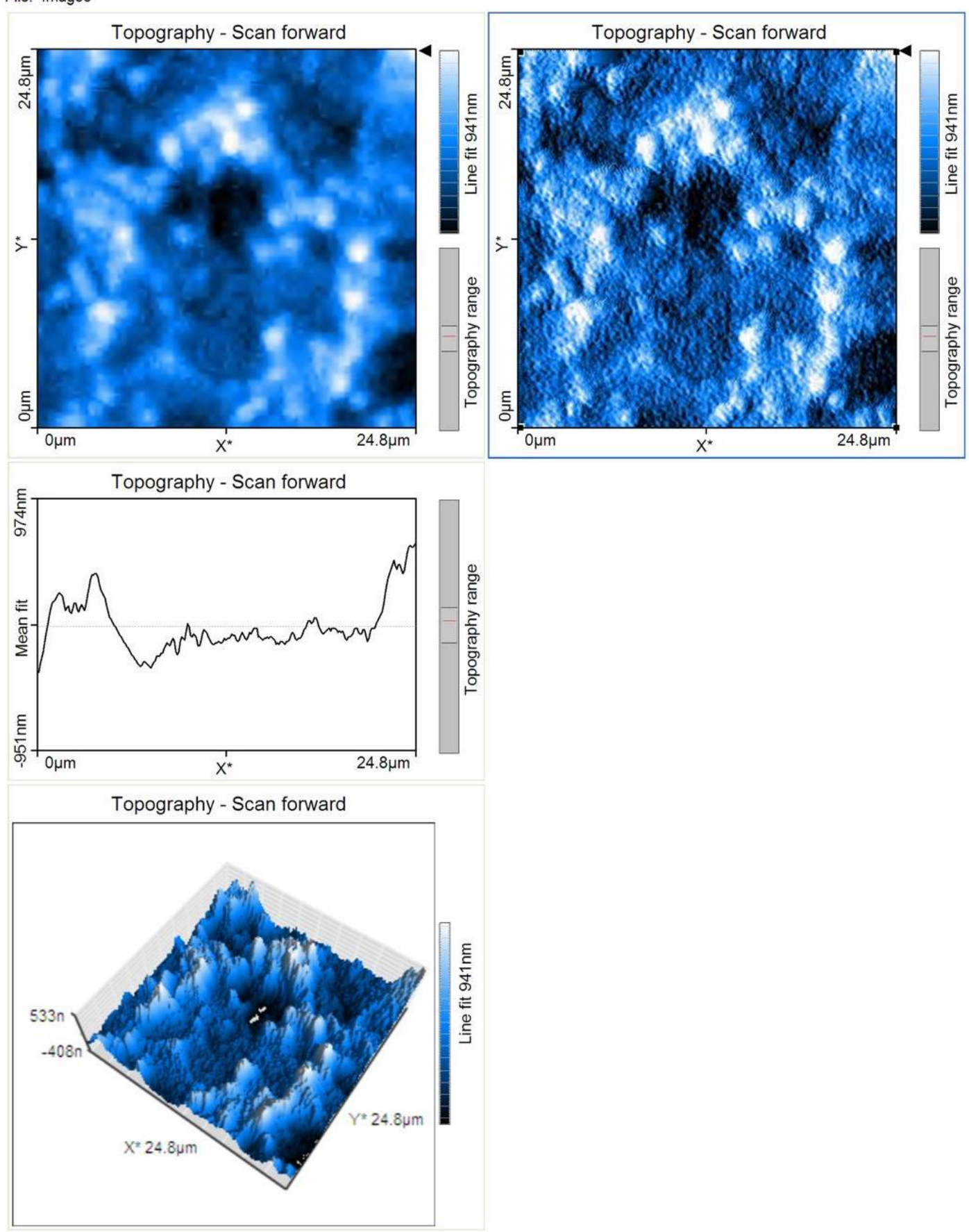

Parameter:

\begin{tabular}{|c|c|c|c|}
\hline \multicolumn{2}{|c|}{-- Area Roughness -- } & \multirow{2}{*}{$\begin{array}{l}\text { Lines } \\
\text { X-Slope }\end{array}$} & \multirow{2}{*}{$\begin{array}{l}=256 \\
=1.5^{\circ}\end{array}$} \\
\hline Area & $=618 \mathrm{pm}^{\wedge} 2$ & & \\
\hline $\mathrm{Sa}$ & $=146.1 \mathrm{~nm}$ & Y-Slope & $=2.5^{\circ}$ \\
\hline $\mathrm{Sq}$ & $=179.96 \mathrm{~nm}$ & Rotation & $=-14.2 f^{\circ}$ \\
\hline Sy & $=1127.2 \mathrm{~nm}$ & X-Pos & $=0 \mathrm{fm}$ \\
\hline $\mathrm{Sp}$ & $=646.37 \mathrm{~nm}$ & Y-Pos & $=0 \mathrm{fm}$ \\
\hline Sv & $=-480.85 \mathrm{~nm}$ & Z-Plane & $=0 \mathrm{fm}$ \\
\hline $\mathrm{Sm}$ & $=164.41 \mathrm{pm}$ & Overscan & $=5 \%$ \\
\hline \multicolumn{2}{|c|}{-- Line Roughness -- } & \multicolumn{2}{|c|}{ Const. Height-Mode= Disabled } \\
\hline$R_{a}$ & $=15 a 82 \mathrm{~nm}$ & nato & $=20 \_\cap R-3 \cap \cap R$ \\
\hline
\end{tabular}

$\begin{array}{ll}\text { Excitation ampl. } & =0.17 \mathrm{~V} \\ \text { Error range } & =20 \mathrm{~V} \\ - \text { - Global }- & \\ \text { Op. mode } & =\text { Dynamic Force } \\ \text { Cantilever type } & =\text { ACLA } \\ \text { Head type } & =\text { EZ2-AFM } \\ \text { Scan head } & =10-07-239 . \text { hed } \\ \text { Software ver. } & =1-5-1-0 \\ \text { Firmware ver. } & =2-1-1-2 \\ \text { Controllor C/NI } & =\text { กว_nR-252 }\end{array}$




\section{Nanosurf Image Document}

File: Image7
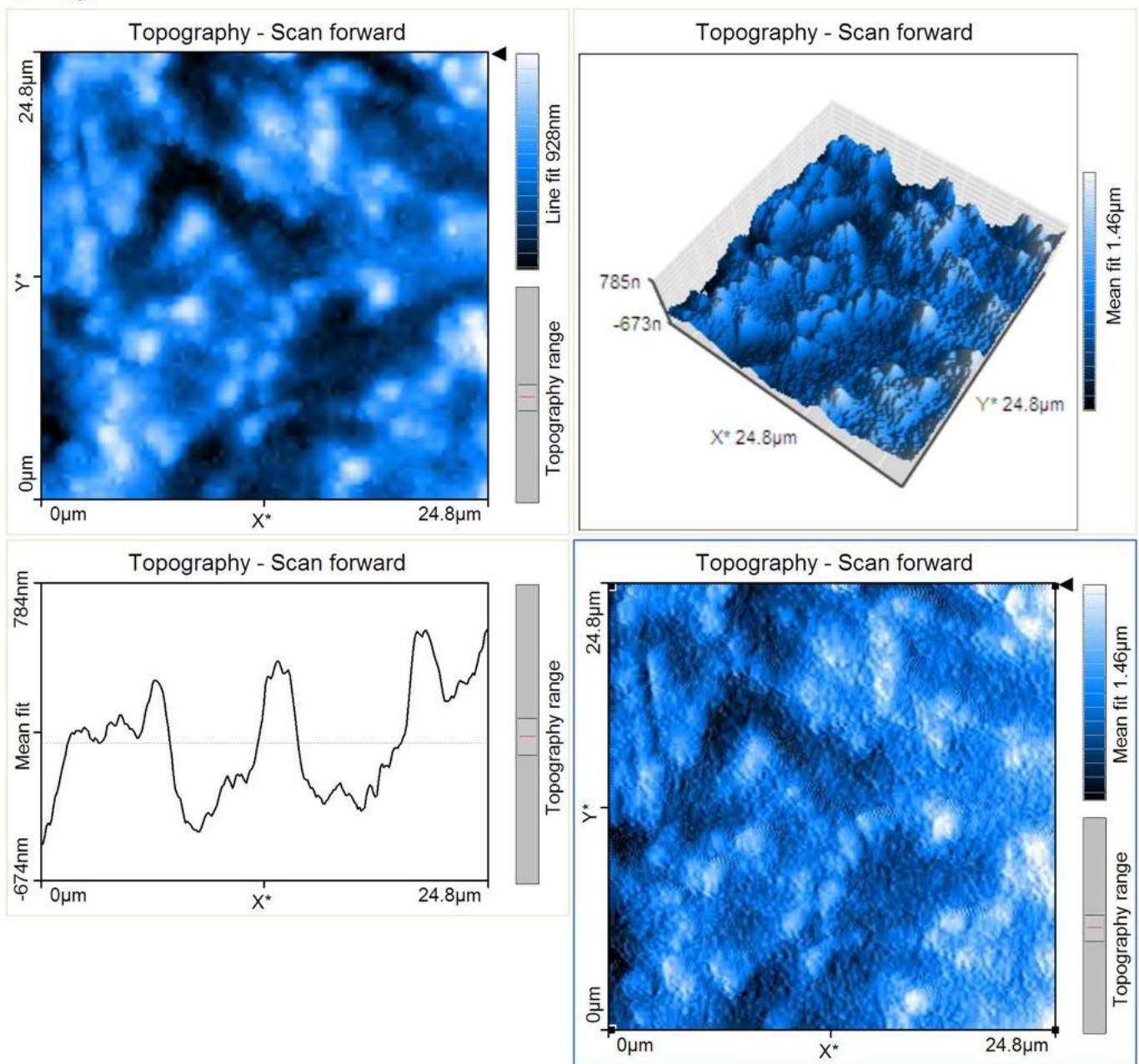

Parameter:

\begin{tabular}{|c|c|c|c|c|c|}
\hline \multicolumn{2}{|c|}{-- Area Roughness -- } & \multirow{2}{*}{$\begin{array}{l}\text { Lines } \\
\text { X-Slope }\end{array}$} & \multirow{2}{*}{$\begin{array}{l}=256 \\
=1.5^{\circ}\end{array}$} & \multirow{2}{*}{$\begin{array}{l}\text { Excitation ampl. } \\
\text { Error range }\end{array}$} & \multirow{2}{*}{$\begin{array}{l}=0.18 \mathrm{~V} \\
=20 \mathrm{~V}\end{array}$} \\
\hline Area & $=618 \mathrm{pm}^{\wedge} 2$ & & & & \\
\hline $\mathrm{Sa}$ & $=183.66 \mathrm{~nm}$ & Y-Slope & $=2.5^{\circ}$ & -- Global -- & \\
\hline $\mathrm{Sq}$ & $=227.7 \mathrm{~nm}$ & Rotation & $=-14.2 f^{\circ}$ & Op. mode & $=$ Dynamic Force \\
\hline Sy & $=1595.9 \mathrm{~nm}$ & X-Pos & $=0 \mathrm{fm}$ & Cantilever type & $=A C L A$ \\
\hline Sp & $=780.47 \mathrm{~nm}$ & Y-Pos & $=0 \mathrm{fm}$ & Head type & $=\mathrm{EZ2}-\mathrm{AFM}$ \\
\hline Sv & $=-815.47 \mathrm{~nm}$ & Z-Plane & $=0 \mathrm{fm}$ & Scan head & $=10-07-239 \cdot$ hed \\
\hline Sm & $=26.789 \mathrm{pm}$ & Overscan & $=5 \%$ & Software ver. & $=1-5-1-0$ \\
\hline \multicolumn{2}{|c|}{-- Line Roughness -- } & \multicolumn{2}{|c|}{ Const. Height-Mod $\epsilon=$ Disabled } & Firmware ver. & $=2-1-1-2$ \\
\hline $\mathrm{Ra}$ & $=151.36 \mathrm{~nm}$ & Date & $=22-08-2008$ & Controller $\mathrm{S} / \mathrm{N}$ & $=023-06-252$ \\
\hline $\mathrm{Rq}$ & $=175.7 \mathrm{~nm}$ & Time & $=19: 39: 12$ & -- Module -- & \\
\hline Ry & $=736.93 \mathrm{~nm}$ & \multicolumn{2}{|l|}{-- Feedback -- } & Controller Board & $=2$ \\
\hline Rp & $=393.13 \mathrm{~nm}$ & Set point & $=46 \%$ & AFM Basic Module & $=2$ \\
\hline Rv & $=-343.8 \mathrm{~nm}$ & P-Gain & $=10000$ & \multicolumn{2}{|c|}{ AFM Dynamic Module $=2$} \\
\hline $\mathrm{Rm}$ & $=1648.9 \mathrm{fm}$ & I-Gain & $=1400$ & \multicolumn{2}{|c|}{ AFM Extension Module $=1$} \\
\hline -- Scan -- & & Tip voltage & $=0 \mathrm{~V}$ & Video Module & $=0$ \\
\hline Image size & $=25 \mu \mathrm{m}$ & Feedback mode & $=$ Free & Signal Module S & $=0$ \\
\hline Scan direction & $=U p$ & Feedback algo. & = Adaptive PI & Signal Module A & $=0$ \\
\hline Time/Line & $=0.5 \mathrm{~s}$ & Vibration freq. & $=179.044 \mathrm{kHz}$ & Nanosurf Report & $=0$ \\
\hline Points & $=256$ & Vibration ampl. & $=0.7 \mathrm{~V}$ & Scripting Interface & $=0$ \\
\hline
\end{tabular}


APPENDIX C: Potentiodynamic Polarization Data for Non-abraded Samples

OC, N-0

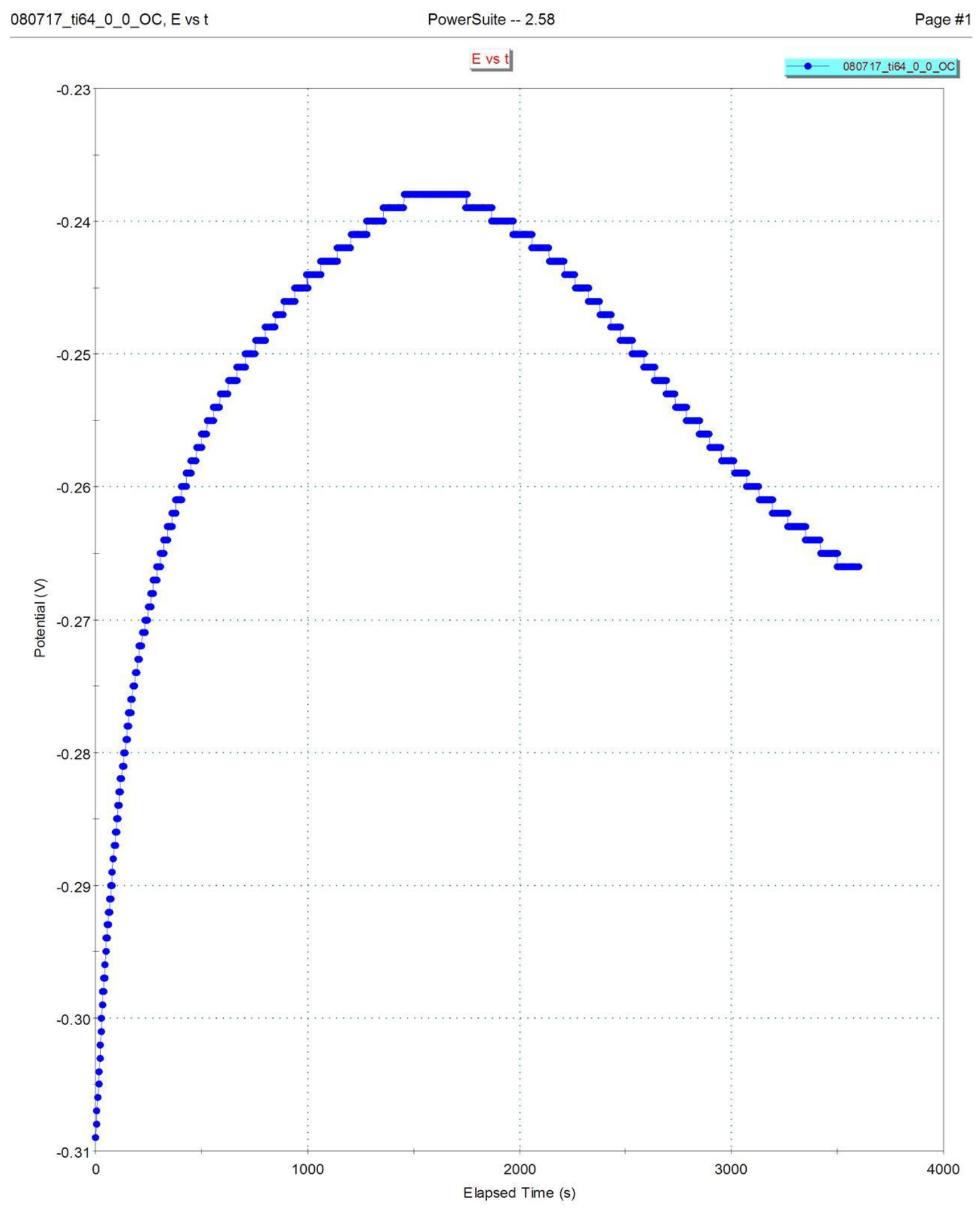

144 
CP, N-0

\begin{tabular}{ccc} 
080717_ti64_0_0_CP, E vs $\log (1)$ & PowerSuite -- 2.58 & Page \#1 \\
\hline Ev $\log (1)$ & $\bullet \quad$ 080717_ti64_0_0_CP
\end{tabular}

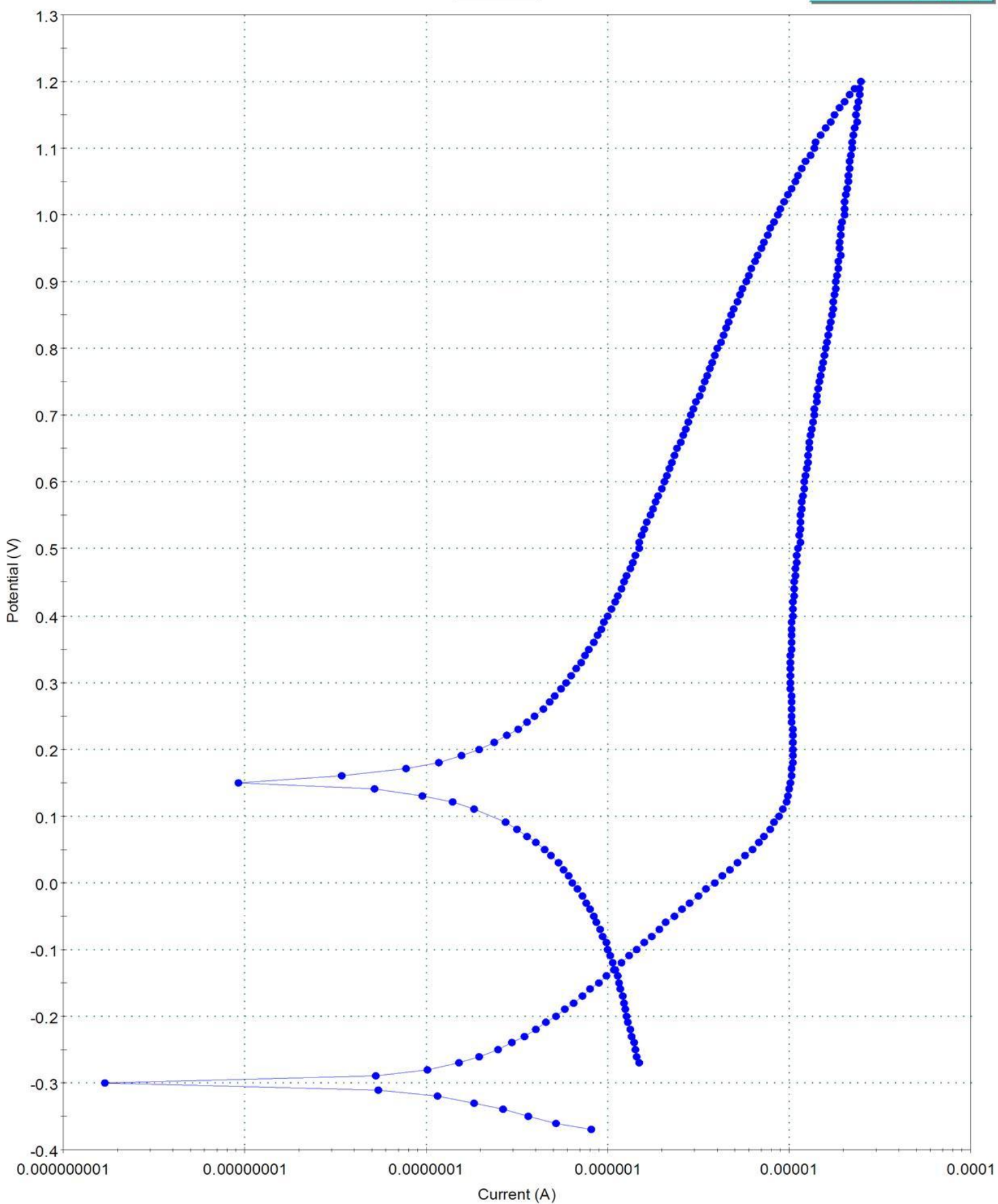


OC, N-600-1

080606_ti64_2_OC, E vs t

PowerSuite -- 2.58

Page \#1

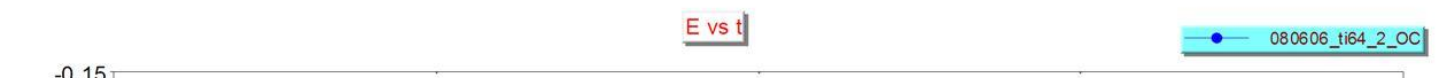

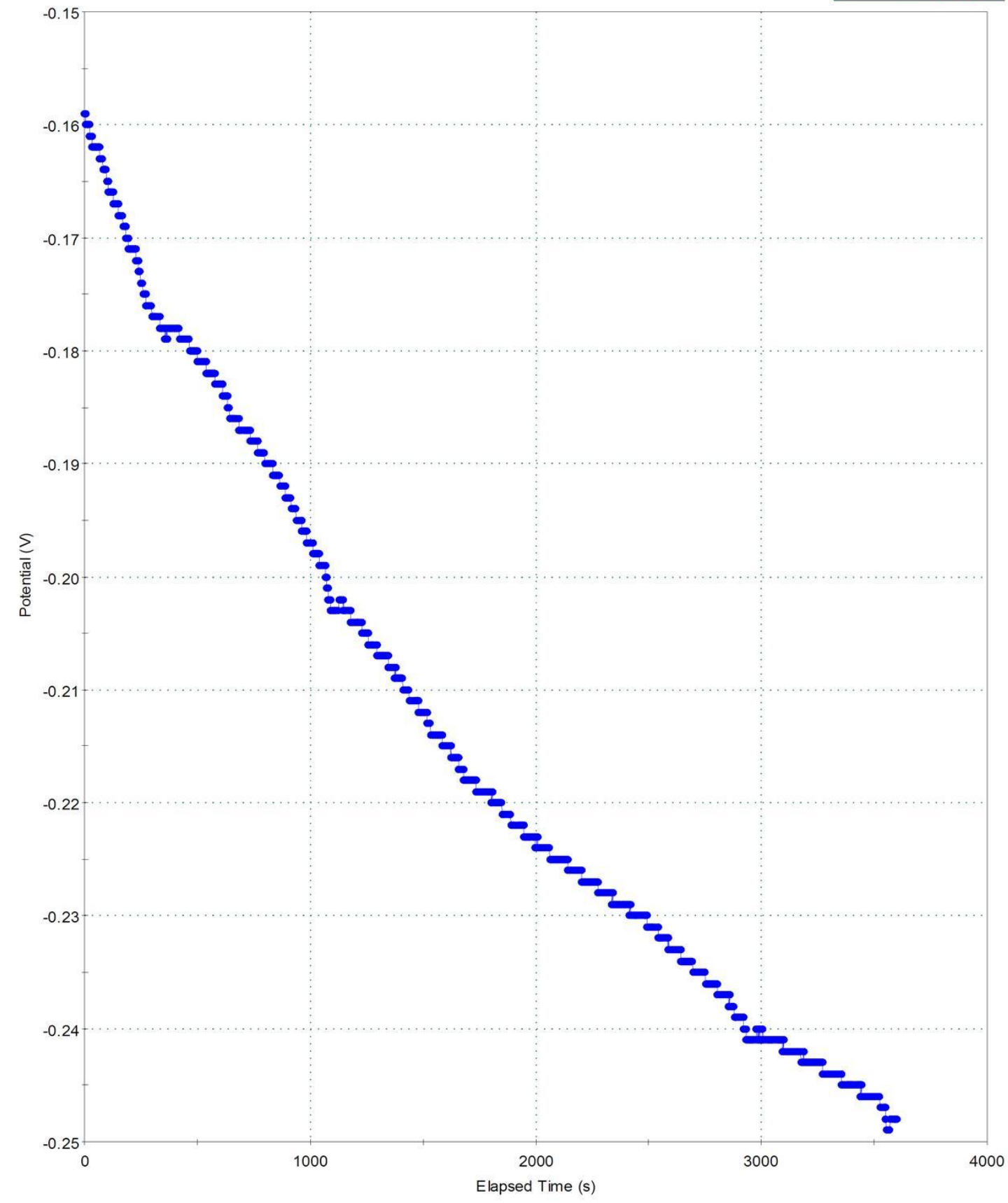


CP, N-600-1

080606_ti64_2_CP, E vs log( 1 )

PowerSuite -- 2.58

Page \#1

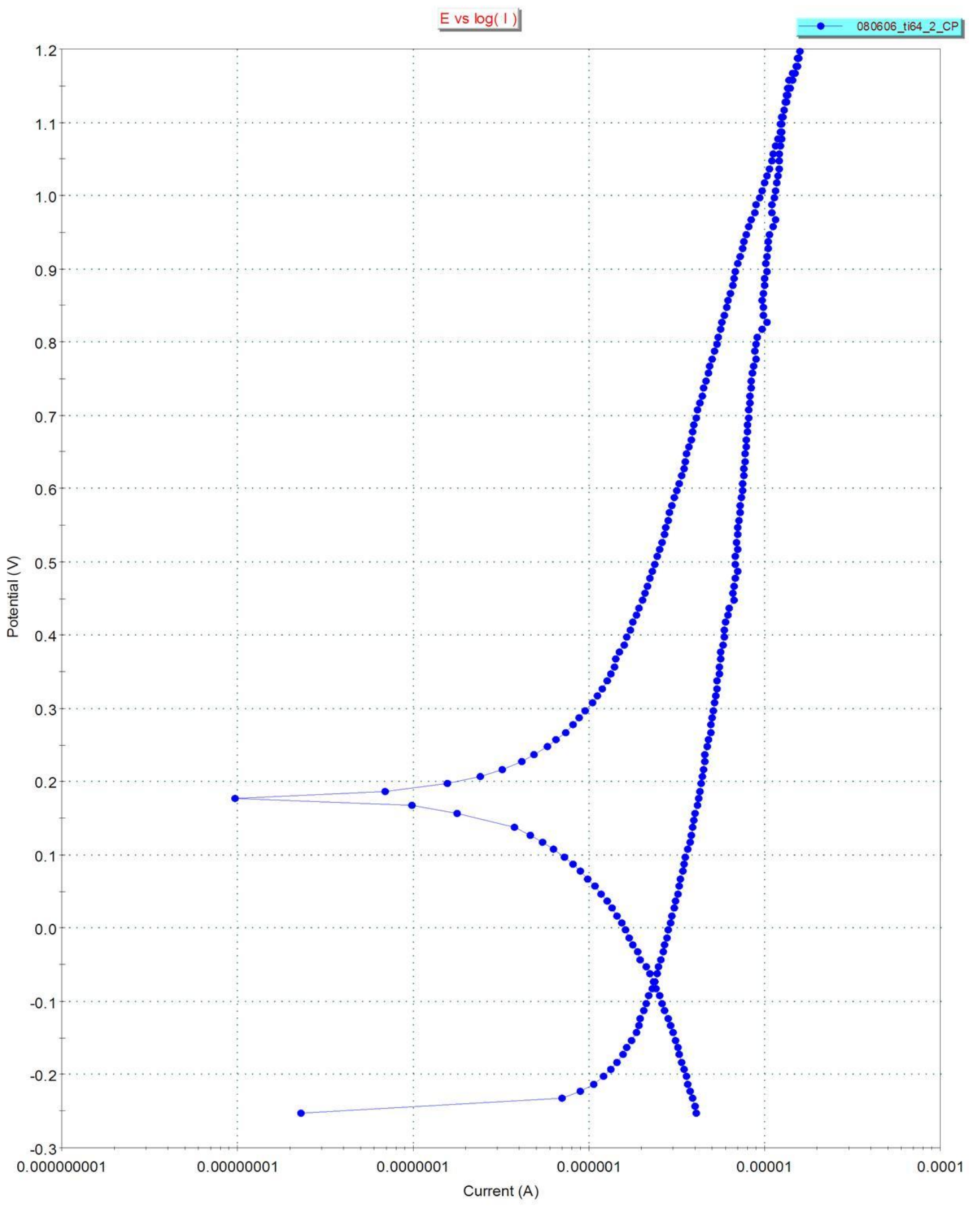


OC, N-600-4

080606_ti64_3_OC, E vs t

PowerSuite -- 2.58

Page \#1

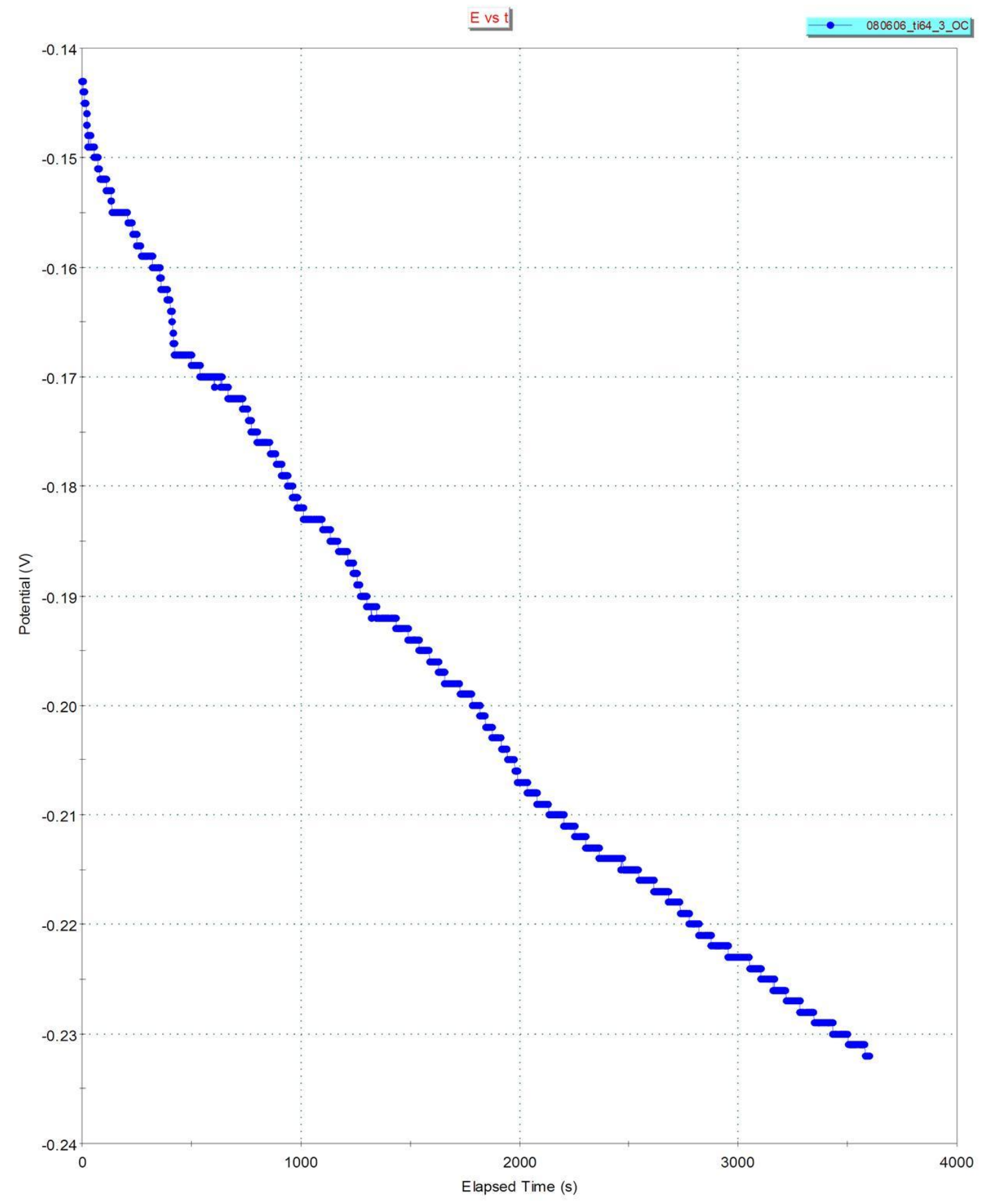


CP, N-600-4

080606_ti64_3_CP, E vs $\log (1)$

PowerSuite -- 2.58

Page \#1

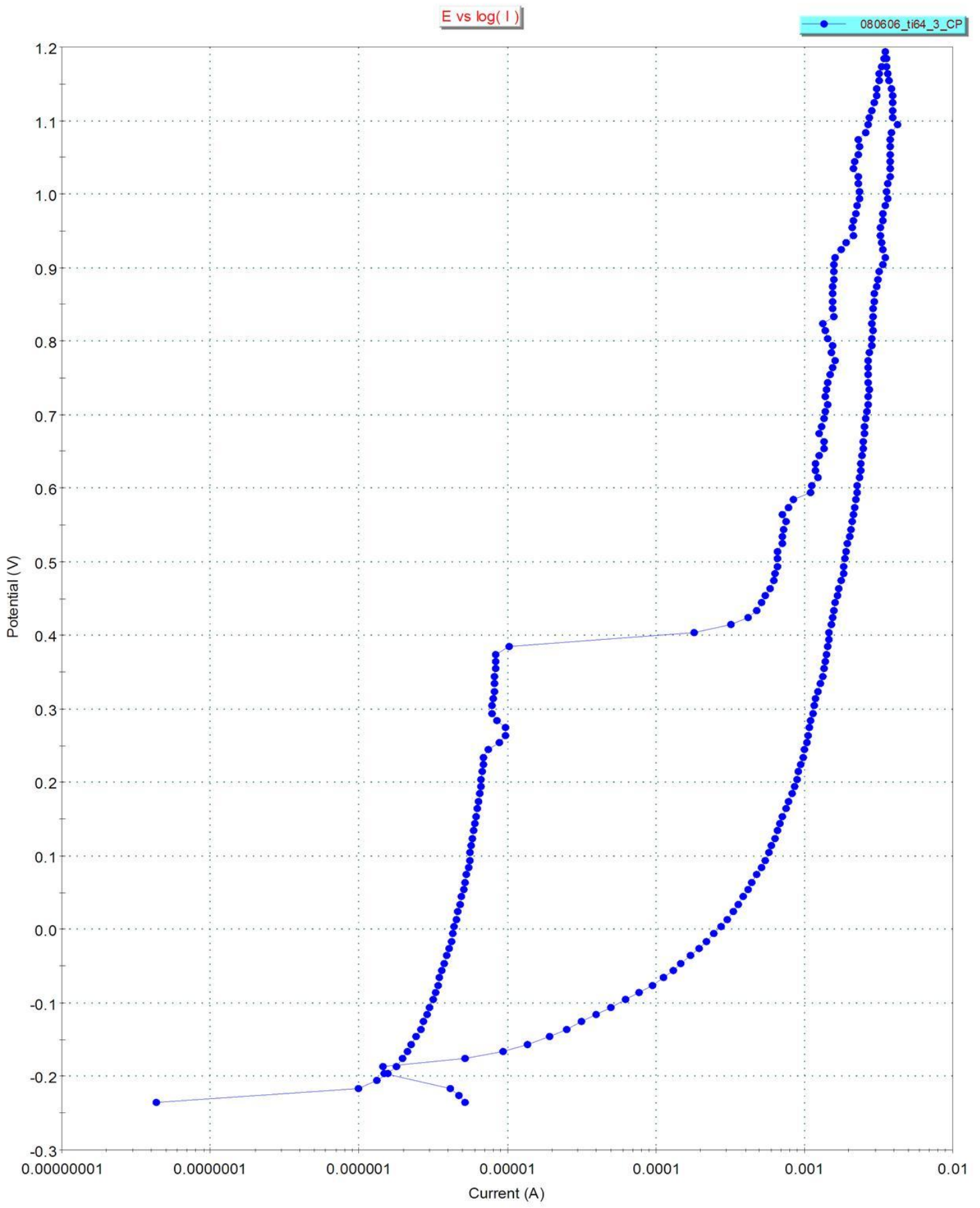


OC, N-600-8

\begin{tabular}{ccc} 
080605_ti64_1_OC, Evs t & PowerSuite -- 2.58 & Page \#1 \\
\hline & E vs t & — 080605_ti64_1_oc
\end{tabular}

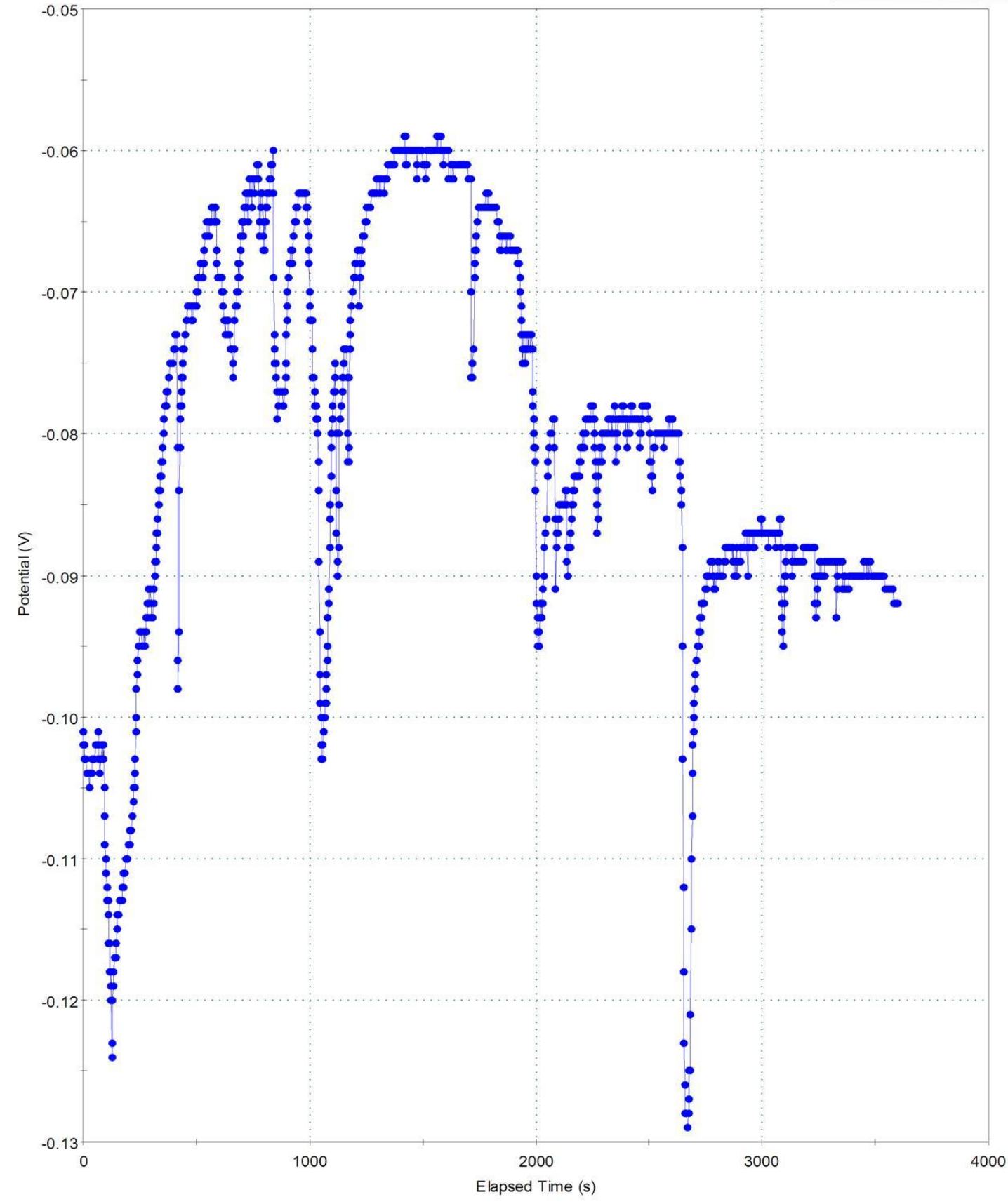


CP, N-600-8

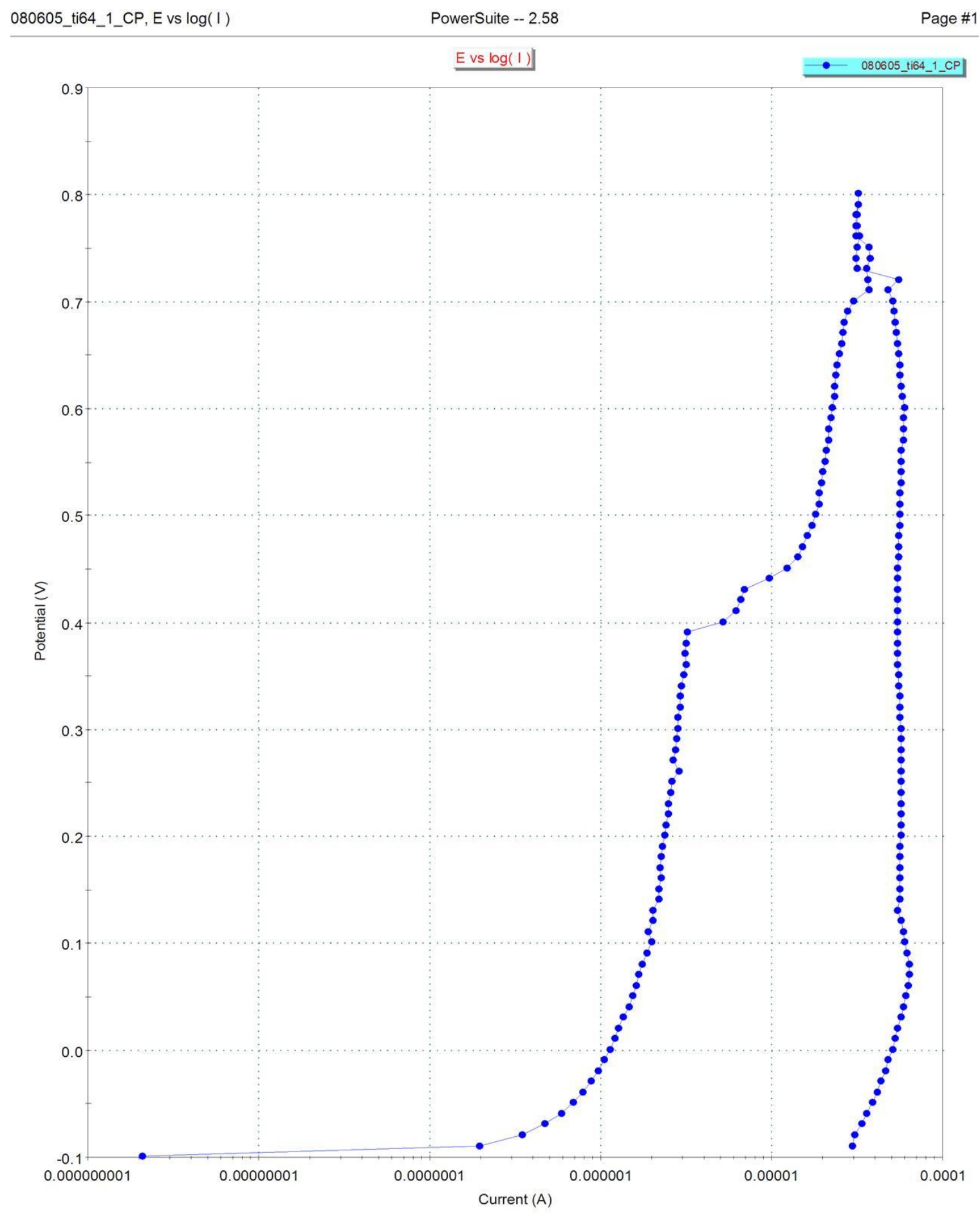


OC, N-600-16

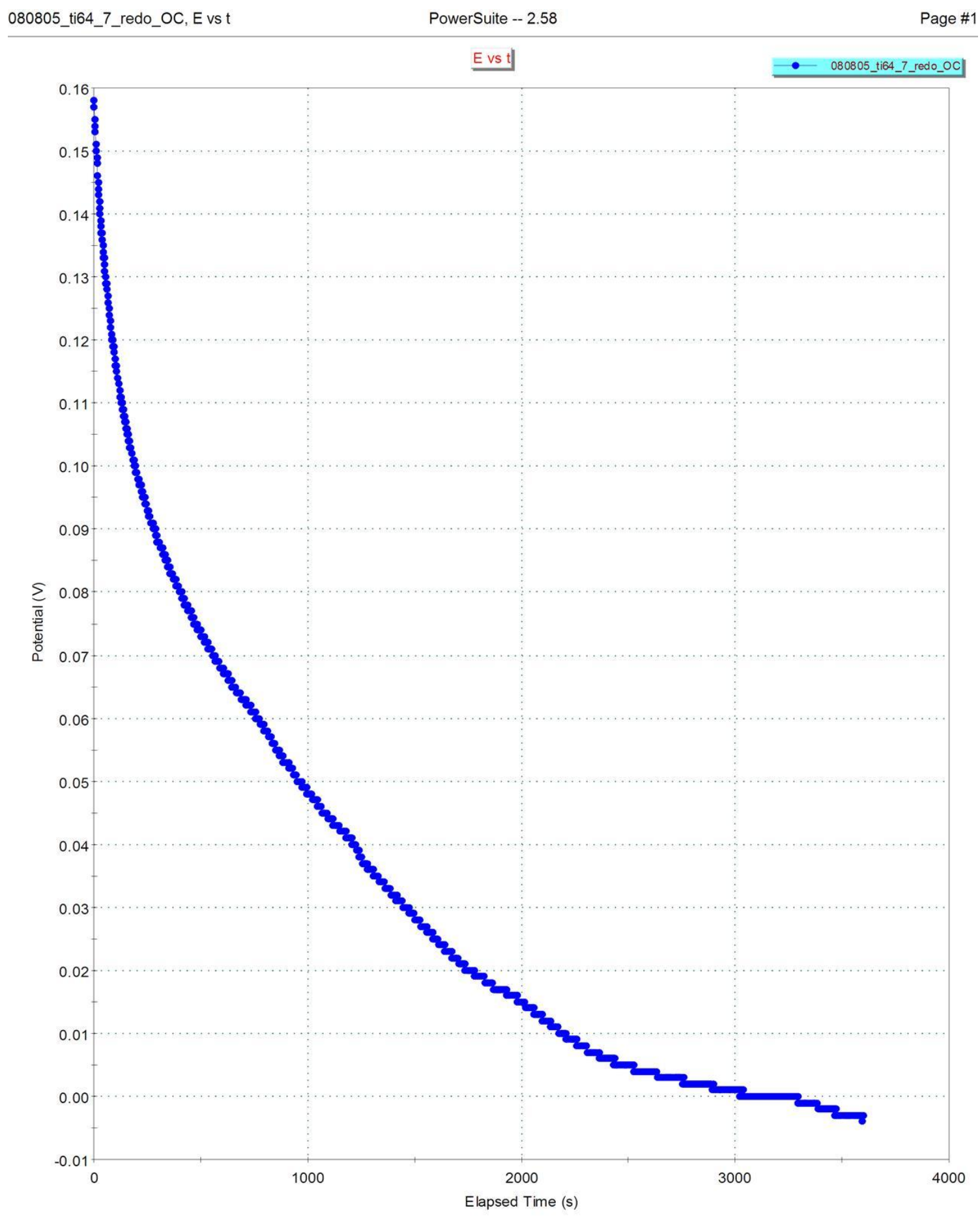


CP, N-600-16

\begin{tabular}{ccc} 
080805_ti64_7_redo_CP, Evs $\log (1)$ & PowerSuite - 2.58 & Page \#1 \\
\hline & E vs $\log (1) !$ & -080805 _ti64_7_redo_CP
\end{tabular}

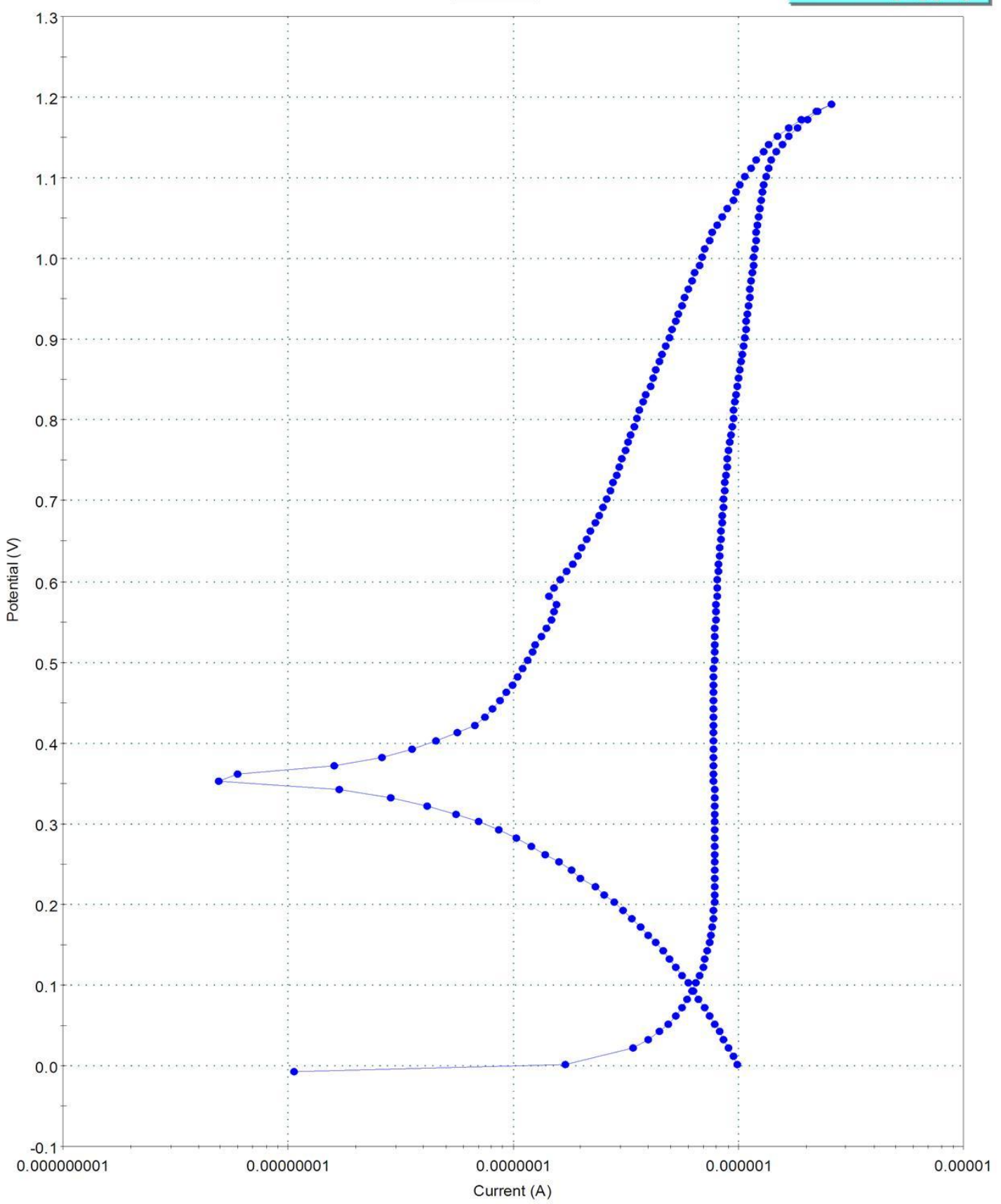


OC, N-675-1

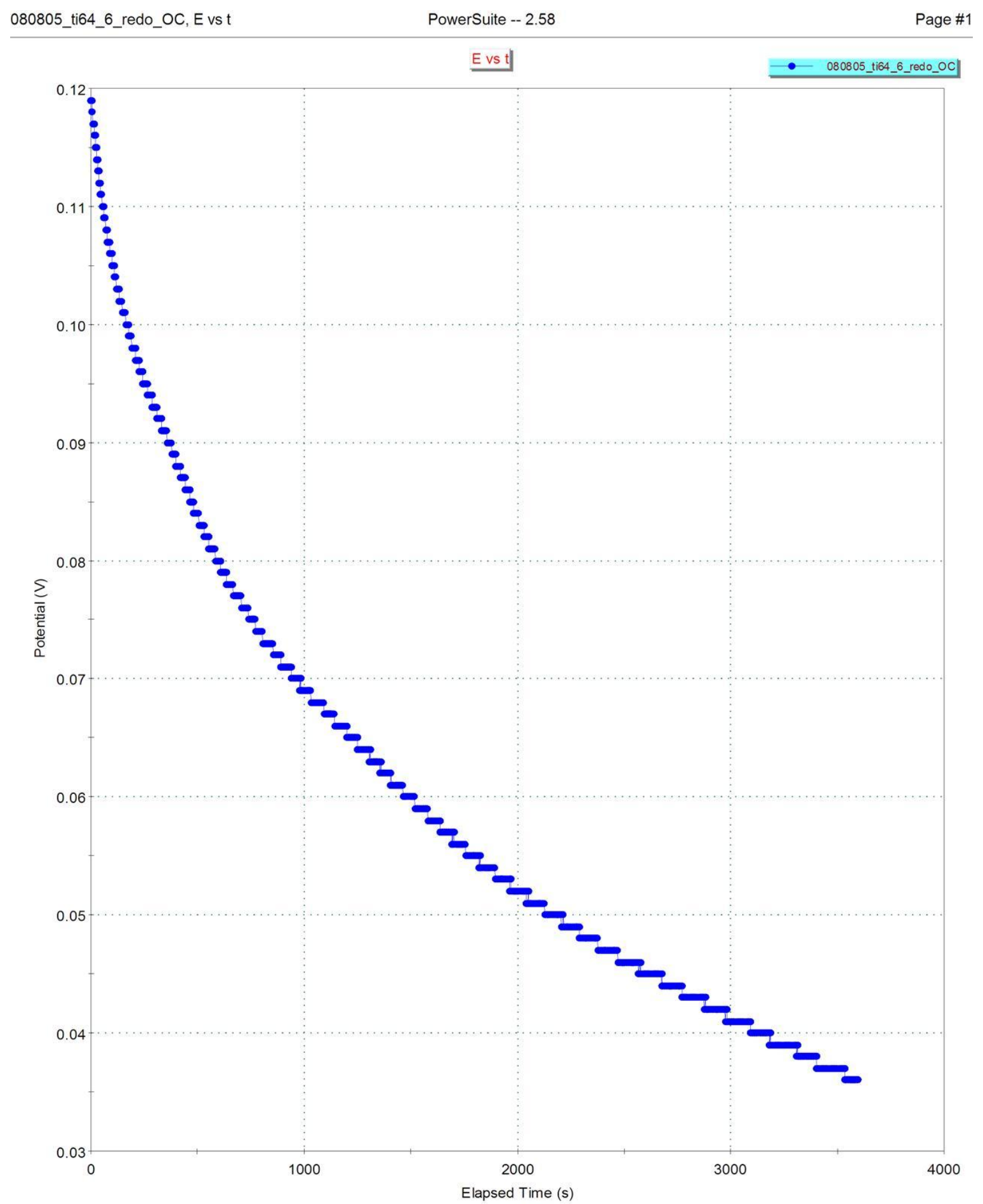

154 
CP, N-675-1

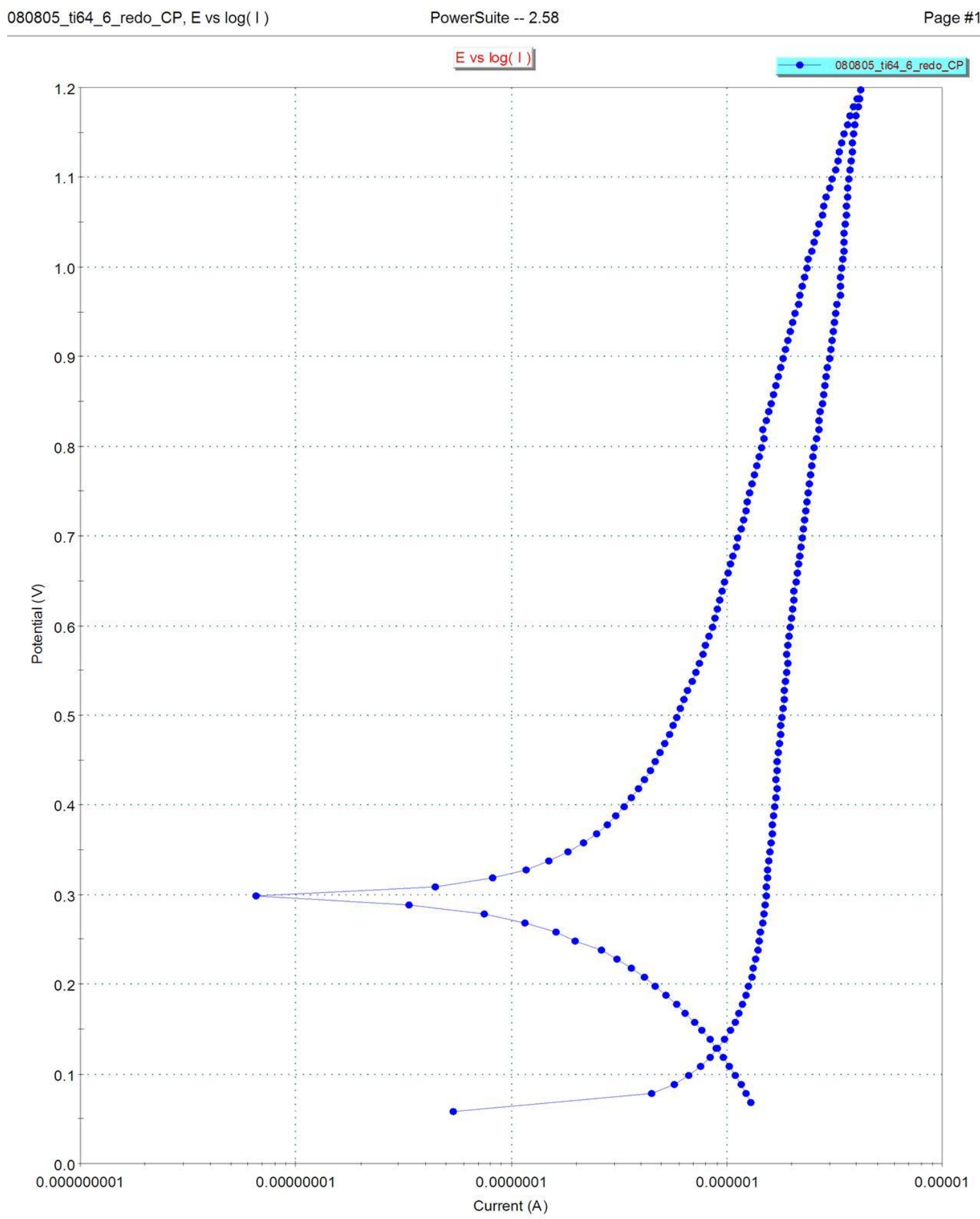


OC, N-675-4

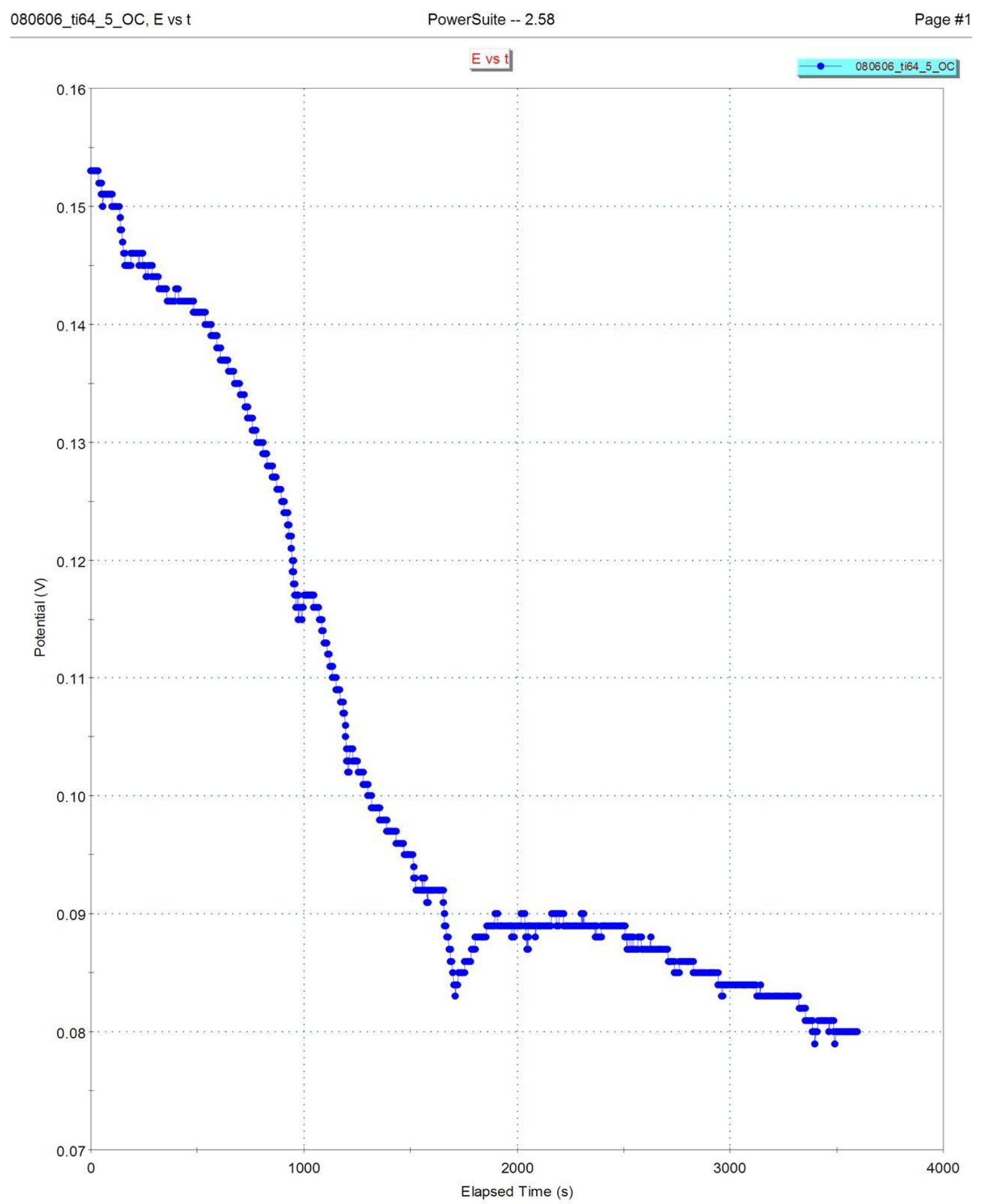

156 


\section{CP, N-675-4}

080606_ti64_5_CP, E vs $\log (1)$

PowerSuite -- 2.58

Page \#1

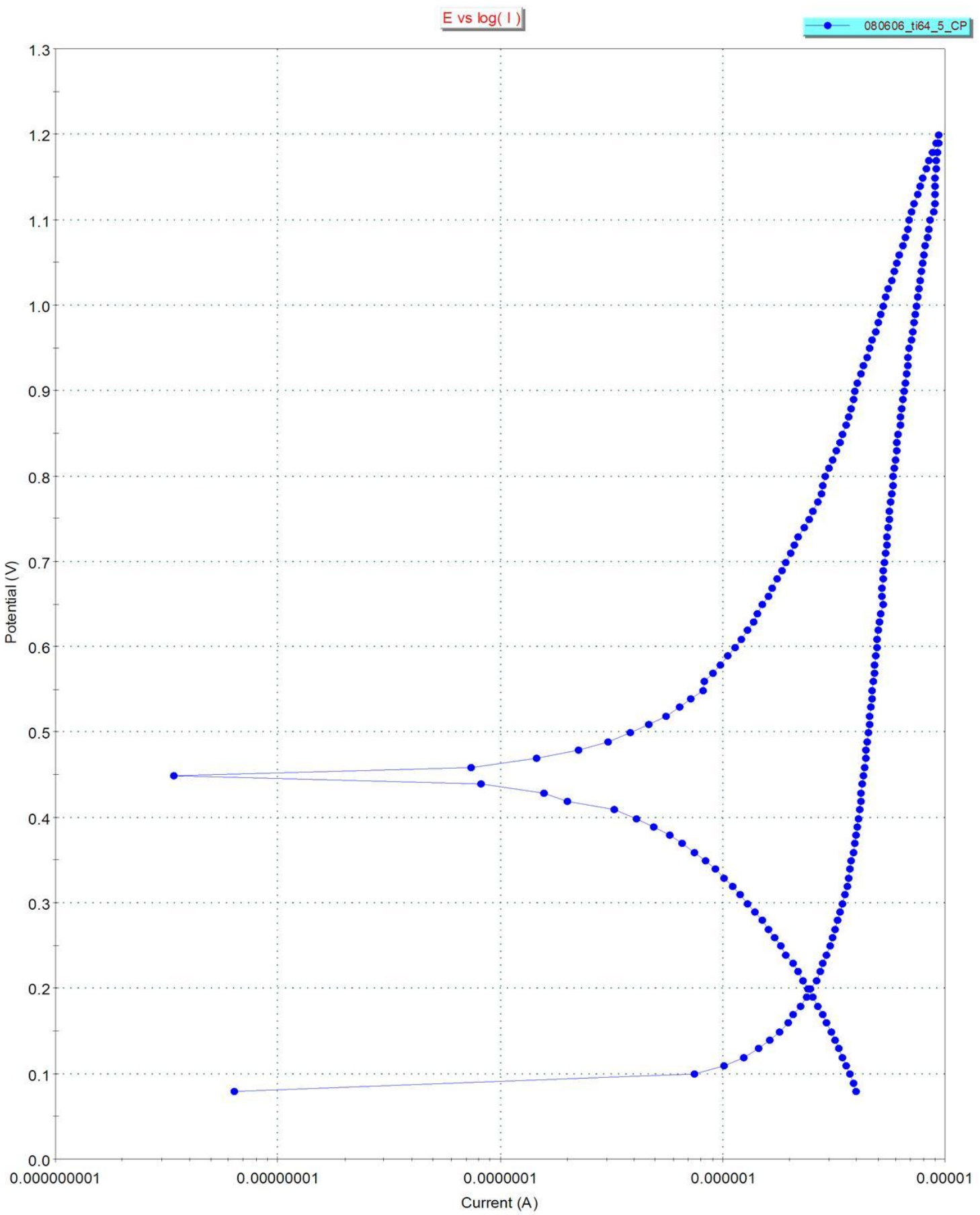


OC, N-675-8

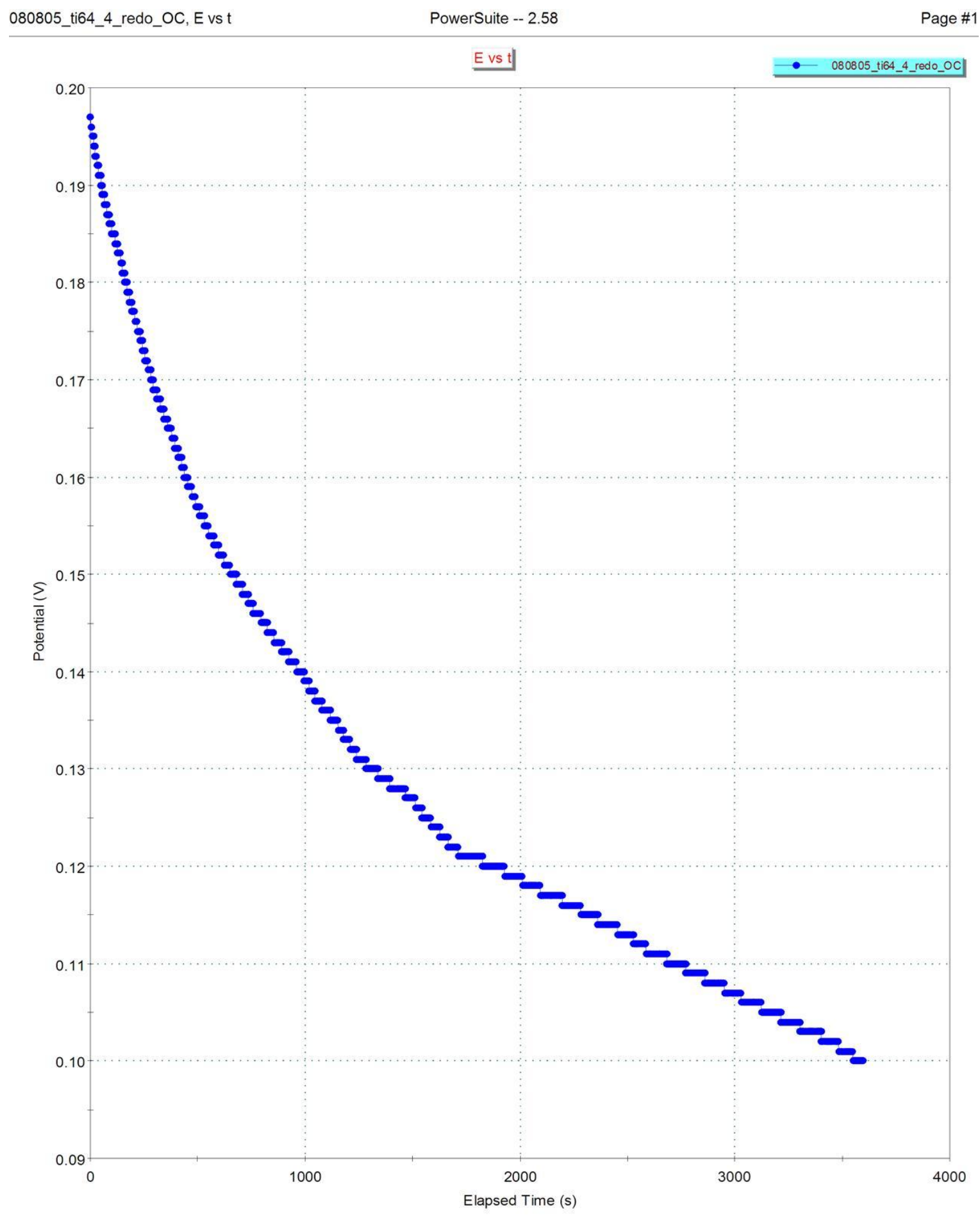




\section{CP, N-675-8}

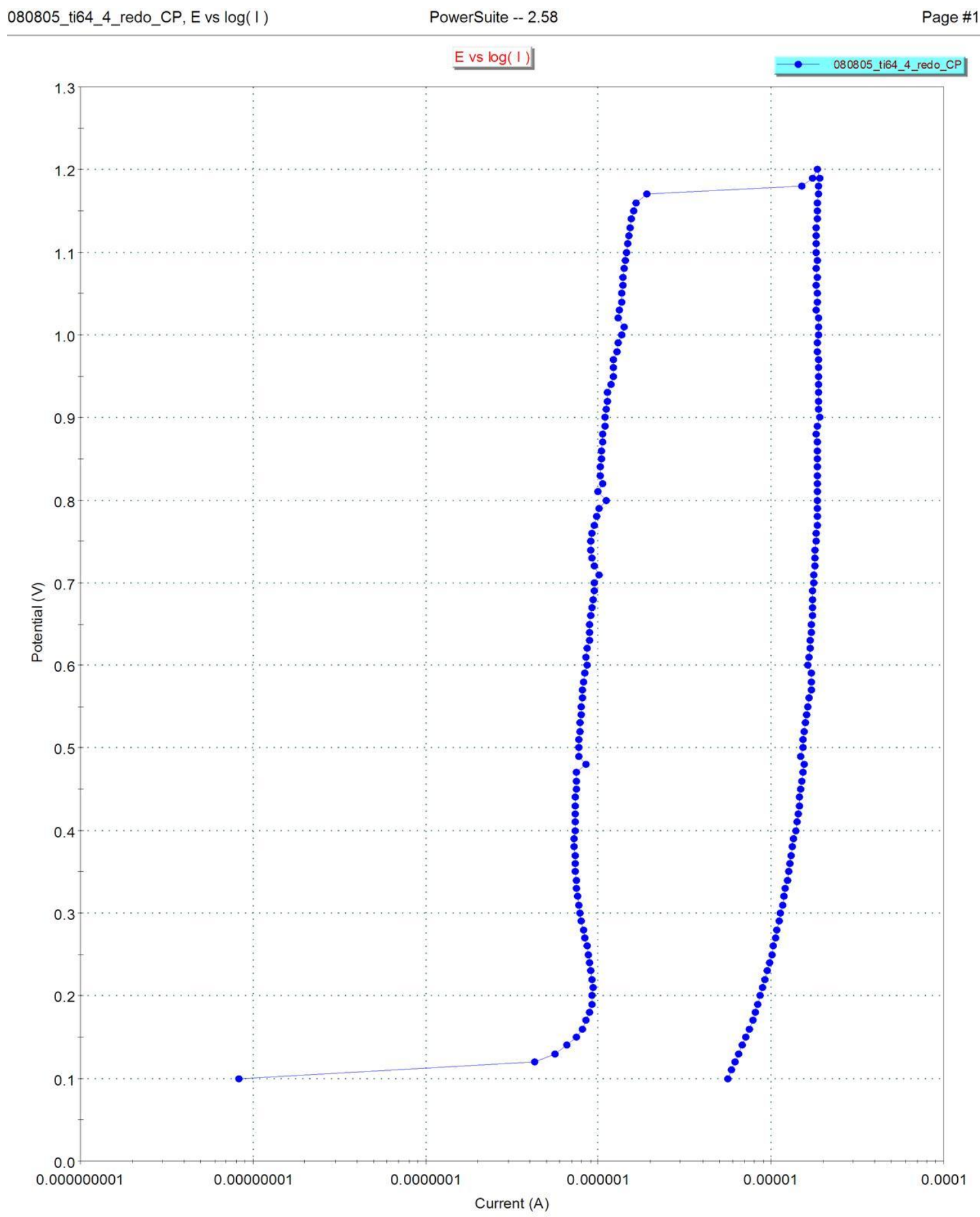


OC, N-675-16

080805_ti64_8_redo_OC, Evs t

PowerSuite -- 2.58

Page \#1

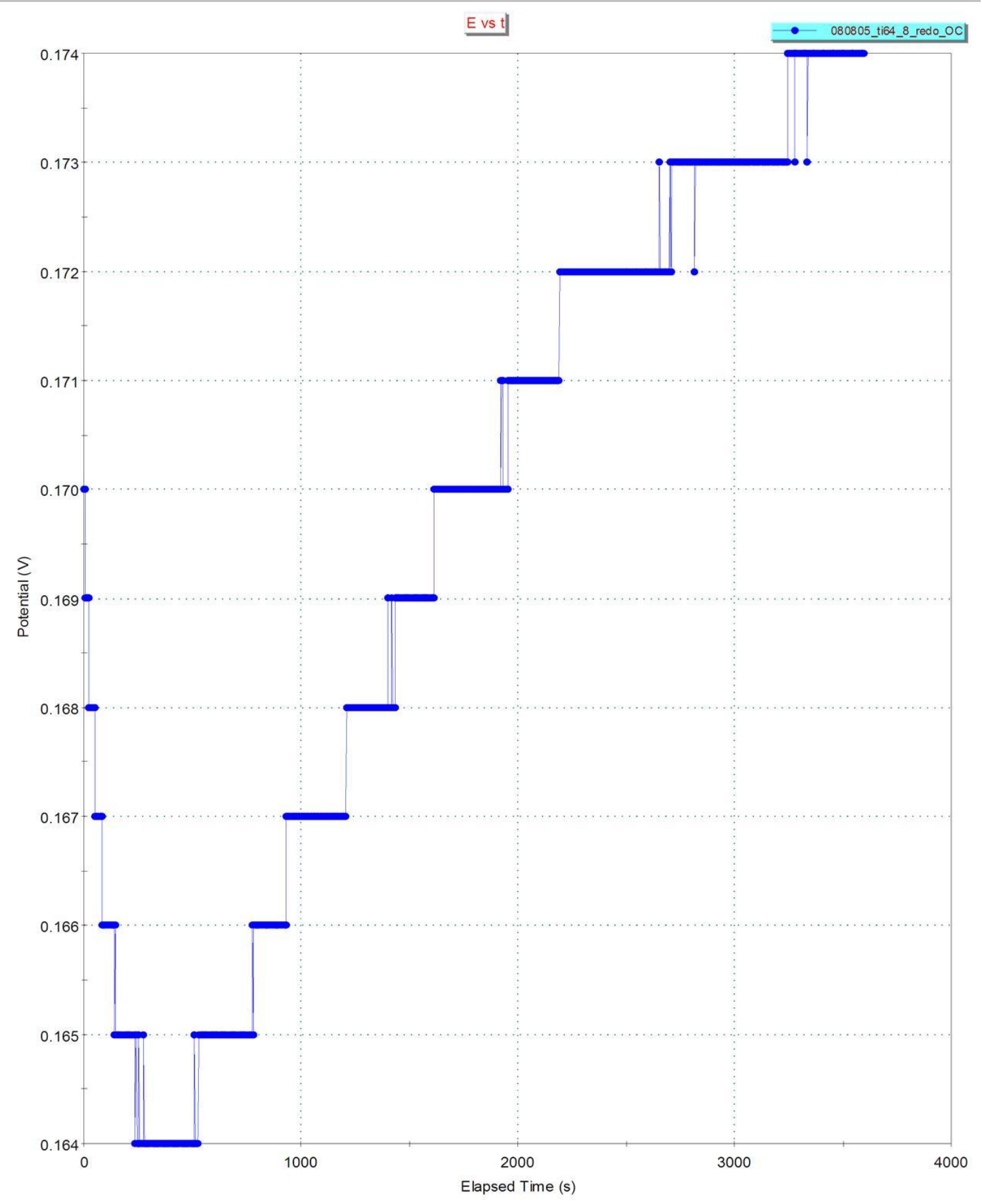


CP, N-675-16

080805_ti64_8_redo_CP, E vs log( I )

PowerSuite -- 2.58

Page \#1

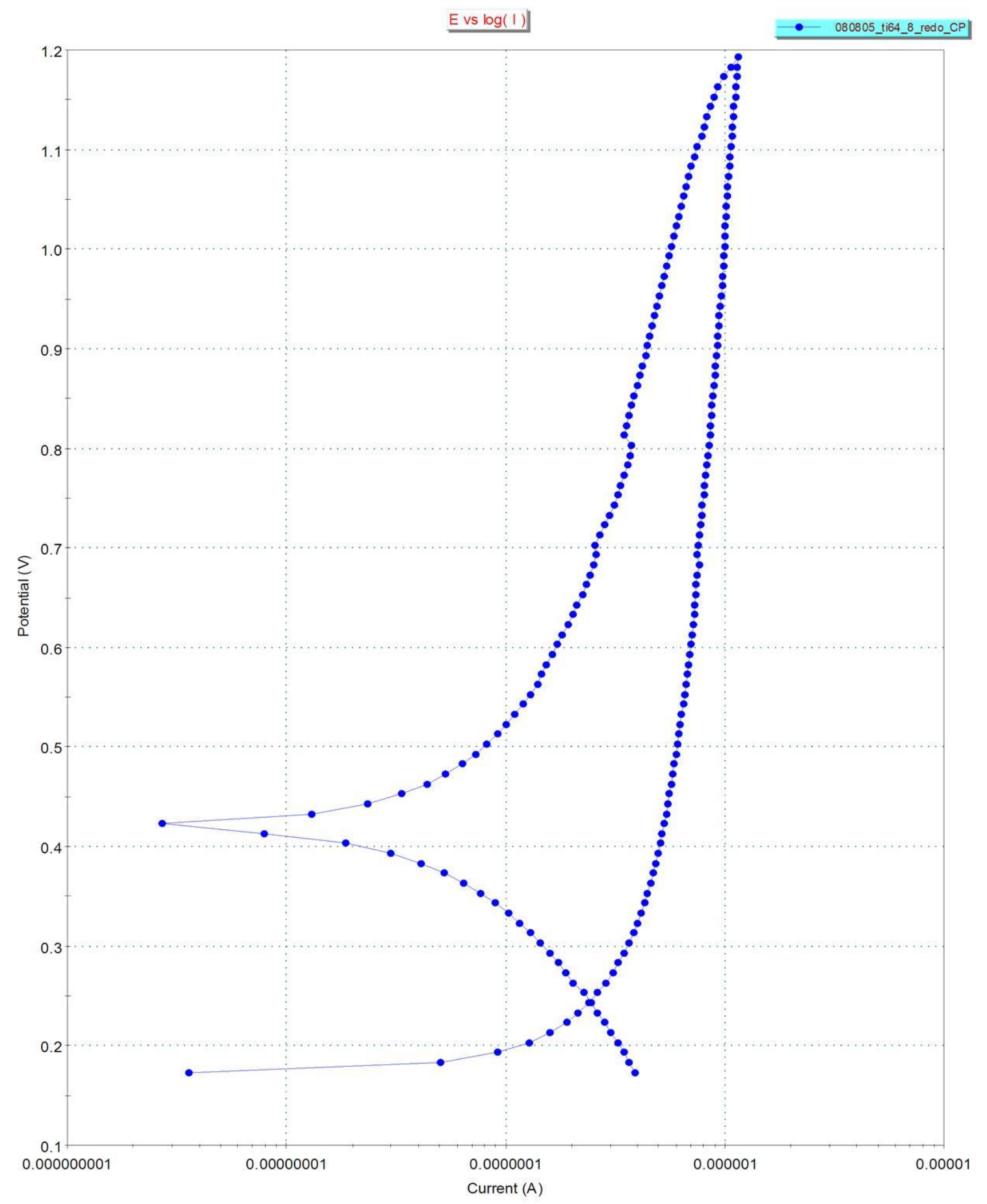


APPENDIX D: Minitab Calculations for HRc Data

\section{One-way ANOVA: HRc RT, HRc 600, HRc 675}

$\begin{array}{lrrrrr}\text { Source } & \text { DF } & \text { SS } & \text { MS } & \text { F } & P \\ \text { Factor } & 2 & 13.78 & 6.89 & 3.11 & 0.057 \\ \text { Error } & 36 & 79.88 & 2.22 & & \\ \text { Total } & 38 & 93.66 & & & \\ \text { S }=1.490 & \text { R-Sq }=14.72 \% & \text { R-Sq }(\text { adj })=9.98 \%\end{array}$

$\begin{array}{lrrr}\text { Level } & \text { N } & \text { Mean } & \text { StDev } \\ \text { HRc RT } & 7 & 34.329 & 2.216 \\ \text { HRC 600 } & 16 & 34.281 & 1.354 \\ \text { HRc 675 } & 16 & 33.087 & 1.236\end{array}$

Individual 95\% CIs For Mean Based on Pooled StDev

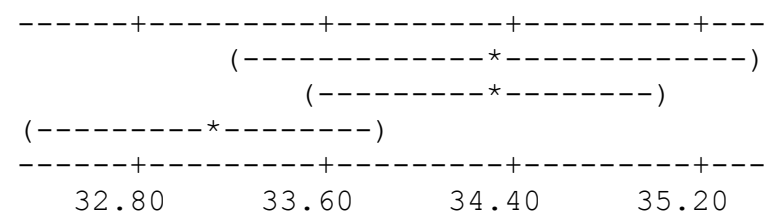

Pooled StDev $=1.490$

\section{One-way ANOVA: HRc 675 versus Time(675)}

$\begin{array}{lrrrrr}\text { Source } & \text { DF } & \text { SS } & \text { MS } & F & P \\ \text { Time (675) } & 3 & 7.597 & 2.532 & 9.09 & 0.002 \\ \text { Error } & 12 & 3.342 & 0.279 & & \\ \text { Total } & 15 & 10.939 & & & \\ \text { S }=0.5278 & \text { R-Sq }=69.45 \% & \text { R-Sq (adj) }=61.81 \%\end{array}$

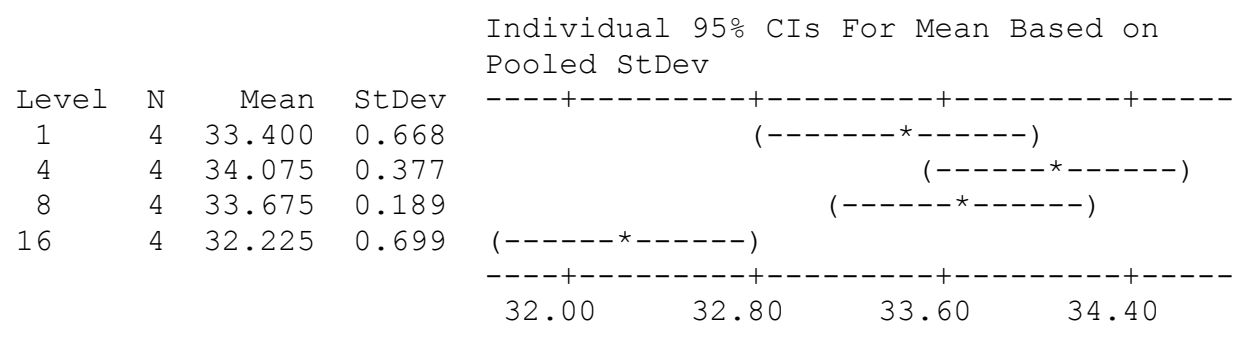

Pooled StDev $=0.528$ 


$\begin{array}{lrrrrr}\text { Source } & \text { DF } & \text { SS } & \text { MS } & F & P \\ \text { Time } & 3 & 2.365 & 0.788 & 1.62 & 0.238 \\ \text { Error } & 12 & 5.855 & 0.488 & & \\ \text { Total } & 15 & 8.220 & & & \\ S=0.6985 & \text { R-Sq }=28.77 \% & \text { R-Sq }(\text { adj })=10.96 \%\end{array}$

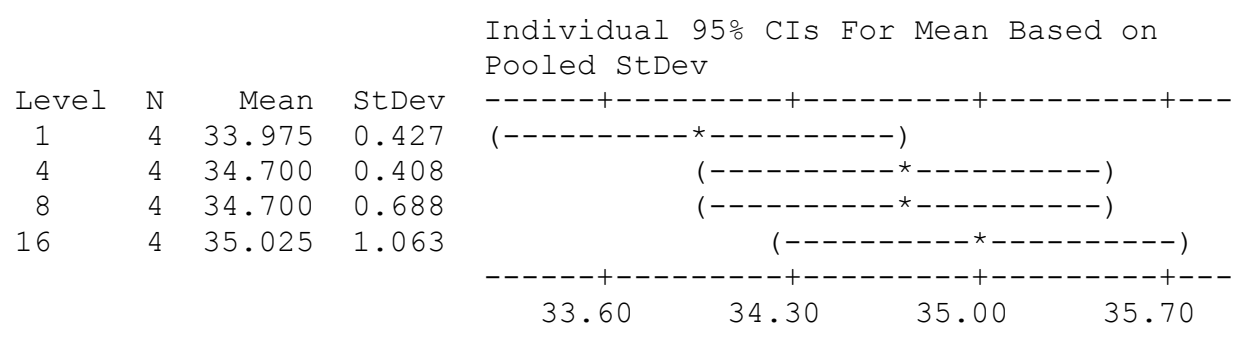

Pooled StDev $=0.699$

\section{One-way ANOVA: HRc 600, C6}

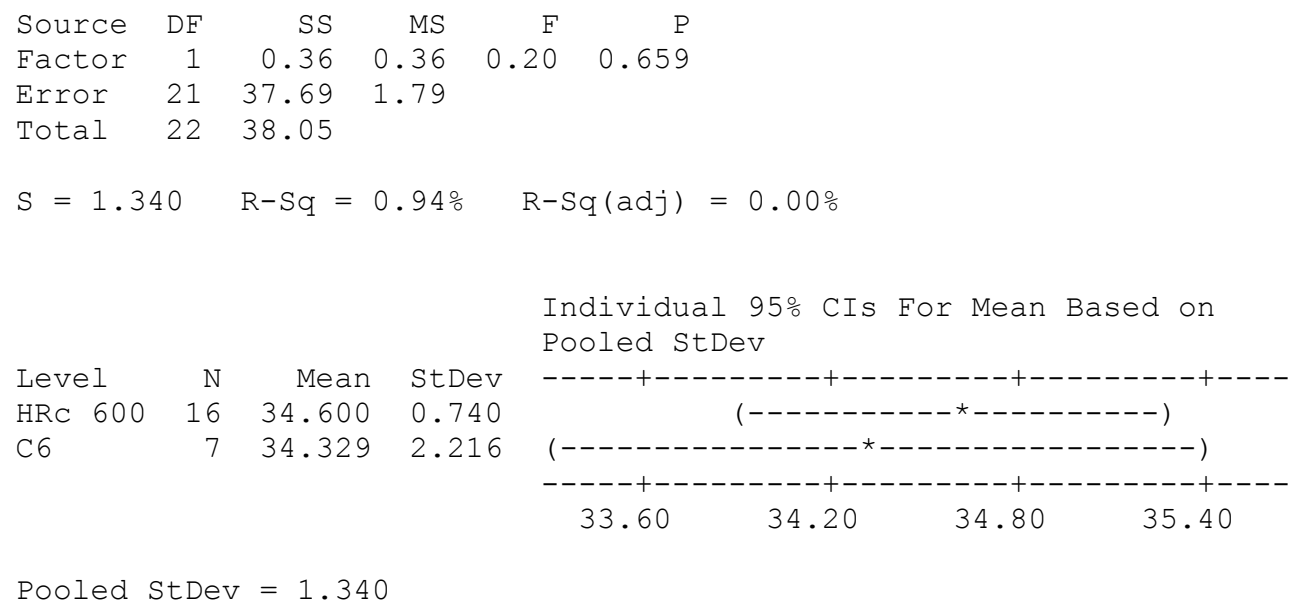

\section{One-way ANOVA: HRc 675, C6}




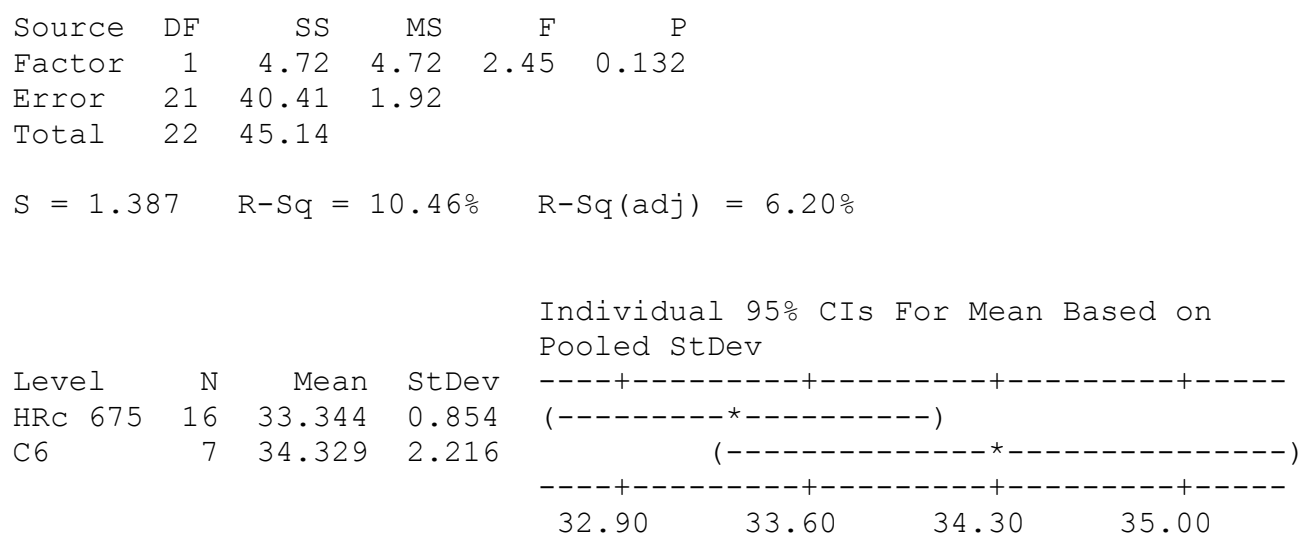

Pooled StDev $=1.387$

\section{One-way ANOVA: HRc 675, HRc 600}

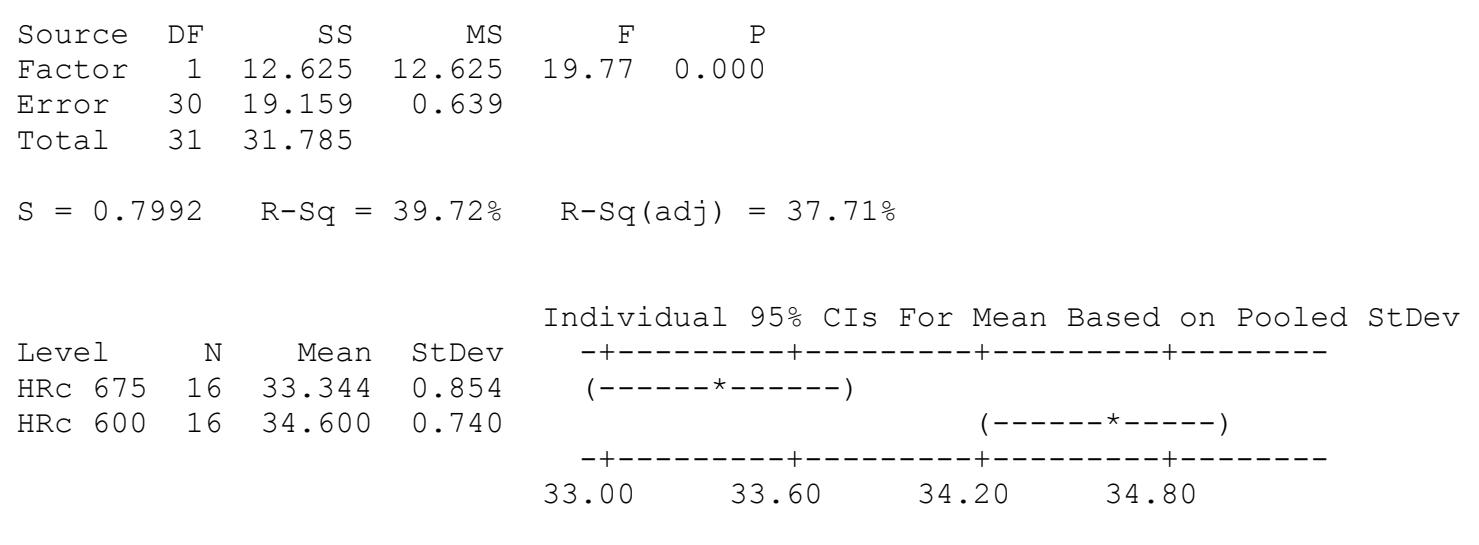

Pooled StDev $=0.799$ 